\title{
Über die Funktion von Zinkfinger Proteinen bei der Induktion des Mesoderms in Xenopus laevis
}

\author{
Dissertation \\ zur Erlangung des Doktorgrades \\ der Mathematisch-Naturwissenschaftlichen Fakultäten \\ der Georg-August-Universität zu Göttingen
}

vorgelegt von

Ulrike Dürr

aus Hamburg

Göttingen 2001 
D7

Referentin: Prof. Dr. M. Schäfer

Korreferent: Prof. Dr. W. Engel

Tag der mündlichen Prüfung: 30. 10. 2001 


\section{INHALTSVERZEICHNIS}

Inhaltsverzeichnis

Abkürzungsverzeichnis

1.1 Die Bedeutung induktiver Wechselwirkungen in der Embryogenese 1

1.2 Der Dpp Signalweg in der frühen Embryogenese von Drosophila melanogaster 2

1.3 Schnurri in der Entwicklung von Drosophila melanogaster 4

1.4 Embryogenese von Xenopus laevis 6

1.5 Induktionsprozesse in der frühen Embryogenese von Xenopus laevis 7

1.6 Der TGF $\beta$ Signalweg in Vertebraten $\quad 8$

1.7 Transkriptionskontrolle durch Smad Proteine in Vertebraten 10

1.8 Struktur und Funktion von Zink Finger Proteinen 12

1.9 Zink Finger Multigenfamilien 13

1.10 Schnurri-Proteine i.e.S. $\quad 14$

1.11 Ziel der Arbeit 16

$\begin{array}{ll}\text { 2. Material } & 17\end{array}$

$\begin{array}{lll}2.1 & \text { Versuchstiere } & 17\end{array}$

2.2. Bakterienstämme und Genbanken 17

$\begin{array}{lll}2.3 & \text { Vektoren und Oligonukleotide } & 17\end{array}$

2.4 Enzyme und Reaktionssysteme (Kits) 28

2.5 Radioisotope 28

2.6 Medien und Lösungen 28

2.7 Antikörper und Chemikalien 30

2.8 Geräte 31

3. Methoden $\quad 32$

3.1 DNA-Methoden $\quad 32$

3.1.1 Präparation von Plasmid-DNA $\quad 32$

3.1.1.1 Isolierung von Plasmiden im analytischen Maßstab (TELT) 32

3.1.1.2 Isolierung von Plasmiden im präparativen Maßstab 32

3.1.2 Konzentrationsbestimmung von Nukleinsäuren 33

$\begin{array}{ll}\text { 3.1.3 Restriktionsspaltung von DNA } & 33\end{array}$

3.1.4 Agarose-Gelelektrophorese 33

3.1.4.1 Nicht-denaturierende Agarose-Gelelektrophorese 33

3.1.4.2 Denaturierende Agarose-Gelelektrophorese 34 
3.1.5 Polymerase-Kettenreaktion (PCR) 34

3.1.6 PCR-vermittelte in vitro-Mutagenese $\quad 35$

3.1.7 DNA-Sequenzierung und Sequenzanalyse $\quad 35$

3.1.8 Aufreinigung von DNA-Fragmenten 36

3.1.8.1 PCR Purification Kit (Qiagen) 36

3.1.8.2 Isolierung von DNA-Fragmenten aus Agarose-Gelen 36

3.1.9 Subklonierung von DNA-Fragmenten 36

$\begin{array}{ll}\text { 3.1.10 Ligation von DNA-Fragmenten } & 37\end{array}$

3.1.11 Dephosphorylierung von DNA-Fragmenten 37

3.1.12 Auffüllen überhängender DNA-Enden $\quad 37$

$\begin{array}{ll}\text { 3.1.13 Klonierung von PCR-Produkten } & 37\end{array}$

3.1.14 Herstellung elektrokompetenter Bakterienzellen $\quad 38$

$\begin{array}{ll}\text { 3.1.15 Elektrotransformation kompetenter Bakterienzellen } & 38\end{array}$

3.1.16 Nachweis der Integration klonierter DNA-Fragmente 39

3.2. RNA-Methoden $\quad 39$

3.2.1 Isolierung von DNA-freier Gesamt-RNA aus Xenopus 39

3.2.1.1 Embryonalstadien $\quad 39$

3.2.1.2 Adulte Gewebe und Organe 40

3.2.1.3 Animale Kappen 40

3.2.2 Reverse-Transkriptase-Polymerase-Kettenreaktion (RT-PCR) 41

3.2.2.1 Semiquantitative RT-PCR 41

3.2.2.2 Auftrennung im Acrylamid-Harnstoffgel 41

3.2.2.3 Phsphorylierung von DNA-Fragmenten 42

3.2.3 In vitro-Synthese von RNA $\quad 42$

3.2.3.1 In vitro-Synthese markierter RNA-Sonden 42

3.2.3.2 In vitro-Synthese von Cap-mRNA für Mikroinjektionen 42

3.2.3.3 Aufreinigung synthetischer RNA 43

3.2.4 Isolation homologer cDNASequenzen mit Hilfe degenerierter Oligonukleotide43

3.3 Durchmustern einer cDNA Bank $\quad \mathbf{4 3}$

3.3.1 Bestimmung des Phagentiters $\quad 44$

3.3.2 Phagenplattierung $\quad 44$

3.3.2.1 Phagenplattierung auf NZY-Agarplatten $\quad 44$

3.3.2.2 Phagenplattierung in Mikrotiterplatten $\quad 44$

3.3.3 Anreicherung eines Kandidaten-Phagen $\quad 44$

3.3.4 Isolation eines spezifischen Phagen 45

3.3.5 Zirkularisierung (Exision) des Phagen-Inserts 45

3.4 Präparation von Xenopus-Embryonalstadien $\quad 46$

3.4.1 Präparation von Xenopus-Testis 46

3.4.2 Stimulation der Eiablage 46

3.4.3 Befruchtung und Entwicklung 46

3.5 Histochemie und Immunhistochemie $\quad 47$ 
3.5.1 Fixierung von Xenopus Embryonen $\quad 47$

3.5.2 $\beta$-Galaktosidase-Färbung $\quad 47$

3.5.3 "Whole mount" in situ Hybridisierung 47

3.5.3.1 Rehydrieren der Embryonen $\quad 47$

3.5.3.2 Proteinase K-Behandlung $\quad 47$

$\begin{array}{ll}\text { 3.5.3.3 Refixierung } & 48\end{array}$

$\begin{array}{ll}\text { 3.5.3.4 Waschen } & 48\end{array}$

3.5.3.5 Antikörper-Inkubation $\quad 48$

3.5.3.6 Farbentwicklung $\quad 49$

3.5.3.7 Abstoppen der Färbung und Auswertung $\quad 49$

3.6 Mikroinjektion von Xenopus Embryonen $\quad 50$

3.7 Präparation und Kultivierung von animalen Gewebeexplantaten (,,animal $\begin{array}{lc}\left.\text { caps }^{6}\right) & 51\end{array}$

3.8. Proteinmethoden $\quad 51$

3.8.1 In vitro Translation $\quad 51$

3.8.2 SDS-Polyacrylamid-Gelelektrophorese (SDS-PAGE; nach Laemmli, 1970) 51

3.8.3 Extraktion und Detektion von Proteinen aus injizierten Embryonen 52

3.8.4 Ko-Immunopräzipitation von Proteinen aus injizierten Embryonen 52

3.8.5 Western Blot 53

3.9 Mikroinjektion in Xenopus Oozyten 53

3.9.1 Präparation von Oozyten $\quad 53$

3.9.2 Kollagenasebehandlung von Oozyten $\quad 54$

3.9.3 Mikroinjektion von Oozyten und Kern-Zytoplasma-Trennung 54

3.9.4 Immunopräzipitation $\quad 54$

4. Ergebnisse $\quad 55$

4.1 Isolierung und Charakerisierung schnurri-verwandter cDNAs aus 55

Xenopus laevis

4.1.1 Isolierung und Charakterisierung von Xshn1 Primärsequenz 56

4.1.2 Isolierung und Charakterisierung von Xshn2 Primärsequenz 57

4.1.3 Isolierung und Charakterisierung von Xshn3 Primärsequenz 59

4.1.4 Vergleich der Xenopus Schnurri Aminosäuresequenzen mit denen verwandter

Proteine aus Säugern

4.1.4.1 Vergleich der Xshn1 Aminosäuresequenz mit denen verwandter Proteine aus Säugern

4.1.4.2 Vergleich der Xshn2 Aminosäuresequenz mit denen verwandter Proteine aus Säugern

4.1.4.3 Vergleich der Xshn3 Aminosäuresequenz mit denen verwandter

Proteine aus Säugern 
4.1.5 Vergleich der Zinkfinger Domänen aller bekannten Vertreter der

Schnurri Proteinfamilie

4.1.6 Vergleich der Aminosäuresequenz von Xshn3 mit dem Drosophila

Schnurri Protein

4.2 Zeitliche und räumliche Expression von Xshn Transkripten in Xenopus laevis Embryonen

4.2.1 Zeitliche Expression von Xshn Transkripten in Xenopus laevis Embryonen

4.2.2 Ermittlung der räumlichen Verteilung von Xshn Transkripten in Xenopus laevis Embryonen

4.2.2.1 Ermittlung der räumlichen Verteilung von Xshn Transkripten in Xenopus Embryonen durch quantitative RT-PCR

4.2.2.2 Ermittlung der räumlichen Verteilung von Xshn Transkripten durch "whole mount" in situ Hybridisierung

4.2.3 Expression von Xshn mRNAs in Geweben adulter Xenopus laevis Frösche

4.3 Expression des Xshn3 Gesamtlängenproteins in Xenopus Embryonen

\subsection{Subzelluläre Lokalisation von Xshn3 Proteinfragmenten in Xenopus}

Oozyten

\subsection{Interaktion von Xshn3 mit Smad Proteinen}

4.5.1 Interaktion von Xshn3 Proteinfragmenten mit aktivierten Smad Proteinen

4.5.2 Interaktion von Xshn3 Proteinfragmenten mit Komplexen aktivierter Smad Proteine

4.5.3 Abhängigkeit der Interaktion von Xshn3 mit Smad Proteinen von der Aktivität des Smad Signalweges

\section{6 Überexpressionsexperimente mit Xshn3 Fusionsproteinen im Xenopus} Embryo

4.6.1 Analyse der Phänotypen von mit Xshn3 Fusionskonstrukten injizierten Xenopus Embryonen

4.6.2 Überexpression der Smad-bindenden Xshn3 Proteinfragmente 5 und 8 im Xenopus Embryo

4.6.3 Kooperation des Xshn3-Proteinfragmentes 7 (AS 1880-2578) mit Smad2

4.6.4 Repression mesodermaler Markgergene durch Xshn-Fusionsproteine

4.6.4.1 Repression des endogenen mesodermalen Markergens Xbra durch Zinkfinger Fusionsproteine

4.6.4.2 Ein Zinkfinger-Repressorkonstrukt und ein Zinkfinger-Aktivatorkonstrukt inhibieren Mesoderminduktion in animalen Kappen

4.6.4.3 Ein Zinkfinger-Repressorkonstrukt induziert neurales Gewebe in animalen Kappen 
5. Diskussion

5.1 Xschnurri Proteine als Homologe des Drosophila Schnurri Proteins

5.1 Xshn mRNAs werden während der mesodermalen Musterbildungsprozesse im Xenopus Embryo exprimiert

5.2 Versuch der Überexpression des Gesamtlängen Xshn3

5.4 Xshn3 besitzt definierte Kernimport- und Kernexport-Aktivität

5.5 Xshn3 interagiert in vivo mit Smad Proteinen

5.6 Vergleich der Positionen von Interaktions- und Kokalisationsdomänen zwischen Xshn3 und dem Drosophila Schnurri Protein

5.7 Überexpression der carboxyterminalen Zinkfinger Domäne von Xshn3 führt zu starken Entwicklungsstörungen im Xenopus Embryo

5.8 Xshn-Zinkfinger Aktivator- und Repressorkonstrukte reprimieren Mesoderminduktion im Xenopus Embryo

\section{Zusammenfassung}

7. Literaturverzeichnis

8. Anhang

8.1 Xshn1 cDNA Sequenz und abgeleitete Peptidsequenz (partiell)

8.2 Xshn2 cDNA Sequenz und abgeleitete Peptidsequenz (partiell)

8.3 Xshn3 cDNA Sequenz und abgeleitete Peptidsequenz

Danksagung

Lebenslauf 


\section{Abkürzungen}

ad

Amp

APS

AS

bp

${ }^{\circ} \mathrm{C}$

cDNA

CHAPS

$\mathrm{Ci}$

cpm

dNTP

DMSO

dm

DNA

DTT

EDTA

Flag

FREON

$\mathrm{g}$

$\mathrm{h}$

HEPES

hs

$\mathrm{IgG}$

kan

$\mathrm{kb}$

$\mathrm{kDa}$

LB

$\min$

$\mathrm{mm}$

$\mathrm{mm}$

mRNA

MT

NLS

OD

PAGE

PBS

PCR

pfu

PMSF

rn

RNA

rNTP auf

Ampicillin

Ammoniumperoxodisulfat

Aminosäuren

Basenpaare

Grad Celsius

komplementäre DNA

3-[(3-Cholamisoprpyl)dimethylammonio]-1-propansulfat

Curie, $1 \mathrm{Ci}=37 \mathrm{GBq}$

Counts per minute (Zerfälle pro Minute)

2'-Desoxyribonukleosid-5'-triphosphat

Dimethylsulfoxid

Drosophila melanogaster, Fruchtfliege

Desoxyribonukeinsäure

1,4,-Dithiothreitol

Ethylendiamintetraacetat

Flag-tag, Epitopmarkierung

1,1,2-Trichlorotrifluoroethan

Gramm

Stunde

4-(2-Hydroxyethyl)-1-piperazin-ethansulfonsäure

Homo sapiens, Mensch

Immunglobulin $\mathrm{G}$

Kanamycin

Kilobasen

Kilodalton

Luria Bertani (Medium)

Minute

Millimeter

Mus musclus (Hausmaus)

Messenger-RNA

Myc-tag, Markierung aus sechs myc-Epitopen

Kernlokalisationssignal (nuclear localization signal)

Optische Dichte

Polyacrylamidgelektrophorese

Phosphat-gepufferte Salzlösung (phosphate buffered saline)

Polymerasekettenreaktion (polymerase chain reaction)

Plaque-forming units

Phenylmethylsulfonylfluorid

Rattus norvegicus, Ratte

Ribonukleinsäure

Ribonukleosid-5'-triphosphat 


$\begin{array}{ll}\text { RT } & \text { Raumtemperatur } \\ \text { RT-PCR } & \text { Reverse Transkriptase-PCR } \\ \text { s } & \text { Sekunde } \\ \text { SDS } & \text { Natriumdodecylsulfat (sodium dodecyl sulfate) } \\ \text { Taq } & \text { Thermus aquaticus } \\ \text { TBE } & \text { Tris-Borat-EDTA-Elektrophoresepuffer } \\ \text { TBS } & \text { Tris-gepufferte Salzlösung (tris buffered saline) } \\ \text { TE } & \text { Tris-EDTA } \\ \text { TEMED } & \text { N,N,N,N-Tetraethylendiamin } \\ \text { Tet } & \text { Tetracyclin } \\ \text { Tris } & \text { Tris(hydroxymethyl)aminoethan } \\ \text { U } & \text { Unit, Enzymeinheit } \\ \text { Upm } & \text { Umdrehungen pro Minute } \\ \text { UTR } & \text { Untranslated Region (nicht translatierte Region) } \\ \text { Vol. } & \text { Volumen } \\ \text { v/v } & \text { Verhältnis Volumen zu Volumen } \\ \text { w/v } & \text { Verhältnis Gewicht zu Volumen } \\ \text { xl } & \text { Xenopus laevis, Südafrikanischer Krallenfrosch }\end{array}$




\section{Einleitung}

\subsection{Die Bedeutung induktiver Wechselwirkungen in der Embryogenese}

Die Entwicklungsbiologie wird oft als das Herz der Biologie bezeichnet. Sie untersucht, wie sich aus einer einzelnen totipotenten Zelle ein vielzelliger Organismus mit unterschiedlich spezialisierten Zelltypen bildet, deren genetische Ausstattung dabei identisch bleibt. Die Entwicklungsbiologie fragt, wie die Gene einer befruchteten Eizelle in der Lage sind, differenzierte Zellgruppen und Organe mit definerter räumlicher Anordnung zueinander hervorzubringen. Zellen und Zellgruppen senden dabei Signale aus, die ihre Interaktionen untereinander vermitteln. Dass hierbei auch Gruppen von Zellen das Entwicklungsschicksal angrenzender Zellgruppen bestimmen können, wurde erstmals 1924 von Hans Spemann und Hilde Mangold beschrieben. Sie zeigten, dass ein Explantat der dorsalen Urmundlippe eines Molchembryos während der Gastrulation nach Transplantation in einen zweiten Embryo dort eine zweite Körperachse induzieren kann. Für diese zweite Achse wurde maßgeblich Gewebe des Empfängerembryos rekrutiert, dessen Entwicklungsschicksal vom verpflanzten "Organisator" umbestimmt wurde (Spemann und Mangold, 1924). Bei dem hier beschriebenen Phänomen der Induktion steuert eine Gruppe von Zellen das Entwicklungsschicksal einer angrenzenden Gruppe von Zellen mithilfe diffusibler Signalmoleküle (Gurdon, 1992). Dabei können manche dieser Signalmoleküle, sog. Morphogene, abhängig von ihrer lokalen Konzentration eine Differenzierung der Zielzellen zu unterschiedlichen Zelltypen bewirken (Wolpert, 1998).

Zielzellen reagieren auf induktive äußere Signale durch Änderung ihrer Genaktivität, indem über sog. Transkriptionsfaktoren Gene oder Gengruppen an- oder abgeschaltet werden. Auf diese Weise regulieren induktive Signale über die Aktivität von DNA-bindenden Transkriptionsfaktoren die Expression von untergeordneten Strukturgenen in der Embryonalentwicklung. Die molekularen Mechanismen, über die bestimmte Signale in veränderte Genaktivität münden, sind z.T. evolutionär hoch konserviert. Ein Beispiel hierfür ist der TGF $\beta$ Signalweg, der essentiell an den frühen Musterbildungsprozessen sowohl von Invertebraten als auch von Vertebraten beteiligt ist. Komponenten des TGF $\beta$ Sinalweges sind vom Nematoden Caenorhabditis über die Fruchtfliege Drosophila bis zu den Säugern beschrieben. Die vorliegende Arbeit bezieht genauere Untersuchungen an Drosophila melanogaster und eigene Arbeiten an Xenopus laevis ein.

\subsection{Der Dpp Signalweg in der frühen Embryogenese von Drosophila melanogaster}

Drosophila melanogaster ist seit über 70 Jahren Untersuchungsobjekt der klassischen Genetik. Zunächst wurde eine Vielzahl von Mutanten phänotypisch beschrieben, jedoch konnten die genetischen Grundlagen dieser Mutationen erst viel später analysiert werden (Übersicht in Johnston und Nüsslein-Volhard, 1992). An der frühen Musterbildung entlang der dorso-ventralen (D-V) Achse des Drosophila Embryos sind zwei Signalwege beteiligt: Ein maternaler Weg mündet in einen Aktivitätsgradienten des Morphogens Dorsal (Dl), das 
im ventralen Bereich des Embryos konzentrationsabhängig Zielgene in begrenzten Domänen aktiviert. Zusätzlich reprimiert Dl die Expression von $d p p$ und zerknüllt und begrenzt deren Expressionsdomänen auf den dorsalen Bereich des prä-zellulären Blastoderm-Embryos (Übersicht in Rusch und Levine, 1996).

Decapentaplegic (Dpp) ist ein homologes Protein der Vertebraten "Bone Morphogenic Proteins 2/4" (BMP2/4), wirkt als Wachstumsfaktor und ist Schlüsselkomponente eines zweiten, zygotischen Weges. Dpp bildet einen Aktivitätsgradienten, der den dorsalen Bereiches des Embryos spezifiziert (Ferguson und Anderson, 1992; Wharton et al., 1993). Später in der Entwicklung ist Dpp wesentlich an der Spezifizierung von Zellschicksalen beteiligt, sowie an Wachstum und Differenzierung der Imaginalscheiben (Übersicht in Neumann und Cohen, 1997).

Der Signalweg, über den Dpp die Expression von Zielgenen im Zellkern reguliert, ist zwischen Invertebraten und Vertebraten hoch konserviert. In beiden Fällen sind heteromere Rezeptorkomplexe und intrazelluläre Signalübermittler der Smad Familie beteiligt. Der Mechanismus des Weges wurde zuerst bei Drosophila beschrieben und kann als Prototyp gelten.

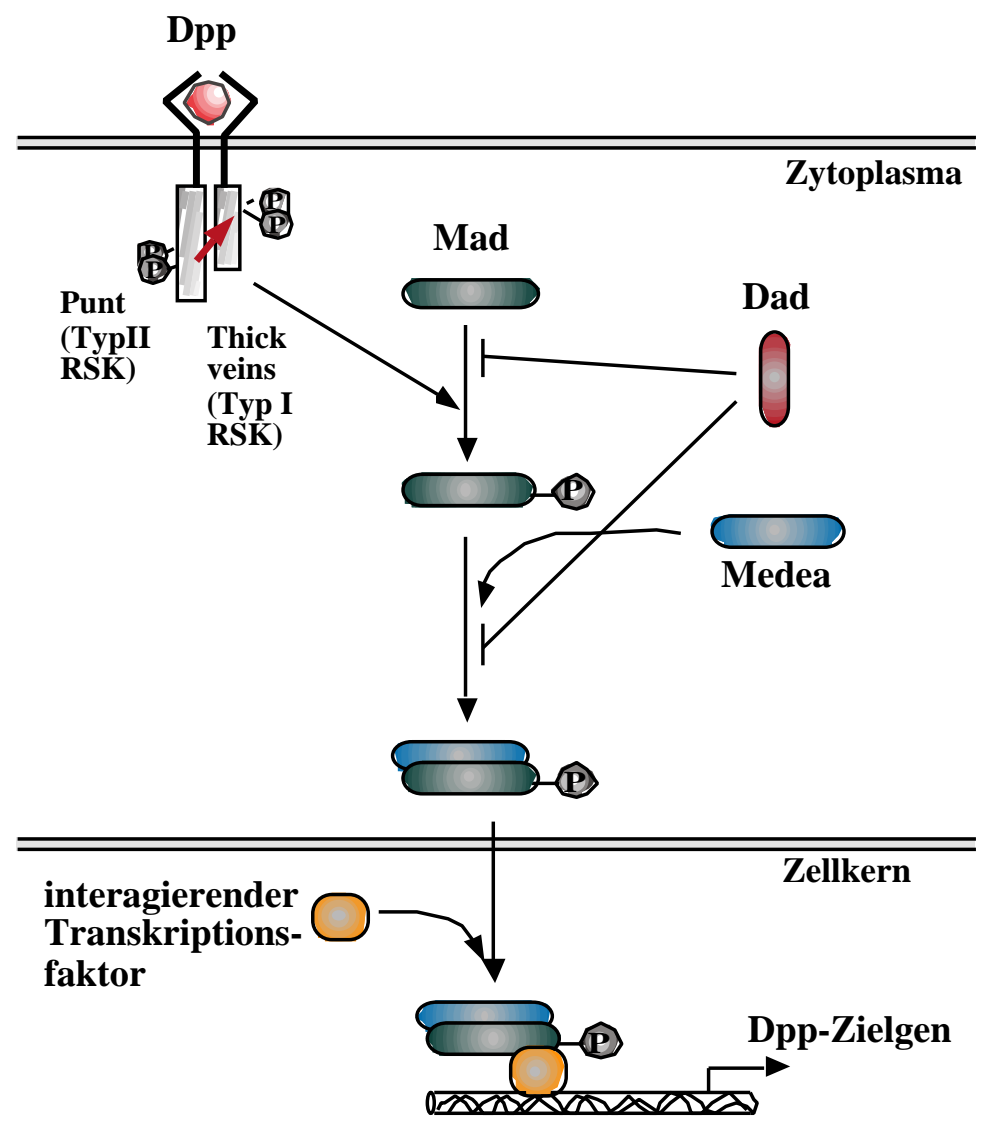

Abb. 1.1: Der Dpp Signalweg in Drosophila melanogaster. Der Ligand Dpp induziert die Bildung eines heteromeren Komplexes aus der Typ I Rezepter Ser/Thr Kinase (RSK) Thick veins (Tkv) und der Typ II Rezeptor Ser/Thr Kinase Punt (Put). Eine konstitutive Kinaseaktivität in Put transphosphoryliert und aktiviert Tkv. In der Folge wird das zytoplasmatische, Rezeptor-regulierte R-Smad-Protein Mad phosphoryliert und aktiviert. Es assoziiert mit dem Ko-Smad Medea, mit dem es in den Kern transloziert und dort mithilfe interagierender Transkriptionsfaktoren die Expression von Zielgenen zu regulieren. Dad inhibiert den Signalweg, indem es stabil mit dem Rezeptorkomplex assoziiert und somit die Aktivierung von Mad verhindert. 
Der Ligand Dpp aktiviert an den Zielzellen einen heteromeren Komplex der transmembranen Rezeptoren Punt (Put, Typ II Serin/Threonin Kinase Rezeptor) und Thick veins (Tkv, Typ I Serin/Threonin Kinase-Rezeptor). Tkv phosphoryliert nun das zytoplasmatische Protein Mothers against decapentaplegic (Mad) (Raftery et al., 1995; Sekelsky et al.; 1995, Newfeld et al., 1996; Maduzia et al., 1997), welches mit dem verwandten Protein Medea assoziiert (Ko-Smad, Raftery et al., 1996; Das et al., 1998; Hudson et al., 1998; Inoue et al., 1998), als Komplex in den Zellkern transloziert und die Aktivität von Zielgenen reguliert. Das Protein "Daughters against dpp" (Dad; Tsuneizumi et al., 1997) wird durch Dpp induziert und reguliert den Signalweg negativ, indem es stabil mit dem Rezeptor Tkv assoziiert und die Tkvvermittelte Phosphorylierung von Mad verhindert. Gleichzeitig verhindert Dad eine HeteroOligomerisierung von Mad mit Medea und damit einen Kerntransport des Komplexes (Inoue et al., 1998).

Die Aufgabe von aktiviertem Mad im Zellkern ist es, die Expression von Zielgenen wie vestigial (vg; Williams et al., 1990), optomotor blind (omb; Grimm et al., 1996) oder spalt (sal; de Celis et al., 1996) zu regulieren (Kim et al., 1997; Szuts et al., 1998; Xu et al., 1998). Eine direkte Bindung von Mad an die DNA wurde von Kim et al. (1997) gezeigt. Mad bindet danach an eine GC-reiche Sequenz mit dem Konsensus GCCGNCGC, wie sie im $v g-Q$ Enhancer vorkommt. In den meisten Fällen ist die Aktivierung von Zielgenen durch den DppWeg aber nicht allein durch die transaktivierende Wirkung von Mad zu erklären.

Dpp agiert außer in der D-V Musterbildung im frühen Embryo auch in der A-P (anterioposterioren) Musterbildung der Flügel-Primordien. In beiden Fällen bildet Dpp als Morphogen einen Aktivitätsgradienten aus. Schwellenwerte dieser Aktivität werden von den Zielzellen erkannt und mit der Aktivierung oder Repression von Zielgenen beantwortet (Übersicht in Neumann und Cohen, 1997).

Der Dpp Gradient wird sowohl in der D-V-Musterbildung im gesamten Embryo als auch in der A-P-Musterbildung in der Flügel-Imaginalscheibe in eine Reihe unterschiedlicher zellulärer Antworten umgesetzt. Unterschiedliche extrazelluläre Dpp-Konzentrationen führen zu unterschiedlichen Konzentrationen von aktiviertem Mad im Zellkern. Mad kann im Zellkern an Zielpromotoren mit unterschiedlichen Affinitäten für Mad binden, so dass daraus konzentrationsabhängige Schwellenwert-Antworten resultieren. Umfangreiche Untersuchungen in Vertebraten deuten zudem darauf hin, dass eine Regulation von Zielgenen durch Mad-Proteine eine Kooperation mit sequenzspezifischen Transkriptionsfaktoren benötigt.

Unterschiede in der Konzentration eines Morphogens sind weit entfernt vom Ort seiner Synthese schwerer zu interpretieren. In diesem Zusammenhang wirkt der TranskriptionsRepressor Brinker (Brk) in Regionen geringer Dpp Aktivität als Teil eines FeedbackMechanismus, der geringe Unterschiede in der Aktivität des Morphogens verstärkt (Campbell und Tomlinson, 1999; Jazwinska et al., 1999a, 1999b). In der Flügel-Imaginalscheibe ist in Regionen geringer Dpp-Konzentration die Repression der Expression von brk durch Mad Voraussetzung für die Expression von Zielgenen. Nach dem Modell von Jazwinska et al. (1999a) (Abb. 1.2.B) genügt in Bereichen geringer Dpp-Aktivität eine Repression der Expression von brinker, um die Expression von omb zu ermöglichen. Bei Verlust von Brk in den Zellen werden Zielgene niedriger Dpp-Konzentration auch ohne das induktive Signal von Dpp exprimiert. In Regionen, die näher an der Quelle des Dpp Signals liegen, wird neben der 
Repression von brinker eine direkte Aktivierung von Promotoren durch Mad vermutet (Jazwinska et al., 1999a, Marty et al., 2000).
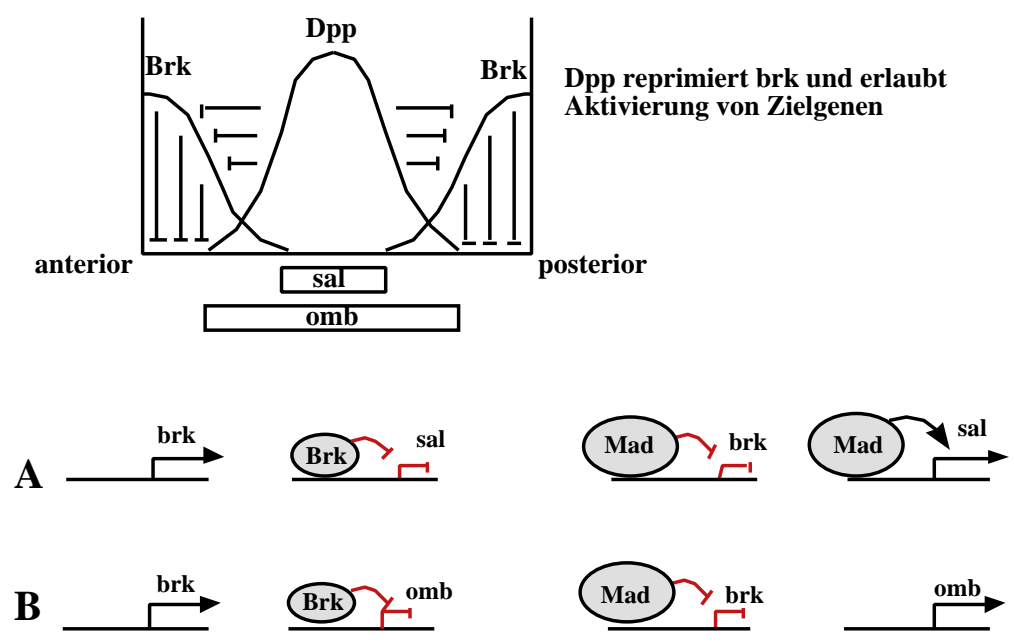

Abb. 1.2: Modell der anterior-posterioren (A-P) Musterbildung in der FlügelImaginalscheibe durch den Dpp-Antagonisten Brinker: oben: Dpp wird in der Mitte der Imaginalscheibe exprimiert und muss die Transkription von brk reprimieren, um eine Expression der Zielgene sal und omb zu ermöglichen. die Expression von vg beinhaltet keine Repression von brk. unten: Zwei Modelle der Regulierung von dpp Zielgenen durch Brk: (A) Für die Expression von sal wird außer der Repression von brk eine direkte Aktivierung des sal Promotors durch Mad benötigt. (B) Für die Expression von omb genügt eine Repression der Expression von brk durch den Dpp Signalweg (Mad) (nach Jazwinska et al., 1999b).

Bisher wurde kein Brinker-homologes Protein in Vertebraten beschrieben. Ergebnisse aus Überexpressionsexperimenten mit Brinker in Xenopus Embryonen lassen aber das Vorkommen eines solchen Proteins vermuten (Minami et al., 1999).

\subsection{Schnurri in der Entwicklung von Drosophila melanogaster}

Der Zink Finger Transkriptionsfaktor Schnurri (Shn; Nüsslein-Volhard et al., 1984) wird in Zellen benötigt, die das Signal des Morphogens Dpp erhalten. Mutationen im Gen für schnurri beeinträchtigen die Expression einer Vielzahl von Dpp-induzierten Genen sowohl in der D-V Musterbildung des ganzen Embryos als auch in der A-P Musterbildung der FlügelImaginalscheiben (Arora et al., 1995, Grieder et al., 1995, Staehling-Hampton et al., 1995, Torres-Vazquez et al., 2000 und 2001, Marty et al., 2000, Dai et al., 2000). Im Kontext des gesamten Embryos ähnelt der Phänotyp von shn-mutanten Embryonen denen mit Defekten in anderen Komponenten des Dpp Weges, nämlich $d p p$, $t k v$, mad oder med. Allerdings sind die shn Embryonen schwächer ventralisiert als die genannten Mutanten (Arora et al., 1995, Grieder et al., 1995, Staehling-Hampton et al., 1995). Schnurri wird möglicherweise für eine Regulation der Expression einer Untergruppe von Dpp Zielgenen benötigt. Weiterhin kommt Shn eine Funktion in der Dpp-vermittelten Regulation der Proliferation von Spermatogonien zu, wo Shn in den die Spermatogonien umgebenen Zystenzellen benötigt wird (Matunis et al., 1997). Bei der Entwicklung der Speicheldrüse in Parasegment 2 vermittelt Shn im dorsalen Bereich des Segmentes die Dpp-induzierte Repression von Speicheldrüsen-typischen 
Zielgenen (Henderson et al., 1999). Shn ist im Zellkern lokalisiert und assoziiert direkt mit Signal-aktiviertem Mad Protein (Dai et al., 2000, Udagawa et al., 2000). Shn bindet über seine aminoterminale Doppelzinkfinger-Domäne direkt an die DNA-Zielsequenz GGGAACGTTCCC und mit der weiter carboxyterminal gelegenen DoppelzinkfingerDomäne an die Sequenz GGGGAATTCCC (Dai et al., 2000).

Genauere Untersuchungen zur Funktion von Shn im Zellkern haben zu einer differenzierteren Interpretation seiner Funktion geführt. Ein Funktionsverlust von shn während der Embryogenese führt in keinem Fall zu einem vergleichbar starken Phänotyp wie der Verlust der anderen Komponenten des Dpp Weges. Nach Marty et al. (2000) wirkt Shn bei einem Teil der Funktionen von Dpp mit: In Regionen relativ geringer Dpp Aktivität interagieren Shn und Mad miteinander und bewirken die Repression von brk. Dabei wird der Transkriptions-Aktivator Mad durch seine Kooperation mit Shn zum Repressor von brk. In Regionen hoher Dpp Aktivität wirken zusätzlich überschüssige Mad/Med Komplexe als direkte Aktivatoren von Zielgenen.

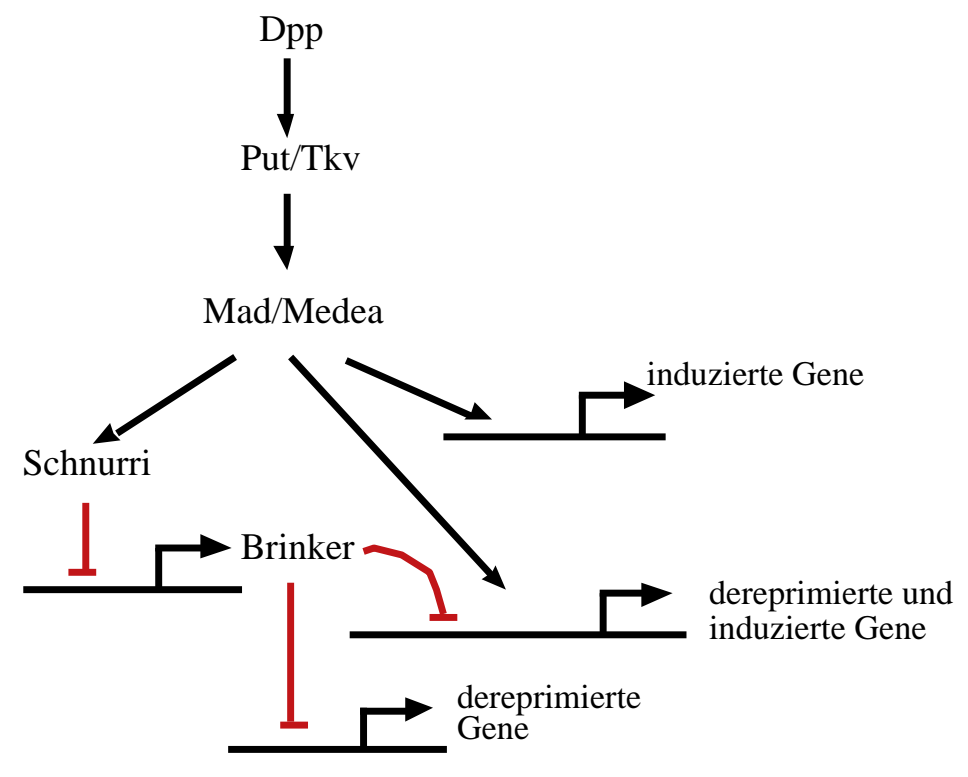

Abb. 1.3: Modell der Regulierung von Zielgenen durch Dpp in Drosophila.

Schnurri ist essentiell für die Dpp-vermittelte Repression der brk-Transkription, ist aber nicht notwendig für die Aktivierung von Zielgenen. Pfeile zeigen eine Aktivierung, Querbalken zeigen eine Repression von Zielgenen (nach Marty et al., 2000).

Torres-Vanquez et al. (2001) vermuten für Shn weiterhin eine zusätzliche, Brk-unabhängige Aktivierung von Dpp Zielgenen. Ein Bereich mit zwei ählichen Sequenzen im ultrabithorax $(u b x B)$ Promotor wird von Shn gebunden. Diese Bindungsstellen werden für eine in vivo Expression von $u b x$ benötigt, wobei Mad und Shn kooperativ auf die Expression wirken (Dai et al., 2000). Wegen der oben genannten Hinweise kann angenommen werden, dass Shn an der Regulation von Dpp Zielgenen beteiligt ist und als DNA-bindender Kofaktor von Mad agiert. Möglicherweise kommt Shn analog zu anderen Transkriptionsfaktoren in Vertebraten die Aufgabe zu, die Spezifität von Mad für eine Auswahl von Promotoren zu erhöhen. Auch muss nicht notwendigerweise festgelegt sein, ob Shn ein Repressor oder Aktivator ist. Analog der Funktion von Dorsal (Dl) in Drosophila (Mannervik et al., 1999; Chen und Coury, 
2000) oder anderer Proteine in Vertebraten ist es möglich, dass das in den Zielzellen vorkommende Spektrum von Transkriptionsfaktoren und Kofaktoren über die letztliche Aktivität von Shn entscheidet (Torres-Vazquez et al., 2001).

\subsection{Embryogenese von Xenopus laevis}

In der Ordnung der Anura (Froschlurche), gehört Xenopus zur Unterordnung Aglossa (Zungenlose). Die Tiere eignen sich hervorragend für die Untersuchung der frühen Embryonalentwicklung, da sie sich einfach in Aquarien halten und züchten lassen und durch Gonadotropin-Injektion die Ablage einer großen Zahl von Eiern stimuliert werden kann. Die Eier lassen sich in vitro befruchten und kultivieren, entwickeln sich relativ schnell und sind durch ihre Größe von 1-2 mm Durchmesser vielen Manipulationen wie Mikroinjektionen und Transplantationen zugänglich. Die frühe Embryogenese wurde von Nieuwkoop und Faber (1967) beschrieben und in Stadien eingeteilt (NF-Stadien). Das Ei weist mit der Unterteilung in eine pigmentierte animale Region und eine unpigmentierte, dotterreiche vegetale Region eine primäre Asymmetrie auf. Die Befruchtung erfolgt in der animalen Hemisphäre und löst den Prozess der kortikalen Rotation aus, in dessen Folge die zukünftige dorsal-ventrale (DV) Achse des Embryos festgelegt wird. Dabei definiert der Eintrittspunkt des Spermiums die zukünftige ventrale Seite des Embryos. Bereits die erste Zellteilung legt die dritte Asymmetrieebene fest, indem die Zygote entlang der animal-vegetalen Achse in die spätere linke und rechte Körperhälfte geteilt wird.

Die Entwicklung der Zygote verläuft anschließend relativ schnell. In etwa drei Stunden bildet sich ein Zellhaufen (Morula), der sich nach weiteren zwei Stunden zur Hohlkugel (Blastula) mit primärer Leibeshöhle (Blastocoel) entwickelt. Zu diesem Zeitpunkt setzt die zygotische Transkription ein $(\mathrm{MBT}=$ Mid Blastula Transition $)$.

In der nachfolgenden Gastrulation erfolgt eine Umlagerung ganzer Zellschichten, in deren Folge die drei Keimblätter Ektoderm, Mesoderm und Entoderm festgelegt werden. Zukünftiges Mesoderm wandert hierzu aktiv über den Blastoporus im vegetalen Bereich der Gastrula ein und bewirkt auch eine Invagination des Entoderms. Im Embryo entsteht eine sekundäre Leibeshöhle, der Urdarm (Archenteron), und die primäre Leibeshöhle wird verdrängt. Das Mesoderm lagert sich zwischen Ektoderm und Entoderm. Das Ektoderm entwickelt sich im weiteren Verlauf zu Nervensystem, Haut und Sinnesorganen. Das Mesoderm bildet Muskeln, Knochen, Chorda dorsalis (Notochord), Mesenchym, Herz, Blutgefäßsystem, Niere und Urogenitalsystem. Aus dem Entoderm entwickeln sich u.a. die inneren Organe wie Magen, Darm, Leber, Pankreas, Lunge und Harnsystem. Nach Abschluss der Gastrulation erfolgt die Neurulation, während der sich im Ektoderm entlang der anteriorposterioren Achse eine Neuralrinne auffaltet, die sich zum Neuralrohr schließt. 


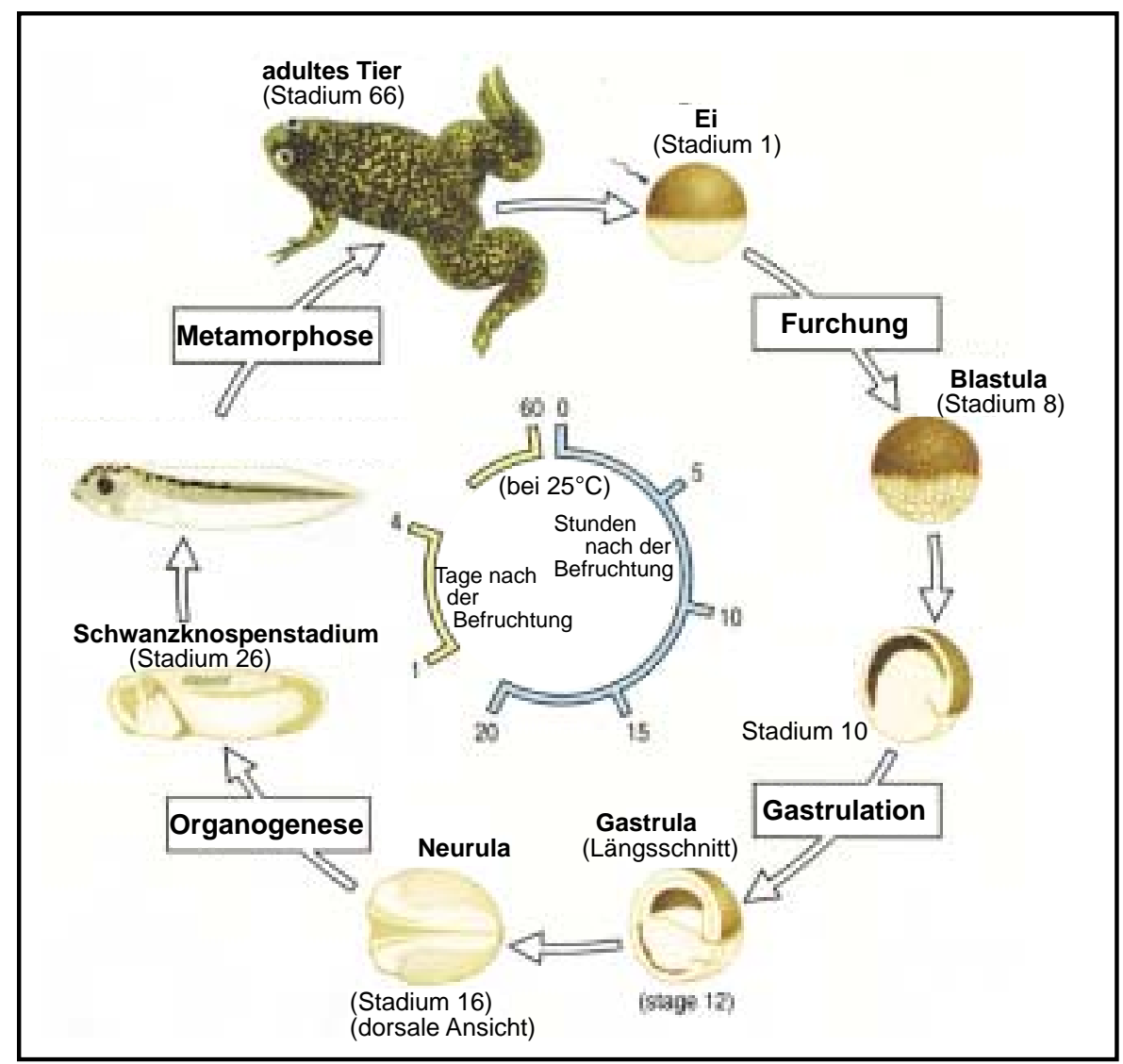

Abb. 1.4: Embryonalentwicklung des Krallenfrosches Xenopus laevis. Aus der Zygote entwickelt sich nach wiederholten Furchungsteilungen eine Hohlkugel, die Blastula. Während der Gastrulation invaginieren Entoderm und Mesoderm über den Blastoporus und verdrängen so die primäre Leibeshöhle, das Blastocoel. In der Folge sind die drei Keimblätter, Ektoderm, Entoderm und Mesoderm angelegt. Während der Neurulation bilden sich die Strukturen des zentralen Nervensystems heraus. In der weiteren Organogenese werden aus den entsprechenden Keimblättern die Organe differenziert. Während der Morphogenese werden larvale Strukturen aufgelöst, und das adulte Tier entsteht (nach Wolpert, 1988).

Hiermit geht die frühe Embryonalentwicklung in die Organogenese über. Der Embryo entwickelt sich zur Kaulquappe, die nach etwa sieben Wochen eine Metamorphose durchläuft und von Kiemen- auf Lungenatmung umstellt, den Schwanz rückbildet und die Ernährung umstellt. Xenopus laevis wird nach etwa einem Jahr geschlechtsreif (Übersicht in Wolpert, 1998).

\subsection{Induktionsprozesse in der frühen Embryogenese von Xenopus laevis}

Bereits kurz nach der Befruchtung aktiviert der Prozess der kortikalen Rotation im Bereich des grauen Halbmondes maternale Signalwege, die hier ein dorsal induzierendes Zentrum, das Nieuwkoop Zentrum, entstehen lassen. Maternale Komponenten des sog. klassischen Wnt- und des TGF- $\beta$ Signalweges überlagern sich in diesem entodermalen Bereich. Sie bewirken nach Einsetzen der zygotischen Transkription in der Mid-Blastula-Transition 
sezernierten Signalmolekülen, u.a. aus der TGF $\beta$ - und der FGF-Familie. Dadurch entsteht ein zweites organisierendes Zentrum, der Spemann Organisator, der die Fähigkeit besitzt, das Entwicklungsschicksal angrenzender, für die Signale kompetenter Zellpopulationen zu bestimmen.
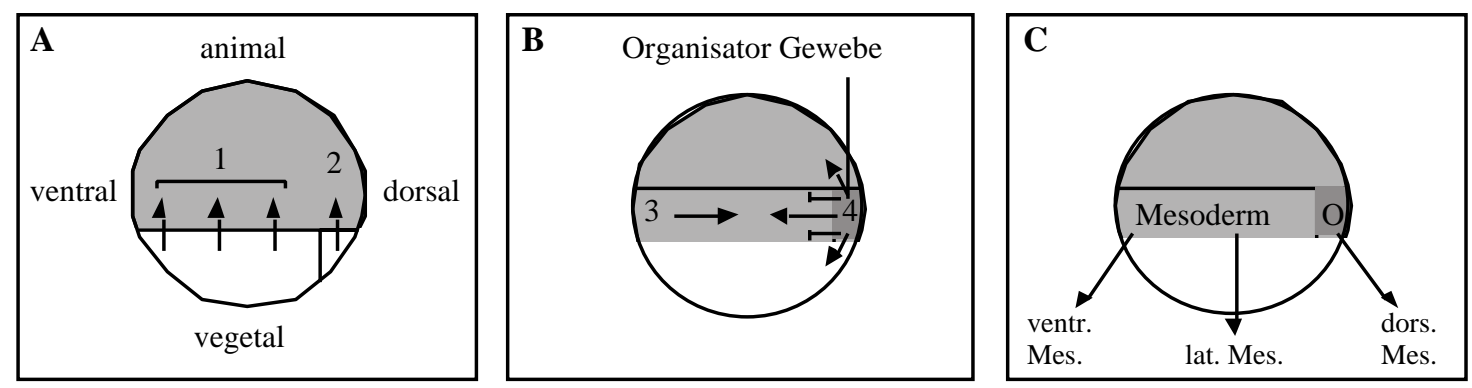

Abb. 1.5: Induktive Prozesse in der frühen Embryonalentwicklung von Xenopus laevis. Dargestellt ist die laterale Ansicht früher Embryonalstadien. (A) Im mittleren Blastula Stadium (NF 8.5) induzieren Signale von der vegetalen Hemisphäre in der darüber gelegenen marginalen Zone das Mesoderm. Ventrale Signale (1) induzieren ventrales Mesoderm, während dorsale Signale aus dem Nieuwkoop Zentrum in der dorsalen marginale Zone den Organisator induzieren (2). (B) Frühes Gastrula Stadium (NF 9.5/10). Ventralisierende Signale (3) wirken den dorsalisierenden Signalen (4) entgegen. Die dorsalisierenden Signale inaktivieren die ventralisierenden Signale und senden Sigale in die benachbarten Regionen (Pfeile): in das laterale Mesoderm (Dorsalisierung des Mesoderms), in das darüberliegende Ektoderm (Neurale Induktion) und in das darunterliegende Entoderm (Anteriorisierung des Entoderms). (C) Mit Beginn der Gastrulation (NF 10) ist die Musterbildung des Mesoderms weitgehend festgelegt.

Hier beteiligte Signalmoleküle wirken als Morphogene und bilden Gradienten mit einer höchsten Aktivität im Organisator selbst. Der dorsalisierenden Aktivität aus dem Organisator wirkt eine ventralisierende Aktivität entgegen, die von BMP-4 und Xwnt-8 vermittelt wird und Mesoderm-modifizierend wirkt. Zu den dorsal-induzierenden Faktoren aus dem Organisator kommen wiederum ventral-inhibierende Aktivitäten, die BMP-4 bzw. Xwnt-8 extrazellulär binden und inaktivieren. Insgesamt entsteht im Mesoderm ein dorso-ventraler (D-V) Gradient, der im weiteren Verlauf zur Differenzierung der verschiedenen mesodermalen Gewebetypen führt. Der Spemann Organisator induziert zudem das Neuroektoderm, indem er Signale planar entlang des Ektoderms aussendet, die durch Inhibition von BMP-4 permissiv auf die Entwicklung von Neuroektoderm wirken und gleichzeitig ein anteriorposteriores (A-P) Muster im Neuroektoderm etablieren.

Zur A-P Musterbildung des Neuroektoderms trägt außerdem das einwandernde dorsale Mesoderm bei, das sich innen am prospekiven Neurektoderm nach anterior vorbeibewegt und Signale vertikal an das darüberliegende Ektoderm aussendet. Hierbei gelangt früh über die dorsale Urmundlippe einwanderndes Mes-Endoderm nach anterior in die Kopfregion des Embryos. Dieses Mes-Endoderm sendet v.a. die Wnt-Inhibitoren Cerberus, Frizbee und Dickkopf aus und induziert Kopfstrukturen, während posteriores, später einwanderndes Mesoderm die BMP-Antagonisten Chordin und Noggin sezerniert und posteriore Strukturen induziert. Zusätzlich bildet Retinsäure (RA) einen Gradienten mit posteriorisierender Wirkung im dorsalen Bereich des Embryo aus (Übersichten in Bouwmeester und Leyns, 1997; Kimelman und Griffin, 2000; McDowell et al., 1999; Dale und Jones, 1999). 


\subsection{Der TGF $\beta$ Signalweg in Vertebraten}

Die Transforming Growth Factor $\beta$ (TGF $\beta$ ) Familie von sezernierten Signalproteinen beinhaltet Bone-Morphogenic Proteins (BMPs), Activin und das eigentliche TGF $\beta$ und ist an fundamentalen Prozessen wie der Embryonalentwicklung, der Regulation von Zellwachstum, Differenzierung, Gewebe-Regeneration und Apoptose beteiligt. Die elementaren Schritte der Signalübermittlung in den Zellkern verlaufen analog dem Dpp Weg. Signale der BMPs werden von den Rezeptor-regulierten (R-) Smads Smad1, -5 und -8 in den Zellkern vermittelt, während Signale von Activin und TGF $\beta$ durch die R-Smads Smad2 und -3 vermittelt werden (Übersicht in Hata, 2001). Die Auswahl der R-Smads erfolgt durch die jeweils aktivierten Typ I Rezeptor Kinasen.

Als "antagonistic Smads" wirken Smad6 und Smad7. Smad6 inhibiert den Signalweg, indem es einen Komplex mit dem phosphorylierten R-Smad eingeht und dessen Assoziation mit dem Ko-Smad unterbindet (Hata et al.,1998). Smad7 bindet stabil an Typ I RSKs und inhibiert dadurch die Phosphorylierung der R-Smads (Hayashi et al., 1997). Smad7 ist vornehmlich Inhibitor des Activin/TGF $\beta$ Signalweges, während Smad6 spezifisch den BMP Signalweg blockiert (Hata et al., 1998; Ishisaki et al., 1999). Die Expression von Smad6 und -7 wird in vielen Zelllinien durch den Smad Signalweg selbst aktiviert, wodurch der Signalweg nach gewisser Zeit wieder abgeschaltet wird (Ishisaki et al., 1998; Nagarajan et al., 1999; Takase et al., 1998).

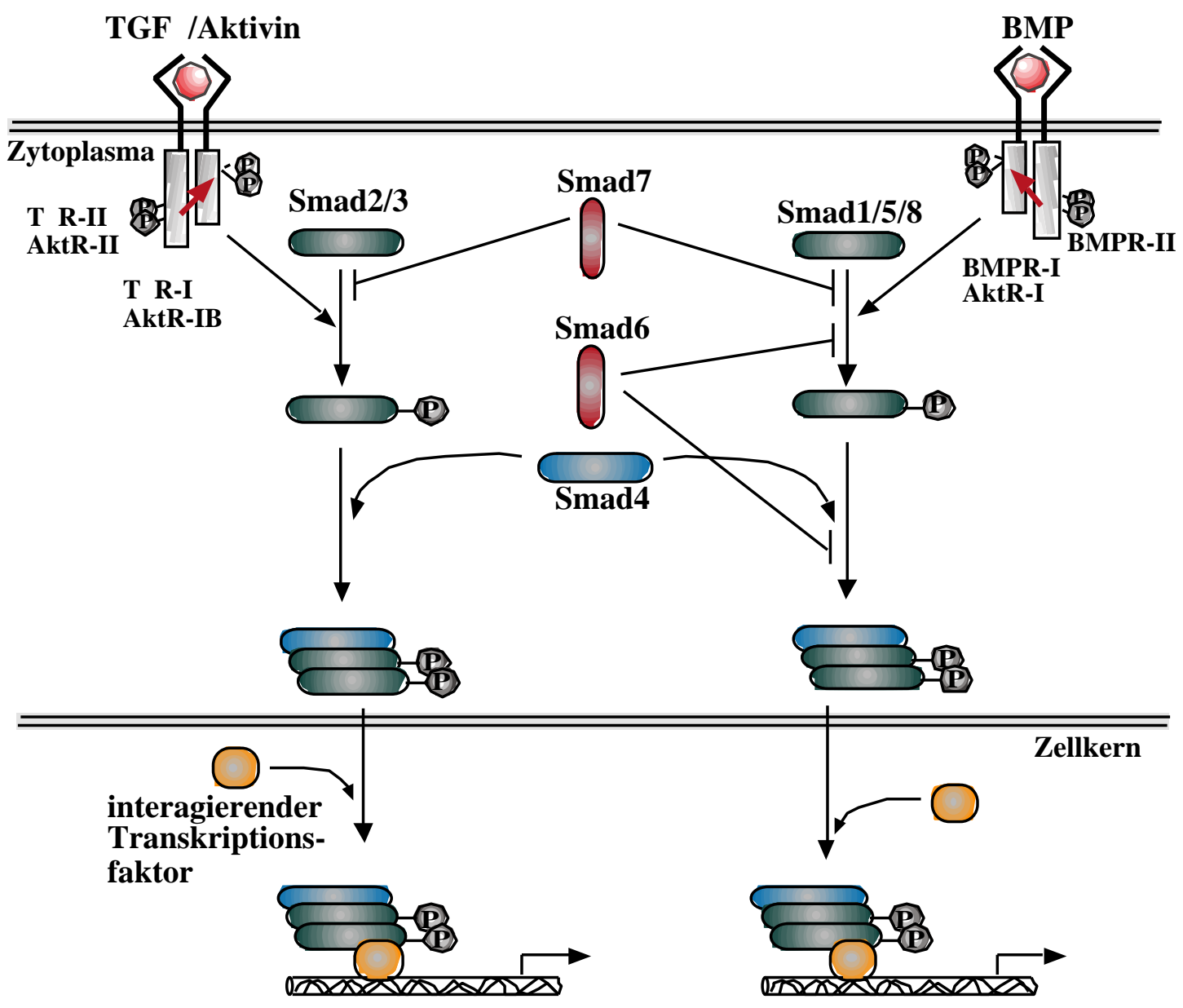


Abb. 1.6 (S. 9): Die Signalvermittlung der TGF- $\beta$ Signalmoleküle in Vertebraten durch Rezeptor-regulierte Smad Proteine und antagonistische Smads. Nach TypI RezeptorAktivierung werden die Rezeptor-regulierten Smad Proteine phosphoryliert, bilden homomere Komplexe miteinander und heteromere Komplexe mit dem Ko-Smad Smad4. Diese Komplexe translozieren in den Zellkern und regulieren zusammen mit sequenzspezifisch DNA-bindenden Transkriptionsfaktoren die Aktivität von Zielgenen. Die inhibitorischen Smad Proteine, Smad6 und Smad7, konkurrieren mit den Rezeptor-regulierten Smads um die Interaktion mit Rezeptor Kinasen oder durch Inhibition der Komplexbildung von R-Smads mit Smad4 (nach Piek et al., 1999).

\subsection{Transkriptionskontrolle durch Smad Proteine in Vertebraten}

Der strukturelle Aufbau der Smad Proteine ist vom Nematoden Caenorhabditis bis zu den Säugern erhalten, und den hoch konservierten Domänen MH1 (major homology domain1) und MH2 sind diskrete Funktionen zuzuordnen. In der latenten, nicht phosphorylierten Form der R-Smads interagieren MH1 und MH2 Domäne miteinander, wodurch eine Assoziation mit Smad4 und die Kernlokalisation des Komplexes verhindert wird (Hata et al., 1997).

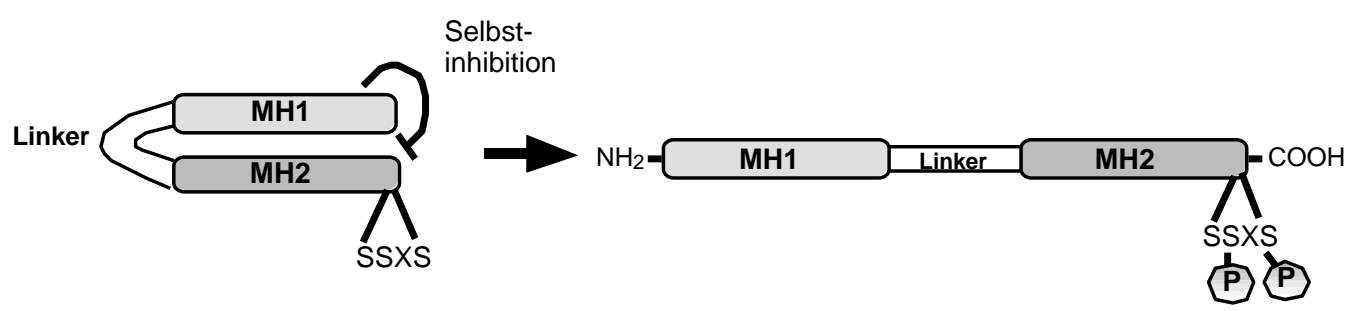

Abb. 1.7: Eine Selbstinhibition der latenten R-Smad Proteine wird nach Phosphorylierung durch die Typ I RSK an ihrem C-Terminus aufgehoben. Dadurch wird die Interaktion der RSmads mit dem Ko-Smad und der Kerntransport möglich. MH1, MH2: major homology domain 1 und -2 .

Rezeptor-aktivierte Smad Proteine interagieren mit einer Vielzahl von Proteinen von ganz unterschiedlicher Funktion. Darunter sind neben vielen Transkriptionsfaktoren und Kofaktoren auch Inhibitoren des Signalweges sowie Komponenten des Proteinabbaus. Dazu kommen Komponenten anderer Signalwege, mit dem der TGF $\beta$ Signalweg in Wechselwirkung steht und deren Aktivitäten sich gegenseitig verstärken oder unterdrücken (signalling crosstalk). Die Menge und Kombination von in der Zelle vorhandenen Transkriptionsfaktoren, Kofaktoren und die Aktivität weiterer Signalwege bestimmt offensichtlich, wie das eingehende Smad-Signal auf transkriptioneller Ebene interpretiert wird. Der zunächst einfach erscheinende TGF $\beta$ Signalweg erweist sich hier als zunehmend komplexer (Übersicht in Piek et al., 1999; Zimmermann und Padgett, 2000). Eine Vielzahl der derzeit bekannten mit Smad Proteinen interagierenden Faktoren ist in Abb. 1.8 dargestellt. 


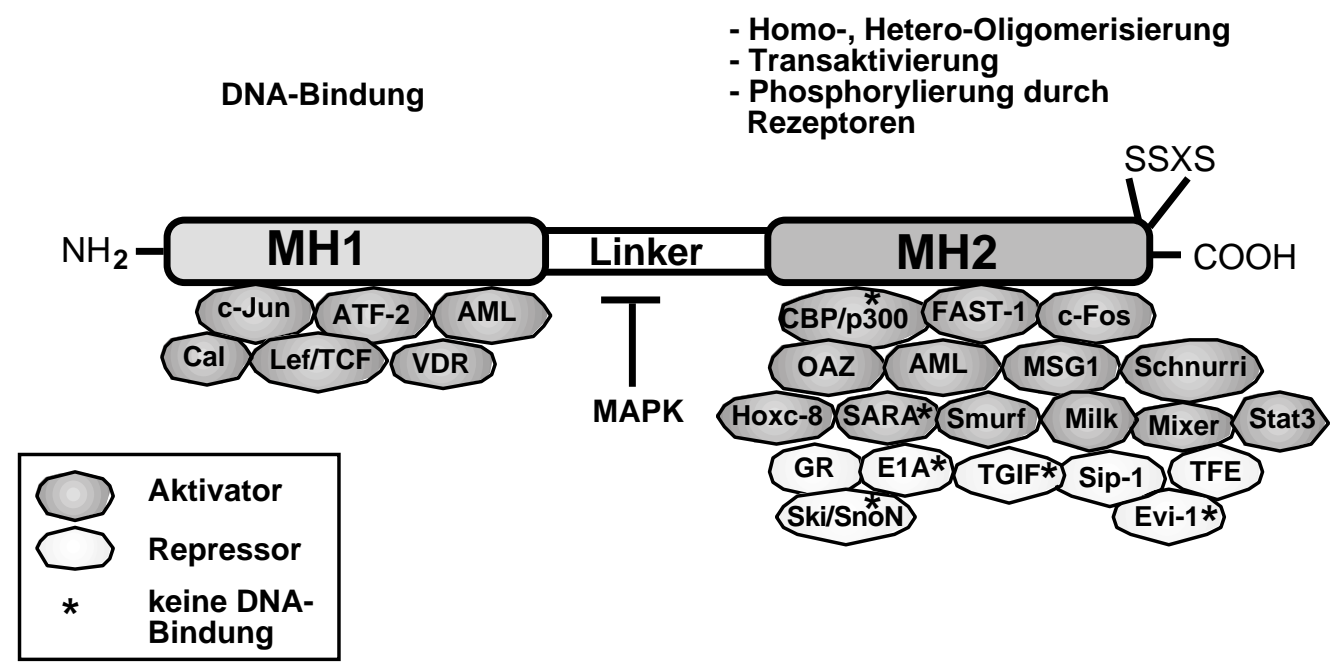

Abb. 1.8: Funktion von Smad Proteindomänen. Zwei hoch konservierte Domänen MH1 und MH2 ("Major Homology Domain" 1 und 2) werden von einer variablen Linkerregion verbunden. Den Domänen der R-Smads konnten diskrete Funktionen zugeordnet werden. Sowohl Aktivatoren als auch Repressoren der Transkription sowie Komponenten anderer Signalwege interagieren mit Smad Proteinen.

Im Zellkern bindet die MH1 Domäne der R-Smad Proteine und von Smad4 sequenzspezifisch an DNA und interagiert wie die MH2 Domäne mit anderen Proteinen. Die MH2 Domäne der R-Smads wirkt transaktivierend und bildet das Substrat für die Aktivierung durch die Rezeptoren. Die optimale DNA-Zielsequenz für Smad3 und Smad4 ist die Sequenz GTCT (Smad Binding Element, SBE; Zawel et al., 1998). Mit geringen Abweichungen findet sich eine palindromische Anordnung dieser Sequenz in vielen TGF $\beta$ Zielpromotoren. Die Affinität der Smad Komplexe für diese Sequenz ist aber relativ gering, so dass eine Kooperation der Smad Komplexe mit zusätzlichen Transkriptionsfaktoren als Voraussetzung für eine Tanskriptionskontrolle durch Smads allgemein angenommen wird. Als Beispiel sei der Winged Helix Transkriptionsfaktor FAST-1 genannt, der die DNAbindende Komponente im Transkriptions-aktivierenden Komplex mit Smad2 und Smad4 auf dem mix.2 und dem gsc Promotor bildet (Chen et al., 1996, 1997; Labbé et al., 1998). Im Komplex mit Smad3 wirkt FAST1 dagegen inhibierend auf die Transkription des gsc Promotors (Labbé 1998). Dieses ist ein Beispiel dafür, dass Smad2 und Smad3 in bestimmten Situationen gegensätzliche Aktivität besitzen könnten.

Eine positive gegenseitige Beeinflussung von Signalwegen erfolgt auf mehreren Ebenen. Komponenten des HGF, EGF und FGF-induzierten MAP-Kinase Weges sind in der Lage, Smad-Proteine durch Phosphorylierung zu aktivieren. Andersherum aktivieren die RezeptorKinasen des Smad-Signalweges Komponenten des MAP-Kinase Weges. Auf Ebene der Transkription kooperieren dann die jeweiligen DNA-bindenden Komponenten, Jun, Fos und Smad-Komplexe bei der Aktivierung von Zielpromotoren (De Caestecker et al., 1998; Brown et al., 1999; Zhang et al., 1998; Wong et al., 1999).

Eine negative Beeinflussung des TGF- $\beta$ Signalweges wurde ebenfalls auf mehreren Ebenen beobachtet. Von Kretzschmar et al. (1997, 1999) wurde eine MAP-Kinase-vermittelte 
Inhibition der Kernlokalisation von Smad2 durch Phosphorylierung in seiner Linkerregion beobachtet. Mehrere Signalwege regulieren den TGF- $\beta$ Signalweg negativ, indem sie die Expression von Smad7 induzieren. Dazu gehören der TGF- $\beta$ Signalweg selbst, sowie die durch Interfron $\gamma$ aktivierten JAK und STAT Proteine (Ulloa et al., 1999). Ebenso wirkt der das Signalmolekül TNF $\alpha$ über den Transkriptionsfaktor NFKB/RelA (Bitzer et al., 2000). Weiterhin werden aktivierte Smad Proteine z.T. ubiquitiniert und proteolytisch abgebaut (Zhu et al., 1999; Lo und Massagué, 1999).

\subsection{Struktur und Funktion von Zinkfinger Proteinen}

Transkriptonsfaktoren besitzen über definierte DNA-Bindungsmotive sequenzspezifische DNA-Bindungsaktivität. Zink-koordinierte Finger sind sehr häufige DNA bindende Motive unter eukaryotischen Transkriptionsfaktoren, wobei stabil gefaltete Mini-Domänen in modularer Anordnung sequenzspezifisch DNA binden können. Zinkfinger Domänen werden nach der Anzahl und Position von Cysteinen und Histidinen in der Primärsequenz klassifiziert, die für die Koordination von Zink Ionen zur Verfügung stehen. Mittlerweile können mehr als 10 verschiedene Klassen von Zink-koordinierenden Domänen definiert werden. Die Cys-Cys, His-His $\left(\mathrm{C}_{2} \mathrm{H}_{2}\right)$ Klasse besitzt die größte Zahl von Mitgliedern, deren Prototyp TFIIIA ist (Brown et al., 1985). Andere Kompositionen von Cysteinen und Histidinen finden sich wie folgt: $\mathrm{C}_{8}$ (Steroid-Thyroid Rezeptoren), $\mathrm{C}_{6}$ (Gal4 Familie), $\mathrm{C}_{3} \mathrm{HC}$ (RING-Finger Familie), $\mathrm{C}_{2} \mathrm{HC}$ (retrovirales Nukleocapsid), $\mathrm{C}_{2} \mathrm{HC}_{5}$ (LIM-Domäne) und $\mathrm{C}_{4}$ (GATA-1) (Übersicht in Berg und Shi, 1996). Zinkfinger Domänen können außer der Bindung an DNA auch Interaktion mit anderen Proteinen oder mit RNA vermitteln. Sie spielen wichtige Rollen in Zellwachstum, Differenzierung und in der Entwicklung. Einige Zinkfinger Transkriptionsfaktoren wie TFIIIA und SP1 werden ubiquitär exprimiert. Andere dagegen werden sehr lokal exprimiert und haben sehr spezifische Aufgaben z.B. in der Segmentierung des Embryos, wie die Drosophila Proteine Krüppel und Hunchback (Stanojevic et al., 1989; Kadonaga et al., 1987; Treisman und Desplan, 1989).

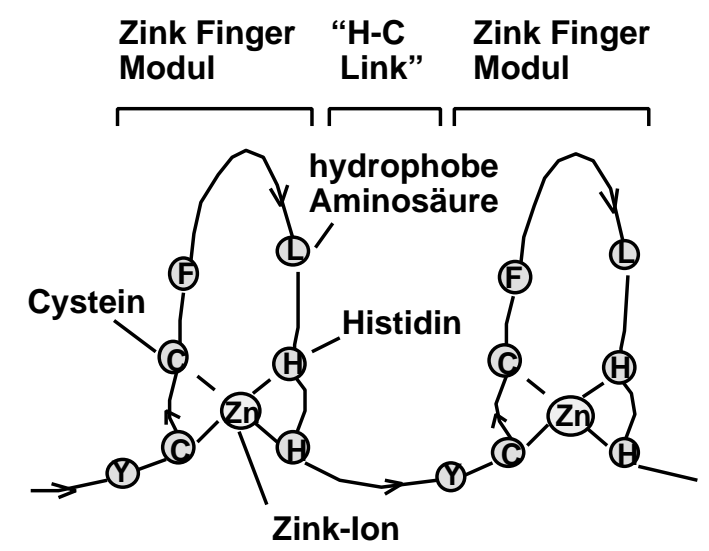

Abb. 1.9: Schematische Darstellung einer Zinkfinger-Domäne des $\mathbf{C}_{2} \mathbf{H}_{2}$-Typs. Zwei benachbarte Zinkfinger-Module sind durch einen konservierten H/C-Link miteinander verbunden. Die Cystein- und Histidin-Seitenketten koordinieren ein Zink-Ion, während drei weitere konservierte Aminosäuren (Phe, F; Leu, L; Tyr, Y) zur Bildung einer hydrophoben Struktur beitragen (nach Romaniuk, 1985) 


\subsection{Zinkfinger Multigenfamilien}

Das Genom von Vertebraten enthält schätzungsweise 1000 Gene für Zinkfinger Proteine des $\mathrm{C}_{2} \mathrm{H}_{2}$ Typs (Bellefroid et al., 1989). Ein Großteil der in Vertebraten vorkommenden Gene für Zinkfinger Proteine ist wahrscheinlich erst spät in der Evolution durch Gen-Amplifikation entstanden. Ihre biologische Funktion ist größtenteils unbekannt. Es existiert aber eine kleine Gruppe evolutionär hoch konservierter Zinkfinger Proteine, die als Trankriptions-Regulatoren während der Embryogenese und in der Zelldifferenzierung beteiligt sind (Übersicht in ElBaradi und Pieler, 1991; Pieler und Bellefroid, 1994). Diese lassen sich über Sequenz und Anordnung ihrer Zinkfinger Cluster folgenden Typen zuordnen: der EGR-, der WT1, der SP1, der GLI und der Schnurri-Typen.

Vertreter des Schnurri (Shn) Typs von Zinkfinger Proteinen zeichnen sich besonders durch ihre Größe aus, die 1000 bis 2700 Aminosäuren beträgt. Ihnen können die SIP-1 Gruppe, die EVI-1 Gruppe und die Schnurri Gruppe zugeordnet werden. Die Proteine besitzen meist zwei Zinkfinger Cluster, die weit voneinander entfernt im Protein positioniert sind und zueinander Sequenzhomologie aufweisen. Im den meisten Fällen besitzen beide Zinkfinger Cluster ähnliche bis identische DNA-Bindungseigenschaften, sind z.T. aber auch an Protein-Protein Wechselwirkungen beteiligt. Alle drei Gruppen besitzen eine Funktion in der TGF $\beta$ Signaltransduktion.

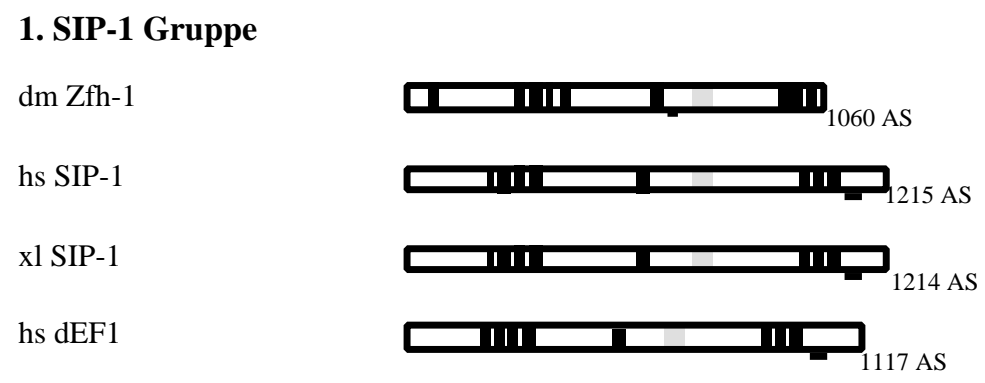

2. EVI-1 Gruppe hs EVI-1 mm EVI-1

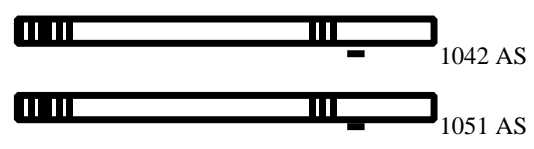

\section{Schnurri-Gruppe}

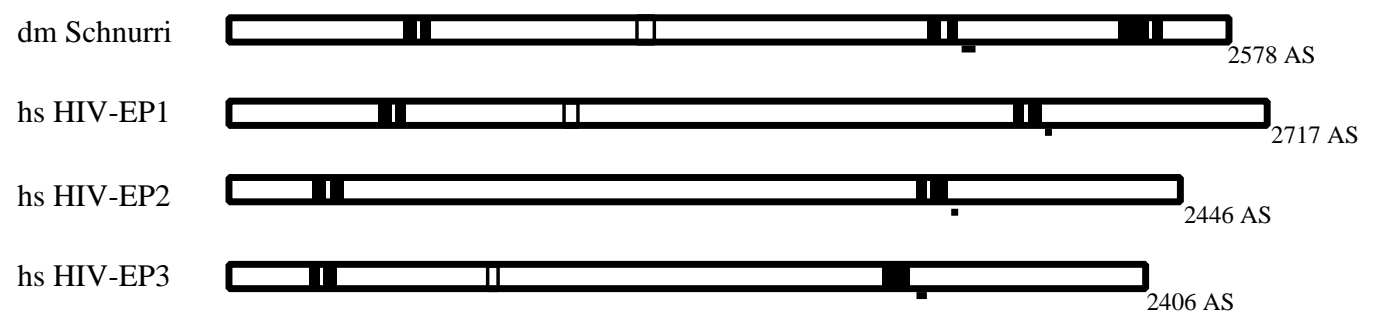

Abb. 1.10: Struktureller Vergleich von Schnurri-verwandten Zinkfinger Proteingruppen. Querbalken bezeichnen die Primärsequenz der Proteine. 
Die Proteine hSIP1 und XSIP1, "Smad Interacting Proteins" und das humane $\delta E F 1$, sowie das Drosophila Protein Zfh-1 bilden eine Gruppe DNA bindender Zinkfinger Proteine. hSIP1 und XSIP1 interagieren mit aktivierten Formen der Proteine XSmad1, -2 und hSmad3, und im Xenopus Embryo reprimiert hSIP1 den XBrachyury Promotor im Bereich der Neuralplatte (Verschueren et al., 1999; Remacle et al., 1999).

EVI-1 ist ein sequenzspezifischer Transkriptions-Repressor, der den antiproliferativen Effekt von TGF- $\beta$ inhibiert (Kurokawa et al., 1998a, 1998b; Bartholomew et al., 1997). Evi-1 interagiert über seine aminoterminale Zinkfinger Domäne mit der aktivierten Smad3-MH2 Domäne und rekrutiert gleichzeitig den Korepressor CtBP (Izutsu et al., 2001).

\subsection{Schnurri-Proteine i.e.S.}

Die Gruppe der Schnurri-verwandten Proteine enthält sehr große ZinkfingerTranskriptionsfaktoren mit Proteingrößen von mehr als $280 \mathrm{kDa}$. Zu ihnen gehören Schnurri (Drosophila melanogaster), HIV-EP1, HIV-EP2 und HIV-EP3 (human immunodeficiency virus-enhancer binding protein-1, -2 und -3; Nomenklatur der Vertebraten-Proteine in Anlehnung an Hicar et al., 2001). Allein das Drosophila Schnurri Protein besitzt am Carboxyterminus ein zusätzliches Cluster von 3 Zinkfingern. Die drei Schnurri-verwandten Proteine aus Säugern wurden vielfach unabhängig voneinander und oft nur partiell isoliert. Zwei Doppelzinkfinger Motive des $\mathrm{C}_{2} \mathrm{H}_{2}$ Typs sind weit voneinander entfernt in den Proteinen positioniert. Bis auf das Protein HIV-EP2 besitzen die Proteine im mittleren Bereich einen weiteren Zinkfinger des $\mathrm{C}_{2} \mathrm{HC}$ Typs. Außerhalb der konservierten Zinkfinger Domänen variieren die Sequenzen von HIV-EP1, -2 und -3 stark. Hicar et al. (2001) beschreiben weitere in Sequenz und relativer Position konservierte Domänen, deren Funktion jedoch nicht charakterisiert ist.

Die jeweiligen Doppelzinkfinger Domänen der Proteine sind zueinander stark sequenzhomolog. Eine Reihe von Untersuchungen zeigten eine spezifische Bindung der

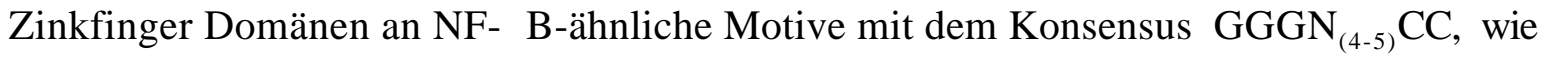
eines im HIV-LTR (Long Terminal Repeat) vorkommt (Dörflinger et al., 1999; Fan und Maniatis, 1990; Baldwin et al., 1990; Maekawa et al., 1989). Das $\kappa \mathrm{B}$ Motiv ist ein wichtiges Enhancer-Element, das die Genexpression als Antwort auf virale Antigene, Mitogene und Zytogene vermittelt (Übersichten in Baeuerle und Henkel, 1994; Ghosh et al., 1998). Neben rel/NF- $\kappa \mathrm{B}$ binden an die $\mathrm{\kappa B}$ Motive auch NKBF (neuronal $\kappa \mathrm{B}$ binding factor, Moerman $e t$ al., 1999), BETA (brain-specific enhancer binding transcription activator, Korner et al., 1989), und DBF-1 und -2 (developing brain factors-1 und -2, Cauley und Verma, 1994). Die genannten Proteinen werden im Gehirn exprimiert.

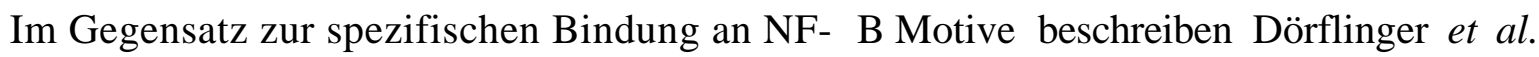
(1999) für HIV-EP2 eine spezifische Bindung an eine TC-reiche Squenz im Somatostatin Rezeptor II Gen Enhancer. Die Autoren vermuten für HIV-EP2 eine Bindung an häufig in 
Promotoren vorkommende GC- oder TC-reiche Sequenzelemente. Vermutet wird daher eine Funktionen als Adaptorprotein für andere Faktoren oder als "Entwindungshelfer" von Chromatin. Wu et al. (1993, 1996) beschreiben darüber hinaus eine Bindung der carboxyterminalen Zinkfinger Domäne des murinen HIV-EP3 an die V(D)J Rekombinations Signal Sequenz (RSS).

Das Protein HIV-EP1 wird in der adulten Maus differentiell exprimiert, mit einer höchsten Expression im Gehirn (Nakamura et al., 1990, Brady et al., 1995). Die Zinkfinger Domänen des humanen HIV-EP1 binden an Promotorsequenzen von Genen des "Major Histocompatibility Complex Class 1" (MHC-class1) (Van`T Veer et al., 1992; Baldwin et al., 1990; Mitchelmore et al., 1991; Rustgi et al., 1990). Tanaka et al., (2000) beobachteten für das murine Protein, dass im Stadium d8.5 des Mausembryos die Expression bei ansonsten ubiquitärer Verteilung in Regionen von undifferenziertem Knorpelgewebe (z.B. Rippen, Wirbelsäule) ausgespart ist. Die Autoren bemerken, dass HIV-EP1 in diesen Regionen als Transkriptions-Repressor des Col2A1 Kollagen Gen Enhancers wirkt, wobei nur die carboxyterminale Doppelzinkfinger Domäne an den Enhancer bindet. Muchardt et al. (1992) und Kantorow et al. (1993) berichten für das murine und das humane homologe Gen von Spleißvarianten, die kürzere Proteine hervorbringen, welche jeweils nur für die aminoterminale oder die carboxyterminale Doppelzinkfinger Domäne kodieren.

HIV-EP2 besitzt als einziges der Schnurri Proteine keinen $\mathrm{C}_{2} \mathrm{HC}$ Zinkfinger im mittleren Bereich des Proteins. In Säugern wird ein einziges Transkript von ca. $10 \mathrm{~kb}$ differenziell in adulten Geweben exprimiert (Makino et al., 1994, Ron et al., 1991, Nomura et al., 1991, Dörflinger et al., 1999). Die stärkste Genexpression findet sich bei Mensch, Maus und Ratte im Gehirn und in Skelettmuskeln (Ron et al.,1991, Makino et al., 1994, Dörflinger et al., 1999). Im Gehirn der Maus wird HIV-EP2 in definierten Domänen mit dem Initiatorprotein SEF-2 koexprimiert, mit dem es in Aktivierung der Genexpression des SomatostatinRezeptors-2 (SSTR-2) kooperiert. SSTR-2 reguliert die Ausschüttung einer Reihe von Hormonen aus der Adenohypophyse (Dörflinger et al, 1999).

Auch das Protein HIV-EP3 wird in der Maus differentiell exprimiert, mit einer stärksten Expression in der Thymusdrüse (Wu et al., 1993, 1996). Die Autoren berichten von zwei Spleißvarianten von $10 \mathrm{~kb}$ und $4.5 \mathrm{~kb}$ Länge, deren Funktion jedoch unbekannt ist.

Über keines der Proteine HIV-EP1, -2 und -3 ist eine Funktion während der frühen dorsoventralen Musterbildungsprozesse im Embryo bekannt. 


\subsection{Ziel der Arbeit}

Im Rahmen der Diplomarbeit "Isolierung und Charakterisierung von zum Drosophila melanogaster Zinkfinger Protein Schnurri homologen Proteinen aus dem Krallenfrosch Xenopus laevis" (Dürr 1997) wurden drei partielle, Schnurri-verwandte cDNA Sequenzen, Xshn1, -2 und -3, isoliert und in Ansätzen charaktierisiert. Es konnte eine Expression aller drei Gene maternal und während der frühen Musterbildungsprozesse des Xenopus Embryo nachgewiesen werden. Erste phänotypische Untersuchungen von Embryonen, denen ein dominant-negatives Fusionskonstrukt mikroinjiziert wurden, gaben deutliche Hinweise auf einen Einfluss von Schnurri-Proteinen auf die Regulation der frühen Musterbildung im Embryo.

Ziel der vorliegenden Arbeit war es, die Funktion der Xenopus Schnurri Proteine während der frühen Embryonalentwicklung zu spezifizieren und besonders eine mögliche Beteiligung in der Signalvermittlung der TGF $\beta$ Familie von Morphogenen zu untersuchen. Hierzu sollte zunächst das Expressionsverhalten der Gene genauer untersucht und Überexpressionsexperimente vervollständigt werden. Für eine funktionelle Analyse sollte die cDNA Sequenz mindestens eines der Xenopus Schnurris vervollständigt werden und schließlich eine Kooperation von Xshn mit Mitgliedern der Smad Familie von intrazellulären Vermittlern der TGF $\beta$ Liganden untersucht werden. 


\section{Material}

\subsection{Versuchstiere}

Der Afrikanische Krallenfrosch (Xenopus laevis) gehört zur Familie der zungenlosen Froschlurche (Pipidae) der Ordnung Anura. Pigmentierte und Albino-Frösche wurden von Dipl.-Ing. Horst Kähler (Hamburg) und den Firmen Xenopus I (Ann Arbor, USA) und Nasco (Ft. Atkinson, USA) erworben. Die Tiere wurden gemäß den Tierschutzbestimmungen gehalten und behandelt. Die Bestimmung der Embryonalstadien erfolgte nach Nieuwkoop und Faber (1967).

\subsection{Bakterienstämme und Genbanken}

\section{Bakterien:}

Es wurden E. coli-Stämme der folgenden Genotypen verwendet (Stratagene $\mathrm{GmbH}$, Heidelberg, New England Biolabs, Schwalbach/Taunus):

XL1-Blue $\quad \operatorname{rec} A 1$, endA1, gyrA96, thi-1, hsdR17, supE44, relA1, lac[F' proAB, lacI ${ }^{\mathrm{Z}} \mathrm{Z} \Delta \mathrm{M} 15, \mathrm{Tn} 10$ (Tet $\left.\left.^{\mathrm{r}}\right)\right]^{\mathrm{c}}$.(Bullock et al., 1987)

XL1-Blue MRF， D(mcrA)183, $\Delta$ (mcrCB-hsdSMR-mrr)173, endA1, supE44, thi-1, recA1, gyrA96, relA1 lac[F' $\left.\operatorname{proAB} \operatorname{lacI}^{\mathrm{q}} \mathrm{Z} \Delta \mathrm{M} 15, \operatorname{Tn} 10\left(\mathrm{Tet}^{\mathrm{r}}\right)\right]^{\mathrm{c}}$

XLOLR D(mcrA)183, $\Delta$ (mcrCB-hsdSMR-mrr)173, endA1, thi-1, recA1, gyrA96, relA1 lac[F' proAB, $\left.\operatorname{lacI}^{\mathrm{q}} \mathrm{Z} \Delta \mathrm{M} 15, \mathrm{Tn} 10\left(\mathrm{Tet}^{\mathrm{r}}\right)\right]^{\mathrm{c}}, \mathrm{Su}^{-}, \lambda^{\mathrm{r}}$

GM2163 $\mathrm{F}^{-}$ara-14 leuB6 fhuA31 lacY1 tsx78 glnV44 galK2 galT22 mcrA dcm-6 hisG4 rfbD1 rpsL136 dam13::Tn9 xylA5 mtl-1 thi-1 mcrB1 hsdR2

\section{cDNA-Banken:}

Zur Isolation von cDNA-Sequenzen standen zwei $\lambda$-Zap Express cDNA-Banken (Stratagene $\mathrm{GmbH}$, Heidelberg) zur Verfügung. Eine davon wurde von Dr. T. Hollemann erstellt und enthielt cDNA aus präparierten Köpfen bzw. Schwanzspitzen von Xenopus-Embryonen (Stadium 28-31, Hollemann et al., 1996). Die zweite cDNA Bank wurde von Dr. Yong Long Chen aus artifiziellem Chorda dosalis Gewebe hergestellt (Hollemann et al.,1998). Die Erststrang-Synthese der cDNAs erfolgte mit Hilfe von "random" (zufällig zusammengesetzten) oder „oligo-dT“ hexameren Oligonukleotiden. Die Einzelfraktionen der cDNA-Banken enthielten näherungsweise jeweils 50.000 unabhängige Phagen.

\subsection{Vektoren und Oligonukleotide}

Konstrukte, welche nicht im Rahmen dieser Arbeit erstellt wurden, sind mit entsprechenden Referenzen gekennzeichnet. 


\section{Vektoren}

Für Überexpressionsstudien wurden cDNAs in den pCS2+ Vektor (Rupp et al., 1994, Turner und Weintraub, 1994) bzw. dessen Derivate kloniert. Der pCS2+ Vektor besitzt einen starken eukaryotischen Promotor (sCMV IE94), gefolgt von einem prokaryotischen SP6-Promotor, der die in vitro Sythese der RNA erlaubt. Es folgt eine Polyadenylierungssequenz des SV40Virus, die von zwei Polylinkern umgeben ist. In SP6-transkribierter 'CAP'-mRNA war dieses Polyadenylierungssignal am 3'-Ende enthalten. Modifizierte pCS2+ Versionen konnten eine Epitopmarkierung (MT, 6× Myc) und/oder eine Kernlokalisationssequenz (NLS bzw. MTNLS) enthalten, oder zytoplasmatische Galaktosidase (cßgal) bzw. ein Fusionskonstrukt exprimieren. Um zu vermeiden, daß mögliche regulatorische Sequenzen der 5' oder 3' untranslatierten Region (UTR) die Translation der synthetischen mRNA beeinträchtigten, wurde nur der offene Leserahmen der cDNA subkloniert. Mit dem pCS2+MT Vektor konnten die synthetisierten Proteine mit sechs aminoterminalen MT-Epitopen markiert und mit antiMT-Antikörpern nachgewiesen werden. Der Vektor pCS2+NLSMT vermittelte den Proteinen ein zusätzliches Kernokalisationssignal. Mit Hilfe des pCS2+Flag Vektors konnten synthetisierte Proteine mit anti-Flag-Antikörpern nachgewiesen werden. Plasmide, die aus anderen Laboren bezogen wurden, sind durch Angabe der Erstveröffentlichung gekennzeichnet.

\section{Konstrukte und cDNAs für Überexpression im Xenopus Embryo}

$\underline{X S h n 1}$

pBK-CMV_Xshn1(3.34): enthält den 5' EcoRI/3' XhoI-klonierten 3'-Bereich von Xshn1 (1908 bp) sowie 1055 bp der vollständigen 3' untranslatierten Region incl. poly(A) Sequenz. Zur Synthese von antisense-RNA wurde mit EcoRI linearisiert und mit T7 transkribiert, um Antisense RNA von 2,6 kb Länge zu erhalten.

pGEM-T_Xshn1(31.3): enthält ein T/A kloniertes Fragment von 0,9 kb aus Xshn1, das durch PCR auf einem Phagengemisch der Fraktion 1.31 der Chorda dorsalis cDNA Bank erhalten wurde. Es wurden die Primer und pBK-CMV-5' und shn3 (degen) in der PCR verwendet.

\section{$\underline{X \operatorname{shn} 2}$}

pBK-CMV_Xshn2(3.19): enthält den 5' EcoRI/3' XhoI-klonierten 3'-Bereich von Xshn2 (3867 bp) sowie 830 bp der vollständigen 3' untranslatierten Region incl. poly(A) Sequenz von Xshn2.

pGEM-T_Xshn2(3.15): enthält ein T/A kloniertes PCR Produkt von 0,7 kb aus dem offenen Leserahmen von Xshn2. Die PCR wurde mit den Primern pBK-CMV-shn4 und Xshn2-19L auf einem Phagengemisch der Xenopus Kopf-cDNA Bank Fraktion 3.15 (Hollemann et al., 1996) durchgeführt.

pCS2+NLSMT_Xshn2ZF-enR: Der Vektor pCS2+NLSMT-enR (Bellefroid et al., 1996) enthält die Drosophila engrailed Repressionsdomäne (AS 2-298) (Smith et al., 1996), kloniert in die XbaI/SnaBI Stelle. In die EcoRI/XbaI Stelle wurde die PCR-amplifizierte Xshn2 
Doppelzinkfinger Domäne der AS GGFK-KCLE (78 AS) kloniert. Für sense mRNA wurde mit ApaI linearisiert und mit Sp6 transkribiert.

pCS2+NLSMT_Xshn2ZF-E1a: Die PCR-amplifizierte Xshn2 Doppelzinkfinger Domäne der AS GGFK-KCLE (78 AS) wurde in die EcoRI/XbaI Stelle vor die adenovirale Transaktivierungsdomäne (AS 121-220) des Proteins E1a (Richter et al., 1985) kloniert. Für sense mRNA wurde mit ApaI linearisiert und mit Sp6 transkribiert.

$\underline{X s h n 3}$

pBK-CMV_Xshn3(5.20): enthält den 5' EcoRI/3' XhoI-klonierten 3'-Bereich von Xshn3 (1,7 $\mathrm{kb})$ sowie $1,1 \mathrm{~kb}$ der vollständigen 3' untranslatierten Region incl. poly(A) Sequenz von Xshn3.

pGEM-T_Xshn3(11d/Xshn3-2L): enthält ein partielles Fragment (1486 bp) der Xshn3 cDNA Sequenz (bp 4647-6132), das in einer RT-PCR Reaktion auf Gesamt-RNA aus Xenopus Stadien mittels degeneriertem und spezifischem Oligonukleotid (shn11U-deg/Xshn3-2L) gewonnen wurde. Für antisense-RNA wurde mit ApaI linearisiert und mit SP6 transkribiert.

pGEM-T_Xshn3(6d/Xshn3-11L)): enthält ein partielles Fragment (1701 bp) der Xshn3 cDNA Sequenz (bp 3033-4733), das in einer RT-PCR Reaktion auf Gesamt-RNA aus Xenopus Stadien mittels degeneriertem und spezifischem Oligonukleotid (shn6U-deg/Xshn3-11L) gewonnen wurde. Für antisense-RNA wurde mit NotI linearisiert und mit T7 transkribiert.

pBK-CMV-Xshn3(3.25): enthält den 5' EcoRI/3' XhoI-klonierten Bereich von 2973 bp der cDNA von Xshn3 (bp 950-3922), isoliert aus einer Xenopus Kopf cDNA-Bank. Zur Synthese von antisense-RNA wurde mit NotI linearisiert und mit T7 transkribiert.

pBK-CMV_Xshn3(3.12): enthält den 5' EcoRI/3' Xhol-klonierten 5'-Bereich von Xshn3 (1037 bp) sowie 240 bp der 5' untranslatierten Region, isoliert aus einer Xenopus Kopf cDNABank. Zur Synthese von antisense-RNA wurde mit NotI linearisiert und mit T7 transkribiert.

pCS2+MT_Xshn3-ORF: enthält den offenen Leserahmen von Xshn3 (Nukleotide 241-7974 der cDNA). Das Konstrukt wurde in mehreren Schritten erstellt. Ein ausgehend von pBKCMV_Xshn3(3.12) erstelltes PCR-Fragment 1 (Xshn3-Mun1F(aa1)/Xshn3-XhoIR(aa1075)) von $3.3 \mathrm{~kb}$ Länge, das 5' von einer MunI-Schnittstelle und 3' von einer XhoI-Schnittstelle flankiert war, wurde in die EcoRI/XhoI Klonierungsstelle des pCS2+MT Vektors inseriert, wobei die EcoRI-Schnittstelle 5' zum Insert inaktiviert und außerdem das Start-ATG (Methionin) in TGG (Trp) konvertiert wurde. Zudem wurde 3' im Insert die letzte Aminosäure von von GTG (Valin) zu CTC (Lys) konvertiert. Im zweiten Schritt wurde ausgehend von pBK-CMV_Xshn3(5.20) ein 5' mit XbaI und 3' mit SpeI flankiertes PCR-Fragment 3 (Xshn3XbaIF(aa 1933)/Xshn3-SpeI-stop(aa2578)) von $2.0 \mathrm{~kb}$ Länge ungerichtet in das mit XbaI linearisierte Konstrukt pCS2+MT_Xshn3(1) inseriert, wobei die 3' gelegene XbaISchnittstelle eliminiert und ein Stop-Kodon eingefügt wurde. Im dritten Schritt wurde 
ausgehend von pGEM-T_Xshn3(11d/Xshn3-2L) ein 5' und 3' mit XbaI flankiertes PCRFragment "2b" (Xshn3-XbaIF(aa1490)/Xshn3-XbaIR(aa1933)) von 1.3 kb Länge ungerichtet in das mit XbaI linearisierte Konstrukt pCS2+MT_Xshn3(1+3) inseriert. Hierbei wurde im 5' Bereich des neu inserierten Fragmentes "2b" die erste Aminosäure von AAA (Lysin) zu AGA (Arginin) konvertiert. Im vierten Schritt wurde ausgehend von pGEM-T_Xshn3(6d/Xshn311L) ein 5' mit XhoI und 3' mit XbaI flankiertes PCR-Fragment "2a" (Xshn3XhoIF(aa1075)/Xshn3-XbaIR(aa1933)) von $1.2 \mathrm{~kb}$ Länge in das mit XhoI und XbaI linearisierte Konstrukt pCS2+MT_Xshn3(1+2b+3) inseriert. Hierbei wurde im 5'Bereich des Insertionsfragmentes "2a" eine stille Mutation eingefügt: GAA (Aspartat) wurde zu GAG konvertiert. Eine weitere stille Mutation wurde im 3’ Bereich des Insertionsfragmentes "2a" eingefügt, indem TCC (Serin) zu TCT konvertiert wurde. In diesem Klonierungsschritt wurde eine Dam-Methylierung der XbaI-Schnittstelle im Übergang der Insertionsfragmente $2 b$ und 3 des Konstruktes pCS2+NLSMT_Xshn3 $(1+2 b+3)$ genutzt, die ermöglichte, trotz zweier XbaI Schnittstellen im Vektor pCS2+MT_Xshn3(1+2b+3) diesen mit XbaI lediglich zu linearisieren.

pCS2+MT_Xshn3-ORF(wt): wurde aus dem Plasmid pCS2+MT_Xshn3-ORF hergestellt. Um drei Punktmutationen im Bereich des Insertionsfragmentes 2a von pCS2+MT_Xshn3ORF zu korrigieren (Arg>Gly bei bp 3323; Asp>Lys bei bp 3543; Glu>Gly bei bp 3580 des offenen Leserahmens), wurde zunächst das Konstrukt pCS2+NLSMT_Xshn3-Fragm.4 in drei Schritten durch PCR-gestützte in vitro Mutagenese korrigiert. Anschließend wurde aus dem Konstrukt pCS2+NLSMT_Xshn3-Fragm.6 über zwei XbaI Schnittstellen ein Fragment von $1.9 \mathrm{~kb}$ (bp 4467-6353) in das XbaI-linearisierte Konstrukt pCS2+NLSMT_Xshn3Fragm.4(wt) inseriert, um das größere Konstrukt pCS2+NLSMT_Xshn3-Fragm.4-6(wt) zu erhalten. Aus diesem konnte dann ein SacI/SpeI Fragment von 3.4 kb (bp 2234-5590 des offenen Leserahmens) in das ebenso linearisierte Konstrukt pCS2+NLSMT_Xshn3-ORF überführt werden, wodurch der mutierte Bereich durch den korrigierten ersetzt wurde. Das Produkt wurde mit dem Zusatz (wt) für ,,wildtyp“ versehen: pCS2+NLSMT_Xshn3-ORF(wt). Alle Klonierungsschritte wurden durch Sequenzierung auf ihre Richtigkeit überprüft.

pCS2+MT_Xshn3 3loop1: ist eine in vitro mutierte Form von pCS2+MT_Xshn3-ORF(wt), in der drei stille Mutationen bei Xshn3-Aminosäureposition 218, 220 und 221 eingefügt wurden. Die hierfür verwendeten Primer sind: Xshn3-loop1-F und Xshn3-loop1-R.

pCS2+Flag_Xshn3(ORF) und pCS2+Flag_Xshn3(ORF)(wt): enthalten den offenen Leserahmen von Xshn3 (Nukleotide 241-7974 der cDNA). Die Konstrukte wurden analog den Konstrukten pCS2+MT_Xshn3-ORF und pCS2+MT_Xshn3-ORF(wt) erstellt.

pCS2+Flag_Xshn3 $\Delta$ loop1: ist eine in vitro mutierte Form von pCS2+Flag_Xshn3-ORF(wt), in der drei stille Mutationen bei Xshn3-Aminosäureposition 218, 220 und 221 eingefügt wurden. Die hierfür verwendeten Primer waren: Xshn3-loop1-F und Xshn3-loop1-R.

pCS2+NLSMT_Xshn3(Fragm.1) und pCS2+MT_Xshn3(Fragm.1): enthalten die ersten 1956 bp des offenen Leserahmens von Xshn3 (Nukleotide 141-2204). Ausgehend von 
pCS2+MT_Xshn3-ORF wurde in einer PCR mit Linker-Oligonukleotiden (Xshn3MunIF(aa1)/Xshn3-XhoI-stop(aa652)) ein Fragment von 2.0 kb Länge amplifiziert und nach dem A/T-cloning System ungerichtet in den Vektor pGEM-T eingefügt (pGEMT_Xshn3(Fragm.1)). Das Start-ATG (Methionin) wurde durch das Linker-Oligonukleotid in TGG (Tryptophan) konvertiert. 3' der cDNA Sequenz wurde durch das Linker-Oligonukleotid ein zusätzliches Stop-Kodon (TAA) eingefügt. Nach Sequenzierung wurde das Insertionsfragment über seine Linker-Oligonukleotide mit $\mathrm{MfeI} / \mathrm{XhoI}$ isoliert und gerichtet in die EcoRI/XhoI Schnittstellen der Vektoren PCS2+NLSMT und PCS2+MT kloniert. Die 5' EcoRI-Schnittstellen wurde dabei zerstört. Zur Synthese von sense-mRNA wurde mit NotI linearisiert und mit Sp6 transkribiert.

pCS2+NLSMT_Xshn3(Fragm.2) und pCS2+MT_Xshn3(Fragm.2): enthalten die ersten 3225 bp des offenen Leserahmens von Xshn3 (Nukleotide 141-3465 der cDNA). Ausgehend von pCS2+MT_Xshn3-ORF wurde ein ClaI/XhoI Fragment von $3.5 \mathrm{~kb}$ (MT-Bereich bis bp 3225 des offenen Leserahmens von Xshn3) ausgeschnitten und in den ClaI/XhoI linearisierten Vektor pCS2+NLSMT bzw. pCS2+MT inseriert. Hierbei wurde das resultierende Proteinfragment am Carboxyterminus um vier Aminosäuren aus dem Vektor verlängert. Zur Synthese von sense-mRNA wurde mit NotI linearisiert und mit Sp6 transkribiert.

pCS2+NLSMT_Xshn3(Fragm.3) und pCS2+MT_Xshn3(Fragm.3): enthalten bp 12753227 des offenen Leserahmens von Xshn3. Ausgehend von pCS2+MT_Xshn3-ORF wurde in einer PCR mit Linker-Oligonukleotiden (Xshn3-MunIF(aa425)/Xshn3-XhoI-stop(aa1075)) ein Fragment von $3.2 \mathrm{~kb}$ Länge amplifiziert und nach dem A/T-cloning System ungerichtet in den Vektor pGEM-T eingefügt (pGEM-T_Xshn3(Fragm.3)). Hierbei wurde 5' durch das LinkerOligonukleotid die Klonierungsstelle MunI eingefügt, während 3' durch das LinkerOligonukleotid ein zusätzliches Stop-Kodon (TAA) angefügt wurde.

Das Start-ATG (Methionin) wurde durch das Linker-Oligonukleotid in TGG (Tryptophan) konvertiert. Nach Sequenzierung wurde das Insertionsfragment über seine LinkerOligonukleotide über MfeI/XhoI isoliert und gerichtet in die EcoRI/XhoI Schnittstellen der Vektoren PCS2+NLSMT und PCS2+MT kloniert. Die 5' EcoRI-Schnittstellen wurde dabei zerstört. Zur Synthese von sense-mRNA wurde mit NotI linearisiert und mit Sp6 transkribiert.

pCS2+NLSMT_Xshn3(Fragm.4)(wt) und pCS2+MT_Xshn3(Fragm.4)(wt): enthalten bp1626-5249 des offenen Leserahmens von Xshn3. Ausgehend von pCS2+MT_Xshn3-ORF wurde in einer PCR mit Linker-Oligonukleotiden (Xshn3-XhoI(aa542)/Xshn3-XhoIstop(aa1749)) ein Fragment von 3.6 kb Länge amplifiziert und nach dem A/T-cloning System ungerichtet in den Vektor pGEM-T eingefügt (pGEM-T_Xshn3(Fragm.4)). 3' der cDNA Sequenz wurde durch das Linker-Oligonukleotid ein zusätzliches Stop-Kodon (TAA) eingefügt. Durch PCR-gestützte in vitro Mutagenese wurde eine Punktmutation bei bp 3225 des klonierten Leserahmens eingefügt, um die dortige XhoI Restriktionsschnittstelle zu eliminieren. Lysin (CTC) wurde zu Valin (GTC) konvertiert, was einer Rückmutation innerhalb der Xshn3 Aminosäuresequenz entsprach (pGEM-T_Xshn3(Fragm.4- $\Delta$ XhoI)). Nach Sequenzierung wurde das Insertionsfragment 4 über seine Linker-Oligonukleotide mit XhoI isoliert und ungerichtet in die XhoI Schnittstelle des Vektors PCS2+NLSMT kloniert. Um drei 
Punktmutationen innerhalb des Fragmentes zu korrigieren (Arg>Gly bei bp 3323; Asp>Lys bei bp 3543; Glu>Gly bei bp 3580 des offenen Leserahmens), wurde die Sequenz der PCS2+NLSMT-Variante in drei Schritten durch PCR-gestützte Mutagenese korrigiert. Anschließend konnte das Insertionsfragment über seine flankierenden XhoI-Schnittstellen in den Vektor pCS2+MT transferiert werden. Zur Synthese von sense-mRNA wurde mit NotI linearisiert und mit Sp6 transkribiert.

pCS2+NLSMT_Xshn3(Fragm.5) und pCS2+MT_Xshn3(Fragm.5)(wt): enthalten bp 32255249 des offenen Leserahmens von Xshn3. Ausgehend von pCS2+MT_Xshn3-ORF wurde in einer PCR mit Linker-Oligonukleotiden (Xshn3-XhoI(aa1075)/Xshn3-XhoI-stop(aa1749)) ein Fragment von $2.0 \mathrm{~kb}$ Länge amplifiziert und nach dem A/T-cloning System ungerichtet in den Vektor pGEM-T eingefügt (pGEM-T_Xshn3(Fragm.5)). Im 5' Bereich des Insertionsfragmentes wurde dabei eine stille Mutation aus dem Konstrukt pCS2+MT_Xshn3ORF übernommen: GAA (Aspartat) war zu GAG konvertiert. 3' der cDNA Sequenz wurde durch das Linker-Oligonukleotid ein zusätzliches Stop-Kodon (TAA) eingefügt. Nach Sequenzierung wurde das Insertionsfragment 5 über seine Linker-Oligonukleotide mit XhoI isoliert und ungerichtet in die XhoI Schnittstelle des Vektors PCS2+NLSMT kloniert. Um drei Punktmutationen innerhalb des Fragmentes zu korrigieren (Arg>Gly bei bp 3323; Asp>Lys bei bp 3543; Glu>Gly bei bp 3580 des offenen Leserahmens), wurde die Sequenz der PCS2+NLSMT-Variante in drei Schritten durch PCR-gestützte in vitro Mutagenese korrigiert. Anschließend konnte das Insertionsfragment über seine flankierenden XhoI-Schnittstellen in den Vektor pCS2+MT transferiert werden. Zur Synthese von sense-mRNA wurde mit NotI linearisiert und mit Sp6 transkribiert.

pCS2+NLSMT_Xshn3(Fragm.6)(wt) und pCS2+MT_Xshn3(Fragm.6)(wt): enthalten bp 3225-6357 des offenen Leserahmens von Xshn3. Ausgehend von pCS2+MT_Xshn3-ORF wurde in einer PCR mit Linker-Oligonukleotiden (Xshn3-XhoI(aa1075)/Xshn3-XhoIstop(aa2119)) ein Fragment von 3.2 kb Länge amplifiziert und nach dem A/T-cloning System ungerichtet in den Vektor pGEM-T eingefügt (pGEM-T_Xshn3(Fragm.6)). Im 5'Bereich des Insertionsfragmentes wurde dabei eine stille Mutation aus dem Konstrukt pCS2+MT_Xshn3ORF übernommen: GAA (Aspartat) wurde zu GAG konvertiert. 3' der cDNA Sequenz wurde durch das Linker-Oligonukleotid ein zusätzliches Stop-Kodon (TAA) eingefügt. Nach Sequenzierung wurde das Insertionsfragment 6 über seine Linker-Oligonukleotide mit XhoI isoliert und ungerichtet in die XhoI Schnittstelle des Vektors PCS2+-NLSMT kloniert. Um drei Punktmutationen innerhalb des Fragmentes zu korrigieren (Arg>Gly bei bp 3323; Asp>Lys bei bp 3543; Glu>Gly bei bp 3580 des offenen Leserahmens), wurde die Sequenz der PCS2+NLSMT-Variante in drei Schritten durch PCR-gestützte in vitro Mutagenese korrigiert. Anschließend konnte das Insertionsfragment über seine flankierenden XhoISchnittstellen in den Vektor pCS2+MT transferiert werden. Zur Synthese von sense-mRNA wurde mit NotI linearisiert und mit Sp6 transkribiert.

pCS2+NLSMT_Xshn3(Fragm.7) und pCS2+MT_Xshn3(Fragm.7): enthält mit bp 56407736 das 3' Ende des offenen Leserahmens von Xshn3. Ausgehend von pCS2+MT_Xshn3ORF wurde in einer PCR mit Linker-Oligonukleotiden (Xshn3-XhoIF(aa1880)/Xshn3-XhoI- 
stop(aa2578)) ein Fragment von 2.1 kb Länge amplifiziert und nach dem A/T-cloning System ungerichtet in den Vektor pGEM-T eingefügt. Hierbei wurde 5' eine XhoI Restriktionsstelle eingefügt; 3' wurde durch das Linker-Oligonukleotid ein zusätzliches Stop-Kodon (TAA) angefügt. Nach Sequenzierung wurde das Insertionsfragment 7 über seine LinkerOligonukleotide mit XhoI ausgeschnitten und ungerichtet in die XhoI Schnittstellen der Vektoren PCS2+NLSMT und PCS2+MT kloniert. Zur Synthese von sense-mRNA wurde mit NotI linearisiert und mit Sp6 transkribiert.

pCS2+NLSMT_Xshn3(Fragm.8) und pCS2+MT_Xshn3(Fragm.8): enthält mit bp 63577736 das 3' Ende des offenen Leserahmens von Xshn3. Ausgehend von pCS2+MT_Xshn3ORF wurde in einer PCR mit Linker-Oligonukleotiden (Xshn3-XhoIF(aa1880)/Xshn3-XhoIstop(aa2578)) ein Fragment von 1.4 kb Länge amplifiziert, unmittelbar mit dem Restriktionsenzym XhoI behandelt, aufgereinigt und über seine Linker-Oligonukleotide ungerichtet in die XhoI Schnittstellen der Vektoren PCS2+NLSMT und PCS2+MT kloniert. Zur Synthese von sense-mRNA wurde mit NotI linearisiert und mit Sp6 transkribiert.

pCS2+NLSMT_Xshn3ZF: In die EcoRI/XbaI Stelle wurde die PCR-amplifizierte Xshn3 Doppelzinkfinger Domäne der AS GGYK-KCLD (78 AS) kloniert. Für die Synthese von sense-mRNA wurde mit NotI linearisiert und mit Sp6 transkribiert.

pCS2+NLSMT_Xshn3ZF-enR: Der Vektor pCS2+NLSMT-enR (Bellefroid et al., 1996) enthält die Drosophila engrailed Repressionsdomäne (AS 2-298) kloniert in die XbaI/SnaBI Stelle. In die EcoRI/XbaI Stelle des wurde die PCR-amplifizierte Xshn3 Doppelzinkfinger Domäne der AS GGYK-KCLD (78 AS) kloniert. Für die Synthese von sense mRNA wurde mit ApaI linearisiert und mit Sp6 transkribiert.

pCS2+NLSMT_Xshn3ZF-VP16: Der Vektor pCS2+NLSMT-VP16 enthält die carboxyterminale Transaktivierungsdomäne (AS 414-490) des viralen Proteins VP16 (Sadowski et al., 1988; Cress et al., 1991). In die EcoRI/XbaI Stelle wurde die PCRamplifizierte Xshn3 Doppelzinkfinger Domäne der AS GGYK-KCLD (78 AS) kloniert. Für die Synthese von sense-mRNA wurde mit NotI linearisiert und mit Sp6 transkribiert.

\section{Smad Konstrukte:}

pCS2+Flag-Smad1: enthält den offenen Leserahmen von Xenopus Smad1 (Nukleotide 1601551 der cDNA von 1769 bp) (Graff et al.,1996; EMBL accession number L77888). Der offene Leserahmen wurde in einer PCR mit den Primern Xsmad1-EcoRI-F(aa1)/Xsmad1Xho1Stop(aa464) amplifiziert, das Produkt direkt verdaut und gerichtet in den entsprechend linearisierten Vektor pCS2+FLAG inseriert. Zur Synthese von sense-mRNA wurde mit NotI linearisiert und mit Sp6 transkribiert.

pCS2+Smad1: enthält die gesamte Smad1 cDNA, kloniert von C. Blumenstock, zur Verfügung gestellt von C. Niehrs. Zur Synthese von sense mRNA wurde mit NotI linearisiert und mit Sp6 transkribiert. 
pCS2+Flag-Smad2: enthält den offenen Leserahmen von Xenopus Smad2 (Nukleotide 511448 der cDNA von 1709 bp) (Graff,J.M. et al., 1996; EMBL accession number L77885). Der offene Leserahmen wurde in einer PCR mit den Primern Xsmad2-EcoRI-F(aa1)/Xsmad1Xho1Stop(aa466) amplifiziert, das Produkt direkt verdaut und gerichtet in den entsprechend linearisierten Vektor pCS2+FLAG inseriert. Zur Synthese von sense-mRNA wurde mit NotI linearisiert und mit Sp6 transkribiert.

pRN3+Smad2: enthält den offenen Leserahmen (EcoRI/NotI PCR-Produkt) von Xenopus Smad2 im Vektor pRN3, zur Verfügung gestellt von C. Niehrs. Zur Synthese von sense mRNA wurde mit KpnI linearisiert und mit T3 transkribiert.

pCS2+Flag-Smad3: enthält den offenen Leserahmen von hSmad3 ohne das Start-Methionin (Nukleotide 70-1341 der cDNA von 2303 bp) (Riggins et al., 1996; EMBL accession number U68019). Der offene Leserahmen inklusive eines 5'-liegenden Flag-Epitopes und ohne das Start-Methionin von Smad3 wurden aus dem Vektor CS2-Flag-Smad3 (Joan Massagué, Sloan Kettering Institute, NY, USA) mit dem Restriktionsenzym EcoRI ausgeschnitten und ungerichtet in den ebenfalls EcoRI behandelten Vektor pCS2+ inseriert. Zur Synthese von sense-mRNA wurde mit NotI linearisiert und mit Sp6 transkribiert.

pCS2+Smad4-Flag: enthält den offenen Leserahmen von hSmad4 (Nukleotide 130-1784 der cDNA von 2681 bp) (Zhang et al.,1996; EMBL accession number NM_005359). Das Konstrukt PCD_D4_3'FLAG wurde 3' des offenen Leserahmens von hSmad4 und des 3' gelegenen FLAG-Epitopes mit dem Restriktionsenzym ApaI linearisiert, überhängende Enden zu stumpfen Enden überführt, das gesamte hSmad4-FLAG Insertionsfragment inclusive $66 \mathrm{bp}$ der 5'UTR von hSmad4 anschließend mit BamHI ausgeschnitten und gerichtet in den BamHI/SnaBI-linearisierten Vektor pCS2+ inseriert, wobei die SnaBI Schnittstelle zerstört wurde. Zur Synthese von sense-mRNA wurde mit NotI linearisiert und mit Sp6 transkribiert.

pCS2+Flag-Smad5: enthält den offenen Leserahmen von hSmad5 (Nukleotide 131-1525 der cDNA von 2200 bp) (Riggins et al., 1996; EMBL accession number U59913). Aus dem Konstrukt pFlag-CMV2-Smad5 wurde in zwei Schritten der offene Leserahmen von hSmad5 mit 30 Nukleotiden der Vektorsequenz aus pCF in die EcoRI/XbaI Schnittstelle des Vektors pCS2+FLAG integriert. Zunächst wurde ein ca. 450 Nukleotide großes EcoRI/XbaI Fragment des 3'Bereiches inklusive Stopkodon in den Zielvektor eingebracht, um im zweiten Schritt die EcoRI/EcoRI-isolierten 5' Region ungerichtet hinzuzufügen. Zur Synthese von sense-mRNA wurde mit NotI linearisiert und mit Sp6 transkribiert.

pCS2+Flag-Smad6: enthält den offenen Leserahmen von mSmad6 (1488 Nukleotide) (Imamura et al., 1997; EMBL accession number NM_008542). Aus dem Vektor FLAGmSmad6/pcDNA3 wurde mit den Restriktionsenzymen BamHI/XhoI das $1.5 \mathrm{~kb}$ lange Insertionsfragment FLAG-mSmad6 isoliert und gerichtet in den ensprechend linearisierten Vektor pCS2+ inseriert. Das Start-ATG in mSmad6 im Übergang zum FLAG-Epitop war mutiert. Zur Synthese von sense-mRNA wurde mit NotI linearisiert und mit Sp6 transkribiert. 
pCS2+Flag-Smad7: enthält den offenen Leserahmen von XSmad7 (Nukleotide 89-1234 der cDNA) (Nakayama et al.1998, umbenannt von XSmad8 zu XSmad7; EMBL accession number AF026125). Aus dem Vektor pCS2+XSmad7 wurde der offene Leserahmen von 1.1 kb mit den Primern XSmad7-EcoRIF(aa1)/XSmad7-XhoIStop(end) amplifiziert. Das PCRProdukt wurde direkt verdaut (EcoRI/XhoI) und gerichtet in den ensprechend linearisierten Vektor pCS2+FLAG inseriert. Das Start-ATG in mSmad7 im Übergang zum FLAG-Epitop war deletiert. Zur Synthese von sense-mRNA wurde mit NotI linearisiert und mit Sp6 transkribiert.

pCS2+MT-FAST-1(208): enthält die Kodons 62-519 von Xenopus FAST-1 und 171 Nukleotide der 3' UTR (Chen et al., 1996; EMBL accession number U70980). Zur Synthese von sense-mRNA wurde mit NotI linearisiert und mit Sp6 transkribiert.

pSP64T_BMP-4 (Köster et al., 1991; lin BamHI, transkr. SP6)

activinßB (Wittbrodt und Rosa, 1994; lin. XbaI, transkr. SP6)

caBMP-Rec. (Xu et al., 1995; lin. NotI, transkr. SP6)

dnARI (Hemmati-Brivanlou und Melton, 1992; lin. EcoRI, transkr. SP6)

dn BMP-Rec.(Graff et al., 1994; lin. EcoRI, transkr. SP6)

pCS2+NLSßgalactosidase (Chitnis et al, 1995; lin. NotI, transkr. SP6)

pCS3MTSip1ORF (Verschueren et al., 1999; lin. Asp718, transkr. SP6) enthält den offenen

Leserahmen von 3645 bp des murinen SIP1.

pCS3MTSip1 $\triangle$ SBD (Verschueren et al., 1999; lin. Asp718, transkr. SP6) enthält den offenen Leserahmen von SIP1 mit einer internen Deletion der minimalen Smad-Interaktionsdomäne bei AS 437-487.

\section{Markerkonstrukte zur Synthese von antisense RNA für Hybridisierungen}

Xbra: $\quad$ (Cunliffe und Smith, 1992; lin Bgl II, transkr.T7)

Gsc: $\quad$ (Blumberg et al., 1991; lin EcoRI, transkr.T7)

\section{Oligonukleotide}

Oligonukleotide wurden von den Firmen NAPS (Göttingen), Eurogentech (Seraing, Belgien), MWG-Biotech (Ebersberg) und Gibco (Karlsruhe) bezogen. Die Sequenzen sind in 5' $\rightarrow 3$ ' Richtung wiedergegeben. Die variablen Nukleotide der degenerierten Oligonukleotide sind in folgender Weise abgekürzt:

$$
\begin{array}{llll}
\mathrm{h}=\mathrm{A} / \mathrm{C} / \mathrm{T} & \mathrm{y}=\mathrm{C} / \mathrm{T} & \mathrm{r}=\mathrm{A} / \mathrm{G} & \mathrm{b}=\mathrm{G} / \mathrm{T} / \mathrm{C} \\
\mathrm{n}=\mathrm{A} / \mathrm{C} / \mathrm{G} / \mathrm{T} & \mathrm{v}=\mathrm{G} / \mathrm{A} / \mathrm{C} & \mathrm{w}=\mathrm{A} / \mathrm{T} & \mathrm{d}=\mathrm{G} / \mathrm{A} / \mathrm{T} \\
\mathrm{s}=\mathrm{C} / \mathrm{G} & \mathrm{m}=\mathrm{A} / \mathrm{C} & \mathrm{k}=\mathrm{G} / \mathrm{T} &
\end{array}
$$


$\underline{\mathrm{Xshn} 1}$

Xshn1-5L

Xshn1-6U

Xshn1-7U

Xshn1-8U

Xshn1-9L

Xshn1-10L

Xshn1-11U

Xshn1-12L

Xshn1-13L

Xshn1-14L

Xshn1-15U

Xshn1-16L

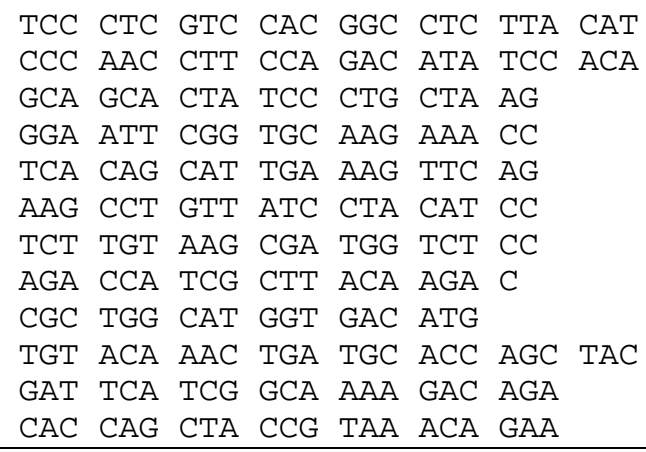

$\underline{\underline{X s h n} 2}$

Xshn2-1L

AAT GTC TTT CTC TCC ATG G

Xshn2-2U

Xshn2-3L

AAG CAG AGG AAT GCA GTA G

Xshn2-4L

CCA TCT GCT ATA CTG AGA

Xshn2-5U

GTT CTA CTG CAC TTA ATT C

Xshn2-6L

Xshn2-7U

CAG TTC TCA GAT GCA GAG

ACA GGA TCA GAG TCG TAC

Xshn2-8U

ATT TCT CAC CAG GGC TAT G

Xshn2-9L

CAT GGA AGA CAG AAC TGG

Xshn2-12L

ACA GGA TCA GAG CTG TC

TTG CAG TAT CCT CAG ACA GAA ACA C

Xshn2-13U

Xshn2-14L

CTG TGG CAT AAT TCC TCT TCT

CTG TAA ATG GTG CTC AAA ATG

CTG TGG CAT AAT TCC TCT TCT

Xshn2-16L

CTG TAA ATG GTG CTC AAA ATG

Xshn2-17U

Xshn2-18L

Xshn2-19L

TCA ACT ACC TGC CGA GAA ACT G

GGC CGG GTA CAG AAA GGG AAT AG

GGG CAG TTT CTC GGC AGG TAG TTG

AGA GCC GGA CTT GTT GTT C

TCC CCA GAT TGA GTC CAT TC

Xshn2-21L

TAT ATC GAG GTC TGA GAG CAT TGG

AGC GTG GGT GAT GAG GAA GAT A

GTT GTG ATT GCT GAG ATG GAG ATG

ATG AAA TGG GAC GAC CTG GCT GAT

Xshn2-23U

Xshn2-25L GCG GAA TTC AGG AGG TTC AAA TCA AAT GAA GAC

Xshn2-ZF-EcoRI-F ATC TCT AGA TCC AGG CAT TTC TTC ATA TGT GC

Xshn2-ZF-XbaI-R

$\underline{\underline{X} \operatorname{shn} 3}$

Xshn3-1U

Xshn3-2L

Xshn3-3U

Xshn3-4L

Xshn3-5U

Xshn3-7L

Xshn3-8L

Xshn3-9U

Xshn3-10L

Xshn3-11L

Xshn3-12U

Xshn3-13L

Xshn3-14L

Xshn3-15L

Xshn3-15U

Xshn3-16L

Xshn3-17L

Xshn3-18U

Xshn3-19L

Xshn3-20L

Xshn3-21L

ACC TCT CAT CCA AAG CAC G

TCC ACG GAT GTA CAC ATA C

TCA AGA TAC AGA TGA CTC

TCT GAA GGC ACA ATT GTC

ATC CAG AGG CAG AAG CAG

CTG CAT TCA GAG TAA GCC

AAG GTG AAT TTC TCA GAC TTC TG

GCA TTA GAA CTA CGG CTG ACA

TAG GAT TTG GCA CGG ACA CT

AGT TCT AAT GCT ATG TTT GGA TGC

TAC TGG GGC ATT AGA ACA ACC TT

GAC ATT TCA CTT CCA CTC TTT CTT G

AAG GTT GTT CTA ATG CCC CAG TA

GTC TCA TTT CTC TTG GCA CAC C

AGC CAA TCA ATT AAG GGT TCT A

TGC ACA TCT GTT CTC CGC TTA T

TGG CTT ATC TGG CTG CTC TGA T

TGG CCT GCG GAC TGA TTC TA

ATA TGT AGG ACT TTG GTG AGT

GGT TCT TCT GAG ATT TCA GT

ACT ATC ATG AAC CTC AGA C

Xshn3-24L (stop)

TTA CAT TGT TCC CCT GCT ATG 
Xshn3-25L (stop)

Xshn3-26U

Xshn3-27U

Xshn3-28L

Xshn3 ZF EcoRI-F

Xshn3 ZF XbaI-R

Xshn3-F MunI aa1

Xshn3-R XhoI aa1075

Xshn3-F XhoI aa1075-2

Xshn3-R XbaI aa1933-1

Xshn3-R XbaI aa1933-2

Xshn3-R SpeI aa2578

Xshn3-R XbaI aa1490

Xshn3-F MunI 426 (neu)

Xshn3-stop XhoI 542

Xshn3-F XhoI 542

Xshn3-stop XhoI 652

Xshn3-stop XhoI 1075

Xshn3-F XbaI aa1490

Xshn3-R XhoI 1749

Xshn3-stop XhoI 1749

Xshn3-stop XhoI 1945

Xshn3-stop XhoI 2118

Xshn3-F XhoI 2119

Xshn3-stop XhoI 2119

Xshn3-R Xhol 2578

Xshn3-Mut F XhoI 1075

Xshn3-Mut R XhoI 1075

Xshn3-loop1-F

Xshn3-loop1-R

Xshn3-F GR 1108-2

Xshn3-R GR 1108-2

Xshn3-F KN 1180-2

Xshn3-R KN 1180-2

Xshn3-F GD 1193-2

Xshn3-R GD 1193-2
TCA CAC TGT CTT ACT CTT TG

TGA CCA GGA AAC ACA TGA A

ACA ACC ATC CAT GGA AGT TA

CCT ACT GGA ATC ATG CTG TA

GCG GAA TTC TGG CGG ATA AAA TCA AAT GA

GTC TCT AGA TCC AAA CAC TTT TTG CTG TGG

GCG CAA TTG GCC TCG GAC AAA ACA GAT CCA

ACA CCT CGA GTC TTT CTT GGG AAA CAA TAT T

AAG ACT CGA GGT GAA ATG TCA AGG AAC AGG A

AGG ATT CTA GAT CTT GTT CGG TAC T

CGA ACA AGA TCT AGA ATC CTT TC

GGT AAC TAG TAT TTA GGT TGC TAT AAC

TAT GTC TAG ATG CAG AAA GTT TGC TT

GCG CAA TTG TGG CCT GCG GAC TGA TTC TAG

AGA CTC GAG AAC TCT GGG GCT ATC AGC

GTT CTC GAG TCT GCC AGT GAA CAT

GTC CTC GAG TTA TGA GGg TTG AAG TTT TAG GA

CAC CTC GAG TTA TCT TTC TTG GGA AAC AAT ATT

TGC ATC TAG ACA TAG CAT TAG AAC TAC G

AGC CTC GAG AAC CTC TTC TGA TTT ATC A

AGC CTC GAG TTA AAC CTC TTC TGA TTT ATC A

AGC CTC GAG TTA TAC TCT CCT TGG CTC ATT

AGA CTC GAG TTA GTC CAT AGA ATT GGA CTG GGA

TAT CTC GAG TTA ACT GTC CAT AGA ATT GGA CTG

TAT CTC GAG TTA ACT GTC CAT AGA ATT GGA CTG

AAG CTC GAG TTA GGT TGC TAT AAC CAG CC

GTT TCC CAA GAA AGA GTC GAG GTG AAA TGT CAA GG

CCT TGA CAT TTC ACC TCG ACT CTT TCT TGG GAA AC

CTG AAA AAC AAG GGC ATA AAG TCG CAC TGA AAC TAC TGC

GCA GTA GTT CAG GTG CGA CTT TAT GCC CTT GTT TTT CAG

ATA GAC TCT GTT GAA AGA AAT TCA CCT GTT CC

GGA ACA GGT GAA TTT CTT TCA ACA GAG TCT AT

CCG TCT AGT ACG TCA ATA TAA TAT TCA GGT TCC AGA A

TTC TGG AAC CTG AAT ATT ATA TTG ACG TAC TAG ACG G

GGT TAC TGA AGA ACC AGA TAA AGA TCC AGA AAT CCA AGC

GCT TGG ATT TCT GGA TCT TTA TCT GGT TCT TCA GTA A CC

\section{degenerierte Oligonukleotide}

\begin{tabular}{llllllllllll}
\hline Xshn-1d & CAR & CAY & AAY & ATH & CAR & GTI & CCI & GAR & ATH & CG & \\
Xshn-2d & AAR & TAY & ATH & TGY & GAR & GAR & TGY & GGI & ATH & CG & \\
Xshn-3d & CAY & TTY & TTC & ATR & TGI & GCY & TTI & GAY & TTC & ATR & TG \\
shn-4U & CAR & AAR & CCI & GGI & AAR & TAY & ATI & TGY & CAR & TAY & TG \\
shn-4d & GAR & GAR & GCN & CAY & AAR & AAR & GAR & CAY & AAR & CC & \\
Shn-deg-4U & ARA & ARC & MNG & GNA & ART & AYA & THT & GYS & MNT & AYT & G \\
Shn-deg-5U & AAR & GAR & CCN & GAR & AAR & ACN & GAR & GAR & TTY & CAR & TGG \\
Shn-deg-6U & GAR & AAY & TTY & GAR & AAY & CAY & AAR & AAR & TTY & TAY & TG \\
shn-7U & ATG & GGN & KRN & AAR & GGN & ATH & ATG & GA & & & \\
shn-8U & AAR & CNT & AYA & ARA & ART & GGG & A & & & & \\
shn-9L & CKR & CAN & GRY & TCR & CAY & TCR & AAC & AT & & & \\
Shn-deg-10L & TGR & TAY & TTN & GGN & GCR & AAR & CAR & TC & & & \\
shn-11L & GAR & GAY & TGY & TTY & GCN & CCN & AAR & TAY & CA & & \\
C2HC R & TAI & TAY & TTY & TTR & TGI & TGY & TCI & TAR & TTI & TC & \\
\hline & & & & & & & & & & &
\end{tabular}




\section{Smad Oligonukleotide}

\begin{tabular}{|c|c|c|c|c|c|c|c|c|c|c|}
\hline Xsmad1 EcoR-F & $\mathrm{CAC}$ & GAA & $\mathrm{TTC}$ & AAA & TGT & GAC & GAG & $\mathrm{CTT}$ & GTT & $\mathrm{CTC} \mathrm{C}$ \\
\hline Xsmad1 XhoI-R & AGG & $\mathrm{CTC}$ & GAG & TTA & AGA & GAC & CGA & GGA & GAT & GGG AT \\
\hline Xsmad1-F-2 & $\mathrm{GCT}$ & TGT & $\mathrm{TCT}$ & $\mathrm{CCT}$ & $\mathrm{TCA}$ & $\mathrm{CCA}$ & G & & & \\
\hline Xsmad2 XhoI-R & AGG & $\mathrm{CTC}$ & GAG & TTA & GGA & $\mathrm{CAT}$ & $\mathrm{GCT}$ & TGA & $\mathrm{GCA}$ & GCG \\
\hline Xsmad2-F-2 & $\mathrm{CCG}$ & $\mathrm{CAT}$ & GTT & $\mathrm{ATC}$ & $\mathrm{TAC}$ & TGC & A & & & \\
\hline Xsmad7-F EcoRI aa1 & GCG & GAA & TTC & $\mathrm{ATT}$ & CAG & GAC & CAA & ACG & ATC & GGT \\
\hline Xsmad7-stop XhoI(end) & CAG & $\mathrm{CTC}$ & GAG & TCA & CCG & $\mathrm{GTT}$ & $\mathrm{ATT}$ & $A A A$ & TAT & CAC \\
\hline
\end{tabular}

\section{Marker Oligonukleotide für RT-PCR}

\begin{tabular}{|c|c|c|c|c|c|c|c|c|}
\hline CG13-F & AGT & TGT & TGA & TTT & TGT & GAA & $\mathrm{AAC}$ & $\mathrm{C}$ \\
\hline CG13-R & $\mathrm{CTT}$ & $\mathrm{CTT}$ & CTA & $\mathrm{AAT}$ & CAA & CAA & $\mathrm{ACA}$ & GG \\
\hline N-CAM F & $\mathrm{CAC}$ & $\mathrm{AGT}$ & TCC & $\mathrm{ACC}$ & AAA & TGC & & \\
\hline N-CAM R & GGA & ATC & AAG & CGG & $\mathrm{TAC}$ & AGA & & \\
\hline H4-F & CGG & GAT & $\mathrm{AAC}$ & $\mathrm{ATT}$ & CAG & GGT & ATC & $\mathrm{ACT}$ \\
\hline H4-R & $\mathrm{ATC}$ & $\mathrm{CAT}$ & GGC & GGT & $\mathrm{AAC}$ & TGT & $\mathrm{CTT}$ & $\mathrm{CCT}$ \\
\hline Mix.2-F & GGT & TTC & AGC & $\mathrm{ATC}$ & $\mathrm{TCA}$ & GCG & $\mathrm{ACG}$ & \\
\hline Mix.2-R & TTG & GTA & TGA & GGA & $\mathrm{GCT}$ & $\mathrm{GTT}$ & AGG & \\
\hline XAG-F & GAG & TTG & $\mathrm{CTT}$ & $\mathrm{CTC}$ & TGG & $\mathrm{CA}$ & & \\
\hline XAG-R & CTG & $\mathrm{ACT}$ & GTC & CGA & $\mathrm{TCA}$ & GAC & & \\
\hline Pint-F & $\mathrm{CCT}$ & TAG & $\mathrm{CCC}$ & $\mathrm{TAC}$ & $\mathrm{ATC}$ & TGA & $\mathrm{ACA}$ & A \\
\hline Pint-R & TAA & AGG & GAG & CTG & AGG & $\mathrm{ATA}$ & GGT & $\mathrm{C}$ \\
\hline Chordin-F & $\mathrm{CTA}$ & AGG & GCC & $\mathrm{CAT}$ & GGT & $\mathrm{TCA}$ & CGA & $\mathrm{T}$ \\
\hline Chordin-R & $\mathrm{ATT}$ & GGC & $\mathrm{ACG}$ & GAT & TGG & $\mathrm{GTT}$ & GGT & A \\
\hline XWnt8-F & TGT & GGC & CGG & GTC & TGA & $\mathrm{ACT}$ & TAT & $\mathrm{TTT}$ \\
\hline Xwnt8-R & GTC & ATC & TCC & GGT & GGC & $\mathrm{CTC}$ & TGT & $\mathrm{TCT}$ \\
\hline Xbra-F & GGA & TCG & TTA & $\mathrm{TCA}$ & $\mathrm{CCT}$ & $\mathrm{CTG}$ & & \\
\hline Xbra-R & GTG & TAG & $\mathrm{TCT}$ & GTA & GCA & GCA & & \\
\hline Xgsc-F & $\mathrm{ACA}$ & $\mathrm{ACT}$ & GGA & AGC & $\mathrm{ACT}$ & GGA & & \\
\hline Xgsc-R & $\mathrm{TCT}$ & $\mathrm{TAT}$ & TCC & AGA & GGA & $\mathrm{ACC}$ & & \\
\hline Noggin-F & AGT & TGC & $A G A$ & TGT & GGC & $\mathrm{TCT}$ & & \\
\hline Noggin-R & AGT & $\mathrm{CCA}$ & AGA & GTC & $\mathrm{TCA}$ & GCA & & \\
\hline Xvent1-F & GCA & $\mathrm{TCT}$ & $\mathrm{CCT}$ & TGG & $\mathrm{CAT}$ & $\mathrm{ATT}$ & TGG & \\
\hline Xvent1-R & TTC & $\mathrm{CCT}$ & $\mathrm{TCA}$ & GCA & TGG & TTC & $A A C$ & \\
\hline Xvent2-F & TGA & GAC & TTG & GGC & $\mathrm{ACT}$ & GTC & TG & \\
\hline Xvent2-R & $\mathrm{CCT}$ & CTG & TTG & $\mathrm{AAT}$ & GGC & TTG & $\mathrm{CT}$ & \\
\hline
\end{tabular}

\section{Sonstige Oligonukleotide}

\begin{tabular}{llllllll}
\hline T7 & TAA & TAC & GAC & TCA & CTA & TAG & GG \\
T7 $($ pCS $)$ & ATA & CGA & CTC & ACT & ATA & GG & \\
T3 & ATT & AAC & CCT & CAC & TAA & AGG & GA \\
SP6 & GAT & TTA & GGT & GAC & ACT & ATA & G \\
MT (RR67) & GAG & CTT & GGG & CGA & CCT & CA & \\
PBK-CMV-5 & CGC & GCC & TGC & AGG & TCG & ACA & CTA \\
\hline
\end{tabular}

\subsection{Enzyme und Reaktionssysteme (Kits)}

\section{Enzyme:}

alkalische Phosphatase (1 U/ $\mu \mathrm{l})$

Restriktionsendonukleasen

RNAsin $(40 \mathrm{U} / \mu \mathrm{l})$

RNase A
Boehringer Mannheim, Mannheim New England Biolabs GmBH, Schwalbach Promega Deutschland GmbH, Mannheim Sigma-Aldrich Chemie GmbH, Deisenhofen 
RNase T1

Proteinase K

Lysozym

SP6 RNA-Polymerase $(50 \mathrm{U} / \mu \mathrm{l})$

T7 RNA-Polymerase (50 U/ $\mathrm{Ll})$

Taq DNA-Polymerase (5 U/ $\mu \mathrm{l})$

Pfu turbo DNA-Polymerase $(2.5 \mathrm{U} / \mu \mathrm{l})$

T4 DNA-Ligase (1 U/ $\mu \mathrm{l})$

T4-Polynukleotidkinase (10 U/ $\mu \mathrm{l})$

Lambda-Phosphatase (5U/ml)
Sigma-Aldrich Chemie GmbH, Deisenhofen

Merck KGaA, Darmstadt

Biomol GmbH, Hamburg

Stratagene GmbH, Heidelberg

Stratagene GmbH, Heidelberg

Perkin-Elmer, Weiterstadt

Stratagene GmbH, Heidelberg

GibcoBRL, Eggenstein

New England Biolabs GmBH, Schwalbach

USB, (Amersham Pharmacia), Freiburg

$\underline{\text { Kits: }}$

PCR purification Kit

QIAEX Gel Extraction Kit

Qiagen GmbH, Hilden

Qiagen GmbH, Hilden

RNeasy Mini Kit

RT-PCR Kit

SP6 mMESSAGE mMACHINE Kit

Qiagen $\mathrm{GmbH}$, Hilden

Perkin-Elmer, Weiterstadt

Ambion Inc., Austin, USA

pGEM-T Kit

Promega Deutschland GmbH, Mannheim

TNT-Coupled Reticulocyte Lysate System Promega Deutschland GmbH, Mannheim

QuikChange Site-Directed Mutagenesis Kit Stratagene GmbH, Heidelberg

RNA Transcription Kit

Stratagene GmbH, Heidelberg

Dye Terminator Cycle Sequencing Kit

Applied Biosystems GmbH, Weiterstadt

\subsection{Radioisotope}

$\left[\gamma{ }^{32} \mathrm{P}\right]-\mathrm{dATP},>5.000 \mathrm{Ci} / \mathrm{mmol}$

$\left[{ }^{35} \mathrm{~S}\right]$-Methionin, $1.000 \mathrm{Ci} / \mathrm{mmol}$

Amersham Buchler, Braunschweig

Amersham Buchler, Braunschweig

\subsection{Medien und Lösungen}

Alle nicht gesondert aufgeführten Medien und Pufferlösungen wurden nach Sambrook et al. (1989) hergestellt. Wenn nicht anders beschrieben, wurden die Lösungen mit doppelt destilliertem Wasser angesetzt und durch Autoklavieren für $20 \mathrm{~min}$ bei $121^{\circ} \mathrm{C}$ sterilisiert.

Hitzelabile Substanzen wurden durch Membranfilter (Porendurchmesser $0.2 \mu \mathrm{m}$, Sartorius) sterilfiltriert. Nährmedien wurden nach dem Autoklavieren bis auf ca. $50^{\circ} \mathrm{C}$ abgekühlt und mit den entsprechenden Selektivantibiotika versetzt.

\section{Nährmedien:}

Luria-Bertani (LB)-Medium: 1\% (w/v) Bacto-Trypton (DIFCO), 0.5\% (w/v) Hefeextrakt (DIFCO), $1 \%$ (w/v) NaCl, pH 7.5

LB-Agar: $1.5 \%(w / v)$ Agar (DIFCO) in LB-Flüssigmedium

NZY-Medium: 1\% (w/v) NZ-Amin (Casein Hydrolysat), 0.5\% (w/v) Hefeextrakt (DIFCO), $0.5 \%$ (w/v) NaCl, $8.1 \mathrm{mM} \mathrm{MgSO} 47 \mathrm{H}_{2} \mathrm{O}, \mathrm{pH} 7.5$ 
NZY-Agar: $1.5 \%(w / v)$ Agar in NZY-Flüssigmedium

NZY-Top-Agar: $0.7 \%$ (w/v) Agar in NZY-Flüssigmedium

\section{Antibiotika:}

Antibiotika-Stammlösungen wurden aliquotiert und in $1.5 \mathrm{ml}$-Eppendorfgefäßen bei $-20^{\circ} \mathrm{C}$ aufbewahrt.

Ampicillin: $100 \mathrm{mg} / \mathrm{ml}$ in $\mathrm{dH}_{2} \mathrm{O}$, Verdünnung 1:1.000 (Endkonzentration: $100 \mu \mathrm{g} / \mathrm{ml}$ )

Tetracyclin: $5 \mathrm{mg} / \mathrm{ml}$ in Ethanol, Verdünnung 1: 400 (Endkonzentration: $12.5 \mu \mathrm{g} / \mathrm{ml}$ )

Kanamycin: $10 \mathrm{mg} / \mathrm{ml}$ in $\mathrm{dH}_{2} \mathrm{O}$, Verdünnung 1: 200 (Endkonzentration: $50 \mu \mathrm{g} / \mathrm{ml}$ )

Penicillin/Streptomycin: $10.000 \mathrm{U} / \mathrm{ml}$ Penicillin, $10 \mathrm{mg} / \mathrm{ml}$ Streptomycin (Sigma),

Verdünnung 1:1.000 - 1:10.000

\section{Puffer und Stammlösungen:}

Tris-HCl-Puffer (pH 7.5 oder 9.5): $1 \mathrm{M}$ Tris-HCl, pH 7.5 bzw. 9.5

TBE (10 x): $0.9 \mathrm{M}$ Tris Base, $0.9 \mathrm{M}$ Borsäure, 0.02 M EDTA

PBS (10 x): 8\% (w/v) NaCl, 2\% (w/v) KCl, $65 \mathrm{mM} \mathrm{Na}_{2} \mathrm{HPO}_{4} 12 \mathrm{H}_{2} \mathrm{O}, 18 \mathrm{mM} \mathrm{KH}_{2} \mathrm{PO}_{4}, \mathrm{pH}$ 7.2-7.4

SSC (20 x): $3 \mathrm{M} \mathrm{NaCl}, 0.3 \mathrm{M} \mathrm{Na-Citrat,} \mathrm{pH}$ 7.2-7.4

SSPE (20 x): $3 \mathrm{M} \mathrm{NaCl}, 0.2 \mathrm{M} \mathrm{Na}_{2} \mathrm{HPO}_{4} \cdot 2 \mathrm{H}_{2} \mathrm{O}, 20 \mathrm{mM}$ EDTA, pH 7.4

$\mathbf{M g C l}_{2}$-Lösung: $1 \mathrm{M} \mathrm{MgCl}_{2} \cdot 6 \mathrm{H}_{2} \mathrm{O}$

MgSO$_{4}$-Lösung: $1 \mathrm{M} \mathrm{MgSO}_{4} \cdot 7 \mathrm{H}_{2} \mathrm{O}$

LiCl-Lösung: $4 \mathrm{M} \mathrm{LiCl}$

NaCl-Lösung: $5 \mathrm{M} \mathrm{NaCl}$

KCl-Lösung: $1 \mathrm{M} \mathrm{KCl}$

Natrium-Acetat-Lösung: $3 \mathrm{M} \mathrm{NaCH}_{3} \mathrm{COO}$

Natriumdihydrogenphosphat-Lösung: $1 \mathrm{M} \mathrm{NaH}_{2} \mathrm{PO}_{4}: \mathrm{H}_{2} \mathrm{O}$

Di-Natriumhydrogenphosphat-Lösung: $1 \mathrm{M} \mathrm{Na}_{2} \mathrm{HPO}_{4} \cdot 2 \mathrm{H}_{2} \mathrm{O}$

Ethidiumbromid-Lösung: $10 \mathrm{mg} / \mathrm{ml}$ Ethidiumbromid

Ficoll: $10 \%$ (w/v) Ficoll, sterilfiltriert

EDTA: 0.5 M EDTA, pH 8.0

Maltose-Lösung: $20 \%$ Maltose $\cdot \mathrm{H}_{2} \mathrm{O}$, sterilfiltriert

SDS-Lösung: $10 \%(\mathrm{w} / \mathrm{v})$ Natriumdodecylsulfat

Tween-20-Lösung: $20 \%(\mathrm{v} / \mathrm{v})$

Triton-X100-Lösung: $25 \%(\mathrm{v} / \mathrm{v})$

Denhardt's (100 x): 2\% (w/v) BSA, $2 \%$ (w/v) PVP, $2 \%$ (w/v) Ficoll

\subsection{Antikörper und Chemikalien}

anti-Digoxigenin/AP (Boehringer Mannheim, Mannheim): Fab-Fragmente von Digoxigeninspezifischen Antikörpern (aus Ziege), konjugiert mit alkalischer Phosphatase

anti-c-MT (9E10; Santa Cruz Biotechnology, Santa Cruz, CA, USA): Monoklonaler Antikörper (Maus), welcher spezifisch das MT-Epitop von Fusionsproteinen bindet

anti-FLAG M2 (Sigma): Monoklonaler Antikörper (Maus), welcher spezifisch das FLAGEpitop von N-terminalen Fusionsproteinen bindet 
anti-Maus IgG1/PO (Biorad Deutschland, München): Sekundäre Antikörper (aus Ziege) gegen Maus IgG1, konjugiert mit Peroxidase

Biochemische Feinchemikalien wurden von den Firmen Boehringer Mannheim, Fluka, Roth, Serva und Biomol bezogen. Alle anderen Chemikalien stammten von den Firmen Fluka, Baker oder Merck und wiesen den höchsten Reinheitsgrad (p.A.) auf. Die komplexen Medienbestandteile wurden von DIFCO Laboratories (Detroit, Michigan, USA) bezogen.

\subsection{Geräte}

Gebrauchswaren und Geräte wurden, soweit nicht anders erwähnt, von den folgenden Firmen bezogen: Abimed (Hannover), Costar (Bodenheim), Eppendorf (Hamburg), Falcon (Heidelberg), Schütt (Göttingen), Greiner (Frickenhausen), Kranich (Göttingen), Qiagen (Hilden), Sarstedt (Langenhagen), Siemens (Hannover)

\section{Mikroinjektion}

Microinjector 5242

Nadelzieher

Eppendorf, Hamburg

$\underline{\text { PCR }}$

UNOII Thermoblock

Leitz, Wetzlar; Science Products, Hofheim

TRIO Thermoblock

Biometra, Göttingen

Optik

Stereomikroskop

Biometra, Göttingen

Kameraaufsatz

Stemi SV6, Zeiss, Oberkochen

Fotomikroskop

MC80, Zeiss, Oberkochen

Axioskop, Zeiss, Oberkochen

Computer

Hardware

Power Macintosh 7500/100

Power Macintosh G3

Software

Bild/Grafikverarbeitung

Adobe Photoshop Version 4.0 (Adobe Systems

Europe Ltd., Edinburgh, Schottland)

Freehand Version 7.0 - 9.0 (Macromedia Inc.,

San Francisco, USA)

DNA/Protein-Sequenzverarbeitung

Lasergene (DNASTAR Inc., Madison, USA)

MacMolly Tetra, Version 1.2 (Soft Gene

$\mathrm{GmbH}$, Berlin)

Blast-Suchsystem für Datenbanken (Altschul et al., 1990)

RNA-Structure 3.5 (Chan et al., 1991)

(http://rna.chem.rochester.edu)

Textverarbeitung

Microsoft Word Version 8.0 für Power

Macintosh (Microsoft Corporation $\mathrm{GmbH}$,

Unterschleißheim) 
Datenbanken

XMMR (Xenopus Molecular Marker Resource)

http://cbrmed.ucalgary.ca/pvize/html/WWW/Welcome.html

ExPASy (Expert Protein Analysis System) proteomics server of the Swiss Institute of

Bioinformatics (SIB), www.expasy.ch

$\underline{\text { Histologie }}$

Vibratom

Gastromaster Mikrodissektionsgerät
Typ 1000, Pelco International, Redding, California, USA

Xenotek Engineering, Belleville, Illinois, USA

\section{Methoden}

\subsection{DNA-Methoden}

\subsubsection{Präparation von Plasmid-DNA}

\subsubsection{Isolierung von Plasmiden im analytischen Maßstab (TELT)}

Zur schnellen Präparation geringer Mengen von Plasmid-DNA für Restriktionsanalysen, Sequenzierungen oder Subklonierungen wurden von $3 \mathrm{ml}$ einer Bakterien-Übernachtkultur in einem Eppendorfgefäß zweimal $1.5 \mathrm{ml}$ für $5 \mathrm{~min}$ bei $6.000 \mathrm{Upm}$ in der Tischzentrifuge sedimentiert und das Bakterienpellet in $300 \mu \mathrm{l}$ TELT-Puffer resuspendiert. Nach Zugabe von $30 \mu \mathrm{l}$ Lysozym-Lösung $(10 \mathrm{mg} / \mathrm{ml})$ wurde $5 \mathrm{~min}$ bei RT inkubiert und die Zellen durch $2 \mathrm{~min}$ Inkubation in einem kochenden Wasserbad aufgeschlossen. Die Proben wurden 2 min auf Eis inkubiert und anschließend 10-15 min bei 14.000 Upm zentrifugiert. Nach dem Entfernen des Pellets mit einem sterilen Zahnstocher wurde die Lösung zur Präzipitation der DNA mit $0.7 \mathrm{x}$ Vol. $(200 \mu \mathrm{l})$ Isopropanol versetzt. Die Plasmid-DNA wurde durch Zentrifugation für $15 \mathrm{~min}$ bei $14.000 \mathrm{Upm}$ gefällt und das Pellet einmal mit $70 \%$ Ethanol gewaschen. Nach dem Trocknen für $20 \mathrm{~min}$ im Wärmeblock be $37{ }^{\circ} \mathrm{C}$ wurde das Pellet in $40 \mu \mathrm{l} \mathrm{H}_{2} \mathrm{O}$ resuspendiert und $1 \mu \mathrm{l}$ einer RNAse A-Lösung $(1 \mathrm{mg} / \mathrm{ml})$ zugegeben. Für die meisten weiteren Schritte wie Restriktionsanalysen oder Subklonierungen konnte die so gewonnene Plasmid-DNA ohne weitere Aufreinigung verwendet werden. Für eine Sequenzierung wurden 3-5 $\mu$ l eingesetzt.

TELT-Puffer: 50 mM Tris- $\mathrm{HCl}$ (pH 7.5), 1 mM EDTA (pH 8.0), 3.2 M LiCl, $0.5 \%$ TritonX100

Lysozym-Lösung: 10 mg/ml Lysozym (Biomol) 


\subsubsection{Isolierung von Plasmiden im präparativen Maßstab}

Zur Präparation größerer Mengen reiner Plasmid-DNA für Klonierungen oder präparative Restriktionsverdaus wurde das Reaktionssystem "Plasmid Midi Kit" (Qiagen) eingesetzt. Die Methode beruht auf der alkalischen Lyse der Bakterienzellen und anschließender Aufreinigung der Plasmid-DNA über Anionenaustauscher-Säulen. Am Vortag wurden $50 \mu 1$ einer Bakterien-Flüssigkultur oder eine Bakterienkolonie in $50 \mathrm{ml}$ LB-Medium mit dem entsprechenden Selektivantibiotikum überimpft und über Nacht unter Schütteln (200 Upm) bei

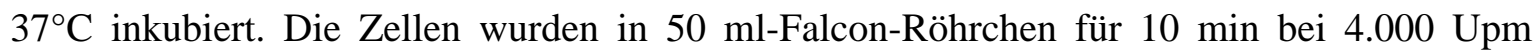
abzentrifugiert (Sorvall RC-5B) und das Pellet in $4 \mathrm{ml}$ Puffer P1 vollständig resuspendiert. Nach Zugabe von $4 \mathrm{ml}$ Puffer P2 wurde 2 min geschwenkt und anschließend $4 \mathrm{ml}$ Puffer P3 zugegeben. Nach erneutem Schwenken wurde das Bakterienlysat in 12 ml-PPN-Röhrchen überführt und für $5 \mathrm{~min}$ in einem SS34-Rotor bei $10.000 \mathrm{Upm}$ zentrifugiert. Der klare Überstand wurde auf eine mit $3 \mathrm{ml}$ Puffer QBT äquilibrierte Qiagen-tip 100 Säule geladen und die Säule mit $10 \mathrm{ml}$ Puffer QC gewaschen. Die Plasmid-DNA wurde mit $5 \mathrm{ml}$ Puffer QC in frische PPN-Röhrchen eluiert. Zur DNA-Fällung wurde 0.7 x Vol. (3.5 ml) Isopropanol zugegeben, gut gemischt und für $15 \mathrm{~min}$ im SS34-Rotor $\left(10.000 \mathrm{Upm}, 4^{\circ} \mathrm{C}\right)$ zentrifugiert. Das DNA-Pellet wurde mit $1.0 \mathrm{ml}$ 70\% Ethanol gewaschen und nach dem Trocknen in 50-100 $\mu \mathrm{l}$ Puffer TE aufgenommen. Zum Lösen der DNA wurde der Ansatz für 5 min auf $65^{\circ} \mathrm{C}$ erhitzt und die Lösung vorsichtig durchmischt.

\subsubsection{Konzentrationsbestimmung von Nukleinsäuren}

Nukleinsäure-Konzentrationen wurden in einem Spektralphotometer (Pharmacia Biotech) bei $260 \mathrm{~nm}$ gegen einen Leerwert bestimmt. Die Konzentration wurde aus der $\mathrm{OD}_{260 \mathrm{~nm}}$ wie folgt errechnet:

- $\mathrm{OD}_{260}=1$ entspricht $50 \mu \mathrm{g}$ dsDNA

- $\mathrm{OD}_{260}=1$ entspricht $40 \mu \mathrm{g}$ RNA

- $\mathrm{OD}_{260}=1$ entspricht $33 \mu \mathrm{g}$ Oligonukleotid

Um die Reinheit (Proteinfreiheit) eines Nukleinsäure-Präparats abzuschätzen, wurde außerdem die OD bei $280 \mathrm{~nm}$ gemessen. Der Quotient $\mathrm{OD}_{260 \mathrm{~nm}} / \mathrm{OD}_{280 \mathrm{~nm}}$ beträgt bei proteinfreier DNA bzw. RNA 1.8-2.0.

\subsubsection{Restriktionsspaltung von DNA}

Zur analytischen und präparativen Spaltung von Plasmid-DNA wurde diese mit 2 bis $10 \mathrm{U}$ einer Restriktionsendonuklease pro $1 \mu \mathrm{g}$ DNA bis zu 24 Stunden bei $37{ }^{\circ} \mathrm{C}$ im entsprechenden Restriktionspuffer inkubiert. Um unspezifische Enzymaktivität ("star activity") zu vermeiden, wurden nicht mehr als 10\% Enzymvolumen im Gesamtansatz verwendet.

\subsubsection{Agarose-Gelektrophorese}

\subsubsection{Nicht-denaturierende Agarose-Gelektrophorese}

Um DNA-Fragmente nach ihrer Größe aufzutrennen, wurden sie in einer Agarosematrix einem horizontalen elektrischen Feld ausgesetzt. Je nach Größe der DNA-Fragmente wurden Gele aus 0.6-2.5\% (w/v) Agarose in TBE-Puffer verwendet, denen zum Nachweis der DNA- 
Banden $0.5 \mu \mathrm{g} / \mathrm{ml}$ Ethidiumbromid zugegeben wurde. Vor dem Auftragen der DNA-Proben in die Geltaschen wurden die Proben mit 1 Vol. DNA-Probenpuffer versetzt. Die Elektrophoresen wurden bei $40-150 \mathrm{~V}$ in einer horizontalen Elektrophoresekammer (hauseigene Werkstatt) in TBE-Laufpuffer durchgeführt.

Anschließend wurden die DNA-Banden auf einem UV-Leuchttisch (Herolab) sichtbar gemacht und anhand eines Videodokumentationssystems (EASY View) dokumentiert. Durch paralleles Auftrennen einer Molekulargewichtsstandardlösung ("One kb Ladder", Gibco) konnte die Größe der DNA-Fragmente bestimmt werden.

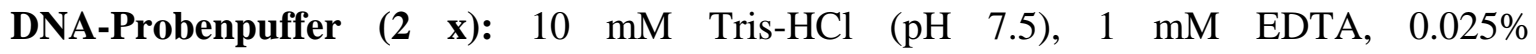
Bromphenolblau, $0.025 \%$ Xylencyanol, $30 \%$ (v/v) Glycerin

DNA-Molekulargewichtsstandard "One kb Ladder": 1 x DNA-Probenpuffer, 1/20 Vol. Boehringer Puffer H (10 x), 0.4 Vol. TE, 50 ng/ $\mu$ l "One kb Ladder" (Gibco, $1 \mu \mathrm{g} / \mu \mathrm{l}), 0.025 \%$ Bromphenolblau, 0.025\% Xylencyanol, 30\% (v/v) Glycerin

\subsubsection{Denaturierende Agarose-Gelektrophorese}

Um RNA im elektrischen Feld entprechend ihrer Größe und unter Verhinderung der Bildung von Sekundärstrukturen aufzutrennen, wurden Formaldehyd-haltige Agarosegele gefahren. Agarose wurde in RNAse-freiem $\mathrm{H}_{2} \mathrm{O}$ gelöst, nach dem Abkühlen mit 1/5 Endvol 5x RNALaufpuffer und 1/5 Vol 37\%iger Fomaldehydlösung versetzt und zu einem Gel gegossen. Während der Auftrennung im elektrischen Feld wurde der Puffer gegen die Laufrichtung der RNA regelmäßig umgeschichtet. Das Gel wurde anschließend in DEPC-Wasser gewaschen, in SSC äquilibriert und die RNA in einem Kapillarblot auf Nitrozellulose übertragen. Nach UVQuervernetzung der RNA mit dem Trägermaterial wurde die Nitrozellulose in Methylenblau für ca. 10 min gefärbt und in RNAse-freiem $\mathrm{H}_{2} \mathrm{O}$ entfärbt.

5x RNA-Laufpufer: $2.575 \%$ MOPS, $50 \mathrm{mM}$ Natriumazetat, $6.25 \mathrm{mM}$ EDTA in DEPC- $\mathrm{H}_{2} \mathrm{O}$, $\mathrm{pH} 7.0$

Agarose-Gel: 0.8\% Agarose, 1x RNA-Laufpuffer, 4\% Formaldehyd, in DEPC- $\mathrm{H}_{2} \mathrm{O}$ Methylenblau-Lösung: einige Krümel gelöst in $\mathrm{H}_{2} \mathrm{O}$

\subsubsection{Polymerase-Kettenreaktion (PCR)}

Die Polymerase-Kettenreaktion (PCR) dient der enzymatischen Amplifikation spezifischer DNA-Segmente. Hierzu wurden Oligonukleotide einer Länge von 18-30 Nukleotiden aus geeigneten flankierenden Bereichen der zu amplifizierenden Sequenz ausgewählt und von verschiedenen Herstellern (z.B. NAPS, MWG-Biotech) synthetisiert. Als Matrize ("template") dienten gereinigte Plasmid-DNA oder Flüssigkultur-Aliquots von Phagen oder Bakterien.

Ein Reaktionsansatz war wie folgt zusammengesetzt: 1 x PCR-Puffer (Perkin-Elmer), je 0.2 $\mathrm{mM}$ dNTPs, je 0.15 - $1.5 \mu \mathrm{M}$ sense- und antisense-Oligonukleotid, 0.5-1 U/20 $\mu \mathrm{l} \mathrm{Taq-}$ Polymerase (Perkin-Elmer) und 1-100 ng DNA-"template". Das Reaktionsvolumen betrug 20$100 \mu \mathrm{l}$. Zum Schutz vor Verdunstung während der Temperaturzyklen wurde der Ansatz beim Verwenden des "TRIO-Thermoblocks" (Biometra) mit Mineralöl überschichtet. Im "UNO IIThermoblock" (Biometra) war dies nicht erforderlich, da der Heizdeckel des Gerätes Kondensation verhinderte. Die Abfolge der einzelnen Schritte der PCR wurde durch Variation 
der Inkubationstemperatur im PCR-Gerät gesteuert; das Denaturieren der DNA-Matrize erfolgte bei $95{ }^{\circ} \mathrm{C}$, das Anlagern der Oligonukleotide je nach Spezifität und Schmelzpunkt der Oligonukleotide bei $40-60^{\circ} \mathrm{C}$ und der Elongationsschritt bei $72^{\circ} \mathrm{C}$. Ein Standardprotokoll für die Synthese eines bis zu 1.000 bp großen DNA-Segmentes bestand aus 30-40 Zyklen von je 1 min Denaturierung bei $95^{\circ} \mathrm{C}, 1 \mathrm{~min}$ Anlagerung der Oligonukleotide bei $50-60^{\circ} \mathrm{C}$ und $1 \mathrm{~min}$ Polymerisierung pro kb bei $72{ }^{\circ} \mathrm{C}$. Diesem Programm wurde ein Denaturierungsschritt von 2-3 min bei $95^{\circ} \mathrm{C}$ vorgeschaltet und nach Beendigung der Zyklen ein zusätzlicher Elongationsschritt von $10 \mathrm{~min}$ bei $72^{\circ} \mathrm{C}$ angehängt.

Um die Fehlerfrequenz bei der DNA-Amplifikation zu reduzieren, wurde zur Synthese von DNA-Fragmenten, die für Klonierungen verwendet werden sollten, Pfu-Turbo-Polymerase (Stratagene) mit 3' $\rightarrow$ 5' Exonuklease- ("Proof-reading") aktivität verwendet.

Nukleotid-Mischung: (dNTPs, Biomol, Hamburg) dATP, dGTP, dCTP, dTTP, je $100 \mathrm{mM}$ wurden zu gleichen Anteilen vermischt (Endkonzentration jeweils $25 \mathrm{mM}$ )

\subsubsection{PCR-vermittelte in vitro-Mutagenese}

Zur gezielten Veränderung von DNA-Sequenzen wie z. B. dem Einbringen oder Eliminieren von Restriktionsschnittstellen wurde das "QuikChange Site-Directed Mutagenesis Kit" (Stratagene) eingesetzt. Hierbei wurden in einer PCR-Amplifikation des gesamten Matrizenplasmids mit $P f u$-Polymerase zwei komplementäre Oligonukleotide, welche die gewünschte Mutation enthielten, direkt eingebaut und zu zwei zirkulären, nicht verknüpften DNA-Strängen elongiert. Die methylierte Matrizen-DNA wurde anschließend mit dem methylierungsabhängigen Restriktionsenzym Dpn I degradiert, während das mutierte, unmethylierte Syntheseprodukt erhalten blieb. Nach Transformation von E. coli-XL1 Blue Zellen wurden die Strangbrüche im Vektor durch bakterielle Reparaturenzyme repariert. Der Erfolg der Mutagenese wurde durch Sequenzierung und in vitro-Translation von PlasmidDNA aus einzelnen Bakterienkolonien überprüft.

\subsubsection{DNA-Sequenzierung und Sequenzanalyse}

Die Sequenzierung von doppelsträngiger DNA erfolgte mit dem "Dye Terminator Cycle Sequencing Kit" (Applied Biosystems). Das Verfahren basiert auf der DidesoxyKettenabbruchmethode nach Sanger (1977). Im Ansatz sind Didesoxyanaloga (ddNTPs) der vier verschiedenen dNTPs enthalten, welche je nach Base mit unterschiedlichen Fluoreszenzfarbstoffen markiert sind und in die neusynthetisierten DNA-Stränge eingebaut werden. Aufgrund des Fehlens der 3'-Hydroxylgruppe bei der Didesoxyribose kommt es zu statistisch verteilten Kettenabbrüchen, wodurch ein Gemisch unterschiedlicher Kettenlängen erzeugt wird. Nach der Auftrennung dieses Gemisches in einem denaturierenden 7\% Polyacrylamidgel können die jeweils 3'-terminalen Nukleotide der unterschiedlich langen DNA-Polymere mittels eines Lasers detektiert werden. Die Sequenzreaktionen wurden in 0.5 ml-Eppendorfgefäßen durchgeführt und enthielten folgende Komponenten: $4 \mu \mathrm{l}$ "Dye Terminator Ready Mix", 10 pmol Oligonukleotid, 0.75 -1 $\mu$ g ds DNA-"template", $\mathrm{dH}_{2} \mathrm{O}$ ad 20 $\mu \mathrm{l}$.

Im Thermocycler (Perkin-Elmer) durchliefen die Ansätze das folgende Programm: $30 \mathrm{~s} 96^{\circ} \mathrm{C}$, $15 \mathrm{~s} 50^{\circ} \mathrm{C}, 4 \min 60^{\circ} \mathrm{C}(26$ Zyklen $)$. 
Zur Aufreinigung wurde der von Mineralöl befreite Sequenzansatz mit $\mathrm{dH}_{2} \mathrm{O}$ auf ein Gesamtvolumen von $100 \mu \mathrm{l}$ aufgefüllt und mit 0.1 x Vol. 3 M Natriumacetat ( $\mathrm{pH}$ 5.2) sowie 2.5 x Vol. Ethanol versetzt. Die Ansätze wurden 15-20 min bei RT und $14.000 \mathrm{Upm}$ in einer Tischzentrifuge (Eppendorf) präzipitiert. Das Pellet wurde mit $250 \mu \mathrm{l} 70 \%$ Ethanol gewaschen und in bei RT getrocknet. Nach dem Resuspendieren in $2.8 \mu$ Formamid/10 mM EDTA wurde das Pellet bei $-20^{\circ} \mathrm{C}$ gelagert. Vor dem Auftragen auf das Gel wurden die Proben für 2 min bei $95{ }^{\circ} \mathrm{C}$ denaturiert.

Die Sequenzreaktionen wurden im hauseigenen Sequenzierlabor (A. Nolte) aufgetrennt und dokumentiert. Computergestützte Sequenzanalysen konnten mit Hilfe der Programme Lasergene (DNASTAR Inc., Madison, USA) und MacMolly Tetra, Version 1.2 (Soft Gene $\mathrm{GmbH}$, Berlin) durchgeführt werden.

\subsubsection{Aufreinigung von DNA-Fragmenten}

\subsubsection{PCR Purification Kit (Qiagen)}

Um Produkte aus präparativen PCR-Ansätzen oder linearisierte Vektor-DNA aufzureinigen, wurde das "PCR Purification Kit" (Qiagen) verwendet. Der Ansatz wurde möglichst ölfrei in ein frisches $1.5 \mathrm{ml}$-Eppendorfgefäß überführt und mit $\mathrm{dH}_{2} \mathrm{O}$ auf ein Gesamtvolumen von 100 $\mu l$ aufgefüllt. Nach Zugabe von $500 \mu$ Puffer PB wurde der Ansatz gemischt und auf eine QIAquick Säule mit DNA-bindender Silicagel-Membran überführt. Nach Zentrifugation bei 8.000 Upm für 1 min wurde mit $750 \mu$ Puffer PE gewaschen und zum Trocknen der Membran erneut zentrifugiert, zunächst bei $8.000 \mathrm{Upm}$ für $1 \mathrm{~min}$, dann bei 14.000 für $1 \mathrm{~min}$. Die Säule wurde in ein frisches $1.5 \mathrm{ml}$-Eppendorfgefäß gesetzt, $5 \mathrm{~min}$ bei $37^{\circ} \mathrm{C}$ vollständig getrocknet und die DNA in $20-30 \mu$ erhitztem $\left(60^{\circ} \mathrm{C}\right) \mathrm{dH}_{2} \mathrm{O}$ durch Zentrifugation eluiert.

\subsubsection{Isolierung von DNA-Fragmenten aus Agarose-Gelen}

Zur präparativen Isolation einzelner DNA-Fragmente aus Restriktionsspaltungen wurden diese gelelektrophoretisch aufgetrennt und die gewünschte DNA-Bande auf einem UV-Leuchttisch mit einer sauberen Skalpellklinge ausgeschnitten. Das isolierte Agarosestück wurde in ein Eppendorf-Reaktionsgefäß überführt und ausgewogen. Zur DNA-Extraktion wurde das "QIAEX Gel Extraction Kit" (Qiagen) verwendet. Dazu wurde das Gelstück mit einem mindestens dreifachen Volumen Puffer QX1 versetzt und 10 min bei $50^{\circ} \mathrm{C}$ im Wasserbad unter mehrfachem Invertieren vollständig aufgelöst. Die Lösung wurde auf eine QIAquickSäule geladen und $1 \mathrm{~min}$ in der Tischzentrifuge zentrifugiert (8.000 Upm). Die Säule wurde mit $500 \mu \mathrm{l}$ Puffer QX1 und anschließend mit $500 \mu$ Puffer PE gewaschen, in ein frisches 1.5 ml-Eppendorfgefäß gesetzt, 5 min bei $37^{\circ} \mathrm{C}$ getrocknet und die DNA in 20-30 $\mu$ erhitztem $\left(60{ }^{\circ} \mathrm{C}\right) \mathrm{dH}_{2} \mathrm{O}$ durch Zentrifugation eluiert.

\subsubsection{Subklonierung von DNA-Fragmenten}

Zur gerichteten Klonierung von DNA-Fragmenten (Inserts) in Vektoren wurden möglichst zwei verschiedene Restriktionsendonukleasen gewählt, die inkompatible überhängende DNAEnden generierten. Der Vektor und das Insert wurden mit entsprechenden Restriktionsendonukleasen über Nacht verdaut, gelelektophoretisch isoliert und in die Ligation eingesetzt. Vektoren, die glatte oder kompatible DNA-Enden aufwiesen, wurden vor der 
Auftrennung dephosphoryliert. Beim Fehlen geeigneter Restriktionsschnittstellen in den zu klonierenden DNA-Segmenten konnten diese in der PCR angefügt werden, indem Oligonukleotide verwendet wurden, die an ihrem 5'-Ende um das entsprechende Restriktionsmotiv sowie 3 zusätzliche Nukleotide verlängert waren.

\subsubsection{Ligation von DNA-Fragmenten}

Zur Verknüpfung von DNA-Fragmenten mit Vektor-DNA wurden diese mit 1 U T4-DNALigase (Gibco) im vom Hersteller mitgelieferten Puffer (5 x T4-Ligase Puffer, Gibco) bei $18^{\circ} \mathrm{C}$ über Nacht in einem Gesamtvolumen von $10 \mu$ inkubiert. Dabei wurden in der Regel $100 \mathrm{ng}$ Vektor-DNA und Insert-DNA in äquimolarer Menge (bei DNA-Fragmenten ab ca. 3 $\mathrm{kb}$ Größe) bzw. in einem bis zu dreifachen molaren Überschuss (bei kürzeren DNAFragmenten) eingesetzt.

\subsubsection{Dephosphorylierung von DNA-Fragmenten}

Um eine Selbstligation von geschnittenen Vektoren mit kompatiblen oder nichtüberhängenden ("blunt") DNA-Enden zu vermeiden, wurden sie an ihren 5'-Enden dephosphoryliert. Hierzu wurde die geschnittene Vektor-DNA mit 2 U Kälber-IntestinalPhosphatase (CIP, Boehringer-Ingelheim) in 1/10 Vol. 10 x CIP-Puffer bei $37{ }^{\circ} \mathrm{C} 1 \mathrm{~h}$ inkubiert. In Anwesenheit von $5 \mathrm{mM}$ EGTA wurde die Phosphatase anschließend $10 \mathrm{~min}$ bei $75^{\circ} \mathrm{C}$ hitzeinaktiviert. Einfach verdaute Vektoren wurden mittels des "PCR Purification Kit" (Qiagen) aufgereinigt, doppelt verdaute Vektoren wurden durch Gelelektrophorese von dem herausgeschnittenen Fragment abgetrennt und aus dem Agarose-Gel isoliert.

CIP-Puffer (10 x, Boehringer): $100 \mathrm{mM}$ Tris- $\mathrm{HCl}$ (pH 8.3), $10 \mathrm{mM} \mathrm{ZnCl}_{2}, 10 \mathrm{mM} \mathrm{MgCl}$

\subsubsection{Auffüllen überhängender DNA-Enden}

Um die überhängenden Enden von $\mathrm{zu}$ klonierenden DNA-Fragmenten nach Restriktionsverdaus oder aus PCR-Reaktionen aufzufüllen, wurden diese mit T4-DNAPolymerase behandelt. Die DNA wurde mit Hilfe des "PCR purification Kits" aufgereinigt und in 1 x T4 DNA-Polymerasepuffer (Boehringer) unter Zugabe von $0.3 \mathrm{mM}$ dNTPs mit 8 U T4DNAPolymerase in einem Gesamtvolumen von $70 \mu \mathrm{l} 30 \mathrm{~min}$ bei $37^{\circ} \mathrm{C}$ inkubiert. Das DNAFragment wurde gelelektrophoretisch aufgereinigt und in $25 \mu \mathrm{TE}$ aufgenommen. Zur Ligation wurde die DNA mit T4-Polynukleotid-Kinase (PNK, Boehringer) an ihren 5'-Enden phosphoryliert. Hierzu wurde die DNA-Lösung in 1 x T4-Kinase Puffer mit 20 U T4-PNK (10 $\mathrm{U} / \mu \mathrm{l})$ für $30 \mathrm{~min}$ bei $37^{\circ} \mathrm{C}$ inkubiert, erneut aufgereinigt und in die Ligation eingesetzt.

T4-Polynukleotid-Kinase Puffer (10 x): $0.5 \mathrm{M}$ Tris- $\mathrm{HCl}(\mathrm{pH} 7.5), 0.1 \mathrm{M} \mathrm{MgCl}_{2}, 10 \mathrm{mM}$ DTT, $10 \mu \mathrm{g}$ BSA

\subsubsection{Klonierung von PCR-Produkten}

Die aus einer mit Taq-Polymerase durchgeführten PCR hervorgehenden DNA-Fragmente besitzen zu etwa 50\% einzelne Adenin-Überhänge an ihren 3'-Enden, die von der TaqPolymerase angefügt wurden. Dieser Umstand wurde ausgenutzt, um die PCR-Produkte direkt und ungerichtet in Vektoren zu ligieren, welche stumpfe (,blunt“) Enden besaßen und an ihren 5'-DNA-Enden mit entsprechenden Thymidin-Überhängen versehen waren. Aufgereinigte 
PCR-Produkte konnten in Ligationen mit dem so präparierten Vektor pGEM-T (Promega) eingesetzt werden. Sollten PCR-Produkte in den Vektor pGEM-T kloniert werden, die mit der Pfu-turbo Polymerase amplifiziert waren, welche keine Adenin-Überhänge anfügt, so wurde das aufgereinigte $P f u$-PCR-Produkt mit der Taq Polymerase in Gegenwart von $0.2 \mathrm{mM}$ dATP im entsprechenden Puffer für 30 min bei $72{ }^{\circ} \mathrm{C}$ inkubiert. Ein Ligationsansatz des "pGEM-T Kits" (Promega) war wie folgt zusammengesetzt: $1 \mu$ T4-Ligase Puffer $(10 \mathrm{x})$ oder $5 \mu \mathrm{l}$ "Rapid ligation buffer" (2 x), $1 \mu$ l pGEM-T Vektor (50 ng/ $\mu$ l), x $\mu$ l PCR-Produkt (in $\mathrm{dH}_{2} \mathrm{O}$ ), $1 \mu \mathrm{l}$ T4-Ligase, $\mathrm{dH}_{2} \mathrm{O}$ ad $10 \mu \mathrm{l}$.

\subsubsection{Herstellung elektrokompetenter Bakterienzellen}

Zur Anzucht von Bakterien, die kompetent für die Elektrotransformation mit Plasmid-DNA waren, wurde zunächst ein Einzelkolonieausstrich des gewünschten Bakterienstammes auf LB-Agar-Platten (z.B. E. coli XL1-Blue mit $12.5 \mu \mathrm{g} / \mathrm{ml}$ Tetracyclin) angefertigt und eine einzelne Bakterienkolonie in $20 \mathrm{ml}$ LB-Flüssigmedium überimpft. Nach Inkubation über Nacht unter Schütteln (200 Upm) bei $37^{\circ} \mathrm{C}$ wurden am folgenden Tag 21 LB-Flüssigmedium mit der Übernachtkultur inokuliert. Bis zum Erreichen der exponentiellen Wachstumsphase der Bakterien $\left(\mathrm{OD}_{600}=0.6-0.8\right)$ wurde erneut bei $200 \mathrm{Upm}$ und $37^{\circ} \mathrm{C}$ inkubiert und die Bakterienkultur anschließend im Eisbad gekühlt. Alle folgenden Schritte wurden mit auf $4^{\circ} \mathrm{C}$ vorgekühlten Lösungen und Geräten durchgeführt. Die Zellen wurden bei $4^{\circ} \mathrm{C}$ für $10 \mathrm{~min}$ in einer Sorvall-CL6B-Kühlzentrifuge (7.000 Upm; GSA-Rotor) sedimentiert. Der Überstand wurde verworfen und das Sediment zunächst im Ausgangsvolumen an sterilem $\mathrm{dH}_{2} \mathrm{O}$ resuspendiert. Nach erneuter Zentrifugation wurden die folgenden Waschschritte durchgeführt: 1 x 1 Vol. $10 \%$ (v/v) Glycerin in $\mathrm{dH}_{2} \mathrm{O}, 1 \times 0.5$ x Vol. $10 \%$ (v/v) Glycerin in $\mathrm{dH}_{2} \mathrm{O}, 1 \times 1 / 20 \mathrm{Vol}$. $10 \%(\mathrm{v} / \mathrm{v})$ Glycerin in $\mathrm{dH}_{2} \mathrm{O}$. Das Zellpellet wurde in maximal $2 \mathrm{ml} 10 \%$ (v/v) Glycerin in $\mathrm{dH}_{2} \mathrm{O}$ resuspendiert. Aliquots von je $40 \mu \mathrm{l}$ der Zellsuspension wurden in 1.5 ml-Eppendorfgefäße überführt, in flüssigem Stickstoff schockgefroren und bei $-70^{\circ} \mathrm{C}$ gelagert.

\subsubsection{Elektrotransformation kompetenter Bakterienzellen}

Zur Elektrotransformation wurde das Elektroporationsgerät "E. coli Pulser" der Firma Biorad verwendet. Vor der Pulsgabe wurden alle Schritte auf Eis durchgeführt. Ein Aliquot mit $40 \mu \mathrm{l}$ kompetenten Bakterien in einem 1.5 ml-Eppendorfgefäß wurde auf Eis aufgetaut und mit 1-2 $\mu$ l DNA-Lösung vermischt. Der Transformationsansatz wurde in eine Elektroporationsküvette $(\mathrm{d}=0.1 \mathrm{~cm})$ überführt und luftblasenfrei an den Boden der Küvette geklopft. Die Küvette wurde einem elektrischen Puls von $1.8 \mathrm{kV}$ und $25 \mu \mathrm{F}$ ausgesetzt. Sofort nach der Pulsgabe wurden $0.5 \mathrm{ml}$ LB-Medium in die Küvette pipettiert und gut mit der Bakteriensuspension vermischt. Verschiedene Volumina (z. B. 20, $200 \mu \mathrm{l}$ ) der Suspension wurden mittels steriler Glaskugeln auf bei $37^{\circ} \mathrm{C}$ vorgewärmten LB-Agar-Platten verteilt, die ein der Plasmidresistenz entsprechendes Selektivantibiotikum enthielten. Bei Pulszeiten von 3.9-4.5 s konnte eine gute Transformationseffizienz erwartet werden. Konnte zur Kontrolle der Insertion eine Blau/Weiß-Selektion durchgeführt werden, wurden vor dem Ausplattieren der Zellen auf jede Platte $40 \mu \mathrm{l}$ IPTG-Lösung und $40 \mu \mathrm{l}$ X-Gal-Lösung aufgebracht. Die Platten wurden bei $37^{\circ} \mathrm{C}$ über Nacht invertiert im Brutschrank inkubiert und konnten anschließend bei $4{ }^{\circ} \mathrm{C}$ gelagert werden. 
IPTG (Isopropylthiogalactosid): $100 \mathrm{mM}$ IPTG in $\mathrm{dH}_{2} \mathrm{O}$

X-Gal (5-Bromo-4-chloro-3-indolyl-ß-D-galactopyranosid): $\quad 20 \quad \mathrm{mg} / \mathrm{ml} \quad \mathrm{X}$-Gal $\quad$ in Dimethylformamid

\subsubsection{Nachweis der Integration klonierter DNA-Fragmente}

Um Bakterienklone zu identifizieren, die das gewünschte Insertionsfragment enthielten, wurde eine PCR mit Flüssigkultur-Aliquots ("culture-PCR") der Bakterienkolonien oder direkt mit Koloniematerial durchgeführt ("colony-PCR"). Alternativ wurden von einigen Bakterienkolonien Plasmidpräparationen im analytischen Maßstab durchgeführt, welche im Anschluss in Restriktionsverdaus analysiert werden konnten. In die PCR-Reaktionen wurde eine Kombination von zwei gegenläufigen Oligonukleotiden eingesetzt, die den Übergang von Vektor- und Insertsequenz amplifizierte. Das resultierende Produkt konnte somit nur bei erfolgreicher Integration des Inserts in der gewünschten Orientierung gebildet werden. Die Insertion von DNA-Fragmenten, deren Sequenz nicht bekannt war, konnte durch Verwendung zweier gegenläufiger vektorspezifischer Oligonukleotide überprüft werden, wobei an der Produktgröße der Integrationserfolg zu erkennen war.

In einem Ansatz der "colony-PCR" (22.5 $\mu$ l Gesamtvolumen) wurden $2.5 \mu$ l Flüssigkultur eingesetzt. Von "positiven" Bakterienkolonien konnten Flüssigkulturen zur präparativen Plasmidisolation angeimpft werden.

\subsection{RNA-Methoden}

Zur Inaktivierung von RNasen wurden die zum Arbeiten mit RNA bestimmten Gefäße mit 0.5 $\mathrm{N} \mathrm{NaOH}$ für mindestens 10 min behandelt und mit DEPC- $\mathrm{dH}_{2} \mathrm{O}$ gespült. Kunststoffgefäße wurden fabrikneu und unbehandelt verwendet. Hitzelabile Substanzen wurden in DEPC- $\mathrm{dH}_{2} \mathrm{O}$ gelöst. Bei der Arbeit mit RNA wurden Latex-Einmalhandschuhe getragen und filtergestopfte Pipettenspitzen verwendet.

DEPC-dH $\mathrm{d}_{2} \mathbf{O}: 0.1 \%(\mathrm{v} / \mathrm{v})$ Diethylpyrocarbonat in $\mathrm{dH}_{2} \mathrm{O}$, Inkubation für $4-12 \mathrm{~h}$ bei $37^{\circ} \mathrm{C}$ und anschließendes Autoklavieren für 20 min bei $121^{\circ} \mathrm{C}$.

\subsubsection{Isolierung von DNA-freier Gesamt-RNA aus Xenopus}

Isolierte DNA-freie Gesamt-RNA aus Xenopus wurde in der RT-PCR zu Expressionsstudien und für cDNA-Klonierungen verwendet. Zur Analyse von Induktionsprozessen wurde RNA aus manipulierten animalen Gewebeexplantaten ("animal caps") extrahiert und in quantitative RT-PCR-Reaktionen eingesetzt.

\subsubsection{Embryonalstadien}

Um Gesamt-RNA aus Xenopus-Embryonen zu extrahieren, wurde in einem $1.5 \mathrm{ml}$ Eppendorfreaktionsgefäß pro Ansatz je $0.4 \mathrm{ml}$ Extraktionspuffer in einem Thermoblock (Gesellschaft für Laborgeräte, Wertheim/Main) auf $45^{\circ} \mathrm{C}$ vorgewärmt. Zu dem Puffer wurden $20 \mu \mathrm{l}$ einer Proteinase K-Lösung $(20 \mathrm{mg} / \mathrm{ml})$ gegeben und diese Mischung sofort auf die gefrorenen Embryonen (je 10 pro Präparation) pipettiert. Durch 8faches Auf- und Absaugen 
der Probe in einer $1 \mathrm{ml}$-Einmalspritze mit G30-Kanüle wurden die Embryonen homogenisiert und die DNA geschert. Der Extrakt wurde bei $45^{\circ} \mathrm{C}$ für $45 \mathrm{~min}$ inkubiert und phenolextrahiert (1 x 1 Vol. Phenol, 1 x 1 Vol. Phenol/Chloroform, 1 x 1 Vol. Chloroform). Die RNA wurde durch Zugabe von 0.1 Vol. $10 \mathrm{M} \mathrm{NH}_{4}$-Acetat und 2.5 Vol. Ethanol durch Zentrifugation in einer Eppendorf-Tischzentrifuge (14.000 Upm, $30 \mathrm{~min}, \mathrm{RT}$ ) gefällt und in $40 \mu \mathrm{LEPC}-\mathrm{dH}_{2} \mathrm{O}$ aufgenommen. Um kontaminierende genomische DNA zu degradieren, wurde die RNALösung nach Zugabe von $2 \mu \mathrm{l}$ RNase-freier DNAse (20 U/ $\mu$ l, Boehringer), $5 \mu 110 \mathrm{x}$ DNasePuffer, $2 \mu \mathrm{l} 20 \mathrm{mM}$ Dithiothreitol und $1 \mathrm{ml}$ RNasin (40 U/ $\mu \mathrm{l}$, Stratagene) $30 \mathrm{~min}$ bei $37^{\circ} \mathrm{C}$ inkubiert. Anschließend wurde die RNA über RNeasy-Säulen aufgereinigt und ihre Konzentration photometrisch bestimmt.

Extraktionspuffer (1 x): 50 mM Tris- $\mathrm{HCl}(\mathrm{pH} 7.5), 5$ mM EDTA (pH 8), $40 \mathrm{mM} \mathrm{NaCl}, 0.5 \%$ SDS in DEPC- $\mathrm{dH}_{2} \mathrm{O}$

DNase-Puffer (10 x): $400 \mathrm{mM}$ Tris- $\mathrm{HCl}(\mathrm{pH} 8.0), 60 \mathrm{mM} \mathrm{MgCl}{ }_{2}, 100 \mathrm{mM} \mathrm{NaCl}, 1 \mathrm{mM}$ $\mathrm{CaCl}_{2}$ in DEPC-dH $\mathrm{H}_{2} \mathrm{O}$

\subsubsection{Adulte Gewebe und Organe}

Möglichst nach der Präparation von Hoden aus Xenopus Männchen wurden diesen Gewebe und Organe entnommen und mit 1 x MBSH gewaschen. Die zur RNA-Extraktion bestimmten Gewebe und Organe wurden in Flüssigstickstoff eingefroren und mit einem in Flüssigstickstoff gekühlten Mörser pulverisiert. Das Pulver wurde in vorgekühlten $1.5 \mathrm{ml}$ Eppendorfreaktionsgefäßen in $50 \mu$ l-Aliquots aufgeteilt und bis zur Extraktion bei $-70^{\circ} \mathrm{C}$ gelagert. Die RNA-Extraktion wurde wie unter 3.2.1.1 beschrieben durchgeführt.

\subsubsection{Animale Kappen}

Um RNA aus kultivierten animalen Explantaten (animalen Kappen) zu extrahieren, wurden diese im gewünschten Stadium in einem möglichst geringen Puffervolumen in $1.5 \mathrm{ml}$ Eppendorfgefäße überführt, in Flüssigstickstoff schockgefroren und bei $-70^{\circ} \mathrm{C}$ gelagert. Zur RNA-Extraktion wurde das "RNeasy Mini Kit" verwendet. Unmittelbar nach der Entnahme aus dem Flüssigstickstoff wurde den Proben $350 \mu$ l Puffer RLT mit 1\% (v/v) BMercaptoethanol zugegeben. Die animalen Kappen wurden durch 5-6maliges Auf-und Absaugen in einer automatischen $1 \mathrm{ml}$ Gilsen Pipettenspitze homogenisiert und 1 Vol. 70\% Ethanol zugefügt. Nach Mischen durch Pipettieren wurden die Proben auf RNeasy Säulen pipettiert und $15 \mathrm{~s}$ bei $8.000 \mathrm{Upm}$ zentrifugiert. Anschließend wurden die Säulen je $1 \mathrm{x}$ mit $700 \mu$ Puffer RWE und zweimal mit $500 \mu$ Puffer RPE gewaschen, 2 min bei 14.000 Upm trockenzentrifugiert und bei $37{ }^{\circ} \mathrm{C}$ getrocknet. Die RNA wurde zunächst in $40 \mu \mathrm{l}$ RNasefreiem $\mathrm{dH}_{2} \mathrm{O}$ eluiert und wie unter 3.2.1.1 beschrieben mit RNase-freier DNase I behandelt. Nach einer erneuten Aufreinigung mit Hilfe des "RNeasy Mini Kits" wurde die RNA in $3 \mu l$ RNase-freiem $\mathrm{dH}_{2} \mathrm{O}$ pro Kappe eluiert. 


\subsubsection{Reverse-Transkriptase-Polymerase-Kettenreaktion (RT-PCR)}

Zur Analyse der Expression von Genen in Embryonalstadien, adulten Geweben oder Organen oder zur Klonierung von cDNAs wurde mRNA revers transkribiert und die erhaltene cDNA in der PCR amplifiziert. Hierbei wurde mit dem "RT-PCR Kit" (Perkin-Elmer) gearbeitet.

\subsubsection{Semiquantitative RT-PCR}

Die reverse Transkription von RNA wurde in einem Ansatz des RT-PCR Kits (Perkin Elmer) durchgeführt, der wie folgt zusammengesetzt war: $2 \mu \mathrm{l} 10 \mathrm{x}$ PCR-Puffer II, $4 \mu \mathrm{l} 25 \mathrm{mM}$ $\mathrm{MgCl}_{2, \text { je }} 2 \mu \mathrm{l}$ dATP; dCTP; dGTP; dTTP-Lösung (10 mM), $1 \mu$ RNase Inhibitor (20 U/ $\left.\mu \mathrm{l}\right), 1$ $\mu \mathrm{l}$ Random Hexamers $(50 \mu \mathrm{M}), 1 \mu \mathrm{l}$ Reverse Transkriptase (50 U/ $\mu \mathrm{l})$, bis zu $3 \mu \mathrm{l}$ DNA-freie Gesamt-RNA (bis zu $1 \mu \mathrm{g}$ ), RNase-freies $\mathrm{dH}_{2} \mathrm{O}$ ad $20 \mu \mathrm{l}$. Der Ansatz wurde gemischt und mit $50 \mu$ Mineralöl überschichtet. In einem PCR-Gerät (Trio, Biometra) durchlief er mit das folgende Temperaturprofil: $10 \mathrm{~min} 22{ }^{\circ} \mathrm{C}$ (Anlagerung der Oligonukleotide), $30 \mathrm{~min} 42^{\circ} \mathrm{C}$ (reverse Transkription), 5 min $99^{\circ} \mathrm{C}$ (Inaktivierung der reversen Transkriptase), Abkühlen auf $4^{\circ} \mathrm{C}$.

Die so erhaltene cDNA wurde anschließend in eine PCR-Reaktion eingesetzt, indem jedem Ansatz folgende Komponenten hinzugefügt wurden: $8 \mu \mathrm{l} 10$ x PCR-Puffer II, $2 \mu \mathrm{l} 25 \mathrm{mM}$ $\mathrm{MgCl}_{2}$ (Endkonzentration $1.5 \mathrm{mM}$ ), $1 \mu \mathrm{l}$ je $15 \mu \mathrm{M}$ sense- und antisense-OligonukleotidLösung, $0.5 \mu \mathrm{l}$ Taq-Polymerase (5U/ $\mu$ l, Perkin-Elmer), $\mathrm{dH}_{2} \mathrm{O}$ ad $80 \mu \mathrm{l}$ (Gesamtvolumen der Reaktion: $100 \mu \mathrm{l})$.

Sollte das Produkt der PCR radioaktiv markiert werden, wurden außerdem pro Ansatz $0.25 \mu \mathrm{l}$ $\left[\alpha{ }^{32} \mathrm{P}\right]-\mathrm{dCTP}(10 \mu \mathrm{Ci} / \mu \mathrm{l}$, Amersham) zugefügt. Die gewählte Zyklenzahl der analytischen RT-PCR befand sich möglichst im Bereich des linearen Anstiegs der Produktmenge. Die radioaktiv markierten PCR-Produkte wurden auf einem 6\% Polyacrylamid/Harnstoffgel in $1 \mathrm{x}$ TBE bei konstant $400 \mathrm{~V}$ aufgetrennt. Dazu wurden je $8 \mu$ leines PCR-Ansatzes mit $4 \mu \mathrm{l}$ Formamid-TBE-Farbstoff-Mix versetzt und vor dem Auftragen 5 min bei $80^{\circ} \mathrm{C}$ denaturiert. Als Größenstandard diente mit Polynukleotidkinase (PNK) radioaktiv markierte "One kb Ladder" (Gibco).

Formamid-TBE-Farbstoff-Mix: 1 x TBE, 50\% (v/v) Formamid (deionisiert), $0.025 \%$ Bromphenolblau, $0.025 \%$ Xylencyanol in $\mathrm{dH}_{2} \mathrm{O}$

\subsubsection{Auftrennung im Polyacrylamid/Harnstoffgel}

Radioaktive RT-PCR-Produkte wurden auf einem denaturierenden $6 \%$ Polyacrylamid/Harnstoffgel der Maße 270 × 200 x $0.5 \mathrm{~mm}$ in einer Standard-Gelkammer (Werkstatt des Instituts) aufgetrennt. Die Glasplatten des Gels wurden vor dem Gießen mit Repell-Silan behandelt. Vor dem Auftragen der Proben wurde ein Vorlauf von 10 min bei 400 V durchgeführt. Nach einem zweistündigen Gellauf wurde das Gel in 10\% Methanol/10\% Essigsäure fixiert, gewässert und auf Filterpapier (Whatman $3 \mathrm{M}$ ) bei $65^{\circ} \mathrm{C}$ vakuumgetrocknet. Anschließend wurde es über Nacht auf einer Phosphoimager-Platte (Molecular Dynamics) exponiert.

Repell-Silan: 5\% Dimethyldichlorsilan in Chloroform

6\% Polyacrylamid/Harnstoff-Stammlösung (1 x): 8 M Harnstoff, 5.7\% Acrylamid, 0.3\% Bisacrylamid in $1 \mathrm{x}$ TBE. Die Lösung wurde deionisiert (Mischbettionenaustauscher, Biorad 
A6501-X8CD) und filtriert $(0.45 \mu \mathrm{m})$. Zum Ansetzen einer Gellösung wurden $50 \mathrm{ml}$ der $6 \%$ Polyacrylamid/Harnstoff-Stammlösung filtriert $(0.22 \mu \mathrm{m})$ und zur Polymerisation $44 \mu \mathrm{l}$ TEMED und $180 \mu 1$ 10\% APS zugefügt.

\subsubsection{Phosphorylierung von DNA-Fragmenten}

Um den DNA-Molekulargewichtsgrößenstandard "One kb Ladder" radioaktiv zu markieren, wurden die DNA-Fragmente in Gegenwart von $\left[\gamma{ }^{32} \mathrm{P}\right]$-dATP mit T4-Polynukleotidkinase am 5'-Ende phosphoryliert. Hierzu wurde $1 \mu \mathrm{l}(=1 \mu \mathrm{g})$ "One kb Ladder" mit $10 \mathrm{U}$ T4Polynukleotidkinase (New England Biolabs) und $2 \mu \mathrm{l}\left[\gamma_{-}{ }^{32} \mathrm{P}\right]$-dATP (Amersham) in $1 \mathrm{x}$ T4PNK-Puffer in einem Gesamtvolumen von $20 \mu$ für $30 \mathrm{~min}$ bei $37^{\circ} \mathrm{C}$ inkubiert. Anschließend wurde der Ansatz mit dem "PCR Purification Kit" von freien Nukleotiden gereinigt, in $50 \mu \mathrm{l}$ $\mathrm{dH}_{2} \mathrm{O}$ eluiert und mit Formamid/10 mM EDTA auf $100 \mu \mathrm{l}$ aufgefüllt. Die Radioaktivität des kinasierten Markers wurde durch Messung der Zerfälle pro Minute $(\mathrm{dpm}=$ disintegrations per minute) in einem "Quick Count"-Gerät (Bioscan, Washington DC, USA) bestimmt und so eingestellt, dass pro Spur eine Aktivität von 20.000 dpm aufgetragen wurde.

\subsubsection{In vitro-Synthese von RNA}

\subsubsection{In vitro-Synthese markierter RNA-Sonden}

Zur Synthese von markierten antisense-RNA-Sonden für in situ Hybridisierungen wurden in vitro Transkriptionen in Anwesenheit von Digoxigenin-markiertem rUTP durchgeführt. Als "template" für die RNA-Polymerase diente linearisierte Plasmid-DNA, die mit dem "RNeasy Mini Kit" (Qiagen) aufgereinigt worden war.

Ein Transkriptionsansatz (RNA Transkriptions-Kit, Stratagene) setzte sich aus den folgenden Komponenten zusammen: $5 \mu \mathrm{l} 5$ Transkriptionspuffer, je $1 \mu 10$ mM rATP; rCTP; rGTP, $0.64 \mu \mathrm{l} 10 \mathrm{mM}$ rUTP, $0.36 \mu \mathrm{l} 10 \mathrm{mM}$ Digoxigenin-rUTP (Boehringer), $1 \mu \mathrm{l} 0.75 \mathrm{M}$ DTT, $1 \mu \mathrm{l}$ RNAsin (40 U/ $\mu \mathrm{l}), 5 \mu \mathrm{l}$ linearisierte "template"-DNA $\left(0.2 \mu \mathrm{g} / \mu \mathrm{l}\right.$, in RNase-freiem dH $\left.{ }_{2} \mathrm{O}\right), 1 \mu \mathrm{l}$ T3, T7 oder SP6-RNA-Polymerase (10 U/ $\mu \mathrm{l})$, RNase-freies $\mathrm{dH}_{2} \mathrm{O}$ ad $25 \mu \mathrm{l}$.

Der Ansatz wurde $2 \mathrm{~h}$ bei $37^{\circ} \mathrm{C}$ inkubiert und anschließend die DNA-Matrize durch Zugabe von $2 \mu \mathrm{l}$ RNase-freier DNAse I (Boehringer) 15 min bei $37^{\circ} \mathrm{C}$ verdaut. Die RNA-Sonde wurde mit Hilfe des Reaktionssystems "RNeasy Mini Kit" aufgereinigt.

\subsubsection{In vitro-Synthese von Cap-mRNA für Mikroinjektionen}

Synthetische mRNA für Mikroinjektionen wurde bei Konstrukten mit SP6 Promotor mit Hilfe des "SP6 mMESSAGE mMACHINE Kits" (Ambion) und bei Expressionsvektoren mit T3 und T7 Promotoren mit dem RNA Transkriptions-Kits (Stratagene) hergestellt. In beiden Fällen wird bei der in vitro Synthese der RNA am 5'-Ende der Transkripte eine 7-Methylguanosin"Kappe" (CAP) angefügt.

Ein Ansatz des "SP6 mMESSAGE mMACHINE Kits“ enthielt: $2 \quad \mu 1 \quad 10 \quad x \quad$ SP6 Reaktionspuffer, $10 \mu \mathrm{l} 2 \mathrm{x}$ rNTP/CAP Mix, $5 \mu \mathrm{l}$ DNA-Matrize $(0.2 \mu \mathrm{g} / \mu \mathrm{l}$ in RNase-freiem $\mathrm{dH}_{2} \mathrm{O}$ ), $2 \mu \mathrm{l}$ SP6-Enzym Mix, RNase-freies $\mathrm{dH}_{2} \mathrm{O}$ ad $20 \mu \mathrm{l}$. Nach 2-3 h Inkubation bei $37^{\circ} \mathrm{C}$ wurde dem Ansatz zur Degradation der DNA-Matrize $1 \mu$ RNase-freie DNase I zugegeben und $15 \mathrm{~min}$ bei $37^{\circ} \mathrm{C}$ verdaut. 
Ein Ansatz nach dem RNA Transkriptions-Kit war wie folgt zusammengesetzt: $10 \mu \mathrm{l} 5 \mathrm{x}$ Transkriptionspuffer, je $5 \mu 10 \mathrm{mM}$ rATP; rCTP; rGTP; rUTP, $2 \mu \mathrm{l} 0.75 \mathrm{M}$ DTT, $1 \mu \mathrm{l}$ RNAsin $(40 \mathrm{U} / \mu \mathrm{l}), 9 \mu \mathrm{l} 10 \mathrm{mM}$ 7-Methylguanosin $\left[7 \mathrm{mG}\left(5^{\prime}\right)_{\mathrm{ppp}}\left(5^{\prime}\right) \mathrm{G}\right], 1 \mu \mathrm{l}$ RNasin, $5 \mu \mathrm{l}$ linearisierte "template"-DNA $\left(0.2 \mu \mathrm{g} / \mu \mathrm{l}\right.$, in RNase-freiem $\left.\mathrm{dH}_{2} \mathrm{O}\right), 2 \mu \mathrm{l}$ T3 oder T7-RNAPolymerase $(10 \mathrm{U} / \mu \mathrm{l})$, RNase-freies $\mathrm{dH}_{2} \mathrm{O}$ ad $50 \mu \mathrm{l}$. Hier wurde ebenfalls $2 \mathrm{~h}$ bei $37^{\circ} \mathrm{C}$ inkubiert, $2 \mu \mathrm{l}$ DNase I zugefügt und weitere $15 \mathrm{~min}$ bei $37^{\circ} \mathrm{C}$ verdaut.

\subsubsection{Aufreinigung synthetischer RNA}

Um synthetische RNA oder linearisierte "template"-DNA von Salzen, Enzymen und Nukleotiden abzutrennen, wurden die Ansätze mit Hilfe des "RNeasy Mini Kits" (Qiagen) aufgereinigt. Der Reaktionsansatz wurde dazu mit RNase-freiem $\mathrm{dH}_{2} \mathrm{O}$ auf ein Gesamtvolumen von $100 \mu \mathrm{l}$ aufgefüllt und $350 \mu \mathrm{l}$ Puffer RLT sowie $250 \mu \mathrm{l}$ Ethanol zupipettiert. Nach dem Mischen wurde die Lösung auf eine RNeasy-Säule übertragen und $15 \mathrm{~s}$ bei 8.000 Upm zentrifugiert. Es wurde zweimal mit je $500 \mu$ Puffer RPE gewaschen und die Säule trockenzentrifugiert und bei $37{ }^{\circ} \mathrm{C}$ für 10 min getrocknet. Die RNA wurde mit $20 \mu \mathrm{l}$ RNase-freiem, auf $50{ }^{\circ} \mathrm{C}$ vorgewärmtem $\mathrm{dH}_{2} \mathrm{O}$ in ein frisches Eppendorfgefäß eluiert.

\subsubsection{Isolation homologer cDNA-Sequenzen mit Hilfe degenerierter Oligonukleotide}

Zur Isolation von unbekannten cDNA-Sequenzen aus Xenopus wurden zunächst mit Hilfe eines Sequenz-Alignment-Programms (MegAlign, DNASTAR) die aus anderen Organismen bekannten Sequenzen des gesuchten Proteins verglichen. Aus Sequenzbereichen, die eine hohe Homologie aufwiesen und zudem vorzugsweise einen hohen Anteil von im genetischen Code nur durch ein oder zwei Basentripletts repräsentierten Aminosäuren (z. B. Methionin, Tryptophan) enthielten, wurden "degenerierte" Oligonukleotide ausgewählt. Diese bestanden aus einer Mischung von sämtlichen in anderen Organismen vertretenen Nukleotidsequenzen dieses Bereiches, welche bei der Synthese zufällig neu rekombiniert wurden. Paare degenerierter Oligonukleotide wurde in hoher Konzentration $(0.5-1.5 \mu \mathrm{M})$ in eine RT-PCR Reaktion auf Gesamt-RNA aus Xenopus Embryonalstadien eingesetzt, wobei verschiedene Anlagerungs-Temperaturen der Oligonukleotide $\left(50-60^{\circ} \mathrm{C}\right)$ parallel getestet wurden.

Entsprach das erhaltene Produkt der erwarteten Größe, konnte es in den pGEM-T Vektor kloniert und sequenziert werden. Basierend auf der erhaltenen Sequenzinformation konnten spezifische Oligonukleotide entworfen werden, um weitere Sequenzinformation über die cDNA zu erhalten.

\subsection{Durchmustern einer cDNA Bank}

Um einen Phagen zu isolieren, der die gesuchte cDNA enthielt, wurden fraktionierte Xenopus $\lambda$-Zap Express (Stratagene) cDNA-Phagenbibliotheken mit Hilfe der PCR unter Verwendung degenerierter oder spezifischer Oligonukleotide durchgemustert. Durch wiederholte Verdünnung und Vermehrung der Phagen aus positiven Fraktionen wurde der gesuchte Phage in Flüssigkultur angereichert, bis ein reiner Phagenklon durch Ausplattieren isoliert werden konnte. Der isolierte Einzelphage wurde schließlich mittels eines Helferphagen in ein 
zirkuläres Phagemid konvertiert, das im weiteren als Plasmid in Bakterien vermehrt werden konnte.

\subsubsection{Bestimmung des Phagentiters}

Zur Bestimmung des Titers einer Phagensuspension wurde in SM-Puffer eine Verdünnungsreihe der Phagen erstellt $\left(10^{-1}-10^{-10}\right)$. Diese wurde auf NZY-Agarplatten wie unten beschrieben ausplattiert und bei $37^{\circ} \mathrm{C}$ über Nacht inkubiert. Die entstandenen Plaques (plaque forming units = pfu) wurden ausgezählt und auf die unverdünnte Phagensuspension hochgerechnet (pfu/ml).

SM-Puffer: $10 \mathrm{mM}$ Tris- $\mathrm{HCl}(\mathrm{pH} 7.5), 8 \mathrm{mM} \mathrm{MgSO}$, $100 \mathrm{mM} \mathrm{NaCl}, 0.01 \%$ Gelatine, sterilfiltriert $(0.45 \mu \mathrm{m})$

\subsubsection{Phagenplattierung}

Ein Einzelkolonieausstrich des Bakterienstammes E. coli XL1-Blue MRF' wurde auf tetracyclinhaltigen LB-Agarplatten angefertigt. Mit einer MRF'-Einzelkolonie wurde eine Tagkultur in $50 \mathrm{ml}$ LB-Flüssigmedium mit Tetracyclin, $10 \mathrm{mM} \mathrm{MgSO}_{4}$ und $0.2 \%$ Maltose angeimpft. Nach ca. $5 \mathrm{~h}$ Wachstum wurden die Zellen bei $4.000 \mathrm{Upm}$ für $10 \mathrm{~min}$ in einem GSA-Rotor pelletiert und in $10 \mathrm{mM} \mathrm{MgSO}_{4}$ zu einer $\mathrm{OD}_{600}$ von 0.5 resuspendiert. Zur Infektion mit Phagen wurden $600 \mu \mathrm{l}$ der Bakteriensuspension zusammen mit $2.5 \mu \mathrm{l}$ der Phagensuspension $20 \mathrm{~min}$ bei $37^{\circ} \mathrm{C}$ für die Präadsorption geschwenkt. Dies erfolgte in $1.5 \mathrm{ml}-$ Eppendorfgefäßen oder in 12 ml-PPN-Röhrchen.

\subsubsection{Phagenplattierung auf NZY-Agar-Platten}

Das Präadsorptionsgemisch aus Bakterien und Phagen wurde zu $3 \mathrm{ml}$ flüssigem, auf exakt $48^{\circ} \mathrm{C}$ vorgewärmten, NZY-Top-Agar gegeben, zügig gemischt und der Inhalt auf vorgewärmten NZY-Agarplatten $(\mathrm{d}=9.5 \mathrm{~cm})$ gleichmäßig verteilt. Nach $1 \mathrm{~h}$ Inkubation bei RT zum vollständigen Erstarren des Top-Agars wurden die Platten invertiert bei $37^{\circ} \mathrm{C}$ über Nacht inkubiert.

\subsubsection{Phagenplattierung in Mikrotiterplatten}

Sollten die Phagen in Titerplatten amplifiziert werden, wurden $6.4 \mathrm{ml}$ NZY-Flüssigmedium zu dem Gemisch aus Bakterien und Phagen in das $12 \mathrm{ml}$-PPN-Röhrchen pipettiert und jeweils in Aliquots zu $100 \mu$ laf 8 x 8 Vertiefungen einer 96-Loch-Titerplatte verteilt. Die Platten wurden mit Klebefolie verschlossen und über Nacht bei $37^{\circ} \mathrm{C}$ und $250 \mathrm{Upm}$ geschüttelt. Eine gute Amplifikation der Phagen war am folgenden Tag an einem klaren Phagenüberstand und Sedimenten aus Bakterienzelltrümmern zu erkennen.

\subsubsection{Anreicherung eines Kandidaten-Phagen}

Um positive Phagenfraktionen zu identifizieren, wurden Aliquots einzelner Fraktionen einer cDNA-Bank in einer PCR mit degenerierten oder spezifischen Oligonukleotiden getestet, wobei wie in der "colony"-PCR vorgegangen wurde. Verschiedene Verdünnungen (von unverdünnt bis $10^{-5}$ ) der positiven Phagen-Einzelfraktionen wurden in 8 x 8 Aliquots à $100 \mu \mathrm{l}$ in Mikrotiterplatten plattiert und diese nach der Amplifikation erneut in der PCR analysiert. Um das Verfahren zu vereinfachen, wurden jeweils $8 \mu$ der horizontalen Reihen A (1-8) bis H 
(1-8) der Platte zu einem Gemisch (Pool) vereint und in der PCR getestet. Zeigte eine Reihe ein positives Signal, konnte die positive Fraktion in dieser Reihe durch eine zweite PCR auf Aliquots der Einzelfraktionen lokalisiert werden. Positive Fraktionen wurden in $1.5 \mathrm{ml}$ Eppendorfgefäße überführt und nach Zugabe von zwei Tropfen Chloroform zur Konservierung der Phagen bei $4^{\circ} \mathrm{C}$ aufbewahrt. Es wurde jeweils mit den positiven Fraktionen weitergearbeitet, welche aus der höchsten Verdünnungsstufe hervorgingen. Die Verdünnungsund Amplifikationsrunden wurden mehrfach wiederholt, bis der gesuchte Phage in der Fraktion gegenüber anderen Phagen möglichst stark angereichert war.

\subsubsection{Isolation eines spezifischen Phagen}

Um einen reinen Klon des gesuchten Phagen zu isolieren, wurde die angereicherte Fraktion auf NZY-Agar-Platten ausplattiert. Einzelne Phagen-Plaques von ca. $1 \mathrm{~mm}$ Durchmesser wurden mit der Spitze einer Pasteurpipette ausgestochen und in je $100 \mu \mathrm{l}$ SM-Puffer überführt. Aliquots der Plaque-Suspensionen wurden in der PCR getestet. Positive Einzelplaques konnten nach Zugabe von zwei Tropfen Chloroform bei $4^{\circ} \mathrm{C}$ in $1.5 \mathrm{ml}$-Eppendorfgefäßen gelagert werden. Um die Reinheit des Phagen sicherzustellen, wurden Aliquots der positiven Einzelphagensuspension erneut ausplattiert und 8-12 Plaques ausgestochen. Waren sämtliche der ausgestochenen Phagenplaques in der PCR erneut positiv, konnte davon ausgegangen werden, dass ein reiner Klon vorlag.

\subsubsection{Zirkularisierung (Exzision) des Phagen-Inserts}

Zur Exzision des Phagemids aus dem reinen Phagenklon musste zunächst eine hoch konzentrierte ("high titer") Phagensuspension erzeugt werden. Dazu wurde der reine Phage auf Agarplatten zu konfluentem Wachstum ausplattiert. Die Phagen wurde durch Zugabe von 2-3 ml SM-Puffer zur Agar-Platte für ca. $3 \mathrm{~h}$ bei RT durch Inkubation auf einer Wippe vom Agar abgeschwemmt und in ein $50 \mathrm{ml}$ Falcon-Röhrchen überführt. Nach Zugabe von $75 \mu \mathrm{l}$ Chloroform wurde gemischt, $10 \mathrm{~min}$ bei $10.000 \mathrm{Upm}$ zentrifugiert und der Überstand in ein 1.5 ml-Eppendorfgefäß überführt. Der konzentrierte Phagenüberstand wurde nach Zugabe von $0.3 \%$-Vol Chloroform bei $4{ }^{\circ} \mathrm{C}$ gelagert.

Zur Vorbereitung der Exzision wurden Über-Nacht-Kulturen der E. coli Stämme XL1-Blue MRF' und XLOLR angeimpft, aus welchen Tagkulturen inokuliert wurden. Die XLOLRZellen wurden bis zum Erreichen einer $\mathrm{OD}_{600}=1.0$ kultiviert und bei $4{ }^{\circ} \mathrm{C}$ zwischengelagert. Die $\mathrm{OD}_{600}$ der MRF'-Zellen wurden in $10 \mathrm{mM} \mathrm{MgSO}_{4}$ auf 1.0 eingestellt. In einem $12 \mathrm{ml}$ PPN-Röhrchen wurden $200 \mu \mathrm{l}$ der MRF'-Zellsuspension zusammen mit $250 \mu \mathrm{l}$ der hochkonzentrierten Einzelphagensuspension und $1 \mu \mathrm{l}$ ExAssist-Helferphage 15 min bei $37^{\circ} \mathrm{C}$ unter Schwenken inkubiert. Nach Zugabe von $3 \mathrm{ml}$ LB-Flüssigmedium wurde 2.5 h bei $37^{\circ} \mathrm{C}$ geschüttelt. Hierbei wurde ein definierter Bereich des Phagen, welcher die inserierte cDNA enthielt, vom Helferphagen einzelsträngig amplifiziert, zirkularisiert und als Phagemid verpackt aus dem Wirtbakterium ausgeschleust. Zum Abtöten des Wirtsbakteriums wurde anschließend der Ansatz für 15 min auf $70^{\circ} \mathrm{C}$ erhitzt, die Bakterien abzentrifugiert und der Phagemid-Überstand in ein neues 12 ml-PPN-Röhrchen überführt. Um den E. coli Stamm XLOLR mit dem Phagemid zu infizieren, wurden in 1.5 ml-Eppendorfgefäßen je $10 \mu$ oder $100 \mu \mathrm{l}$ Phagemid-Überstand mit $200 \mu \mathrm{l}$ frischen XLOLR-Zellen $\left(\mathrm{OD}_{600}=1.0\right) 15 \mathrm{~min}$ bei $37^{\circ} \mathrm{C}$ geschwenkt. Nach Zugabe von $300 \mu$ LB-Medium wurde für weiter 45 min unter Schwenken 
bei $37^{\circ} \mathrm{C}$ inkubiert. Aus jedem Ansatz wurden 2 x $200 \mu \mathrm{l}$ auf LB-Agarplatten mit Kanamycin ausplattiert und über Nacht bei $37^{\circ} \mathrm{C}$ inkubiert. Mit den entstandenen BakterienEinzelkolonien konnten im Anschluss Flüssigkulturen angeimpft und das isolierte Plasmid mit der gesuchten cDNA amplifiziert werden.

\subsection{Präparation von Xenopus-Embryonalstadien}

\subsubsection{Präparation von Xenopus-Testis}

Zur Befruchtung der Gelege musste möglichst vor Beginn der Eiablage Testis aus Xenopus Männchen entnommen werden. Dazu wurde ein Männchen dekapitiert und ventral aufgeschnitten. Die weißlichen, ovalen Hoden wurden in eiskalten 1x MBSH-Puffer überführt. Unter Zugabe von Penicillin/Streptomycin konnten sie bei $4^{\circ} \mathrm{C}$ bis zu einer Woche gelagert werden.

MBSH (1x): $10 \mathrm{mM}$ HEPES (pH 7.4), $88 \mathrm{mM} \mathrm{NaCl}, 1 \mathrm{mM} \mathrm{KCl}, 2.4 \mathrm{mM} \mathrm{NaHCO}{ }_{3}, 0.82 \mathrm{mM}$ $\mathrm{MgSO}_{4}, 0.41 \mathrm{mM} \mathrm{CaCl}_{2}, 0.66 \mathrm{mM} \mathrm{KNO}$

\subsubsection{Stimulation der Eiablage}

Um die Eiablage für den folgenden Morgen zu stimulieren, wurden einem Weibchen gegen 20 Uhr 500-700 U humanes Gonadotropin (2000 U/ml) mittels einer $1 \mathrm{ml}$-Spritze mit G27Kanüle in den dorsalen Lymphsack injiziert. Die Weibchen wurden über Nacht bei ca. $18{ }^{\circ} \mathrm{C}$ gehalten. Zur meist spontanen Eiablage wurden die Weibchen über eine leere Petrischale gehalten.

\subsubsection{Befruchtung und Entwicklung}

Die Gelege wurden mit Spermien aus präparierten Hoden befruchtet. Um die Spermien freizusetzen, wurde ca. 1/10 eines Hodens mit einer Mikroschere in $100 \mu 1 \mathrm{x}$ MBSH mazeriert. Unmittelbar vor Gebrauch wurden die in 1 x MBSH inaktiven Spermien mit $900 \mu 1$ $\mathrm{dH}_{2} \mathrm{O}$ verdünnt. Durch die Verringerung der Ionenkonzentration erlangten die Spermien ihre volle Beweglichkeit. Die Spermien wurden zügig auf den Gelegen verteilt, die zur Einzelschicht auseinandergezogen wurden. Nach ca 5 min wurde mit $0.1 \mathrm{x}$ MBSH überschichtet. Eine Stunde nach der Befruchtung wurden die Embryonen durch 3 minütige Inkubation in $2 \%$ Cystein ( $\mathrm{pH}$ 7.8-8.0) unter Schwenken von ihrer Gallerthülle befreit und dreimal mit 0.1 x MBSH gespült. Die Embryonen wurden auf einer Temperierplatte bei 14$20^{\circ} \mathrm{C}$ bis zu den gewünschten Stadien inkubiert. Um die Feinstrukturen von Albinoembryonen besser zu erkennen, konnten diese mit dem Vitalfarbstoff Nilblau angefärbt werden.

2\% Cystein-HCl: 2\% (w/v) L-Cystein-HCl, $\mathrm{pH}$ mit $\mathrm{NaOH}$ auf 7.8 einstellen Nilblau-Färbelösung: $0.01 \%(\mathrm{w} / \mathrm{v})$ Nilblau in $0.1 \mathrm{x} \mathrm{MBSH}$, vor Gebrauch filtrieren 


\subsection{Histochemie und Immunhistochemie}

\subsubsection{Fixierung von Xenopus Embryonen}

Waren die Embryonen für "whole mount" in situ Färbungen bestimmt, wurden sie in $5 \mathrm{ml}$ Schraubdeckelglasröhrchen auf einer Wippe für eine Stunde in 1 x MEMFA fixiert und anschließend in $100 \%$ Ethanol bei $-20^{\circ} \mathrm{C}$ gelagert.

MEM (10 x): 1 M MOPS, 20 mM EGTA, $10 \mathrm{mM} \mathrm{MgSO}_{4}$

MEMFA (1 x): 1 x MEM, 3.7 \% Formaldehydlösung

\subsubsection{B-Galactosidase-Färbung}

Zur Analyse der Verteilung koinjizierter B-Galactosidase mRNA in Xenopus Embryonen wurden die Embryonen nach der Fixierung in 1 x MEMFA 2-3mal 5 Minuten mit PBS gespült und bei Raumtemperatur in B-Galactosidase-Färbelösung bis zum Erreichen der gewünschten Farbintensität inkubiert. Zum Abstoppen der Farbreaktion wurden die Embryonen einmal mit PBS gewaschen, erneut eine Stunde in 1 x MEMFA fixiert und in $100 \%$ Ethanol bei $-20^{\circ} \mathrm{C}$ gelagert.

B-Galactosidase-Färbelösung: 1 x PBS, $1 \mathrm{mg} / \mathrm{ml} \mathrm{X-Gal,} 5 \mathrm{mM} \mathrm{K} \mathrm{K}_{3} \mathrm{Fe}(\mathrm{CN})_{6}, 5 \mathrm{mM}$ $\mathrm{K}_{4} \mathrm{Fe}(\mathrm{CN})_{6}, 2 \mathrm{mM} \mathrm{MgCl}$

Stammlösungen: $500 \quad \mathrm{mM} \quad \mathrm{K}_{3} \mathrm{Fe}(\mathrm{CN})_{6}, \quad 500 \quad \mathrm{mM}_{4} \quad \mathrm{~K}_{4} \mathrm{Fe}(\mathrm{CN})_{6}, \quad 40 \quad \mathrm{mg} / \mathrm{ml} \quad \mathrm{X}-\mathrm{Gal} \quad$ in Dimethylsulfoxid

\subsection{3 "Whole mount" in situ Hybridisierung}

Um die räumliche und zeitliche Expression von Genen zu analysieren, wurde die endogene mRNA von Xenopus-Embryonen in situ mit komplementären, Digoxigenin-markierten antisense-RNA Sonden hybridisiert und in einer Färbereaktion detektiert. Zur Kontrolle der Spezifität wurde markierte sense-RNA eingesetzt.

\subsubsection{Rehydrieren der Embryonen}

Soweit nicht anders erwähnt, wurden bei jedem Schritt $5 \mathrm{ml}$ Lösung verwendet. Pro $5 \mathrm{ml}$ Schraubdeckelröhrchen wurden nicht mehr als 20 Embryonen gleichzeitig behandelt.

\begin{tabular}{|l|l|l|l|l|}
\hline & Ethanol (\%) & Puffer (\%) & Dauer (min) & Anzahl \\
\hline 1. & Ethanol 100\% & & 5 & $1 \times$ @ \\
\hline 2. & Ethanol 75\% & $\mathrm{dH}_{2} \mathrm{O} 25 \%$ & 5 & $1 \mathrm{x} @$ \\
\hline 3. & Ethanol 50\% & $\mathrm{dH}_{2} \mathrm{O} 50 \%$ & 5 & $1 \mathrm{x} @$ \\
\hline 4. & Ethanol 25\% & $\mathrm{PTw} 75 \%$ & 5 & $1 \mathrm{x} @$ \\
\hline 5. & & $\mathrm{PTw} 100 \%$ & 5 & $4 \mathrm{x} @$ \\
\hline
\end{tabular}

$@=$ kopfüber $($ Drehrad $)$

\subsubsection{Proteinase K-Behandlung}

Um die Embryonen durchlässiger für die RNA-Hybridisierungssonden zu machen, wurden sie bis zu $25 \mathrm{~min}$ bei RT in $1 \mathrm{ml}$ PTw-Puffer inkubiert, dem $0.5 \mu$ Proteinase K-Lösung (Merck, $20 \mathrm{mg} / \mathrm{ml}$ ) zugegeben wurde (Endkonzentration $10 \mu \mathrm{g} / \mathrm{ml}$ ). Dabei wurden die Embryonen 
optisch kontrolliert; zeigten sich leichte Schäden an einem Embryo, wurde die Behandlung sofort abgebrochen.

\subsubsection{Refixierung}

Die durch Proteinase K-Behandlung fragilen Embryonen wurden durch Acetylierung und Inkubation in PTw/Formaldehydlösung refixiert. Die Embryonen wurden in $0.1 \mathrm{M}$ Triethanolamin-Lösung ( $\mathrm{pH}$ 7.5) umgepuffert, durch zweimalige Zugabe von Acetanhydrid acetyliert und anschließend in PTw $+4 \%$ FA refixiert.

\begin{tabular}{|l|l|l|l|l|}
\hline & Puffer & Zugabe von & Dauer (min) & Anzahl \\
\hline 1. & 0.1 M Triethanolamin & & 5 & $2 \mathrm{x} @$ \\
\hline 2. & 0.1 M Triethanolamin & 12.5 ul Acetanhydrid & 5 & $1 \mathrm{x} @$ \\
\hline 3. & & 12.5 ul Acetanhydrid & 5 & $1 \mathrm{x} @$ \\
\hline 4. & PTw & & 5 & $2 \mathrm{x} @$ \\
\hline 5. & PTw + 4\% FA & & 20 & $1 \mathrm{x} @$ \\
\hline 6. & PTw & & 5 & $5 \mathrm{x} @$ \\
\hline
\end{tabular}

Anschließend wurde der PTw-Puffer bis auf $1 \mathrm{ml}$ entfernt und $250 \mu \mathrm{l}$ Hybridisierungs-Lösung zugegeben. Nach dem Absinken der Embryonen in die Hybridisierungslösung wurde der Überstand abgenommen, durch $500 \mu$ l Hybridierungslösung ersetzt und 10 min bei $60^{\circ} \mathrm{C}$ im Wasserbad inkubiert. Die Hybridisierungslösung wurde erneut ausgetauscht und die Embryonen für mindestens $6 \mathrm{~h}$ bei $60^{\circ} \mathrm{C}$ prähybridisiert. Nach dem Abnehmen des Überstands und Zugabe der RNA-Sonde (Endkonzentration $1 \mu \mathrm{g} / \mathrm{ml}$ ) in $500 \mu$ l Hybridisierungslösung wurde über Nacht unter leichtem Schütteln bei $60^{\circ} \mathrm{C}$ hybridisiert.

\subsubsection{Waschen}

Um unspezifisch gebundene, einzelsträngig vorliegende Sonden-RNA zu entfernen, wurden die Embryonen unter stringenten Bedingungen gewaschen und mit $10 \mu \mathrm{g} / \mathrm{ml}$ RNase A und 10 U/ml RNase T1 verdaut. Die Sonden-RNA konnte bei $-20^{\circ} \mathrm{C}$ gelagert und mehrfach verwendet werden.

\begin{tabular}{|l|l|l|l|l|}
\hline & Puffer & Temperatur $\left({ }^{\circ} \mathrm{C}\right)$ & Dauer $(\min )$ & Anzahl \\
\hline 1. & Hvbridisierungspuffe & 60 & 10 & $1 \times$ \\
\hline 2. & $2 \times$ SSC & 60 & 20 & $3 \times$ \\
\hline 3. & $2 \times$ SSC mit RNasen & 37 & 30 & $2 \times$ \\
\hline 4. & $2 \times$ SSC & RT & 10 & $1 \times$ \\
\hline 5. & $0.2 \times$ SSC & 60 & 30 & $2 \times$ \\
\hline 6. & MAB & RT & 15 & $2 \times$ \\
\hline
\end{tabular}

\subsubsection{Antikörper-Inkubation}

Die Hybride aus digoxigeninmarkierter Sonden-RNA und endogener mRNA konnten mit einem Digoxigenin-spezifischen Antikörper, an den alkalische Phosphatase gekoppelt war, nachgewiesen werden. Zur Blockieren unspezifischer Bindungsstellen wurden die Embryonen 
vor Zugabe des Detektions-Antikörpers in 2\% Boehringer Mannheim Blockierungs-Reagenz und 20\% hitzeinaktiviertem Pferdeserum (Biochrom KG, Berlin) inkubiert.

\begin{tabular}{|l|l|l|l|l|}
\hline & Puffer & Temperatur $\left({ }^{\circ} \mathrm{C}\right)$ & Dauer $(\min )$ & Anzahl \\
\hline 1. & MAB $+2 \%$ BMB & RT & 60 & $1 \mathrm{x}-$ \\
\hline 2. & MAB + 2\% BMB & RT & 60 & $1 \mathrm{x}-$ \\
\hline 3. & MAB + 2\% BMB & RT & 240 & $1 \mathrm{x}-$ \\
\hline 4. & MAB (Waschen) & RT & 30 & $2 \mathrm{x}-$ \\
\hline 5. & MAB (Waschen) & 4 & über Nacht & $1 \mathrm{x}-$ \\
\hline
\end{tabular}

$-=$ horizontale Wippe

\subsubsection{Farbentwicklung}

Alkalische Phosphatase setzt die Substrate NBT/BCIP zu einem dunkelvioletten Farbstoff um. Die Färbereaktion wurde im Dunkeln durchgeführt, bis der gewünschte Kontrast einer hohen Signalintensität bei schwacher Hintergrundfärbung erreicht wurde.

\begin{tabular}{|l|l|l|l|l|}
\hline & Puffer & Temperatur $\left({ }^{\circ} \mathrm{C}\right)$ & Dauer $(\min )$ & Anzahl \\
\hline 1. & MAB & RT & 60 & $1 \mathrm{x}$ \\
\hline 2. & APB & RT & 5 & $2 \mathrm{x}$ \\
\hline 3. & APB + NBT/BCIP & RT & 5 min $-24 \mathrm{~h}$ & $1 \mathrm{x}$ \\
\hline
\end{tabular}

\subsubsection{Abstoppen der Färbung und Auswertung}

Nach dem Erreichen der gewünschten Farbintensität wurde die Färbereaktion durch Spülen mit $\mathrm{dH}_{2} \mathrm{O}$ abgestoppt. Durch Inkubation in Methanol konnte die Hintergrundfärbung unter optischer Kontrolle reduziert werden. Anschließend wurden die Embryonen in einer absteigenden Methanolreihe rehydriert und in 1 x MEMFA fixiert. In 1 x MEM-Puffer konnten sie bei $4^{\circ} \mathrm{C}$ gelagert werden.

\begin{tabular}{|l|l|l|l|l|}
\hline & Lösung & Temperatur $\left({ }^{\circ} \mathrm{C}\right)$ & Dauer $(\min )$ & Anzahl \\
\hline 1. & $\mathrm{dH}, \mathrm{O}$ & RT & 1 & $1 \mathrm{x}$ \\
\hline 2. & Methanol 100\% & RT & $1-5$ & $1 \mathrm{x}$ \\
\hline 3. & Methanol 75\% & RT & 1 & $1 \mathrm{x}$ \\
\hline 4. & Methanol 50\% & RT & 1 & $1 \mathrm{x}$ \\
\hline 5. & Methanol 25\% & RT & 1 & $1 \mathrm{x}$ \\
\hline 6. & $\mathrm{dH}, \mathrm{O}$ & $\mathrm{RT}$ & 1 & $1 \mathrm{x}$ \\
\hline 7. & MEMFA & $\mathrm{RT}$ & über Nacht & $1 \mathrm{x}$ \\
\hline
\end{tabular}

Um die Färbung im Inneren eines Embryo sichtbar zu machen, konnte er in einer 2:1 Mischung von Benzylbenzoat und Benzylalkohol inkubiert und zügig fotografiert werden.

Mit einem Stereomikroskop (Stemi SV6, Zeiss) mit Kameraaufsatz wurden die Ergebnisse auf Ektachrome 64T Kunstlichtdiafilmen (Kodak) dokumentiert. 
PTw (1 x): 1 x PBS, $0.1 \%$ Tween-20

Hybridierungs-Lösung: $50 \%$ Formamid (deionisiert), 5 x SSC, $1 \mathrm{mg} / \mathrm{ml}$ Torula-RNA, 10 $\mu \mathrm{g} / \mathrm{ml}$ Heparin, $1 \times$ Denhardt's, 0.1\% Tween-20, 0.1\% CHAPS, 10 mM EDTA, RNase freies $\mathrm{dH}_{2} \mathrm{O}$

RNasen: $20 \mu \mathrm{g} / \mathrm{ml}$ RNase A, $10 \mathrm{U} / \mathrm{ml}$ RNase T1

MAB (5 x): $500 \mathrm{mM}$ Maleinsäure, $750 \mathrm{mM} \mathrm{NaCl}$, pH 7.5

BMB (10\%): 1 x MAB mit 10\% (w/v) BMB (Boehringer Mannheim Blocking Reagent, Nr. 1096 176) wurde zum Lösen erhitzt, autoklaviert und in Aliquots eingefroren.

Alkaline Phosphatase Buffer (APB): $100 \mathrm{mM}$ Tris- $\mathrm{HCl}$ (pH 9.5), $50 \mathrm{mM} \mathrm{MgCl}_{2}, 100 \mathrm{mM}$ $\mathrm{NaCl}, 0.1 \%$ Tween-20

Färbelösung NBT/BCIP: Pro ml APB wurden $1.75 \mu \mathrm{l}$ NBT (Boehringer, $100 \mathrm{mg} / \mathrm{ml}$ in 70\% Dimethylformamid) und $3.5 \mu \mathrm{l} \mathrm{BCIP}$ (Boehringer, $50 \mathrm{mg} / \mathrm{ml}$ in $100 \%$ Dimethylformamid) eingesetzt.

\subsection{Mikroinjektion von Xenopus-Embryonen}

Proteine wurden im Xenopus Embryo überexprimiert, indem synthetische Cap mRNA in einzelne Blastomere von Xenopus Embryonen des 2- bis 32-Zell-Stadiums injiziert wurden. Die mRNA-Lösung wurde in eine mit einem Nadelziehgerät (Leitz und Narishige) ausgezogene Glaskapillare (GC100F-16, Clark Electromedical Instruments, Reading, England) gefüllt, die Nadel in eine luftdruckregulierte Mikromanipulationsapparatur (Mikroinjektor 5242, Eppendorf) eingespannt und die Spitze mit einer Uhrmacherpinzette unter Beobachtung abgebrochen. Um zu gewährleisten, dass die Spitze der Nadel fein genug war, wurde der Injektionsdruck möglichst hoch (1.500-2.000 hPa) gehalten. Durch Variation der Injektionszeit (meist 0.1-0.3 s) wurde das $\mathrm{zu}$ injizierende Volumen auf 4-10 $\mathrm{nl}$ näherungsweise eingestellt, indem der Tropfendurchmesser (d) anhand einer Skala bestimmt wurde $(\mathrm{d}=0.2 \mathrm{~mm} \approx 4.2 \mathrm{nl}, \mathrm{d}=0.25 \mathrm{~mm} \approx 8.2 \mathrm{nl}, \mathrm{d}=0.3 \mathrm{~mm} \approx 14.1 \mathrm{nl})$. Vor der Injektion wurden die Embryonen in Injektionspuffer inkubiert und auf Objektträger aufgebracht, die mit Homogenaten aus unbefruchten Xenopus-Eiern beschichtet waren. Nach 2 h Inkubation in Plastikkulturschalen (Greiner) wurden die Embryonen in Post-Injektionspuffer umgepuffert, der nach ca. $1 \mathrm{~h}$ gegen $0.1 \mathrm{x}$ MBSH ausgetauscht werden konnte. Bei längeren Kulturzeiten wurde dem Puffer Penicillin/Streptomycin zugefügt. Zur Fixierung wurden die Embryonen bei RT $1 \mathrm{~h}$ in $1 \mathrm{x}$ MEMFA inkubiert und anschließend in $1 \mathrm{x}$ MEM bei $4^{\circ} \mathrm{C}$ gelagert.

Die fotografische Dokumentation von phänotypischen Effekten der Injektion auf die Embryonalentwicklung erfolgte mit Hilfe eines Stereomikroskops (Stemi SV 6, Zeiss) mit Kameraaufsatz (Zeiss) und Kunstlichtdiafilmen (Ektachrome 64T, Kodak).

Injektionspuffer: $1 \%$ Ficoll, 1 x MBSH

Post-Injektionspuffer: $0.5 \%$ Ficoll, 0.1 x MBSH 


\subsection{Präparation und Kultivierung von animalen Gewebeexplantaten ("animal caps")}

Für die Analyse von manipulierten animalen Kappen wurde synthethische mRNA in den animalen Pol beider Blastomere von Embryonen im 2-Zell-Stadium injiziert. Nach dem Erreichen des Blastula-Stadiums (8-9.5) wurden die injizierten Embryonen sowie nichtmanipulierte Kontrollembryonen in 0.5 x MBSH-Puffer überführt und mit Hilfe von Uhrmacherpinzetten von der Vitellinmembran befreit. Aus dem am animalen Pol befindlichen Dach des Blastocoels wurde mit Hilfe eines "Gastromaster"-Mikrodissektionsgeräts (Xenotek Engineering) ein Explantat mit einem Durchmesser von ca. $400 \mu \mathrm{m}$ herausgeschnitten und die animalen Kappen vorsichtig in Plastik-Kulturschalen mit einer Beschichtung aus 1\% Agarose in $0.5 \mathrm{x}$ MBSH mit Penicillin/Streptomycin überführt. Bis unbehandelte Kontrollembryonen das gewünschte Stadium erreicht hatten, wurden die animalen Kappen auf einer Kühlplatte bei $18^{\circ} \mathrm{C}$ kultiviert.

\subsection{Protein-Methoden}

\subsubsection{In vitro Translation}

Mit dem TNT-gekoppelten Retikulozytenlysat System (Promega) war es möglich zu kontrollieren, ob von erstellten Expressionskonstrukten Proteine der erwarteten Größe exprimiert werden konnten. Ausgehend von einer cDNA im entsprechenden Expressionsvektor konnte hier das gewünschte Protein in einem einzigen Ansatz durch Kopplung von Transkription mit Translation in vitro synthetisiert werden. Folgende Komponenten wurden in einem Ansatz möglichst luftblasenfrei zusammenpipettiert: $25 \mu \mathrm{l}$ TNT Kaninchen-Retikulozytenlysat, $2 \mu \mathrm{l}$ TNT Reaktionspuffer, $1 \quad \mu \mathrm{l} \quad 1 \quad \mathrm{mM}$ Aminosäuremischung ohne Methionin, $8 \mu{ }^{35} \mathrm{~S}-$ Methionin $(10 \mu \mathrm{Ci} / \mu \mathrm{l} ; 1.000 \mathrm{Ci} / \mathrm{mmol}), 1 \mu \mathrm{l}$ RNasin (40 U/ $\mu \mathrm{l}), 2 \mu \mathrm{g}$ zirkuläre Plasmid-DNA ("Template"), $1 \mu \mathrm{l} \mathrm{SP6,} \mathrm{T3} \mathrm{oder} \mathrm{T7} \mathrm{RNA-}$ Polymerase (10 U/ $\mu \mathrm{l})$, RNase-freies $\mathrm{dH}_{2} \mathrm{O}$ ad $50 \mu \mathrm{l}$.

Durch Pipettieren wurde der Ansatz durchmischt und 120 min bei $30^{\circ} \mathrm{C}$ im Heizblock inkubiert. Im Anschluss wurde $1 \mu \mathrm{l}$ des Ansatzes in $17 \mu \mathrm{l}$ Protein-Probenpuffer aufgenommen und 3 min bei $95^{\circ} \mathrm{C}$ denaturiert. Die Proben wurden abzentrifugiert und in der SDS-PAGE aufgetrennt (s. 3.8.2).

Protein-Probenpuffer (Sol E; 2 x): 0.2 M DTT, 6\% SDS, 0.2 Vol. Sol D, 35\% Glycerin, Bromphenolblau

\subsubsection{SDS-Polyacrylamid-Gelelektrophorese (SDS-PAGE; nach Laemmli, 1970)}

Proteine wurden nach dem Molekulargewicht in SDS-Polyacrylamidgelen aufgetrennt. Zur Fokussierung der Proben wurde dem Trenngel ein Sammelgel vorgeschaltet. Das Trenngel war je nach der Größe der aufzutrennenden Proteine aus 6-12 \% Acrylamid, 0.4 Vol Sol B, $0.1 \%$ SDS in $\mathrm{dH}_{2} \mathrm{O}$ zusammengesetzt. Das Sammelgel enthielt 0.5 Vol Sol A, 0.4 Vol. Sol D, $0.1 \%$ SDS und $0.1 \%$ Thiodiglykol in $\mathrm{dH}_{2} \mathrm{O}$. Zum Gießen eines Gels der Maße 110 x 140 x 0.5 
mm wurden $25 \mathrm{ml}$ Trenngel-Lösung und $5 \mathrm{ml}$ Sammelgel-Lösung angesetzt und zur Polymerisation je $5 \mu \mathrm{l} / \mathrm{ml}$ 10\% APS und $2.5 \mu \mathrm{l} / \mathrm{ml}$ TEMED zugegeben. 1/8 des Gelvolumens wurde vom Sammelgel eingenommen. Das Gelvolumen eines Mini-Gels (Biometra) betrug 86 x 77 x $1 \mathrm{~mm}^{3}$. Die Auftrennung erfolgte für ca. $3 \mathrm{~h}$ (Minigele: $1 \mathrm{~h}$ ) bei $35 \mathrm{~mA}$ in einer Gelkammer (Werkstatt des Instituts) mit 1 x Elektrodenpuffer. Zur Autoradiographie wurde das Gel $1-2 \mathrm{~h}$ bei $65^{\circ} \mathrm{C}$ vakuumgetrocknet und auf einer Phosphoimager-Platte über Nacht exponiert.

Sol A: $30 \%$ Acrylamid, $0.8 \%$ Bisacrylamid

Sol B: 1.5 M Tris- $\mathrm{HCl}$ (pH 8.8), 3 mM EDTA (filtriert, autoklaviert)

Sol D: $0.5 \mathrm{M}$ Tris- $\mathrm{HCl}$ (pH 6.8), 4 mM EDTA (filtriert, autoklaviert)

10 x Elektrodenpuffer: 30 g Tris-Base, 144 g Glycin, $50 \mathrm{ml} 20 \%$ SDS in $\mathrm{dH}_{2} \mathrm{O}$ ad 11

10\% APS: $1 \mathrm{~g} / 10 \mathrm{ml}$ in $\mathrm{dH}_{2} \mathrm{O}$, aliquotiert bei $-20^{\circ} \mathrm{C}$ lagern

\subsubsection{Extraktion und Detektion von Proteinen aus injizierten Embryonen}

Zum Nachweis der Expression epitopmarkierter Proteine aus injizierten Embryonen wurden 10 Embryonen in $1.5 \mathrm{ml}$ Eppendorf-Gefäße überführt und in $100 \mu \mathrm{l}$ eiskaltem Homogenisierungspuffer mit einer automatischen Pipette durch 10maliges Auf-und Abpipettieren homogenisiert. Die Homogenate wurden für $15 \mathrm{~min}$ bei $13.000 \mathrm{Upm}\left(4^{\circ} \mathrm{C}\right)$ in einer Kühl-Tischzentrifuge (Heraeus) zentrifugiert. $80 \mu \mathrm{l}$ der klaren mittleren Phase wurden mit $40 \mu 13 \times$ Protein-Probenpuffer vereint, $5-10 \min$ bei $95^{\circ} \mathrm{C}$ denaturiert und ein Anteil der Proben in einem SDS-Gel aufgetrennt. Anschließend wurden die aufgetrennten Proteine im Western Blot auf eine Nitrocellulosemembran transferiert und mit entsprechenden Antikörpern nachgewiesen.

Homogenisierungspuffer: $40 \mathrm{mM}$ Tris- $\mathrm{HCl}(\mathrm{pH} 7.8), 150 \mathrm{mM} \mathrm{NaCl}, 1 \% \mathrm{~N}-\mathrm{P} 40,25 \%$ Glycerin, 1.0 mM PMSF, Complete ${ }^{\mathrm{TM}}$ Protease-Inhibitoren (Boehringer)

\subsubsection{Ko-Immunopräzipitation von Proteinen aus injizierten Embryonen}

Um die Komplexbildung von zwei unterschiedlich epitopmarkierten Proteinen in injizierten Embryonen nachzuweisen, wurden die Cap-mRNAs beider Proteine zusammen als in beide Zellen des 2-Zell Stadiums injiziert. Nach Kultivierung bis zum Gastrula Stadium wurden 10 Embryonen in $500 \mu \mathrm{l}$ IP-Puffer homogenisiert und auf Eis gehalten. Zum Abtrennen des Dotters wurde $100 \mu \mathrm{l}$ FREON zugegeben, gut gemischt und bei $13.000 \mathrm{Upm}$ für $15 \mathrm{~min}$ zentrifugiert. Die wässrige Phase wurde mit $10 \mu \mathrm{l}$ Gamma-Bind Sepharose (Amersham Pharmacia Biotech) versetzt und für $1 \mathrm{~h}$ bei $4{ }^{\circ} \mathrm{C}$ rotiert. Die Sepharose wurde pelletiert und der klare Überstand mit dem Erstantikörper ( $1 \mu \mathrm{l} \alpha$ FLAG-M2) für mindestens $6 \mathrm{~h}$ bei $4{ }^{\circ} \mathrm{C}$ rotiert. $20 \mu \mathrm{l}$ Sephraose wurden zugegeben und erneut für $1 \mathrm{~h}$ rotiert. Das Pellet wurde $3 \mathrm{x}$ mit $500 \mu \mathrm{l}$ IP-Puffer gewaschen, mit $40 \mu \mathrm{l} 3 \mathrm{x}$ Auftragspuffer versetzt, $10 \mathrm{~min}$ bei $100{ }^{\circ} \mathrm{C}$ denaturiert und der gesamte Überstand in einem SDS-Gel aufgetrennt. Anschließend wurden die aufgetrennten Proteine im Western Blot auf eine Nitrocellulosemembran übertragen und mit entsprechenden Antikörpern nachgewiesen. 
IP-Puffer: $40 \mathrm{mM}$ Tris- $\mathrm{HCl}(\mathrm{pH} 7.8), 100 \mathrm{mM} \mathrm{NaCl}, 0.5 \%$ N-P40, $1.0 \mathrm{mM}$ PMSF, Complete ${ }^{\mathrm{TM}}$ Protease-Inhibitoren (Boehringer)

FREON: 1,1,2-Trichlorotrifluoroethan (Sigma)

\subsubsection{Western Blot}

Durch Elektrotransfer konnten Proteingemische nach der gelelektrophoretischen Auftrennung auf Nitrocellulosemembranen übertragen und die immobilisierten Proteine mit Hilfe spezifischer Antikörper detektiert werden. Zum Elektrotransfer wurde ein "Fastblot"-Gerät (Semidry-Verfahren) der Firma Biometra (Göttingen) verwendet. Auf 3 Lagen befeuchtetes Filterpapier (Whatman) wurde eine Nitrocellulosemembran $(0.45 \mu \mathrm{m}, \mathrm{BA} 85$; Schleicher \& Schuell) gebettet, darauf das Gel plaziert und mit 3 Lagen in Elektrotransferpuffer getränktem Filterpapier luftblasenfrei bedeckt. Dieser "Sandwich" wurde zwischen die angefeuchteten Flächenelektroden des Elektroblotgeräts plaziert. Der Transfer erfolgte bei $0.85 \mathrm{~mA}$ pro $\mathrm{cm}^{2}$ Gelfläche über einen Zeitraum von 3 h. Der Erfolg des Proteintransfers konnte anhand des "Caleidoscope" Proteinstandards (Biorad) verfolgt werden, dessen farbige Banden auf die Nitrozellulosemembran übertragen wurden. Zur Blockierung unspezifischer Bindungsstellen wurde der Blot in 1 x PBS mit 5\% (w/v) Magermilchpulver über Nacht bei $4^{\circ} \mathrm{C}$ auf der Wippe inkubiert. Nach kurzem Waschen in 1 x PBS- oder TBS-Tween (0.05\%) wurde die Membran in Plastikfolie eingeschweißt mit $15 \mathrm{ml}$ verdünntem Erstantikörper (anti-FLAG $1: 20.000$, anti-myc: $1: 2.000) 3 \mathrm{~h}$ bei $4^{\circ} \mathrm{C}$ inkubiert. Nach dem Waschen in $1 \mathrm{x}$ PBST/TBST $(1 \mathrm{x} \mathrm{kurz}$, 2 x 5 min, 2 x 15 min, RT) wurde die Membran erneut eingeschweißt und in 15 ml PBSTween mit $1: 15.000$ verdünntem Zweitantikörper (Ziege-anti-Maus-Antikörper, Peroxidasegekoppelt, Biorad) $1 \mathrm{~h}$ bei $4^{\circ} \mathrm{C}$ inkubiert. Überschüssiger Antikörper wurde durch Waschen (s.o.) entfernt. Durch Zugabe des "SuperSignal Western Pico Chemiluminiscent Substrate" (Amersham) wurde die ECL-Reaktion gestartet. Dazu wurden je $1.5 \mathrm{ml}$ "Stable Peroxide"Lösung und $1.5 \mathrm{ml}$ "Luminol-Enhancer"-Lösung in einem $15 \mathrm{ml}-F a l c o n$ Röhrchen gemischt, der Inhalt auf die Membran gegeben und für $3 \mathrm{~min}$ bei RT inkubiert. Die an den Zweitantikörper gekoppelte Peroxidase oxidiert das Substrat Luminol zu einem lumineszierenden Produkt. Zum Nachweis der Chemilumineszenz-Signale wurde die in Folie eingeschlagene Membran für $30 \mathrm{sec}$ bis $45 \mathrm{~min}$ in einer Filmkassette gegen "Hyperfilm" (Amersham) exponiert und der Film entwickelt.

\subsection{Mikroinjektion in Xenopus Oozyten}

\subsubsection{Präparation von Oozyten}

Die Oozyten wurden durch eine partielle Ovar-Ektomie gewonnen (Terns und Goldfarb, 1998). Zunächst wurde das Xenopus Weibchen mit 0,15\% Tricaine (3-Aminobenzoesäureethylester in Leitungswasser) für ca. $15 \mathrm{~min}$ bei RT narkotisiert und anschließend auf Eis gelegt. Kranial eines der Hinterbeine wurde auf einer Seite in die Oberhaut des Abdomens ein ca. 0,5 cm langer Schnitt gesetzt. Ebenso wurde die darunter liegende Muskelschicht durchtrennt. Mit Pinzetten wurden einige der Ovarienlobi herausgezogen und mit einer Schere abgetrennt. Anschließend wurden Muskelschicht und Oberhaut mit Katzendarm zugenäht. Der 
Frosch wurde anschließend über Nacht in 0,6 \%-iger NaCl-Lösung gehalten. Innerhalb von 36 Monaten war mit einer Regeneration des Ovars zu rechnen.

\subsubsection{Kollagenasebehandlung von Oozyten}

Um Oozyten $\mathrm{zu}$ vereinzeln und die Follikelzellen $\mathrm{zu}$ entfernen, wurde eine Kollagenasebehandlung durchgeführt. In einer $1 \mathrm{mg} / \mathrm{ml}$ Kollagenase (Type 1A, Sigma) enthaltenden Pufferlösung wurden die Oozyten $2 \mathrm{~h}$ bei Raumtemperatur bei $33 \mathrm{Upm}$ rotiert. Bei ausreichender Vereinzelung der Ooyten wurde die Behandlung vorzeitig abgebrochen. Die Oozyten wurden $3 \mathrm{x}$ mit $1 \mathrm{x}$ MBSH gewaschen und bis zur weiteren Verwendung bei $18^{\circ} \mathrm{C}$ gelagert.

Kollagenase-Puffer: $82.5 \mathrm{mM} \mathrm{NaCl}, 2.5 \mathrm{mM} \mathrm{KCl}, 1 \mathrm{mM} \mathrm{MgCl}, 5 \mathrm{mM}$ HEPES (pH 7.5), 1 $\mathrm{mg} / \mathrm{ml}$ Kollagenase

\subsubsection{Mikroinjektion von Oozyten und Kern-Zytoplasma-Trennung}

Für die Mikroinjektionen wurden Oozyten der Stadien V und VI genutzt. Sechs verschiedene Stadien wurden von Dumont (1972) definiert, die sich in der Größe und der äußeren Färbung unterscheiden. Die Oozyten des Stadiums V sind 1000 bis $1200 \mu \mathrm{m}$ groß. Die dunkle animale Hemisphäre und die helle vegetale Hemisphäre sind deutlich voneinander abgetrennt. Stadium VI Oozyten werden bis $1300 \mu \mathrm{m}$ groß und besitzen ein weißes äquatoriales Band. Die Mikroinjektion erfolgte grundsätzlich wie die von Xenopus Embryonen. Allerdings wurden die Oozyten submers in $1 \mathrm{x}$ MBSH auf einem Gazenetz mikroinjiziert. Zytoplasmatische Injektionen erfolgte in die vegetalen Seite, Kerninjektionen in den animalen Pol, unter welchem sich der Kern befindet. In das Zytoplasma wurden pro Oozyte 30-80 nl Eines TNTAnsatzes injiziert, während in den Kern etwa $20 \mathrm{nl}$ injiziert wurden. Der Kern wurde durch die Injektion vom Retikulozytenlysat dauerhaft rot gefärbt, so dass erfolgreiche Mikroinjektion bei der späteren Trennung von Zytoplasma und Kern optisch kontrolliert werden konnte. Für jeden Zeitpunkt wurden 10 Oozyten aufgearbeitet, wobei die Kerne manuell mit Uhrmacherpinzetten vom Zytoplasma getrennt wurden. Die Inkubation der Oozyten erfolgte bei $18^{\circ} \mathrm{C}$.

\subsubsection{Immunopräzipitation:}

Die injizierten Proteine wurden über ihr Myc-Epitop (MT) mit dem Myc-Antikörper (9E10) in einer Immunopräzipitation nachgewiesen. Für die Präparation von Immunopellets wurden 15 $\mu \mathrm{l}$ Gammabind Sepharose (Pharmacia) pro Pellet $3 \mathrm{x}$ mit NET-2 Puffer gewaschen und mit 10 $\mu \mathrm{l}$ Myc-Antikörperlösung pro Pellet $2 \mathrm{~h}$ bei RT in NET-2 Puffer rotiert. Die Pellets wurden erneut 3 x mit NET-2 gewaschen und konnten bei $4^{\circ} \mathrm{C}$ gelagert werden. Kerne und Zytoplasmen wurden in $500 \mu \mathrm{l}$ NET-2 mit einer blauen Pipettenspitze homogenisiert und 15 min bei $13.000 \mathrm{Upm}$ und $4^{\circ} \mathrm{C}$ zentrifugiert. Der Überstand wurde auf ein Immunopellet gegeben und $1 \mathrm{~h}$ bei $4^{\circ} \mathrm{C}$ rotiert. Nach der Inkubation wurde das Pellet 3 x mit NET-2 gewaschen und mit $40 \mu 13$ x SDS-Auftragspuffer versetzt. Die Proben wurden $10 \mathrm{~min}$ bei $100^{\circ} \mathrm{C}$ denaturiert und in einem SDS-Gel aufgetrennt.

NET-2: 50 mM Tris-HCl (pH 7.4), $150 \mathrm{mM} \mathrm{NaCl,} \mathrm{0.05 \%} \mathrm{NP-40}$ 


\section{Experimente und Ergebnisse}

$\mathrm{Zu}$ Beginn der vorliegenden Arbeit waren die vollständige DNA-Sequenz des schnurri-Gens (shn) von Drosophila melanogaster sowie aus eigenen Vorarbeiten im Rahmen der Diplomarbeit Abschnitte von drei shn-verwandten cDNAs (Xshn1, -2, -3) aus Xenopus laevis bekannt (s. Einleitung und Dürr, 1997) $\mathrm{Zu}$ allen drei isolierten Xenopus cDNAs bzw. den abgeleiteten Peptidsequenzen konnten sequenzverwandte Säuger-Proteine in Datenbanken gefunden werden.

Um die Funktion shn-verwandter Gene während der Embryonalentwicklung von Vertebraten untersuchen zu können, wurde im ersten Teil der vorliegenden Arbeit die vollständige cDNA Sequenz eines der shn-verwandten Gene (Xshn3) sowie zusätzliche cDNA Sequenzen der zwei weiteren shn-verwandten Gene (Xshn1, Xshn2) aus Xenopus Datenbanken isoliert. Die von den cDNAs abgeleiteten Proteinsequenzen wurden mit veröffentlichten Sequenzen aus Säugern verglichen und eine Zuordnung versucht.

Anschließend wurde das räumliche und zeitliche Expressionsmuster der Gene in der frühen Embryogenese detalliert untersucht. Weitere funktionelle Analysen wurden mit dem Protein Xshn3 durchgeführt. Die subzelluläre Lokalisation einzelner Fragmente von Xshn3 wurde mithilfe des Xenopus Oozyten Systems analysiert, und in einer Deletionsanalyse wurde die in vivo Kooperation von Xshn3 mit Mitgliedern der Smad Familie von intrazellulären Signalüberträgern des TGF $\beta$ Signalweges in Xenopus Embryonen untersucht. Zur funktionellen Analyse der Xenopus Shn Proteine während der frühen Musterbildungsprozesse im Xenopus Embryo wurden Zinkfinger-Fusionsproteine und Xshn3-Proteinfragmente in Xenopus Embryonen überexprimiert und ihre Wirkung auf frühe Entwicklungsprozesse untersucht. Aus beobachteten Störungen der Embryonalentwicklung oder Veränderungen der Expression von Markergenen der frühen Musterbildung sollten so Rückschlüsse auf die eigentliche Funktion der Schnurri-Proteine gezogen werden.

\subsection{Isolierung und Charakterisierung schnurri-verwandter cDNAs aus Xenopus laevis}

Im Rahmen der Diplomarbeit „Isolierung und Charakterisierung von zum Drosophila melanogaster Zinkfinger Protein Schnurri homologen Sequenzen aus dem Krallenfrosch Xenopus laevis" (Dürr, 1997) wurden partielle cDNA Sequenzen von 2.7 - 4.7 kb Länge von drei verschiedenen shn-verwandten Genen aus Хепориs cDNA Banken isoliert und in Ansätzen charakterisiert. Es wurde nun zunächst versucht, die cDNA Sequenz mindestens eines der Gene zu vervollständigen, um eine funktionelle Analyse anschließen zu können. Unter Zuhilfenahme der bekannten Xenopus cDNA Sequenzen und verwandten Sequenzen aus Ratte, Maus und Mensch wurde versucht, überlappende cDNA Sequenzen aus Phagenbibliotheken und durch RT-PCR cDNA Sequenzen aus präparierter embryonaler Gesamt-RNA zu isolieren. 


\title{
4.1.1 Isolierung und Charakterisierung von Xshn1 Primärsequenz
}

In der vorangegangenen Arbeit war das 3’Ende von Xshnl aus einer Xenopus cDNA Bank isoliert worden. Die isolierte cDNA enhielt $1.9 \mathrm{~kb}$ (von insgesamt etwa 7-8 kb) offenen Leserahmens und die vollständige 3' untranslatierte Region von $0.6 \mathrm{~kb}$ eines $\mathrm{zu}$ shn verwandten Proteins. Weitere cDNA-Banken wurden wie in der vorangegangen Arbeit mit einem degenerierten Primerpaar durchgemustert, das von der Region der carboxyterminalen Doppelzinkfinger Domäne des Drosophila Shn Proteins abgeleitet war. Positive Fraktionen wurden mit spezifischen Primerpaaren aus den drei Xenopus Schnurri cDNAs untersucht, um die Fraktionen den einzelnen Xshn Subtypen zuordnen zu können. Mit Hilfe des Primerpaares Xshn1-5U/Xshn1-7L konnte aus der Phagenfraktion 2.12 einer artifiziellen Chorda dorsalis Bibliothek (Hollemann et al., 1998) ein Phage angereichert werden, aus dem nach zwei Anreicherungsrunden der 5'Bereich der enthaltenen partiellen cDNA von Xshn3 durch PCR mit den Primern pBK-CMV-F/Xshn1-7L amplifiziert und direkt sequenziert wurde. Die cDNA Fraktion enthielt 321 bp oder 107 AS zusätzlicher Sequenzinformation aus Xshnl (Vgl Abb. 4.1). Damit konnten insgesamt ca. 30\% des offenen Leserahmens identifiziert werden.

Die partielle cDNA-Sequenz und die davon abgeleitete Aminosäuresequenz von Xshn1 sind im Anhang dargestellt, wobei der im Rahmen dieser Arbeit isolierte Sequenzbereich markiert ist.

\section{HIV-EP3}
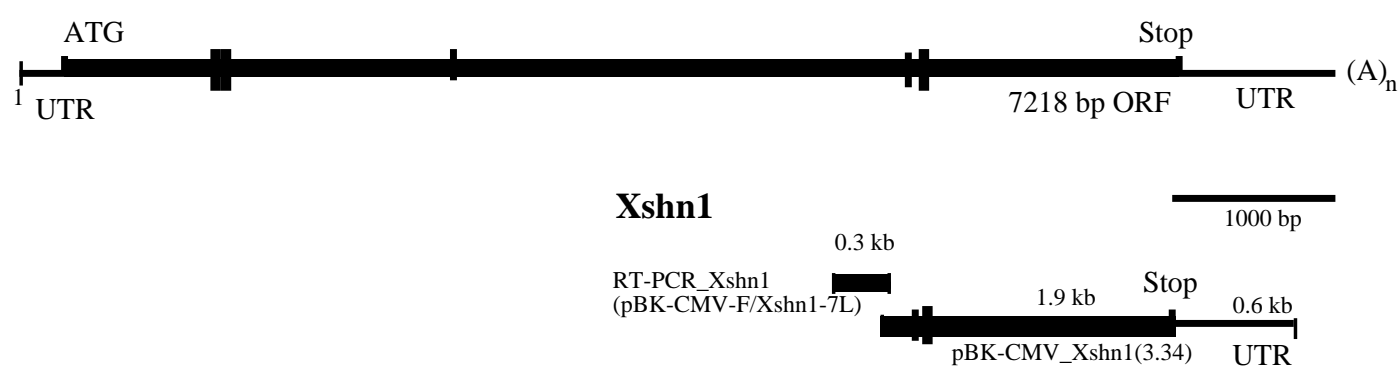

\begin{abstract}
Abb. 4.1: Schema der isolierten cDNA Fragmente von Xshn1. Oben dargestellt ist die Struktur der cDNA des humanen HIV-EP1, dem nächsten zu Xshn1 verwandten Protein. Darunter dargestellt sind die entsprechenden isolierten Xshn1 Fragmente. Der offene Leserahmen ist durch einen dicken Balken gekennzeichnet; vertikale Balken zeigen die Position der Zinkfinger Domänen. UTR, untranslatierte Region; (A) $)_{n}$, Poly-A Sequenz; ATG, Start-Methionin; ORF, offener Leserahmen (open reading frame).
\end{abstract}

In der von der partiellen cDNA Sequenz abgeleiteten Peptidsequenz von Xshn1 wird die carboxyterminale Doppelzinkfinger Domäne gefolgt von einer Glutamat/Aspartat-reichen sauren Domäne, die eine mögliche Transaktivierungsdomäne darstellt (Ptashne, 1988). Die partielle Peptidsequenz von Xshn1 enthält einen signifikanten Anteil von 11\% Serin-, 7\% Threonin- und $11 \%$ Prolin-Aminosäuren. Prolin verursacht einen Knick in der Sekundärstruktur eines Proteins und kann zu einer besseren Exposition benachbarter Aminosäure-Seitenketten für modifizierende Enzyme führen (Stryer, 1996). 28 Wechsel von Serin und Prolin und der hohe Anteil von Ser-, Thr- und Tyr-Aminosäuren ließ eine mögliche posttranslationale Modifizierung durch Phosphorylierungen vermuten. Tatsächlich enthält das partielle Protein eine signifikante Zahl putativer Phosphorylierungsstellen für verschiedene Proteinkinasen. $10 \%$ aller Aminosäuren stellen mögliche Ziele von Serin-, Threonin- oder Thyrosinkinasen dar (nach Datenbanken des 
"Expert Protein Analysis System" (ExPASy) des "Swiss Institute of Bioinformatics" (SIB) (www.expasy.org)). Viele der putativen Phosphorylierungsstellen sind gleichzeitig mögliche Zielsequenzen verschiedener Kinasen. Folgende Kinasen besitzen eine signifikante Zahl von Zielsequenzen innerhalb des partiellen Proteins Xshn2: CaMII (12x), CKI (KaseinkinaseI, 24x), CKII (KaseinkinaseII, 19x), GSK3 (Glykogensynthasekinase3, 13x), PKA (cAMP-abhängige ProteinkinaseA, 18x) und PKC (ProteinkinaseC, 17x). Die isolierte cDNA-Sequenz und die davon abgeleitete Peptidsequenz sind im Anhang dargestellt. In Abb. 4.2 ist die partielle Aminosäuresequenz von Xshn1 dargestellt.

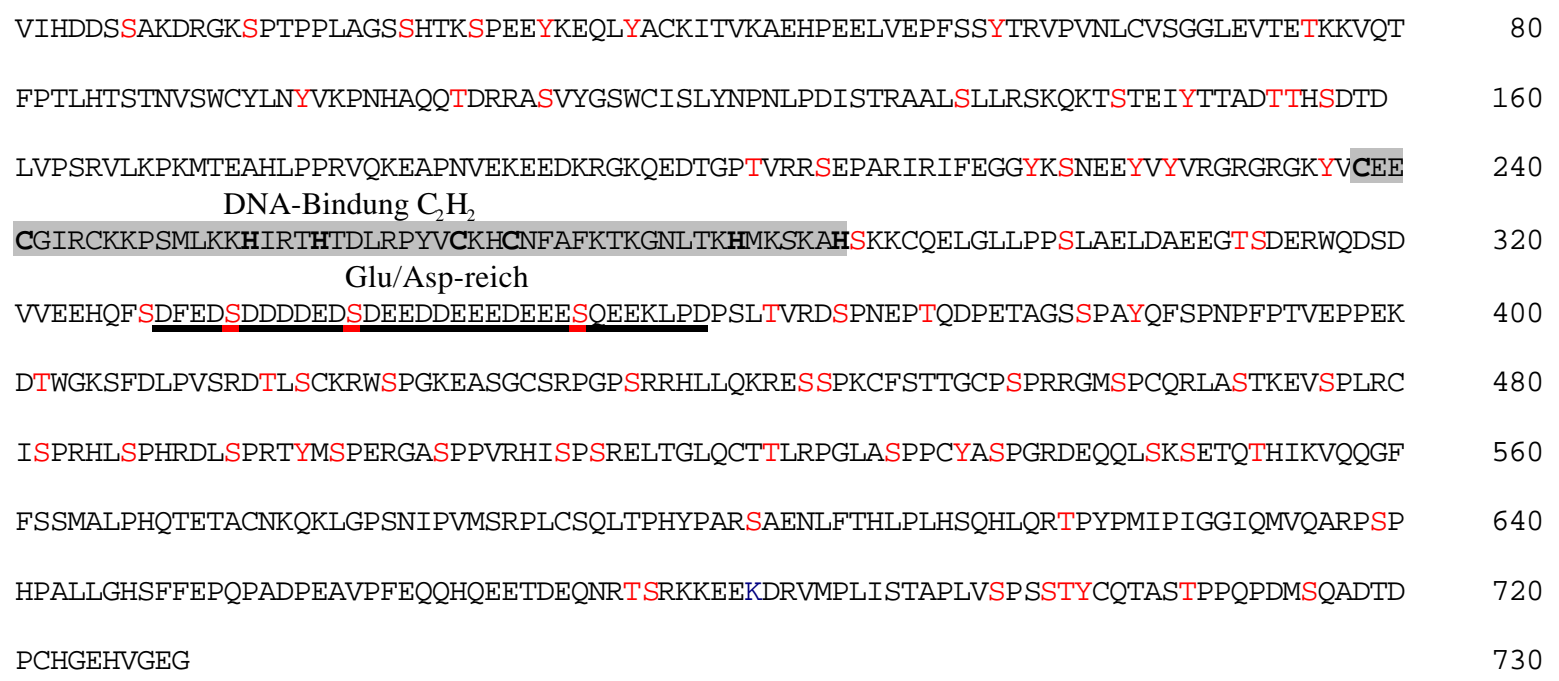

Abb. 4.2: Partielle Peptidsequenz von Xshn1. Die Sequenz deckt etwa das carboxyterminale Drittel des Gesamtproteins ab. Eine konservierte Zinkfinger DNA-Bindungsdomäne ist grau hinterlegt. Die an der Komplexierung von Zinkionen beteiligten Cysteine und Histidine sind durch Fettdruck hervorgehoben. Eine Glu/Asp-reiche putative Transaktivierungsdomäne ist unterstrichen. Putative Phosphorylierungsstellen für Serin-, Threonin oder Tyrosinkinasen sind rot hervorgehoben.

\subsubsection{Isolierung und Charakterisierung von Xshn2 Primärsequenz}

Von der cDNA von Xshn2 waren aus der vorangegangen Arbeit $3.9 \mathrm{~kb}$ aus dem $3^{\prime}$ Bereich des offenen Lesrahmens (von insgesamt etwa 7-8 kb) und eine vollständige $3^{\prime}$ UTR von $0.8 \mathrm{~kb}$ bekannt. Das spezifische Primerpaar Xshn2-2U/Xshn2-1L diente zur Identifizierung weiterer Xshn2-enthaltener Phagenfraktionen aus der Xenopus emryonalen Kopf cDNA Bibliothek. Aus der Fraktion 3.15 konnte ein weiterer Phage angereichert werden, dessen Insertionsfragment eine zusätzliche cDNA Sequenzinformation von $1.2 \mathrm{~kb}$ nach 5' über die bekannte Sequenz hinaus enthielt (Vgl. Abb. 4.3). Ein Durchmusterung sämtlicher embryonaler Kopf cDNA BankFraktionen mit verschiedenen Xshn2-spezifischen Primerpaaren aus dem 5'-Bereich der bekannten Xshn 2 cDNA Sequenz ergab, dass 13 weitere Fraktionen cDNAs mit möglicherweise zusätzlicher Sequenzinformation enthielten. Die partielle cDNA-Sequenz und die davon abgeleitete Aminosäuresequenz von Xshn2 sind im Anhang dargestellt, wobei der im Rahmen dieser Arbeit isolierte Sequenzbereich markiert ist. Die abgeleitete partielle Aminosäuresequenz von Xshn2 deckt mit 1697 Aminosäuren etwa 70\% des offenen Leserahmens des Gesamtproteins $\mathrm{ab}$. 


\section{HIV-EP2}

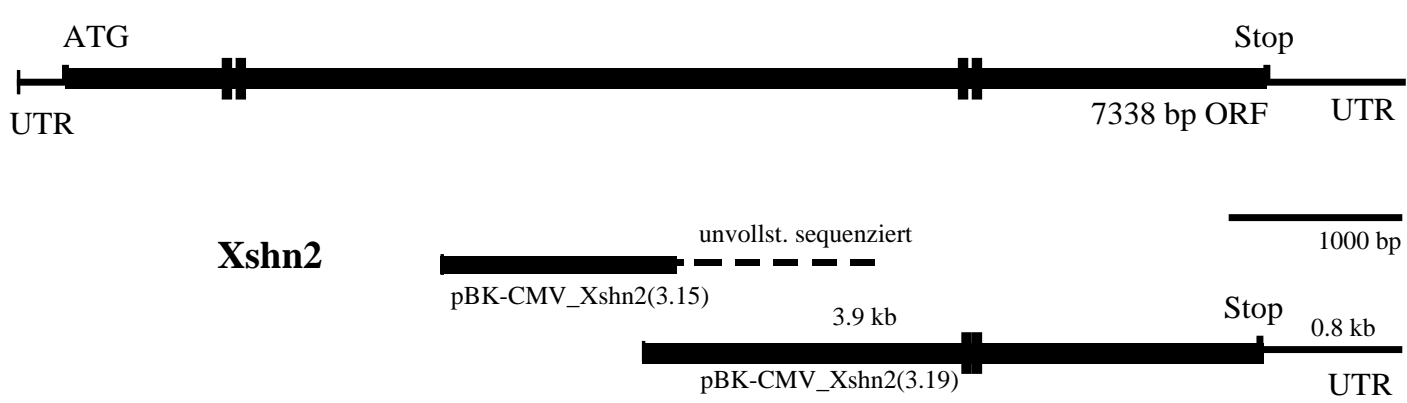

Abb. 4.3: Schema der isolierten cDNA Fragmente von Xshn2. Oben dargestellt ist die Struktur der cDNA des humanen HIV-EP2, darunter die entsprechenden isolierten Xshn2 Fragmente. Der offene Leserahmen ist durch einen dicken Balken gekennzeichnet; vertikale Balken zeigen die Position der Zinkfinger Domänen. UTR, untranslatierte Region; (A) , Poly-A Sequenz; ATG, StartMethionin; Stop, Stop-Kodon; ORF, offener Leserahmen (open reading frame).

Die partielle Peptidsequenz von Xshn2 enthält in ihrer aminoterminalen Region Serin-reiche Regionen und ein putatives Kernlokalisationssignal (NLS). Die carboxyterminale Doppelzinkfinger Domäne wird gefolgt von einer Glu/Asp-reichen sauren Domäne. Weiterhin enthält Xshn2 carboxyterminal der sauren Domäne eine signifikante Zahl tandemartig angeordneter putativer Phosphorylierungsstellen mit dem Konsensus RXXSPXK/R. Dieser Konsensus ist mögliche Zielsequenz der Proteinkinasen CamII, PKA und PKC (nach Datenbanken des "Expert Protein Analysis System" (ExPASy) des "Swiss Institute of Bioinformatics" (SIB, www.expasy.org). Ebenso stellt die in der genannten Sequenz enthaltene Sequenz S/TPXK/R eine Phosphorylierungsstelle für die Proteinkinase $\mathrm{p} 34^{\text {cdc2 }}$ dar. Insgesamt enthält auch die partielle Xshn2 Peptidsequenz einen signifikanten Anteil von 15\% Serin Aminosäuren. Weiterhin besteht die Sequenz zu 7\% aus Threonin und zu 7.5\% aus Prolin. Auch für dieses Protein lassen sich posttranslationale Phosphorylierungen vermuten. Es kommen 52 Wechsel von Serin und Prolin innerhalb des partiellen Proteins vor. Eine Analyse mit Hilfe von Datenbanken ergab, dass $11 \%$ aller Aminosäuren möglicherweise durch Serin-, Threonin- und Tyrosin-Kinasen phosphoryliert werden können. In Abb. 4.4 sind diese Aminosäuren rot hervorgehoben. Signifikante Zahlen putativer Phosphorylierungsstellen fanden sich für folgende Kinasen: CaMII (32x), CKI (KaseinkinaseI, 85x), CKII (KaseinkinaseII, 43x), GSK3 (Glykogensynthasekinase3, 62x), PKA (cAMP-abhängige ProteinkinaseA, 37x) und PKC (ProteinkinaseC, 34x).

SVGDEEDIPMGSSLGSPMLSDLDIKLQEIARAGLVVSGQEYPYSGSQELFDIAARFHHQPGSP ISLLDESSSVTDRDKNA

EVVSKKPPGNVISVIQHTNSLSRPNSFERSESTELLACQQDKPSSP SEACDSGNTMSSISPEWTQSGDISDASARPSP SQ

QSQQTAYHMPPRLVRQHNITVPEIRVTEEPDKPEKEPEIPVKEPEKTPEEFQWPQRSETLSQLPAEKLPPKKKRLRLADM Ser-reich

DNSSGESSFDSTGTSLSRSPSQESNLSHSSSFSMSFDREEILKVATFTKQDEITKQTEFLTVPPGSYSLSVPGQPHHKEM

RRSSSEQIPCPSLTEIPEIRSKSFDYGNLTHASASGATTTTLSPNRERKKCFLVRQASFSGFPENTQTEQETAGNQEPSE

QAHTCRRSSQILWHNSSSSLSCSISVLSEDTANIPIGTSAQPTTSTSSHYSQSVGTHDPLLHKTPYVPKRHLQEQQNTF I 


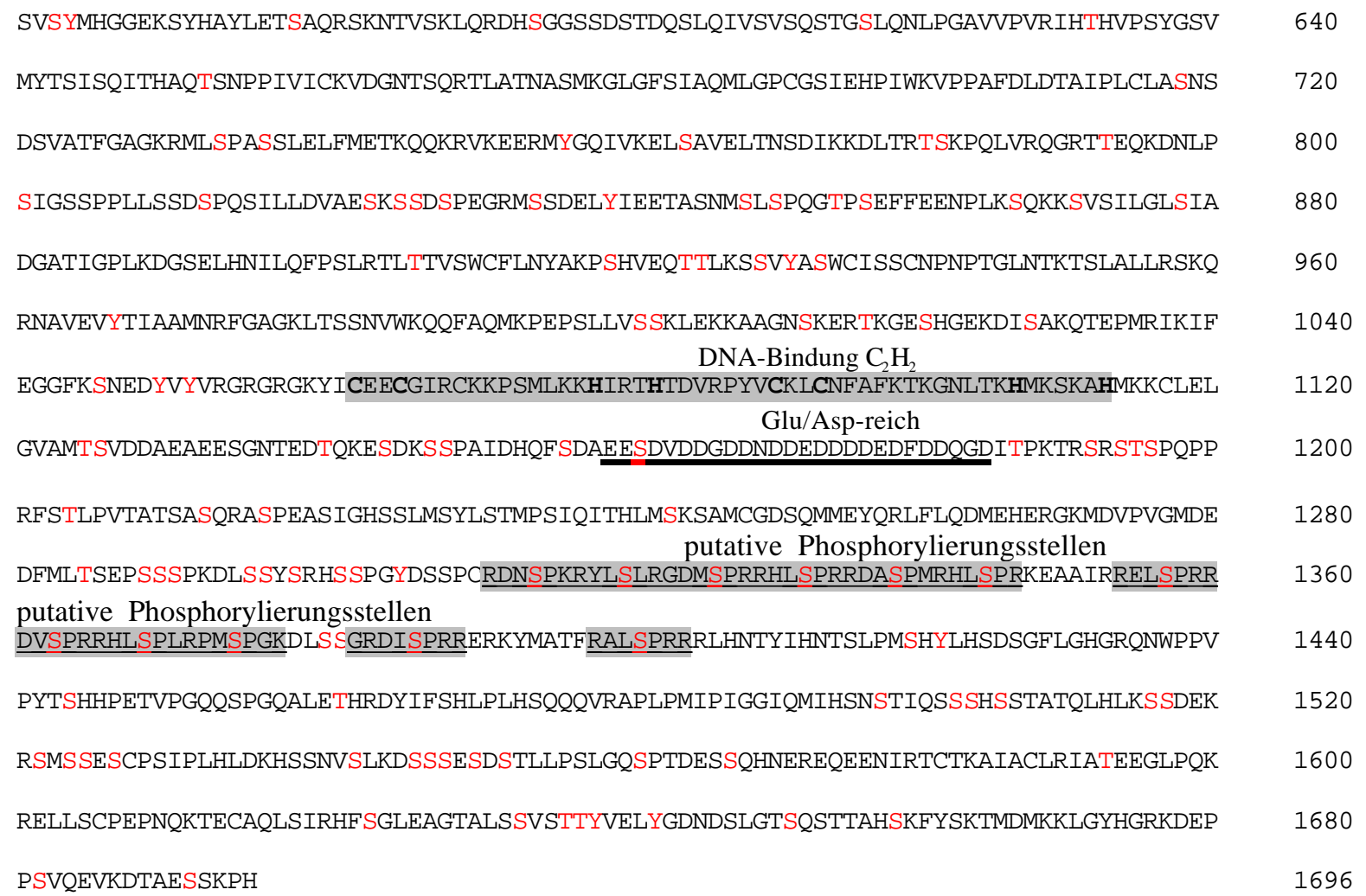

Abb. 4.4: Partielle Peptidsequenz von Xshn2. Die Sequenz deckt etwa die carboxyterminalen $70 \%$ des Gesamtproteins ab. Die konservierte Zinkfinger DNA-Bindungsdomäne ist grau hinterlegt. Die an der Komplexierung von Zinkionen beteiligten Cysteine und Histidine sind durch Fettdruck hervorgehoben. Eine Glu/Asp-reiche putative Transaktivierungsdomäne ist fett unterstrichen. Eine Serin-reiche Region ist einfach unterstrichen. Putative Phosphorylierungsstellen für Serin-, Threonin oder Tyrosinkinasen sind rot hervorgehoben. Tandemartig angeordnete putative Phosphorylierungsstellen sind grau hinterlegt und unterstrichen.

\subsubsection{Isolierung und Charakterisierung von $X \operatorname{shn3}$ Primärsequenz}

Die cDNA von Xshn3 konnte vollständig kloniert werden. Bei Beginn der Arbeit waren $2.1 \mathrm{~kb}$ aus dem 3' Ende des offen Leserahmens oder 27\% der Peptidsequenz und eine vollständige 3' UTR von 0.6 kb bekannt (pBK-CMV_Xshn3(5.20)). Aus den zur Verfügung stehenden cDNA Banken konnten zunächst keine überlappenden Phagenklone isoliert werden, die zusätzliche Sequenzinformation enthielten. Das zu Xshn3 sequenzhomologe humane Protein HIV-EP1 (Maekawa et al., 1989, Fan und Maniatis, 1990) diente als Grundlage zur Positionierung degenerierter Primer, mit denen nach 5' überlappende cDNA Sequenzen durch RT-PCR amplifiziert werden konnten (vgl Abb. 4.5). Die RT-PCR wurde auf gesamt-RNA der Xenopus Embryonalstadien NF 34-38 als Matritze durchgeführt. RT-PCR-Produkte von erwarteter Länge wurden in das Plasmid pGEM-T kloniert und vollständig sequenziert. Zunächst wurde als $5^{\prime}$ Primer der degenierte Primer shn-11d und als 3’ Primer der spezifische Primer Xshn3-2L benutzt, um ein Fragment von 1.5 kb Länge zu amplifizieren (pGEM-T_Xshn3(11d/Xshn3-2L). In der zweiten RT-PCR wurde als 5' Primer der degenierte Primer shn-6d und als 3' Primer der spezifische Primer Xshn3-11L benutzt, um ein Fragment von $1.7 \mathrm{~kb}$ Länge zu amplifizieren (pGEMT_Xshn3(6d/Xshn3-11L)). Mit einem spezifischen Primerpaar aus dem 5’ Bereich der 
neuen Sequenzinformation konnten aus éiner Xenopus embryonalen Kopf cDNA Bank zwei weitere cDNAs angereichert, isoliert und die enthaltenden Plasmide exzisiert werden (pBKCMV_Xshn3(3.12) und pBK-CMV_Xshn3(3.25)), die zusammen den gesamten 5'Bereich von $X s h n 3$ inklusive 5' UTR abdeckten. Nach vollständiger Sequenzierung der cDNAs wurde der offene Leserahmen von Xshn3 aus vier der überlappenden cDNAs zu einem Gesamtkonsrukt in den Vektoren pCS2+MT und pCS2+FLAG vereinigt (vgl. Kap. 2.3).

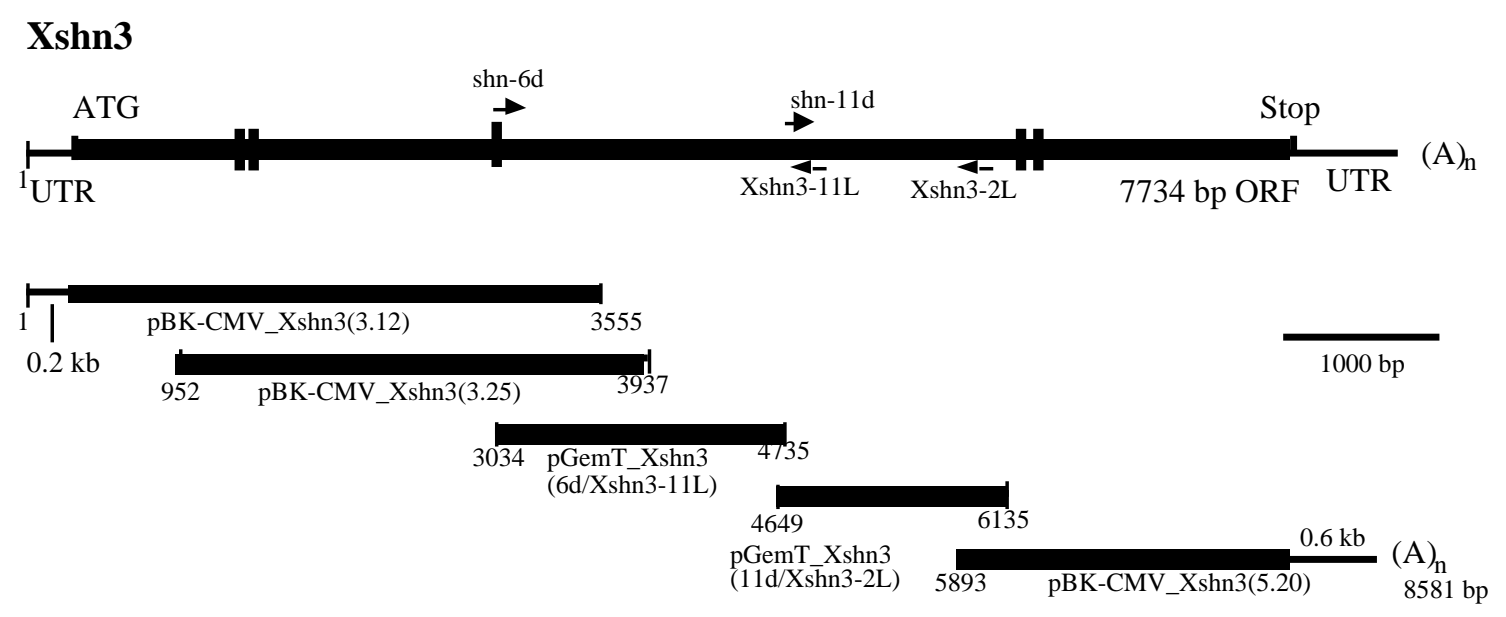

\begin{abstract}
Abb. 4.5: Schema der isolierten partiellen Xshn3 cDNA-Sequenzen aus Phagenbibliotheken und RT-PCR Reaktionen, aus denen eine Gesamtlängen Xshn3 cDNA-Sequenz abgeleitet wurde (Kap. 3.1.6). Der dicke Balken zeigt den offenen Leserahmen von Xshn3 mit Position der für die Zinkfinger kodierenden Sequenzbereiche (vertikale Striche), flankiert von den untranlatierten Regionen (UTR) und der poly(A) Sequenz (A) ; ATG, Start-Methionin; ORF, offener Leserahmen (open reading frame). Im offenen Leserahmen sind Name und Position der Primer angegeben, die für die Isolierung der RT-PCR Fragmente eingesetzt wurden. Für die Teilsequenzen ist die Art ihrer Isolierung (Phagenbank-Fraktion oder RT-PCR) sowie in Basenpaaren Beginn und Ende der Sequenz in Bezug auf die Gesamtlängen-cDNA angegeben.
\end{abstract}

Die vollständige cDNA Sequenz und die davon abgeleitete Peptidsequenz von Xshn3 sind im Anhang dargestellt. Die darin dargestellte Sequenz wurde von Nukleotid 1-3937 aus cDNA-Bank Sequenz, von Nukleotid 3938-5892 aus RT-PCR-Sequenz und von Nukleotid 5893-8581 aus cDNA-Bank Sequenz zusammengestellt. Die kodierende Region von Xshn3 wird im 5'Bereich und im 3'-Bereich von nicht translatierten Bereichen flankiert. Das erste mögliche Startkodon liegt bei Nukleotidposition 245 der cDNA. Dieser Bereich, mit einem Startkodon innerhalb der Sequenz 5'- ACC AGC AGG AGG AGG ATC ATG CCT C -3', entspricht nicht der von Kozak (1991) ermittelten Konsensus-Startsequenz 5'- A/G-X-X-A-U-G-G -3'. Andere Startkodone werden jedoch in allen drei Leserahmen von Stopsequenzen gefolgt. Zudem entspricht die von der dargestellten Startsequenz abgeleitete Peptidsequenz der von den homologen Proteinen aus Maus und Mensch (vgl. Abb. 4.12). Dem offenen Leserahmen folgt eine 3'-untranslatierte Region von $0.6 \mathrm{~kb}$ und eine poly(A) Sequenz. Hier befinden sich mehrere AU-reiche Sequenzmotive, jedoch kein Polyadenylierungssignal der Sequenz AAUAAA. Der offene Leserahmen von Xshn3 kodiert für ein Protein von 2578 Aminosäuren Länge, das zwei Doppelzinkfinger Domänen des $\mathrm{C}_{2} \mathrm{H}_{2}$ Typs und einen Zinkfinger des $\mathrm{C}_{2} \mathrm{HC}$ Typs enthält. Carboxyterminal der zweiten Doppelzinkfinger Domäne ist ein stark saurer Abschnitt zu finden. Im Protein befinden sich basische, Lys/Arg-reiche Sequenzen, die mögliche Kernlokalisationssignale (NLS) darstellen. 
Weiterhin befindet sich im mittleren Bereich ein Serin-reicher Abschnitt, der Zielsequenz von Proteinkinasen sein könnte. Weiterhin kommt ein zum Drosophila Schnurri Protein verwandter Sequenzabschnitt vor, der eine mögliche Dimerisierungsdomäne darstellen könnte. Auch Xshn3 enthält einen signifikanten Anteil von 15\% Serin Aminosäuren. Weiterhin besteht die Sequenz zu $6 \%$ aus Threonin und $\mathrm{zu} 7 \%$ aus Prolin. Auch hier lassen sich posttranslationale Phosphorylierungen vermuten. Es kommen 48x Wechsel von Serin und Prolin Seitenketten vor. Ein Anteil von 10\% aller Aminosäuren könnte möglicherweise durch Serin-, Threonin- und Tyrosin-Kinasen phosphoryliert werden. Signifikante Zahlen putativer Phosphorylierungsstellen fanden sich für folgende Kinasen: CaMII (25x), CKI (KaseinkinaseI, 129x), CKII (KaseinkinaseII, 54x), GSK3 (Glykogensynthasekinase3, 82x), PKA (cAMP-abhängige ProteinkinaseA, 41x) und PKC (ProteinkinaseC, 39x). In Abb. 4.6 ist die vollständige Aminosäuresequenz von Xshn3 dargestellt, wobei die putativen Phosphorylierungsstellen rot hervorgehoben sind.

putatives NLS

MPRTKQIHPKNLRDKIEEAQKKLKSPEEPQAEIVEAGSRACLEVVKGVKRKKIVTENHLKKIPKSPLRNAGKGKQKPEIE

AFPSSSCDPLVFGGCKDKQCLLDQLRKQDIKESKAGELTVKSLKPGTSMQAKKLSVPPDLCNGRREDKDMDIKQTLSRQN

ISSSLNNTKSANISLENMNKPCSTANSAFDVLLRAMEPELSNLNQSWPPCGTQTEKQGHKVAPETTASNSSVSQSEFSSR

YVYYHQGDQSSQISQSIKGSTNVQDRLGIEHEKCNSDTGLQNMHSSCF SSSLEPTKQVYHVALNP SIADPSSSLTQVLSL DNA-Bindung $\mathrm{C}_{2} \mathrm{H}_{2}$

QGNSSSPTNSSKLSVNSPYSLAQVASLISGEQMCNIVLKDQKLKKQGKYICEYCSRACAKP SVLLKHIRSHTGERPYPCV DNA-Bindung $\mathrm{C}_{2} \mathrm{H}_{2}$

TCGFSFKTKSNLYKHKKSHAHAIKLGLGLRTDSSGALLSHDSEKALCIHSDVDESGESDDEYISEERQEDQNVPESQCIK

RPDDSEMVPQKESKILSNSQVLVSKNNSLQGNGVEARLTELPKVVVYPVSTSPLRADSPRVLESASEHFVAQIPELHTQK

KNPHVLSVCSLSEMEQSCDKNCELAEIDDKQQINNATSHAQLQRQQATDYSQEQPKCLLSPRSLGSTDSGYFSRSESVDQ putative

AMSPPTPFLKLQP S SEKDFSKNLSSVTQINATVTPLVQQIYVEKPTI ITGAMRPPLVTKTLEERISKLISDNEAVVDDKQ Dimerisierungsdomäne

LDSVKPRRTSLSRRGSIDSPKSYIFKDSFQFDLKPVGRRTSSSSDIPKSPFTPTDKSKQVFFLSVP SQFTSMDCLPITRS

NSMP TTGYSEVPPVMPASHPLRGSHSFDEKIGSLCDDVFVSGP S TPQQVAHPRTLVRQAAVEDSSATEHFGLGPARSMDE $\mathrm{C}_{2} \mathrm{HC}$

NYPGSKVSSEVLLPRSKSFVQGSSVDRIKKAHSRGTMFECE TCRNRYRKLENFENHKKFYCSELHGPKSKTVCREPEQRT

TMNISQPQIFHYRVAASTGALEQPLQIRKRRKMKSVGDDDEPQQSDSNTAPENMEVLKNLKSTKNSSTITILGSQSCSVS

TVSPQIHFVSRNTDASSEIKLSTLEKNKNIVSQERVEVKCQGTGISVIQHTNSLSKPNSFEKIDSVERNSPVPLQEPQKS

LPLS INAAVGSHEDKIACTPQNSP TRSIDIPRSEVHDSNRGVS TEKTVLVTQSRLVRQYNIQVPEILVTEEPDKDPEIQA NDQETHEKF SWPQRSGSLSNLPTEKLPPKKKRIRLADLEHSSAES SFDSTISRSLSRES SLSRAS SF SASFDKEEPFKSD

SVTKTDGMTKSSEFLTIPTSLNTFGVSREMRRSArEQINCTQP SMEVIEYRSKSFDCGSMSRSRSMSPTNSVTSKFQSSM

LSSANVPLLERRRGPLVKQISLNIGQESPVS TVKPKNLQTEKGILSQMHATEPSLNAELLCAPLTQHSLCSSSLNSSHKF

LLNQDF ISCVQS STEGEEKEKNVLSKEKAPFYAPKYQLKFQKTRESKLSASKHSIRTTADNIYEVHSSVST ISDIKGAVS

NICTLQQTESSSGKSFGKILNTKTVVVPVHNYSNSSYCGYFELLPEILVTQDQGHKITSEANSVSVPNPKDCIIMAKCPD

EPSGPLTVARKICTYKSSVQESTRSIVPVSGLLTQQETSASSKRMLSPANSLDIAMEKHQKRVKDESGAAFNSNIQINLN 
DNA-Bindung $\mathrm{C}_{2} \mathrm{H}_{2}$

\begin{tabular}{|c|c|}
\hline $\begin{array}{l}\text { NHLQSLDPSTEQDLESFPNKNEPRRVKIFDGGYKSNEEYVYIRGRGRGKYICEECGIRCKKP SMLKKHIRTHTDVRPYHC } \\
\text { DNA-Bindung } \mathrm{C}_{2} \mathrm{H}_{2} \\
\text { Glu/Asp-reich }\end{array}$ & 2000 \\
\hline TYCNFSFKTKGNLTKHMKSKAHSKKCLDMGGPVDDQDTDDSGERQRYTGERTGFDADDSDGGDDDDNEDEDEDSQAESGL & 2080 \\
\hline SATPSVTASPQHYPFRNSQQAASNTDEDPQLQHCFSQSNSMDSLPKALITRMTAMTTSTICRPESHEERSKVNLPRETTS & 2160 \\
\hline PPSAASSP KSLCHQMSVDYPEAEAESLGATKSVHVPSVINLIPKEKLSMNMPSSPVDRSTQTMDSYTDATDSYVHQHKST & 2240 \\
\hline KSTQQP S STEPPHTHLFSHLPLHSQQPARSPYSMIPVGGIQLVPAGLAAYSTFMPFQAAPVQLTIPAMGVIHRTSSAVGD & 2320 \\
\hline KTAEVPNTPNP IGVAEVNGVVPCIP IGQINMAGLSAPSLQP LNVETLS ILGLSNTNVAPQIHP SGLTLNAVGLQYLTTSP & 2400 \\
\hline QSNPSP QTHIPGLQILNIALPTLIPSISP ITVESQGVSDQSSSCSPAAGKGSAAFTVADTKNMKQTESLQGSSGVQDCHK & 2480 \\
\hline ILRDLSVTEEKPLGGCLTADKGPQSKQCSNISSSKVKISSSADLYVKANSDSANKPPVSHTF SLLRHQRRTEMISRQ & 2560 \\
\hline QVCDSSSDDDEDRLVIAT & 2578 \\
\hline
\end{tabular}

Abb. 4.6: Vollständige Peptidsequenz von Xshn3. Die konservierten Zinkfinger DNABindungsdomänen des $\mathrm{C}_{2} \mathrm{H}_{2}$ Typs sind grau hinterlegt. Eine Zinkfinger Domäne des $\mathrm{C}_{2} \mathrm{HC}$ Typs ist ebenfalls grau hinterlegt. Die an der Komplexierung von Zinkionen beteiligten Cysteine und Histidine sind durch Fettdruck hervorgehoben. Eine Glu/Asp-reiche putative Transaktivierungsdomäne ist fett unterstrichen. Eine Serin-reiche Region ist einfach unterstrichen, ebenso zwei putative Kernlokalisationssignale (NLS). Putative Phosphorylierungsstellen für Serin-, Threonin oder Tyrosinkinasen sind rot hervorgehoben. Eine Serin-reiche Region ist unterstrichen. Ebenso ist eine putative Dimerisierungsdomäne unterstrichen (vgl. Kap. 4.1.9).

\subsubsection{Vergleich der Xenopus Schnurri Aminosäuresequenzen mit denen verwandter Proteine aus Säugern}

Die von den cDNA-Sequenzen abgeleiteten Aminosäuresequenzen wurden mit in Datenbanken gespeicherten Peptidsequenzen verglichen (National Center for Biotechnology Information; www.ncbi.nlm.nih.gov/BLAST/), um ihre Verwandschaft zu bekannten Proteinen zu ermitteln. Die drei aus Xenopus isolierten Schnurri-verwandten cDNA Sequenzen konnten als Verwandte der Säuger-Proteine HIV-EP1, -2 und -3 identifiziert werden (Nomenklatur nach Hicar et al., 2001).

Eine Zusammenstellung der veröffentlichten und eigenen Sequenzen Schnurri-verwandter Proteine ist in Tabellen 4.1 bis 4.3 aufgeführt. Mit den angegebenen Proteinen wurden direkte Sequenzvergleiche durchgeführt, um Information über konservierte Proteindomänen zu erhalten und den Grad der Konservierung der Proteine quantifizieren zu können. 
Tab. 4.1: HIV-EP1

\begin{tabular}{|c|c|c|c|c|}
\hline & Name & Länge & EMBL ,accesion number “6 & Referenz \\
\hline hs & $\begin{array}{l}\text { HIV-EP1/ PRDII-BF1 } \\
\text { MBP1 (partiell) }\end{array}$ & $2717 \mathrm{AS}$ & $\begin{array}{l}\text { NM_002114/X51435 } \\
\text { M32019 }\end{array}$ & $\begin{array}{l}\text { Maekawa et al., 1989, } \\
\text { Fan und Maniatis, } 1990 \\
\text { Baldwin } \text { et al., } 1990\end{array}$ \\
\hline $\mathrm{mm}$ & $\alpha$ ACRYBP1 & $2688 \mathrm{AS}$ & L36825/NM007772 & Nakamura et al., 1990 \\
\hline $\mathrm{xl}$ & Xshn3 & $2578 \mathrm{AS}$ & - & diese Arbeit \\
\hline & $\begin{array}{l}\text { IV-EP1 } \\
\text { RDII-BF1 } \\
\text { IBP1 } \\
\text { ACRYBP1 } \\
\text { shn3 }\end{array}$ & $\begin{array}{l}\text { interferone } \\
\text { major histc } \\
\text { alphaA-cr } \\
\text { Xenopus S }\end{array}$ & $\begin{array}{l}\text { positive regulatory domain II-bin } \\
\text { patibility complex binding protei } \\
\text { in enhancer binding protein } 1 \\
\text { ri } 3\end{array}$ & $\begin{array}{l}\text { nding protein } \\
\text { ing factor } 1 \\
1\end{array}$ \\
\hline
\end{tabular}

Tab. 4.2: HIV-EP2

\begin{tabular}{|c|c|c|c|c|}
\hline & Name & Länge & EMBL ,accesion number “6 & Referenz \\
\hline hs & $\begin{array}{l}\text { mbp2 } \\
\text { HIV-EP2 (partiell) }\end{array}$ & $2461 \mathrm{AS}$ & $\begin{array}{l}\text { X65644 } \\
\text { M60119 }\end{array}$ & $\begin{array}{l}\text { van’t Veer et al., } 1992 \\
\text { Nomura et al., } 1991\end{array}$ \\
\hline $\mathrm{mm}$ & $\begin{array}{l}\text { MIBP1 } \\
\text { mMBP2 } \\
\text { ATBP2 } \\
\end{array}$ & $2437 \mathrm{AS}$ & $\begin{array}{l}\text { NM_010437 } \\
\text { NP_034567 } \\
?\end{array}$ & $\begin{array}{l}\text { Dorflinger } \text { et al., } 1999 \\
\text { Dorflinger } \text { et al., } 1999\end{array}$ \\
\hline rn & $\begin{array}{l}\text { MIBP1 } \\
\text { AGIKBP1 (partiell) } \\
\text { ATBP1 }\end{array}$ & $2437 \mathrm{AS}$ & $\begin{array}{l}\text { D37951 } \\
\text { M65251 } \\
\text { X54249 }\end{array}$ & $\begin{array}{l}\text { Makino et al., } 1994 \\
\text { Ron et al., } 1991 \\
\text { Mitchelmore } \text { et al., } \\
1991\end{array}$ \\
\hline $\mathrm{xl}$ & Xshn2 (partiell) & $?$ & - & diese Arbeit \\
\hline \multicolumn{5}{|c|}{$\begin{array}{ll}\text { mbp2 } & \text { major histocompatibility complex binding protein2 } \\
\text { HIV-EP2 } & \text { human immunodeficiency virus type 1-enhancer binding protein } 2 \\
\text { MIBP1/ -2 } & \text { c-myc intron binding protein } 1 /-2 \\
\text { mMBP2 } & \text { mouse major histocompatibility complex binding protein2 } \\
\text { ATBP1 /-2 } & \text { angiotensinogen enhancer binding protein } 1 /-2 \\
\text { AGIKBP1 } & \text { rat angiotensinogen gene-inducible enhancer-binding protein } 1 \\
\text { Xshn2 } & \text { Xenopus } \text { Schnurri } 2\end{array}$} \\
\hline
\end{tabular}

Tab. 4.3: HIV-EP3

\begin{tabular}{|c|c|c|c|c|}
\hline & Name & Länge & EMBL „,accesion number“6 & Referenz \\
\hline hs & HIV-EP3 & $2406 \mathrm{AS}$ & NM_024503 & Hicar et al., 2001 \\
\hline $\mathrm{mm}$ & mKRC & $2348 \mathrm{AS}$ & L46815 & Wu et al., 1996 \\
\hline $\mathrm{xl}$ & Xshn1 (partiell) & $?$ & - & diese Arbeit \\
\hline & $\begin{array}{l}\text { IV-EP3 } \\
\text { KRC }\end{array}$ & \multicolumn{3}{|c|}{$\begin{array}{l}\text { human immunodeficiency virus type 1-enhancer binding protein } 3 \\
\text { mouse DNA binding protein Rc for the kappa B motif of transcription } \\
\text { and for the } \mathrm{V}(\mathrm{D}) \mathrm{J} \text { recombination signal sequences } \\
\text { Xenopus Schnurri } 1\end{array}$} \\
\hline
\end{tabular}

Tabellen 4.1 - 4.3: Zusammenstellung der unabhängig voneinander beschriebenen Schnurriverwandten cDNA Sequenzen aus Vertebraten. Angegeben sind Proteinlänge (AS), "EMBL accession number" und Referenz der Erstveröffentlichung. Die in der vorangegangenen Arbeit (Dürr, 1997) und dieser Arbeit emittelten Xenopus Sequenzen wurden den Gruppen zugeordnet. Die "accession number" der Sequenzen, die für Sequenzvergleiche in dieser Arbeit benutzt wurden, sind durch Fettdruck hervorgehoben. 


\title{
4.1.4.1 Vergleich der Xshn1 Aminosäuresequenz mit denen verwandter Proteine aus Säugern
}

Während der vorausgegangenen Arbeit konnte als Xshn1-verwandtes Protein durch Datenbankanalyse das murine mKRC (Wu et al., 1996) identifiziert werden. Ein AminosäureSequenzvergleich hatte außerhalb der carboxyterminalen Doppelzinkfinger-Domäne der beiden Proteine eine sehr geringe Sequenzidentität der Proteine ergeben (Dürr, 1997). Es war daher unsicher, ob die beiden Proteine als Homologe anzusehen waren, oder ob sie zwei verschiedene Mitglieder einer vielleicht größeren Gruppe von Schnurri-verwandten Proteinen darstellten. Im Verlauf der vorliegenden Arbeit wurde von Hicar et al. (2001) ein humanes Protein beschrieben, das zum murinen mKRC $80 \%$ Sequenzdentität besitzt. Im Carboxyterminus, der mit der partiellen Xshn1 Sequenz überlappt, besitzen die Proteine 78\% Identität zueinander und zum bekannten Bereich des Xenopus Xshn1 Protein 48\% bzw. 49\% Sequenzidentität. Das murine und das humane Protein stellen daher sicher Homologe dar, während das Xenopus Protein sich deutlich von ihnen unterscheidet. Vergleicht man dagegen nur die carboxyterminale Doppelzinkfinger Domäne der genannten drei Proteine mit denen aller bekannten weiteren Schnurri-verwandten Proteine, so lässt sich das Xenopus Protein eindeutig den Proteinen HIV-EP3 und mKRC zuordnen (s. Abb. 4.1.8). Abb. 4.7 zeigt einen schematischen Vergleich der Peptide HIV-EP3 und Xshn1.

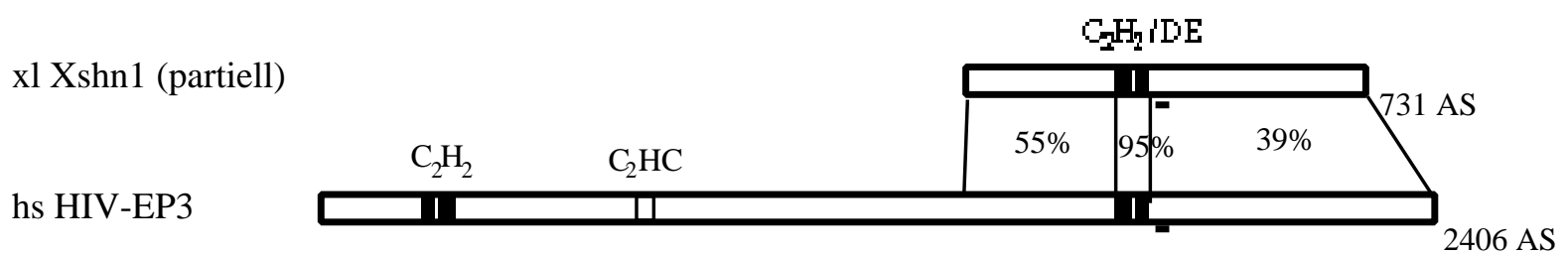

\begin{abstract}
Abb. 4.7: Schematische Darstellung der aus der Xenopus laevis Xshn1 cDNA Sequenz abgeleiteten Proteinsequenz und der am nächsten verwandten humanen Proteinsequenz. Lange Querbalken stellen die Primärsequenz der Proteine dar, deren Länge in Aminosäuren (AS) angezeigt ist. Schwarze Balken zeigen die Position von Zinkfinger DNA Bindungsdomänen $\left(\mathrm{C}_{2} \mathrm{H}_{2}\right)$, z.T. gefolgt von Glu/Asp-reicher Region (D/E). Ein leerer Kasten bezeichnet eine Zinkfingerdomäne des $\mathrm{C}_{2} \mathrm{HC}$ Typs. Für die duch Striche verbundenen Abschnitte der jeweils homologen Proteine ist die Sequenzähnlichkeit in Bezug auf ihre Aminosäure-Identitäten in Prozent dargestellt. Die Sequenzidentitäten wurden für folgende Regionen berechnet: ZF4/5 = GRG-ELG, vgl. Abb. 4.2.
\end{abstract}

Bei einem direkten Aminosäure-Sequenzvergleich von Xshn1 mit seinen humanen homologen Proteinen (Abb. 4.8) wird der hohe Grad der Sequenzidentität in der Zinkfinger DNABindungsdomäne und angrenzenden Regionen deutlich. Im aminoterminal hierzu gelegenen Bereich weicht die Xshn1 Sequenz deutlich von denen der Säugerproteine ab. Im Carboxyterminus findet sich nur ein kurzer konservierter Sequenzbereich, der auch in den beiden anderen Schnurri-Proteinen zu finden ist (vgl. Abb. 4.12.) Von der genannten Region abgesehen, divergieren dagegen die Carboxytermini aller drei dagestellten Proteine deutlich voneinander. 
$\mathrm{xl}$..PFSSYTRVPVNLCVSGGLEVTETKKVQTFPTLHTSTNVSWCYLNYVKPNHAQQTDRRASVYGSWCISL hs SL-L-ETSSR-AK. . . . SQ-G-DS---LQ--S---T-----------I----I-HA---S---AG----$\mathrm{mm}$ SL-L-DTSPK-AK. . . . LQ L-G-DS---LQ--S---T----------I----I-HA---S---AG-----

YNPNLPDISTRAALSLLRSKQKTSTEIYTTADTTHSDTDLLVPSRVLKPKMTEAHLP . . . PRVQKEAPN ------GV--K-----------V-K-T--M-TAP-PEAGR----SSR--R---V---SLVS-EG--DLAR

carboxyterminale VEKEEDKRGKQEDTGP TVRRSEPARIRIFEGGYKSNEEYVYVRGRGRGKYVCEEC GIRCKKPSMLKKH IR

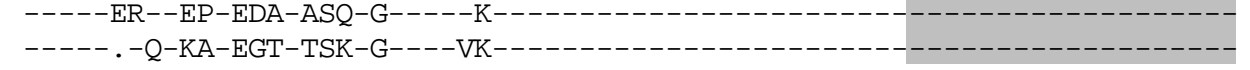

Zinkfinger $\left(\mathrm{C}_{2} \mathrm{H}_{2}\right)$ TH TDLRPYVCKHCNFAFKTKGNLTKHMKSKAH SKKCQELGLLPP SLAELDAEEGTSD . . . . . ERWQDSD ----V--------H----

Glu/Asp-reiche Region

VVEEHQFSDFEDSDDDDEDSDEEDDEEEDEEESQEE..........KLPDPSLTV ....RDSPN A--------L----S-S. -L--DE--DEE- . . -QD-LSRP S SEAPP P GPPHA-RAD-SP ILGPQPPDAPA A--------L-----S-S. $-\mathrm{L}--\mathrm{DEE}---\mathrm{E}-----\mathrm{D}-\mathrm{LSGPCSEAAPPCLPPT}$-QEN-SPVEGPQAPD . . S

EPTQDPETAGSSPAYQFSPNP.........FPTVEPPEKDTWGKSFDLPVSRDTLSCKR.WSPGKEASG SG-EATRGSSV-E-ERLTASSCSMSSQSMPGL-WLG-APLGSVE-DTGSAL-YKPV-PR-P---S---G. TSDEVPEGSSI-E-THLTASSCSTP SRGTQGL-RLGLAPL . . . E-DMSSAP-PKAT-PR-P---S---G.

CSRPGP SRRHLLQKRESSP . KCFSTTGCPSPRRGMSPCQRLASTKEVSPLRCISPR. HLSPH . . . . RD .---PLARK-S-T-ND---QR-SPARE. PQASAP SP-GLHVDPGRGMG--P-G---LQ---LTLCPLG-E .---SVTRK-S-T-ND---QQ-SPARE . AQASVTST-GPQMGP GRDLG-HL-G---PE--RLTPYPIG-E

LSPRTYMSP . .ERGASPPVRHISPSRELTGLQCTTLRPGLASPPCYASPGRDEQQLSKSETQTHIKVQQG -A--AHVLSKL-GTTDPGLPRY--T-RWSPG-AES . P-RS-P-GKW-LA-PGSP SAGEHGPGLGL . APRV APA . ..... GL-RATDTGTPRY--T-RWSLG-AES . P-QTVL-GKW-LA-PCSP SADKSGLGLGP . VPRA

FFSSMALPH . . . QTETAC . . . NKQKLGPSNIPVMSRPLCS . . . . . QLTPHYPARSAENLFTHLPL LFPPAP---KLLSRSPETCASPWQKAESRS--CS-GPAH--S-RPF SALHDFHG-IL--TE--I-SLLQPVP---TLLSRSPETCTSAWRKTESRS--AG-GP . . . -FPRPF SAPHDFHG-LPS-SE--I-S-

zwischen HIV-EP1, -2 und

-3 konservierte Domäne

HSQHLQRTPYPMIPIGGIQMVQARP SP HPALL . . . . . . . . . . . . GHSFFEPQPADPE --L-S-A-C-L------------GAQ-TV-PGPCAAWVSGF SGGGSDLTGAREAQER-RWSPTESP SA

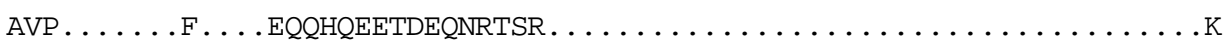
S-SPVAKVSKFTLSS-LEGRDYPK-RE--GGGP GRPPDWTP HGTGAPAEP TP THSPCTPPDTLPRPPQGR

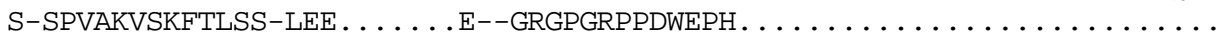

KEEKDRVMPL .........ISTAPLVSPSSTYC ............ QTASTPPQPDMSQ RAAQSWSPR-ESPRAPANPEP SA-P--DRS--VG-LAEASARFPARTRNLSGESRTRQDSPKP SGSGEPR ....-LKP-QDPWAHTAPAPH-CPKATR. . . ..........WH-PGGASWGHHTHWPT . ...

Abb. 4.8: Sequenzvergleich der zu Xshn1 homologen Proteine von Xenopus (xl), Mensch (hs) und Maus (mm). Die Zinkfinger Domäne (ZF) wurde dunkelgrau hinterlegt. Die an der ZinkKoordinierung beteiligten Cysteine und Histidine sind druch Fettdruck hervorgehoben. Eine Glu/Asp-reiche Region ist fett unterstrichen. Eine zwischen HIV-EP1, -2 und -3 konservierte Domäne ist grau hinterlegt. Striche kennzeichnen identische Aminosäuren, Punkte stehen für eingefügte Z wischenräume. Die Zahlen am rechten Rand bezeichnen die Aminosäureposition im Xenopus Protein. Xenopus, diese Arbeit; Mensch: Hicar et al., 2001; Maus, Wu et al., 1996. 
Da im Verlauf der vorliegenden Arbeit von anderen Arbeitsgruppen keine Proteinsequenzen veröffentlicht wurden, die auf eine vierte Unterfamilie von Vertebraten Schnurri Proteinen hindeuten könnten, kann trotz deutlicher Sequenzvariabilität stark vermutet werden, dass Xshn1 zum murinen mKRC und dem humanen HIV-EP3 homolog ist.

\title{
4.1.4.2 Vergleich der Xshn2 Aminosäuresequenz mit denen verwandter Proteine aus Säugern
}

Während der vorausgegangenen Arbeit waren zu Xshn2 bekannte Proteine aus dem Menschen und der Ratte beschrieben worden (van’t Veer et al., 1991, Makino et al., 1994, Mitchelmore et al., 1991). Dörflinger et al., (1999) beschrieben im Verlauf der vorliegenden Arbeit das homologe Protein aus der Maus. Die Säugerproteine besitzen über 90\% Sequenzidentität zueinander und jeweils ca. $60 \%$ Sequenzidentität zum überlappenden Bereich von Xshn2. Über die gesamte Sequenz wechseln sich hoch konservierte Bereiche mit weniger konservierten Bereichen ab. Das Protein Xshn2 kann als homologes Protein zu den dargestellten Proteine angesehen werden.

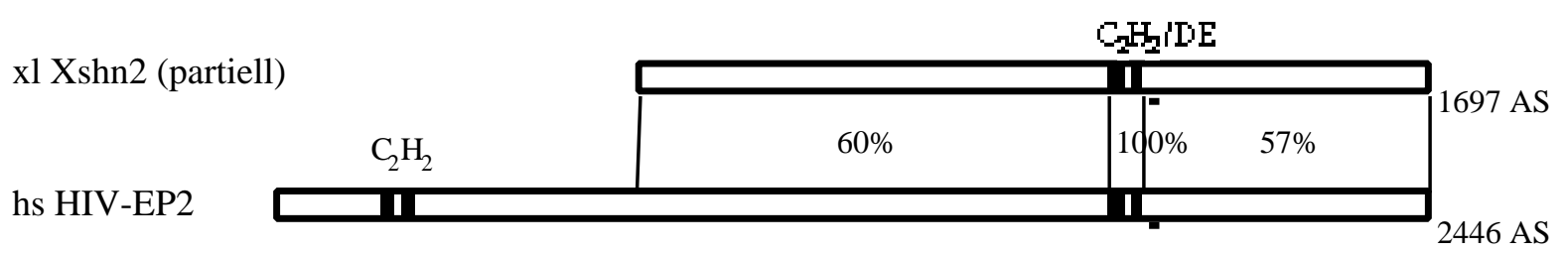

\begin{abstract}
Abb. 4.9: Schematische Darstellung der aus den Xenopus laevis Xshn2 cDNA Sequenzen abgeleiteten Proteinsequenzen und der am nächsten verwandten humanen Proteinsequenz. Lange Querbalken stellen die Primärsequenz der Proteine dar, deren Länge in Aminosäuren (AS) angezeigt ist. Schwarze Balken zeigen die Position von Zinkfinger DNA Bindungsdomänen $\left(\mathrm{C}_{2} \mathrm{H}_{2}\right)$, z.T. gefolgt von Glu/Asp-reicher Region (D/E). Für die durch Striche verbundenen Abschnitte der jeweils homologen Proteine sind die Sequenzidintitäten in Bezug auf ihre Aminosäure-Identitäten in Prozent dargestellt. Die Sequenzidentitäten wurden für folgende Regionen berechnet: ZF4/5 = GRG-ELG (vgl. Abb. 4.4).
\end{abstract}

In den gegenübergestellten Proteinen wird die hoch konservierte carboxyterminale Doppelzinkfinger Domäne von einer Glutamat-/Aspartat-reichen Region gefolgt. Weiterhin lässt sich ein konserviertes putatives Kernimportsignal (NLS) identifizieren. Es findet sich außerdem ein serinreicher Bereich, der einen hohen Anteil putativer Phosphorylierungsstellen enthält (Abb. 4.10). 
$x 1$ NTMSSISPEWTQSGDISDASARPSP SQQSQQTAYHMPPRLVRQHNITVPEIRVTEEPDKPEKEPEIPVKE ISEAPV----APP--GAESGGKP S----V--QS--TQ---------Q------------------AQS -VLEAPV----APP--GGESGSKPT----VP-HS--AQ--------- Q $-------------------\mathrm{A}-\mathrm{T}--$ VLEGPV----APP--GAESGS--T----VP-HS--GQ----------Q-------------------A-T--

Ser-reiche Region

PEKTPEEFQWPQRSETLSQLPAEKLPPKKKRLRLADMDNSSGESSFDSTGTSLSRSP SQESNLSHSSSFS

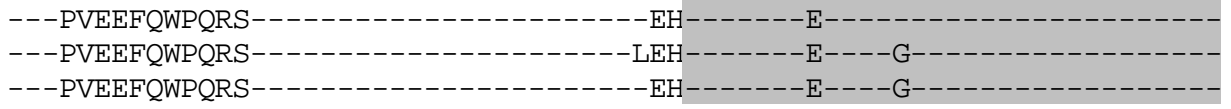

MSFDREEILKVATFTKQDEITKQTEFLTVPPGSYSLSVPGQPHHKEMRRSSSEQIPCPSLTEIPEIRSKS ---E---TS-LSALP----FGKHS-----------------HH-Q------C-----M---HPA-V--V----------TV-LTAPP----SGKHS----------------HH-Q-----C----M---HP--V----------- D-TV-LTAPP----SGKHS----------------HH-Q-----C----M---HP--V-------

FDYGNLTHASASGATTTTLSPNRERKKCFLVRQASF SGFPENTQTE . . QETAGNQEP SEQAHTCRRSSQI ------S--PV---AAS-V--S------------SF--S--IS-G-VGMDQSVK--QL-HL-AGL--G. . ----- S--PVA-TSP S-L--S-----------SF--S--IA-G-AGVDP SVK--HM-HL-AGL-AA . $------S--P V A--S P S-L--S-----------S F--S--I A-G-A G M D P S V K--Q L--L-A G L-A A . ~$.

LWHNSSSSLSCSISVLSEDTANIPIGTSAQPTTSTS.SHYSQS . . . . . . VGTHDPLLHKTPYVPKRHL .--HGPPAV . . . -PP-QQEDPGKQVAGPCP-LS-GP. L-LAQPQS-MTSK--P--PHL-P-QETIPFS-I .- . . . PSV . . . -PP-PG-DPGKQV . GTCG-LS-GPPL-LTQQQIMHMDSQESLRN---QP-S-MTSK-.- . . . TTV . . .PP-PG-DPGKQVVGPCGQLS-GPPL-LAQQQIMHMDSQESLRN---QP-S-MTGK--

QEQQNTF IHPDKTVYPPVHNA. FQLPYTSVCMAQLP IHHPFMWPTCADPLQRHFEHHL . QQLQKTYFKQP MHMD SQESLRN---QP-IQ--L--FQ-PT---VH--AQQ-PW- . . ...-A--PHPFA-HP--S-G-PS P--PHL-P-Q-AVPFS-IQ--L--FQ-PT---VH--AQQSPW- . . . . T--PHPFGP HP-NS-S-PP--PHL-P-Q-AVPFS-IQ--L--FQ-PT---VH--AQQ-PW- . . . . A--PHPFTPHP-NS-S-P-

SQSDIHSYY . LDP TQDLTGSKSVSYMHGGEKSYHAYLETSAQRSKNTVSKLQRDHSGGSSDS . . TDQSLQ F-TE---S-P-EHVAEH--K-PAE-A-TK-QT-PC-SGA-GLHP--LLP-FPS-Q-SK-TETP. SE-V-Q F-A-L--S-P-EHVAEH--K--AD-P-AK-QT-PC-SG--GLHS--LPL-FPS-PGSK-TETP . TE-L-R F-A------S-EHVAEH--K--AD-P-AK-QT-PC-SGA-GLHS--LPP-FPS-PGSK-TEAPPTE-L-R

IVSVSQSTGSLQNLPGAVVPVRIHTHVPSYGSVMYTSISQITHAQTSNPP IVICKVDGNTSQRTLATNAS EDFA-ANA----S---T------Q---------------- . . LGQNS-A-------E-MT----V---A EDFA-ENA-P--S---T------Q Q----------------- . . LGQNS-A-------E-MT----V---A

MKGLGF SIAQMLGPCGSIEH . PIWKVPPA. .FDLDTAIPLCLASNSDSVATFGAGKRMLSPASSLELFME -Q-I--N---V--QHAGL-KY----A-QTLPLG-ESS-----P-T--S---L-GS---------------Q-I-LN---V--QHTGL-KY------QTLPLG-ESS-----P-T--NA-SL-GS-----------------Q-I--N---V--QRTGL-KY------QTLPLG-ESS-----P-T---A-SL-------------------

TKQQKRVKEERMYGQIVKELSAVELTNSDIKKDLTRTSKPQLVRQGRTTEQKDN . LPS IGSSPPLLSSDS ----------K------E----------------S-PQ--------CAS-P--G. -Q -GS--FSS--PS-

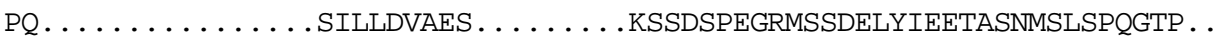
S-DYPSVSP SSREPFPPSKEM-SGSRA . . . PLPGQ--GP-ESKES-----D-D----D--M---SSSLP S-D . . . HP SASGPFPPNREI-PGSRAPPRR . . . . - F-GPS-S-E-----DMD--S-D--M---SSALP S-D . . . HPAASGPFPPNREI-SGSRAPPRR . . . . - F-GPS-S-E-----D-D--S-D--M---SSSLP

... SEFFEENPLKSQKKSVSILG. LSIADGATIGP . . . . LKDGSELHNILQFP SLRTLTTVSWCFLNYAK AGDGQLE--G. .-GH-RP-GM-VRMAS-P SGNVADSTLL-T-MADFQQ---------T---------- TTGGGQQE--G. . -AR-LP-SM-VHMASGP-GNVANSTLLFT-VADFQQ----------T---------- TTGG-QQED-G. . -AR-LP-SM-VHMASGP-GNVANSTLLFT-VADFQQ----------T-----------T-

PSHVEQTTLKSSVYASWCISSCNPNPTGLNTKTSLALLRSKQRNAVEVYTIAAMNRFGAGKLTSSNVWKQ $-\mathrm{NY}-\mathrm{Q}-\mathrm{A}-\mathrm{F}-----------------\mathrm{S}------\mathrm{T}-------\mathrm{KITA}-\mathrm{I}--\mathrm{L}---\mathrm{H}-\mathrm{P}-\mathrm{T}------\mathrm{SA}---$ $--\mathrm{F}-\mathrm{Q}-\mathrm{A}-\mathrm{F}------------------\mathrm{S}------\mathrm{T}--------\mathrm{KITA}-\mathrm{I}--\mathrm{L}---\mathrm{H}-\mathrm{P}---------\mathrm{S}----$ $-\mathrm{NF}-\mathrm{Q}-\mathrm{A}-\mathrm{F}----------------\mathrm{S}------\mathrm{T}--------\mathrm{KITA}-\mathrm{I}--\mathrm{L}---\mathrm{H}-\mathrm{P}-\mathrm{T}------\mathrm{SA}---$ 


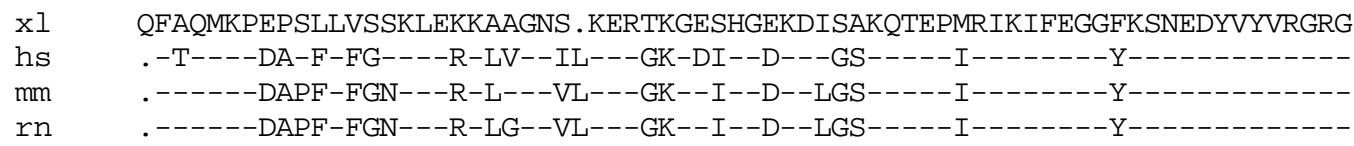

carboxyterminale Zinkfinger Domäne $\left(\mathrm{C}_{2} \mathrm{H}_{2}\right)$ RGKYICEEC GIRCKKP SMLKKH IRTH TDVRPYVC KLCNFAFKTKGNLTKHMKSKAHMKKCLELGVAMTSV

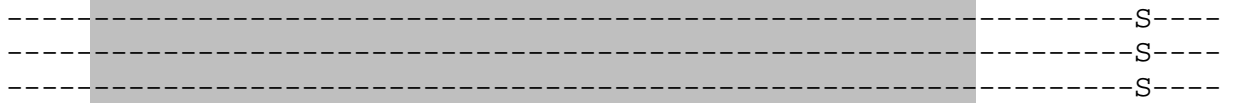

D/E-reich

DDAEAEESGNTEDTQKESDK....SSPAIDHQF SDAEESDVDDGDDNDDEDDDDEDFDDQGDITPKTRSRS $--\mathrm{T}-\mathrm{T}--\mathrm{AE}-\mathrm{L}--\mathrm{LH}-\mathrm{AAE}-\mathrm{HSM}--\mathrm{IST}-----------\mathrm{GE}-------\mathrm{D}-\mathrm{E}-\mathrm{ED}-------\mathrm{L}--------$

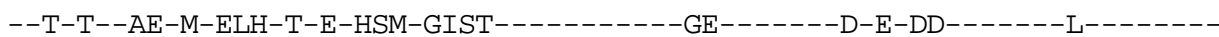

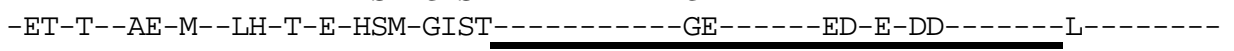

TSPQPPRFSTLPVTATSASQRASPEAS IGHSSLMSYLSTMP SIQITHLMSKSAMCGDSQMMEYQRLF . . $---------S---N V G A V P H G V P S D S-L-----I---V T L---R V-Q--T P-D S-E-T--T------Q S K$ $---------S---N V G A V A H G V P S D S-\mathrm{L}-----\mathrm{I}---\mathrm{VTL}---\mathrm{QV}-\mathrm{Q}--\mathrm{TP}-\mathrm{DS}-\mathrm{D}-\mathrm{T}--\mathrm{T}------\mathrm{Q} S \mathrm{SK}$ $---------S---N V G A V A H G V P$ SD S-L-----I---VTL---QV-Q--TP-DS-E-T--T------QSK

Phosphorylierungs-/DNABindungsstellen

LQDMEHERGKMDVPVGMDEDFMLTSEP SSSPKDLSSYSRHSSPGYDSSPCRDNSPKRYLSLRGDMSPRRH

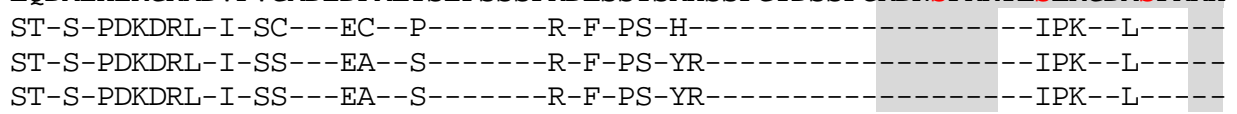

Phosphorylierungs-/DNA-Bindungsstellen

LSPRRDASPMRHLSPRKEAAIRRELSPRRDVSPRRHLSPLRPMSPGKDLSSGRDISPRRERKYMATFRAL $------\mathrm{L}---------\mathrm{T}----\mathrm{L}---\mathrm{M}-. \mathrm{Q}------------\mathrm{R}--\mathrm{V}-----$
-

SPRRRLHNTYIHNTSLPMSHYLHSDSGFLG . . HGRQNWPPVPYTSHHPETVPGQQSPGQAL . . ETHRDYI $----\mathrm{A}-\ldots$. Y -- PP-S-GQ--QAEP IV--PPNL-RGL-Q---F-LYGDQEGAYEHPGSSLFP-GPN--V $----\mathrm{A}-\ldots$. YP-PP-S-GQ--QTEP IV--PPNL-RGI-Q---F-LYGDQEGAYEHHGSSLFP-GP T--V $----\mathrm{A}-\ldots$. Y $--\mathrm{PP}-\mathrm{P}-\mathrm{GQ}--\mathrm{QTEP}$ IV--PPNL-RGL-Q---F-LYGDQEGAYEHHGSSLFP-GPT--V

FSHLPLHSQQQVRAPLPMIP IGGIQMIHSNSTIQSSSHSSTATQLHLKSSDEKRSMSSESCP SIPLHLDK -------------- I--V-V-----V--MPPAL--L-P-PTLP-PMEGFE--KGA-G--FSKD-YV-SK $---------------I--V-V-----V--L P P A L-G L-P P P T L P-P T E G-E--K G A P G-A F A K D-Y I-S R$ --------------I--V-V-----V--LPPAI-GL-PPPTLP-PTEG-E--KGAPG-ALTQD-YT-SR

HSSN . . .VSLKDSSSESDST . . . LLPSLGQSPTDESSQHNEREQEENIRTCTKAIACLRIATEEGL . . P QHEKRGPHA-QS-GPP-TPSSPR-- . .MK--TSED-LNAT---------Q--------S--------AALLGRHEKQAPQV-QS-GLP-SPSSPR-- . .MK--TSED-LNST--------Q-------S-------AALLGA RHEKQAPHV-QS-GLP-SPSSPR-- . . MK--TSED-LNST---------Q--------S--------AALLGA

QKRELLSCPEPNQKT . ECAQLSIRHF SGLEAGTALSSVSTTYVELY . GDNDSLGTSQSTTAHSKFYSKT . DQPARVQ . .--H-NPLGS-HV------RP-P-Q . . PCT-A-HPD-HD-EK-NF----TPL---T----SC DPPTWVQ . .-SP-KPL-S-HV-----G-P-P-Q . .PCT-AAHPD-HD-EK-TF----TAV--PT----SS DQP TWVQ . .-SP-KPL-S-HI-------P-P-Q . . LCT-AAHPD-HD-EK-TF----TAV--PT----GS

Abb. 4.10: Sequenzvergleich der Xshn2-homologen Proteine von Xenopus (xl), Mensch (hs), Maus (mm) und Ratte (rn). Die Zinkfingerdomänen (ZF) wurden dunkelgrau hinterlegt. Die an der Zink-Koordinierung beteiligten Cysteine und Histidine der $\mathrm{C}_{2} \mathrm{H}_{2}$ Zinkfinger sind druch Fettdruck hervorgehoben. Eine Glu/Asp-reiche Region ist fett unterstrichen. Ein konservierter Bereich putativer Phosphorylierungs- oder DNA-Bindungsstellen ist ebenfalls grau markiert, wobei die möglicherweise phosphorylierten Serine rot markiert sind. Striche kennzeichnen identische Aminosäuren, Punkte stehen für eingefügte Zwischenräume, die Zahlen am rechten Rand bezeichnen die Aminosäureposition im Xenopus Protein. Xenopus, diese Arbeit; Mensch: Hicar et al., 2001; Maus, Wu et al., 1996. 
Xshn2 enthält eine signifikante Zahl von tandemartig angeordneten putativen Phosphorylierungsstellen mit dem Konsensus RXXSPXK/R. Eine derartige Wiederholung solcher Elemente kommt in keinem der anderen Xshn Proteine vor, ist aber z.T. innerhalb der Xshn2-verwandten Proteine konserviert (vgl. Abb. 4.10). Der genannte Konsensus ist mögliche Zielsequenz der Proteinkinasen CaMII, PKA und PKC (www.expasy.org). Ebenso bildet die in der genannten Sequenz enthaltene Sequenz S/TPXK/R eine Phosphorylierungsstelle für die Proteinkinase $\mathrm{p} 34^{\mathrm{cdc} 2}$. Weiterhin wird vermutet, dass die enthaltene Sequenz SPXK an DNABindung an AT-reichen Sequenzelementen beteiligt sein könnte (Churchill et al., 1989). Es wurde vermutet, dass die Sequenz $\beta$-Faltblatt Strukturen bildet, über die das Protein an die kleine Furche der DNA binden kann (Suzuki, 1989). Funktionelle Untersuchungen mit der entsprechenden Proteindomäne von HIV-EP2 sind nicht bekannt.

\title{
4.1.4.3 Vergleich der Xshn3 Aminosäuresequenz mit denen verwandter Proteine aus Säugern
}

Ein Vergleich der Aminosäuresequenz von Xshn3 mit den homologen Sequenzen aus dem Menschen und der Maus ermöglichte eine eindeutige Zuordnung zu dem humanen Protein HIVEP1 (Fan und Maniatis 1990, Baldwin et al., 1990, Maekawa et al., 1991) und dem murinen Protein $\alpha$ ACRYBP1 (Nakamura et al., 1990). Über die gesamte Länge besitzt das Xenopus Protein $51 \%$ Identität zum humanen und $47 \%$ Identität zum murinen homologen Protein. Mit Identitäten von 95\% sind die Doppelzinkfinger Domänen sehr hoch konserviert.

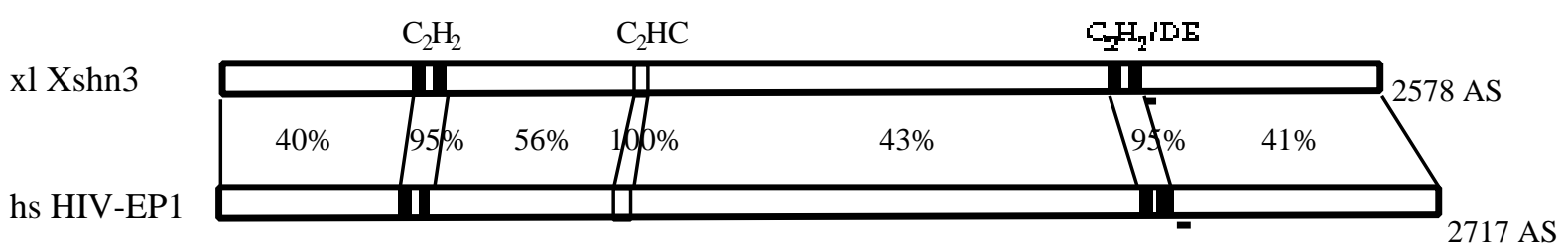

\begin{abstract}
Abb. 4.11: Schematische Darstellung der aus den Xenopus laevis Xshn3 cDNA Sequenzen abgeleiteten Proteinsequenzen und der am nächsten verwandten humanen Proteinsequenz. Lange Querbalken stellen die Primärsequenz der Proteine dar, deren Länge in Aminosäuren (AS) angezeigt ist. Schwarze Balken zeigen die Position von Zinkfinger DNA Bindungsdomänen $\left(\mathrm{C}_{2} \mathrm{H}_{2}\right)$, z.T. gefolgt von einer Glu/Asp-reicher Region (D/E). Leere Kästen bezeichnen Zinkfingerdomänen des $\mathrm{C}_{2} \mathrm{HC}$ Typs. Für die duch Striche verbundenen Abschnitte der jeweils homologen Proteine ist die Sequenzähnlichkeit in Bezug auf ihre Aminosäure-Identitäten in Prozent dargestellt. Die Sequenzidentitäten wurden für folgende Regionen berechnet: aminoterminal $\mathrm{C}_{2} \mathrm{H}_{2}=$ KKQ-GLG; $\mathrm{C}_{2} \mathrm{HC}=\mathrm{CET}-\mathrm{FYC}$; carboxyterminal $\mathrm{C}_{2} \mathrm{H}_{2}=$ GRG-DMG (vgl. Abb. 4.6).
\end{abstract}

Gleichzeitig mit dem Vergleich von Xshn3 mit den Säuger-homologen Proteinen HIV-EP1 wurde auch ein Vergleich von Xshn3 mit den Proteinen HIV-EP2 und HIV-EP3 durchgeführt. Durch den Vergleich mit HIV-EP1 und -2 sollten zusätzlich Proteindomänen identifiziert werden, die zwischen allen drei Vertretern der Vertebraten Schnurri-verwandten Proteinen konserviert sind. Eine Reihe solcher konservierter Sequenzbereiche konnte identifiziert werden (Abb. 4.12). Die eigenen Ergebnisse stimmten mit den Sequenzvergleichen von Hicar et al., (2001) weitgehend überein. In Abb. 4.12 sind diese konservierten Aminosäuren als grau hinterlegte Bereiche 
dargestellt. Bei den konservierten Abschnitten handelt es sich um die Zinkfinger Domänen, um Serin-reiche Bereiche, eine Glutamat-/Aspartat-reiche Region, zwei mögliche Kernlokalisationssignale, die Konsensussequenzen des SV40-Typs enthalten (KK/RXK/R; Kalderon et al., 1884) und konservierte Bereiche, die nicht weiter charakterisiert werden konnten. Weiterhin ist in Abb. 4.12 ein Sequenzbereich als putative Dimerisierungsdomäne gekennzeichnet. Es handelt sich hierbei um einen zum Drosophila Schnurri Protein verwandten Sequenzabschnitt (vgl. Kap. 4.1.9).

putatives NLS

xl MPRTKQIHPKNLRDKIEEAQKKLKSPEEPQAEIVEAGSRACLEVVKGVKRKKIVTENHLKKIPKSPLRNA

GKGKQKPEIEAFPSSSCDPLVFGGCKDKQCLLDQLRKQD . . IKESK . . . . . . . AGELTVKSLKPGTSM LQA-H-QNT-ESSFA. . . . . -LHSASESH . . . . . . K--NYIPVKNG-QFTKQNGETPGI IAEAS-SEE-V LQT-H-QNT-EP-F- .....-LPSASESH . . . . . K-HNCVPA-QGRQFTKQNGETPGM-AE-SES-DLV

QAKK . . . LSVP . . . PDLCNGRREDKDMDIKQTLSRQNISSSLNNTKSANISLENMNKPCST . . . . ANSA SP--PLF-QQ- . . SE-RRW-S-GA-PAKF SD-DE-CD----SSKTRTDN-.-CISSH-G-TSPSYT-TSP-- . . T-S-HQRSE-RRW-S-GS-P TRLSG-DG-RD---SSSKARTDN- .-CSSPC---TPPSYTSTA

FDVLLRAMEPELSNLNQSWPPCGTQTEK ...........QGHKVAPETTASNSSVSQSE.FS.SRYVY $-----\mathrm{K}-------\mathrm{T}-\mathrm{S}-\mathrm{KGS}--\mathrm{AIK}---\mathrm{LRPNKTARSPPKLKNSSMDAPNQT-QEL-AE-Q.S-CTS-T}$. ---- K-------T-S-KGSS-AIK---LRPNKTVRSP SKLKNSSLDAPNAT-PDL-VE-PCPPCTS-P .

YHQGDQSSQISQSIKGSTNVQDRLGIEHEKCNSDTGLQNMH . SSC . .FSSSL . . . . . . EPTK . . QVYHVA ....VHM-AAQKNEQ-AMQSASH-YHQ--HFVPKSNQH-QQLPG-SG-TG--TNLQNQ-NAKLE---NI... . VHVASTQK-EQVAAQCVSH-YSSQDHLVPKLSQ--QQLPGHLG-TG--TNLHTL-S--LEPI-NT-

LNPSIA.DPSSSLTQVLSLQGN . . . . . . . SSSPTNSSKLSVNSPYSLAQVASLI . . SGEQMCNIVLKDQK 364 VTS-VGLTSP--RS--TPQNQQMDSASPL-I--A--TQSPPMP I-NSTH---VVNQ-V-----LLVTSTVGLTSP-TR---TPPHQQMDSVSPL-V--AS-TQSPP GP I--S-H---VVSQ-V----SLL-R---

aminoterminale Zinkfinger Domäne $\left(\mathrm{C}_{2} \mathrm{H}_{2}\right)$ LKKQGKYICEYC SRACAKP SVLLKH IRSH TGERPYPCVTCGF SFKTKSNLYKH KKSHAHAIKLGLGLRTD

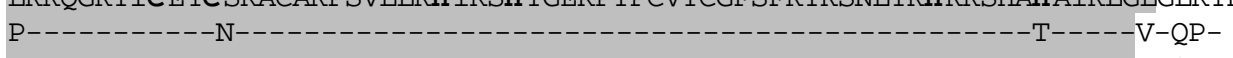

$\mathrm{P}-----------\mathrm{N}-------------------------------------------------\mathrm{T}-----\mathrm{V}-\mathrm{QPE}$

SSGALLSHDSEKALCIHSDVDESGESDDEYISEERQED . . . . . QNVPESQCIKRPDDSEMVPQKESKIL AG-LF---E-P---S-----ED----EE-GATD---H- . . L LGAMELQNVHI---MSNA-TLLK . . SSFT AG-LF--QECP---SV---IED----DE-GLADG--NNPCV . . . KDLQPV-TMKTVSNP-SLPK . . . LI

SNSQVLVSKNNSLQGNGVEAR. LTELPKVVVYPVSTSPLRADSPRVLESASEHFVAQ . . . . . IP.ELHT PS-PEN-IGDFL--DRSA-SQAV--------HH-TV----T---KAMDPKP-LSS--KQKDLQVT . NVQP PSNSDH-VRGF-S-DRPSDSQAP--------HP-SMP--KT-CLQ-ANPNP-LPSP- . . . . S-RD--V

zwischen HIV-EP1,

QKKNPHVLSVCSLSEMEQSCDKNCELAEIDDKQQINNATSHAQLQRQQATDYSQEQPKCLL. SPRSLGST LSA-MSQGG-SR-ETN-N-HQ-G. DMNPLEG--DSHVG-V----------------QGK-- . ASILS-SA--S--EMD-SCHQ-G.DVIQSEG-PDSHSG-AH---------EDP---QGK--L--------

\section{-2 und -3 konserviert} DSGYFSRSESVDQAMSPPTPFLKLQPSSEKDFSKNL. SSVTQINATVTPLVQQIYVEKPTIITGAMRPPL ---------A---V-----FARTF-TMDP-PA-NGGAPGPR-S-PAP SALAT . . G--SSVV--Q-----

\section{putative Dimerisierungsdomäne}

VTKTLEERISKLISDNEAVVDDKQLDSVKPRRTSLSRRGSIDSPKSYIFKDSFQFDLKPVGRRTSSSSDI A---------------- $\mathrm{L}---------------------------------------------------$

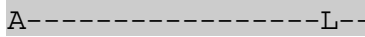

PKSPFTPTDKSKQVFFLSVP SQFTSMDCLP ITRSNSMP TTGYSEVPP. VMPASHPLRGSHSFDEKIGSLC

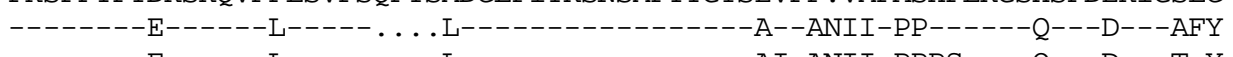


Zinkfinger $\left(\mathrm{C}_{2} \mathrm{HC}\right)$

VDRIKKAHSRGTMFECETCRNRYRKLENFENHKKFYC SELHGPKSKTVCREPEQRTTMNISQPQIFHYRV IEKK-SHQG-------------------------------T-VAM----HSPVPGGL----L---LEKK-SHQG - T-AAV--A-HGPAPGGA---VL---

\section{zwischen HIV-EP1,}

-2 und -3 konserviert, NLS

AASTGALEQPLQIRKRRKMKSVGDDDEPQQSDSNTAPENMEVLKNLKS . . . . . . TKNSSTITILGSQSC -G-S-IW--TP-------------E-L--NE-G-S-KSS-G-QFQNALGCNP SLP-H-V--RSDQQHK . $--\mathrm{P}-\mathrm{AVW}--\mathrm{TP}------------$ EEDL-PHE-GRS--SADA-QLQPV $\ldots . .$. PGAAPSP SKHT-AT .

zwischen HIV-EP1, -2 und -3 konserviert SVSTVSPQIHFVSRNTDASSEIKLST . LEKNKNIVSQERVEVKCQGTGISVIQHTNSLSKPNSFEKIDSV NIQLQNSH--L-A-GPEQTMDP----IM-QQISSAA-DKI-LQRH------------------D-PEPF AADQAHRGVQL-A-GPERALPL-QCPMV-QQL-AAA-DKM-VKRQ-G------------R----D-PEPL

ERNSPVPLQEPQKSLPLSINAAVGSHEDKIACTPQNSPTRS IDIP . . RSEVHDSNRGVSTEKTVLVTQS --AS--SF--LNRTGNSGSLKVI-ISQEESHP SRDGSHP HQLALSDAL-G-LQE-S-KSPS-RH--GQP-GGITFS---LGRTGMPGALKVI-MAPEEGHPPQDA . .MHQTALSHNL-G-PRE-A-KIPS-RY--GQPL

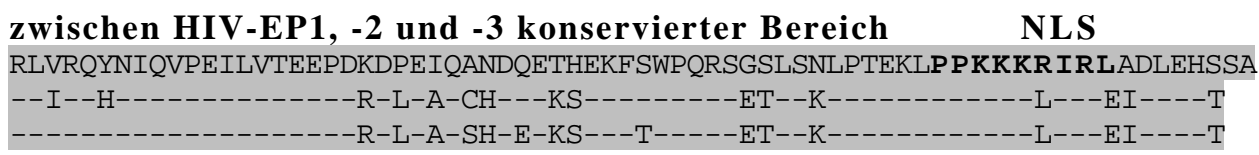

zwischen HIV-EP1, -2 und -3 konservierte Bereiche

ESSFDSTISRSLSRESSLSRASSF SASFDKEEPFKSDSVTKTDGMTKSSEFLTIPTSLNTFGVS . . REM

\section{zwischen HIV-EP1, -2 und -3 konservierter Bereich}

RRSASEQINCTQP SMEVIEYRSKSFDCGSMSRSRSMS . PTNSVTSKFQSSMLSSANVPLLERRRGPLVKQ --T---------T----SDL---------IT-PQTTP . L-ELQPP SSP-RVGVTGH------------R--A-----S-VPTL---SDF----------IA--HVVPALVE-QP-YS--AVGGT-H-------------IR-

ISLNIGQESPVSTVKPKNLQTEKGILSQMHAT . . EPSLNAELLCAPLTQHSLCS . . . . . . . SSLN ---G-APD-HL-P-HPTSFQNT . .A-P SVN-VPYQGPQ-TSTS- . EF SANTLH-QTQVKDLQAET-NSS $---\mathrm{N}-\mathrm{ASD}-\mathrm{HL}-\mathrm{PGSAAA}---\mathrm{I}$. . V-PSVNTVPFQAPR-PDMAS . -DCPA-TVHPQALAKDLQAEI--SS

SSHKF . . . . . . . LLNQDFIS . . . . . . CVQSSTEGEEKEKNVLSKEKAPF . . YAPKYQLK . . FQK -TNV-PVQQLCDIN----IHAPP SHQSTQLSL-V--Q-SKPD--SVLSGSSKSEDCF------HCQV-TS -TDT-PPQQLFGAH---KTNT-LSHQNTPLPLPVSAQ-GKPDAAPTACVSSTGEGSF-------QCQA-TS

.... TRESKLSASKHSIRTTADNIYEVHSSVSTISDIKGAVSNICTLQQTES . SSGKSFGKILNTKTVVV GP SCSSNPVH-LPNQV-SDPVGTDHC-T-ATLPTKL-DSMSNSHPL-PPELR. PLGSQVQ-VP SSFMLP I DQGCSA.PLR-SPNQVLPGQ-GADPCPA-EAPPAKAADPMAKPCPL-PLELGLPRDEVLQ-QLP SFVLP-

PVHNYSNSSYC. GYFELLPEILVTQDQGHKITSEANSVSVPNPKDCI IMAKCPDEP SGPLTVARK . IC. RLQS . -VPA--FATLTS--Q------LPNQPICQT-HSV--ISEEQNSVPTLQKGHQNA-PNPE-EFL-E PQKR.NVTVD-FTPVTS--Q------LPNMP ICQT-QSL--VSEEQNSMP-SQNYLQNASPTPE-ELA-K

zwischen HIV-EP1, -2 und -3 konserviert .TYKSSVQESTRS I .......VVVSGLLTQQETSASSKRMLSPANSLDIAMEKHQKRVKDESGAAFNSNI NVFSEMS-NSSL-ESLPITQKISVGR-SP---S-----------------------A---N--VCATDV TVLPEVG-SVPV-ESSPTVQK-SVGR-SP---S------------------------A---N--VCST-- 


\section{Glu/Asp-reich}

NF SFKTKGNLTKHMKSKAH SKKCLDMG . . . GPVDDQDTDDSGERQRYTGERTGFDADDSDG . . GDDDDNE

\begin{tabular}{l}
$--------------------V-L-V S V-L I-E---E E-D-K--F G C--S-Y-L E E---P D E--N D--$ \\
\hline \hline
\end{tabular}

\section{Glu/Asp-reich}

DEDEDSQAESGLSATPSVTASPQHYPFRNSQQAASNTDEDPQLQHCFS . . QSNSMDSLPKALITRMTAMT -D--------V------------L-S-S-L-DPVS----VRITD---GVHTDP--V--R-------VLS

TSTI . C. RPESHEERSKVNLPRETTSPPSAASSPKSLCHQMSVDYPEAEAESLGATKSVH . . . . VPSVI -AQSDYN. -KTLSPGKARQRAA-DENDTIPSVDTSR-P-H--------SE.-ILRSSMAGK . . . . AVAIT -VQS . . SPNRTDLPAKARQSTEKDEHEQAPPADTPR-PGH-L--H . .SS-SDV-RSPAAGNPAAGS-GAA

zwischen HIV-EP1, -2 und -3

NLIPKEKLSMNMPSSPVDRSTQTMDSYTDATDSY . VHQHKSTKSTQQP SSTEPPHTHLF SHLPLHSQQP Q.... SPS-VRL-PAAAEH-P--AAGMP SVASP HPDPQEQ-QQITL-PTPGLPS----------------Q V. ... QDS-VGL-PAVAQLNP-PAARISSSVSP HPDSQDQKQQI ILQPPP GLPS----------------Q

konserviert
ARSPYSMIPVGGIQLVPAGLAAYSTFMPFQAAPVQLTIPAMGVIHRTSSAVGDKTAEVPNTPN.PIGVAE
S-T--N-V-----HV-----. T-----V-L--G--------VS-V----LGTHRNTVT--SG-T-.-A----
S-T--N-V-----HV-T---. T----V-I--G-M------VS-----VGTS--TIT-ASGSP-RPT----

VNGVVPCIPIGQINMAGL . . . SAPSLQ . . PLNVETLSILGLSNTNVAPQIHP SGLTLNAVGLQYLTTSP LSS--------- RVP--QNL-T-G--SLPS-SM--VN-V--A---M---V--P--A-------V--ANLSS----------HVP--QNL--PA--SLTS-GM--VNLV--A-ATVG--G--P--A-------V-ANA-

.... QSNPSPQTHIPGLQILNIALPTLIPSISP ITVESQGVSDQSSSCSPAAGKGSAAFTVADTKNMKQTE .SS--S-A--A-------------------V-QVA-DA--APEMPA-Q-K-CETQPKQTS-ASANQVSR-A. .--S-A-PA--Q--------------VG-VA-GTT-TPETTAPN-K-MELQ . . . . . MPAGQGHSA-

SLQGSSGVQ . . DCHKILRDLSVTEEKP . . . LGGCLTADKGPQSKQC . . . SNISSSKVKISSSADLYVK -P--LPT--RENAK-V-NPPAPAGDHARLDG-SK. MDTE-AASANHV . KPKPELTSIQGQPA-TSQPLLPP---PEGPQETPQTV . . . SGP SADHARPEDSTK.MDTK-GP SAGHVL . . PGR-PAQAQPAPTPEALQ- 


\title{
4.1.5 Vergleich der Zinkfinger Domänen aller bekannten Vertreter der Schnurri Protein Familie
}

Mehrere Autoren beobachteten eine sequenzspezifische DNA-Bindung der isolierten Zinkfinger Domänen der Schnurri-homologen Proteine aus Säugern. Es wurden sequenzspezifische Bindungen an den IGK Gen Enhancer, an eine V(D)J Rekombinations-Signalsequenz, an Promotorsequenzen von Genen der MHC-Klasse1 und an andere Sequenzelemente beschrieben. Beide in den Proteinen jeweils vorkommenden Doppelzinkfinger Motive sind zueinander sequenzhomolog und besitzen identische DNA-Bindungseigenschaften (Fan und Maniatis 1990). Um den Grad der Konservierung der Zinkfinger Domänen zwischen den Xenopus Schnurri Proteinen und den bekannten Mitgliedern der homologen Säuger-Proteine zu untersuchen, wurden Aminosäure-Sequenzvergleiche dieser Regionen durchgeführt (Abb. 4.13).
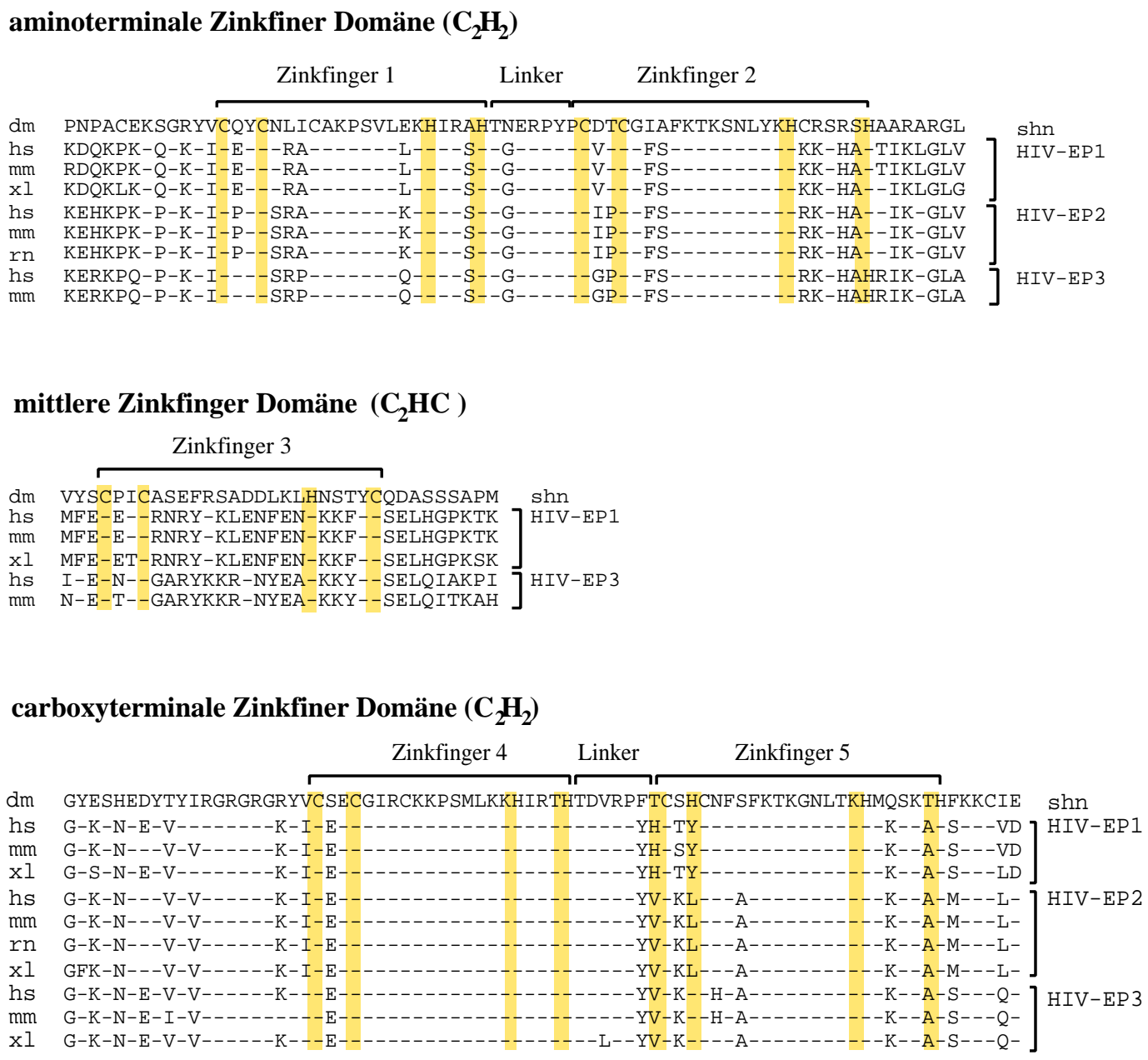

\begin{abstract}
Abb. 4.13: Aminosäure-Sequenzvergleich der Zinkfinger Regionen aller bekannten Mitglieder der Schnurri Zinkfinger Proteinfamilie. Identische Aminosäuren sind durch Striche gekennzeichnet. Die an der Komplexierung von Zink-Ionen beteiligten Aminosäuren sind gelb hinterlegt.
\end{abstract}

Die Doppelzinkfinger Domänen zeigen eine hohe Sequenzidentität. Innerhalb der Untergruppen HIV-EP1, -2 und -3 ist die Identität noch höher. Die aus Sequenzvergleichen der Gesamtproteine ermittelten Gruppierungen lassen sich durch Vergleich der Zinkfingerregionen bestätigen. Der 
hohe Konservierungsgrad der Doppelzinkfiner Regionen lässt eine Bindungsfähigkeit an gleiche DNA Sequenzelemente vermuten. Der Zinkfinger des $\mathrm{C}_{2} \mathrm{HC}$ Typs ist weniger hoch konserviert und kommt in der HIV-EP2 Gruppe nicht vor. Eine Funktion dieser Domäne ist nicht bekannt.

\title{
4.1.6 Vergleich der Aminosäuresequenz von Xshn3 mit dem Drosophila Schnurri Protein
}

Das Drosophila Protein Shn interagiert in vivo und in vitro mit dem Protein Mad über einen Sequenzbereich, der bei AS 1441-1635 lokalisiert wurde (Dai et al., 2000). Weiterhin zeigten Udagawa et al. (2000), dass im Bereich von AS 567-909 eine Dimerisierungs-Domäne lokalisiert ist. Es wurde daher untersucht, ob Sequenzelemente außerhalb der Zinkfinger Domänen zwischen Shn und Xshn3 konserviert sind, die auf eine vergleichbare Aktivität der Proteine hindeuten könnten.

Über die gesamte Länge der Proteine Shn und Xshn3 findet sich eine Identität von nur 18\%. Bei näherer Untersuchung kann außer der konservierten Doppelzinkfinger Domänen nur ein einziger Bereich mit konservierten Aminosäuren identifiziert werden. Dieser Bereich umfasst den Bereich der AS 780-840 des Drosophila Shn Proteins, innerhalb dessen eine Dimerisierungs-Domäne lokalisiert wurde (Abb. 4.14).

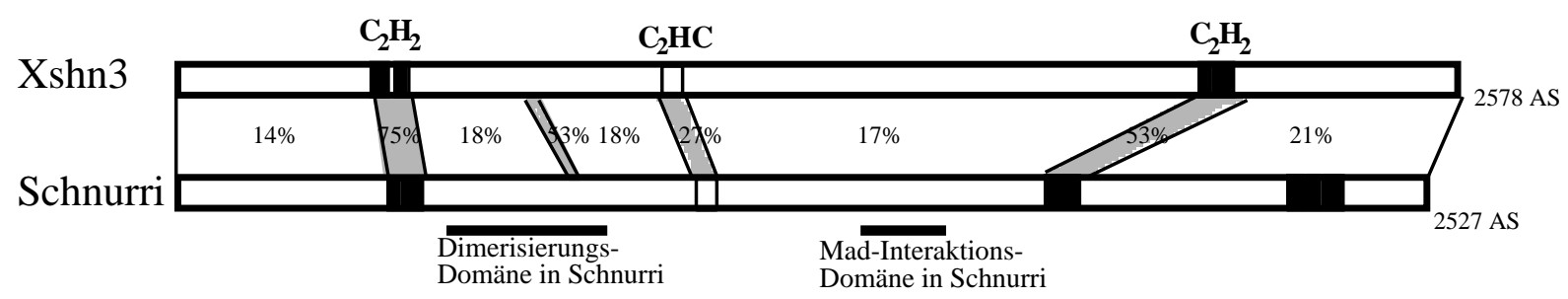

\begin{abstract}
Abb. 4.14: Schematischer Vergleich von Xshn3 und Drosophila Schnurri. Für konservierte und weniger konservierte Bereiche sind die Aminosäure-Identitäten in Bezug auf die XenopusAminosäuresequenz angegeben (zwischen den Sequenzen). $\mathrm{C}_{2} \mathrm{HC}$ und $\mathrm{C}_{2} \mathrm{H}_{2}$ : Zinkfinger Domänen. Die Position einer Dimerisierungs- und einer Mad-Interaktionsdomäne innerhalb des Schnurri Proteins sind durch schwarze Balken gekennzeichnet.
\end{abstract}

Ein Untersuchung weiterer Schnurri-verwandter Proteine der Vertebraten nach Sequenzmotiven, die dem konservierten Bereich innerhalb der Shn Dimerisierungsdomäne ähneln, zeigte, dass hier ein Motiv liegt, das zwischen Schnurri, der HIV-EP1- und der HIV-EP3 Gruppe konserviert ist. Ein Sequenzvergleich ist in Abb. 4.15 dargestellt.

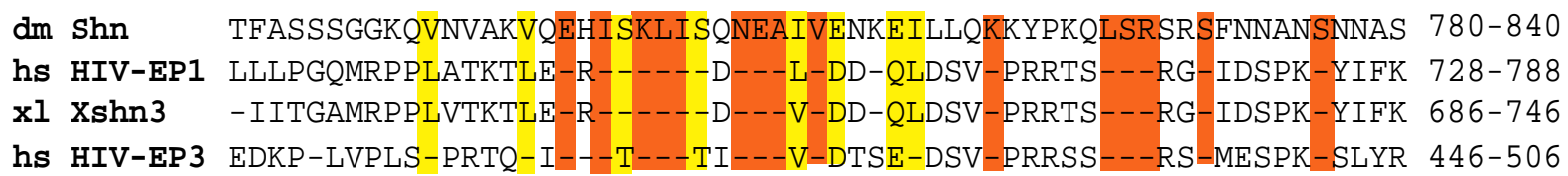


Abb. 4.15 (S.74): Aminosäure-Sequenzvergleich eines Bereiches von Drosophila Schnurri, Xenopus Xshn3 und den humanen HIV-EP1 nd HIV-EP3. Der untersuchte Bereich befindet sich zwischen der ersten Doppelzinkfinger Domäne und dem $\mathrm{C}_{2} \mathrm{HC}$ Zinkfinger. Aminosäuren, die zwischen allen Sequenzen identisch sind, sind orange unterlegt, konservierte Aminosäureaustausche sind gelb gekennzeichnet. Die Nummern am Rand kennzeichnen die Position der Aminosäuresequenz innerhalb der Proteine. Als konserviert gelten folgende Aminosäureaustausche: V-I-L-M; D-E-N-Q; K-R; S-T.

Der zwischen den Vertebraten Proteinen und Drosophila Shn konservierte Sequenzbereich erstreckt sich über etwa 30 Aminosäuren. Der Bereich enthält 8 konservierte Austausche und 15 identische Aminosäuren. Der Grad der Konservierung dieses Sequenzbereiches ist damit deutlich erkennbar.

Es lässt sich zusammenfassen, dass in Vertebraten drei paraloge, zum Drosophila Schnurri Zinkfinger Transkriptionsfaktor verwandte Proteine, HIV-EP1, -2 und -3, beschrieben wurden. Zu diesen Proteinen wurden in dieser Arbeit cDNAs der homologen Proteine in Xenopus identifiziert. Die Vertebraten Proteine ähneln dem Drosophila Protein in ihrem strukturellen Aufbau, lassen aber ein carboxyterminales Zinkfinger Triplett vermissen. Die drei Vertebraten-Gene sind vermutlich durch Genduplikation- und Diversifikation im Laufe der Evolution entstanden. Eine hohe Konservierung in der Primärsequenz der DNA-bindenden Zinkfinger Domänen lässt vermuten, dass die Proteine identische DNA-Bindungseigenschaften besitzen. Eine bis auf einige Sequenzbereiche hohe Divergenz außerhalb der Zinkfinger Domänen lässt dagegen Spezialisierungen in den Proteinfunktionen vermuten. Eine Aufspaltung der Funktion von Schnurri Proteinen auf die Vermittlung der Signale verschiedener TGF $\beta$ Familienmitglieder ist nicht auszuschließen.

Alle Vertebraten-Proteine sind reich an möglichen Phosphorylierungsstellen und könnten durch posttranslationale Modifikationen in ihrer Aktivität reguliert werden. 


\subsection{Zeitliche und räumliche Expression von Xshn Transkripten in Xenopus laevis Embryonen}

In der Fruchtfliege Drosophila vermittelt der Transkriptionsfaktor Schnurri das Signal des extrazellulären Liganden Dpp. Um als Transkriptionsfaktor im Dpp Signalweg agieren zu können, muss Schnurri zeitlich und räumlich in den Regionen der Dpp-Aktivität als Protein zur Verfügung stehen. Dasselbe gilt für die transmembranen Dpp-Rezeptoren Thick veins (Tkv), Saxophone (Sax) und Punt (Put), sowie für die intrazellulären Vermittler des Dpp-Signals, Mad und Medea (vgl. Einleitung).

Als Hinweis auf die zeitliche und räumliche Aktivität eines Proteins gilt allgemein der Nachweis der Expression seines Genes als mRNA. "Whole mount" in situ Hybridisierungen mit epitopmarkierter antisense-RNA liefern ein detailliertes Bild über das zeitliche und räumliche Expressionsverhalten von Genen während der Embryonalentwicklung. Der TGF $\beta$-Ligand Dpp wird im Embryo nach Einsetzen der zygotischen Transkription im dorsalen Bereich des Blastoderm Embryos exprimiert und bildet einen Aktivitätsgradienten von dorsal bis etwa zur Hälfte des Embryos (St. Johnston und Gelbart, 1987, Padgett et al., 1987). Die Dpp Rezeptoren Tkv, Punt und Sax werden im Ektoderm und im darunterliegenden Mesoderm exprimiert und damit in der Region der Dpp Aktivität (Übersicht in Raftery und Sutherland, 1999). Tkv und Punt werden im Zeitraum der Zellularisierung des Blastoderms verstärkt dorsal exprimiert, wohingegen Sax eine gleichmäßigere Expression zeigt. Die Aktivität von Sax wird aber nur im dorsalen Bereich, der Amnioserosa, benötigt (Wharton, 1995 (Übersicht); Ruberte et al., 1995). Die Rezeptoren zeigen damit breitere Expressionsdomänen als der Ligand, dessen Signal sie weiterleiten.

Der Transkriptionsfaktor Schnurri wird mit den Komponenten des Dpp Signalweges räumlich und zeitlich koexprimiert. Schnurri-Transkripte finden sich maternal, und vom Zeitpunkt der Befruchtung bis zur Gastrulation ist das Expressionsmuster von Schnurri dem von Dpp sehr ähnlich (Grieder et al., 1995). Damit zeigt sich eine enge zeitliche und räumliche Korrelation der Expression dieser Komponenten des Dpp Signalweges in Drosophila.

Im Xenopus Embryo ist zwischen dem dorsalisierenden Activin-Weg und dem ventralisierenden BMP-Weg zu unterscheiden. Sowohl Activin als auch BMP und ihre jeweiligen Rezeptoren werden im Xenopus Embryo maternal und während des Blastula Stadiums in der gesamten marginalen Zone sowie im zukünftigen Ektoderm exprimiert. Erst während der Gastrulation lokalisieren im Activin-Weg beteiligte Komponenten mehr dorsal und posterior, während BMPWeg-Komponenten hier reprimiert zu sein scheinen und verstärkt in ventralen und anterioren Regionen akkumulieren (Kondo et al., 1991; Dale et al., 1992; Mathews et al., 1992; HemmatiBrivanlou et al., 1992; Graff et al., 1994; Fainsod et al., 1994; Hemmati-Brivanlou und Thomsen, 1995; Chang et al., 1997; Frisch und Wright, 1998).

Die zytoplasmatischen Signalvermittler Smad1 (BMP-Weg), Smad2 (Aktivin-Weg) und Smad4 (Ko-Smad) werden im Xenopus Embryo ebenfalls maternal und in frühen Gastrula Embryonen ubiquitär exprimiert (Thomson, 1996; Graff et al., 1996; Lagna et al., 1996). Zusätzlich ist es Faure et al. (2000) gelungen, die zeitliche und räumliche Verteilung von phosphorylierten (aktivierten) R-Smad Proteinen im Xenopus Embryo während der frühen Musterbildungsprozesse 
zu ermitteln. Unphosphorylierte Smad1 und Smad2 Proteine sind demnach ubiquitär im Embryo verteilt. Das aktivierte Phospho-Smad1 lässt sich ab dem Stadium NF 9 ubiquitär nachweisen und wird zum Stadium NF 10.25 auf ventrale Regionen limitiert. Phospho-Smad2 konnte im Stadium NF 9 nur dorsal nachgewiesen werden, zeigt im Stadium NF 10.25 dagegen eine ubiquitäre Verteilung.

Aus den beschriebenen Expressions- und Aktivitätsmustern lässt sich keine scharfe räumliche Trennung des BMP- und des Activin-Sinalweges im frühen Xenopus Embryo ableiten.

Für die Analyse des zeitlichen und räumlichen Expressionsverhaltens von Xshn1, -2 und -3 im Xenopus Embryo wurden "whole mount" in situ Hybridisierungen mit epitopmarkierter antisense RNA und quantitative RT-PCRs auf Gesamt-RNA von Gewebefragmenten oder Geweben adulter Frösche durchgeführt.

\subsubsection{Zeitliche Expression von Xshn Transkripten in Xenopus laevis Embryonen}

Im Rahmen der Diplomarbeit (Dürr, 1997) wurden für Xshn1, -2 und -3 vorläufige Analysen über das zeitliche Expressionsverhalten der mRNA in Xenopus Embryonen durchgeführt. Diese Ergebnisse wurden in der folgenden Untersuchung präzisiert. Die Analyse einer größeren Zahl von frühen Embryonalstadien zeigte einen biphasischen Verlauf der Expression aller drei Xshn mRNAs (Abb. 4.16). Analog der Drosophila Schnurri mRNA werden die Xshn1, -2 und -3 mRNAs maternal exprimiert. Nach Einsetzen der zygotischen Transkription (NF 8) bleibt die Expression bis zum Einsetzen der Gastrulation (NF 10) konstant und sinkt während der späten Gastrulation und der Neurulation (NF 12 - NF 20) ab, um zu Beginn der Organogenese im Schwanzspitzen-Stadium (NF 30) wieder zuzunehmen.

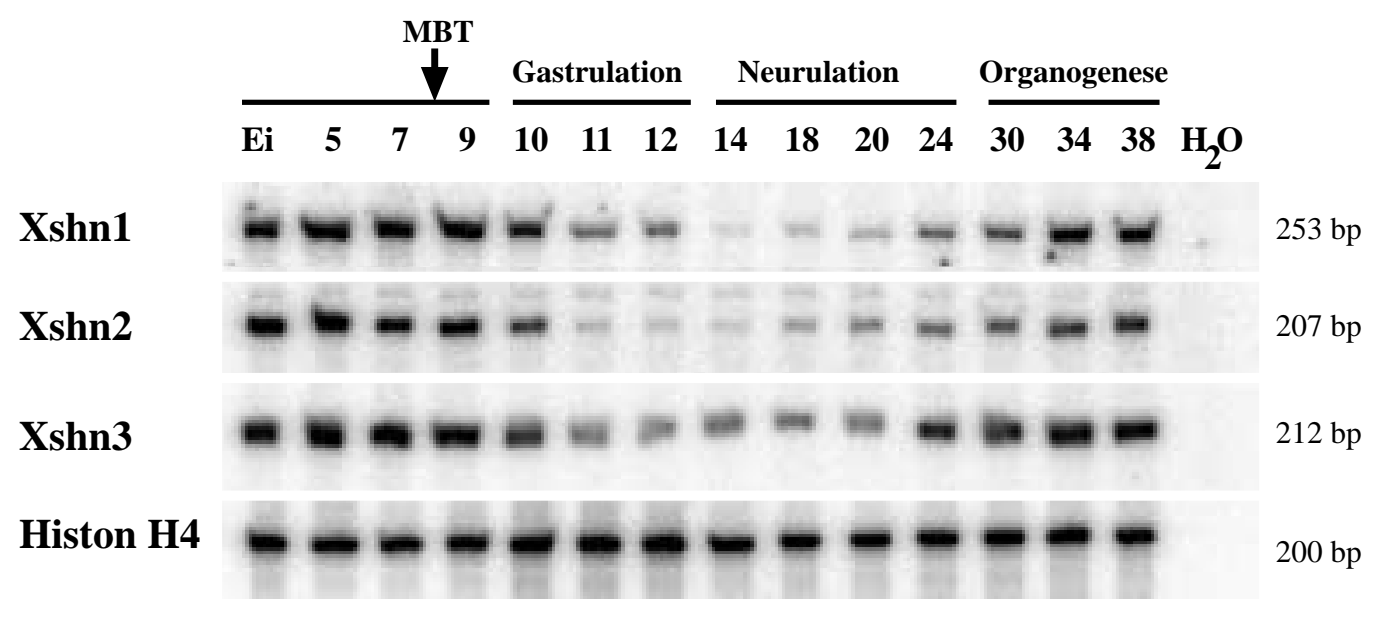

Abb. 4.16: Quantitative radioaktive RT-PCR auf gesamt-RNA früher Xenopus Embryonalstadien. Die Zahlen über den Banden geben die Stadien der untersuchten Embryonen an (nach Nieuwkoop und Faber, 1967). Als Kontrolle der eingesetzten RNA-Menge wurden Reaktionen auf gleichmäßig exprimierter Histon H4 RNA mitgeführt. Am rechten Rand ist die Länge der jeweiligen PCR-Produkte angegeben. 
Zusammengefasst bedeuten die Ergebnisse der RT-PCR, dass die Expressionen von Xshn1, -2 und -3 zeitlich mit der Aktivität der TGF $\beta$ Signalwege während der Musterbildung des Mesoderms korrelieren.

\subsubsection{Ermittlung der räumlichen Verteilung von Xshn Transkripten in Xenopus Embryonen}

Die frühe dorso-ventrale Musterbildung des Mesoderms findet im Xenopus Embryo bald nach Einsetzen der zygotischen Expression im Blastula Stadium und während der sich anschließenden Gastrulation statt. Um zu untersuchen, ob Xshn-1, -2 und -3 in dieser Entwicklungsphase lokal begrenzt aktiv sein könnten, wurde die Expression ihrer mRNAs in sehr frühen Gastrula Embryonen durch quantitative RT-PCR und in verschiedenen embryonalen Stadien durch "whole mount" in situ Hybridisierung untersucht.

\subsubsection{Ermittlung der räumlichen Verteilung von Xshn Transkripten in Xenopus Embryonen durch quantitative RT-PCR}

Bereits mit der ersten Reifeteilung sind die zukünftigen Körperachsen des Xenopus Embryos festgelegt. Mit Bildung der dorsalen Urmundlippe bei Einsetzen der Gastrulation im Stadium NF 10 lassen sich im Embryo zukünftige Körperregionen und prospektive Gewebe sicher lokalisieren. Es ist daher möglich, aus diesen Embryonen Gewebefragmente z.B. prospektiv dorsalen, lateralen oder ventralen Mesoderms manuell zu isolieren. Diese Tatsache wurde genutzt, um für das folgende Experiment frühe Gastrula Embryonen (NF 10) manuell in neun definierte Fragmente zu zerteilen (vgl. Abb. 4.18 A). Einander entsprechende Fragmente von 10 Embryonen wurden vereint, aus ihnen die gesamt-RNA isoliert und in eine quantitative radioaktive RT-PCR mit Xshn-spezifischen Primern eingesetzt.

Um die korrekte Präparation der Gewebefragmente zu verifizieren, wurde die Expression von regional exprimierten Markergenen der mesodermalen Differenzierung in RT-PCRs auf den isolierten RNAs untersucht. Xbrachyury (Xbra, Smith et al., 1991) wird im Stadium NF 10 panmesodermal exprimiert, wohingegen Goosecoid (Gsc, Cho et al., 1991) ein Markergen für prospektiv dorsales Mesoderm darstellt. Dagegen wird Wnt8 in lateralem und ventralem Mesoderm exprimiert (Christian et al., 1991 und 1993). Zur Veranschaulichung zeigt Abb. 4.17 "whole mount" in situ Hybridisierungen der Markergene im frühen Gastrula Stadium. 


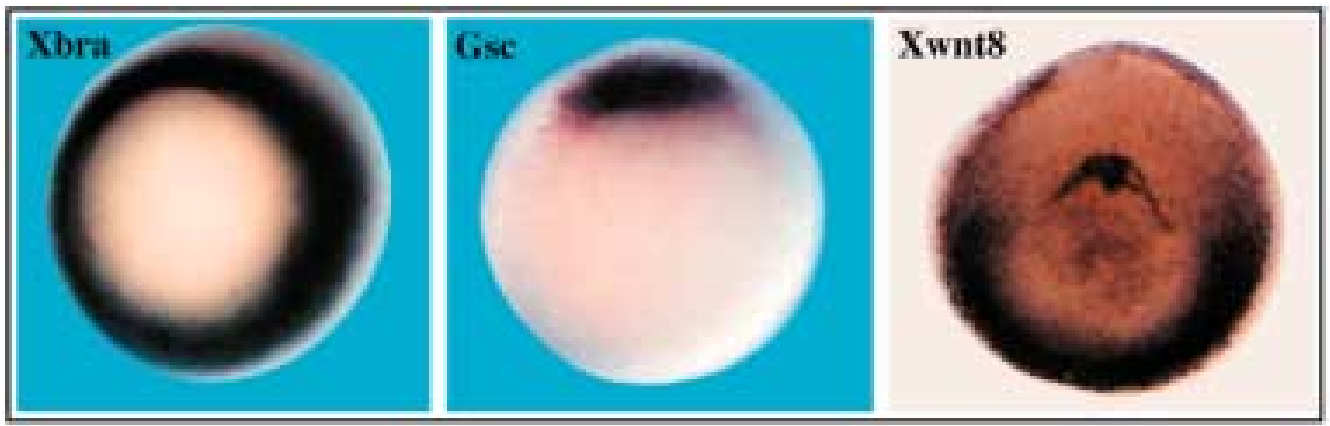

Abb. 4.17: mRNA-Verteilung der mesodermalen Markergene Gsc, Xbra und Wnt8 im Stadium NF 10. Die Embryonen sind von vegetal gezeigt, dorsale Urmundlippe nach oben. Gsc und Xbra Hybridisierungen: eigene Arbeit; Xwnt8: Moon und Weintraub (Xenopus Molecular Marker Resource-Datenbank, XMMR).

Abb. 4.18 B zeigt die Ergebnisse der Expressionsanalyse durch quantitative RT-PCR. Xbra wird danach in allen mesodermalen Gewebefragmenten gleichmäßig exprimiert. Stärkere Expression findet sich auch im Entoderm, jedoch zeigt Xbra kaum Signale im präparierten ektodermalem Gewebe. Transkripte für Gsc mRNA finden sich v.A. im dorsalen Mesoderm und im Entoderm. Geringe Gsc Expression findet sich im lateralen Mesoderm. Wnt8 mRNA war im lateralen und im ventralen Mesoderm, sowie im Entoderm nachzuweisen. Alle drei Gene zeigen zusätzlich eine Expression im Entoderm. Eine Kontamination des Entoderm-Gewebes mit dorsalem Mesoderm während der Präparation der Gewebefragmente ist unwahrscheinlich, weil dies nicht die Expression des ansonsten ventral exprimierten Markers Wnt8 erklärt. Die entodermale Expression der genannten Marker wird nicht als Artefakt angesehen. Insgesamt stimmen die Ergebnisse der Kontroll-RT-PCRs mit in "whole mount" in situ Hybridisierungen ermittelten Expressionsmustern überein.

Die Xshn RNAs werden gleichmäßiger als die mesodermalen Markergene exprimiert. Xshn1, -2 und -3 zeigen annähernd konstante Expressionsstärken im gesamten Ektoderm, Mesoderm sowie im animalen Pol. Xshn1 ist zusätzlich im Entoderm verstärkt exprimiert, während Xshn2 hier eine geringere Expression zeigt. Die Expression der Xshn mRNAs während der frühen Gastrulation mit Ausnahme der entodermalen Expression von Xshn1 und- 2 als ubiquitär bezeichnet werden.

Die erzielten Ergbnisse lassen es möglich erscheinen, dass Xshn Proteine bei einer Vermittlung der Signale dorsalisierender und ventralisierender TGF $\beta$ Signalmoleküle während der frühen Musterbildung im Embryo mitwirken. Eine mögliche Spezialisierung einzelner Xshn Proteine auf bestimmte TGF $\beta$ Signalwege ist nicht abzuleiten. 
A

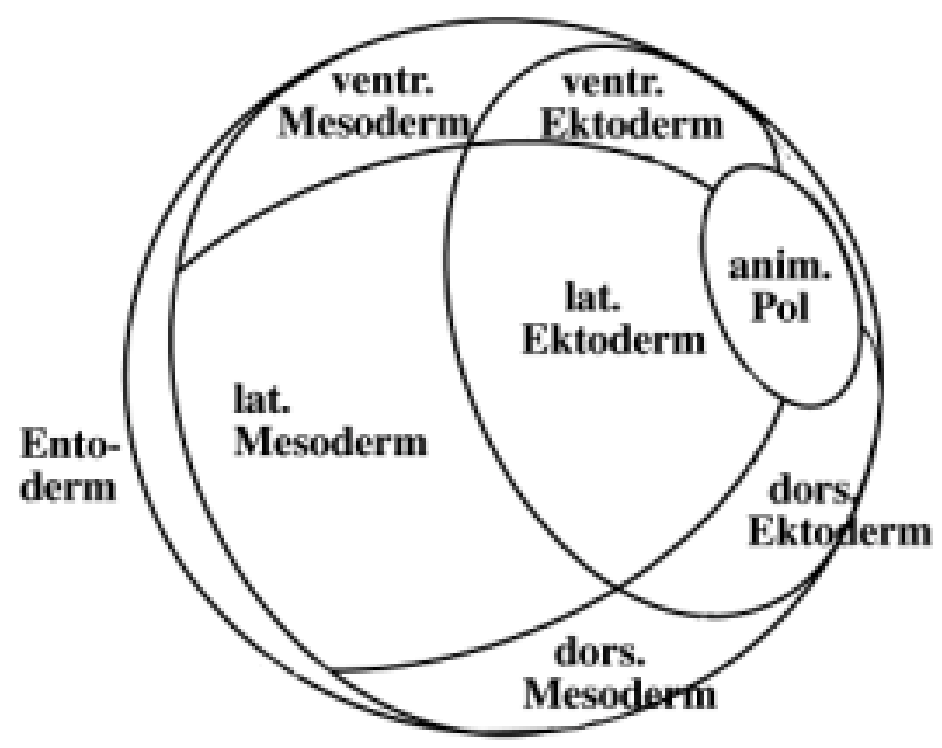

B

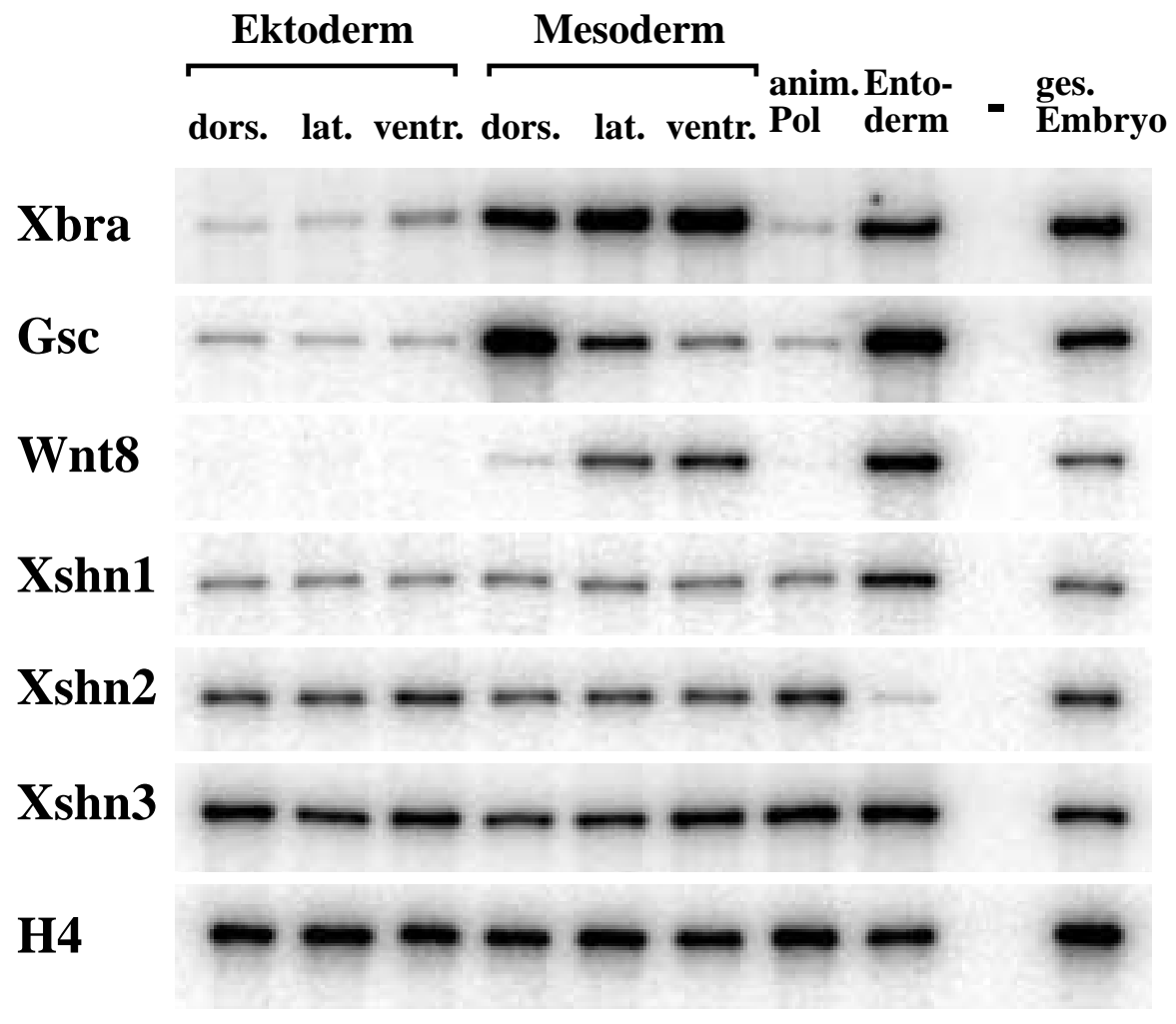

Abb. 4.18: Expressionsanalyse von Xshn Transkripten in Xenopus laevis Gastrula Embryonen durch quantitative radioaktive RT-PCR: (A) Schema der Schnittebenen entlang derer die gezeigten Fragmente aus zehn Gastrula Embryonen (NF 10) manuell zerteilt wurden. Einander entsprechende Fragmente wurden vereint und aus ihnen die Gesamt-RNA isoliert. (B) Quantitative radioaktive RT-PCR auf gesamt-RNA der gezeigten Fragmente. Die Markergene Xbra, Gsc und Xwnt8 dienten als Kontrolle der korrekten Präparation der Fragmente. 


\subsubsection{Ermittlung der räumlichen Verteilung von Xshn Transkripten durch "whole mount" in situ Hybridisierung}

Um Information über die räumliche Verteilung der Transkripte auch in späteren Embryonalstadien zu erhalten, wurden "whole mount" in situ Hybridisierungen durchgeführt. In der Maus sind vergleichbare Untersuchungen erst für Stadien ab der Neurulation bekannt (e8.5, entspricht etwa NF 20: Neurulation und erste Somiten). Für das murine HIV-EP1 (Xshn3) wurde von Tanaka et al. (2000) eine "whole mount" in situ Hybridisierung von murinen Embryonalstadien e8.5 und e12.5 (beginnende Organogenese) beschrieben. Im Embryonalstadium e8.5 wird HIV-EP1 mit Aussparungen des Neuralrohres und der Somiten ubiquitär exprimiert. Im Stadium e12.5 findet sich zudem eine Aussparung in Regionen der Knorpelbildung wie der Rippen oder der Wirbelsäule. Für das murine HIV-EP2 (Xshn2) wurde für die embryonalen Stadien e13.5 und e15.5 (Differenzierung der Organe) eine spezifische Expression in der Zunge, den Spinalganglien sowie definierten Strukturen im anterioren Neuralrohr beschrieben (Dörflinger et al., 1999). Vergleichbar späte Stadien wurden in Xenopus nicht untersucht.

Untersuchungen mit antisense RNA Sonden von Xshn1 ergaben keine über die bisherigen Ergebnisse hinausgehende Informationen (Dürr, 1997). Demnach ließen sich Xshn1 Transkripte ab dem frühen Schwanzknospenstadium (NF 26) im Gehirn und später auch im Auge nachweisen. Xshn2 Expression konnte in den sich differenzierenden Somiten als charakteristisches "Fischgrätenmuster" und ab dem Stadium NF 30 zusätzlich in definierten Regionen des Gehirns sowie in der Haftddrüse nachgewiesen werden.

Es war in der Vergangenheit nicht gelungen, mit einer Xshn3 antisense RNA-Sonde von $2.8 \mathrm{~kb}$ Länge aus dem 3'Bereich der cDNA eine spezifische Expression von Xshn3 Transkripten im Embryo nachzuweisen. Eine "whole mount" in situ Hybridisierung wurde daher wiederholt, als Sequenzinformation über die gesamte Länge der $8.5 \mathrm{~kb}$ messenden cDNA Sequenz vorlag.

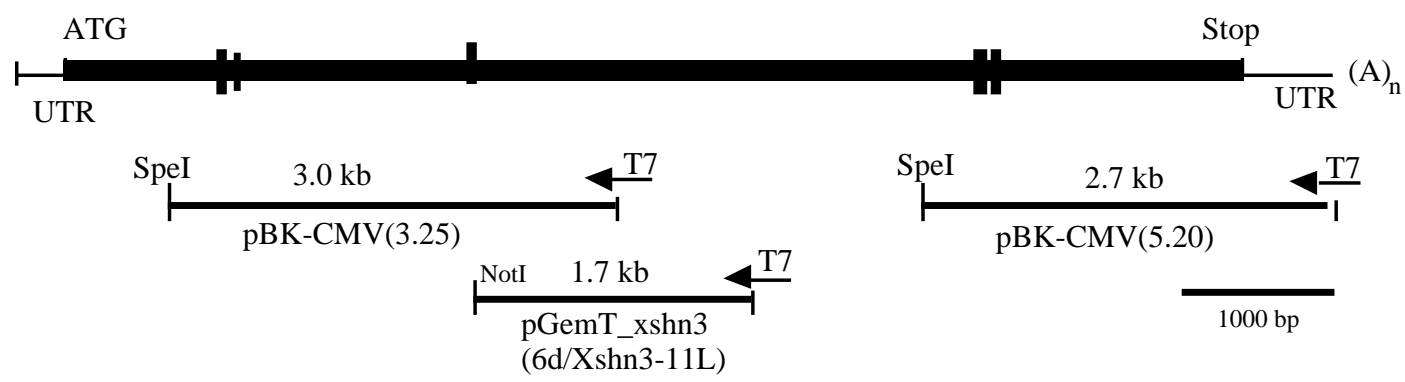

\footnotetext{
Abb. 4.19: Position der für eine "whole mount" in situ Hybridisierung eingesetzten RNA-Sonden innerhalb der cDNA Sequenz von Xshn3. Oben: Struktur der Xshn3 cDNA. Unten: Position und Länge der antisense RNA Sonden. Die Sonden deckten $75 \%$ der cDNA von $8.5 \mathrm{~kb}$ ab. Folgende Plasmide wurden für die Herstellung von Sonden kombiniert: Der Vektor pBK-CMV_Xshn3(3.25) wurde mit SpeI linearisiert und mit der T7 RNA-Polymerase in vitro transkribiert. Der Vektor pGemT_Xshn3(6d/Xshn3-11L) wurde mit NotI linearisiert und mit T7 transkribiert, und der Vektor pBK-CMV-Xshn3(5.20) wurde mit SpeI linearisiert und mit T7 transkribiert. Die Färbung der ,whole mount" in situ Hybridisierung wurde für vier Tage bei $4{ }^{\circ} \mathrm{C}$ durchgeführt.
} 


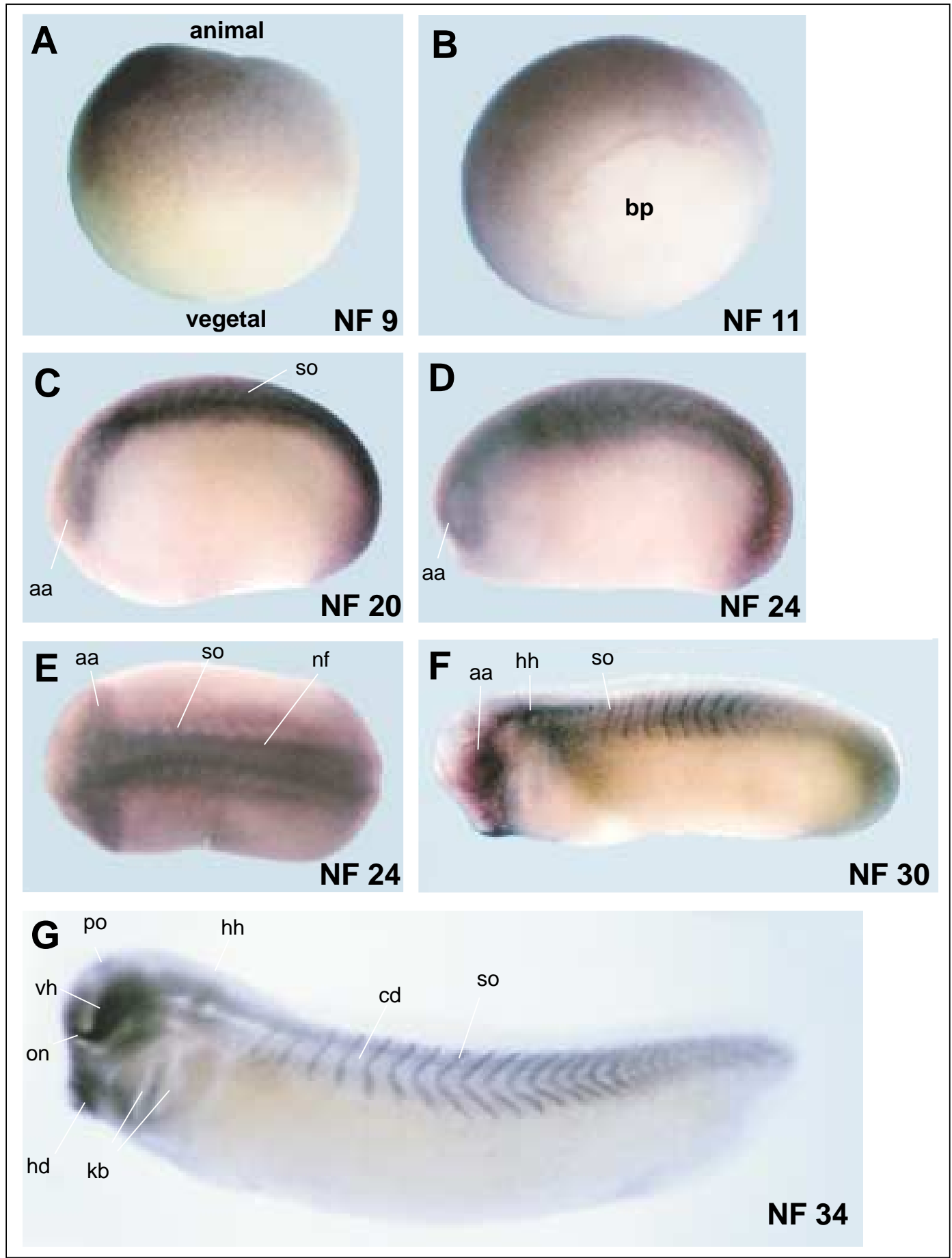

Abb. 4.20: Räumliche Verteilung von Xshn3 Transkripten in der frühen Embryogenese von Xenopus

laevis. "Whole mount" in situ Hybridisierungen an unpigmentierten Embryonen wurden mit Digoxigenein-markierten Xshn3 "antisense" Sonden durchgeführt. Der Embryo des Stadiums 34 wurde im Anschluss an die Färbung durch Klären transparent gemacht. (A) Im Stadium 9 ist die Färbung verstärkt im animalen Bereich, aber schwach auch vegetal zu erkennen. (B, vegetale Ansicht) Im mittleren Gastrula Stadium (NF 11) ist die Färbung am stärksten im dorso-animalen Bereich des Embryo zu erkennen, findet sich aber auch als einzelne Punkte im einwandernden Entoderm. (C) Im späten Neurula Embryo (NF 20) konzentriert sich die Färbung im dorsalen Mesoderm und Neuroektoderm. Die sich entwickelnden Somiten sind zu erkennen. (D) Im Stadium NF 20 zeigt sich zusätzlich eine Färbung um die Augen. (E) Eine dorsale Ansicht eines Stadium 24 Embryo zeigt die Konzentration der Färbung in den Neuralfalten, den sich entwickelnden metameren Somiten und in den Augenanlagen. (F) Die laterale Ansicht eines Stadium 30 Embryos (Organogenese) zeigt eine "fischgrätenartige" Färbung der Somiten, eine Färbung im Hinterhirn und um die Augenvesikel. (G) Die Klärung eines Stadium 34 Embryos macht eine Färbung im Vorderhirn und dem otischen Nerv sowie dem Pinealorgan, dem Hinterhirn und der Haftdrüse sichtbar. Der Bereich der Chorda dorsalis und der sich entwickelnden Wirbelsäule sowie der Kiemenbögen sind von der Färbung ausgespart. Abkürzungen: aa: Augenanlage, so: Somiten, nf: Neuralfalten, av, Augenvesikel, hh: Hinterhirn, kb: Kiemenbögen, hd: Haftdrüse, on: olfaktorischer Nerv, vh: Vorderhirn, po: Pinealorgan, cd: Chorda dorsalis. 
Die Ergebnisse der "whole mount" in situ Hybridisierung sind in Abb. 4.20 dargestellt. Insgesamt erwies sich die Intensität der Xshn3 Färbung, wie zuvor die von Xshn1 und -2, als gering. Xshn3 Transkripte sind im Blastula-Stadium (NF 9) am stärksten in der animalen Hemisphäre zu erkennen, sind aber auch vegetal erkennbar. Im mittleren Gastrula Stadium (NF 11) zeigt sich die Färbung in einem weiten dorsal-animalen Bereich, der prospektives Ektoderm und Mesoderm umfasst. Es ist aber auch Färbung ventral und im einwandernden Entoderm zu erkennen. Während der Neuralstadien (NF 20 - NF 24) färben die Xshn3 Sonden verstärkt den gesamten dorsalen Bereich, das Neuroektoderm sowie die sich differenzierenden Somiten. Gleichmäßige, schwächere Färbung ist aber auch ubiquitär zu beobachten. Mit Beginn der Organogenese (NF 30 - NF 34) zeigt sich v.A. in den Somiten ein sog. "Fischgrätenmuster" der Expression. Im Stadium 30 ist Färbung im Hinterhirn sowie im Bereich der Augenvesikel zu erkennen. Ein Embryo des Stadiums 34 wurde transparent gemacht, wodurch zusätzlich Färbungen im Pinealorgan, im Vorderhirn, im otischen Nerv und in der Haftdrüse zu erkennen sind. Wegen der in den früheren Stadien eher diffusen Expression ist hier zu bemerken, dass Bereiche der Chorda dorsalis und der sich entwickelnden Wirbelsäule, aber auch der Kiemenbögen von einer Färbung ausgespart scheinen. Den genannten Gewebetypen ist gemein, dass hier Knorpelbildung stattfindet. Die Färbungen waren insgesamt zu schwach, um die Anfertigung von Gewebeschnitten zu erlauben.

Die Ergebnisse der Expressionsanalysen zeigen eine ubiquitäre Expression aller drei Xshn mRNAs vor und während der Gastrulation von Xenopus Embryonen. Schnurri Proteine stehen daher vermutlich im Zeitraum der Musterbildung des Mesoderms durch TGF $\beta$ Faktoren zur Verfügung. Eine Differenzierung der Expression findet erst in Stadien der Organogenese statt.

\subsubsection{Expression von Xshn mRNAs in Geweben adulter Xenopus laevis Frösche}

In einer Reihe von Untersuchungen wurde eine differentielle Expression der zu Xshn homologen Gene in adulten Geweben von Säugern beschrieben. Die Expression ist für jedes der drei Gene HIV-EP1, -2 und -3 charakteristisch. In Northern Blots konnten zudem z.T. neben dem Haupttranskript von ca. 9.5 kb Länge gewebsspezifisch weitere Transkripte von ca. 4.5 kb Länge nachgewiesen werden. Ein zu den Säuger-Genen ähnliches Expressionsmuster der Xenopus Gene könnte einen zusätzlichen Hinweis auf die funktionelle Konservierung der Gene in Vertebraten liefern. Unter der Annahme einer solchen Konservierung wäre für Xshn1 eine Expression in Milz, Knochenmark und Thymusdrüse zu erwarten (Wu et al., 1993, 1996). Xshn2 mRNA könnte im Gehirn und den Skelettmuskeln stark exprimiert sein, während nur wenige Gewebe entodermalen Ursprungs eine Expression zeigen sollten (Ron ert al. 1991, Nomura et al., 1991, Makino et al., 1994, Dörflinger et al., 1999). Für Xshn3 wäre eine Expression v.A. im Gehirn und in der Thymusdrüse zu vermuten, jedoch nicht in der Leber oder in Muskelgewebe (Nakamura et al., 1990, Brady et al., 1994, Tanaka et al., 2000).

Im Rahmen der vorliegenden Arbeit wurde eine quantitative radioaktive RT-PCR auf gesamt-RNA aus präparierten Geweben adulter Xenopus Tiere durchgeführt, um zu ermitteln, ob und in welcher Intensität die Xenopus Schnurri mRNAs gewebspezifisch exprimiert werden (Abb. 4.21). 


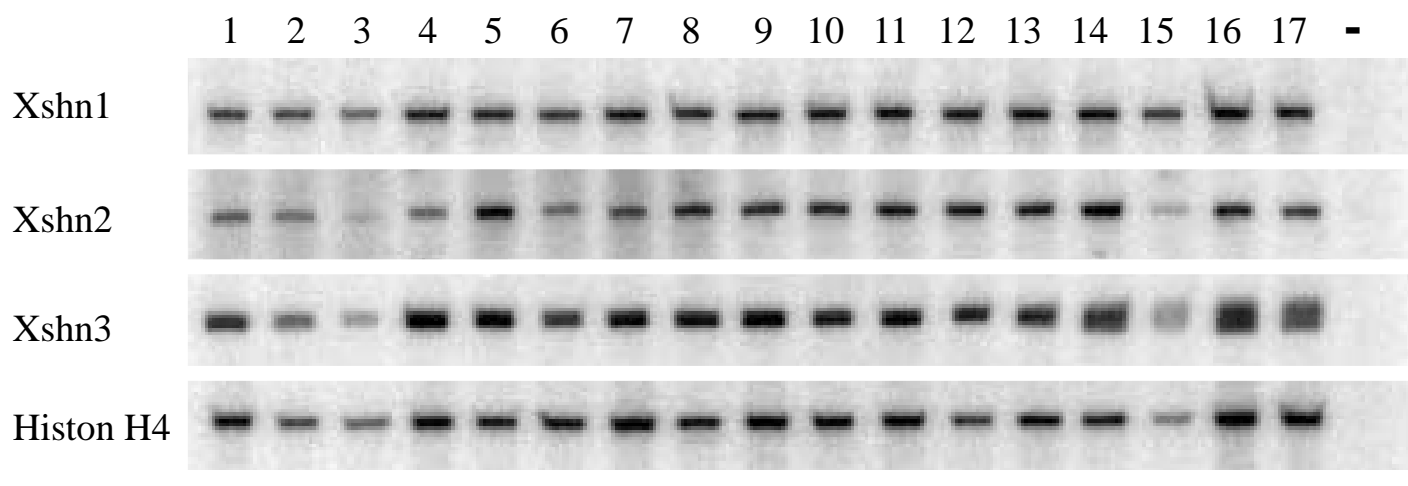

$\begin{array}{llllll}1 & \text { Haut } & 7 & \text { Milz } & 13 & \text { Auge } \\ 2 & \text { Herz } & 8 & \text { Leber } & 14 & \text { Gehirn } \\ 3 & \text { Skelettmuskeln } & 9 & \text { Niere } & 15 & \text { Rückenmark } \\ 4 & \text { Speiseröhre } & 10 & \text { Lunge } & 16 & \text { Ovar } \\ 5 & \text { Magen } & 11 & \text { Harnblase } & 17 & \text { Testis } \\ 6 & \text { Darm } & 12 & \text { Fettgewebe } & - & \text { Kontrolle }\end{array}$

Abb. 4.21: RT-PCR mit Xshn-spezifischen Primerpaaren auf gesamt-RNA aus verschiedenen Geweben adulter Xenopus laevis Frösche. Als spezifische Primer wurden folgende Primer im mittlerenBereich der cDNAs verwandt: Xshn1: Xshn1-5U/Xshn1-7L; Xshn2: Xshn2-2U/Xshn2-1L; Xshn3: Xshn3-1U/Xshn3-2L. Zur Kontrolle der gleichmäßigen quantitativen Beladung der Ansätze mit gesamt-RNA dienten Reaktionen mit Histon H4-spezifischen Primern.

Wie in Abb. $4.21 \mathrm{zu}$ erkennen, sind Xshn1, -2 und -3 mRNAs in allen untersuchten adulten Geweben nachzuweisen. Eine geringere Intensität der Banden von Xshn2 und Xshn3 in Herzmuskel- und in Rückenmark korreliert mit geringer Bandenintensität der Histon H4 Kontrolle in diesen Geweben. Alle drei mRNAs werden mit geringen Intensitätsunterschieden in allen untersuchten Geweben exprimiert.

Eine differentielle Expression von Xshn1, -2 und -3 in adulten Geweben, wie sie für die entsprechenden Säuger-Gene beschrieben wurde, bestätigte sich nicht. 


\subsection{Expression des Xshn3 Gesamtlängenproteins in Xenopus Embryonen}

Im Rahmen der vorliegenden Arbeit wurde die cDNA von Xshn3 vollständig isoliert. Dieses eröffnete die Möglichkeit, funktionelle Analysen anzuschließen, die das Ziel hatten, eine mögliche Funktion von Xshn3 im TGF $\beta$ Signalweg zu beschreiben.

Eine gängige Methode zur Untersuchung der Funktion eines Proteins in Xenopus ist die Überexpression seiner mRNA im Embryo. Durch Mikroinjektion von synthetischer mRNA eines Proteins in einzelne Blastomere der ersten Teilungsstadien wird eine Überrepräsentierung des resultierenden Proteins in den resultierenden Körperregionen bewirkt. Aus morphologischen Veränderungen der Embryonen aufgrund der Überexpression eines Proteins in definierten Körperregionen kann u.U. auf die eigentliche Funktion des Proteins rückgeschlossen werden.

Aus den überlappenden cDNA-Fragmenten von Xshn3 wurde der vollständige offene Leserahmen von $7.7 \mathrm{~kb}$ Länge in die Vektoren pCS2+MT und pCS2+Flag kloniert (vgl. Kap. 2.3). Die resultierenden aminoterminal epitopmarkierten Proteine sollten ein Molekulargewicht von 293 bzw. $284 \mathrm{kDa}$ besitzen.

Nach einer in vitro Synthese von mRNA für MT-Xshn3 und Flag-Xshn3 zeigten sich in AgaroseKontrollgelen statt einer einzigen Bande drei Banden. Außer der erwarteten Bande von ca. $9 \mathrm{~kb}$ ließen sich zusätzliche Banden bei etwa $2 \mathrm{~kb}$ und bei $0.7 \mathrm{~kb}$ beobachten. Abb. 4.22 zeigt ein solches RNA-Kontrollgel.

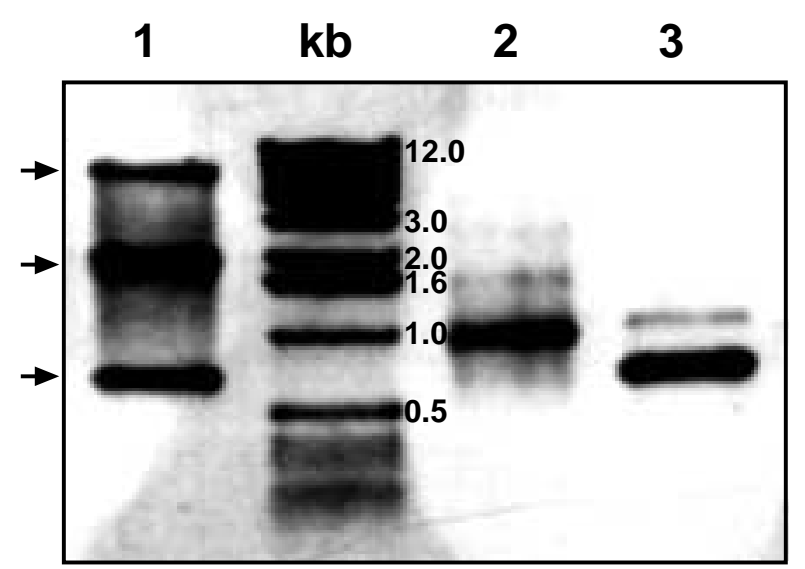

Abb. 4.22: Agarose-Gelelektrophorese von in vitro synthetisierter mRNA. Die mRNAs wurde in einem 1\%igen Agarosegel elektorphoretisch aufgetrennt. 1, Flag_Xshn3(wt) mRNA; kb, DNAStandard "one kb ladder"; 2, NLS-MT_Xshn3ZF mRNA; 3, NLS-MT_Xshn3-VP16 mRNA. Pfeile weisen auf die drei mRNA Banden der Xshn3-Probe hin. Neben einiger Banden des DNALängenstandards ist die Länge der Fragmente in kb angegeben.

Für das Auftreten von drei Banden ließen sich verschiedene Ursachen denken, die z.T. mit der Verwendung bakterieller RNA-Polymerasen für die Synthesereaktion zusammenhängen konnten. Die zusätzlichen Banden konnten durch Transkriptions-Abbrüche während der Synthesereaktion entstanden sein. Ebenso könnte es sich um mRNA-Produkte durch interne TranskriptionsInitiationen handeln. Weiterhin könnten die drei Banden unterschiedlich gefaltete Formen desselben Gesamtlängen-mRNA Moleküls darstellen, die im gezeigten, nicht-denaturierenden Agarose Gel zu Bildung von drei Banden führten. 
Um zu ermitteln, ob es sich bei den beobachteten Banden lediglich um unterschiedlich gefaltete Formen der Gesamtlängen-mRNA handelte, wurde die mRNA in einem denaturierenden, Formaldehyd enthaltenden Agarose-Gel aufgetrennt. Parallel wurde der DNA-Längenstandard "one kb-ladder" aufgetrennt. Das Ergebnis ist in Abb. 4.23 dargestellt.

Abb. 4.23: Denaturierende Gelektrophorese von in vitro transkribierter, epitopmarkierter Gesamtlängen-Xshn3 mRNA. Synthetische mRNA des aminoterminal MT- und des Flagepitopmarkierten Gesamtlängen-Xshn3 wurde in einer denaturierenden Agarose-Gelelektrophorese aufgetrennt, auf Nitrozellulose übertragen und angefärbt. Parallel wurden DNA-Fragmente des "one kb-ladder" Längenstandards aufgetrennt. Am rechten Rand ist die Länge der erkennbaren Fragmente des Standards angegeben. MT, 6xMTXshn3-mRNA; Flag, Flag-Xshn3 mRNA.

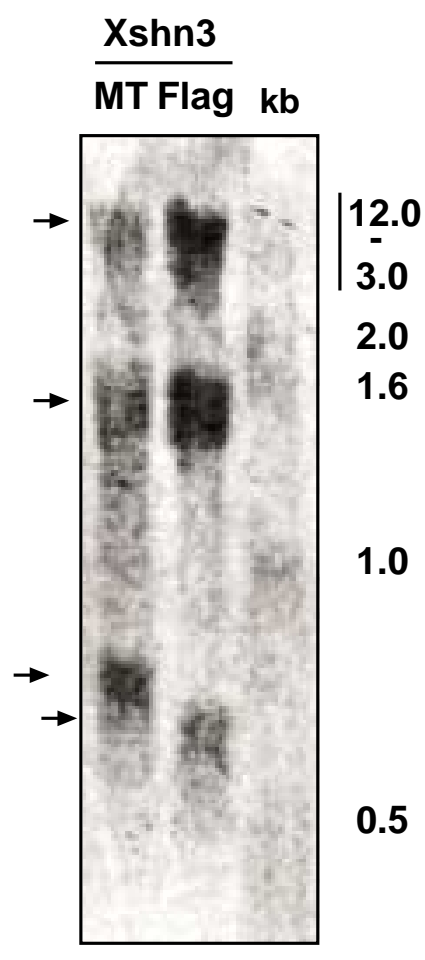

Eine denaturierende Gelelektrophorese ergab auch hier für die MT- und die Flag-epitopmarkierte Form von Xshn3 drei Banden im Gel. Die Länge der aufgetrennten Fragmente ließ sich nicht genau bestimmen. Es fiel hierbei in diesem Versuch auf, dass die Fragmente des Flagepitopmarkierten Xshn3 Transkriptes schneller im elektrischen Feld liefen als die des MTepitopmarkierten Transkriptes. Tatsächlich ist das aminoterminale Flag-Epitop 226 bp kürzer als das 6xMT-Epitop. Der schnellere Lauf des kurzen Fragmentes der Flag-Variante der Xshn3 mRNA könnte ein Hinweis für einen TranskriptionsAbbruch und gegen interne Initiationen der Transkription sein.

Eine in vitro Synthese von Xshn3 mRNA resultiert wahrscheinlich in einer zu frühen Termination der Transkription an zwei Positionen innerhalb der Xshn3 mRNA.

Wenn die kürzeren Produkte der in vitro mRNA-Synthese Abbruchfragmente der Transkription waren, so sollte es möglich sein, das Gesamtlängen-mRNA Produkt von 8 kb Länge durch Elution aus einem Agarosegel zu isolieren und von den Abbruchfragmenten zu trennen. Es wurde im Folgenden versucht, die mRNA-Einzelfragmente der MT-Xshn3 mRNA-Synthesereaktion aus einem nicht-denaturierenden Agarose Gel zu isolieren. Abb. 4.24 zeigt, dass es möglich war, alle drei RNA-Banden zu isolieren und in reiner Form anzureichern. 

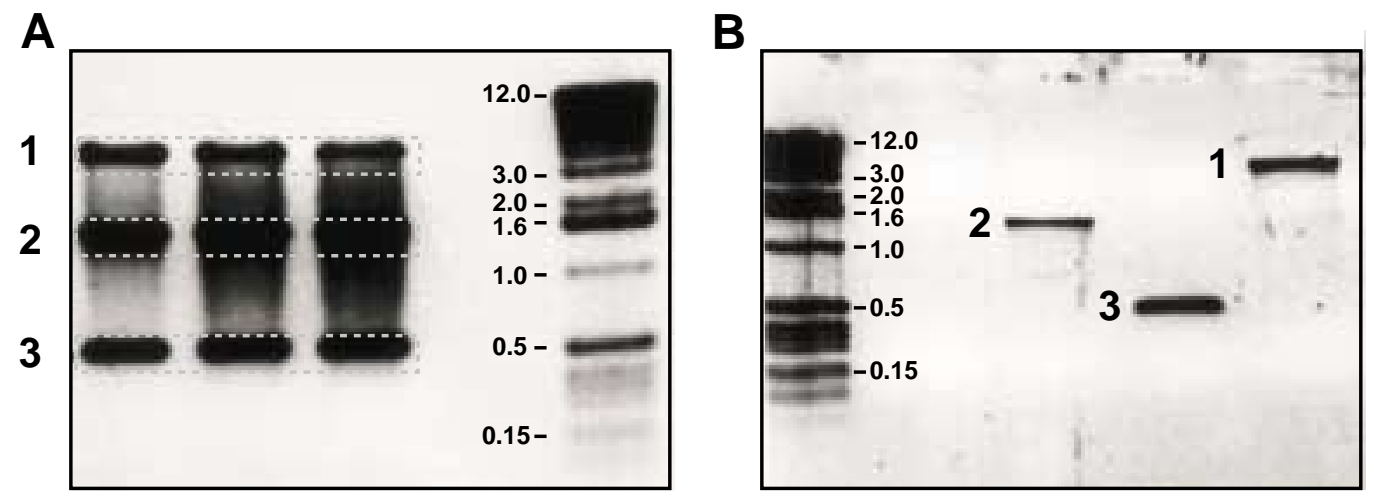

\begin{abstract}
Abb. 4.24: Isolierung von synthetischen MT-Xshn3 mRNA-Fragmenten nach Auftrennung in einem Agarose-Gel. Die Produkte einer in vitro mRNA Synthesereaktion wurden in einem 0.8\%igen RNAse-freien Agarose-Gel elektrophoretisch aufgetrennt. Einzelne Banden wurden ausgeschnitten und die RNA aus den Gelblöckchen eluiert. (A) Gelelektrophorese einer gesamten Synthesereaktion, anschließend ausgeschnittene Banden sind durch grau gestrichelte Kästen markiert; (B) Auftrennung der aus den Gelblöckchen eluierten mRNA-Fragmente. 1, obere Bande; 2, mittlere Bande; 3, untere Bande. Seitlich ist jeweils der "one kb-ladder" DNA-Längenstandard zu erkennen. Die Länge einiger DNA-Fragmente ist in kb angezeigt.
\end{abstract}

Die Ausbeute der reinen mRNA Längenfragmente war relativ gering und die Methode zu aufwendig, um ausreichend reine Gesamtlängen-mRNA für Überexpressionsstudien zu erhalten. Um signifikante Mengen eines derartig großen Proteins in Xenopus Embryonen überexprimieren zu können, müssen große Mengen (mehrere ng pro Embryo) synthetischer mRNA injiziert werden. Dieses war mit der gewählten Methode nicht zu gewährleisten.

Die Ursache für einen Abbruch der Transkription an zwei definierten Positionen innerhalb der Xshn3 Sequenz wurde in der Bildung von haarnadelförmigen Sekundärstrukturen innerhalb der neu synthetisierten mRNA vermutet. Eine Rückfaltung der RNA am Ort der Synthese an der Matritzen-DNA würde eine weitere RNA-Synthese durch die bakteriellen RNA-Polymerasen verhindern. Die Bildung von Haarnadelschleifen ist eine in Bakterien häufige Form der Transkriptions-Termination (Knippers et al., 1985). Die Intention war daher, GC-reiche Sequenzabschnitte innerhalb der Xshn3 cDNA zu identifizieren, die eine Bildung von Haarnadelschleifen verursachen könnten und diese Sequenzen durch in vitro Mutagenese zu destabilisieren.

Der aminoterminale Transkriptionsabbruch wurde etwa bei bp 600 innerhalb des offenen Leserahmens von Xshn3 vermutet. Die genaue Position des Abbruchs im mittleren Teil der cDNA war nicht genau abzuschätzen. Deshalb wurde das Plasmid pCS2+Flag_Xshn3(wt) an verschiedenen Positionen innerhalb der cDNA Sequenz linearisiert und in eine in vitro Transkription eingesetzt. Es sollte ermittelt werden, welche Fragmente die Bildung von Abbruchfragmenten gerade noch zuließen. Abb. 4.25 zeigt schematisch die Position der Linearisierungen und das Ergebnis der in vitro Transkriptionen. Die Transkriptionsabbrüche ereigneten sich vor bp 4225 (lin. SphI) und vermutlich hinter bp 1990 (SacI). 
A

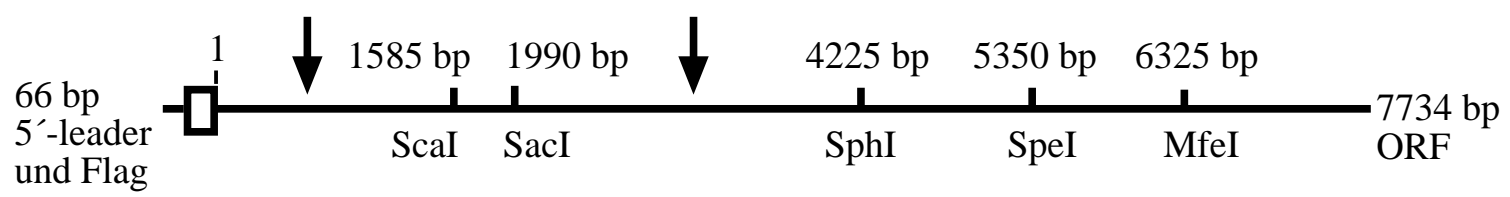

B

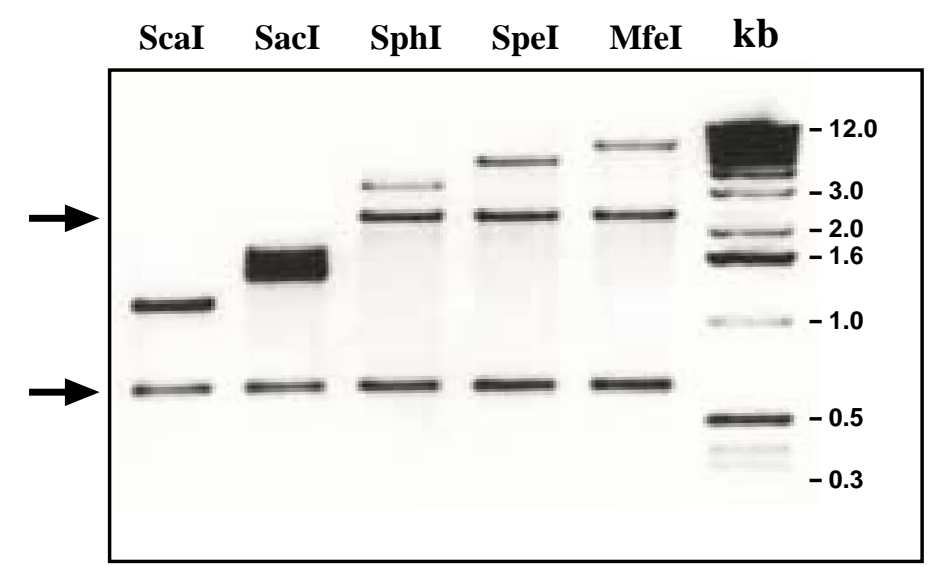

Abb. 4.25: Kartierung der für Transkriptionsterminationen verantwortlichen Sequenzbereiche innerhalb des Proteins Xshn3. Das Plasmid pCS2+Flag_Xshn3(wt) wurde mit den in (A) angegebenen Restriktionsenzymen linearisert. Die Position der Restriktionsschnittstellen bezieht sich auf den offenen Leserahmen der Xshn3 cDNA. Pfeile kennzeichnen die ungefähre Position der Transkriptionsabbrüche. (B) Die linearisierten Plasmide wurden in eine in vitro Transkription eingesetzt, die mRNA in einer Agarose-Gelelektrophorese aufgetrennt und die Länge von RNAAbbruchfragmenten abgeschätzt. Die wiederholt beobachteten Abbruchfragmente sind durch Pfeile gekennzeichnet

Um die Abbruchstelle um bp 3000 genauer zu lokalisieren, wurde ein NcoI-NcoI-Fragment von bp 2375 bis bp 3975 aus den Plasmiden pCS2+MT_Xshn3(wt) und pCS2+Flag_Xshn3(wt) in den Vektor pGEMT subkloniert, wie in Abb. 4.25 mit verschiedenen Restriktionsenzymen linearisiert und transkribiert. Der TranskriptionsAbbruch konnte dadurch etwa auf eine Position bei bp 3.100 innerhalb der Xshn3 cDNA lokalisiert werden (nicht gezeigt).

Mithilfe des Programmes "RNA-structure" wurden die Sequenzbereiche der Abbruchregionen nach möglichen Haarnadelschleifen-bildenden Sequenzen hin untersucht. Bei bp 617-662 konnte eine Sequenz identifiziert werden, die einen RNA-Doppelstrang aus 11 Basenpaaren verursachen könnte. Die Struktur ist in Abb. 4.26 A dargestellt. Im 3'-Bereich um bp 3.100 konnte keine mögliche Haarnadelschleife identifiziert werden. 
A

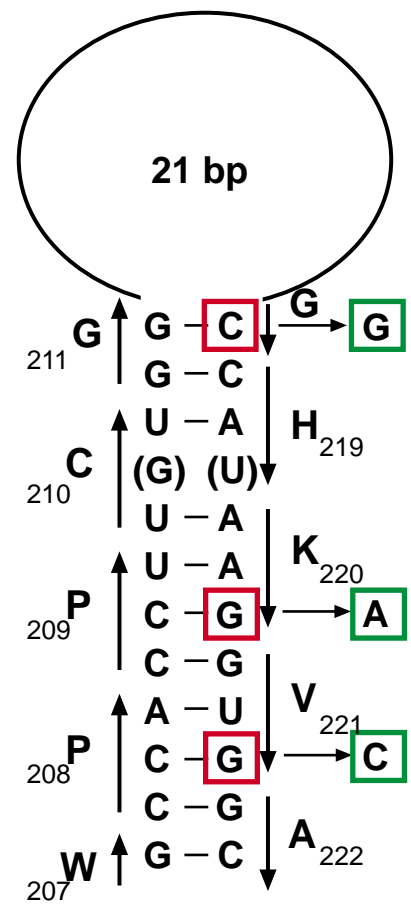

B

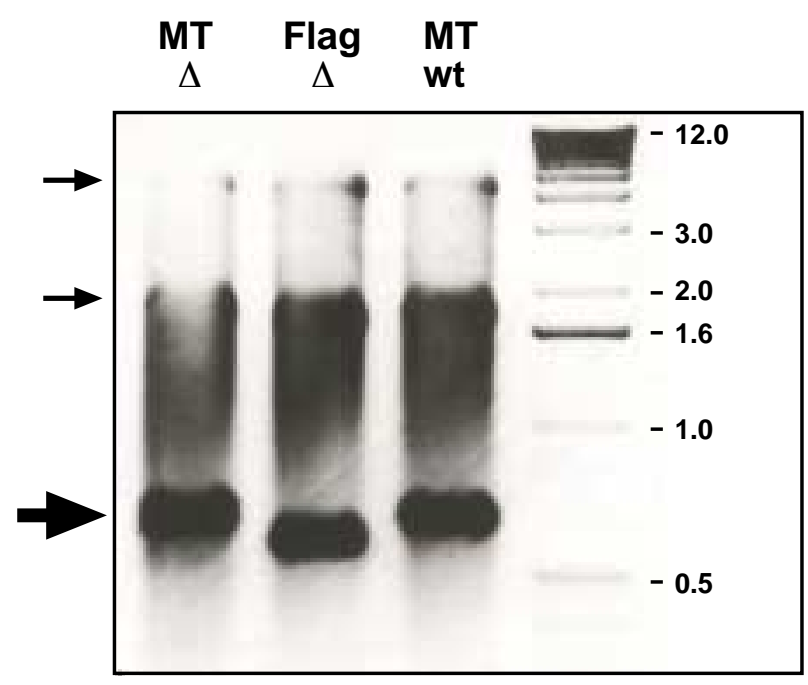

Abb. 4.26: In vitro Mutagenese einer möglichen RNA-Haarnadelschleife-verursachenden Region innerhalb der Xshn3 cDNA Sequenz. (A) Sequenz und Struktur einer möglichen Haarnadelschleife. Neben den beteiligten Basen sind die von den Basentripletts kodierten Aminosäuren mit ihrer Position innerhalb des offenen Leserahmens von Xshn3 angegeben. Drei Basen wurden von der rot markierten zur grün markierten Identität mutiert. (B) Agarose Gelelektrophorese von in vitro transkribierten mutierten Formen (MT $\Delta$ und Flag $\Delta$ ) und einer unmutieren Form (MT wt) von Xshn3. Kleine Schwarze Pfeile zeigen die Banden der längeren Xshn3 Transkripte. Ein dicker Pfeil deutet auf die mRNA-Abbruchfragmente, die durch Mutagenese eliminiert werden sollten.

In einer in vitro Mutagenese wurden drei an der Bildung der 5'-gelegenen Haarnadelschleife beteiligte Basen so mutiert, dass die Aminosäuresequenz des Peptides erhalten blieb. Die Position der Basen ist in der Abb. 4.26A dargestellt. Die Mutagenese wurde durch Sequenzierung bestätigt. Eine in vitro Transkription der sequenzveränderten Plasmide pCS2+MT_Xshn3 $\Delta$ loop1 und pCS2+Flag_Xshn3 $\Delta$ loop1 zeigte keine Veränderung in der Bildung der Abbruchfragmente gegenüber dem unmutierten Plasmid pCS2+MT_Xshn3(wt) (Abb. 4.26B). Die untersuchte mögliche Haarnadelschleife war vermutlich nicht Ursache für den Transkriptionsabbruch. Möglicherweise werden die zur Termination der Transkription führenden Sekundärstrukturen aus komplexeren Rückfaltungen der mRNA gebildet. Es wurde keine weitere Analyse von möglichen Sekundärstrukturen innerhalb der Xshn3 cDNA Sequenz durchgeführt.

In der eukaryotischen Zelle werden mRNAs über ihre poly(A) Sequenz stabilisiert (Übersicht in Wilusz et al., 2001). Da es sich bei den kürzeren Xshn3 mRNA Fragmenten um Abbruchfragmente handelt, besitzen diese Moleküle keine Sequenz für ein Polyadenylierungssignal an ihrem 3'-Ende. Es kann daher vermutet werden, dass diese Moleküle in der Zelle weniger stabil sind als solche mit einem Polyadenylierungssignal. Bei einer Mikroinjektion von in vitro synthetisierter mRNA sollten daher die kürzeren Fragmente bevorzugt degradiert werden. Es bliebe die Gesamtlängen-mRNA als Matritze für die Synthese des Xshn3 Proteins übrig. Um zu testen, ob dieser einfache Weg der Injektion des mRNA-Gemisches in Xenopus Embryonen zur Synthese eines einzigen Proteins von etwa 280 kDa Größe führen 
könnte, wurde das mRNA Gemisch für das MT-epitopmarkierte Gesamtlängen Xshn3 Protein ubiqitär in Xenopus Embryonen überexprimiert. Gesamtextrakte von Gastrula Embryonen wurden im Western Blot auf Expression der Proteine untersucht. Das Experiment wurde fünfmal wiederholt. In einem einzigen Fall konnte eine schwache Bande der erwarteten Göße von ca. 280 kDa detektiert werden. In jedem Fall konnten kürzere Proteinfragmente detektiert werden. Abb. 4.27 zeigt das Ergebnis zwei solcher Versuche.
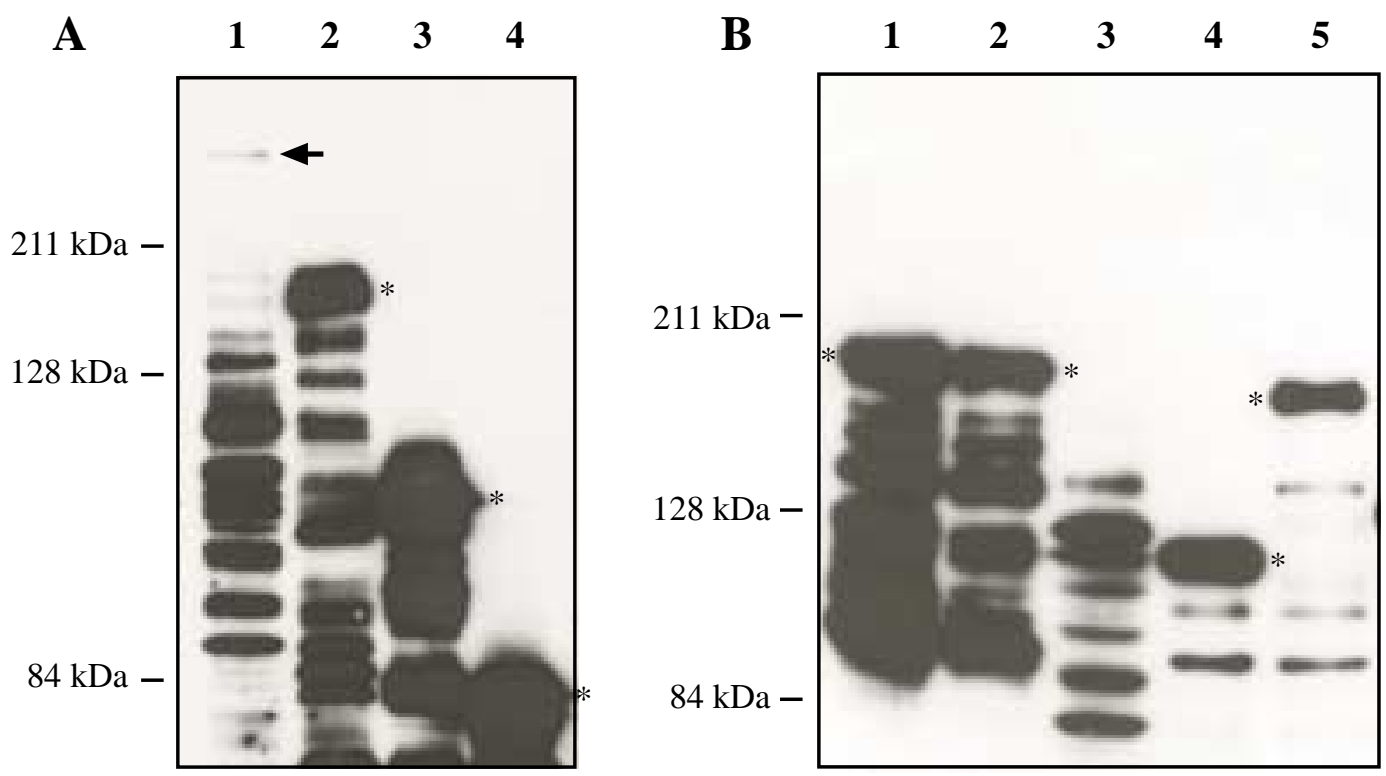

\begin{abstract}
Abb. 4.27: Nachweis der Expression des Gesamtlängen-Xshn3 Proteins von 290 kDa Größe in Xenopus Embryonen. Synthetische mRNA für aminoterminal MT-epitopmarkierte Proteine wurde in Xenopus Embryonen injiziert. Aus Gesamtextrakten von je 10 Embryonen wurde 1/5 Vol. in einer 6\% PAGE augetrennt und die überexprimierten Proteine immunologisch nachgewiesen. Banden der exprimierten Proteine sind durch Sterne gekennzeichnet; Die Gesamtlängen-Xshn3 Bande ist durch einen Pfeil markiert. (A) Folgende mRNAs wurden injiziert: 1, pCS2+MT_Xshn3(wt) (4 ng/Emb.); 2, pCS2+MT_Xshn3(AS 542-1749) (4 ng/Emb.) ; 3, pCS2+MT_Xshn3(AS 1076-1749) (3 ng/Emb.); 3, pCS2+MT_Fast1 (2 ng/Emb.). (B) Gesamtextrakte wurden wie in (A) analysiert: 1, pCS3+MTSip1ORF (4ng/Emb.); 2, pCS3+MTSip1 $\triangle$ SBD (4 ng/Emb); 3, pCS2+MT_Xshn3(wt) (6 ng/Emb.); 4, pCS2+MT_Xshn3(AS 1-652) (2 ng/Emb.); 5, pCS2+MT_Xshn3(AS 1-1075) (4 ng/Emb.).
\end{abstract}

Während Xshn-Fragmente und andere relativ große Proteine wie Sip1 und Sip1 $\triangle$ SBD (delta Smad-binding domain, Verschueren et al., 1999) stabil in Xenopus Embryonen exprimiert wurden, konnte Xshn3 nur ein einziges mal als schwache Bande im Western Blot detektiert werden. Charakteristische kürzere Proteinfragmente konnten dagegen wiederholt beobachtet werden. Es wurde daher vermutet, dass die injizierte mRNA zwar aktiv, aber nicht bis zum Ende des längsten der drei injizierten Transkripte translatiert wurde.

Eine weitere Möglichkeit für die geringe Expression des Gesamtlängenproteins konnte in einer verminderten in vivo Stabilität der injizierten synthetischen mRNA liegen. Um die Stabilität der Xshn3 mRNA in der eukaryotischen Zelle $\mathrm{zu}$ untersuchen, wurde Plasmid-DNA (pCS2+MT_Xshn3(wt)) in Xenopus Embryonen des zwei-Zell Stadiums und in den Zellkern von Oozyten der Stadien 5-6 injiziert und die Synthese des resultierenden Transkriptes durch RT-PCR 
analysiert. Der verwendete Plasmidvektor pCS2+MT enthält einen starken eukaryotischen Promotor, der eine Synthese des resultierenden Transkriptes in eukaryotischen Zellen ermöglicht. Mit Hilfe eines Primerpaares aus dem 3'-Ende der mRNA, das selektiv die aus dem Vektor stammende Sequenz, nicht aber die des endogenen Transkriptes erkennt, konnte die vollständige Transkription der Xshn3 mRNA in der Oozyte und im Embryo nachgewiesen werden. Das Primerpaar Xshn3-23U/T7 amplifizierte dabei ein Fragment von 311 bp Länge am 3'-Ende der mRNA vor einem SV40 Polyadenylierungssignal.

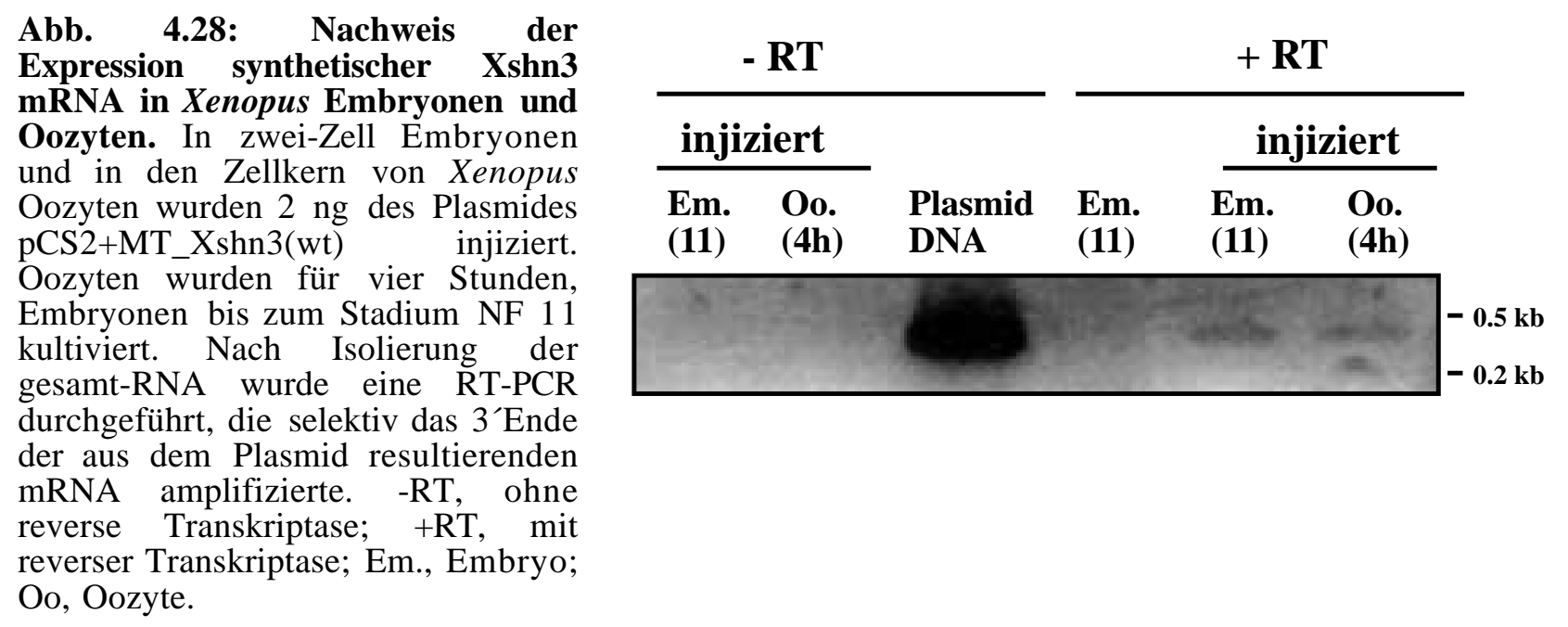

Sowohl in Embryonen als auch in Oozyten konnte das 3'-Ende der in vivo transkribierten Xshn3 mRNA nachgewiesen werden (Abb. 4.28). Eine fehlende oder geringe Expression des Xshn3 Proteins nach Injektion synthetischer mRNA wurde daher vermutlich nicht durch Instabilität seiner mRNA verursacht.

Die Injektion von Plasmid-DNA eignet sich jedoch nicht dazu, ein Protein gleichmäßig im Xenopus Embryo überzuexprimieren. Der Grund liegt in der ungleichen Verteilung der injizierten Plasmid-DNA auf die Tochterzellen nach einer mitotischen Zellteilung. Dadurch werden die resultierenden Proteine nach wiederholten Zellteilungen im Xenopus Embryo mosaikartig exprimiert. Konzentrationsabhängige phänotypische Effekte überexprimierter Proteine können unter diesen Bedingungen nicht analysiert werden.

Eine quantitative Überexpression des Gesamtlängen Xshn3 Proteins in Xenopus Embryonen war nicht möglich. 


\subsection{Subzelluläre Lokalisation von Xshn3 Proteinfragmenten in Xenopus Oozyten}

Der Zellkern, eine der charakteristischen Organellen der eukaryotischen Zelle, wird vom Zytoplasma durch eine Hülle aus zwei Membranen getrennt. Aufgrund der Kompartimentierung der Zelle und der räumlichen Trennung von Transkription und Translation sind gerichtete Transportprozesse zwischen Zellkern und Zytoplasma notwendig. Ein konstanter Fluss von Makromolekülen, wie der Import von Transkriptionsfaktoren oder der Export von Ribosomen, muß in beiden Richtungen durch die Kernmembran erfolgen.

Die Translokation erfolgt durch den Kernporenkomplex, der in die Kernmembran integriert ist (Feldherr et al., 1984). Der Transport zwischen Kern und Zytoplasma ist ein signalvermittelter und energieabhängiger Prozess, der durch eine Vielzahl von Rezeptoren und löslichen Faktoren reguliert wird. Peptidsequenzen innerhalb der Proteine dienen als Signale für den Kernimport oder -export. Die Signalsequenzen werden von Proteinen der Import- oder Exportmaschinerie gebunden und der Transportprozess eingeleitet.

Wegen seiner Ähnlichkeit zum nukleären Drosophila Schnurri und zu DNA bindenden homologen Proteinen aus Säugern wurde für das Protein Xshn3 angenommen, dass es als Transkriptionsfaktor im Zellkern aktiv ist. So konnte beispielsweise das endogene zu Xshn3 homologe humane Protein HIV-EP1 in humanen MG63 Zellen im Zellkern nachgewiesen werden (Fan und Maniatis, 1990). Auch das Drosophila Protein Schnurri wurde nach Überexpression in COS-Zellen im Zellkern lokalisiert (Udagawa et al., 2000). Die Untersuchung der subzellulären Lokalisation von Drosophila Schnurri-Fragmenten hatte dagegen gezeigt, dass ein mittleres Fragment von AS 566-909 im Zytoplasma von COS-Zellen akkumuliert.

Viele Proteine besitzen sowohl Kernimport- als auch -exportaktivität. Erst die unterschiedliche Rate, mit der die Moleküle importiert und exportiert werden, bewirkt eine Akkumulation der Proteine in einem der Zellkompartimente. So ist auch für das Xenopus Protein Xshn3 denkbar, dass es außer Kernimport- auch exportaktivität besitzt. Eine Identifizierung von im Zellkern oder im Zytoplasma akkumulierenden Xshn3 Proteinfragmenten sollte daher helfen, mögliche Importoder Exportsignale innerhalb des Proteins zu identifizieren.

Der Kernimport wird von Kernlokalisationssignalen (NLS) vermittelt. Die am besten charakterisierten derartigen Signale bestehen aus einer zusammenhängenden (monopartiten) Sequenz aus basischen Aminosäuren, z.B. im SV40-T-Antigen (KK/RXK/R; Kalderon et al., 1984), oder aus zwei durch variable Aminosäuren getrennten (bipartite) basischen Abschnitten, wie der Nukleoplasmin Typ. (Dingwall et al., 1988; Robbins et al., 1991). Außer diesen basischen Typen von Kernlokalisationssignalen existieren weitere Arten, beispielsweise eine aus einer Glycin-reichen, 38 Aminosäuren langen Sequenz in hnRNP A1 (Michael et al., 1995b; Siomi und Dreyfuss, 1995). Diese sog. M9 Domäne ist verantwortlich sowohl für den Import als auch für den Export des Proteins.

Als Kernexportsignale (NES) kommen wiederholt Leucin-reiche Sequenzabschnitte vor, wie im viralen HIV-1 Protein Rev oder in PKI (protein kinase A inhibitor, Wen et al., 1995) und IkB (Fritz und Green, 1996). Andere Exportsignale dienen z.T. gleichzeitig als Importsignale und sind 
nicht durch einheitliche Sequenzcharakteristika zu beschreiben (Michael et al., 1997; Tabernero et al., 1996; Tang et al., 1997).

Die Analyse der subzellulären Lokalisation von epitopmarkierten Xshn3 Proteinfragmenten wurde in Xenopus Oozyten analysiert. Oozyten eignen sich durch ihre Größe, die besondere Größe ihres Zellkerns und ihre gute Kultivierbarkeit zur Kartierung von Import- und Exportsequenzen. Bei dieser Methode werden radioaktiv markierte, in vitro translatierte Proteine in das Zytoplasma bzw. in den Kern von Stadium 5 bis 6 Oozyten mikroinjiziert. Zu verschiedenen Zeitpunkten nach der Injektion werden Zytoplasmen und Kerne manuell getrennt und die injizierten Proteine isoliert, gelelektrophoretisch aufgetrennt und autoradiographisch quantifiziert. Abb. 4.29A zeigt schematisch die im folgenden Versuch eingesetzten aminoterminal epitopmarkerten Xshn3 Proteinfragmente.

Für die Analyse der subzellulären Lokalisation von Xshn3 Fragmenten wurden ${ }^{35}$ S-markierte Myc-Epitop-markierte Xshn3 Proteinfragmente im TNT System in vitro hergestellt. Nach der Mikroinjektion dieser Proteine in den Zellkern bzw. in das Zytoplasma von Xenopus Oozyten wurde an drei Zeitpunkten nach der Mikroinjektion die subzelluläre Lokalisation der Fragmente bestimmt. Als Kontrolle für die Durchführung des Experimentes diente das ribosomale Protein L5, das definierte Import- und Exportsequenzen besitzt (Claussen et al., 1999; Rosorius et al., 2000). Abb. 4. 29B zeigt das Ergebnis der Experimente.

Das aminoterminale Proteinfragment (AS 1-652) befindet sich nach einer Injektion in das Zytoplasma nach 6 Stunden etwa zu 50\% im Zellkern. $24 \mathrm{~h}$ nach der Injektion sind ca. 70\% des Proteinfragmentes im Kern nachzuweisen. Das Proteinfragment wird demnach zwar deutlich aber nicht vollständig importiert. Dasselbe Proteinfragment zeigt nach Injektion in den Zellkern schwache Translokation in das Zytoplasma. 24 Stunden nach der Kerninjektion sind höchstens 10\% des Proteins aus dem Zellkern exportiert. Möglicherweise verhindert die gleichzeitige schwache Exportaktivität dieses Fragmentes eine vollständige nukleäre Akkumulation nach Zytoplasma-Injektion.

Das mittlere Fragment (AS 1076-1749) zeigt schwache Kernimport-Aktivität, aber keine Exportaktivität. Interessanterweise bildet das Fragment nach Auftrennung über eine PAGE eine unscharfe Bande. Dies deutet auf uneinheitliches Molekulargewicht der Moleküle in dieser Spur hin, was seine Ursache in der Phosphorylierung des Proteinfragmentes haben kann. Diese Vermutung konnte durch Phosphatasebehandlung der aus der Oozyte isolierten Proteine vor ihrer gelelektrophoretischen Auftrennung bestätigt werden. Die unklare Bande konnte zu einer scharfen Bande überführt werden. Der "Schmier" findet sich bereits zum Zeitpunkt $\mathrm{t}=0$, an dem sich das Protein maximal $10 \mathrm{~min}$ in der Oozyte befunden hatte. Zudem findet sich die phosphorylierte Form des Proteins sowohl im Zellkern als auch im Zytoplasma. Die Phosphorylierung des Fragmentes (AS 1076-1749) muss unmittelbar nach der Injektion in die Oozyten stattgefunden haben, da ein Kontrollgel des in vitro translatierten Fragmentes vor der Injektion eine einzige scharfe Bande zeigte (nicht gezeigt). Innerhalb der Sequenz dieses Proteinfragmentes (AS 10761749) befinden sich mehrere konservierte serinreiche Abschnitte, die mögliche Zielsequenzen von Kinasen darstellen. 
A

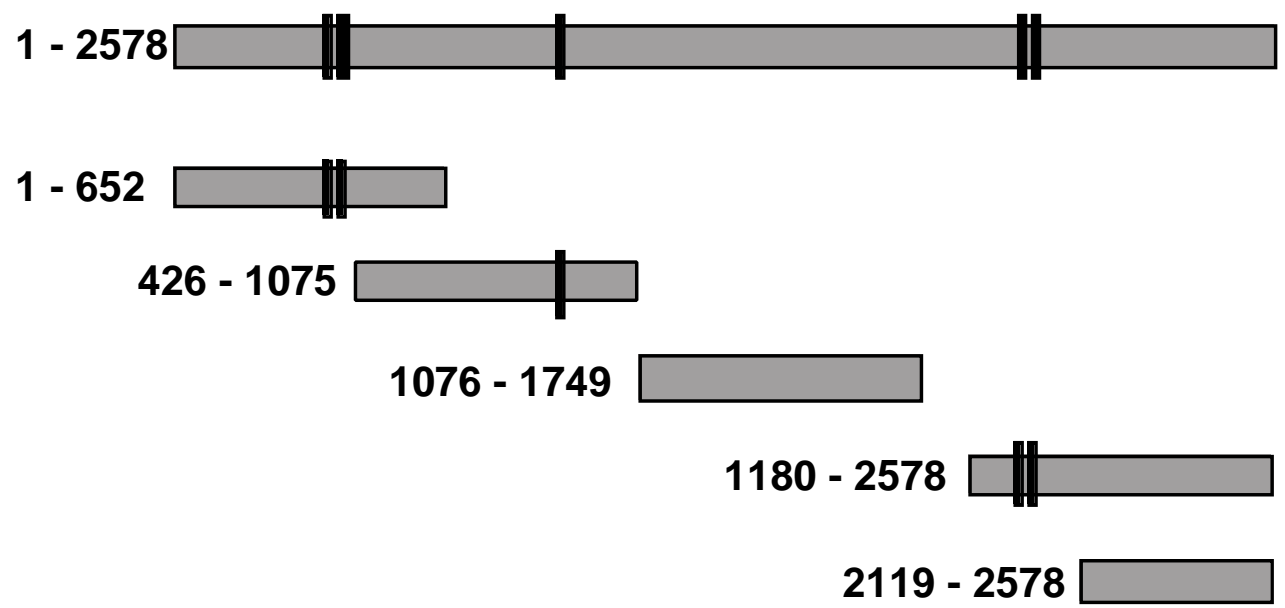

B

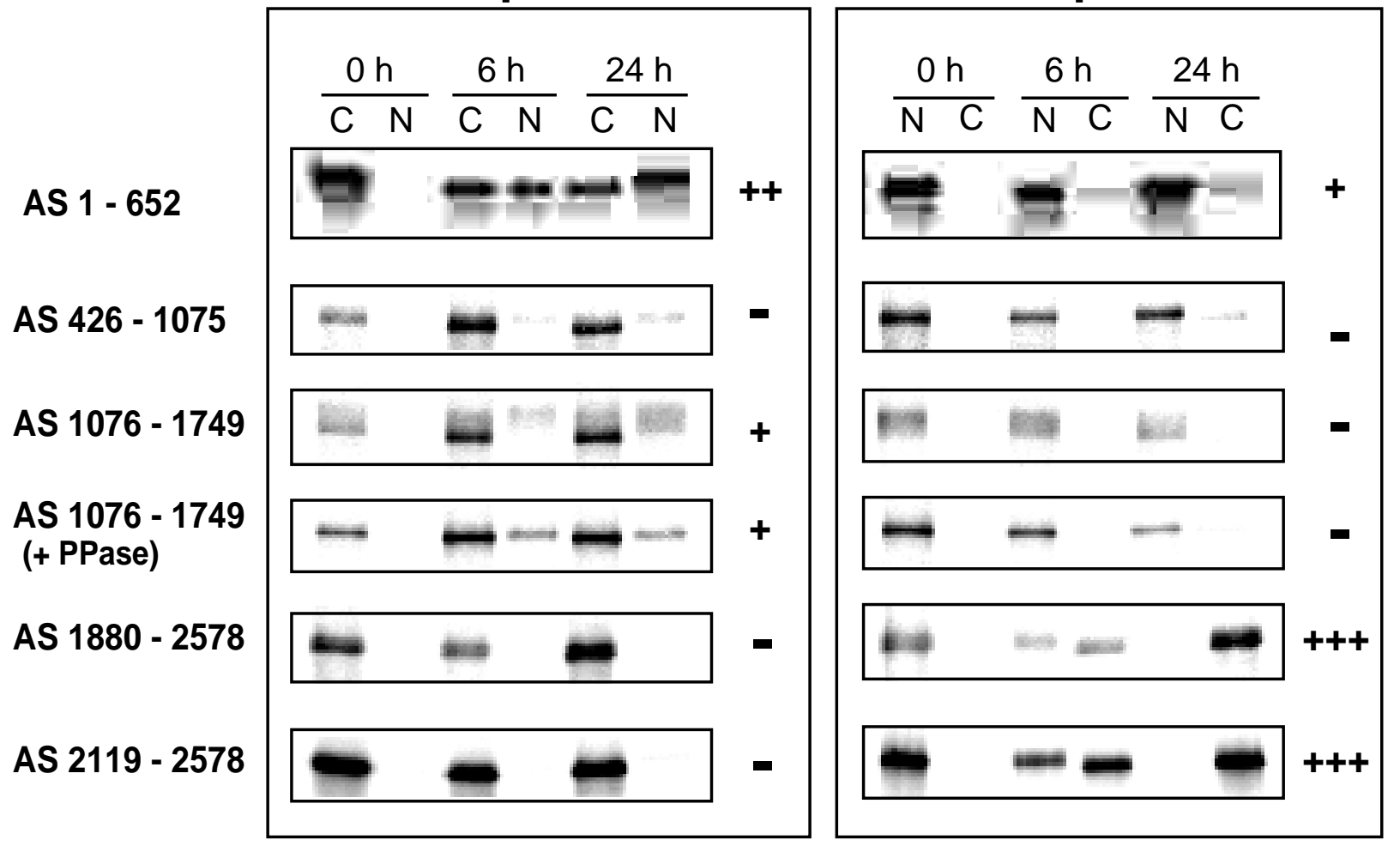

Import

Abb. 4.29: Ergebnis der Untersuchungen zur subzellulären Lokalisation von Xshn3 Proteinfragmenten in Xenopus Oozyten. (A) Schematische Darstellung der Xshn3 Proteinfragmente, deren subzelluläre Lokalisation in Xenopus Oozyten untersucht wurde. Vertikale Balken stellen die Position der Zinkfinger-Domänen dar. Die Zahlen bezeichnen die Aminosäurebereiche der Fragmente. Zusätzlich waren die Fragmente aminoterminal Mycepitopmariert. (B) Subzelluläre Lokalisation von Xshn3 Proteinfragmenten in Xenopus Oozyten. In vitro translatierte, Myc-Epitop- und radioaktiv markierte Fragmente des Xshn3 Proteins wurden in das Zytoplasma bzw. in den Zellkern von Oozyten des Stadiums 5 bis 6 mikroinjiziert. Sofort, nach $6 \mathrm{~h}$ oder $24 \mathrm{~h}$ wurden Kern (N) und Zytoplasma (C) von je 10 Oozyten manuell voneinander getrennt, die injizierten Proteine durch Immunpräzipitation aufgereinigt und in einer SDSGelelektrophorese aufgetrennt. Das Gel wurde gegen eine Autoradiographieplatte exponiert. PPase, $\lambda$-Phosphatase 
Zwei Proteinfragmente (AS 1880-2578 und AS 2119-2578) decken den Carboxyterminus von Xshn3 ab. Beide Fragmente werden nicht in den Zellkern importiert aber vollständig exportiert.

Xshn3 besitzt in der Xenopus Oozyte klar definierte Import- und Exportaktivitäten, die in weit voneinander entfernten Regionen des Proteins lokalisiert sind. Es wurde daher innerhalb der Xshn3 Peptid-Primärsequenz nach Elementen gesucht, die mögliche Import- oder Exportsignale darstellen könnten.

Innerhalb des aminoterminalen, importierten Proteinfragmentes konnte eine Signalsequenz identifiziert werden, die dem basischen SV40- oder Nukleoplasmin-Typ eines Importsignals entspricht. Es finden sich in der Region weitere basische Aminosäuren, insgesamt bei AS 46-68. Die Sequenz ist: KGVKRKKIVTENHLKKIPKSPLR. Die basischen Aminosäuren sind hervorgehoben, das NLS des SV40-Typs ist doppelt unterstichen. Diese Sequenz ist innerhalb der HIV-EP1 Gruppe von Vertebraten Proteinen weitgehend konserviert (vgl. Abb. 4.12).

Das zweite untersuchte Proteinfragment (AS 426-1075) überlappt in seinem Aminoterminus über einen Bereich von 226 Aminosäuren mit dem Fragment (AS 1-652). Dieses zweite Proteinfragment zeigt weder Export- noch Importaktivität. Dies bestätigt die Vermutung, dass die für den Import verantwortliche Signalsequenz aus dem Fragment (AS 1-652) in dessen Aminoterminus vor AS 426 liegt.

Im Fragment (AS 426-1075) konnte ein in Vertebraten konservierter basischer Sequenzabschnitt der Sequenz RKRRKMK (AS 988-994) identifiziert werden. Diese Sequenz enthält eine ImportKonsensussequenze des SV40 Typs (KK/RXK/R). Das Xshn3 Fragment zeigt dagegen kaum Importaktivität in der Xenopus Oozyte. Im Xshn3-Fragment AS 1076-1749 findet sich ebenfalls ein putatives NLS bei AS 1225-1234. Hier, in der Sequenz KLPPKKKRIR, überlappen zwei Kernlokalisationssignale des SV40 Typs. Das diese Sequenz enthaltende Proteinfragment wird in der Oozyte schwach importiert.

Die beiden carboxyterminalen Xshn3 Proteinfragmente werden in der Oozyte vollständig exportiert. Ein mögliches Exportsignal wird daher im Überlappungsbereich beider Fragmente vermutet.

Charakteristische Exportsignale des Rev-Typs enthalten eine Leucin-reiche Sequenz, die vier charakteristisch angeordnete Leucin-Seitenketten der Sequenz LXXLTL (Übersichten in Görlich und Kutay, 1999; Kaffmann und O’Shea, 1999). Derartige Signale kommen in den HIV1 und -2 Rev Proteinen vor und im Protein TFIIIA (Sequenzvergleich in Fridell et al., 1996), sowie in den Proteinen PKI (vgl. Wen et al., 1995) und IאB (Haskill et al., 1991). Das genannte Motiv ist allerdings oft degeneriert oder in anderen Proteinen gar nicht zu finden. Im Carboxyterminus von Xshn3 findet sich kein derartiges Motiv, jedoch die Sequenz LTL. Eine Gegenüberstellung der Exportsignale des Rev-Typs verschiedener Proteine ist in Abb. 4.30 dargestellt. Ebenfalls dargestellt ist ein ähnlicher Sequenzbereich aus dem Xshn3 Protein. 


\begin{tabular}{|lll|}
\hline HIV1 Rev (hs) & QLPPLERLTLD & -84 \\
HIV2 Rev (hs) & TIQHLQGLTIQ & -82 \\
TFIIIA (xl) & NGSLLDKLTIQ & - C-term \\
TFIIIA (ba) & PLPVLENLTLK & - C-term \\
PKI (hs) & ALPPLERLTLE & -42 \\
IkB (hs) & IQQQLGQLTLE & -275 \\
Xshn3 (xl) & PQIHPSGLTLN & -2389 \\
\hline
\end{tabular}

Abb. 4.30: Gegenüberstellung von Kernexportsignalen des Rev-Typs verschiedener Proteine.

(Sequenzvergleiche aus Fridell et al., 1996; Wen, 1995; Haskill et al., 1991). Darunter eine ähnliche Sequenz aus dem Carboxyterminus von Xshn3 dargestellt. Rechts ist die Position der letzten Aminosäure innerhalb des Gesamtproteins angegeben.

Exportsignale besitzen jedoch nicht immer einheitliche Sequenzcharakteristika. Gelegentlich finden sich hydrophobe, Leucin-reiche Sequenzen als Exportsignale (Michael et al., 1997; Tabernero et al., 1996; Tang et al., 1997). Innerhalb des Carboxyterminus von Xshn3 findet sich ein konservierter, hydrophober Bereich von 21 Aminosäuren, der vier Leucine und sechs Isoleucine enthält. Die Sequenz ist: IPGLQILNIALPTLIPSISPI (AS 2410-2430). Eine ähnliche Sequenz ist nicht als Kernexportsignal bekannt. Es lässt sich nicht voraussagen, ob hier ein Exportsignal lokaliert ist.

Die Versuche gaben weiterhin Hinweise auf eine Phosphorylierung des Xshn3 Proteins in seinem mittleren Bereich. Wie in Kap. 4.1.3 dargestellt, ist Xshn3 reich an putativen Phosphorylierungsstellen für verschiedene Proteinkinasen. Innerhalb des in der Oozyte offensichtlich phosphorylierten Sequenzbereiches befindet sich ein auffällig Serin-reicher Sequenzabschnitt der Sequenz SSAESSFDSTISRSLSRESSLSRASSFSAS (AS 1241-1270, putative Phosphorylierungsstellen rot). Dieser Bereich kann durch mehrere Proteinkinasen modifiziert werden: CaMII (4x), CKI (5x), GSK3 (6x) und PKA (3x) (nach SIB: www.expasy.org). Eine Funktion dieser möglichen Modifikationen ist nicht abzuleiten.

Eine Zusammenfassung der Ergebnisse ist in Abb. 4.31 dargestellt

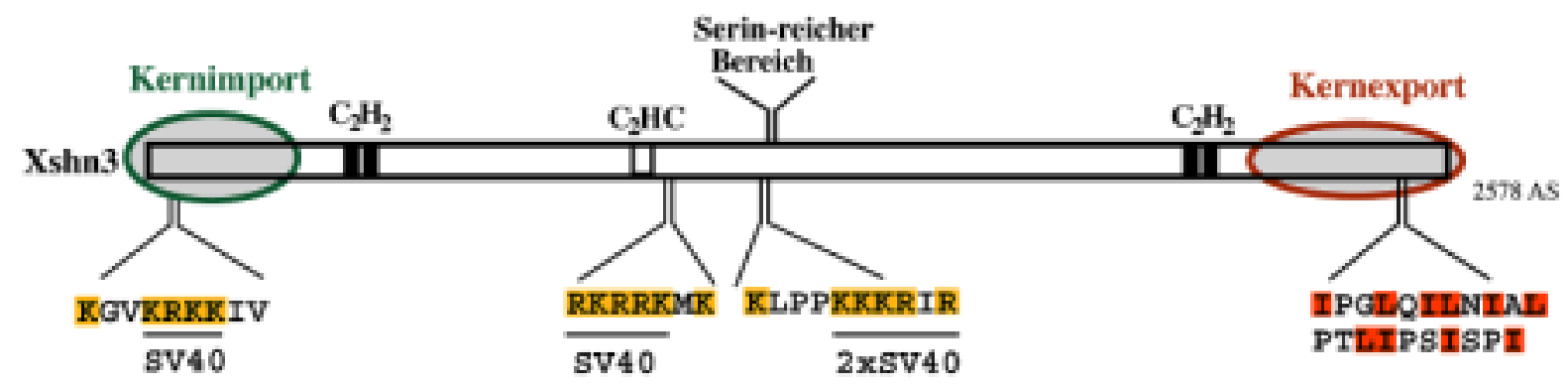

\footnotetext{
Abb. 4.31: Ergebnisse der Untersuchung zur subzellulären Lokalisation von Xshn3 Proteinfragmenten in Xenopus Oozyten. Der Querbalken stellt die Primärsequenz von Xshn3 mit Position der Zinkfinger Domänen (Kästen) dar. Regionen mit Import- bzw. Exportaktivität sind durch Ovale gekennzeichnet. Darunter sind mögliche Import- und Exportsignale und ihre Position innerhalb des Xshn3 Porteins dargestellt. Basische Aminosäuren sind gelb hinterlegt. NLSKonsensussignale des SV40 Typs sind gekennzeichnet. Hydrophobe Aminosäuren sind rot hinterlegt. Die Position eines Serin-reichen Bereiches ist angegeben.
} 
Es lässt sich zusammenfassen, dass einzelne Fragmente von Xshn3 in der Xenopus Oozyte klar definierte Kernimport- und -exportaktivitäten besitzen. Die möglichen Signalsequenzen hierfür sind in weit voneinander entfernten Regionen des Proteins lokalisiert. Weitere konservierte Kernlokalisationssignale des SV40 Typs im mittleren Bereich von Xshn3 zeigen in der Oozyte nur schwache Aktivität.

Für das Gesamtlängenprotein bedeuten die Import- und Exportaktivität, dass eine Lokalisation sowohl im Zellkern als auch im Zytoplasma möglich sein könnte. Denkbar ist, dass über den Phosphorylierungsstatus von Xshn3 dessen subzelluläre Lokalisation und Aktivität als Trankriptionsfaktor reguliert werden könnte.

Für das Säuger-Protein HIV-EP1 wurden Spleißvarianten beschrieben, die entweder für den aminoterminalen oder den carboxyterminalen Bereich des Proteins kodieren würden (Muchardt et al.,1992; Kantorow et al., 1993). Unterschiedliche Proteinfragmente könnten möglicherweise in unterschiedlichen Zellkompartimenten verschiedene Aktivitäten besitzen.

\subsection{Interaktion von $\mathrm{Xshn} 3$ mit Smad Proteinen}

In Drosophila vermittelt das Protein Mad die Information des extrazellulären Liganden Dpp in den Zellkern. Im Zellkern assoziiert Mad u.a. mit Schnurri, um die Expression von brinker zu reprimieren (Marty et al., 2000) und die Aktivierung des $u b x B$ Promotors zu bewirken (Dai et al., 2000). Erst kürzlich konnte gezeigt werden, dass Mad und Schnurri direkt miteinander interagieren (Udagawa et al., 2000; Dai et al., 2000), wobei eine diskrete Mad-Interaktionsdomäne innerhalb des Schnurri Proteins lokalisiert werden konnte. Diese liegt im Sequenzbereich von AS 1441-1635, welcher sich zwischen dem isolierten $\mathrm{C}_{2} \mathrm{HC}$ Zinkfinger und der zweiten Doppelzinkfingerdomäne befindet. Mad interagiert über seine MH2 Domäne mit Schnurri (Dai et al., 2000). In transfizierten COS-Zellen konnte Schnurri im Zellkern nachgewiesen werden. Eine Interaktion mit ko-transfiziertem Mad Protein zeigte in diesem System keine Abhängigkeit der Interaktion von der Aktivierung des Mad-Signalweges durch zusätzlich ko-transfizierten TkvRezeptor (Dai et al., 2000).

Wegen der hohen Konservierung der TGF $\beta$ Signalwege zwischen Vertebraten und Invertebraten wurde vermutet, dass die Schnurri-homologen Proteine HIV-EP1, -2 und -3 mit Vertebraten-Smad Proteinen interagieren. Ebenso war denkbar, dass diese Interaktion in Abhängigkeit von der Aktivierung der R-Smad Proteine stattfindet, die einen Kerntransport des heteromeren RSmad/Smad4 Komplexes bewirkt.

In den folgenden Versuchen sollte eine in vivo Interaktion zwischen dem zu HIV-EP1 homologen Protein Xshn3 und den Smad-Proteinen der Vertebraten untersucht werden. Aminoterminal MTepitopmarkierte Fragmente des Xshn3 Proteins wurden hierfür zusammen mit aminoterminal Flag-epitopmarkierten Smad Proteinen in Xenopus Embryonen überexprimiert. Den Xshn3 Proteinfragmenten wurde aminoterminal zusätzlich ein heterologes Kernlokalisationssignal (NLS) angefügt. Die untersuchten Smad Proteine Smad1 bis -7 stammten aus Xenopus, der Maus und dem Menschen (s. Kap. 2.3). Eine Vielzahl von Untersuchungen bestätigte eine funktionelle 
Konservierung der Proteine über Speziesgrenzen hinaus, z.T. sogar zwischen Xenopus und Drosophila (Newfeld et al., 1996). Zusätzlich zu den Smad Proteinen und den Schnurri Fragmenten wurden die TGF $\beta$-Liganden Aktivin bzw. BMP4 koinjiziert, um die jeweiligen RSmad Proteine maximal durch Phosphorylierung zu aktivieren. Die in vivo Interaktionen zwischen Xshn3 und Smad Proteinen in Xenopus Embryonen wurden im Gastrula Stadium untersucht, da zu diesem Zeitpunkt Smad-Proteine nachweislich auch durch endogene TGF $\beta$ Liganden aktiviert sind und die Musterbildung des Mesoderms während dieser Zeit stattfindet (Faure et al., 2000).

Abb. 4.32 zeigt schematisch die acht Xshn3 Proteinfragmente, die in die Interaktionsstudien eingesetzt wurden. Der Übersichtlichkeit halber werden die Fragmente im Folgenden als Xshn3Fragment 1 bis -Fragment 8 bezeichnet.

1

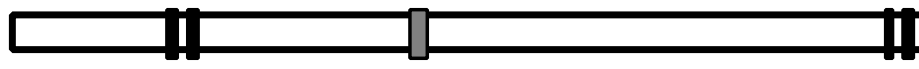

(1)
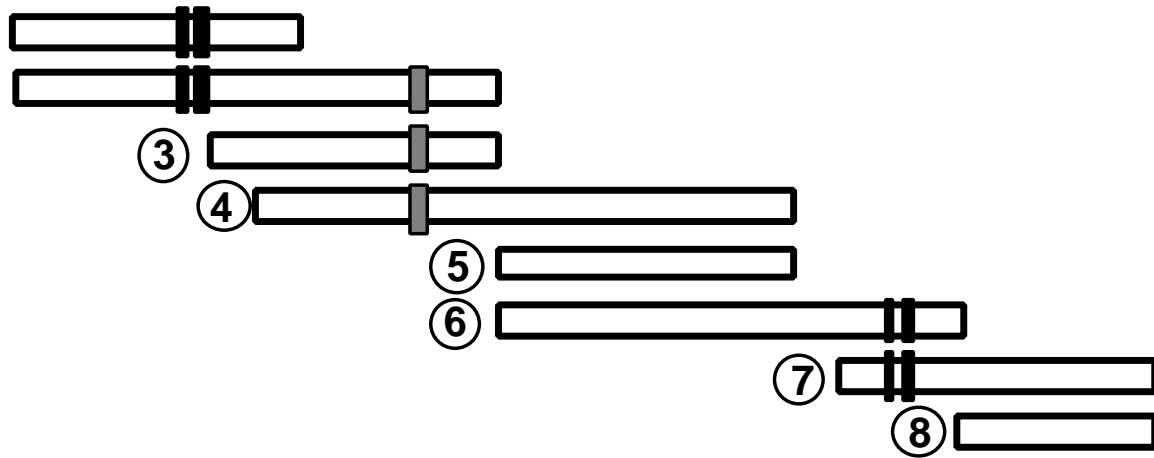

2578

AS 1-652

AS 1-1075

AS 426-1075

AS 542-1749

AS 1076-1749

AS 1076-2119

AS 1880-2578

AS 2119-2578

\begin{abstract}
Abb. 4.32: Schema der für die in vivo Interaktionsstudien mit Smad Proteinen eingesetzten Xshn3 Proteinfragmente. Schwarze Balken bezeichnen Zinkfinger des $\mathrm{C}_{2} \mathrm{H}_{2}$ Typs. Gewürfelte Balken zeigen die Position des $\mathrm{C}_{2} \mathrm{HC}$ Zinkfingers. Rechts ist die Position der Fragmente innerhalb des Gesamtproteins in Aminosäuren angegeben. Zusätzlich waren alle Fragmente aminoterminal mit einem heterologen Kernlokalisationssignal (NLS) und einem MT Epitop versehen. Zur Übersichtlichkeit werden die Fragmente im Folgenden mit Fragment 1 bis Fragment 8 bezeichnet.
\end{abstract}

\title{
4.5.1 Interaktion von Xshn3 Proteinfragmenten mit aktivierten Smad Proteinen
}

Um Interaktionen zwischen Xshn3-Fragmenten und Smad Proteinen nachzuweisen, wurden mikroinjizierte Xenopus Embryonen im Stadium NF 11 homogenisiert, eine Immunpräzipitation gegen Flag-epitopmarkerte Smad Proteine durchgeführt und kopräzipitierte MT-epitopmarkierte Xshn3 Fragmente nach einem Western Blot immunologisch nachgewiesen.

In den folgenden Versuchen wurde die Interaktion einzelner aktivierter R-Smads, Smad1, -2, -3 und -5, mit Xshn3 untersucht. Die Interaktionsstudien mit dem Ko-Smad, Smad4, und den AntiSmads, Smad6 und -7, erfolgte ohne Koexpression von TGF $\beta$ Liganden.

Als Kontrolle für eine spezifische Interaktion der Smad Proteine mit einem koinjizierten Protein wurde die Interaktion von Smad Proteinen mit FAST-1 untersucht. Dieser "winged-helix" Transkriptionsfaktor kooperiert spezifisch mit Smad2 und -3 und reguliert die Aktivität u.a. des goosecoid (gsc) Promotors (Chen et al., 1996, 1997; Yeo et al., 1999). Abb. 4.33 zeigt das Ergebnis dieser Untersuchung. 


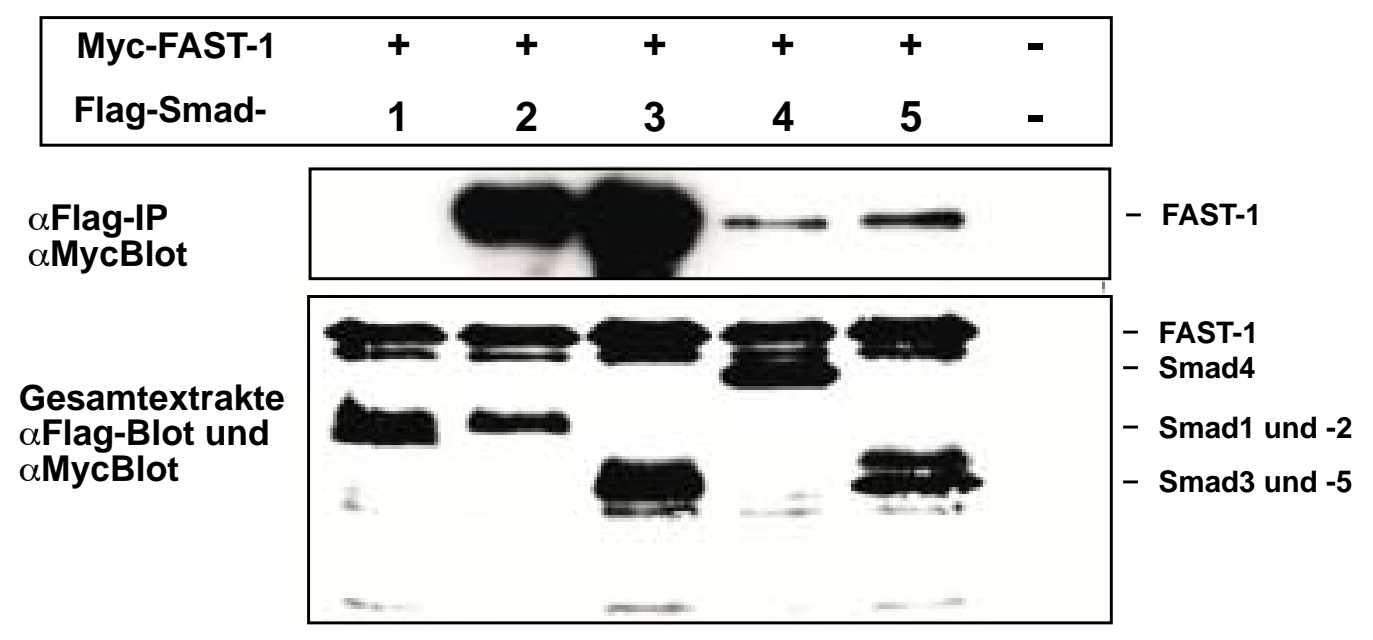

Abb. 4.33: Ko-Immunopräzipitation von MT-FAST-1 mit Smad Proteinen aus mikroinjizierten Xenopus Embryonen des Stadiums 11. Embryonen wurden im 2-Zell Stadium mit 0,7 ng FlagSmad mRNA und $1 \mathrm{ng}$ MT-FAST-1 mRNA injiziert. Im Stadium NF 11 wurden je 10 Embryonen homogenisiert und eine Immunopräzipitation gegen Flag-epitopmarkierte Smads durchgeführt. Kopräzipitiertes MT-FAST-1 wurde in einem anschließenden Immunoblot nachgewiesen. (A) Kopräzipitiertes MT-FAST-1. (B) Gesamtextrakte von je einem Embryo wurden in einem Immunoblot mit $\alpha$-Flag und $\alpha$-MT Antikörpern auf die Expression der überexprimierten Proteine hin untersucht.

Die Interaktionsstudie zwischen FAST-1 und Smad Proteinen zeigte außer starken Signalen für Smad2 und -3 auch schwache Signale für Smad4 und -5. Die letztgenannten zwei Interaktionen sind nicht aus der Literatur bekannt.

In den Untersuchungen zur Interaktion von Smad Proteinen mit Xshn3 Fragmenten konnte eindeutig und wiederholt eine Kopräzipitation einzelner Xshn3 Fragmente nachgewiesen werden. Eine Zusammenstellung der durchgeführten Experimente und der erhaltenen Ergebnisse findet sich in Abb. 4.34.

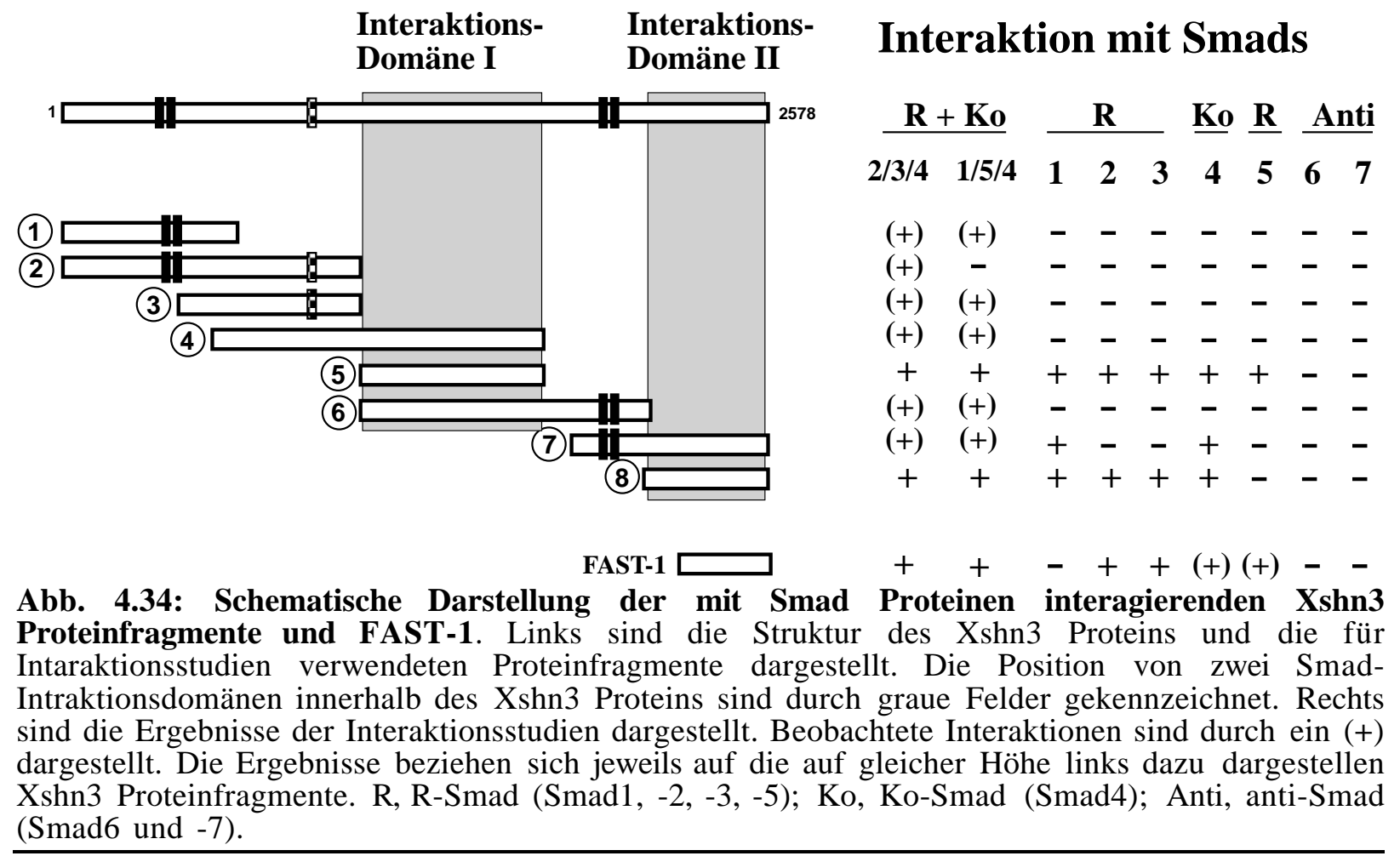


Bei den Untersuchungen der Interaktion einzelner Smad Proteine mit Xshn3 Fragmenten kopräzipitierten das Fragment 5 und das Fragment 8 eindeutig und wiederholt mit fast allen RSmads und mit Smad4. Keine Interaktion konnte zwischen Xshn3 Fragmenten und den AntiSmads Smad6 und -7 nachgewiesen werden. Abb. 4.35 zeigt beispielhaft die Untersuchung der Interaktion von Flag-Smad5 mit den NLS-MT-Xshn3 Fragmenten 1-8. Als Kontrolle diente hier wieder FAST-1, das auch hier, wie in Abb. 4.33 gezeigt, mit Smad5 kopräzipitierte.

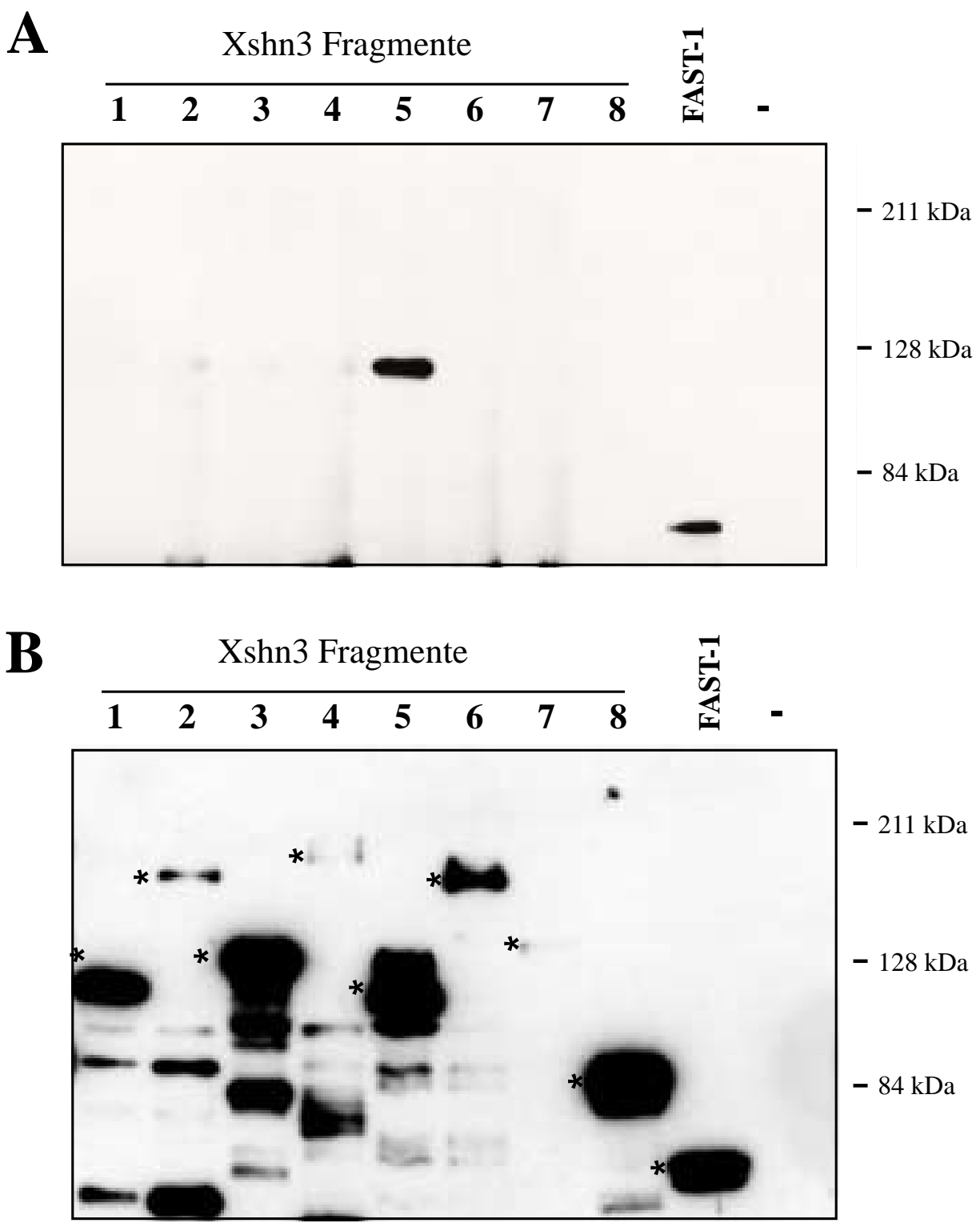

Abb. 4.35: Nachweis der in vivo Interaktion von Xshn3 Proteinfragmenten mit aktiviertem Smad5. 1-4 ng NLS-MT-Xshn3-Fragment mRNA oder MT-FAST-1 mRNA und 0.7 ng Flag-Smad mRNA wurden in beide Blastomere von Xenopus 2-Zell Stadien mikroinjiziert. (A) Im Stadium NF 10.5-11 wurde auf dem Extrakt von je 10 Embryonen eine Ko-Immunopräzipitation gegen Flagepitopmarkiertes Smad5 durchgeführt. In einem Immunoblot wurde kopräzipitiertes MT-Xshn3 bzw. MT-FAST-1 nachgewiesen. (B) Je 7 Embryonen wurden homogenisiert und das Äquivalent eines Embryos einem Immunoblot gegen MT-epitopmarkertes Xshn3 bzw. FAST-1 unterzogen.

Innerhalb der Versuche trat eine gewisse Varianz der Ergebnisse auf. Nachgewiesene Interaktionen konnten nicht in jedem Experiment bestätigt werden. Ein möglicher Grund hierfür könnte in der relativen Größe der Xshn3-Proteinfragmente liegen, die zwischen 60 kDa und 144 
kDa lag. Komplexe aus größeren Proteinen können in Ko-Immunopräzipitationen als grundsätzlich weniger stabil angesehen werden als Komplexe kleinerer Proteine.

So konnten keine Komplexe aus Xshn3-Fragment 4 und -6 mit Smad5 nachgewiesen werden, obwohl beide Fragmente mit dem Fragment 5 überlappen, welches selbst kopräzipitierte. Eine weitere Ursache für eine erschwerte Kopräzipitation der größeren Fragmente könnte auch in der geringeren Intensität ihrer Expression im Xenopus Embryo zu finden sein. In Abb. 4.35 ist zu erkennen, dass in Gesamtextrakten injizierter Embryonen die großen Fragmente in offensichtlich geringerer Konzentration vorlagen. Eine gleichmäßige Expressionsstärke aller Xshn3 Fragmente konnte nicht in allen Fällen durch Injektion größerer Mengen der für die größeren Fragmente kodierenden mRNAs ausgeglichen werden.

Aufgrund der geringeren Expressionsstärke der größeren Xshn3 Fragmente und aufgrund der geringeren Stabilität von Komplexen größerer Proteine kann vermutet werden, dass in den gewählten Versuchsbedingungen eine Interaktion der Xshn3-Fragmente 4 und -6 mit Smad5 nicht nachzuweisen war. Dasselbe gilt für die Interaktion der Fragmente 4 und 6 mit den anderen RSmads und mit Smad4.

Im Verlauf mehrerer Versuchsreihen fiel auf, dass das Xshn3-Proteinfragment 7, welches die carboxyterminale Doppelzinkfinger Domäne sowie den Smad-Interaktionsbereich aus Fragment 8 umfasst, nur selten in Gesamtextrakten injizierter Embryonen nachzuweisen war. Bereits während der Aufarbeitung der Embryonen im Gastrula Stadium fiel auf, dass die mit Xshn3-Fragment 7 mRNA injizierten Embryonen überdurchschnittlich häufig Gastrulationsdefekte zeigten und starben. Bereits vergleichsweise geringe Mengen der mRNA dieses Fragmentes (1 ng) führten zum Zelltod, was den Nachweis der Interaktion mit Smad Proteinen erschwerte. Die Kombination der Smad-Interaktionsdomäne oder anderer im Carboxyterminus gelegener Proteindomänen mit der DNA-bindenden Zinkfinger Domäne vermittelten dem Protein möglicherweise zusätzliche Eigenschaften, die sich als starke Beeinträchtigung der Gastrulationsbewegungen im frühen Embryo auswirkten und zum Zelltod führen können (vgl. hierzu Kap. 4.6).

Es lässt sich zusammenfassen, dass die Xshn3-Proteinfragmente 5 und 8 in vivo mit aktivierten RSmad Proteinen und mit Smad4 interagieren. Keine Interaktion konnte zwischen Fragment 8 und Smad5 sowie zwischen den antagonistisch wirkenden Smads 6 und -7 und den Xshn3 Proteinfragmenten detektiert werden.

\subsubsection{Interaktion von Xshn3 Proteinfragmenten mit Komplexen aktivierter Smad Proteine}

Rezeptor-aktivierte R-Smad Proteine bilden einen Komplex mit dem Ko-Smad Smad4, mit dem sie gemeinsam in den Zellkern importiert werden. In diesen Komplexen kooperieren die Aktivinvermittelnden R-Smads -2 und -3, bzw. die BMP-vermittelnden Smads -1 und -5 mit Smad4. Da die in vivo Aktivität von Smad Proteinen auf einer Kooperation von R-Smads mit Smad4 beruht, sollte untersucht werden, ob Xshn3-Fragmente auch mit Komplexen aktivierter Smad Proteine interagieren. $\mathrm{Zu}$ diesem Zweck wurden Xshn3-Fragmente zusammen mit mehreren Smad Proteinen und den aktivierenden Liganden in Xenopus Embryonen überexprimiert und eine Ko- 
Immunopräzipitation versucht. Diese Versuche sollten die in vivo Situation aktivierter Smad Komplexe reflektieren.

Nach einer Kopräzipitation von Xshn3-Fragmenten mit Smad2, -3 und -4 konnten alle acht Xshn3 Fragmente im Western Blot detektiert werden (Abb. 4.36). Fragment 5 und 8 zeigten auch hier die stärksten Interaktionen mit den Smad Komplexen, was das Vorhandensein von SmadInteraktionsdomänen in diesen Fragmenten unterstreicht. Weiterhin wurden die mit den Fragmenten 5 und 8 überlappenden größeren Proteinfragmente 4 und 6 ebenfalls kopräzipitiert. Das Xshn3-Fragment 7 verursachte in diesem Experiment kein Absterben der Embryonen, so dass eine Kopräzipitation auch mit diesem Fragment gelang.

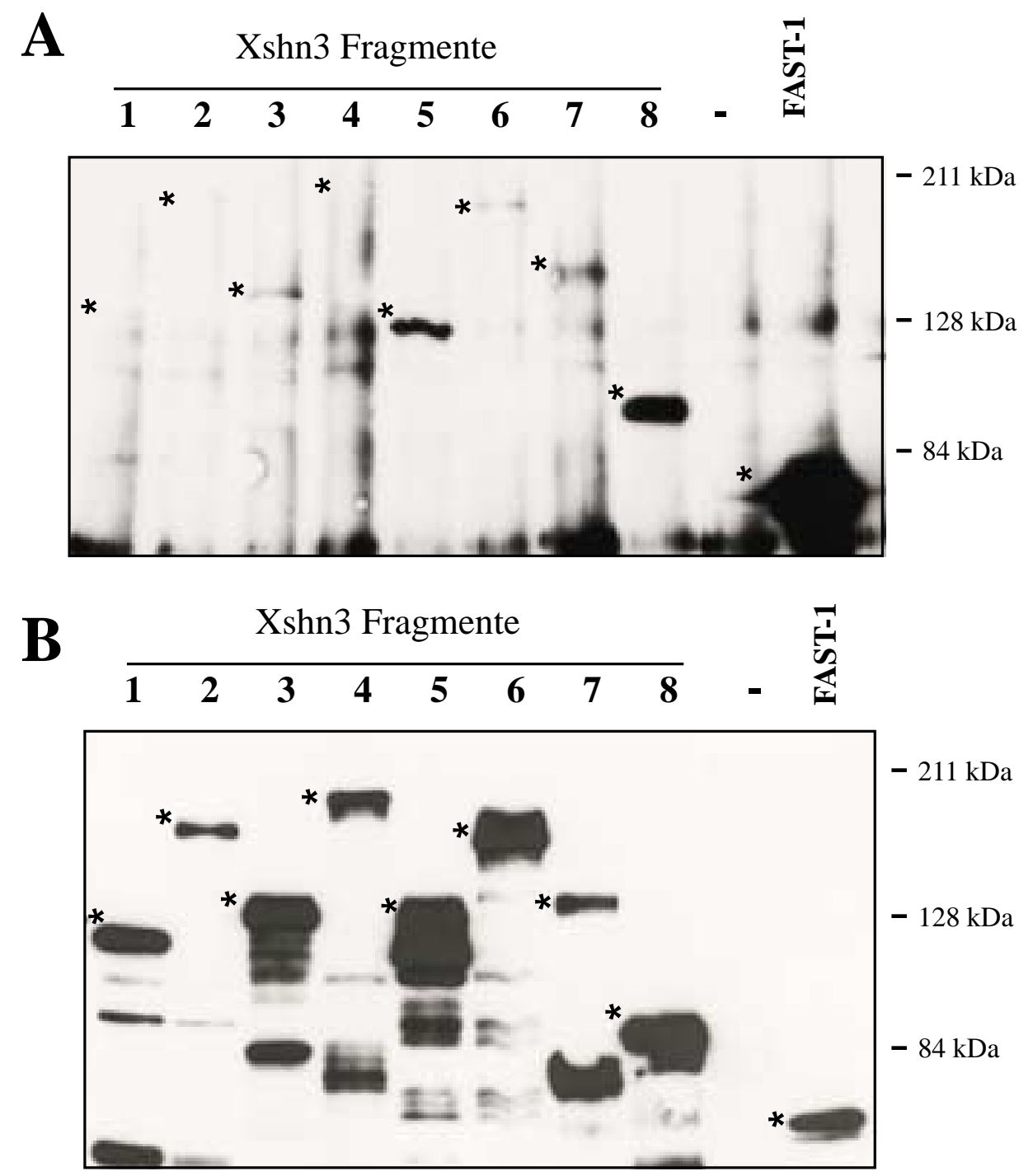

\footnotetext{
Abb. 4.36: Nachweis der in vivo Interaktion von Xshn3 Proteinfragmenten mit aktivierten Smad-Komplexen aus Smad2, -3 und 4. 2-3 ng NLS-MT-Xshn3-Fragment mRNA, 0.7 ng FlagSmad mRNA und $0.5 \mathrm{pg}$ Activin mRNA wurden in beide Zellen von 2-Zell Embryonen injiziert. Im Stadium 11 wurden je 10 Embryonen homogenisiert und eine Immunopräzipitation gegen Flagepitopmarkierte Smads durchgeführt. Kopräzipitierte MT-Xshn3 Fragmente wurden in einem anschließenden Immunoblot nachgewiesen. Als Kontrolle diente das MT-epitopmarkierte Protein Fast-1, welches mit Smad2 interagiert. (A) Ergebnis der Ko-Immunpräzipitation. Banden für kopräzipitierte Proteinfragmente sind durch Sterne markiert. Rechts ist die Proteingröße von Markerproteinen angegeben. (B) Immunoblot gegen die MT-epitopmarkierten Xshn3 Fragmente und MT-Fast-1 aus Gesamtextrakten injizierter Embryonen. 7 injizierte Embryonen wurden wie in (A) homogenisiert und das Äquivalent eines Embryos in einem Western Blot analysiert. Banden der Xshn3 Proteinfragmente sind durch Sterne markiert.
} 
Es fielen hier weiterhin die deutlich erkennbaren Signale der Xshn3 Fragmente 1, 2 und 3 in Abb. 4.36 auf. Eine Interaktion mit Smad Proteinen war für diese Fragmente bisher nicht nachgewiesen worden. Die drei Fragmente überlappen miteinander über einen Bereich von 227 Aminosäuren. Möglicherweise liegt in diesem Bereich carboxyterminal der ersten Doppelzinkfinger Domäne eine weitere, mit Smad Proteinen mit geringerer Affinität interagierende, Proteindomäne, die in den bisher dargestellten Versuchen nicht nachgewiesen werden konnte.

Eine weitere Erklärungsmöglichkeit ergäbe sich aus dem Versuchsansatz, der einen Nachweis einer in vivo Interaktion zwischen den Proteinen anstrebte. Die untersuchten Xenopus Embryonen enthielten alle während der Musterbildung des Mesoderms benötigten endogenen Proteine und Faktoren. Es ist daher denkbar, dass die Interaktion zwischen aktivierten Komplexen aus Smad Proteinen und Xshn3-Fragmenten durch Assoziation von weiteren Proteinen stabilisiert wurde und dies eine Kopräzipitation und Transkriptionsfaktoren erleichterte.

Weiterhin ist denkbar, dass vermittelnde Kofaktoren nur an Smad-Komplexe aus R-Smads plus Ko-Smad binden und nicht Einzel-Smads, und darüber eine indirekte Assoziation der Xshn3 Fragmente 1, 2 und 3 mit den Smad-Komplexen im Embryo zustande kam. Da Smads mit einer Vielzahl von Proteinen kooperieren (vgl. Einleitung), ist eine Bildung von Xshn3-enhaltenden Proteinkomplexen höherer Ordnung in Xenopus Embryonen nicht auszuschließen.

Es fiel weiterhin auf, dass auch FAST-1 im Komplex aus Smad2, -3 und -4 sehr viel stärker kopräzipitierte als mit Smad2 oder -3 allein. Auch dies ist ein Hinweis auf eine Kooperativität der Smad Proteine und zeigt, dass in vivo Komplexe aus Smads die Grundlage für Interaktionen mit Kofaktoren bilden könnten.

Die Position der Smad-Interaktionsdomänen innerhalb von Xshn3 ist in Abb. 4.37 dargestellt.

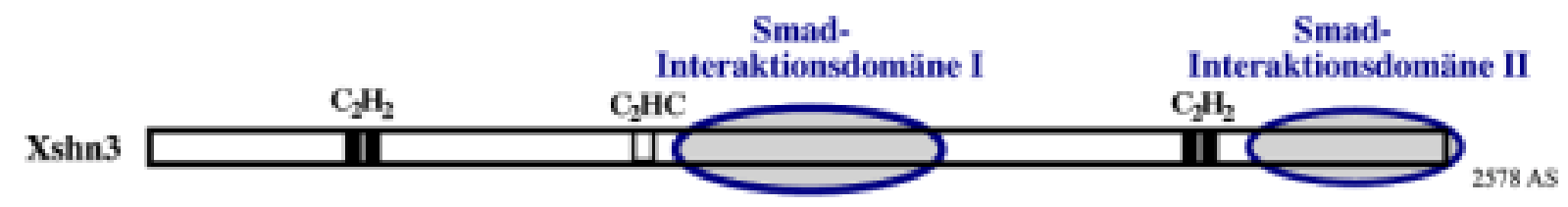

Abb. 4.37: Schematische Darstellung von Xshn3 und der Position ermittelter SmadInteraktionsdomänen. Der lange Querbalken stellt die Primärsequenz von Xshn3 dar. Ovale kennzeichnen die Proteinregionen, die in vivo mit R-Smad Proteinen und mit Smad4 interagieren.

Zusammenfassend zeigen die Ergebnisse, dass sich epitopmarkierte Xshn3 Proteinfragmente in vivo im Komplex mit R-Smad Proteinen und mit Smad4 nachweisen lassen. Zwei interagierende Bereiche lassen sich im Xshn3 Protein beschreiben. Sie liegen im mittleren Bereich des Proteins bei AS 1076-1749 (Fragment 5) und bei AS 1880-2578 (Fragment 8). Die genannten Proteinfragmente kopräzipitieren effektiver mit Komplexen aus R-Smads mit Smad4 als mit RSmads oder Smad4 allein. Sequenzvergleiche der Smad-Interaktionsbereiche zeigen keine Sequenzverwandtschaft zur Mad-Interaktionsdomäne im Drosophila Schnurri Protein. 


\subsubsection{Abhängigkeit der Xshn3-Smad Interaktion von der Aktivität des Smad Signalweges}

Die Fähigkeit von R-Smad Proteinen, Komplexe mit Transkriptionsfaktoren einzugehen, setzt eine Rezeptor-regulierte Smad-Phosphorylierung voraus. Im folgenden Versuch sollte ermittelt werden, ob auch die Assoziation von Smad Proteinen mit Xshn3 Fragmenten von der Aktivierung der Smad Proteine abhängt. Hierzu wurden mit den Smad Proteinen Aktivatoren oder Inhibitoren ihrer Phosphorylierung durch die Rezeptoren koinjiziert und möglicher Interaktion mit einzelnen Xshn3 Proteinfragmenten in einer Ko-Immunopräzipitation untersucht. Als Aktivator der Phosphorylierung von Smad1 diente der Ligand BMP4, für eine Aktivierung von Smad2 wurde Activin koinjiziert. Für eine Inhibition der Smad1-Phosphorylierung wurde ein kinasedefizienter BMP4-Rezeptor koinjiziert. Ein solches funktionsunfähiges Protein soll nach Überexpression im Embryo die Funktion des endogenen Proteins quantitativ übervorteilen und "dominant-negativ" wirken. Analog hierzu sollte ein kinasedefizienter Aktivin Rezeptor die Phosphorylierung von Smad2 unterbinden. Als weitere Inhibitoren der Aktivität von R-Smads wurden die Anti-Smads Smad6 und -7 koinjiziert. Diese verhindern die Aktivierung von R-Smads, indem sie stabil mit den Rezeptor-Kinasen interagieren und die Komplexbildung von R-Smads mit Smad4 unterbinden.

Folgende Interaktionen wurden getestet:

\begin{tabular}{|c|c|c|c|c|c|c|c|}
\hline Xshn3 & Smad & \multicolumn{6}{|c|}{ Aktivatoren und Repressoren } \\
\hline NLS-MT-Xshn3 & Flag-Smad & BMP4 & dn-BR & Aktiv. & $\operatorname{dnAR}$ & Smad6 & Smad7 \\
\hline NLS-MT-Xshn3 & Flag-Smad1 & + & + & & & & \\
\hline Fragm. 5 & Flag-Smad1 + Flag-Smad4 & + & + & & & + & + \\
\hline & Flag-Smad2 & & & + & + & + & + \\
\hline & Flag-Smad $2+$ Flag-Smad 4 & & & + & + & + & + \\
\hline & Flag-Smad3 & & & + & + & & \\
\hline & Flag-Smad3 + Flag-Smad4 & & & + & + & & \\
\hline NLS-MT-Xshn3 & Flag-Smad1 & + & + & & & & \\
\hline Fragm. 8 & Flag-Smad1 + Flag-Smad4 & + & + & & & & \\
\hline & Flag-Smad2 & & & + & + & + & + \\
\hline & Flag-Smad2 + Flag-Smad4 & & & + & + & & \\
\hline & Flag-Smad3 & & & + & + & & \\
\hline & Flag-Smad3 + Flag-Smad4 & & & + & + & & \\
\hline
\end{tabular}

Tab. 4.4: Auflistung der durchgeführten Untersuchungen zur Abhängigkeit der Interaktion von Xshn3 Fragmenten mit Smad Proteinen von der Aktivität des Smad Signalweges. In einer Reihe dargestellt sind die Xshn3 Fragmente und die mit ihnen koinjizierten Smad Komponenten. Zu diesen wurden einzeln die rechts davon angegebenen Aktivatoren oder Inhibitoren der Smad Signalwege koinjiziert. Folgende mRNA-Mengen wurden injiziert: NLS-MT-Xshn3: 2 ng; Smad1, 2,-3: $0.7 \mathrm{ng}$; BMP4: $0.1 \mathrm{ng}$; dnBR (dominant-negativer BMP-Rezeptor): $2 \mathrm{ng}$; Activ. (Activin): $0.01 \mathrm{ng}$ : dnAR (dominant-negativer Activin Rezeptor): $2 \mathrm{ng}$; Smad6, -7: $0.5 \mathrm{ng}$. 
In wiederholten Versuchen zeigte sich in keinem Fall ein Einfluss der koinjizierten Aktivatoren oder Inhibitoren des Smad Signalweges auf die Menge der mit dem epitopmarkierten Smad Protein kopräzipitierten NLS-MT-Xshn3 Fragmenten. Beispielhaft sind die Ergebnisse einiger Untersuchungen in den Abb. 4.38 dargestellt.
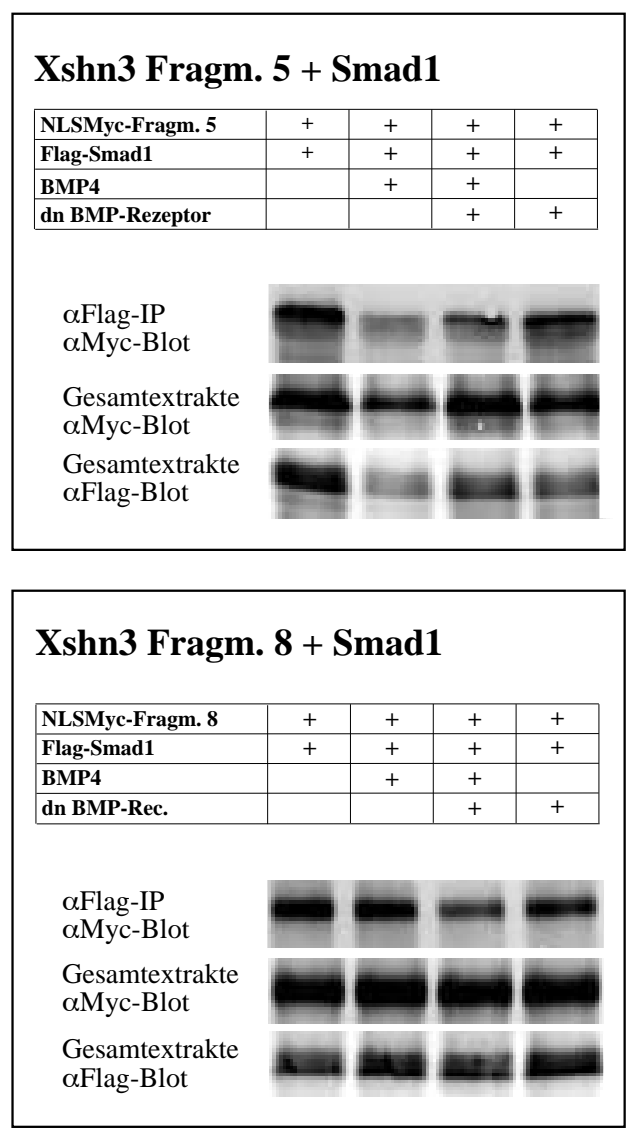
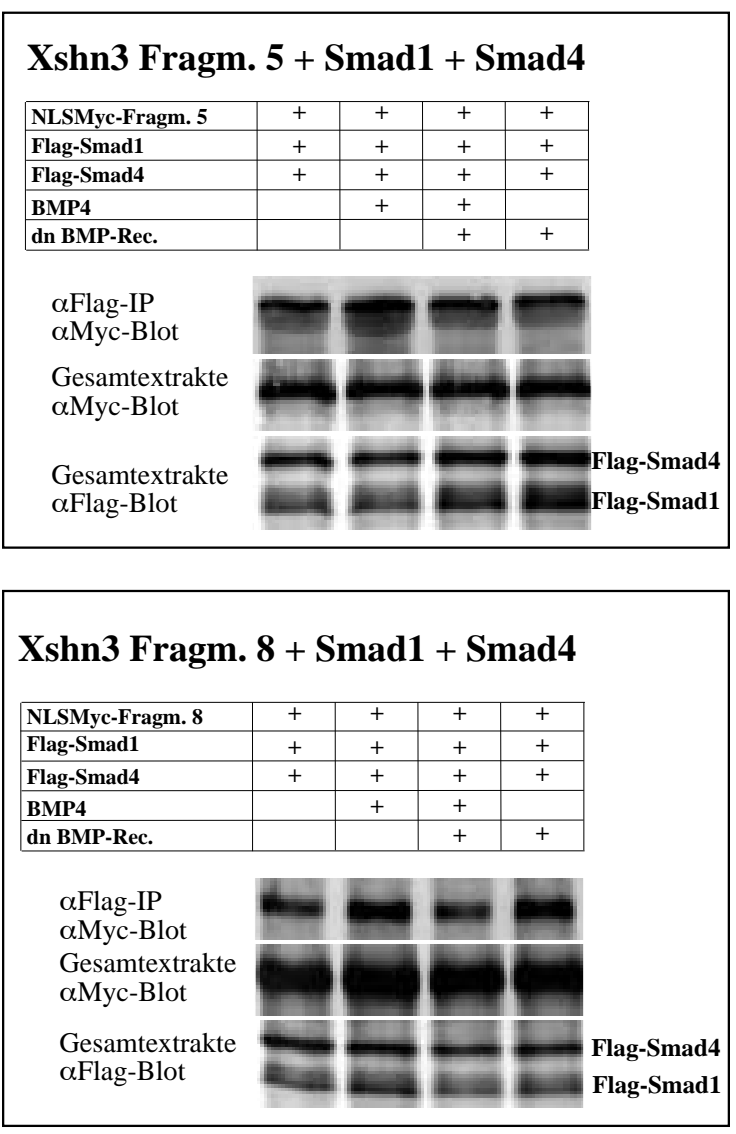

Abb. 4.38: Untersuchung zur Abhängigkeit der in vivo Interaktion von Xshn3 Proteinfragmenten mit Smad Proteinen von der Aktivität des Smad Signalweges. In der Legende $\mathrm{zu}$ Tab. 4.3 angegebene mRNA-Mengen wurden in Xenopus zwei-Zell Stadien injiziert und die Interaktion von Xshn3 Proteinfragmenten mit Smad Proteinen durch Ko-Immunopräzipitation im Stadium NF 11 nachgewiesen.

In Abb. 4.38 ist zu erkennen, dass eine Koinjektion z.B. von Liganden der TGF $\beta$ Familie oder von dominant-negativen Rezeptoren keinen Einfluss auf die Menge kopräzipitierten Xshn3 Proteins hatte. Eine mögliche Ursache könnte in der massiven Überrepräsentierung der injizierten Proteine in den Zellen des Embryos liegen. Dies könnte die zellulären Transportmechanismen überfordern, so dass es zu einer Verteilung der Proteine sowohl im Zytoplasma als auch im Zellkern käme. Durch einfache Überexpressionsstudien ist bekannt, dass die in vivo Aktivität von Smad Proteinen durch einfache Überexpression nachvollzogen werden kann (z.B. Baker und Harland, 1996). Es ist daher möglich, dass die in den eigenen Versuchen konstitutiv erscheinende Interaktion von Smad Proteinen mit Xshn3 Fragmenten nicht die tatsächliche Situation der endogenen Proteine widerspiegelt. 


\section{6 Überexpressionsexperimente mit Xshn3 Fusionskonstrukten im Xenopus Embryo}

Die Ergebnisse der Untersuchungen zur Interaktion von Xshn3 Proteinfragmenten mit Smad Proteinen hatten über diese Fragestellung hinaus einen Hinweis auf eine Aktivität von Xshn3 in der Musterbildung von Xenopus Embryonen gegeben. Es war aufgefallen, dass die Überexpression des Xshn3-Fragmentes 7 (AS 1880-2578) überdurchschnittlich häufig zu Gastrulationsdefekten und zum Tod der Embryonen führte (vgl. Kap. 4.5). Das Proteinfragment 7 enthält die carboxyterminale Zinkfingerdomäne sowie den Carboxyterminus von Xshn3 inklusive der hier gelegenen Smad-Interaktionsdomäne. Im Vergleich zu Fragment 7 hatte Fragment 8, welches den Smad-Interaktionsbereich ohne die Zinkfinger Domäne umfasst, keinen offensichtlichen Effekt auf die frühe Entwicklung von Embryonen. Die Ursache für die Defekte ist möglicherweise in der Kombination der Zinkfinger Domäne mit weiteren carboxyterminal gelegenen Proteindomänen, darunter auch einer Glutamat/Aspartat-reichen Domäne, zu suchen.

Die carboxyterminale Zinkfinger Domäne von Xshn3 bindet mit hoher Wahrscheinlichkeit sequenzspezifisch an DNA. Fan und Maniatis (1990) und Seeler et al. (1994) konnten zeigen, dass die aminoterminale und die carboxyterminale Zinkfinger Domäne des humanen zu Xshn3 homologen Proteins, HIV-EP1, mit gleicher Affinität spezifisch an ein Sequenzelement im Promotor des MHC H2-K $\mathrm{K}^{\mathrm{b}}$ Genes und an ähnliche Sequenzen in anderen Promotoren binden. In eigenen Versuchen konnte nicht beobachtet werden, dass eines der die aminoterminale Zinkfinger Domäne enthaltenden Xshn3 Proteinfragmente, ähnlich dem Fragment 7, zu Störungen der frühen Entwicklung von Xenopus Embryonen führte. Tanaka et al. (2000) beobachteten für das zu Xshn3 homologe Protein der Maus, dass nur die carboxyterminale Zinkfinger Domäne an den Col2A1 Enhancer band, die aminoterminale Domäne dagegen nicht. Eine besondere Funktion des Xshn3 Proteins für die musterbildenden Prozesse in Embryonen ging nach eigenen Ergebnissen offensichtlich von der carboxyterminalen Region des Proteins aus.

In den folgenden Versuchen sollte deshalb untersucht werden, welche Auswirkungen eine Überexpression der carboxyterminalen Zinkfinger Domäne im Embryo auf die Morphogenese und die Induktion von Markergenen der frühen Entwicklung hat.

Zudem sollte untersucht werden, ob Xshn3 eine Funktion als Aktivator oder als Repressor der Transkription besitzen könnte. Über das zu Xshn3 homologe Protein aus Säugern gibt es hierzu widersprïchliche Beobachtungen: Fan und Maniatis (1989) und Seeler et al. (1994) beschreiben eine Aktivierung der HIV-1 Genexpression durch HIV-EP1, während Muchard et al. (1992) dagegen keinen Effekt auf die HIV-Genexpression nach Überexpression von HIV-EP1 beobachten konnten. Für das homologe Protein der Maus berichten Tanaka et al. (2000) von einer spezifischen Repression des $\alpha 1$ (II)Kollagen Gen Enhancers durch HIV-EP1 in Prozessen der Knorpelbildung im Mausembryo. Brady et al. (1995) vermuten dagegen eine Funktion des murinen Proteins als Aktivator des $\alpha$ A Kristallin Gen Promotors.

Es ergibt sich also keine einheitliche Voraussage darüber, ob Xshn3 als Aktivator oder als Repressor der Transkription wirken könnte.

Um diese Frage in Xenopus Embryonen zu untersuchen, wurden Fusionsproteine erstellt und in Xenopus Embryonen überxprimiert. In den Fusionsproteinen wurde die carboxyterminale 
Zinkfinger Domäne von Xshn2 und von Xshn3 an eine heterologe Transkriptions-reprimierende Domäne (Drosophila engrailed, Badiani et al., 1994) oder im Vergleich dazu an eine heterologe Transaktivierungsdomäne (VP16, Cress et al. 1991) gekoppelt (s. Abb. 4.39). Ein zusätzliches Kernlokalisationssignal (NLS) sollte für eine Lokalisation der Proteine im Zellkern sorgen.

Die Fusionsproteine sollten bei Überexpression im Xenopus Embryo dominant-negativ bzw. konstitutiv-aktiv gegenüber der Funktion der endogenen Schnurri Proteine wirken, indem sie quantitativ überrepräsentiert an die DNA-Zielsequenzen der endogenen Schnurri-Proteine binden. Da die Zinkfinger Domänen zwischen den Vertebraten Schnurri Proteinen hoch konserviert sind, wurde vermutet, dass die überexprimierte Zinkfinger Domäne eines der Xshn Proteine auch an DNA-Zielsequenzen anderer Xshn Transkriptionsfaktoren bindet. Information über die spezifische Funktion einzelner Xshn Proteine konnte daher nicht erwartet werden.

Ebenfalls untersucht wurde der Effekt einer Überexpression der isolierten Zinkfinger Domäne auf die Embryognese von Xenopus.

Von besonderem Interesse bei den Untersuchungen war der Einfluss der Fusionsproteine auf die Expression von mesodermalen Markergenen, die der Steuerung durch Faktoren des TGF $\beta$ Signalweges, Activin und BMP4, unterliegen.

Im Vergleich zu den genannten Konstrukten sollte das Xshn3 Fragment 7 (AS 1880-2578) überexprimiert und phänotypische Effekte mit denen der durch die anderen Fusionsproteine erhaltenen Veränderungen verglichen werden. Abb. 4.39 zeigt schematisch die in den folgenden Versuchen verwendeten Fusionsproteine.

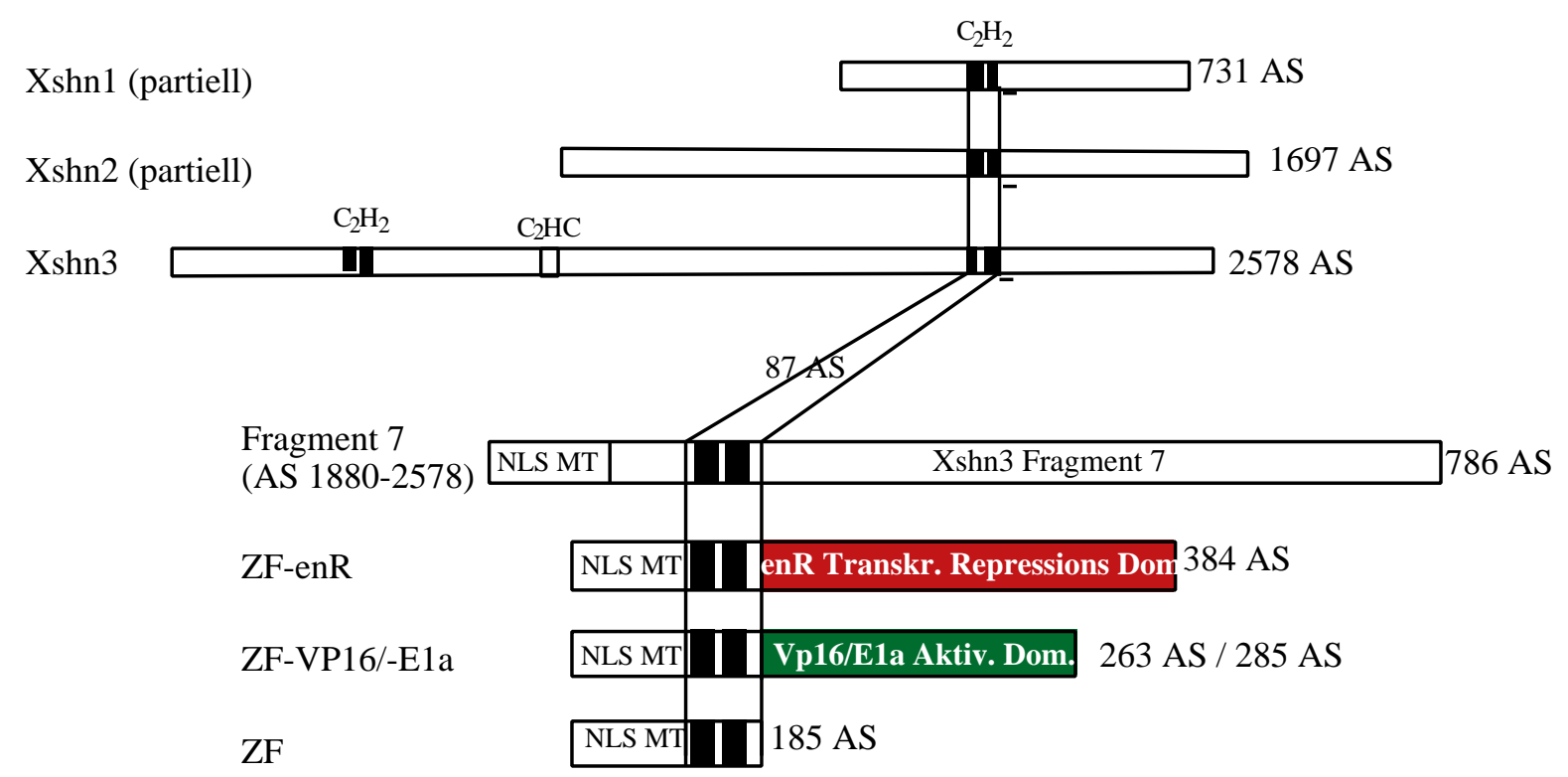

Abb. 4.39: Schema der Fusionsproteine, die durch Mikroinjektion in Xenopus Embryonen überexprimiert wurden. (NLS, Kernlokalisationssignal; MT, (6x Myc-Epitope). Die Zinkfingerdomäne von 87 Aminosäuren umfasste den Bereich GGFK-KCLE (Xshn2) bzw. GGYKKCLD (Xshn3). ZF, Zinkfinger (aus Xshn2 oder Xshn3); enR, Drosophila Engrailed Transkriptions-Repressions Domäne; VP16/E1a, virale Transaktivierungsdomänen. 


\subsubsection{Analyse der Phänotypen von mit Xshn3 Fusionskonstrukten injizierten Xenopus Embryonen}

Der Effekt einer Überexpression der genannten Fusionsproteine wurde zunächst phänotypisch untersucht. Spezifische Asymmetrien vor und während der ersten Zellteilungen von Xenopus Embryonen erlauben es, bereits im 4-Zell Stadium zukünftige Köperregionen wie dorsal, ventral, links oder rechts zu differenzieren. Eine Injektion von mRNA in beide Zellen des 2-Zell Stadiums zielt dagegen auf eine ubiquitäre Überexpression eines Proteins.

Bereits in der vorangegangenen Arbeit hatte sich ein starker Einfluss des ZinkfingerRepressorkonstruktes NLSMT-Xshn2ZF-enR auf die frühe Embryogenese gezeigt (Dürr, 1997). Sowohl eine ubiquitäre als auch eine dorsale oder ventrale Lokalisation der mRNA in Embryonen führte $\mathrm{zu}$ einer Reduktion der sich in diesen Regionen normalerweise entwickelnden Körperstrukturen. Neurale Strukturen blieben dabei z.T. erhalten. Bei ubiquitärer Verteilung des Konstruktes nahmen die Embryonen eine oval-undifferenzierte Gestalt an. Ein derartiger Embryo ist in Abb. 4.40B dargestellt.Die Ergebnisse der Überexpression von NLSMT-Xshn2ZF-enR deuteten auf eine Inhibition von dorsalisierenden und ventralisierenden Mesoderm-induzierenden Signalwegen hin. Es ließ sich eine Inhibition vom Activin- und BMP-Signalweg vermuten.

Um die Frage zu beantworten, ob Xshn3 als Aktivator oder Repressor der Transkription wirken könnte, wurden die in Abb. 4.39 dargestellten Fusionsproteine vergleichend in Xenopus Embryonen überexprimiert und die erhaltenen phänotypischen Veränderungen statistisch ausgewertet und dokumentiert. Die statistischen Auswertungen sind in den Tabellen 4.5 - 4.8 zusammengefasst. Eine Injektion aller vier Fusionsproteine in beide Zellen des 2-Zell Stadiums führte zu Störungen der Musterbildung in den Embryonen. Dabei wurden sehr ähnliche Phänotypen beobachtet (Abb. 4.40). In allen Fällen konnte eine Abhängigkeit der Stärke der Defekte von der Menge injizierter mRNA beobachtet werden. Auffällig war die hohe Zahl von Störungen der Gastrulationsbewegungen (Gastrulationsdefekte). Hierbei gelangen prospektiv
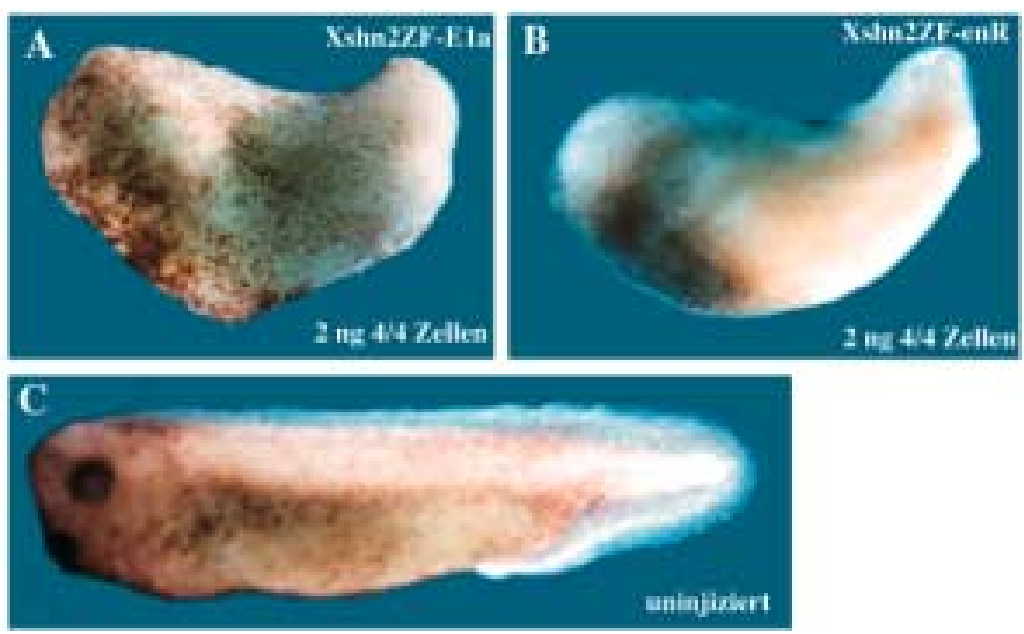

Abb. 4.40: Phänotyp von Xenopus Embryonen nach ubiquitärer Überexpression der Fusionskonstrukte NLSMT-Xshn2ZF-enR und NLSMT-Xshn2ZF-E1a. 2 ng synthetischer mRNA wurden im 2-Zell Stadium injiziert, die Embryonen bis zum Stadium NF 34 kultiviert, fixiert und dokumentiert. (A, B) Phänotyp je eines injizierten Embryos. (C) uninjizierter Kontrollembryo desselben Stadiums. 
entodermales und mesodermales Gewebe unvollständig über den Blastoporus ins Innere des Embryos. Der Blastoporus schließt sich nicht, und der Phänotyp der Embryonen ähnelt in späteren Stadien einer "spina bifida" (offenes Rückenmark) (vgl. Abb. 4.42).

Derartige Gastrulationsdefekte werden durch Störungen der aktiven Wanderungsbewegungen des Mesoderms ("convergent extension") verursacht. Activin ist wesentlich beteiligt an der Vermittlung dieser Prozesse im Mesoderm.

Möglicherweise wurde durch die Injektion des dominant-negativen Konstruktes, des konstitutiv aktiven Konstruktes, der Zinkfingerdomäne allein und des Xshn3-Proteinfragmentes 7 (AS 18802578) der Activin-Signalweg inhibiert.

Injizierte Embryonen, die die Gastrulation vollendeten, zeigten ein breites Spektrum von morphologischen Veränderungen. Diese beinhalteten eine Reduktion von dorsalen Achsenstrukturen, der Bauchregion und des Kopfes. Insgesamt ließ sich für keines der Konstrukte ein einheitlicher Phänotyp beschreiben, sondern jedes verursachte das gesamte Spektrum von Deformationen.

Um die Ursache der Variabilität der Veränderungen zu ermitteln, wurde zusammen mit der mRNA für die Fusionsproteine mRNA für nukleäre $\beta$ Galaktosidase injiziert. Dieses Protein kolokalisiert mit den Fusionsproteinen, bewirkt selbst aber keine phänotypischen Veränderungen. Eine $\beta \mathrm{Gal}-$ Färbung fixierter Embryonen konnte die Verteilung der injizierten Xshn3 Fusionsproteine im Embryo nachvollziehen. Abb. 4.41 zeigt einige Beispiele auf diese Weise behandelter Embryonen. Es ist zu erkennen, dass jeweils die Körperregionen von Deformationen betroffen sind, die durch eine blaue Färbung die Verteilung des Xshn3ZF-enR Proteins anzeigen.
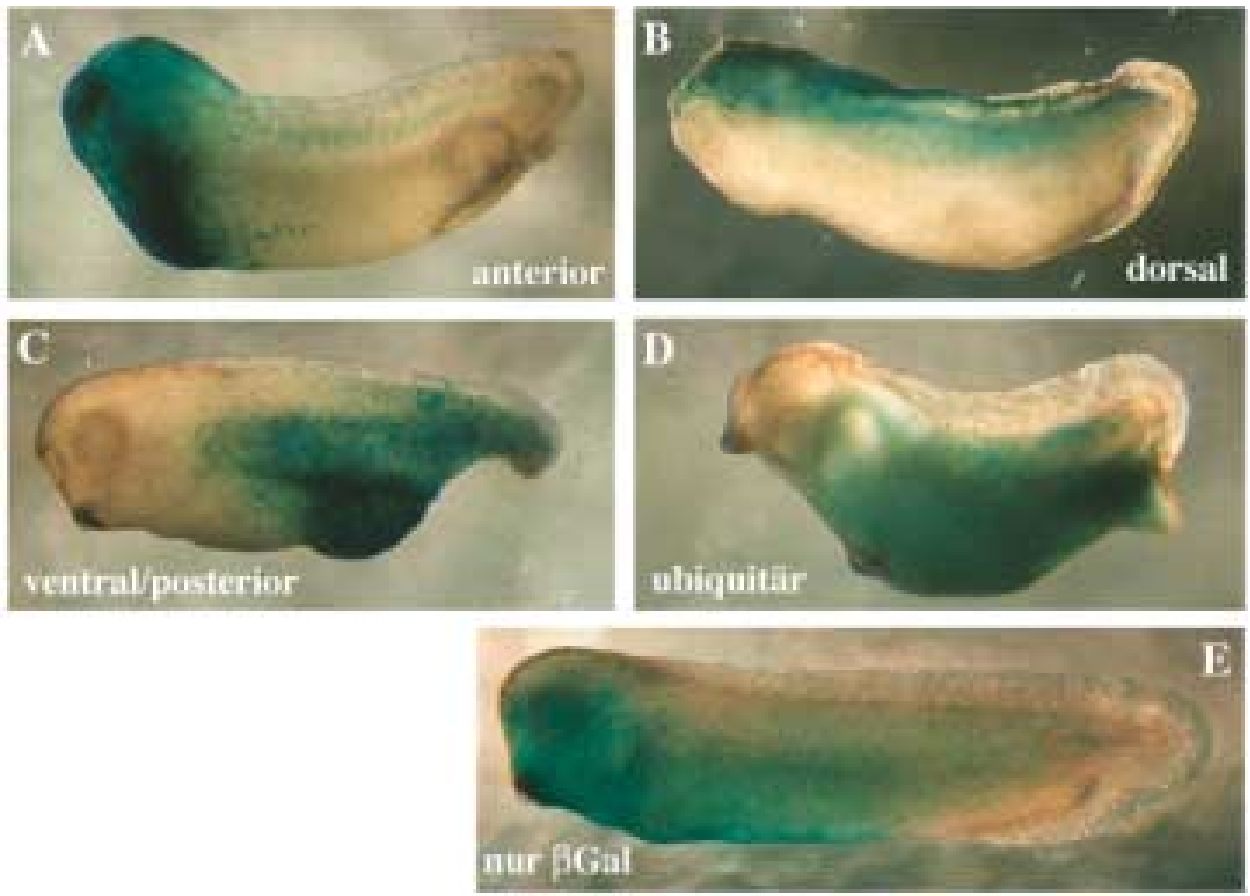

Abb. 4.41: Das Fusionsprotein NLSMT-Xshn3ZF-enR verursacht Entwicklungsdefekte in den Körperregionen, in die die synthetische mRNA gelangt. (A)-(D) $100 \mathrm{ng}$ synthetischer mRNA für NLSMT-Xshn3ZF-enR wurde zusammen mit $15 \mathrm{ng}$ mRNA für nukleäre $\beta$ Galaktosidase in beide Zellen von 2-Zell Embryonen injiziert. Die Embryonen wurden zum Stadium NF 34 kultiviert, fixiert und einer $\beta$ Galaktosidase-Färbung unterzogen. (E) Injektion nur von 15 ng mRNA für nukleäre $\beta$ Galaktosidase in beide Zellen verändert nicht die Morphologie des Embryos. 
Es wurde deutlich, dass die Xshn3 Fusionsproteine selten ubiquitär exprimiert wurden, obwohl sie in beide Zellen des 2-Zell Stadiums injiziert wurden. Weiterhin wurde deutlich, dass die Proteine die Musterbildung in allen Körperregionen des Embryos zu stören vermochten. Ein einheitlicher Phänotyp war nicht zu beschreiben.

Um dennoch die Phänotyen der Injektionsserien quantifizieren zu können, wurden die Defekte grob in folgende Klassen eingeteilt:
1) kein Phänotyp
2) schwacher Phänotyp
3) mittlerer Phänotyp
4) starker Phänotyp
5) Gastrulationsdefekte (offener Blastoporus)

Zur Veranschaulichung sind in Abb. 4.42 für jede Klasse zwei Embryonen abgebildet. Es wird ausdrücklich betont, dass es sich bei der Einteilung um relative Werte handelte.
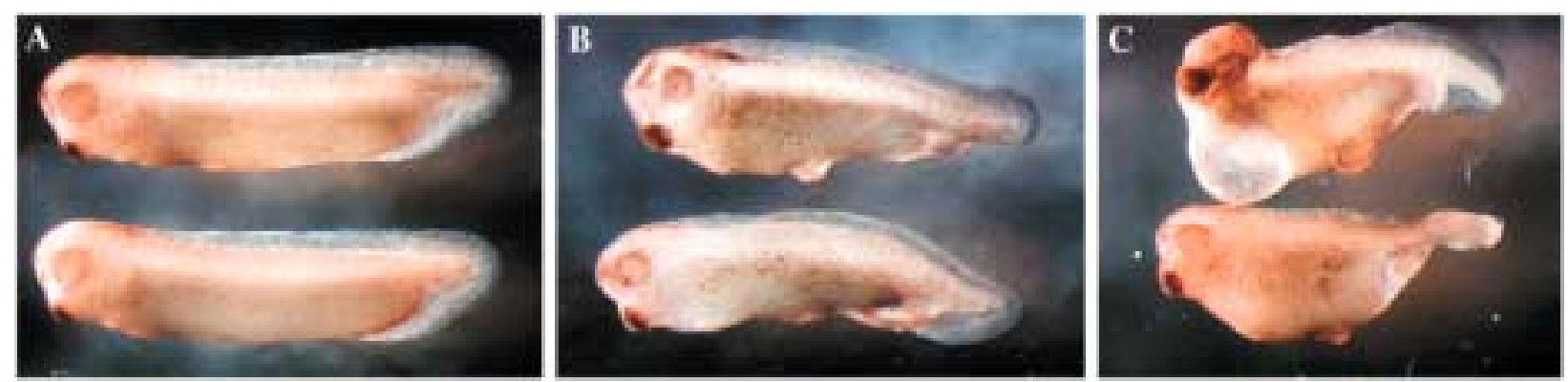

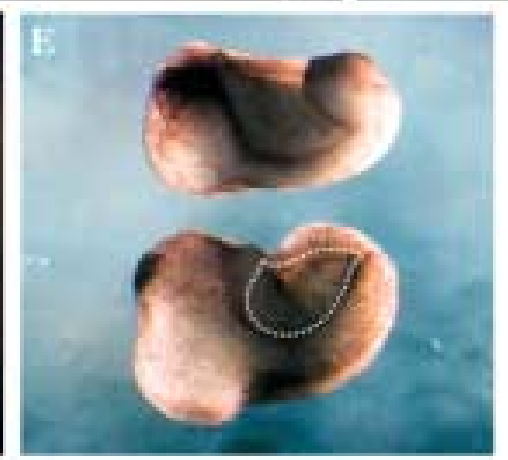

Abb. 4.42: Klassifizierung der durch Injektion der vier in Abb. 4.39 dargestellten Fusionskonstrukte erhaltenen phänotypischen Veränderungen von Xenopus Embryonen. Die Embryonen wurden im 2-Zell Stadium mit unterschiedlichen Mengen synthetischer mRNA für das Fusionsprotein NLSMT-Xshn3ZF-enR injiziert und im Stadium NF 34 dokumentiert. (A) kein Phänotyp; (B) schwacher Phänotyp; (C) mittlerer Phänotyp; (D) starker Phänotyp; (E) Gastrulationsdefekt. Durch den offenen Blastoporus (gestrichelte Linie) ist das Entoderm zu erkennen.

Nach den beschriebenen Bewertungskriterien konnten die Phänotypen injizierter Embryonen quantifiziert werden. Die Auswertung der Injektionsserien ist in den Tabellen. $4.5-4.8$ dargestellt. 
Tab. 4.5: Phänotypen von Embryonen nach Überexpression von NLSMT-Xshn3ZF-enR

\begin{tabular}{|l|c|c|c|c|l|l|}
\hline $\begin{array}{l}\text { NLSMT- } \\
\text { Xshn3ZF- } \\
\text { enR }\end{array}$ & $\begin{array}{l}\text { kein } \\
\text { Phänotyp } \\
\%\end{array}$ & $\begin{array}{l}\text { schwacher } \\
\text { Phänotyp }\end{array}$ & $\begin{array}{l}\text { mittlerer } \\
\text { Phänotyp }\end{array}$ & $\begin{array}{l}\text { starker } \\
\text { Phänotyp }\end{array}$ & $\begin{array}{l}\text { unvollst. } \\
\text { Gastrulation } \\
\%\end{array}$ & $\begin{array}{l}\text { Anzahl } \\
\text { injizierter } \\
\text { Embryonen } \\
\text { n }\end{array}$ \\
\hline $500 \mathrm{pg}$ & 0 & 1 & 2 & 1 & 96 & 134 \\
\hline $250 \mathrm{pg}$ & 0 & 3 & 5 & 6 & 86 & 231 \\
\hline $100 \mathrm{pg}$ & 0 & 6 & 10 & 4 & 80 & 134 \\
\hline $75 \mathrm{pg}$ & 7 & 13 & 41 & 0 & 39 & 79 \\
\hline $50 \mathrm{pg}$ & 4 & 53 & 12 & 0 & 31 & 92 \\
\hline $10 \mathrm{pg}$ & 8 & 58 & 15 & 0 & 19 & 89 \\
\hline
\end{tabular}

Tab. 4.6: Phänotypen von Embryonen nach Überexpression von NLSMT-Xshn3ZF-VP16

\begin{tabular}{|c|c|c|c|c|c|c|}
\hline $\begin{array}{l}\text { NLSMT- } \\
\text { Xshn3ZF- } \\
\text { VP16 }\end{array}$ & $\begin{array}{c}\text { kein } \\
\text { Phänotyp } \\
\qquad \%\end{array}$ & $\begin{array}{c}\text { schwacher } \\
\text { Phänotyp } \\
\%\end{array}$ & $\begin{array}{c}\text { mittlerer } \\
\text { Phänotyp } \\
\%\end{array}$ & $\begin{array}{c}\text { Starker } \\
\text { Phänotyp } \\
\%\end{array}$ & $\begin{array}{c}\text { unvollst. } \\
\text { Gastrulation } \\
\%\end{array}$ & $\begin{array}{l}\text { Anzahl } \\
\text { injizierter } \\
\text { Embryonen } \\
n\end{array}$ \\
\hline $500 \mathrm{pg}$ & 0 & 2 & 5 & 4 & 89 & 114 \\
\hline $250 \mathrm{pg}$ & $\overline{0}$ & 2 & 15 & 3 & 80 & 347 \\
\hline $100 \mathrm{pg}$ & $\overline{0}$ & 3 & 30 & 7 & 60 & 181 \\
\hline $75 \mathrm{pg}$ & 0 & 9 & 55 & 4 & 32 & 148 \\
\hline $\begin{array}{ll}50 & \mathrm{pg}\end{array}$ & $\overline{0}$ & 21 & 45 & $\overline{9}$ & 25 & 112 \\
\hline $10 \mathrm{pg}$ & $\overline{0}$ & 61 & 20 & 7 & 12 & 84 \\
\hline
\end{tabular}

Tab. 4.7: Phänotypen von Embryonen nach Überexpression von NLSMT-Xshn3ZF

\begin{tabular}{|l|c|c|c|c|c|c|}
\hline $\begin{array}{l}\text { NLSMT- } \\
\text { Xshn3ZF }\end{array}$ & $\begin{array}{c}\text { kein } \\
\text { Phänotyp } \\
\%\end{array}$ & $\begin{array}{l}\text { schwacher } \\
\text { Phänotyp }\end{array}$ & $\begin{array}{l}\text { mittlerer } \\
\text { Phänotyp }\end{array}$ & $\begin{array}{l}\text { starker } \\
\text { Phänotyp }\end{array}$ & $\begin{array}{l}\text { unvollst. } \\
\text { Gastrulation }\end{array}$ & $\begin{array}{l}\text { Anzahl } \\
\text { injizierter } \\
\text { Embryonen } \\
\text { n }\end{array}$ \\
\hline & $\%$ & $\%$ & $\%$ & $\%$ & $\%$ & $\mathrm{n}$ \\
\hline $500 \mathrm{pg}$ & 5 & 44 & 10 & 2 & 39 & 120 \\
\hline $250 \mathrm{pg}$ & 58 & 19 & 2 & 0 & 21 & 135 \\
\hline $100 \mathrm{pg}$ & 32 & 20 & 3 & 4 & 41 & 115 \\
\hline $75 \mathrm{pg}$ & 96 & 0 & 0 & 0 & 4 & 46 \\
\hline $50 \mathrm{pg}$ & 93 & 0 & 0 & 0 & 7 & 41 \\
\hline $10 \mathrm{pg}$ & 100 & 0 & 0 & 0 & 0 & 41 \\
\hline
\end{tabular}

Tab. 4.8: Phänotypen von Embryonen nach Überexpression von Xshn3 NLSMT-Fragment 7 (AS1880-2578)

\begin{tabular}{|l|c|c|c|c|l|l|}
\hline $\begin{array}{l}\text { NLSMT- } \\
\text { Xshn3- } \\
\text { Fragment7 } \\
\text { (AS1880- } \\
2578)\end{array}$ & $\begin{array}{l}\text { kein } \\
\text { Phänotyp }\end{array}$ & $\begin{array}{l}\text { schwacher } \\
\text { Phänotyp }\end{array}$ & $\begin{array}{l}\text { mittlerer } \\
\text { Phänotyp }\end{array}$ & $\begin{array}{l}\text { starker } \\
\text { Phänotyp }\end{array}$ & $\begin{array}{l}\text { unvollst. } \\
\text { Gastrulation }\end{array}$ & $\begin{array}{l}\text { Anzahl } \\
\text { injizierter } \\
\text { Embryonen }\end{array}$ \\
\hline $2000 \mathrm{pg}$ & 2 & 4 & 15 & 29 & 50 & $\mathrm{n}$ \\
\hline $1000 \mathrm{pg}$ & 7 & 20 & 27 & 14 & 32 & 105 \\
\hline $500 \mathrm{pg}$ & 62 & 22 & 10 & 5 & 1 & 122 \\
\hline $100 \mathrm{pg}$ & 75 & 21 & 2 & 0 & 2 & 103 \\
\hline
\end{tabular}


Aus den Tabellen 4.5 und 4.6 ist zu erkennen, dass die Fusionsproteine NLSMT-Xshn3ZF-enR und NLSMT-Xshn3ZF-VP16 in etwa gleichem Maße die frühe Entwicklung von Xenopus Embryonen störten. Bereits 75 pg von NLSMT-Xshn3ZF-enR oder -VP16 mRNA fühtren bei etwa einem Drittel der Embryonen zur Inhibition der Gastrulationsbewegungen. Dieselbe Menge mRNA des Xshn3ZF Konstruktes führt dagegen zu keiner signifikanten Beeinträchtigung der Entwicklung der Embryonen.

Zusätzlich ist zu bedenken, dass die für das Zinkfinger Konstrukt NLSMT-Xshn3ZF kodierende mRNA um ein vielfaches kürzer ist als die für das Repressor- oder das Aktivatorkonstrukt. Bei gleicher pg-Menge mRNA wurde daher eine ungleich größere Menge von mRNA Molekülen injiziert. Rechnet man eine höhere Translationsrate kürzerer Proteine dazu, ist zu vermuten, dass eine Überexpression des Xshn3 Zinkfinger-Konstruktes deutlich weniger Einfluss auf die Morphogenese der Embryonen zeigte als die anderen Konstrukte.

In jedem Fall wurde die Vermutung bestätigt, dass eine Kombinaton der carboxyterminalen Zinkfinger Domäne mit weiteren im Carboxyterminus befindlichen Proteinbereichen (Xshn3Fragment 7) konzentrationsabhängig die frühen morphogenetischen Prozesse im Embryo beeinträchtigt.

Im Vergleich zu den Konstrukten NLSMT-Xshn3ZF-enR und -VP16 zeigte das Xshn3 Fragment 7 eine geringere Aktivität. Die erhaltenen Veränderungen gleichen jedoch phänotypisch den durch die anderen Konstrukte erzielten Defekten. Dies bestätigte eine in vivo Aktivität des Xshn3 Fragmentes 7 in Xenopus Embryonen.

Es lässt sich zusammenfassen, dass das dominant-negative und das konstitutiv-aktive Xshn3Zinkfinger Fusionsprotein bei Injektion in 2 von 2 Zellen vergleichbare Störungen der frühen Entwicklungsprozesse im ganzen Embryonen hervorriefen. Das Xshn3-Proteinfragment 7 (AS 1880-2578) führte zu ähnlichen Defekten, jedoch mit geringerer Intensität. Die untersuchte Zinkfinger Domäne allein führte nur in geringem Maße zu Entwicklungsstörungen. Auf eine Aktivität der Xenopus Schnurri Proteine als Aktivatoren oder Repressoren der Transkription gaben die dargestellten Ergebnisse keinen Hinweis.

\subsection{2 Überexpression der Smad-bindenden Xshn3 Proteinfragmente 5 und 8 im Xenopus Embryo}

In vivo Interaktionsstudien im Xenopus Embryo hatten gezeigt, dass es innerhalb des Proteins Xshn3 zwei Bereiche gibt, die mit koinjizierten R-Smad Proteinen interagieren könnten (vgl. Kap. 4.5). Die Interaktion dieser Xshn3 Proteinfragmente 5 (AS 1076-1749) und 8 (AS 2119-2578) mit Smad Proteinen erwies sich bei Überexpression im Embryo als unbeeinflusst von Aktivierung oder Inhibition des Smad Signalweges im Embryo. Sollten die genannten Xshn3 Proteinfragmente daher konstitutiv mit Smad Proteinen interagieren, so könnten sie bei einer Überexpression im Xenopus Embryo an endogene R-Smad Proteine binden und deren Funktion u.U. inhibieren. Als phänotypischer Effekt eines solchen Experimentes wäre daher eine Beeinträchtigung der dorso- 
ventralen Musterbildungsprozesse möglich, die durch Mitglieder der TGF $\beta$ Familie von Zytokinen und Smad Proteinen vermittelt werden.

Die NLS- und MT-epitopmarkierten Xshn3 Proteinfragmente 5 (AS 1076-1749) und 8 (AS 2119-2578) wurden ubiquitär im Xenopus Embryo überexprimert und der Phänotyp der Embryonen im NF 34 ausgewertet. Die überexprimierten Xshn3-Proteinfragmente enthalten keine DNA-Bindungsdomäne. Tab. 4.9 und 4.10 zeigen eine statistische Auswertung der nach ubiquitärer Überexpression der Xshn3 Interaktionsfragmente erhaltenen phänotypischen Veränderungen. In diesem Fall wurden die beobachteten phänotypischen Veränderungen der Embryonen ohne die Kategorie „mittlerer Phänotyp“ ausgewertet.

Wie in vorangegangen Injektionsexperimenten wurden bei den hier beschriebenen Injektionen uneinheitliche phänotypische Veränderungen beobachtet. Deshalb wurden die Veränderungen wie zuvor grob in in "kein"-, "schwacher"- oder "starker" Phänotyp oder unvollständige Gastrulation eingeteilt.

Tab. 4.9: Phänotypen von Embryonen nach Überexpression von Xshn3-Fragment 5 (AS 1076-1749)

\begin{tabular}{|l|c|c|c|c|c|}
\hline $\begin{array}{l}\text { Xshn3-NLS- } \\
\text { MT- } \\
1076-1749\end{array}$ & $\begin{array}{l}\text { kein } \\
\text { Phänotyp }\end{array}$ & $\begin{array}{l}\text { schwacher } \\
\text { Phänotyp }\end{array}$ & $\begin{array}{l}\text { starker } \\
\text { Phänotyp }\end{array}$ & $\begin{array}{l}\text { unvollst. } \\
\text { Gastrulation }\end{array}$ & $\begin{array}{l}\text { Anzahl } \\
\text { injizierter } \\
\text { Embryonen }\end{array}$ \\
\hline & $\%$ & $\%$ & $\%$ & $\%$ & $\mathrm{n}$ \\
\hline $2 \mathrm{ng}$ & 56 & 36 & 0 & 8 & 116 \\
\hline $1 \mathrm{ng}$ & 98 & 1 & 0 & 1 & 104 \\
\hline $0.5 \mathrm{ng}$ & 98 & 0 & 0 & 2 & 101 \\
\hline $0.1 \mathrm{ng}$ & 98 & 1 & 1 & 0 & 101 \\
\hline
\end{tabular}

Tab. 4.10: Phänotypen von Embryonen nach Überexpression von Xshn3-Fragment 8 (AS 2119-2578)

\begin{tabular}{|l|c|c|c|c|c|}
\hline $\begin{array}{l}\text { Xshn3-NLS- } \\
\text { MT- } \\
2119-2578\end{array}$ & $\begin{array}{l}\text { kein } \\
\text { Phänotyp }\end{array}$ & $\begin{array}{l}\text { schwacher } \\
\text { Phänotyp }\end{array}$ & $\begin{array}{l}\text { starker } \\
\text { Phänotyp }\end{array}$ & $\begin{array}{l}\text { unvollst. } \\
\text { Gastrulation }\end{array}$ & $\begin{array}{l}\text { Anzahl } \\
\text { injizierter } \\
\text { Embryonen }\end{array}$ \\
\hline & $\%$ & $\%$ & $\%$ & $\%$ & $\mathrm{n}$ \\
\hline $1 \quad \mathrm{ng}$ & 95 & 4 & 0 & 1 & 101 \\
\hline $0.5 \mathrm{ng}$ & 94 & 3 & 0 & 3 & 93 \\
\hline $0.1 \mathrm{ng}$ & 90 & 7 & 0 & 3 & 104 \\
\hline $0.05 \mathrm{ng}$ & 86 & 10 & 1 & 3 & 120 \\
\hline
\end{tabular}

Tab. 4.9 und 4.10: Auswertung der phänotypischen Veränderungen von mikroinjizierten Embryonen im Stadium NF 34. Die Embryonen wurden im zwei-Zell Stadium in beide Zellen mit den angegebenen Mengen synthetischer mRNA für die NLS- und MT-markierten Xshn3 Proteinfragmente 5 (AS 1076-1749) und 8 (AS 2119-2578) injiziert. Im Stadium NF 34 wurden die Embryonen fixiert und die phänotypischen Veränderungen ausgewertet.

Nach Auswertung der phänotypischen Veränderungen der injizierten Embryonen fiel auf, dass trotz z.T. hoher Mengen injizierter synthetischer mRNA ( 2 ng mRNA) keines der beiden Xshn3 Fragmente signifikante Störungen in der Musterbildung der Embryonen verursachte. 
Zusammenfassend lässt sich feststellen, dass eine Überexpression von mit R-Smads und mit Smad4 interagierenden Xshn3 Proteinfragmenten im Xenopus Embryo nicht zu einer signifikanten Beeinträchtigung der frühen morphogenetischen Prozesse führte.

\subsubsection{Kooperation des Xshn3-Proteinfragmentes 7 (AS 1880-2578) mit Smad2}

Bei der Regulation von Zielgenen kooperieren Smad Proteine im Zellkern mit sequenzspezifisch an DNA bindende Transkriptionsfaktoren. In Drosophila kooperiert Mad mit Schnurri bei der Repression der Expression von brinker. In der vorliegenden Arbeit konnte gezeigt werden, dass auch Xenopus Xshn3 in vivo in Komplexen mit Rezeptor-regulierten Smads und mit Smad4 nachzuweisen ist. Eine Überexpression der beiden Smad-Interaktionsdomänen in Xenopus Embryonen zeigte keinen phänotypisch nachweisbaren Einfluss auf die Entwicklung der Embryonen.

Um eine mögliche Kooperativität von Smads und Xshn3 zu untersuchen, wurde der Effekt einer Koinjektion geringer Mengen Smad2-mNRA mit geringen Mengen mRNA für das Xshn3 Proteinfragment 7 (AS 1880-2578) untersucht.

Tab. 4.11 zeigt eine statistische Auswertung der erhaltenen phänotypischen Veränderungen.

\begin{tabular}{|l|c|c|c|c|c|}
\hline & $\begin{array}{l}\text { kein } \\
\text { Phäno } \\
\text { typ }\end{array}$ & $\begin{array}{l}\text { schwacher } \\
\text { Phänotyp }\end{array}$ & $\begin{array}{l}\text { starker } \\
\text { Phänotyp }\end{array}$ & $\begin{array}{l}\text { unvollst. } \\
\text { Gastrulation }\end{array}$ & $\begin{array}{l}\text { Anzahl } \\
\text { injizierter } \\
\text { Embryonen }\end{array}$ \\
\hline & $\%$ & $\%$ & $\%$ & $\%$ & $\mathrm{n}$ \\
\hline Smad2 & 66 & 25 & 3 & 6 & 108 \\
\hline Xshn3 1880-2578 & 69 & 18 & 0 & 13 & 102 \\
\hline $\begin{array}{l}\text { Smad2 Xshn3- } \\
1880-2578\end{array}$ & 2 & 8 & 18 & 72 & 108 \\
\hline
\end{tabular}

Tab. 4.11: Auswertung der phänotypischen Veränderungen von mikroinjizierten Embryonen im Stadium NF 34. Die Embryonen wurden im vier-Zell Stadium in die zwei ventralen Blastomere mit $0.2 \mathrm{ng}$ Flag-epitopmarkierter synthetischer Smad mRNA und/oder 0.8 ng MT-NLS-markierter Xshn3-Fragment AS 1880-2578 mRNA injiziert. Im Stadium NF 34 wurden die Embryonen fixiert und die phänotypischen Veränderungen ausgewertet.

Eine ventrale Injektion von 200 pg Smad 2 mRNA dorsalisierte die Embryonen schwach, während eine ventrale Injektion von 800 pg der Xshn3 Fragment 7-mRNA einen ähnlichen Phänotyp hervorrief. Eine Koinjektion der genannten Mengen beider mRNAs führte zu überdurchschnittlich starken morphologischen Defekten, die eine Kooperativität beider Proteine vermuten ließ. Besonders auffällig war die starke Häufung von Gastrulationsdefekten, die einer Injektion von mehr als der 10fachen Menge des Xshn3 Fragmentes 7 allein entsprachen.

Abb. 4. 43 zeigt beispielhaft die Phänotypen einiger injizierter Embryonen im Stadium NF 34. 

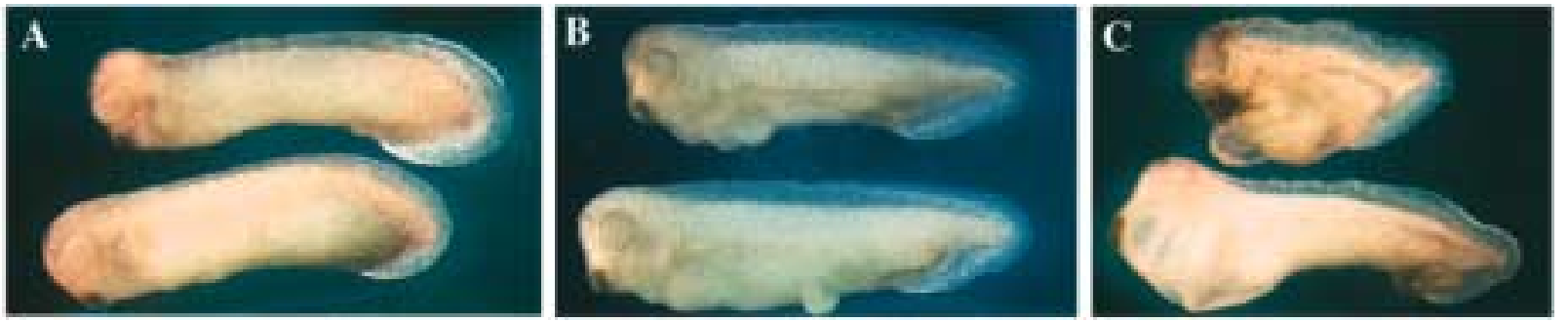

Abb. 4.43: Phänotypische Veränderungen von Xenopus Embryonen im Stadium NF 34 nach ventraler Überexpression von epitopmarkiertem Smad2 und dem NLSMT-markieren Xshn3 Proteinfragment 7 (AS 1880-2578). Die Embryonen wurden im vier-Zell Stadium in beide ventralen Zellen mit $0.2 \mathrm{ng}$ synthetischer mRNA für das Xshn3 Fragment 7 und/oder $0.5 \mathrm{ng}$ synthetischer mRNA für epitopmarkiertes Smad2 injiziert. Im Stadium NF 34 wurden die Embryonen fixiert und photographisch dokumentiert. (A) ventrale Überexpression von Smad2; (B) ventrale Überexpression von NLSMT-Xshn3 Fragment 7 (AS 1880-2578); (C) ventrale Koinjektion von Smad2 mit NLSMT-Xshn3 Fragment 7 (AS 1880-2578).

Aufgrund der beschriebenen Koinjektionsexperimente ist eine Kooperativität des Transkriptionsfaktors Xshn3 mit Smad2 während der Gastrulation im Xenopus Embryo zu vermuten.

\subsubsection{Repression mesodermaler Markergene durch Xshn-Fusionsproteine}

Die Überexpression des dominant-negativen Fusionsproteins Xshn3ZF-enR und des konstitutiv aktiven Fusionsproteins Xshn3ZF-VP16 in ganzen Embryonen hatte vermuten lassen, dass beide Konstrukte inhibitorisch auf die Bildung mesodermaler Gewebe wirken könnten. Die Induktion und Musterbildung des Mesoderms im Xenopus Embryo ist charakterisiert durch die räumlich und zeitlich koordinierte Expression von Markergenen. Im Folgenden sollte daher der Einfluss der genannten Zinkfinger Fusionsproteine auf die Expression von Markergenen der frühen Entwicklung untersucht werden.

\subsubsection{Repression des endogenen mesodermalen Markergens Xbra durch Zinkfinger Fusionsproteine}

Der T-box Transkriptionsfaktor Xbra wird im Gastrula Embryo in der gesamten marginalen Zone, dem prospektiven Mesoderm, um den Blastoporus exprimiert. In "whole mount" in situ Hybridisierungen zeigt sich daher eine ringförmige Expression der mRNA um den Blastoporus. Im folgenden Versuch sollte ermittelt werden, ob die Xshn Repressor- und Aktivatorkonstrukte die Expression des endogenen Xbra reprimieren. Synthetische mRNAs wurden in eine Zelle des 2Zell Embryos injiziert und die Expression des endogenen Xbra im Gastrula Stadium durch „whole mount" in situ Hybridisierungen untersucht (Abb. 4.44). Aktivator- und Repressorkonstrukt reprimierten deutlich die Expression des endogenen Xbra auf der injizierten Seite. Es bestätigte sich eine Repression eines mesodermalen Markergens durch die genannten Konstrukte. 


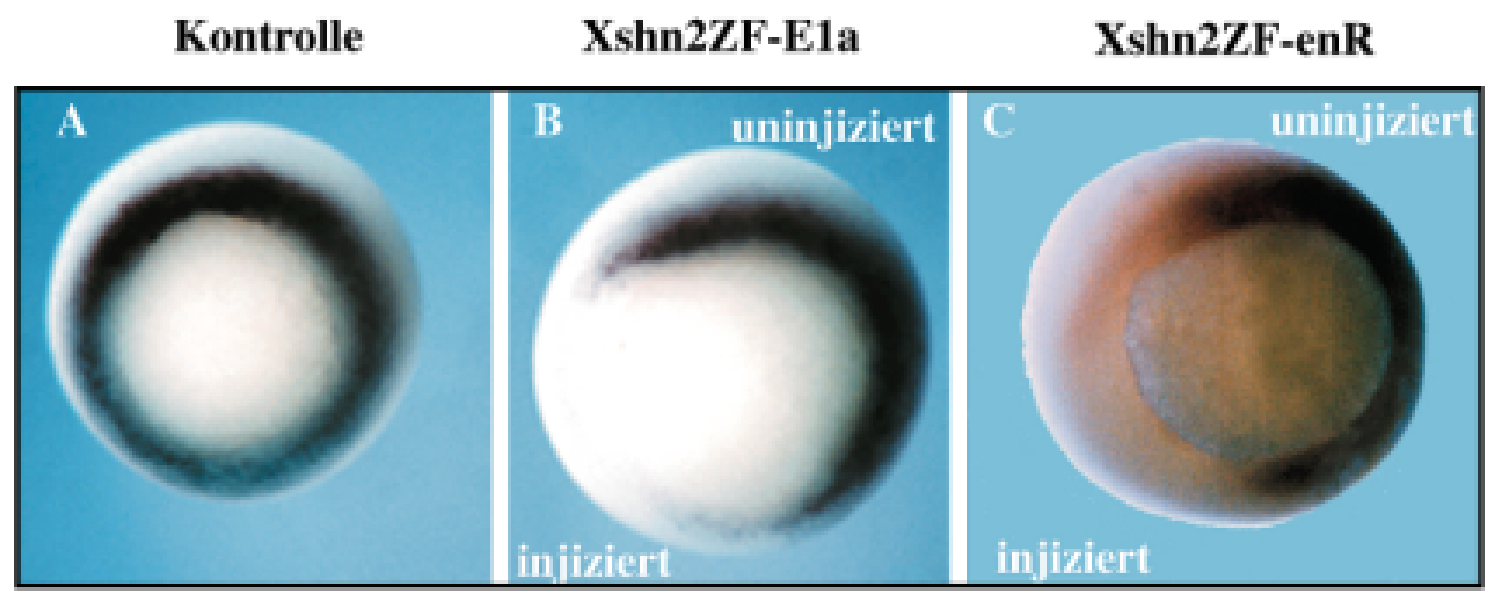

Abb. 4.44: Repression der Expression des endogenen Xbra durch NLSMT-Xshn2ZF-enR und durch Xshn2ZF-E1a. Embryonen wurden in eine von zwei Zellen mit je 1 ng synthetischer NLSMT-Xshn2ZF-enR bzw. NLSMT-Xshn2ZF-E1a mRNA injiziert. Im Gastrula Stadium (NF 11) wurden die Embryonen fixiert und die Xbra Expression in einer "whole mount" in situ Hybridisierung untersucht.

Im gesamten Embryo unterliegt die Expression von Markergenen der frühen Entwicklung einer Regulation durch eine Vielzahl von induktiven Faktoren. Es kann daher u.U. schwierig sein, nach Überexpression eines Proteinfaktors abzuschätzen, ob beobachtete Effekte direkter oder indirekter Natur sind. Um dennoch den Einfluss von exogenen Faktoren auf die Genexpression in Xenopus Geweben zu untersuchen, eignet sich das ,animal cap“ System: Eine isolierte Kultivierung von ektodermalem Gewebe des animalen Pols ("animal cap") aus injizierten Blastula-Embryonen ermöglicht es, den Einfluss von Faktoren auf die Differenzierung eines - infolge unterbliebener Mesoderminduktion - "naiven" Gewebes zu analysieren.

In Abwesenheit von exogenen induktiven Faktoren differenzieren Zellen des "animal cap" Ektoderms zu atypischer Epidermis. Die Zugabe von bestimmten Wachstumsfaktoren zum Kulturmedium oder die Injektion von mRNA dieser Faktoren kann eine mesodermale Differenzierung von "animal cap" Zellen auslösen (z.B. Smith et al., 1990).

In den folgenden Versuchen wurde der Einfluss der Xshn-Aktivator- und Repressorkonstrukte auf die Induktion dorsal-mesodermaler Markergene durch Smad2 getestet. Hierzu wurden unterschiedliche Mengen der entsprechenden synthetischen mRNAs in den animalen Pol im 2Zell Stadium koinjiziert, die Embryonen bis zum Stadium NF 9 kultiviert, die animalen Kappen manuell explantiert und bis zum angegebenen Stadium kultiviert. Auf extrahierter gesamt-RNA wurden quantitative radioaktive RT-PCR Reaktionen durchgeführt.

\subsubsection{Ein Zinkfinger-Repressorkonstrukt und ein Zinkfinger-Aktivator- konstrukt inhibieren Mesoderminduktion in animalen Kappen}

Zunächst wurde im "animal cap" System der Effekt des Repressor- und des Aktivatorkonstruktes auf die induktiven Eigenschaften von Smad2 untersucht. Smad2 ist wesentlicher zytoplasmatischer Vermittler der Information dorsalisierender Faktoren der TGF $\beta$ Familie von Morphogenen in 
Vertebraten. Eine Überexpression von Smad2 zeigt im "animal cap" System dieselben induktiven Eigenschaften wie Activin (Baker und Harland, 1996).

Zunächst wurde der Effekt des Fusionskonstruktes NLSMT-Xshn2ZF-enR auf die Induktion von Markergenen durch Smad2 untersucht (Abb. 4.45). 1 ng synthetischer Smad2 mRNA wurde in den animalen Pol von 2-Zell Embryonen injiziert, animale Kappen explantiert und im Stadium NF 11 auf Expression von Markergenen analysiert. Xbra ist ein generelles mesodermales Markergen, das direkt, also ohne Notwendigkeit vorheriger Proteinesynthese, durch Smad2 induziert wird (Tadano et al., 1993). Gsc wird Organisator-spezifisch in dorsalem Mesoderm exprimiert und reagiert ebenfalls direkt auf eine Induktion durch Activin (Tadano et al., 1993). Xwnt8 ist ein Marker von ventralem und lateralem Mesoderm. $1 \mathrm{ng}$ von NLSMT-Xshn2ZF-enR mRNA induzierte keinen der genannten Marker. Smad2 induzierte die Expression der Marker. Koinjektion von NLSMT-Xshn2ZF-enR reprimierte diese Induktionen in konzentrationsabhängiger Weise. Die Expression von Gsc konnte nicht vollständig unterdrückt werden. Die Ergebnisse zeigen einen negativen Einfluss des Xshn2-Zinkfinger Repressorkonstruktes auf die Induktion mesodermaler Markergene durch Smad2.

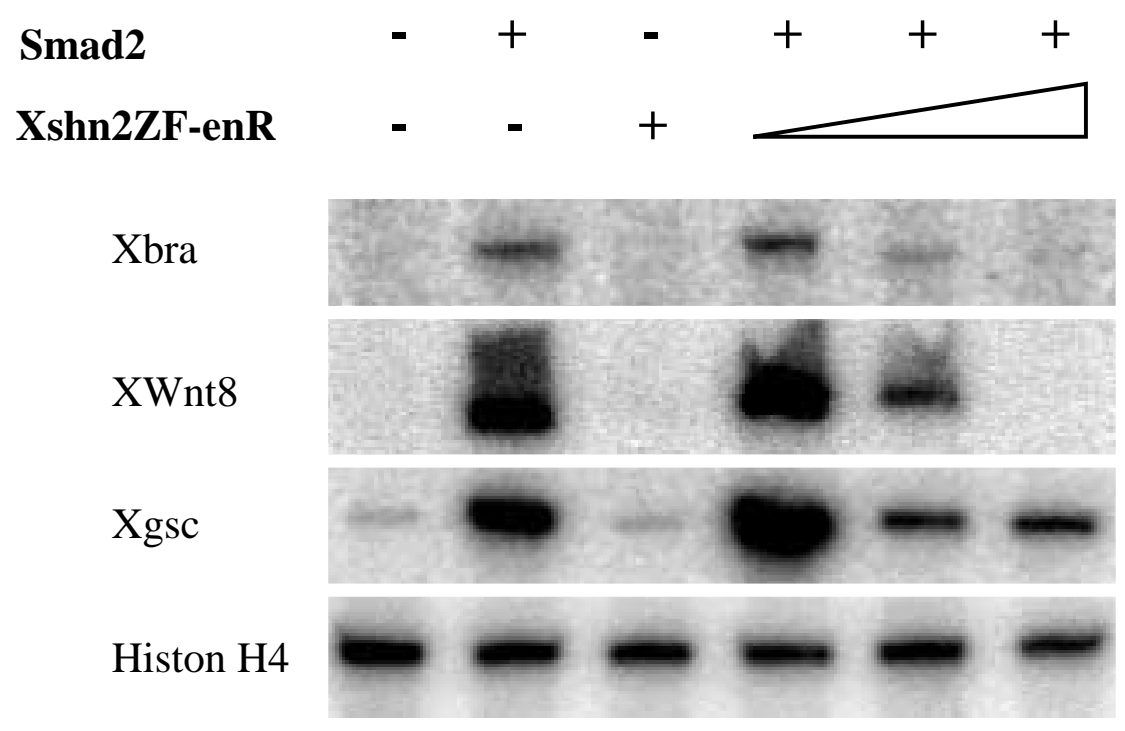

\begin{abstract}
Abb. 4.45: Analyse des Einflusses von NLSMT-Xshn2ZF-enR auf die Smad2- induzierte Expression mesodermaler Markergene in animalen Kappen. Embryonen wurden im 2-Zell Stadium mit $1 \mathrm{ng}$ synthetischer Smad2 mRNA und unterschiedlichen Mengen von NLSMTXshn2ZF-enR mRNA injiziert (Spur 3: $1 \mathrm{ng}$; Spuren 4-6: 0.5ng, $1 \mathrm{ng}, 2 \mathrm{ng}$ ). Animale Kappen wurden im Stadium NF 9 manuell explantiert und entsprechend dem Stadium NF 11 durch quantitative RT-PCR analysiert. Histon H4 diente als Kontrolle für den gleichmäßigen Einsatz von gesamt-RNA.
\end{abstract}

Im Folgenden wurde der Effekt der Fusionskonstrukte Xshn2ZF-E1a und Xshn3ZF-VP16 auf die Induktion mesodermaler Markergene durch Smad2 in animalen Kappen untersucht. In den Fusionskonstrukten wurde die carboxyterminale Doppelzinkfingerdomäne von Xshn2 bzw. Xshn3 mit zwei unterschiedlichen transaktivierenden Domänen gekoppelt. Außer der erwähnten mesodermalen Markergene Xbra und Xwnt8 wurden hierbei weitere Marker untersucht. Mix.2 ist ein Homeoboxprotein, dessen mRNA entodermal und im Organisator exprimiert wird. Mix.2 wird direkt durch Activin induziert (Vize, 1996). Die Expression von Mix.2 wird durch einen Proteinkomplex vermittelt, in dem Smad2 und der "winged-helix" Transkriptionsfaktor FAST-1 
kooperativ an ein ARE (Activin Response Element) im Mix.2 Promotor binden (Yeo et al., 1999). Pintallavis (Pint/XFKH1) ist ein Forkhead Domänen Protein, dessen mRNA ebenfalls direkt im Bereich des Organisators exprimiert wird (Dawid et al., 1993).

Abb. 4.46 zeigt, dass das Konstrukt Xshn2ZF-E1a allein keines der untersuchten Markergene induziert. Dagegen wird die Smad2-vermittelte Induktion dieser Gene durch Xshn2ZF-E1a in allen Fällen konzentrationsabhängig reprimiert. Das Ergebnis gleicht dem in Abb. 4.45 dargestellten Ergebnis mit dem Xshn2-Repressorkonstrukt.

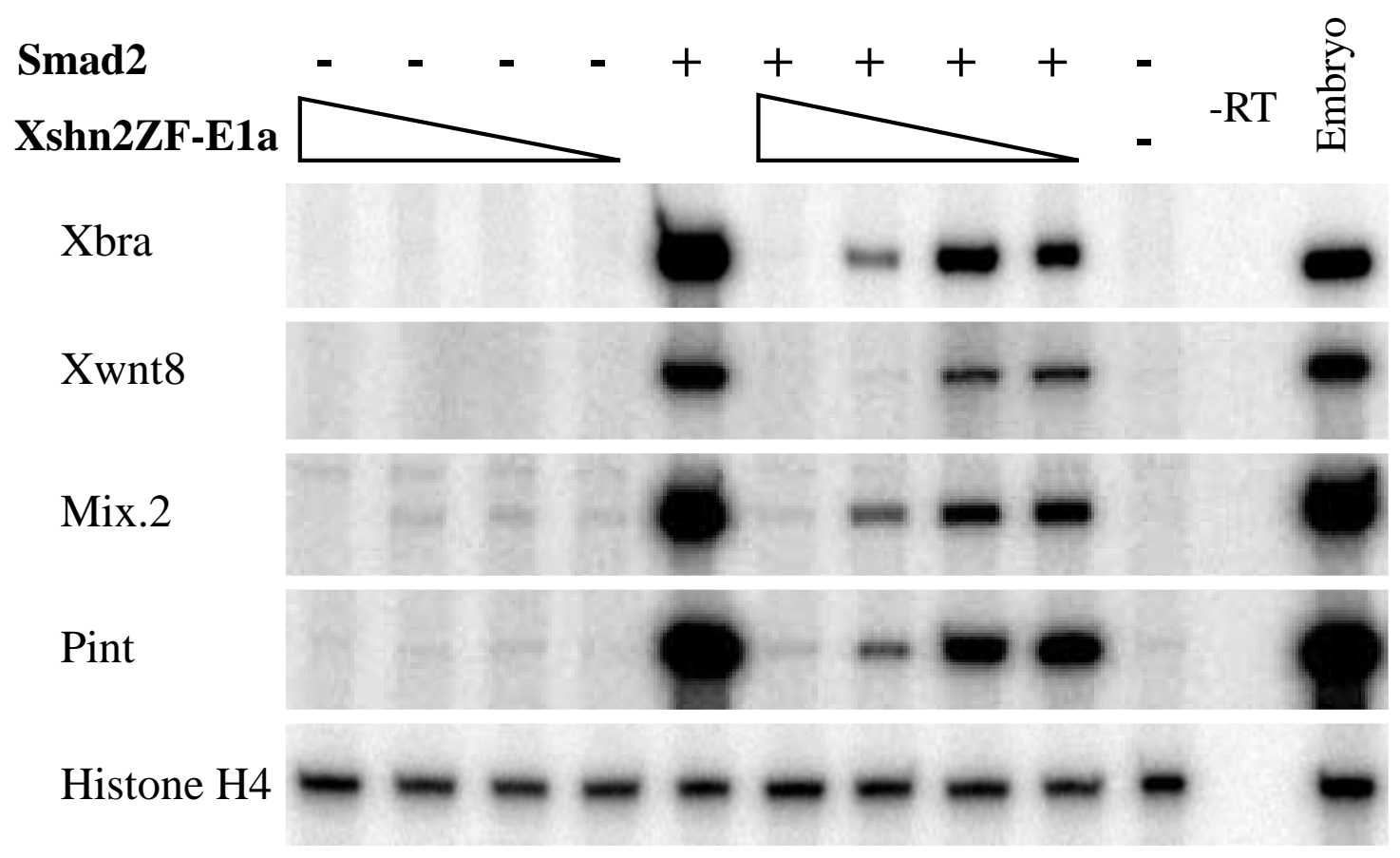

Abb. 4.46: Analyse des Einflusses von NLSMT-Xshn2ZF-E1a auf die Smad2-induzierte
Expression mesodermaler Markergene in animalen Kappen. Embryonen wurden im 2-Zell
Stadium mit $1 \mathrm{ng}$ synthetischer Smad2 mRNA und unterschiedlichen Mengen von NLSMT-
Xshn2ZF-E1a mRNA injiziert (Spur 1-4 und Spur 6-9 v.l.n.r.: 1 ng, 0.5 ng, 0.25 ng, 0.1 ng
NLSMT-Xshn2ZF-E1a mRNA). Animale Kappen wurden im Stadium NF 9 manuell explantiert und
im Stadium NF 11 durch quantitative RT-PCR analysiert. Histon H4 dient als Kontrolle für den
gleichmäßigen Einsatz von gesamt-RNA.

Während der beschriebenen Untersuchungen wurde bekannt, dass das virale Protein E1a spezifisch mit Smad Proteinen interagiert und durch diese Interaktion den Smad Signalweg und damit den antiproliferativen Effekt von TGF $\beta$ negativ beeinflusst (Nishihara et al., 1999). Es war daher nicht auszuschließen, dass es sich bei den beobachteten Effekten mit dem Konstrukt Xshn2ZF-E1a um Artefakte handelte, die aus einer pauschalen Bindung und Inhibition von Smad Proteinen durch die überexprimierten Fusionsproteine resultierten ("squelching"-Effekte). Um auszuschließen, dass es sich in den beschriebenen Ergebnissen um Artefakte handelte, wurde eine andere heterologe transaktivierende Domäne (VP16) an die Schnurri DNA-Bindungsdomäne gekoppelt (Abb. 4.39) und die Versuche in der beschriebenen Weise wiederholt.

Zusätzlich wurde im folgenden Experiment die Expression weiterer Markergene untersucht, die eine Funktion in der Induktion von Neuroektoderm in Xenopus Embryonen besitzen. Die 
Entwicklung von Ektoderm zu Neuroektoderm erfordert in der Region der Neuralplatte eine Inhibition der Aktivität des hier aktiven BMP-Signalweges. Die Inhibition von BMPs in prospektiv neuralem Ektoderm geschieht extrazellulär durch Bindung an BMP-Antagonisten. Zwei dieser Organisator-spezifisch exprimierten, sezernierten BMP-Antagonisten sind Chordin und Noggin (Sasai et al., 1995, Lamb et al., 1993).

Abb. 4.47 zeigt, dass alle bisher untersuchten, durch Smad2 induzierten, mesodermalen Markergene in konzentrationsabhängiger Weise auch durch das Fusionsprotein Xshn3ZF-VP16 reprimiert wurden. Dagegen wurde der neurale Induktor Noggin und in geringem Maße auch Chordin durch das Aktivatorkonstrukt induziert. Dies kann ein indirekter Effekt der Inhibition der Aktivität von Activin- und BMP-Signalwegen durch das injizierte Aktivatorkonstrukt sein, was permissiv auf die Entwicklung von neuralem Gewebe wirkt.

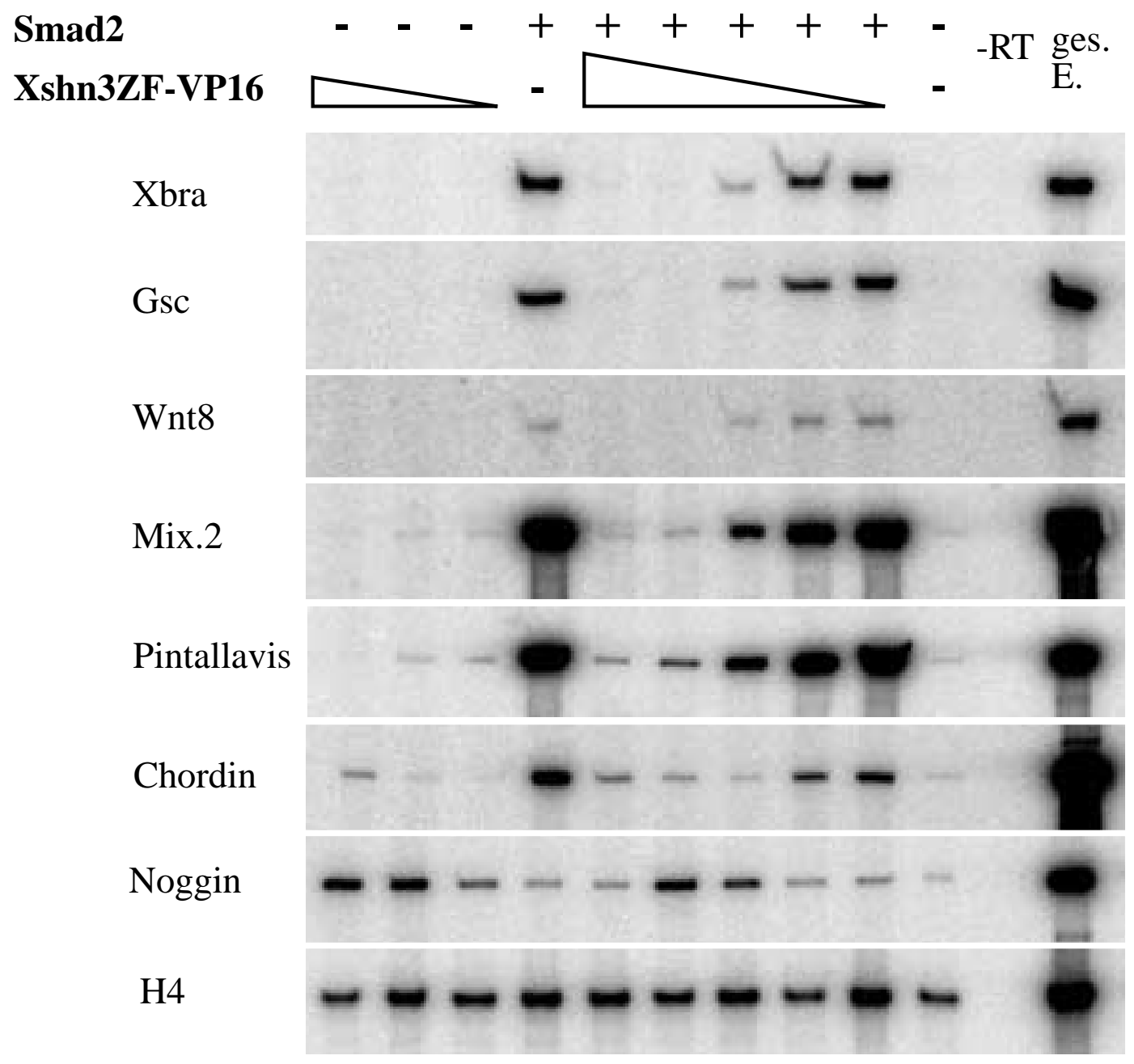

\footnotetext{
Abb. 4.47: Analyse des Einflusses von NLSMT-Xshn3ZF-VP16 auf die Smad2-induzierte Expression mesodermaler und neuraler Markergene in animalen Kappen. Embryonen wurden im 2-Zell Stadium mit $0.5 \mathrm{ng}$ synthetischer Smad2 mRNA und unterschiedlichen Mengen von NLSMT-Xshn3ZF-VP16 mRNA injiziert (Spuren 1-3: $0.5 \mathrm{ng}, 0.1 \mathrm{ng}, 001 \mathrm{ng}$; Spuren 5-9: $0.5 \mathrm{ng}$, $0.1 \mathrm{ng}, 0.01 \mathrm{ng}, 1 \mathrm{pg}, 0,1 \mathrm{pg}$ NLSMT-Xshn2ZF-VP16 mRNA). Animale Kappen wurden im Stadium NF 9 manuell explantiert und entsprechend dem Stadium NF 11 durch quantitative RTPCR analysiert. Histon H4 dient als Kontrolle für den gleichmäßigen Einsatz von gesamt-RNA.
} 


\title{
4.6.4.3 Ein Zinkfinger-Repressorkonstrukt induziert neurales Gewebe in animalen Kappen
}

Die Induktion der früh exprimierten neuralen Induktoren Noggin und Chordin in animalen Kappen nach Injektion von Xshn3ZF-VP16 ließ vermuten, dass neben der Inhibition der Smad2Aktivität auch die Aktivität von ventralisierendem endogenen BMP inhibiert wurde. Neuralisiertes ektodermales Gewebe exprimiert in späteren Stadien den pan-neuralen Marker N-CAM, dessen Expression eine neurale Differenzierung von Zellen anzeigt (Kintner und Melton, 1987). Um zu untersuchen, ob die Schnurri-Konstrukte effektiv den BMP-Signalweg inhibieren und dadurch das Gewebe neuralisieren, wurden animale Kappen untersucht, die unterschiedliche Mengen des Konstruktes Xshn2ZF-enR exprimierten. Abb. 4.48 zeigt, dass eine Injektion von 3 ng synthetischer Xshn2ZF-enR mRNA die Expression von N-CAM in Kappen entsprechend dem Stadium NF 20 (Neurula) bewirkt.

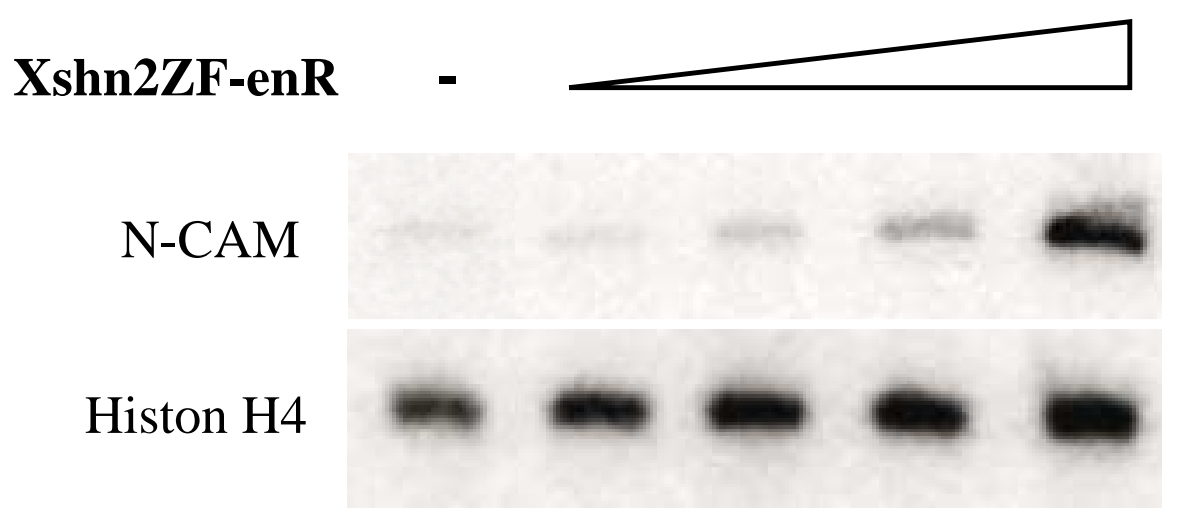

\begin{abstract}
Abb. 4.48: Analyse der Induktion des neuralen Markergenes N-CAM durch NLSMT-Xshn2ZFenR in animalen Kappen des Stadiums NF 20. Im 2-Zell Stadium wurden den Embryonen unterschiedliche Mengen Xshn2ZF-enR mRNA injiziert (0.5 ng, $1 \mathrm{ng}, 2 \mathrm{ng}$, 3ng mRNA). Animale Kappen wurden im Stadium NF 9 manuell explantiert und entsprechend dem Stadium NF 20 durch quantitative RT-PCR analysiert. Histon H4 dient als Kontrolle für den gleichmäßigen Einsatz von gesamt-RNA.
\end{abstract}

Während der Gastrulation streckt sich das einwandernde dorsale Mesoderm in einem Prozess, der als "convergent extension" bezeichnet wird. Dieser Effekt der Elongation des Mesoderms wird auch in animalen Kappen beobachtet, die mit Induktoren der dorsal-mesodemalen Entwicklung (Activin oder Smad2) behandelt wurden. Der folgende Versuch (Abb. 4.49) zeigt, dass das Xshn2ZF-enR Repressorkonstrukt in der Lage ist, eine Smad2-induzierte Elongation von animalen Kappen zu unterdrücken. Die Aktivität des Repressorkonstruktes auf die Entwicklung von dorsalem Mesoderm bestätigt sich damit auch auf der Ebene der Morphogenese. 

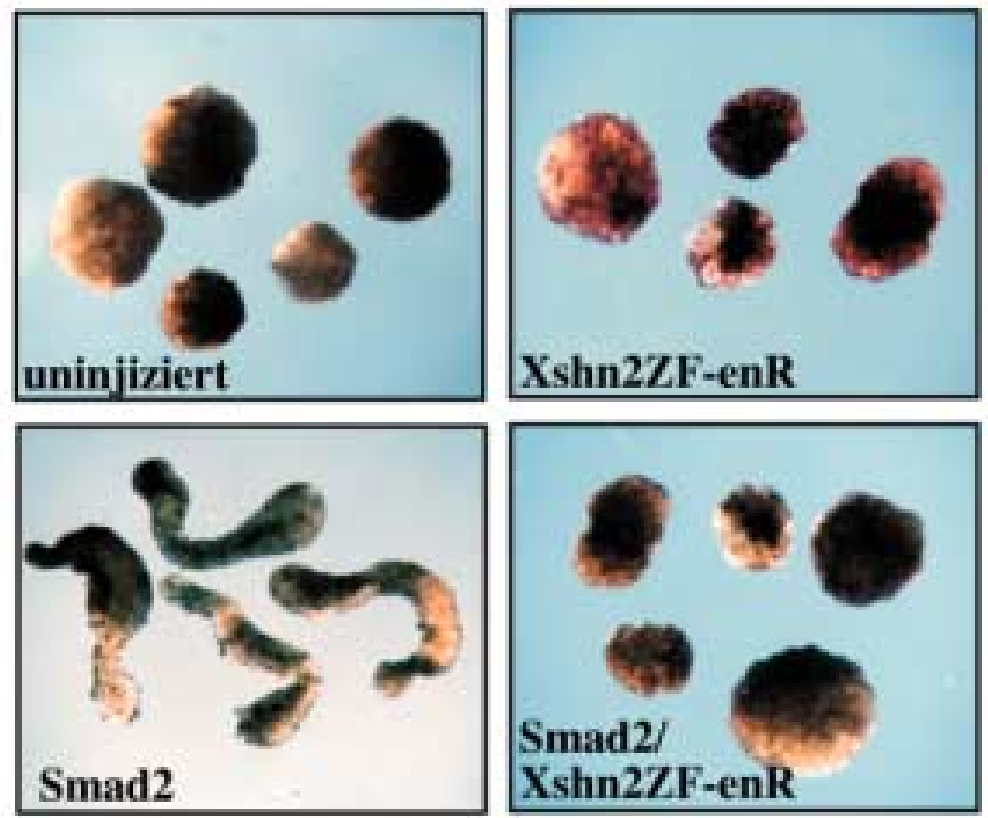

Abb. 4.49: Repression der Smad2-induzierten Elongation von animalen Kappen durch NLSMTXshn2ZF-enR. Embryonen wurden im 2-Zell Stadium mit je 1 ng synthetischer Smad2 bzw. Xshn2ZF-enR mRNA injiziert. Animale Kappen wurden im Stadium NF 9 manuell explantiert und kultiviert, bis unbehandelte Kontrollembryonen das Stadium NF 30 erreicht hatten.

Es lässt sich zusammenfassen, dass überexprimierte Fusionsproteine, in denen die carboxyterminale Doppelzinkfinger Domäne von Xshn2 oder von Xshn3 an eine transaktivierende oder eine reprimierende heterologe Proteindomäne gekoppelt ist, stark die Embryonalentwicklung von Xenopus Embryonen beeinträchtigten. Induktive Effekte des intrazellulären Signalvermittlers Smad2 werden dosisabhängig inhibiert. Die Induktion eines neuralen Markergens durch Xshn2ZF-enR deuten weiterhin auf eine Inhibition auch des BMP-Signalweges hin. Die Wirkung der Fusionsproteine lässt sich auf Ebene des ganzen Embryos, der Morphologie von animalen Kappen sowie auf Ebene der Induktion von mesodermalen Markergenen in animalen Kappen nachweisen. 


\section{Diskussion}

\subsection{Xschnurri Proteine als Homologe des Drosophila Schnurri Proteins}

In der Fruchtfliege Drosophila setzt der Transkriptionsfaktor Schnurri einen Teil des Dpp Signals in die differentielle Regulation von Zielgenen um. Schnurri kooperiert dabei mit Mad bei der sequenzspezifischen Bindung an Promotorsequenzen. Weil der TGF $\beta$ Signalweg, in dem Dpp wirkt, zwischen Invertebraten und Vertebraten außerordentlich hoch konserviert ist, wurde vermutet, dass auch in Vertebraten Schnurri-verwandte Zinkfinger Transkriptionsfaktoren bei der Vermittlung von Signalen des Activin- und des BMPSignalsweges mitwirken. Zu Beginn der vorausgegangenen eigenen Arbeiten (Dürr, 1997) waren bereits Schnurri-verwandte Proteine aus Säugern bekannt, jedoch gab es keine Hinweise auf eine Konservierung ihrer Funktion in TGF $\beta$ Signalwegen. Trotz hoher Sequenzidentität in zwei Doppelzinkfinger Domänen divergierten die Vertebraten-Proteine in ihrer Primärsequenz und in ihrem strukturellen Aufau so stark vom Drosophila Schnurri Protein, dass das Vorkommen von weiteren, näher zu Schnurri verwandten Proteinen in Vertebraten nicht ausgeschlossen werden konnte.

In eigenen Vorarbeiten (Dürr, 1997) wurden aufgrund der hohen Sequenzverwandschaft in ihrer carboxyterminalen Doppelzinkfinger Domäne drei partielle Schnurri-verwandte cDNASequenzen aus einer Xenopus Phagenbibliothek isoliert. Während der Untersuchungen für die vorliegende Arbeit konnten weitere partielle cDNA Sequenzen isoliert werden (Xshn1, -2), während die cDNA Sequenz von Xshn3 vollständig isoliert werden konnte.

Über Sequenzvergleiche mit Schnurri-verwandten Proteinen aus Säugern gelang eine Zuordnung der drei Xenopus Schnurri Proteine zu den Proteinen HIV-EP-1 (Xshn3), HIV-EP2 (Xshn2) und HIV-EP3 (Xshn1) (Nomenklatur nach Hicar et al., 2001). In den vergangenen Jahren wurden keine zum Drosophila Schnurri näher verwandten Sequenzen aus Vertebraten veröffentlicht. Die hohe Konservierung in den Zinkfinger Domänen von Xshn1, -2 und -3 zu Schnurri deutet zudem darauf hin, dass es sich bei den isolierten Sequenzen um Homologe von Schnurri handelt, die durch Genduplikation und -diversifikation entstanden sind.

Eine Analyse der Primärsequenz der drei Xenopus Schnurri Proteine Xshn1, -2 und -3 hatte in allen drei Proteinen auf eine große Zahl putativer Phosphorylierungsstellen für verschiedene Proteinkinasen hingedeutet, unter ihnen KaseinkinaseI und -II, PKA und PKC. Es ist daher möglich, dass die Aktivität der Proteine in der Zelle durch Phosphorylierungen durch die genannten oder verwandte Kinasen in ihrer Aktivität reguliert wird. Im Protein Xshn2 konnte zusätzlich eine repetitive Wiederholung von putativen Phosphorylierungsstellen identifiziert werden, die gleichzeitig mögliche DNA-Bindungsstrukturen für AT-reiche Sequenzelemente auf der DNA darstellen könnte (Churchill et al., 1989). Alle Xshn Proteine besitzen carboxyterminal der zweiten Zinkfingerdomäne eine Glutamat/Aspartat-reiche Region, die eine mögliche Transaktivierungsdomäne darstellt (Ptashne, 1988).

Ein Sequenzvergleich der drei Xenopus Schnurri Proteine miteinander zeigte eine hohe strukturelle Verwandtschaft und eine Konservierung der Aminosäuresequenzen in den 
aminoterminal und carboxyterminal gelegenen Doppelzinkfinger Domänen. Bis auf wenige weitere konservierte Bereiche, die über die Proteine verteilt zu finden sind, divergieren die Sequenzen jedoch sehr stark voneinander. Es ist daher zu vermuten, dass die drei Proteine diskrete zelluläre Funktionen übernehmen, aber über ihre Zinkfinger Domänen an dieselben DNA-Zielsequenzen binden können.

Ein Sequenzvergleich der Vertebraten Schnurri Proteine mit Drosophila Shn zeigte außer Homologien in den zwei Doppelzinkfinger Domänen nur in einem kurzen Sequenzbereich eine Konservierung von Aminosäuren. Der zwischen Shn, Xshn1 und -3 konservierte Bereich liegt innerhalb eines Abschnittes des Drosophila Proteins, in dem eine Dimerisierungsdomäne lokalisiert wurde (Udagawa et al., 2000).

\subsection{Xshn mRNAs werden während der mesodermalen Musterbildungsprozesse im Xenopus Embryo exprimiert}

Die Signalwege der TGF $\beta$ Superfamilie werden in Xenopus nach Einsetzen der zygotischen Transkription während des Blastula Stadiums aktiviert. In diesem Zeitraum der dorsoventralen Musterbildung des Mesoderms werden sowohl die transmembranen Rezeptoren als auch die zytoplasmatischen Vermittler der Signale, die Smad Proteine, ubiquitär im Embryo exprimiert. Auch die drei Xshn Gene werden im Stadium NF 10 ubiquitär in prospektiv mesodermalem und ektodermalem Gewebe exprimert. Im Entoderm zeigt Xshn1 eine stärkere Expression, während Xshn2 hier schwächer exprimiert wird. Eine besondere Funktion von Xshn1 im sich entwickelnden Entoderm lässt sich nicht ableiten.

Eine Analyse der zeitlichen Expression der Xshn mRNAs zeigte einen biphasischen Expressionsverlauf während der frühen Embryonalentwicklung. Die Gene werden maternal und bis zum Stadium NF 9 gleichmäßig exprimiert. Gegen Ende der Gastrulation und während der Neurulation sinkt die Expression ab und nimmt ab dem Stadium NF 20 wieder zu.

Mit den ermittelten Expressionsmustern und Expressionsverläufen erfüllen Xshn1, -2 und -3 die Voraussetzungen als mögliche Vermittler von Signalen der TGF $\beta$ Familie während der frühen Musterbildungsprozesse im Embryo.

Im weiteren Verlauf der Embryonalentwicklung zeigen Xshn1 -2 und -3 z.T. charakteristische Expressionsmuster, wie in der vorangegangenen Arbeit und im Verlauf der vorliegenden Arbeit durch "whole mount" in situ Hybridisierungen ermittelt werden konnte. Xshn1 konnte danach ab dem Stadium 26 in neuralem Gewebe detektiert werden. Es zeigte sich Färbung im Bereich der olfaktorischen Plakoden und im Stadium NF 34 auch im gesamten Gehirn und im Auge. Für keines der zu Xshn Proteinen homologen Proteinen aus Säugern liegen Angaben über die Verteilung der mRNA während der frühen Embryonalentwicklung vor.

Xshn2 zeigte während der späten Neuralstadien eine charakteristische Färbung in den Somiten, sowie im Stadium NF 34 eine punktuelle Färbung im anterioren Gehirn im Bereich der olfaktorischen Plakoden und in der embryonalen Haftdrüse. 
Auch für Xshn3 mRNA konnte eine differentielle Expression detektiert werden, wobei "whole mount" in situ Hybridisierungen bereits im Blastula Stadium eine etwas stärkere Färbung in der animalen Hemisphäre des Embryos zeigten. Dieses Expressionsverhalten entspricht dem anderer Komponenten der TGF $\beta$ Signalwege in diesem Stadium (vgl. Kap. 4.2). Ab der späteren Neurulation konnte Xshn3 mRNA verstärkt in neuralem Gewebe und, ählich Xshn2, in den Somiten nachgewiesen werden.

Interessant erscheint das Expressionsverhalten von Xshn3 bei Einsetzen der Organogenese. Untersuchungen von Embryonen im Stadium NF 34 gaben Hinweise darauf, dass Bereiche der Kiemenbögen und der sich entwickelnden Wirbelsäule von einer mRNA Expression ausgespart sein könnten. Die geringe Intensität der Färbung in den Embryonen ließ die Anfertigung von Gewebeschnitten jedoch leider nicht zu. Das beschriebene Expressionsverhalten könnte dem für das homologe Gen HIV-EP1 in frühen Mausembryonen beschriebenen ähneln. Tanaka et al. (2000) zeigten für das murine HIV-EP1 im Stadium e12.5 bei ansonsten weitgehend gleichmäßiger Verteilung der Transkripte eine Aussparung der Expression im Bereich der sich entwickelnden Wirbelkörper und Rippen. In diesem Bereich wird dagegen verstärkt das $\alpha 1$ (II) Kollagen Gen exprimiert. Die Autoren zeigen, dass HIVEP1 als Repressor des $\alpha 1$ (II) Kollagen Genes wirkt, und dass diese Repression während der Knorpelbildung lokal aufgehoben wird.

BMP wurde ursprünglich wegen seiner Fähigkeit entdeckt, ektopische endochondrale Verknöcherungen $\mathrm{zu}$ induzieren (Reddi et al., 1992). Ektopisches BMP bewirkt die Kondensierung von mesenchymalen Zellen, die in der Folge reifen, die Proliferation einstellen und zunächst Typ II Kollagen exprimieren. BMPs bestimmen hierbei die Rate der Differenzierung der Chondrozyten (Zou et al., 1997). HIV-EP1 wird in diesem Prozess während der frühen Stufen der Entwicklung exprimiert, während der Proliferation jedoch reprimiert, da es als Repressor der Typ II Kollagen Expression wirkt (Tanaka et al., 2000). HIV-EP1 könnte daher eine Funktion in der BMP-vermittelten Repression der Expression von TypII Kollagen während der frühen Stufen der Knorpelbildung zukommen.

Sollte das Expressionsverhalten von Xshn3 zu dem von HIV-EP1 während der Knorpelbildung vergleichbar sein, könnte dies ein Hinweis auf eine funktionelle Konservierung der Gene in Vertebraten sein. Hinweise auf eine direkte Beteiligung von HIVEP1 in der BMP-vermittelten Knorpelbildung sind jedoch nicht bekannt.

In adulten Geweben zeigen die $\mathrm{zu}$ Xshn homologen Gene HIV-EP1, -2 und -3 eine differentielle, für jedes Gen charakteristische Expression ihrer mRNA. HIV-EP1 wird vornehmlich im Gehirn und in der Thymusdrüse exprimiert (Nakamura et al., 1990), während HIV-EP2 v.A. im Skelettmuskel, im Herzmuskel und im Gehirn exprimiert wird (Dörflinger et al., 1999; Makino et al., 1994; Ron et al., 1991). HIV-EP3-Transkripte wurden dagegen verstärkt im Knochenmark und in der Thymusdrüse lokalisiert (Wu et al., 1993, 1996).

Im Gegensatz zu den murinen und humanen Homologen zeigten Xshn1, -2 und -3 Transkripte eine ubiquitäre und gleichmäßige Verteilung in Geweben adulter Xenopus Frösche. Eine Zuordnung der Gene zu ihren Säuger-Homologen über ihr Expressionsverhalten im adulten Tier war daher nicht möglich. 
Es lässt sich zusammenfassen, dass das räumliche und zeitliche Expressionsverhalten der Xshn1, -2 und -3 mRNAs eine Beteiligung ihrer Proteine an Activin- und BMP-vermittelten Musterbildungsprozessen im Xenopus Embryo möglich erscheinen lässt.

\subsection{Versuch der Überexpression des Gesamtlängen Xshn3}

Die cDNA von Xshn3 konnte während der vorliegenden Arbeit vollständig isoliert werden. Daher sollten in der Folge Überexpressionsstudien mit diesem Protein im Xenopus Embryo durchgeführt werden und über beobachtete phänotypische Veränderungen der injizieren Embryonen nach Möglichkeit auf die eigentliche Funktion des Proteins rückgeschlossen werden. Überexpressionen sollten durch Mikroinjektionen von synthetischer mRNA für das Gesamtlängen Protein in Xenopus Embryonen durchgeführt werden. Dies gelang nicht, weil sich innerhalb der in vitro synthetisierten mRNA vermutlich Sekundärstrukturen bildeten, die an zwei Positionen zu einer Termination der Transkription durch die bakteriellen RNAPolymerasen führte. In vitro-Transkriptionsansätze führten daher zur Bildung von Transkripten unterschiedlicher Länge, von denen nur das längste Transkript von $9 \mathrm{~kb}$ für das Gesamtlängenprotein kodierte. Eine Mikroinjektion des mRNA-Gemisches führte nicht zur Synthese einer signifikanten Menge des Gesamtlängen-Xshn3 Proteins von ca. 290 kDa Größe. Stattdessen konnten im Western Blot große Mengen von Abbruchfragmenten des Proteins detektiert werden. Eine Analyse von durch Mikroinjektion des mRNA-Gemisches erhaltenen phänotypischen Veränderungen von Xenopus Embryonen wäre duch die Abbruchfragmente gestört worden.

Es war weiterhin nicht möglich, das Gesamtlängen-Xshn3 Transkript durch Gel-Elution in ausreichender Menge anzureichern, um eine Mikrioinjektion der "reinen" mRNA anzuschließen. Überexpressionsexperimente in Xenopus Embryonen konnten daher nicht durchgeführt werden.

Der für Überexpressionsstudien verwendete Plasmid-Vektor pCS2+ besitzt einen starken eukaryotischen Promotor, der eine Transkription der inserierten cDNA in eukaryotischen Zellen ermöglicht. Möglicherweise wären eukaryotische Zellen in der Lage, die cDNA von Xshn3 vollständig zu transkribieren. Für Überexpressionsstudien in Xenopus Embryonen eignet sich die Injektion von Plasmid-DNA jedoch nicht, weil das resultierende Protein durch ungleiche Verteilung der Plasmid-DNA auf die Zellen punktuell (mosaikartig) exprimiert würde. Dies würde eine Analyse von phänotypischen Veränderungen erschweren. Denkbar wären allenfalls Überexpressionsstudien des Proteins durch transiente Transfektion eukaryotischer Zellen in Zellkultur. 


\subsection{Xshn3 besitzt definierte Kernimport- und Kernexport-Aktivität}

Eine Voraussetzung für die Funktion von Xshn Proteinen als Transkriptionsfaktoren ist ihre Fähigkeit, im Zellkern zu akkumulieren, um dort sequenzspezifisch an DNA zu binden. Die Translokation von Proteinen zwischen Zytoplasma und Zellkern erfolgt durch den Kernporenkomplex und ist ein energieabhängiger Prozess. Der Transport wird von Kernimport- und -exportsignalen innerhalb der Primärsequenz eines Proteins oder eines mit ihm assoziierten Proteins vermittelt.

Sowohl Schnurri als auch das Xshn3-homologe Protein HIV-EP1 konnten im Zellkern lokalisiert werden (Udagawa et al., 2000; Fan und Maniatis, 1990). Für die Analyse der subzellulären Lokalisation des Xshn3 Proteins in Xenopus wurden radioaktiv markierte, synthetische Xshn3-Proteinfragmente in den Zellkern bzw. in das Zytoplasma von Oozyten mikroinjiziert und ihre subzelluläre Verteilung $\mathrm{zu}$ verschiedenen späteren Zeitpunkten bestimmt. Durch die Verwendung von z.T. überlappenden Xshn3-Fragmenten sollte die Position möglicher Import- und Exportsignale innerhalb des Proteins abgeschätzt werden.

Es zeigte sich, dass Xshn3 in der Xenopus Oozyte klar definierte Import- und Exportaktivität besitzt, die in weit voneinander entfernten Bereichen des Proteins lokalisiert sind. Im Aminoterminus zwischen AS 1 und 426 kann ein Signal vermutet werden, das einen weitgehenden Kernimport des aminoterminalen Proteinfragmentes vermittelt. Dasselbe aminoterminale Fragment besitzt geringe Exportaktivität, welche dem Kernimport vermutlich entgegenwirkt. Eine geringe Importaktivität zeigt außerdem nur das Proteinfragment AS 10761749.

Im extremen Carboxyterminus von Xshn3 zwischen AS 2119 und 2578 befindet sich vermutlich eine Signalsequenz, die einen vollständigen Export der entsprechenden Proteinfragmente aus dem Zellkern bewirkt.

Obwohl Xshn3, wie auch die anderen Xshn Proteine, eine signifikante Zahl putativer Phosphorylierungsstellen für verschiedene Kinasen enthält, wurde nur das mittlere Proteinfragment (AS 1076-1749) in der Oozyte durch Phosphorylierung modifiziert.

die zelluläre Situation in der Oozyte reflektiert jedoch nicht die Situation eines Embryos während der Gastrulation. Innerhalb der offensichtlich phosphorylierten Peptidsequenz von Xshn3 befindet sich ein Serin-reicher Sequenzabschnitt von 30 Aminosäuren, der Zielsequenz verschiedener Kinasen wie CKI und PKA darstellen könnte. Das Proteinfragment könnte in dieser Region durch Kinasen der Oozyte modifiziert worden sein.

Bei einer Untersuchung der Amiosäuresequenz von Xshn3 nach möglichen Import- oder Exportsignalen der klassischen, in der Literatur beschriebenen Typen (vgl. Kap. 4.4) ließen sich mehrere Signale des SV40 Typs identifizieren. Im aminoterminalen Bereich des Proteins findet sich bei AS 46-68 eine Lysin/Arginin-reiche Sequenz, die ein SV40 Signal enthält und ein mögliches Importsignal darstellen könnte. Im mittleren Bereich von Xshn3 (AS 12251234), direkt an eine Serin-reiche Region angrenzend, befinden sich zwei kurze, Lysin/Arginin-reiche Sequenzen des SV40 Typs, die zwischen den drei Vertebraten 
Homologen konserviert ist und in der Literatur als mögliches Kernlokalisationssignal diskutiert wird (Arora et al., 1995, Staeling-Hempton et al., 1995). In der Oozyte zeigten diese Sequenzen jedoch geringe Aktivität. Es ist nicht auszuschließen, dass die Aktivität dieser Sequenzen durch Phosphorylierungen im genannten angrenzenden Serin-reichen Peptidbereich in der Oozyte negativ reguliert wurde. In ähnlicher Weise wird ein bipartites NLS in Nukleolin durch Phosphorylierungen und Dephosphorylierungen in einem angrenzenden Sequenzbereich reguliert (Schwab und Dreyer, 1997).

Als typische Kernexport-Signale werden in der Literatur u.a. Leucin-reiche Sequenzabschnitte des Rev-Typs beschrieben (z.B. Fridell et al., 1996). Ein derartiges Motiv konnte im Carboxyterminus von Xshn3 nicht identifiziert werden. Jedoch existiert ein Leucin- und Isoleucin-reicher Bereich (AS 2412-2432), der zwischen Xshn3-Proteinen konserviert ist und ähnliche biochemische Eigenschaften wie eine Leucin-reiche Sequenz besitzen könnte.

Das Vorkommen von klar definierten Import- und Exportaktivitäten in weit voneinander entfernten Regionen des Proteins Xshn3 widerspricht zunächst der Idee eines nukleären Transkriptionsfaktors. Möglich ist jedoch, dass die in vivo Aktivität des Gesamtproteins über die Aktivität der Import- und Exportsignale die reguliert wird. Ein zytoplasmatisches Xshn3 wäre demnach transkriptionell inaktiv. Eine derartige Regulation könnte durch posttranslationale Modifikationen (Phosphorylierungen) und/oder durch Interaktion von Xshn3 mit weiteren Proteinen geschehen, wodurch Import- oder Exportsignale maskiert oder demaskiert würden.

Wiederholt wurde von Spleißvarianten der Xshn3-homologen Gene in Säugern berichtet. Muchard et al. (1990) und Kantorow et al. (1993) konnten in Northern Blots kürzere Spleißvarianten von HIV-EP1 nachweisen, die für Peptide kodieren würden, die jeweils die aminoterminale oder die carboxyterminale Zinkfinger Domäne enthalten. Sollten derartige Spleißvarianten auch bei Xshn3 vorkommen, würden die resultierenden Proteine jeweils nur Kernimport- oder -exportaktivität besitzen. Die Proteine wären in unterschiedlichen Zellkompartimenten lokalisiert.

Es lässt sich zusammenfassen, dass innerhalb von Xshn3 je eine Domäne mit diskreter Importaktivität und Exportaktivität lokalisiert werden konnten.

\subsection{Xshn3 interagiert in vivo mit Smad-Proteinen}

$\mathrm{Zu}$ Beginn der vorliegenden Arbeit gründete sich die Vermutung einer Interaktion von Xshn Proteinen mit Smad Proteinen auf der Beobachtung, dass in Drosophila Mutanten für schnurri denen für $d p p$ oder dessen Rezeptoren phänotypisch ähneln. Parallel zu den eigenen Arbeiten konnte eine direkte Interaktion zwischen den Drosophila Proteinen Mad und Schnurri bestätigt werden (Udagawa et al., 2000; Dai et al., 2000). Diese Interaktionen wurden in vitro und im "yeast two hybrid"-System ermittelt. Eigene Arbeiten zielten darauf ab, mögliche in vivo Interaktionen zwischen Xenopus Xshn3 und Vertebraten Smad Proteinen zu ermitteln. Hierzu 
wurden Interaktionen zwischen überexprimierten Proteinen im Gastrula Stadium von Xenopus Embryonen untersucht. Damit sollte die zelluläre Situation während der Musterbildungsprozesse im Embryo nachvollzogen werden, in der alle Faktoren in den Zellen vorhanden sind, die in diesem Zeitraum Protein-Interaktionen stabilisieren oder destabilisieren könnten.

Es gelang der wiederholte Nachweis einer Interaktion von zwei epitopmarkierten Xshn3Proteinfragmenten (AS 1076-1749 und AS 2119-2578) mit einzelnen ko-exprimierten, epitopmarkierten Smad-Proteinen. Dabei konnten Interaktionen mit Rezeptor-regulierten Smad Proteinen sowie mit dem Ko-Smad Smad4 nachgewiesen werden. Die antagonistischen Smad Proteine Smad6 und -7 konnten nicht in Komplexen mit Xshn3 Proteinfragmenten nachgewiesen werden.

Rezeptor-regulierte Smad Proteine sind als Heteromere mit Smad4 transkriptionell aktiv. Aus diesem Grund wurden außerdem Interaktionen von Xshn3 Proteinfragmenten mit aktivierten Komplexen koexprimierter Smad-Proteine untersucht. Es zeigte sich eine verstärkte Interaktion der mit Einzel-Smads interagierenden Xshn3 Proteinfragmente mit solchen SmadKomplexen. Diese bestanden aus Smad1, -4 und -5 (aktiviert durch koexprimiertes BMP4) bzw. aus Smad2, -3 und 4 (aktiviert durch koexprimiertes Activin). Zusätzlich konnten weitere Interaktionen zwischen Xshn3 Fragmenten und Smad Komplexen beobachtet werden. Zum Einen gelang es, größere, mit den Interaktionsdomänen überlappende, Xshn3 Proteinfragmente zu ko-präzipitieren (Fragmente 4 und 6), die wahrscheinlich aufgrund ihres Molekulargewichtes (130 - $140 \mathrm{kDa})$ vorher nicht in Proteinkomplexen nachzuweisen waren. Zudem kopräzipitierten solche Xshn3 Proteinfragmente mit Smad Komplexen, die nicht mit ermittelten Interaktionsdomänen überlappen (Fragmente 1, 2 und 3).

Allgemein zeigte sich, dass Xshn3 Proteinfragmente besser mit Komplexen aktivierter SmadProteine kopräzipitierten als mit überexprimierten Einzel-Smad Proteinen. Dies bestätigte sich auch in Kontrollversuchen, die eine Kopräzipitation des "winged-helix" Transkriptionsfaktors FAST-1 mit Smad Proteinen anstrebte. Auch hier konnte epitopmarkiertes FAST-1 effektiver in Komplexen aus Smad2 und -3 und -4 nachgewiesen werden als in Komplexen mit Smad2 allein. Eine Kombination aus R-Smad Proteinen mit Smad4 spiegelt offensichtlich die in vivo Situation aktivierter Smad Komplexe besser wieder.

Innerhalb der besprochenen Versuche zeigte sich eine gewisse Varianz der Ergebnisse. Interaktionen von Xshn3 Fragmenten mit koexprimierten Einzel-Smads konnten nicht in jedem Versuch stabil reproduziert werden. Ein möglicher Grund liegt in der relativen Größe auch der kleineren Xshn3 Proteinfragmente, die 65 kDa nicht unterschritt. Komplexe größerer Proteine sind in Kopräzipitations-Experimenten grundsätzlich weniger stabil als Komplexe kleinerer Proteine. Dies zeigte sich auch in der guten Reproduzierbarkeit der Proteinkomplexe mit dem "kleinen" Protein FAST-1. Es ist weiterhin vermutlich der Grund dafür, dass die großen Xshn3 Proteinfragmente, die mit den interagierenden Fragmenten 5 und 8 überlappten, nicht in Komplexen mit Einzel-Smads nachzuweisen waren.

Rezeptor-regulierte Smad-Proteine werden erst nach ihrer Phosphorylierung und Assoziation mit Smad4 transkriptionell aktiv, indem sie in den Kern translozieren und mit 
Transkriptionsfaktoren assoziieren. Es ist daher vorstellbar, dass die beobachteten Assoziationen der Xshn3 Proteinfragmente 5 und 8 mit Smad Proteinen abhängig ist von der Aktivität (dem Phosphorylierungszustand) der Smad Proteine sind. Da für die hier besprochenen Versuche davon ausgegangen wurde, dass Xshn3 als Transkriptionsfaktor im Zellkern aktiv ist, waren die epitopmarkierten Xshn3 Proteinfragmente mit einem zusätzlichen heterologen Kernlokalisationssignal fusioniert.

Eine mögliche Abhängigkeit der Xshn-Smad-Interaktionen vom Phosphorylierungszustand der R-Smads wurde untersucht, indem jeweils aktivierende Liganden (Activin bzw. BMP4) oder dominant-negative Rezeptorkinasen (dn-BMPI-Rezeptor bzw. dn-Activin-I Rezeptor) koinjiziert wurden. In wiederholten Versuchen konnte in keinem Fall eine Abhängigkeit der Interaktion von Xshn3 Fragment 5 und 8 mit Smad Proteinen vom Aktivierungszustand des jeweiligen Signalweges beobachtet werden. Hierfür sind verschiedene Ursachen denkbar.

Es ist nicht auszuschließen, dass die Versuchsbedingungen es den stark in den Zellen überrepräsentierten Proteinen unmöglich machten, in dem anvisierten Zellkompartiment zurückgehalten zu werden. Eine Überexpression mehrerer Proteine würde demnach immer zu ihrer Kolokalisation in der Zelle führen. Sollte daher eine mögliche Interaktion zwischen Smad Proteinen und Xshn3 nur durch Regulation ihrer subzellulären Lokalisation reguliert sein, so wäre dies in den gewählten Versuchsbedingungen nicht nachzuweisen.

Wie im vorangegangen Versuch dargestellt, besitzt Xshn3 definierte Kernimport- und -exportaktivität. Es ist daher nicht auszuschließen, dass Xshn3 eine Funktion im Zytoplasma besitzt und hier konstitutiv mit Smad Proteinen interagiert. Xshn3 könnte dann mit aktivierten Smad Komplexen durch Kotransport in den Zellkern gelangen.

Für die zu Xshn3 homologen Proteine aus Säugern wurde von Spleißvarianten berichtet, die für partielle Proteine kodieren würden die nur den aminoterminalen- oder den carboxyterminalen Bereich des Proteins enthalten würden. Auf Xshn3 übertragen würde das bedeuten, dass die mit Smads interagierende Spleißvariante starke Exportaktivität besitzen würde. Umgekehrt würde die aminoterminale Variante starke Importaktivität besitzen.

\subsection{Vergleich der Position von Interaktions- und Lokalisationsdomänen zwischen Xshn3 und dem Drosophila Schnurri Protein}

Xshn3 interagiert, ähnlich wie das Drosophila Schnurri Protein, mit R-Smad Proteinen. In Xshn3 konnten zwei mit Smad Proteinen interagierende Bereiche lokalisiert werden, während in Shn nur eine Mad-Interaktionsdomäne lokalisiert werden konnte (Dai et al., 2000; vgl. Abb. 5.99). Ein Vergleich der relativen Positionen der Interaktionsdomänen innerhalb der Proteine zeigt, dass in Xshn3 und in Mad je eine Interaktionsdomäne im mittleren Bereich des Proteins lokalisiert ist. In diesem Bereich zeigen die Proteine jedoch keine erkennbare Sequenzverwandtschaft. Die Domänen können nicht als konserviert angesehen werden. Innerhalb von Shn konnte weiterhin eine Dimerisierungsdomäne lokalisiert werden (Udagawa 
et al. 2000). Eine mögliche Dimerisierung wurde in Xshn3 nicht untersucht. Innerhalb des dimerisierenden Bereiches von Shn befindet sich ein kurzer Sequenzbereich, der zwischen Shn, Xshn1 und Xshn3 konserviert ist. Ob dieser Bereich für eine Dimerisierung der Proteine verantwortlich sein könnte, ist nicht bekannt. Ein mittlerer Proteinbereich von Shn zeigte in Zellkultur Exportaktivität (Udagawa et al., 2000). Der entsprechende mittlere Bereich von Xshn3 zeigte keinerlei Exportaktivität.

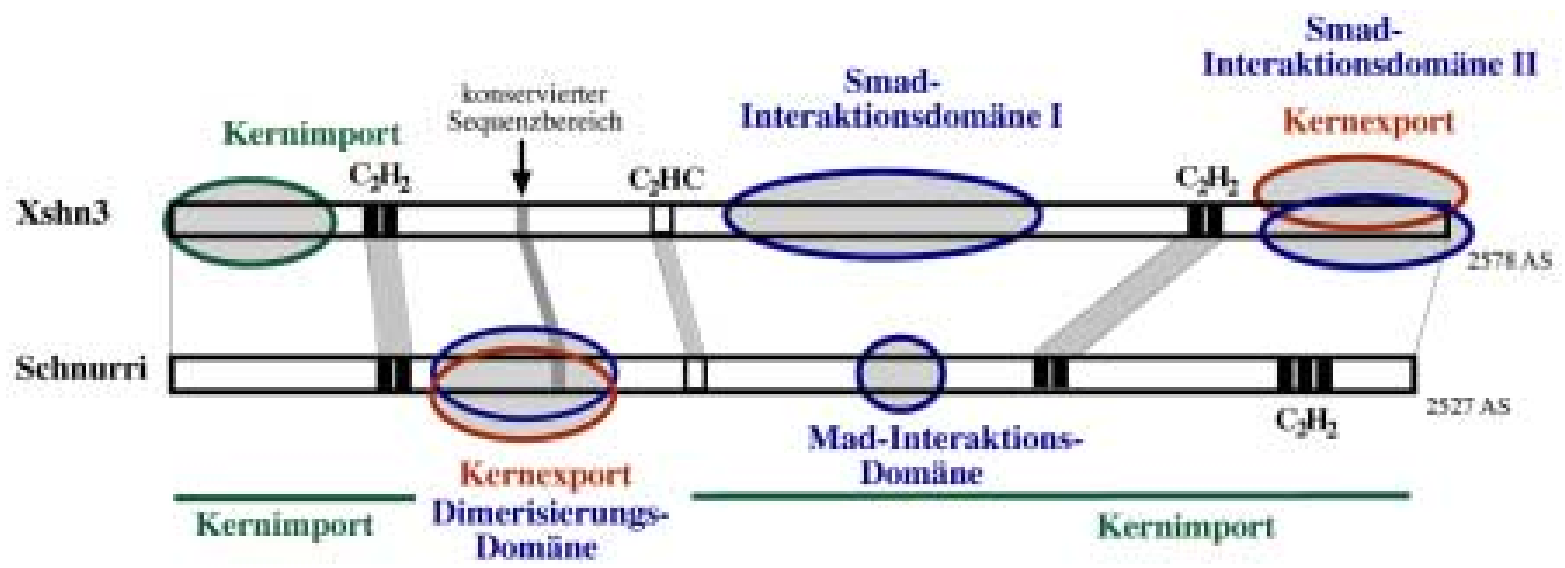

Abb. 5.1: Vergleich funktioneller Domänen zwischen Xshn3 und dem Drosophila Schnurri Protein. Querbalken zeigen schematisch die Primärsequenzen der Proteine. Blöcke zeigen die Position von Zinkfinger Domänen. Ein konservierter Sequenzbereich ist gekennzeichnet. Ovale zeigen die ungefähren Positionen funktioneller Domänen (Drosophila: Udagawa et al., 2000; Dai et al., 2000).

Mögliche funktionelle Domänen ausserhalb der Zinkfinger Domänen zwischen Xshn3 und Shn scheinen nicht in ihrer Sequenz konserviert zu sein. Diese Vermutung kann darin bestätigt gesehen werden, dass sich die Sequenzen der Proteine außerhalb der Zinkfinger Domänen insgesamt sehr stark voneinander unterscheiden. Eine funktionelle Konservierung in TGF $\beta$ Signalwegen ist dennoch v.A. wegen der hohen Konservierung in ihren Zinkfinger Domänen und der Interaktion beider Proteine mit Smad Proteinen nicht auszuschließen.

\section{7 Überexpression der carboxyterminalen Zinkfinger Domäne von Xshn3 führt zu starken Entwicklungsstörungen im Xenopus Embryo}

Gleichzeitig mit den Interaktionsstudien war aufgefallen, dass nach einer Überexpression des Xshn3 Proteinfragmentes 7 (AS 1880-2578) die injizierten Embryonen überdurchschnittlich häufig Gastrulationsdefekte aufwiesen. Bei diesem Phänotyp sind signalvermittelte aktive Wanderungsbewegungen des Mesoderms während der Gastrulation gestört. Als Ursache ist eine Inhibition des Activin-Signalweges wahrscheinlich. Alle Xshn3-Proteinfragmente waren in den Interaktionsstudien mit einem heterologen Kernlokalisationssignal fusioniert, weil eine Aktivität von Xshn3 als Transkriptionsfaktor im Zellkern angenommen worden war. 
Da gezeigt werden konnte, dass die Xshn3 Proteinfragmente 5, 7 und 8 mit Rezeptorregulierten Smad Poteinen und mit dem Ko-Smad, Smad4, interagieren, wurde vermutet, dass eine Überexpression der Fragmente 5, 7 und 8 im Embryo endogene Smad-Signalwege inhibieren könnte. Um mögliche Inhibitionen zu untersuchen, wurden die genannten Xshn3 Fragmente in Xenopus Embryonen überexprimert und phänotypische Veränderungen dokumentiert. Es zeigte sich, dass die Fragmente 5 und 8 allein auch bei hoher mRNA Konzentration nicht signifikant zu Störungen der Embryonalentwicklung führten. Für eine in vivo Aktivität von Xshn3 im TGF $\beta$ Signalweg werden außer der Smad-Interaktionsdomänen möglicherweise weitere Proteindomänen benötigt.

Es erstaunte bei den Überexpressionsstudien, dass das Fragment 7 im Gegensatz zum Fragment $8 \mathrm{zu}$ deutlichen Störungen der Entwicklung führte. Das Fragment 7 überlappt mit dem carboxyterminalen Fragment 8 und enthält zusatzlich zur Smad-Interaktionsdomäne die carboxyterminale Zinkfinger Domäne von Xshn3. Die Kombination der Zinkfinger Domäne mit der Smad Interaktionsdomäne oder anderer im Carboxyterminus gelegener Proteindomänen verlieh dem Peptid offensichtlich zusätzliche Eigenschaften, die sich als Störung der Musterbildung im Embryo auswirkten. Es ist zu vermuten, dass die Defekte durch sequenzspezifische DNA-Bindung der Zinkfingerdomäne und Störungen der transkriptionellen Aktivität von Xshn3-Zielgenen hervorgerufen wurden.

Weiterhin fiel bei den Interaktionsstudien auf, dass die Xshn3 Proteinfragmente 1 und 2, welche die aminoterminale Zinkfinger Domäne enthalten, trotz z.T. starker Überexpression nicht zu offensichtlichen Gastrulationsstörungen oder zum Zelltod führten. Möglicherweise besitzen die aminoterminale und die carboxyterminale Zinkfinger Domäne unterschiedliche DNA-Bindungseigenschaften. Nicht auszuschließen ist sogar, dass die aminoterminale Zinkfinger Domäne nicht an DNA bindet. Hinweise hierzu liefern Untersuchungen von Tanaka et al. (2000), die beobachteten, dass nur die carboxyterminale Zinkfinger Domäne des murinen zu Xshn3 homologen Proteins and den Col2A1 Enhancer bindet. Fan und Maniatis (1990) und Seeler et al. (1994) berichten dagegen von identischen Bindungseigenschaften der isolierten Zinkfinger Domänen.

Es ist aber auch denkbar, dass die Überexpression von Xshn3 Proteinfragmenten nicht die in vivo DNA-Bindungseigenschaften des Gesamtlängenproteins widerspiegelte. So könnten isolierte Zinkfingerdomänen zwar in vitro sequenzspezifisch an DNA binden. Im Kontext des gesamten Proteins könnten dagegen angrenzende Peptidbereiche die DNA-Bindugsfähigkeit der Zinkfinger Domänen modifizieren. Hinweise auf komplexe DNA-Bindungseigenschaften von Zinkfinger Transkriptionsfaktoren mit zwei weit voneinander entfernten DNABindungsdomänen kommen von der Analyse des Proteins Sip-1 (Verschueren et al., 1999).

Sip1 gehört, wie Schnurri und Evi-1, zu einer Gruppe von strukturell verwandten Zinkfinger Transkriptionsfaktoren. Die Proteine besitzen zwei weit voneinander entfernt positionierte Zinkfinger Cluster, die zueinander sequenzverwandt sind. Beide Cluster besitzen identische DNA-Bindungseigenschaften (vgl. Einleitung). Remacle et al. (1999) konnten für das murine Protein Sip1 einen komplexen Mechanismus der DNA-Bindung herausarbeiten. Beide 
Zinkfinger Cluster binden demnach an zwei tandemartig angeordnete Zielsequenzen, die in unterschiedlichem Abstand zueinander in verschiedenen Promotoren identifiziert werden konnten. Für eine Bindung von Sip1 and diese Promotoren müssen sowohl beide DNABindungsstellen als auch beide Zinkfinger Cluster innerhalb des Proteins Sip1 intakt sein. Eine Mutation entweder in einer der tandemartigen DNA-Bindungsstellen oder in einer der DNABindungsdomänen führt zum Verlust der DNA-Bindung durch das Protein Sip1.

Die Ergebnisse bedeuten für die Analyse ähnlicher Zinkfinger Transkriptionsfaktoren wie Schnurri Proteinen, dass aus den beobachteten Aktivitäten einzelner Proteinfragmente nicht notwendigerweise auf die Aktivität dieser Peptiddomänen im Kontext des gesamten Proteins geschlossen werden kann. So ist denkbar, dass die aminoterminale Zinkfinger Domäne von Xshn3 in den Proteinfragmenten 1 und 2 (AS 1-652 und AS 1-1075) bei Überexpression im Embryo keine DNA-Bindungsaktivität zeigte, im Kontext eines Gesamtlängen-Xshn3 Proteins jedoch durchaus eine Funktion bei der sequenzspezifischen DNA-Bindung besitzen könnte. Das Proteinfragment 7 (AS 1880-2578) könnte dagegen auch in isolierter Form zur DNABindung befähigt sein.

\subsection{Xshn-Zinkfinger Aktivator- und Repressorkonstrukte reprimieren Mesoderminduktion im Xenopus Embryo}

Das Xshn3 Proteinfragment 7 (AS 1880-2578) ließ durch seine Inhibition von Activinvermittelten Gastrulationsbewegungen im Embryo eine transkripionelle Aktivität vermuten. Es konnte jedoch nicht beurteilt werden, ob das Proteinfragment auf transkriptioneller Ebene als Aktivator oder als Repressor wirkte. Untersuchungen zur Regulation von Genexpressionen durch Xshn3-homologe Proteine aus Säugern geben hierzu widersprüchliche Angaben. Eine Aktivierung des HIV-1 Enhancers durch HIV-EP1 wurde von Fan und Maniatis (1990) und von Seeler et al. (1994) beobachtet. Muchard et al. (1992) beobachteten dagegen keinen Effekt auf die Expression des genannten Genes. Tanaka et al. (2000) berichten von einer Repression des $\alpha 1($ II)Kollagen Gen Enhancers, während Brady et al. (1995) von einer Aktivierung des $\alpha$ A Kristallin Promotors berichteten. Eine Funktion von Xshn3 als Aktivator oder als Repressor der Transkription ließ sich daher nicht voraussagen.

Um für Xshn3 Hinweise auf eine Aktivität als Repressor oder Aktivator der Transkription zu erhalten, wurden Überexpressionsexperimente mit Xshn3 Zinkfinger-Fusionsproteinen im Xenopus Embryo durchgeführt. Die vermutlich DNA-bindende carboxyterminale Zinkfinger Domäne wurde hierzu mit einer heterologen Transkriptions-reprimierenden Proteindomäne und vergleichend hierzu mit einer Transaktivierungsdomäne gekoppelt. Die Konstrukte wurden zusätzlich mit einem Kernlokalisationssignal versehen. Unterschiedliche Mengen der Proteine wurden gleichmäßig im Xenopus Embryo überexprimiert und die Intensität resultierender phänotypischer Veränderungen der Embryonen quantitativ ausgewertet. Zum Vergleich wurde das mit einem heterologen Kernlokalisationssignal versehene Proteinfragment 7 (AS 1880-2578) ebenso untersucht. 
Es zeigte sich, dass alle drei Fusionsproteine $\mathrm{zu}$ vergleichbaren Defekten der Embryonalentwicklung führten. Größere Mengen injizierter mRNA reprimierten Gastrulationsbewegungen. Embryonen, die die Gastrulation vollendeten, zeigten eine Reduktion in allen Körperregionen, wobei jeweils die Körperregionen reduziert waren, in denen die injizierten Fusionsproteine exprimiert wurden. Es fehlten Kopf-, Bauch-, Rückenoder Bauchstrukturen. In extremen Fällen nahmen die Embryonen eine kugeligundifferenzierte Gestalt an. Das Xshn3 Proteinfragment 7 verursachte dasselbe Spektrum von Veränderungen, jedoch in geringerer Ausprägung. Eine Injektion einer mit einem Kernlokalisationssignal versehenen Zinkfingerdomäne allein führte nicht zu vergleichbaren Defekten. Insgesamt konnte durch die dargestellten Versuche kein Hinweis darüber gewonnen werden, ob Xshn3 als Aktivator oder als Repressor der Transkription wirken könnte. Durch die deutlichen Effekte der Überexpression der Zinkfinger-Fusionsproteine wurde jedoch die Annahme einer DNA-Bindung der isolierten carboxyterminalen Zinkfingerdomäne bestätigt. Zudem wurde vermutet, dass durch die Fusionsproteine sowohl dorsalisierende als auch ventralisierende Signalwege inhibiert wurden.

Die beobachteten Phänotypen ließen eine Inhibition von Schlüsselfaktoren der mesodermalen Differenzierung im frühen Xenopus Embryo vermuten. Es schien möglich, dass die überexprimierten Fusionsproteine die Induktion durch Zielgenen von Faktoren der TGF $\beta$ Familie von Morphogenen störte.

Die morphologischen Defekte injizierter Embryonen ließen vermuten, dass das Zinkfinger Repressorkonstrukt und das -Aktivatorkonstrukt seine Wirkung durch Inhibition der Expression endogenener mesodermaler Markergene ausübten. Dies wurde in ,whole mount“ in situ Hybridisierungen bestätigt, die zeigten, dass nach Mikroinjektion der Konstrukte die Expression von Xbra auf der injizierten Seite reprimiert war.

Um der Vermutung der Repression mesodermaler Markergene nachzugehen, wurde im "animal cap" System untersucht, ob das Zinkfinger-Aktivator- und das ZinkfingerRepressorkonstrukt einen Einfluss auf die Smad2-vermittelte Induktion von dorsalmesodermalen Markergenen besitzen. Es zeigte sich, dass sowohl das Aktivator- als auch das Repressorkonstrukt in konzentrationsabhängiger Weise die Expression aller untersuchten mesodermalen Markergene reprimierten. Gleichzeitig konnte beobachtet werden, dass beide Konstrukte die Expression von Markergenen der neuralen Differnzierung bewirkten. Dies bedeutet, dass außer des dorsalisierenden Activin-Signalweges, in dem Smad2 wirkt, wahrscheinlich auch der ventralisierend wirkende BMP-Signalweg durch die Fusionsproteine reprimiert wurde. Eine Repression der Aktivität von BMP4 ist Voraussetzung für die neurale Differenzierung von Ektoderm im Xenopus Embryo.

Verwirrend erscheint, dass sowohl das Zinkfinger-Aktivatorkonstrukt als auch das Repressorkonstrukt inhibierend auf die Expression mesodermaler Markergene wirkte. Ein genereller reprimierender Effekt auf alle Promotoren durch die Fusionsproteine als Erklärung für diesen Effekt ist unwahrscheinlich, weil dies nicht die Induktion neuraler Markergene 
erklären würde. Vergleichbar widerprüchliche Effekte wurden auch für andere Repressor- und Aktivatorkonstrukte anderer Proteine beschrieben (div. pers. Komm.). Eine Erklärung hierfür ist nicht bekannt.

Das Zinkfinger-Repressorkonstrukt war in der Lage, eine Smad2-vermittelte Elongation von animalen Kappen zu reprimieren. Die Smad2-induzierte Elongation von animalen Kappen spiegelt die morphogenetischen Bewegungen des dorsalen Mesoderms während der Gastrulation wider. Die beobachtete Inhibition der Elongation von animalen Kappen stimmt mit Gastrulationsdefekten überein, die in injizierten ganzen Embryonen beobachtet wurden.

Die beschriebenen Resultate bestätigen die Vermutung einer Aktivität von Xshn3 in BMPund Activin-vermittelten Musterbildungsprozessen. Die Bindung der carboxyterminalen Zinkfinger Domäne an Promotor- oder Enhancersequenzen reichte in Überexpressionsexperimenten offensichtlich aus, um mesodermale Markergene zu reprimieren. Es ist hierbei nicht bekannt, ob es sich bei den Repressionen um direkte oder indirekte Effekte handelte. 


\section{Zusammenfassung}

In der Fruchtfliege Drosophila vermittelt der Zinkfinger Transkriptionsfaktor Schnurri einen Teil der musterbildenden Aktivität des Morphogens Dpp. Der TGF $\beta$ Signalweg, in dem Dpp wirkt, ist zwischen Invertebraten und Vertebraten hoch konserviert. Im Krallenfrosch Xenopus laevis stellen die Dpp-verwandten Moleküle Activin und BMP Schlüsselfaktoren der dorsoventralen Musterbildung des Mesoderms im frühen Embryo dar. Es wurde vermutet, dass auch in Vertebraten Schnurri-verwandte Zinkfinger Transkripitonsfaktoren als Vermittler von Signalen der TGF $\beta$ Familie, Activin und/oder BMP, während früher Musterbildungsprozesse wirken könnten.

Über ihre hohe Konservierug in der carboxyterminalen Doppelzinkfinger Domäne konnten in der vorausgegangen Arbeit (Dürr, 1997) und in der vorliegenden Arbeit drei Schnurriverwandte cDNA Sequenzen, Xshn1, -2 und -3 (Xshn1 und -2 partiell), aus Xenopus laevis isoliert werden. Datenbankanalysen zeigten Homologien der isolierten Sequenzen zu bekannten Proteinen aus Säugern (HIV-EP1, -2 und -3), die jedoch nicht in Bezug auf mögliche Funktionen in der frühen Embryonalentwicklung oder in TGF $\beta$ Signalwegen untersucht waren.

Eine Untersuchung der räumlich-zeitlichen Expression der Xshn1, -2 und -3 mRNAs während der dorso-ventralen Musterbildung in Xenopus laevis zeigte eine Übereinstimmung ihrer Expressionsmuster mit denen bekannter Komponenten des Activin- und des BMP Signalweges. Funktionsanalysen durch Überexpression von Xshn3 (280 kDa Größe) durch Mikroinjektion synthetischer mRNA in Xenopus Embryonen konnten nicht durchgeführt werden.

Untersuchungen zur subzellulären Lokalisation von Xshn3 Proteinfragmenten in mikroinjizierten Xenopus Oozyten ergaben deutliche Hinweise auf eine Kernimport- und eine Kernexport-Aktivität in weit entfernten Regionen des Proteins. Im Embryo könnte die Aktivität von Xshn3 als Transkriptionsfaktor durch Maskierung und Demaskierung von Peptidsignalen durch Proteinkinasen reguliert werden.

Eine in vivo Interaktion zwischen Xshn3-Proteinfragmenten und den zytoplasmatischen Signalvermittlern der TGF $\beta$ Familie, den Smad-Proteinen, konnte in KoImmunopräzipitations-Experimenten mit mikroinjizierten Xenopus Embryonen gezeigt werden. Dabei konnten zwei Smad-Interaktionsdomänen in Xshn3 lokalisiert werden. Die enthaltenen Sequenzbereiche zeigen keine Homologie zur Mad-Interaktionsdomäne im Drosophila Schnurri Protein. Auch die relativen Positionen von Import- und Exportsignalen überlappen nicht mit denen in Schnurri. Die Überexpression von transaktivierenden und von reprimierenden Xshn-Zinkfinger-Fusionsproteinen in Xenopus Embryonen reprimierte deutlich die Expression von mesodermalen Markergenen und inhibierte u.A. durch Activin vermittelte Gastrulationsbewegungen. Gleichzeitig wurden neurale Markergene induziert. Musterbildungsprozesse wurden in allen Körperregionen gestört. Ein vermutlich DNAbindendes und mit Smads interagierendes Xshn3-Proteinfragment wirkte in gleicher Weise.

Die erhaltenen Ergebnisse bestätigen Vermutungen über mögliche Funktionen von Vertebraten-Schnurri Proteinen in frühembryonalen Musterbildungsprozessen, die durch Signalmoleküle der TGF $\beta$ Familie von Morphogenen vermittelt werden. 


\section{Literaturverzeichnis}

Altschul, S.F., Gish, W., Miller, W., Myers, E.W. und Lipman, D.J. (1990). Basic local alignment search tool. J. Mol. Biol. 215:403-410.

Arora, K., Dai, H., Kazuko, S.G., Jamal, J., O’Connor, M., Letsou, A. und Warrior, R. (1995). The Drosophila schurri gene acts in the Dpp/TGF $\beta$ signaling pathway and encodes a transcription factor homologous to the human BMP family. Cell 81:781-790.

Badiani, P., Corbella, P., Kioussisi, D., Marvel, J. und Weston, K. (1994). Dominant interfering alleles define a role for c-Myb in T-cell development. Genes Dev. 8: 770-782.

Baeuerle, P.A. und Henkel, T. (1994). Function and activation of NF- $\kappa B$ in the immune system. Annu. Rev. Immunol. 12:141-179.

Baker, J.C. und Harland, R.M. (1996). A novel mesoderm inducer, Madr2, funcions in the activin signal transducton pathway. Genes Dev. 10:1880-1889.

Baldwin, A.S. Jr, LeClair, K.P., Singh, H. und Sharp, P.A. (1990). A large protein containing zinc finger domains binds to related sequence elements in the enhancers of the class I major histocompatibility complex and kappa immunoglobulin genes. Mol. Cell. Biol. 10:1406-14.

Bartholomew, C., Kilbey, A., Klark, A.M. und Walker, M. (1997). The Evi-1 proto-oncogene encodes a transcriptional repressor activity associated with transformation. Oncogene 14:569-577.

Bellefroid, E.J., Lecocq, P.J., Benhida, A., Poncelet, D.A., Belayew, A. und Marital, J.A. (1989). The human genome contains hundreds of genes coding for finger proteins of the Kruppel type. DNA 8:377-387.

Berg, J.M. und Shi, Y. (1996). The galvanization of biology: a growing appreciation for the roles of zinc. Science 271:1081-1085.

Bitzer, M., von Gersdorff, G., Liang, D., Dominguez-Rosales, A., Berg, A.A., Rojkind, M. und Bottinger, W.P. (2000). A mechanism of suppression of TGF- $\beta$ /SMAD signaling by NF-kappaB/RelA. Genes Dev. 14:187-197.

Blumberg, B., Wright, C.V., De Robertis, E.M. und Cho, K.W. (1991). Organizer-specific homeobox genes in Xenopus laevis embryos. Science 253:194-196.

Bouwmeester, T. und Leyns, L. (1997). Vertebrate head induction by anterior primitive endoderm. BioEssays 19:855-63.

Brady, J.P., Kantorow, M., Sax, C.M., Donovan, D.M. und Piatigorsky, J. (1995). Murine transcription factor $\alpha$ A-crystallin Binding Protein I. J. Biol. Chem. 270:1221-1229.

Brown, R.S., Sander, C., Argos, P. (1985). The primary structure of transcription factor TFIIIA has 12 consecutive repeats. FEBS Lett. 186:271-4.

Brown, J.D., DiChiara, M.R., Anderson, K.R., Gimbrone, Jr. M.A. und Topper, J.N. (1999). MEKK-1, a component of the stress (stress-activated protein kinase/c-Jun N-terminal kinase) pathway, can selectively activate Smad2-mediated transcriptional activation in endothelial cells. J. Biol. Chem. 274:8797-8805. 
Bullock, W.O., Fernandez, J.M. und Short, J.M. (1987). BioTechniques 5:376-379.

De Caestecker, M.P., Parks, W.T., Frank, C.J., Castagnino, P., Bottaro, D.P., Roberts, A.B. und Lechleider, R.J. (1998). Smad2 transduces common signals from receptor serinethreonine and tyrosine kinases. Genes Dev. 12:1587-1592.

Cauley, K. und Verma, I.M. (1994). Kappa B enhancer-binding complexes that do not contain NF-кB are developmentally regulated in mammalian brain. Proc. Natl. Acad. Sci. USA 91:390-394.

de Celis, J.F., Barrio, R. und Kafatos, F.C. (1996). A gene complex acting downstream of dpp in Drosophila wing morphogenesis. Nature 381:421-424.

Chamberlin, H.M., Brown, K.B., Sternberg, P.W. und Thomas, J.H. (1999). Characterization of seven genes affecting Caenorhabditis elegans hindgut development. Genetics 153:731742.

Campbell, G. und Tomlinson, A. (1999). Transducing the Dpp morphogen gradient in the wing of Drosophila: regulation of Dpp targets by brinker. Cell 96:553-562

Chan, L., Zuker, M. und Jacobson, A.B. (1991). A computer method for finding common base paired helices in aligned sequences: application to the analysis of random sequences. Nuc. Acids Res. 19:353-358.

Chang, C., Wilson, P.A., Mathews, S.S. und Hemmati-Brivanlou, A. (1997). A Xenopus type I activin receptor mediates mesodermal but not neural specification during embryogenesis. Dev. 124:827-837.

Chen, G. und Courey, A.J. (2000). Groucho/TLE family proteins and transcriptional repression. Gene 249:1-16.

Chen, X., Rubock, M.J. und Whitman, M. (1996). A transcriptional partner for MAD proteins in TGF-beta signalling. Nature 383:691-696.

Chen, X., Weisberg, E., Fridmacher, V., Watanabe, M. Naco G. und Whitman, M. (1997). Smad4 and FAST-1 in the assembly of activin-responsive factor. Nature 389:85-89.

Chitnis, A., Henrique, D., Lewis, J., Ish-Horowicz, D. und Kintner, C. (1995). Primary neurogenesis in Xenopus embryos regulated by a homologue of the Drosophila neurogenic gene Delta. Nature 375:761-766.

Cho, K.W., Blumberg, B., Steinbeisser, H. und De Robertis, E.M. (1991). Molecular nature of Spemann's organizer: the role of the Xenopus homeobox gene goosecoid. Cell 67:1111-1120.

Churchill, M.E., und Suzuki, M. (1989). 'SPKK' motifs prefer to bind to DNA at A/T-rich sites. EMBO J. 8:4189-4195.

Claussen, M., Rudt, F. und Pieler, T. (1999). Functional modules in ribosomal protein L5 for ribonucleoprotein complex formation and nucleocytoplasmic transport. J. Dev. Chem. 274:33951-8.

Cohen, S. (1997). Morphogens and pattern formation. BioEssays 19:721-729.

Cress, A. und Triezenberg, S.J. (1991). Nucleotide and deduced amino acid sequences of the gene encoding virion protein 16 of herpes simplex virus type 2. Gene 103:235-238. 
Christian, J.L., McMahon, J.A., McMahon, A.P. und Moon, R.T. (1991). Xwnt-8, a Xenopus Wnt-1/int-1-related gene responsive to mesoderm-inducing growth factors, may play a role in ventral mesodermal patterning during embryogenesis. Dev. 111:1045-1055.

Christian, J.L., und Moon, R.T. (1993). Interactions between Xwnt-8 and Spemann organizer signaling pathways generate dorsoventral pattern in the embryonic mesoderm of Xenopus. Genes Dev. 7:13-28.

Dai, H., Hogan, C., Goplakrishnan, B., Torres-Vazquez, J., Nguyen, M., Park, S., Raftery, L., Warrior, R. und Arora, K. (2000). The zinc finger protein Schnurri acts as a Smad partner in mediating the transcriptional response to Dpp. Dev. Biol. 227:373-387.

Dale, L., Howes, Gl, Price, B.M. und Smith, J.C. (1992). Bone morphogenetic protein 4: a ventralizing factor in early Xenopus development. Dev. 115:573-585.

Dale, L. und Jones, C.M. (1999). BMP signalling in early Xenopus development. BioEssays 21:751-760.

Das, P., Maduzia, L.L., Wang, H., Finelli, A.L., Cho, S.H., Smith, M.M. und Padgett, R.W. (1998). The Drosophila gene Medea demonstrates the requirement for different classes of Smads in dpp signaling. Dev. 125:1519-1528.

Dawid, I.B., Otani, H., Curtiss. P. und Taira, M. (1993). Regulatory interactions during embryogenesis in Xenopus laevis. C R Acad Sci III. 316:945-958.

de Celis, J.F., Barrio, R. und Kafatos, F.C. (1996). A gene complex acting downstream of dpp in Drosophila wing morphogenesis. Nature 381:421-424.

Dingwall, C., Robbins, J., Dilworth, S.M., Roberts, B. und Richardson, W.D. (1988). The nucleoplasmin nuclear location sequence is larger and more complex than that of SV40 large T antigen. J. Cell. Biol. 107:841-849.

Dörflinger, U., Pscherer, A., Moser, M., Rummele, P., Schule, R. und Buettner, R. (1999). Activation of somatostatin receptor II expression by transcription factors MIBP1 and SEF-2 in the murine brain. Mol. Cell. Biol. 19:3736-3747.

Dürr, U. (1997). Isolierung und Charakterisierung von zum Drosophila melanogaster Zinkfinger Protein Schnurri homologen Proteinen aus dem Krallenfrosch Xenopus laevis. Diplomarbeit, Universität Göttingen.

Dumont, J.N. (1972). Oogenesis in Xenopus laevis (Daudin). I. Stages of oocyte development in laboratory maintained animals. J. Morphol. 136:153-79.

El-Baradi, T. und Pieler, T. (1991). Zinc finger proteins: what we know and what we would like to know. Mech. Dev. 35:155-169.

Fan, C.M. und Maniatis, T. (1990). A DNA-binding protein containing two widely separated zinc finger motifs that recognize the same DNA sequence. Genes Dev. 4:29-42.

Fainsod, A., Steinbeisser, H. und DeRobertis, E.M. (1994). On the function of BMP-4 in patterning the marginal zone of the Xenopus embryo. EMBO J. 13:5015-5025.

Faure, S., Lee, M.A., Keller, T., ten Dijke, P. und Whitman, M. (2000). Endogenous patterns of TGF $\beta$ superfamily signaling during early Xenopus development. Dev. 127:2917-2931.

Feldherr, C.M., Kallenbach, E. und Schultz, N. (1984). Movement of a karyophilic protein through the nuclear pores of oocytes. J. Cel. Biol. 99:2216-2222. 
Ferguson, E.L. und Anderson, K.V. (1992). Decapentaplegic acts as a morphogen to organize dorsal-ventral pattern in the Drosophila embryo. Cell 71:451-461.

Fridell, R.A., Fischer, U., Lührmann, R., Meyer, B.E., Meinkoth, J.L., Malim, M.H. und Cullen, B.R. (1996). Amphibian transcription factor IIIA proteins contain a sequence element functionally equivalent to the nuclear export signal of human immunodeviciency virus type 1 rev. Proc. Natl. Acad. Sci. USA 93:2936-2940.

Frisch, A. und Wright, C.V.E. (1998). XBMPRII , a novel Xenopus type II receptor mediating BMP signaling in embryonic tissues. Dev. 125: 431-442.

Fritz, C.C. und Green, M.R. (1996). HIV Rev uses a conserved cellular protein export pathway for the nucleocytoplasmic transport of viral RNAs. Curr Biol. 6:848-54.

Ghosh, S., May, M.J. und Kopp, E.B. (1998). NF-кB and rel proteins: Evolutionarily conserved mediators of immune responses. Annu. Rev. Immunol. 16:225-260.

Görlich, D. und Kutay, U. (1999). Transport between the cell nucleus and the cytoplasm. Annu. Rev. Cell Dev. Biol. 15:607-670.

Görlich, D., Vogel, F., Mills, A.D., Hartmann, E. und Laskey, R.A. (1995). Distinct functions for the two importin subunits in nuclear protein import. Nature 377:246-248.

Graff, J.M., Thies, R.S., Song, J.J., Celeste, J., und Melton, D.A. (1994). Studies with a Xenopus BMP receptor suggest theat ventral mesoderm-inducing signals override dorsal signals in vivo. Cell 79:169-179.

Graff, J.M., Bansal, A. und Melton, D.A. (1996). Xenopus Mad proteins transduce distinct subsets of signals for the TGF beta superfamily. Cell 85:479-87.

Grieder, N.C., Nellen, D., Burke, R., Basler, K. und Affolter, M. (1995). schnurri is required for Drosophila Dpp signaling and encodes a zinc finger protein similar to the mammalian transcription factor PRDII-BF1. Cell 81:791-800.

Grimm, S. und Pflugfelder, G.O. (1996). Control of the gene optomotor-blind in Drosophila wing development by decapentaplegic and wingless. Science 271:1601-1604.

Gurdon, J.B. (1992). The generation of diversity and pattern in animal development. Cell 68 : 185-199.

Haskill, S., Beg, A.A., Tompkins, S.M., Morris, J.S., Yurochko, A.D., Sampson-Johannes, A., Mondal, K., Ralph und Baldwin, A.S., Jr. (1991). Characterization of an immediateearly gene induced in adherent monocytes that encodes IкB-like activity. Cell 65:12811289 .

Hata, A., Lagna, G., Massagué, J. und Hemmati-Brivanlou, A. (1998). Smad6 inhibits BMP/Smad1 signaling by specifically competing with the Smad4 tumor suppressor. Genes Dev. 12:186-197.

Hata, A., Lo, R.S., Wotton, D., Lagna, G. und Massague, J. (1997). Mutations increasing autoinhibition inactivate tumour suppressors Smad2 and Smad4. Nature 388:28-29.

Hata, A. (2001). TGF $\beta$ Signaling in Cancer. Exp. Cell Res. 264:111-116.

Hayashi, H., Abdollah, S., Qiu, Y., Cai, J., Xu, Y.Y., Grinnell, B.W., Richardson, M.A., Topper, J.N., Gimbrone, M.A., Wrana, J.L. und Ralb, D. (1997). The MAD-related protein Smad7 associates with the TGF $\beta$ receptor and functions as an antagonist of TGF $\beta$ signaling. Cell 89:1165-1173. 
Hemmati-Brivanlou, A., Melton, D.A. (1992). A truncated activin receptor inhibits mesoderm induction and formation of axial structures in Xenopus embryos. Nature 359:609-614.

Hemmati-Brivanlou, A. und Thomsen, G.H. (1995). Ventral mesodermal patterning in Xenopus embryos: expression patterns and activities of BMP-2 and BMP-4. Dev. Genet. 17:78-89.

Hemmati-Brivanlou, A., Wight, D.A. und Melton, D.A. (1992). Embryonic expression and functional analysis of a Xenopus activin receptor. Dev. Dyn. 194:1-11.

Henderson, K.D., Isaac, D.D. und Andrew, D.J. (1999). Cell fate specification in the Drosophila salivary gland: the intergration of homeotic gene function with the Dpp signaling cascade. Dev. Biol. 205:10-21.

Hicar, M.D., Liu, Y., Allen, C.E. und Wu, L. (2001). Structure of the human zinc finger protein hivep3: molecular cloning, expression, exon-intron structure, and comparison with paralogous genes hivep1 and hivep2. Genomics 71:89-100.

Hollemann, T., Chen, Y., Grunz, H. und Pieler, T. (1998). Regionalized metabolic activity establishes boundaries of retionoic acid signalling. EMBO J. 17:7361-7372.

Hollemann, T., Schuh, R., Pieler, T. und Stick, R. (1996). Xenopus Xsal-1, a vertebrate homolog of the region specific homeotic gene spalt of Drosophila. Mech. Dev. 55:1932 .

Hudson, J. B., Podos, S. D., Keith, K., Simpson, S. L. und Ferguson, E. L, (1998). The Drosophila Medea gene is required downstream of dpp and encodes a functional homolog of human Smad4. Dev. 125:1407-1420.

Imamura, T., Takase, M., Nishihara, A., Oeda, E., Hanai, J., Kawabata, M. und Miyazono, K. (1997). Smad6 inhibits signalling by the TGF-beta superfamily. Nature 389:622-626.

Inoue, H., Imamura, T., Ishidou, Y., Takase, M., Udagawa, Y., Oka, Y., Tsuneizumi, T., Tabata, T., Miyazono, K. und Kawabata, M. (1998). Interplay of signal mediators of Decapentaplegic (Dpp): molecular characterization of Mothers against dpp, Medea, and Daughters against dpp. Mol. Biol. Cell 9:2145-2156.

Ishisaki, A., Yamamoto, K., Nakao. A., Nonaka. K., Ohguchi, M. und ten Dijke, P. (1998). Smad7 is an activin-inducible inhibitor of activin-induced growth arrest and apoptosis in mouse B cells. J. Biol. Chem. 247:24293-24296.

Ishisaki, A., Yamoto, K., Hashimoto, S., Nakao, A., Tamaki, K., Nonaka, K., ten Dijke, P., Sugino, H. und Nishihara, T. (1999). Differential inhibition of Smad6 and Smad7 on bone morphogen. J. Biol. Chem. 274:13637-13642.

Izutsu, K., Kurokawa, M., Imai, Y., Maki, K., Mitani, K. und Hirai, H. (2001). The corepressor CtBP interacts with Evi-1 to repress transforming growth factor signaling. Blood 97:2615-2622.

Jazwinska, A., Kirov, N., Wieschaus, E., Roth, S. und Rushlow, C. (1999a). The Drosophila gene brinker reveals a novel mechanism of Dpp target gene regulation. Cell 96:563-573.

Jazwinska, A., Rushlow, C. und Roth, S. (1999b). The role of brinker in mediating the graded response to Dpp in early Drosophila embryos. Dev. 126:3323-3334.

Johnston, S.D. und Nusslein-Volhard, C. (1992). The origin of pattern and polarity in the Drosophila embryo. Cell 68:201-219. Review. 
Kadonaga, J.T., Carner, K.R., Masiarz, F.R. und Tjian, R. (1987). Isolation of cDNA encoding transcription factor $\mathrm{Sp} 1$ and functional analysis of the DNA binding domain. Cell 51:1079-1090.

Kaffman, A. und O'Shea, E.K. (1999). Regulation of nuclear localization: a key to a door. Annu. Rev. Cell Dev. Biol. 15:291-339.

Kalderon, D., Roberts, B.L., Richardson, W. und Smith, A.E. (1984). A short amino acid sequence able to specify nuclear location. Cell 39:499-509.

Kantorow, M., Becker, K., Sax, C.M., Ozato, K. und Piatigorsky, J. (1993). Binding of tissuespecific forms of alpha A-CRYBP1 to their regulatory sequence in the mouse alpha Acrystallin-encoding gene: double-label immunoblotting of UV-crosslinked complexes. Gene 131:159-165.

Kim, J., Johnson, K., Chen, H.J., Carroll, S. und Laughon, A. (1997). Drosophila Mad binds to DNA and directly mediates activation of vestigial by Decapentaplegic. Nature 388:304308.

Kimelman, D. und Griffin, K.J. (2000). Vertebrate mesendoderm induction and patterning. Curr. Op. Genet. Dev. 10:350-356.

Kintner, C.R. und Melton, D.A. (1987). Expression of Xenopus N-CAM RNA in ectoderm is an early response to neural induction. Dev. 99:311-325.

Knippers, R., Schäfer, K.P. und Fanning, E. (1985). Molekulare Genetik. Georg Thieme Verlag Stuttgart, New York.

Koebernick, K. (2000). Identifikation und funktionelle Analyse von Elementen der Hedgehog Signaltransduktionskaskade in Xenopus laevis. Dissertation, Universität Göttingen.

Kondo, M., Tashiro, K., Fujii, G., Asano, M., Miyoshi, R., Yamada, R., Muamatsu, M. und Shiokawa, K. (1991). Activin receptor mRNA is expressed early in Xenopus embryogenesis and the level of the expression affects the body axis formation. Biochem. Biophys. Res. Commun. 181:684-690.

Korner, M., Tattner, A., Mauxion, F., Sen, R. und Citri, Y. (1989). A brain-specific transcription activator. Neuron 3:563-572.

Köster, M., Plessow, S., Clement, J.H., Lorenz, A., Tiedemann, H. und Knochel, W. (1991). Bone morphogenetic protein 4 (BMP-4), a member of the TGF-beta family, in early embryos of Xenopus laevis: analysis of mesoderm inducing activity. Mech Dev. 33:191-199.

Kozak, M. (1991). An analysis of vertebrate mRNA sequences: intimations of translational control. J. Cell Viol. 115:887-903.

Kretzschmar, M., Doody, J. und Massagué, J. (1997). Opposing BMP and EGF signalling pathways converge on the TGF- $\beta$ family mediator Smad1. Nature 389:618-622.

Kretzschmar, M., Doody, J., Timokhina, I. und Massagué, J. (1999). A mechanism of repression of TGF $\beta /$ Smad signaling by oncogenic Ras. Genes Dev. 13:804-816.

Kurokawa, M., Mitani, K., Imai, Y., Ogawa, S., Yazaki, Y. und Hirai, H. (1998a). The t(3;21) fusion product, AML1/EVI-1, interacts with Smad3 and blocks Transforming Growth Factor- $\beta$-mediated growth inhibition of myeloid cells. Blood 92:4003-4013. 
Kurokawa, M., Mitani, K., Irie, K., Matsuyama, T., Takahashi, T., Chiba, S., Yazaki, Y., Matsumoto, K. und Hirai, H. (1998b). The oncoprotein EVI-1 represses TGF- $\beta$ signalling by inhibiting Smad3. Nature 394:92-96.

Labbe, E., Silvestri, C., Hoodless, P.A., Wrana, J.L. und Attisano, L. (1998). Smad2 and Smad3 positively and negatively regulate TGF beta-dependent transcription through the forkhead DNA-binding protein FAST2. Mol. Cell 2:109-120.

Laemmli, U.K. (1970). Cleavage of structural proteins during the assembly of the head of bacteriphage T4. Nature 227:680-685.

Lagna, G., Hata, A., Hemmati-Brivanlou, A. und Massagué J. (1996). Partnership between DPC4 and SMAD proteins in TGF- $\beta$ signalling pathways. Nature 383:832-835.

Lamb, T.M., Knecht, A.K., Smith, W.C., Stachel, S.E., Economides, A.N., Stahl, N., Yancopolous, G.D. und Harland, R.M. (1993). Neural induction by the secreted polypeptide noggin. Science. 262:713-718.

Lo, R.S. und Massagué, J. (1999). Ubiquitin-dependent degradation of TGF- $\beta$-activated Smad2. Nat. Cell. Biol. 1:472-478.

Maduzia, L.L. und Padgett, R.W. (1997). Drosophila MAD, a member of the Smad family, translocates to the nucleus upon stimulation of the dpp pathway. Biochem. Biophys. Res. Commun. 238:595-598.

Maekawa, T., Sakura, H., Sudo, T. und Ishii, S. (1989). Putative metal finger structure of the human immunodeficiency virus type 1 enhancer binding protein HIV-EP1. J. Dev. Chem. 264:14591-14593.

Makino, R., Akiyama, K., Yasuda, J., Mashiyama, S., Honda, S., Sekiya, T. und Hayashi, K. (1994). Cloning and characterization of a c-myc intron binding protein (MIBP1). Nucleic Acids Res. 22:5679-5685.

Mannervik, M., Nibu, Y., Zhang, H. und Levine, M. (1999). Transcriptional coregulators in development. Science 284:606-609.

Marty, T., Muller, B., Basler, K. und Affolter, M. (2000). Schnurri mediates Dpp-dependent repression of brinker transcription. Nat. Cell Biol. 2:745-749.

Mathews, L.S., Vale, W.W. und Kintner, C.R. (1992). Cloning of a second type of activin receptor and functional characterization in Xenopus embryos. Science 255: 17021705 .

Matunis, E., Tran, J., Gönczy, P., Cadwell, K. und DiNardo, S. (1997). Punt and schnurri regulate a somatically derived signal that restricts proliferation of committed progenitors in the germline. Dev. 124:4383-4391.

McDowell, N. und Gurdon, J.B. (1999). Activin as a morphogen in Xenopus mesoderm induction. Semin. Cell Dev. Biol. 10:311-317.

Michael, W.M., Eder, P.S. und Dreyfuss, G. (1997). The K nuclear shuttling domain: a novel signal for nuclear import and nuclear export in the hnRNP $\mathrm{K}$ protein. Embo $J$. 16:3587-98.

Michael, W.M., Siomi, H., Choi, M., Pinol-Roma, S., Nakielny, S., Liu, Q. und Dreyfuss, G. (1995b). Signal sequences that target nuclear import and nuclear export of premRNA-binding proteins. Cold Spring Harb. Symp. Quant. Biol. 60:663-668. 
Minami, M., Kinoshita, N., Kamoshida, Y., Tanimoto, H. und Tabata, T. (1999). Brinker is a target of Dpp in Drosophila that negatively regulates Dpp-dependent genes. Nature 398: $242-246$.

Mitchelmore, C., Traboni, C. und Cortese, R. (1991). Isolation of two cDNAs encoding zinc finger proteins which bind to the alpha 1-antitrypsin promoter and to the major histocompatibility complex class I enhancer. Nucleic Acids Res. 19:141-147.

Moermann, A.M., Mao, X., Lucas, M.M. und Barger, S.W. (1999). Characterization of a neuronal kappaB-binding factor distinct from NF-кB. Mol. Brain Res. 67, 141-147.

Muchardt, C., Seeler, J.S., Nirula, A., Shurland, D-L. und Gaynor, R.B. (1992). Regulation of human immunodeficiency virus enhancer function by PRDII-BF1 and c-rel gene producs. J. Virol. 66:244-2501.

Nagarajan, R.P., Zhang, J., Li, W. und Chen, Y. (1999). Regulation of Smad7 promoter by direct association with Smad3 and Smad4. J. Biol. Chem. 274:33412-33418.

Nakamura, T., Donovan, D.M., Hamada, K., Sax, C.M., Norman, B., Flanagan, J.R., Ozato, K., Westphal, H. und Piatigorsky, J. (1990). Regulation of the mouse alpha A-crystallin gene: isolation of a cDNA encoding a protein that binds to a cis sequence motif shared with the major histocompatibility complex class I gene and other genes. Mol. Cell. Biol. 10:3700-3708.

Nakayama, T., Snyder, M.A., Grewal, S.S., Tsuneizumi, K., Tabata, T. und Christian, J.L. (1998). Xenopus Smad8 acts downstream of BMP-4 to modulate its activity during vertebrate embryonic patterning. Dev. 125:857-867.

Neul, J.L. und Ferguson, E.L. (1998). Spatially restricted activation of the Sax receptor by Scw modulates Dpp/Tkv signaling in Drosophila dorsal-ventral patterning. Cell 95:483-494.

Neumann, C.J. und Cohen, S.M. (1997). Long-range action of Wingless organizes the dorsalventral axis of the Drosophila wing. Dev. 124:871-80.

Newfeld, S.J., Chartoff, E.H., Graff, J.M., Melton, D.A. und Gelbart, W.M. (1996). Mothers against dpp encodes a conserved cytoplasmic protein required in DPP/TGF-beta responsive cells. Dev. 122:2099-2108.

Nguyen, M., Park, S., Marques, G. und Arora, K. (1998). Interpretation of a BMP activity gradient in Drosophila embryos depends on synergistic signaling by two type I receptors, SAX and TKV. Cell 95:495-506.

Nieuwkoop, P.D. und Faber, P. (1967). Normal Table of Xenopus laevis (Daudin). 2nd edition. North-Holland Publ. Co. Amsterdam.

Nishihara, A., Hanai, J., Imamura, T., Miyazono, K. und Kawabata, M. (1999). E1A inhibits transforming growth factor-beta signaling through binding to Smad proteins. J. Biol. Chem. 274:28716-28723.

Nomura, N., Zhao, M.J., Nagase, T., Maekawa, T., Ishizaki, R., Tabata, S. und Ishii, S. (1991). HIV-EP2, a new member of the gene family encoding the human immunodeficiency virus type 1 enhancer-binding protein. Comparison with HIV-EP1/PRDII-BF1/MBP-1. J. Dev. Chem. 266:8590-8504.

Nüsslein-Volhard, C., Wieschaus, E. und Kluding, H. (1984). Mutations affecting the pattern of the larval cuticle in Drosophila melanogaster. I. Zygotic loci on the second chromosome. Roux's Arch. Dev. Biol. 193:267-282. 
Padgett, R.W., Johnston R.D.S., Gelbart W.M. (1997). A transcript from a Drosophila pattern gene predicts a protein homologous to the transforming growth factor- $\beta$ family. Nature 325:81-84.

Pankratz, M.J. und Jäckle, H. (1990). Making stripes in the Drosophila embryo. Trends in Genetics 6:287-292.

Piek, E., Heldin, C.H. und ten Dijke, P. (1999). Specificity, diversity, and regulation in TGF- $\beta$ superfamily signaling. FASEB 13:2105-2124.

Pieler, T. und Bellefroid, E.J. (1994). Perspectives on zinc finger protein function and evolution - An update. Mol. Biol. Rep. 20:1-8.

Ptashne, M. (1988). How eukaryotic transcriptional activators work. Nature 335:683-689. Review.

Raftery, L.A., Twombly, V., Wharton, K. und Gelbart, W.M. (1995). Genetic screens to identify elements of the decapentaplegic signaling pathway in Drosophila. Genetics 139:241254.

Raftery, L.A. und Sutherland, D.J. (1999). TGF-beta family signal transduction in Drosophila development: from Mad to Smads. Dev. Biol. 210:251-268.

Raftery, L.A. und Wisotzkey, R.G. (1996). Characterization of Medea, a gene required for maximal function of the Drosophila BMP homolog Decapentaplegic. Ann. N. Y. Acad. Sci. 785:318-320.

Rastegar, S., Friedle, H., Frommer, G. und Knochel, W. (1999). Transcriptional regulation of Xvent homeobox genes. Mech. Dev. 81, 139-149.

Reddi, A.H. (1992). Regulation of cartilage and bone differentiation by bone morphogenetic proteins. Curr. Opin. Cell Biol. 4: 850-855.

Remacle, J.E., Kraft, H., Lerchner, W., Wuytens, G., Collart, C., Verschueren, K., Smith, J.C. und Huylebroeck, D. (1999). New mode of DNA binding of multi-zinc finger transcription factors: deltaEF1 family members bind with two hands to two target sites. EMBO J. 18:5073-5084.

Riggins, G.J., Thiagalingam, S., Rozenblum, E., Weinstein, C.L., Kern, S.E., Hamilton, S.R., Willson, J.K., Markowitz, S.D., Kinzler, K.W. und Vogelstein B. (1996). Mad-related genes in the human. Nat. Genet. 13:347-349.

Robbins, J., Dilworth, S.M., Laskey, R.A. und Dingwall, C. (1991). Two interdependent basic domains in nucleoplasmin nuclear targeting sequence: identification of a class of bipartite nuclear targeting sequence. Cell 64:615-623.

Romaniuk, P.J. (1985). Characterization of the RNA binding properties of transcription factor IIIA of Xenopus laevis oocytes. Nucleic Acids. Res. 13:5369-5387.

Ron, D., Brasier, A.R. und Habener, J.F. (1991). Angiotensinogen gene-inducible enhancerbinding protein 1 , a member of a new family of large nuclear proteins that recognize nuclear factor kappa B-binding sites through a zinc finger motif. Mol. Cell. Biol. 11:2887-2895.

Rosorius, O., Fries, B., Stauber, R.H., Hirschmann, N., Bevec, D. und Hauber, J. (2000). Human ribosomal protein L5 contains defined nuclear localization and export signals. J. Dev. Chem. 275:12061-12068. 
Ruberte, E., Marty, T., Nellen, D., Affolter, M. und Basler, K. (1995). An absolute requirement for both the type II and type I receptors, punt and thick veins, for dpp signaling in vivo. Cell 80:889-897.

Rupp RA, Snider L, Weintraub H. (1994). Xenopus embryos regulate the nuclear localization of XMyoD. Genes Dev. 8:1311-1323.

Rusch, J. und Levine, M. (1996). Threshold responses to the dorsal regulatory gradient and the subdivision of primary tissue territories in the Drosophila embryo. Curr. Opin. Genet. Dev. 6:416-423.

Rustgi, A.K., Van 't Veer, L.J. und Bernards, R. (1990). Two genes encode factors with NFkappa B- and H2TF1-like DNA-binding properties. Proc. Natl. Acad. Sci. USA 87, 8707-8710.

Sadowski, I., Ma, J., Triezenberg, S. und Ptashne, M. (1988). Gal4-VP16 is an unusually potent transcriptional activator. Nature 335:563-564.

Sambrook, J., Fritsch, E.F. und Maniatis., T. (1989). Molecular cloning. A laboratory manual. CSH Press, Cold Spring Harbor.

Sanger, R., Niklen, S. und Coulson, A.R. (1977). DNA Sequencing with chain-terminating inhibitors. Proc. Natl. Acad. Sci. USA 74:5463-5467.

Sasai, Y., Lu, B., Steinbeisser, H. und De Robertis, E.M. (1995). Regulation of neural induction by the Chd and Bmp-4 antagonistic patterning signals in Xenopus. Nature 376:333336.

Schwab, M.S. und Dreyer, C. (1997). Protein phosphorylation sites regulate the function of the bipartite NLS of nucleolin. Eur. J. Cell Biol. 73:287-297.

Seeler, J.S., Muchardt, C., Suessle, A. und Gaynor, R.B. (1994). Transcription factor PRDIIBF1 activates human immunodeficiency virus type 1 gene expression. J. Virol. 68:1002-1009.

Sekelsky, J.J., Newfeld, S.J., Raftery, L.A., Chartoff, E.H. und Gelbart, W.M. (1995). Genetic characterization and cloning of mothers against dpp, a gene required for decapentaplegic function in Drosophila melanogaster. Genetics 139:1347-1358.

Siomi, H. und Dreyfuss, G. (1995). A nuclear localization domain in the hnRNP A1 protein. $J$. Cell Biol. 129:551-560.

Smith, J.C., Price, B.M.J., Van Nimmen, K. und Huylebrook, D. (1990). XTC-MIF; a potent Xenopus mesoderm inducing factor, is a homologue of activin A. Nature 345:729-731.

Smith, J.C., Price, B.M., Green, J.B., Weigel, D. und Herrmann, B.G. (1991). Protein Expression of a Xenopus homolog of Brachyury $(\mathrm{T})$ is an immediate-early response to mesoderm induction. Cell 67:79-87.

Spemann, H. und Mangold, H. (1924). Über Induktion von Embryonalanlagen durch Implantation artfremder Organisatoren. Roux's Arch. Entw. Mech. 100:599-638.

Staeling-Hampton, K., Laughon, A.S. und Hoffmann, F.M. (1995). A Drosophila protein related to the human zinc finger transcription factor PRDII/MBP1/HIV-EP1 is required for dpp signalling. Dev. 121:3393-3403.

Stanojevic, D., Hoey, T. und Levine, M. (1989). Sequence-specific DNA-binding activities of the gap proteins encoded by hunchback and Kruppel in Drosophila. Nature 341:331335 . 
St. Johnston, R.D. und Gelbart, W.M. (1997). Decapentaplegic transcripts are localized along the dorsal-ventral axis of the Drosophila embryo. EMBO J. 6:2785-2791.

Stryer, L. (1996). Biochemie. Spektrum Akademischer Verlag, Heidelberg.

Suzuki, M. (1989). SPXX, a frequent sequence motif in gene regulatory proteins. J. Mol. Biol. 207:61-84.

Szuts, D., Eresh, S. und Bienz, M. (1998). Functional intertwining of Dpp and EGFR signaling during Drosophila endoderm induction. Genes Dev. 12:2022-2035.

Tabernero, C., Zolotukhin, A.S., Valentin, A., Pavlakis, G.N. und Felber, B.K. (1996). The posttranscriptional control element of the simian retrovirus type 1 forms an extensive RNA secondary structure necessary for its function. J. Virol. 7:5998-6011.

Tadano, T., Otani, H., Taira, M. und Dawid, I.B. (1993). Differential induction of regulatory genes during mesoderm formation in Xenopus laevis embryos. Dev. Genet. 14:204211.

Takase, M., Imamura, T., Sampath, T.K., Takeda, K., Ichijo, H., Miyazono, K. und Kawabata, M. (1998). Induction of Smad6 mRNA by bone morphogenic proteins. Biochem. Biophys. Res. Commun. 244:26-29.

Tanaka, K., Matsumoto, Y., Nakatani, F., Iwamoto, Y. und Yamada, Y. (2000). A zinc finger transcriptionfactor, $\alpha \mathrm{A}$-Crystallin Binding Protein 1 , is a negative regulator of the chondrocyte-specific enhancer of the $\alpha 1$ (II) collagen gene. Mol. Cell. Biol. 20:44284435 .

Tang, H., Gaietta, G.M., Fischer, W.H., Ellisman, M.H. und Wong-Staal, F. (1997). A cellular cofactor for the constitutive transport element of type D retrovirus. Science 276:14121415.

Terns, M.P. und Goldfarb, D.S. (1998). Nuclear transport of RNAs in microinjected Xenopus oocytes. Methods Cell Biol. 53:559-589.

Thomson, G. (1996). Xenopus mothers against decapentaplegic is an embryonic ventralizing agent that acts downstream of the BMP receptor. Dev. 122:2359-2366.

Torres-Vazquez, J., Park, S., Warrior, R. und Arora, K. (2001). The transcription factor Schnurri plays a dural role in mediating Dpp signaling during embryogenesis. Dev. 128: $1657-1670$.

Torres-Vazquez, J., Warrior, R. und Arora, K, (2000). Schnurri is required for dpp-dependent patterning of the Drosophila wing. Dev. Biol. 227:388-402.

Treisman, J. und Desplan, C. (1989). The products of the Drosophila gap genes hunchback and Kruppel bind to the hunchback promoters. Nature 341:335-337.

Tsukazaki, T., Chiang, T.A., Davison, A.F., Attisano, L. und Wrana, J.L. (1998). SARA, a FYVE domain protein that recruits Smad2 to the TGF $\beta$ receptor. Cell 95:779-791.

Tsuneizumi, K., Nakayama, T., Kamoshida, Y., Kornberg, T.B., Christian, J.L. und Tabata, T. (1997). Daughters against dpp modulates dpp organizing activity in Drosophila wing development. Nature 389:627-631.

Turner DL, Weintraub H. (1994). Expression of achaete-scute homolog 3 in Xenopus embryos converts ectodermal cells to a neural fate. Genes Dev. 8:1434-1447. 
Udagawa Y, Hanai J, Tada K, Grieder NC, Momoeda M, Taketani Y, Affolter M, Kawabata M, Miyazono K. (2000). Schnurri interacts with Mad in a Dpp-dependent manner. Genes Cells 5:359-369.

Ulloa, L., Doody, J. und Massagué, J. (1999). Inhibition of transforming growth factor$\beta /$ SMAD signalling by the interferon-gamma/STAT pathway. Nature 397:710-713.

van 't Veer, L.J., Lutz, P.M., Isselbacher, K.J. und Bernards, R. (1992). Structure and expression of major histocompatibility complex-binding protein 2, a $275-\mathrm{kDa}$ zinc finger protein that binds to an enhancer of major histocompatibility complex class I genes. Proc. Natl. Acad. Sci. USA 89:8971-8975.

Verschueren, K., Remacle, J.E., Collart, C., Kraft, H., Baker, B.S., Tylzanowski, P., Nelles, L., Wuytens, G., Su, M.T., Bodmer, R., Smith, J.C. und Huylebroeck, D. (1999). SIP1, a novel zinc finger/homeodomain repressor, interacts with Smad proteins and binds to 5'CACCT sequences in candidate target genes. J. Dev. Chem. 274:20489-20498.

Vize, P.D. (1996). DNA sequences mediating the transcriptional response of the Mix.2 homeobox gene to mesoderm induction. Dev.Biol. 177:226-231.

Wen, W., Meinkoth, J.L., Tsien, R.Y. und Taylor, S.S. (1995). Identification of a signal for rapid export ofproteins from the nucleus. Cell 82:463-473.

Wharton, K.A., Ray, R.P. und Gelbart, W.M. (1993). An activity gradient of decapentaplegic is necessary for the specification of dorsal pattern elements in the Drosophila embryo. Dev. 117:807-822.

Williams, J.A., Atkin, A.L. und Bell, J.B. (1990). The functional organization of the vestigial locus in Drosophila melanogaster. Mol. Gen. Genet. 221:8-16.

Wilusz., C.J., Wormington, M. und Peltz, S.W. (2001). The cap-to-tail guide to mRNA turnover. Nat. Rev. Mol. Cell Biol. 2:237-246.

Wittbrodt, J. und Rosa, F.M. (1994). Disruption of mesoderm and axis formation in fish by ectopic expression of activin variants: the role of maternal activin. Genes Dev. 8:14481462 .

Wolpert, L. (1998). Principles of development. Oxford University Press, Oxford.

Wong, C., Tougier-Chapman, E.M., Frederick, J.P., Datto, M.B., Liberati, N.T., Li, J.M. und Wang, X.F. (1999). Smad3-Smad4 and AP-1 complexes synergize in transcriptional activation of the c-Jun promoter by transforming growth factor $\beta$. Mol. Cell. Biol. 19:1821-1830.

Wu, L.C., Mak, C.H., Dear, N., Boehm, T., Foroni, L. und Rabbitts, T.H. (1993). Molecular cloning of a zinc finger protein which binds to the heptamer of the signal sequence for V(D)J recombination. Nucleic Acids Res. 21:5067-5073.

Wu, L.C., Liu, Y., Strandtmann, J., Mak, C.H., Lee, B., Li, Z. und Yu, C.Y. (1996). The mouse DNA binding protein $\mathrm{Rc}$ for the kappa $\mathrm{B}$ motif of transcription and for the $\mathrm{V}(\mathrm{D}) \mathrm{J}$ recombination signal sequences contains composite DNA-protein interaction domains and belongs to a new family of large transcriptional proteins. Genomics 35:415-424.

Xu, X., Yin, Z., Hudson, J.B., Ferguson, E.L. und Frasch, M. (1998). Smad proteins act in combination with synergistic and antagonistic regulators to target Dpp responses to the Drosophila mesoderm. Genes Dev. 12:2354-2370.

Xu, R.H., Kim, J., Taira, M., Zhan, S., Sredni, D., Kung, H.F. (1995). A dominant negative bone morphogenetic protein 4 receptor causes neuralization in Xenopus ectoderm. Biochem. Biophys. Res. Commun. 212:212-219. 
Yeo, C.Y., Chen, X. und Whitman, M. (1999). The role of FAST-1 and Smads in transcriptional regulation by activin during early Xenopus embryogenesis. J. Dev. Chem. 274:2658426590 .

Zawel, L., Dai, J.L., Buckhaults, P., Zhou, S., Kinzler, K.W., Vogelstein, B. und Kern, S.E. (1998). Human Smad3 and Smad4 are sequence-specific transcription activators. Mol. Cell 1:611-617.

Zhang, Y., Feng, X., Wu, R. und Derynck, R. (1996). Receptor-associated Mad homologues synergize as effectors of the TGF-beta response. Nature 383:168-172.

Zhang, Y., Wu, R.Y. und Derynck, R. (1998). Smad3 and Smad4 cooperate with c-Jun/c-Fos to mediate TGF- $\beta$-induced transcription. Nature 394, 909-913 und Nature 396:491 erratum.

Zhu, H., Kavsak, P., Abdollah, S., Wrana, J.L. und Thomsen, G.H. (1999). A SMAD ubiquitin ligase targets the BMP pathway and affects embryonic pattern formation. Nature 400:687-693.

Zimmermann, C.M. und Padgett, R.W. (2000). Transforming growth factor $\beta$ signaling mediators and modulators. Gene 249:17-30.

Zou, H., Wieser R., Massagué J. und Niswander, L. (1997). Distinct roles of type I bone morphogenetic proteins receptors in the formation and differentiation of cartilage. Genes Dev. 11:2191-2203. 


\section{Anhang}

Im Folgenden sind die aus Xenopus laevis isolierten cDNA-Sequenzen und die davon abgeleiteten Peptidsequenzen von Xshn1, Xshn2 und Xshn3 dargestellt. Die im Rahmen der vorausgegangenen Arbeit (Dürr, 1997) isolierten Sequenzen sind weiß hinterlegt. Die im Rahmen der vorliegenden Arbeit isolierten Sequenzen sind grau hinterlegt. Am linken Rand sind die Basenpaare ab Beginn der bekannten Xenopus cDNA-Sequenzen angegeben. Am rechten Rand sind die Aminosäuren fortlaufend nummeriert. Zinkfinger Domänen sind doppelt unterstrichen.

\subsection{Xshn1 cDNA Sequenz und abgeleitete Peptidsequenz (partiell)}

$\begin{array}{llllllllllllllllllll}V & I & H & D & D & S & S & A & K & D & R & G & K & S & P & T & P & P & L & A \\ \text { GTC } & \text { ATC } & \text { CAT } & \text { GAT } & \text { GAT } & \text { TCA } & \text { TCG } & \text { GCA } & \text { AAA } & \text { GAC } & \text { AGA } & \text { GGC } & \text { AAA } & \text { AGT } & \text { CCA } & \text { ACT } & \text { CCA } & \text { CCT } & \text { CTT } & \text { GCA }\end{array}$ ACT GTA AAG GCA GAA CAT CCT GAG GAA CTT GTT GAA CCC TTT TCC TCA TAC ACC AGG GTA $\begin{array}{llllllllllllllllllll}\mathrm{P} & \mathrm{V} & \mathrm{N} & \mathrm{L} & \mathrm{C} & \mathrm{V} & \mathrm{S} & \mathrm{G} & \mathrm{G} & \mathrm{L} & \mathrm{E} & \mathrm{V} & \mathrm{T} & \mathrm{E} & \mathrm{T} & \mathrm{K} & \mathrm{K} & \mathrm{V} & \mathrm{Q} & \mathrm{T} \\ \mathrm{C} C \mathrm{C} & \mathrm{G} & \mathrm{AAC} & \mathrm{C} T & \mathrm{~T} & \mathrm{G} & \mathrm{G} & \end{array}$

721 TGT GGA ATT CGG TGC AAG AAA CCA AGC ATG CTA AAA AAA CAT ATT CGT ACC CAC ACT GAC TCA CTA GCA GAA CTG GAT GCA GAG GAA GGG ACC AGT GAT GAG CGA TGG CAG GAT AGT GAT 
$\begin{array}{llllllllllllllllllllllllllllll}D & E & E & D & D & E & E & E & D & E & E & E & S & Q & E & E & K & L & P & D & & 360\end{array}$

1021 GAT GAG GAG GAT GAT GAA GAA GAA GAT GAA GAG GAA AGC CAG GAA GAA AAG CTC CCT GAT $\begin{array}{llllllllllllllllllllllll}\mathrm{P} & \mathrm{S} & \mathrm{L} & \mathrm{T} & \mathrm{V} & \mathrm{R} & \mathrm{D} & \mathrm{S} & \mathrm{P} & \mathrm{N} & \mathrm{E} & \mathrm{P} & \mathrm{T} & \mathrm{Q} & \mathrm{D} & \mathrm{P} & \mathrm{E} & \mathrm{T} & \mathrm{A} & \mathrm{G} & & 380\end{array}$

1081 CCT TCG CTA ACA GTG AGA GAC TCT CCT AAT GAA CCT ACA CAA GAT CCT GAG ACT GCA GGG $\begin{array}{lllllllllllllllllllll}S & S & P & A & Y & Q & F & S & P & N & P & F & P & T & V & E & P & P & E & K & 400\end{array}$

1141 AGT TCG CCA GCA TAC CAG TTC TCC CCC AAT CCA TTT CCC ACT GTA GAG CCA CCT GAG AAG $\begin{array}{lllllllllllllllllllll}D & \text { T } & \text { W } & \text { G } & \text { K } & \text { S } & \text { F } & \text { D } & \text { L } & \text { P } & \text { V } & \text { S } & \text { R } & \text { D } & \text { T } & \text { L } & \text { S } & \text { C } & \text { K } & \text { R } & 420\end{array}$

1201 GAC ACT TGG GGA AAG AGC TTT GAC TTG CCT GTT TCC CGA GAT ACT TTG TCT TGT AAG CGA $\begin{array}{llllllllllllllllllllllll}W & S & P & G & K & E & A & S & G & C & S & R & P & G & P & S & R & R & H & L & & 440\end{array}$

1261 TGG TCT CCT GGC AAG GAA GCA TCA GGG TGC AGT CGG CCA GGT CCA TCA AGA AGA CAC CTT $\begin{array}{lllllllllllllllllllll}\mathrm{L} & \mathrm{Q} & \mathrm{K} & \mathrm{R} & \mathrm{E} & \mathrm{S} & \mathrm{S} & \mathrm{P} & \mathrm{K} & \mathrm{C} & \mathrm{F} & \mathrm{S} & \mathrm{T} & \mathrm{T} & \mathrm{G} & \mathrm{C} & \mathrm{P} & \mathrm{S} & \mathrm{P} & \mathrm{R} & 460\end{array}$

1321 TTG CAG AAG AGA GAA AGT TCA CCA AAA TGT TTT TCA ACA ACT GGT TGT CCC TCA CCT CGC $\begin{array}{lllllllllllllllllllll}R & G & M & S & P & C & Q & R & L & A & S & T & K & E & V & S & P & L & R & C\end{array}$

1381 AGG GGC ATG TCA CCA TGC CAG CGT TTG GCA TCA ACG AAA GAA GTT TCT CCA TTG CGG TGT $\begin{array}{llllllllllllllllllll}I & S & P & R & H & L & S & P & H & R & D & L & S & P & R & T & Y & M & S & P\end{array}$

1441 ATT TCC CCT CGC CAT CTG TCT CCA CAT CGA GAT CTA TCA CCA AGG ACC TAC ATG TCA CCT $\begin{array}{llllllllllllllllllll}E & R & G & A & S & P & P & V & R & H & I & S & P & S & R & E & L & T & G & L\end{array}$

1501 GAG CGT GGG GCC TCC CCA CCA GTG AGA CAT ATT TCC CCA AGT AGA GAG TTG ACA GGT CTT

$\begin{array}{lllllllllllllllllllll}1561 & \text { CAG } & \text { TGC } & \text { ACA } & \text { ACT } & \text { CTA } & \text { AGG } & \text { CCT } & \text { GGG } & \text { CTG } & \text { GCT } & \text { TCA } & \text { CCT } & \text { CCT } & \text { TGT } & \text { TAT } & \text { GCA } & \text { TCC } & \text { CCT } & \text { GGA } & \text { AGG }\end{array}$ $\begin{array}{lllllllllllllllllllllllllll}D & E & Q & Q & L & S & K & S & E & T & Q & T & H & I & K & V & Q & Q & G & F\end{array}$

1621 GAT GAG CAG CAA CTA AGC AAG TCA GAG ACT CAG ACA CAC ATT AAA GTT CAG CAA GGG TTT $\begin{array}{llllllllllllllllllllll}\mathrm{F} & \mathrm{S} & \mathrm{S} & \mathrm{M} & \mathrm{A} & \mathrm{L} & \mathrm{P} & \mathrm{H} & \mathrm{Q} & \mathrm{T} & \mathrm{E} & \mathrm{T} & \mathrm{A} & \mathrm{C} & \mathrm{N} & \mathrm{K} & \mathrm{Q} & \mathrm{K} & \mathrm{L} & \mathrm{G} & 580\end{array}$

1681 TTT TCA TCC ATG GCT CTA CCT CAT CAG ACA GAA ACT GCA TGC AAC AAA CAG AAG CTG GGA $\begin{array}{llllllllllllllllllllll}\mathrm{P} & \mathrm{S} & \mathrm{N} & \mathrm{I} & \mathrm{P} & \mathrm{V} & \mathrm{M} & \mathrm{S} & \mathrm{R} & \mathrm{P} & \mathrm{L} & \mathrm{C} & \mathrm{S} & \mathrm{Q} & \mathrm{L} & \mathrm{T} & \mathrm{P} & \mathrm{H} & \mathrm{Y} & \mathrm{P} & & 600\end{array}$

1741 CCA TCT AAT ATC CCA GTC ATG TCA AGA CCC CTC TGT TCA CAG CTT ACA CCT CAC TAT CCG $\begin{array}{llllllllllllllllllllll}A & R & S & A & E & N & \text { L } & \text { F } & \text { T } & \text { H } & \text { L } & \text { P } & \text { L } & \text { H } & \text { S } & \text { Q } & \text { H } & \text { L } & \text { Q } & \text { R } & 620\end{array}$ 1801 GCA AGA AGT GCA GAA AAC TTG TTC ACC CAC CTA CCG CTG CAC TCT CAG CAT CTG CAA AGA $\begin{array}{llllllllllllllllllll}\mathrm{T} & \mathrm{P} & \mathrm{Y} & \mathrm{P} & \mathrm{M} & \mathrm{I} & \mathrm{P} & \mathrm{I} & \mathrm{G} & \mathrm{G} & \mathrm{I} & \mathrm{Q} & \mathrm{M} & \mathrm{V} & \mathrm{Q} & \mathrm{A} & \mathrm{R} & \mathrm{P} & \mathrm{S} & \mathrm{P}\end{array}$

1861 ACT CCT TAC CCA ATG ATA CCA ATA GGG GGC ATC CAA ATG GTA CAG GCA CGG CCG AGC CCT $\begin{array}{llllllllllllllllllllll}\mathrm{H} & \mathrm{P} & \mathrm{A} & \mathrm{L} & \mathrm{L} & \mathrm{G} & \mathrm{H} & \mathrm{S} & \mathrm{F} & \mathrm{F} & \mathrm{E} & \mathrm{P} & \mathrm{Q} & \mathrm{P} & \mathrm{A} & \mathrm{D} & \mathrm{P} & \mathrm{E} & \mathrm{A} & \mathrm{V} & & 660\end{array}$

1921 CAC CCA GCT CTG TTG GGG CAC TCA TTC TTT GAA CCA CAA CCT GCA GAC CCT GAA GCA GTG

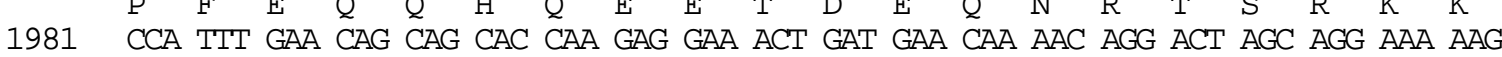
$\begin{array}{llllllllllllllllllllllllllllll}\mathrm{E} & \mathrm{E} & \mathrm{K} & \mathrm{D} & \mathrm{R} & \mathrm{V} & \mathrm{M} & \mathrm{P} & \mathrm{L} & \mathrm{I} & \mathrm{S} & \mathrm{T} & \mathrm{A} & \mathrm{P} & \mathrm{L} & \mathrm{V} & \mathrm{S} & \mathrm{P} & \mathrm{S} & \mathrm{S} & 700\end{array}$

2041 GAG GAA AAA GAC AGG GTA ATG CCC CTC ATC AGC ACA GCC CCA CTA GTT TCC CCC TCA AGC $\begin{array}{lllllllllllllllllllllllll}\mathrm{T} & \mathrm{Y} & \mathrm{C} & \mathrm{Q} & \mathrm{T} & \mathrm{A} & \mathrm{S} & \mathrm{T} & \mathrm{P} & \mathrm{P} & \mathrm{Q} & \mathrm{P} & \mathrm{D} & \mathrm{M} & \mathrm{S} & \mathrm{Q} & \mathrm{A} & \mathrm{D} & \mathrm{T} & \mathrm{D}\end{array}$

2101 ACT TAC TGC CAA ACA GCT TCC ACC CCT CCT CAG CCT GAT ATG TCC CAA GCT GAT ACT GAT $\begin{array}{llllllllllll}P & \mathrm{C} & \mathrm{H} & \mathrm{G} & \mathrm{E} & \mathrm{H} & \mathrm{V} & \mathrm{G} & \mathrm{E} & \mathrm{G} & \text { * }\end{array}$

2161 CCA TGT CAT GGC GAG CAT GTG GGA GAA GGA TGA CTG GAC ACC TTC TAT AGG GAA CAC ACT

2221 CCT TCA AAG CTC TCC ATA TAA TAT CTT GAA TGT TCA GGA TAT AGG GTG ATC ATT TTA GGA 2281 TAC AAG AAG GAA AAC CCT TTA GGA AAC AAG ATT ATC CTA GGA TAT GGA ATA TGG ATC CTA 2341 TAA AGG ATA TAT AAT AAG AAT CCG AGG ATG TAG GAT AAC AGG CTT GTG AAG TGG GTT AAG 2401 GAT CCG TTT AGG ATA CAT GGT AAG AAT CCC GGT ATA TGC AGG CGG GTT TTG GTT GCA CGG 2461 TGT TTG GAT TAT AGA GTG AAA ATC CTA TGG TAT GGG TTA GCA GTC CTT TCG GAA TGA AGG 2521 ACA TTT CCT AGG TTT GGA ATA AAG GTC CCT TGT GGA TAT AAG ATC AAC AGC CTA GGA TTT 2581 AAG AGA GAC TTG CTT ATA GGA TAT GGG ATG CAT ATC CAA GGT ACG GAA AAG GGA TCA ATT 2641 TAG GAT AAG TAA GGA TAT TTA TGG TAC AGA TTA CCA GTC CTT TTA CAA TAC TGA TTT TAG 2701 GAT GTA TAC TAG GCA TCC TGG ATA TTT TTA ATC TAC AAC ATG AAT TAT TTT AGA AAC ACA 2761 GAT AAA TTC TGT TTC TTC CCA TTC TTG TCT TGG AGA AAG GGA CTA CCT TCA TTT CAT TCC 2821 ATT TAT CTC TCT CTT TCC CCT TAG TTC ACT ACT CCC TCT TTC ATA TGC AGT TTA TCT GTG 2881 CCT TTT ATA ACC AAT TTG CTT TTA AAA TGC AAA ACA CAA TAA TCC TAC AAG GAA AAA CTG 
2941 AAC TTT CAA TGC TGT GAA ATA ATG TGG AAT ATT TTC ATC ATT CAC CCA TTC TTA AGA AAT

3001 AAT TAG GTG GGA ATA CAT TCT GTG ACT ACC CAG CTT TGG AAG CCC CAC CCA TTG TTA CTT

3061 TAA TGT GAT ATT GAG ATC TGG GTA GGA TGT GCA CTG AAA AAT TTA AGG TGT TTT ATT TTA

3121 ATT ATT TTT ATT TCT AAC GTA TAT ATC AGA AAA AAA ATA TAT ATA TAT ATA TCT ATA TAT

3181 ATA TAG AGC TGG GAT AGG CGT CAG CCA TGG TGT ACA GAA ATA TAT TTA TAT TAT GAA TTT

3241 ATT TAA AAA AAA AAA AAA AAA A

\subsection{Xshn2 cDNA Sequenz und abgeleitete Peptidsequenz (partiell)}

$\begin{array}{lllllllllllllllllllll} & \text { S } & \text { V } & \text { G } & \text { D } & \text { E } & \text { E } & \text { D } & \text { I } & \text { P } & \text { M } & \text { G } & \text { S } & \text { S } & \text { L } & \text { G } & \text { S } & \text { P } & \text { M } & \text { L } & \text { S } \\ 1 & \text { AGC } & \text { GTG } & \text { GGT } & \text { GAT } & \text { GAG } & \text { GAA } & \text { GAT } & \text { ATA } & \text { CCT } & \text { ATG } & \text { GGT } & \text { AGT } & \text { TCA } & \text { CTT } & \text { GGC } & \text { AGC } & \text { CCA } & \text { ATG } & \text { CTC } & \text { TCA }\end{array}$ $\begin{array}{llllllllllllllllllllllll}\mathrm{D} & \mathrm{L} & \mathrm{D} & \mathrm{I} & \mathrm{K} & \mathrm{L} & \mathrm{Q} & \mathrm{E} & \mathrm{I} & \mathrm{A} & \mathrm{R} & \mathrm{A} & \mathrm{G} & \mathrm{L} & \mathrm{V} & \mathrm{V} & \mathrm{S} & \mathrm{G} & \mathrm{Q} & \mathrm{E}\end{array}$

61 GAC CTC GAT ATA AAA CTT CAG GAG ATT GCA AGA GCC GGA CTT GTT GTT TCA GGG CAA GAA

$\begin{array}{lllllllllllllllllllll} & Y & P & Y & S & G & S & Q & E & L & F & D & I & A & A & R & F & H & H & Q & P \\ 121 & \text { TAT } & \text { CCT } & \text { TAC } & \text { AGT } & \text { GGG } & \text { TCA } & \text { CAA } & \text { GAA } & \text { CTC } & \text { TTT } & \text { GAT } & \text { ATT } & \text { GCT } & \text { GCT } & \text { AGA } & \text { TTT } & \text { CAT } & \text { CAT } & \text { CAG } & \text { CCA }\end{array}$ $\begin{array}{llllllllllllllllllll}G & S & P & I & S & L & L & D & E & S & S & S & V & T & D & R & D & K & N & A\end{array}$

181 GGT AGT CCC ATT TCA TTA TTA GAC GAA TCT TCT TCA GTT ACA GAT CGA GAC AAA AAT GCA

$\begin{array}{llllllllllllllllllll}\text { E } & V & V & S & K & K & P & P & G & N & V & I & S & V & I & Q & \text { H } & \text { T } & \text { N } & \text { S } \\ \text { GAA } & \text { GTA } & \text { GTG } & \text { AGT } & \text { AAA } & \text { AAG } & \text { CCC } & \text { CCG } & \text { GGC } & \text { AAT } & \text { GTC } & \text { ATT } & \text { TCT } & \text { GTA } & \text { ATT } & \text { CAA } & \text { CAT } & \text { ACA } & \text { AAC } & \text { TCC }\end{array}$

$\begin{array}{llllllllllllllllllll}\text { L } & \text { S } & R & \text { P } & N & \text { S } & \text { F } & \text { E } & \text { R } & \text { S } & \text { E } & \text { S } & \text { T } & \text { E } & \text { L } & \text { L } & \text { A } & \text { C } & Q & Q \\ \text { TTA } & \text { AGC } & \text { AGG } & \text { CCT } & \text { AAT } & \text { TCC } & \text { TTT } & \text { GAA } & \text { AGG } & \text { TCA } & \text { GAA } & \text { TCT } & \text { ACA } & \text { GAG } & \text { CTT } & \text { CTA } & \text { GCC } & \text { TGT } & \text { CAG } & \text { CAA }\end{array}$

$\begin{array}{llllllllllllllllllll}\mathrm{D} & \mathrm{K} & \mathrm{P} & \mathrm{S} & \mathrm{S} & \mathrm{P} & \mathrm{S} & \mathrm{E} & \mathrm{A} & \mathrm{C} & \mathrm{D} & \mathrm{S} & \mathrm{G} & \mathrm{N} & \mathrm{T} & \mathrm{M} & \mathrm{S} & \mathrm{S} & \mathrm{I} & \mathrm{S}\end{array}$

361 GAT AAG CCT TCC TCA CCT TCC GAA GCA TGT GAC AGT GGA AAT ACA ATG TCT TCA ATA AGT

$\begin{array}{llllllllllllllllllll}P & E & W & T & Q & S & G & D & I & S & D & A & S & A & R & P & S & P & S & Q\end{array}$

CCA GAA TGG ACT CAA TCT GGG GAT ATC TCT GAT GCT TCA GCA AGA CCA TCT CCA TCT CAG

$\begin{array}{llllllllllllllllllll}\mathrm{Q} & \mathrm{S} & \mathrm{Q} & \mathrm{Q} & \mathrm{T} & \mathrm{A} & \mathrm{Y} & \mathrm{H} & \mathrm{M} & \mathrm{P} & \mathrm{P} & \mathrm{R} & \mathrm{L} & \mathrm{V} & \mathrm{R} & \mathrm{Q} & \mathrm{H} & \mathrm{N} & \mathrm{I} & \mathrm{T}\end{array}$

481 CAA TCA CAA CAA ACA GCA TAT CAT ATG CCT CCT AGA TTA GTC CGC CAG CAC AAC ATT ACA

$\begin{array}{llllllllllllllllllll}V & P & \text { E } & \text { I } & R & V & T & \text { E } & \text { E } & \text { P } & \text { D } & \text { K } & \text { P } & \text { E } & \text { K } & \text { E } & \text { P } & \text { E } & \text { I } & \text { P } \\ \text { GTA } & \text { CCT } & \text { GAG } & \text { ATT } & \text { CGT } & \text { GTA } & \text { ACA } & \text { GAG } & \text { GAG } & \text { CCA } & \text { GAC } & \text { AAA } & \text { CCA } & \text { GAA } & \text { AAG } & \text { GAA } & \text { CCA } & \text { GAA } & \text { ATT } & \text { CCA }\end{array}$

$\begin{array}{llllllllllllllllllll}S & Q & L & P & A & E & K & L & P & P & K & K & K & R & L & R & L & A & D & M\end{array}$

661 TCT CAA CTA CCT GCC GAG AAA CTG CCC CCT AAA AAG AAA CGT CTT CGG CTT GCT GAT ATG $\begin{array}{llllllllllllllllllll}D & N & S & S & G & E & S & S & F & D & S & T & G & T & S & L & S & R & S & P\end{array}$

721 GAT AAC TCA TCT GGA GAA TCC AGC TTT GAT TCC ACA GGT ACA AGT CTC TCT CGT AGC CCA

$\begin{array}{llllllllllllllllllll}S & Q & E & S & N & L & S & H & S & S & S & F & S & M & S & F & D & R & E & E\end{array}$

781 AGT CAA GAA AGT AAT TTA TCC CAC AGT TCA AGC TTT TCA ATG TCA TTT GAT AGA GAA GAG $\begin{array}{llllllllllllllllllll}I & \mathrm{~L} & \mathrm{~K} & \mathrm{~V} & \mathrm{~A} & \mathrm{~T} & \mathrm{~F} & \mathrm{~T} & \mathrm{~K} & \mathrm{Q} & \mathrm{D} & \mathrm{E} & \mathrm{I} & \mathrm{T} & \mathrm{K} & \mathrm{Q} & \mathrm{T} & \mathrm{E} & \mathrm{F} & \mathrm{L}\end{array}$

841 ATA CTG AAA GTT GCA ACA TTT ACT AAG CAA GAT GAA ATA ACA AAG CAA ACA GAA TTT TTA $\begin{array}{llllllllllllllllllll}\mathrm{T} & \mathrm{V} & \mathrm{P} & \mathrm{P} & \mathrm{G} & \mathrm{S} & \mathrm{Y} & \mathrm{S} & \mathrm{L} & \mathrm{S} & \mathrm{V} & \mathrm{P} & \mathrm{G} & \mathrm{Q} & \mathrm{P} & \mathrm{H} & \mathrm{H} & \mathrm{K} & \mathrm{E} & \mathrm{M}\end{array}$

901 ACT GTT CCT CCT GGC TCC TAT TCC CTT TCT GTA CCC GGC CAA CCC CAT CAC AAA GAA ATG $\begin{array}{llllllllllllllllllll}R & R & S & S & S & E & Q & I & P & C & P & S & L & T & E & I & P & E & I & R\end{array}$ AGG CGC TCA TCA TCA GAA CAG ATA CCA TGT CCC AGC CTA ACT GAA ATT CCT GAA ATT CGA 
1141

$\begin{array}{lllllllllllllllllllll}\mathrm{G} & \mathrm{F} & \mathrm{P} & \mathrm{E} & \mathrm{N} & \mathrm{T} & \mathrm{Q} & \mathrm{T} & \mathrm{E} & \mathrm{Q} & \mathrm{E} & \mathrm{T} & \mathrm{A} & \mathrm{G} & \mathrm{N} & \mathrm{Q} & \mathrm{E} & \mathrm{P} & \mathrm{S} & \mathrm{E}\end{array}$

GGC TTC CCG GAA AAT ACC CAG ACT GAG CAA GAA ACA GCT GGA AAT CAA GAA CCC TCA GAG

1201 CAG GCC CAT ACA TGT CGA AGG TCT TCA CAG ATT CTG TGG CAT AAT TCC TCT TCT TCT TTA

$\begin{array}{lllllllllllllllllllll} & \text { S } & \text { C } & \text { S } & \text { I } & \text { S } & \text { V } & \text { L } & \text { S } & \text { E } & \text { D } & \text { T } & \text { A } & \text { N } & \text { I } & \text { P } & \text { I } & \text { G } & \text { T } & \text { S } & \text { A } \\ 1261 & \text { TCA } & \text { TGT } & \text { TCT } & \text { ATA } & \text { AGT } & \text { GTT } & \text { CTG } & \text { TCT } & \text { GAG } & \text { GAT } & \text { ACT } & \text { GCA } & \text { AAT } & \text { ATT } & \text { CCT } & \text { ATT } & \text { GGT } & \text { ACT } & \text { TCT } & \text { GCA }\end{array}$ $\begin{array}{llllllllllllllllllll}Q & \mathrm{P} & \mathrm{T} & \mathrm{T} & \mathrm{S} & \mathrm{T} & \mathrm{S} & \mathrm{S} & \mathrm{H} & \mathrm{Y} & \mathrm{S} & \mathrm{Q} & \mathrm{S} & \mathrm{V} & \mathrm{G} & \mathrm{T} & \mathrm{H} & \mathrm{D} & \mathrm{P} & \mathrm{L}\end{array}$

1321 CAA CCT ACT ACT AGT ACC TCA TCA CAC TAT TCA CAG TCT GTT GGT ACC CAT GAT CCT TTA $\begin{array}{llllllllllllllllllllll}\mathrm{L} & \mathrm{H} & \mathrm{K} & \mathrm{T} & \mathrm{P} & \mathrm{Y} & \mathrm{V} & \mathrm{P} & \mathrm{K} & \mathrm{R} & \mathrm{H} & \mathrm{L} & \mathrm{Q} & \mathrm{E} & \mathrm{Q} & \mathrm{Q} & \mathrm{N} & \mathrm{T} & \mathrm{F} & \mathrm{I} & 480\end{array}$

1381 CTG CAT AAA ACT CCT TAT GTT CCC AAA AGA CAT TTA CAA GAA CAG CAG AAT ACA TTT ATC

$\begin{array}{lllllllllllllllllllll}\mathrm{H} & \mathrm{P} & \mathrm{D} & \mathrm{K} & \mathrm{T} & \mathrm{V} & \mathrm{Y} & \mathrm{P} & \mathrm{P} & \mathrm{V} & \mathrm{H} & \mathrm{N} & \mathrm{A} & \mathrm{F} & \mathrm{Q} & \mathrm{L} & \mathrm{P} & \mathrm{Y} & \mathrm{T} & \mathrm{S} & 500\end{array}$

1441 CAT CCC GAT AAA ACT GTA TAT CCA CCA GTG CAT AAT GCA TTT CAG TTA CCT TAC ACT TCT $\begin{array}{lllllllllllllllllllll}\mathrm{V} & \mathrm{C} & \mathrm{M} & \mathrm{A} & \mathrm{Q} & \mathrm{L} & \mathrm{P} & \mathrm{I} & \mathrm{H} & \mathrm{H} & \mathrm{P} & \mathrm{F} & \mathrm{M} & \mathrm{W} & \mathrm{P} & \mathrm{T} & \mathrm{C} & \mathrm{A} & \mathrm{D} & \mathrm{P} & 520\end{array}$

1501 GTC TGT ATG GCT CAG TTA CCC ATT CAT CAT CCT TTC ATG TGG CCC ACA TGT GCA GAT CCT $\begin{array}{lllllllllllllllllllll}\mathrm{L} & \mathrm{Q} & \mathrm{R} & \mathrm{H} & \mathrm{F} & \mathrm{E} & \mathrm{H} & \mathrm{H} & \mathrm{L} & \mathrm{Q} & \mathrm{Q} & \mathrm{L} & \mathrm{Q} & \mathrm{K} & \mathrm{T} & \mathrm{Y} & \mathrm{F} & \mathrm{K} & \mathrm{Q} & \mathrm{P}\end{array}$

1561 TTG CAG AGG CAT TTT GAG CAC CAT TTA CAG CAA TTA CAA AAG ACT TAT TTT AAg CAG CCT $\begin{array}{lllllllllllllllllllll}S & Q & S & D & I & H & S & Y & Y & L & D & P & T & Q & D & L & T & G & S & K & 560\end{array}$

1621 AGT CAG TCG GAC ATA CAC TCG TAT TAT CTT GAT CCT ACC CAA GAT CTT ACT GGA AGT AAA

$\begin{array}{lllllllllllllllllllll} & \text { S } & \text { V } & \text { S } & \text { Y } & \text { M } & \text { H } & \text { G } & \text { G } & \text { E } & \text { K } & \text { S } & \text { Y } & \text { H } & \text { A } & \text { Y } & \text { L } & \text { E } & \text { T } & \text { S } & \text { A } \\ 1681 & \text { TCT } & \text { GTC } & \text { AGT } & \text { TAC } & \text { ATG } & \text { CAT } & \text { GGT } & \text { GGG } & \text { GAA } & \text { AAA } & \text { AGC } & \text { TAT } & \text { CAT } & \text { GCA } & \text { TAT } & \text { TTA } & \text { GAA } & \text { ACC } & \text { TCT } & \text { GCA }\end{array}$ $\begin{array}{llllllllllllllllllll}Q & \mathrm{R} & \mathrm{S} & \mathrm{K} & \mathrm{N} & \mathrm{T} & \mathrm{V} & \mathrm{S} & \mathrm{K} & \mathrm{L} & \mathrm{Q} & \mathrm{R} & \mathrm{D} & \mathrm{H} & \mathrm{S} & \mathrm{G} & \mathrm{G} & \mathrm{S} & \mathrm{S} & \mathrm{D} \\ \text { CAG } & \text { CGA } & \text { TCT } & \text { AAA } & \text { AAT } & \text { ACA } & \text { GTT } & \text { TCA } & \text { AAA } & \text { TTG } & \text { CAG } & \text { AGA } & \text { GAC } & \text { CAC } & \text { AGT } & \text { GGT } & \text { GGG } & \text { TCA } & \text { AGT } & \text { GAC }\end{array}$ $\begin{array}{llllllllllllllllllll}S & \mathrm{~T} & \mathrm{D} & \mathrm{Q} & \mathrm{S} & \mathrm{L} & \mathrm{Q} & \mathrm{I} & \mathrm{V} & \mathrm{S} & \mathrm{V} & \mathrm{S} & \mathrm{Q} & \mathrm{S} & \mathrm{T} & \mathrm{G} & \mathrm{S} & \mathrm{L} & \mathrm{Q} & \mathrm{N}\end{array}$

1801 TCT ACT GAT CAA AGC CTT CAG ATA GTT TCT GTC TCT CAG AGT ACT GGT TCA CTG CAA AAT $\begin{array}{lllllllllllllllllllll}\mathrm{L} & \mathrm{P} & \mathrm{G} & \mathrm{A} & \mathrm{V} & \mathrm{V} & \mathrm{P} & \mathrm{V} & \mathrm{R} & \mathrm{I} & \mathrm{H} & \mathrm{T} & \mathrm{H} & \mathrm{V} & \mathrm{P} & \mathrm{S} & \mathrm{Y} & \mathrm{G} & \mathrm{S} & \mathrm{V}\end{array}$

1861 TTG CCA GGA GCA GTT GTT CCA GTC AGA ATT CAT ACA CAT GTG CCA TCA TAT GGA AGT GTC $\begin{array}{lllllllllllllllllllll}M & \mathrm{Y} & \mathrm{T} & \mathrm{S} & \mathrm{I} & \mathrm{S} & \mathrm{Q} & \mathrm{I} & \mathrm{T} & \mathrm{H} & \mathrm{A} & \mathrm{Q} & \mathrm{T} & \mathrm{S} & \mathrm{N} & \mathrm{P} & \mathrm{P} & \mathrm{I} & \mathrm{V} & \mathrm{I} & 660\end{array}$

1921 ATG TAT ACC AGT ATT TCT CAA ATT ACT CAT GCA CAG ACC AGC AAC CCA CCA ATT GTA ATT $\begin{array}{llllllllllllllllllll}\mathrm{C} & \mathrm{K} & \mathrm{V} & \mathrm{D} & \mathrm{G} & \mathrm{N} & \mathrm{T} & \mathrm{S} & \mathrm{Q} & \mathrm{R} & \mathrm{T} & \mathrm{L} & \mathrm{A} & \mathrm{T} & \mathrm{N} & \mathrm{A} & \mathrm{S} & \mathrm{M} & \mathrm{K} & \mathrm{G}\end{array}$

1981 TGC AAA GTA GAT GGT AAT ACT TCA CAA AGA ACA CTG GCA ACA AAT GCA TCC ATG AAA GGT $\begin{array}{llllllllllllllllllll}\mathrm{L} & \mathrm{G} & \mathrm{F} & \mathrm{S} & \mathrm{I} & \mathrm{A} & \mathrm{Q} & \mathrm{M} & \mathrm{L} & \mathrm{G} & \mathrm{P} & \mathrm{C} & \mathrm{G} & \mathrm{S} & \mathrm{I} & \mathrm{E} & \mathrm{H} & \mathrm{P} & \mathrm{I} & \mathrm{W}\end{array}$

2041 TTG GGA TTT AGC ATT GCT CAG ATG CTA GGC CCT TGT GGA AGT ATA GAA CAT CCC ATA TGG $\begin{array}{llllllllllllllllllll}K & \mathrm{~V} & \mathrm{P} & \mathrm{P} & \mathrm{A} & \mathrm{F} & \mathrm{D} & \mathrm{L} & \mathrm{D} & \mathrm{T} & \mathrm{A} & \mathrm{I} & \mathrm{P} & \mathrm{L} & \mathrm{C} & \mathrm{L} & \mathrm{A} & \mathrm{S} & \mathrm{N} & \mathrm{S}\end{array}$

2101 AAA GTG CCG CCA GCA TTT GAT TTA GAC ACT GCA ATT CCA TTG TGT CTG GCT TCT AAT TCA $\begin{array}{lllllllllllllllllllll}D & S & V & A & \text { T } & \text { F } & \text { G } & \text { A } & G & \text { K } & \text { R } & \text { M } & \text { L } & \text { S } & \text { P } & \text { A } & \text { S } & \text { S } & \text { L } & \text { E } & 740\end{array}$

2161 GAT AGC GTA GCT ACA TTT GGA GCT GGC AAA CGC ATG CTT TCT CCA GCC AGC AGT TTG GAA $\begin{array}{llllllllllllllllllllll}\mathrm{L} & \mathrm{F} & \mathrm{M} & \mathrm{E} & \mathrm{T} & \mathrm{K} & \mathrm{Q} & \mathrm{Q} & \mathrm{K} & \mathrm{R} & \mathrm{V} & \mathrm{K} & \mathrm{E} & \mathrm{E} & \mathrm{R} & \mathrm{M} & \mathrm{Y} & \mathrm{G} & \mathrm{Q} & \mathrm{I}\end{array}$

2221 CTT TTT ATG GAA ACC AAA CAG CAA AAA CGA GTG AAA GAG GAA AGG ATG TAT GGA CAA ATT $\begin{array}{llllllllllllllllllllll}\mathrm{V} & \mathrm{K} & \mathrm{E} & \mathrm{L} & \mathrm{S} & \mathrm{A} & \mathrm{V} & \mathrm{E} & \mathrm{L} & \mathrm{T} & \mathrm{N} & \mathrm{S} & \mathrm{D} & \mathrm{I} & \mathrm{K} & \mathrm{K} & \mathrm{D} & \mathrm{L} & \mathrm{T} & \mathrm{R} & & 780\end{array}$ 2281 GTT AAA GAA TTA AGT GCA GTA GAA CTA ACT AAT TCA GAC ATT AAA AAG GAT CTG ACA CGT

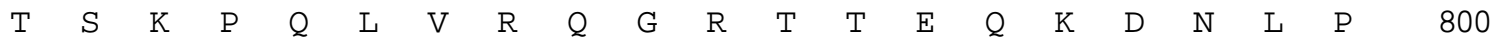
2341 ACC TCA AAA CCT CAG TTG GTA AGG CAA GGA CGT ACA ACA GAG CAG AAG GAT AAT CTC CCT $\begin{array}{lllllllllllllllllllll}S & I & G & S & S & P & P & L & L & S & S & D & S & P & Q & S & I & L & L & D\end{array}$

2401 TCT ATA GGA TCA TCA CCA CCA CTC TTA TCC TCA GAC TCA CCA CAG AGC ATA TTA CTA GAT $\begin{array}{llllllllllllllllllll}V & A & E & S & K & S & S & D & S & P & E & G & R & M & S & S & D & E & L & Y\end{array}$

2461 GTG GCT GAG TCC AAG TCA AGT GAC AGT CCC GAA GGC AGA ATG TCA TCT GAT GAA TTG TAT $\begin{array}{lllllllllllllllllllllllllll}I & \mathrm{E} & \mathrm{E} & \mathrm{T} & \mathrm{A} & \mathrm{S} & \mathrm{N} & \mathrm{M} & \mathrm{S} & \mathrm{L} & \mathrm{S} & \mathrm{P} & \mathrm{Q} & \mathrm{G} & \mathrm{T} & \mathrm{P} & \mathrm{S} & \mathrm{E} & \mathrm{F} & \mathrm{F}\end{array}$ 2521 AAT GAG GAA ACA GCA TCA AAT ATG AGC CTG AGC CCA CAG GGT ACA CCA TCT GAA TTT TTT 
$\begin{array}{lllllllllllllllllllll}E & E & N & P & L & K & S & Q & K & K & S & V & S & I & L & G & L & S & I & A\end{array}$

2581 GAA GAA AAT CCA CTG AAG AGT CAA AAG AAA TCA GTT AGT ATT TTG GGT CTC AGT ATA GCA $\begin{array}{llllllllllllllllllll}D & G & A & \text { T } & \text { I } & G & \text { P } & \text { L } & \text { K } & \text { D } & \text { G } & \text { S } & \text { E } & \text { L } & \text { H } & \text { N } & \text { I } & \text { L } & \text { Q } & F\end{array}$

2641 GAT GGA GCC ACT ATT GGT CCT CTA AAA GAT GGC TCA GAA TTG CAT AAT ATT CTT CAA TTC

$\begin{array}{lllllllllllllllllllll} & \text { P } & \text { S } & \text { L } & \text { R } & \text { T } & \text { L } & \text { T } & \text { T } & \text { V } & \text { S } & \text { W } & \text { C } & \text { F } & \text { L } & \text { N } & \text { Y } & \text { A } & \text { K } & \text { P } & \text { S } \\ 2701 & \text { CCA } & \text { AGC } & \text { TTA } & \text { CGT } & \text { ACA } & \text { CTT } & \text { ACC } & \text { ACT } & \text { GTC } & \text { AGC } & \text { TGG } & \text { TGC } & \text { TTT } & \text { CTA } & \text { AAT } & \text { TAT } & \text { GCT } & \text { AAA } & \text { CCC } & \text { AGC }\end{array}$ $\begin{array}{llllllllllllllllllll}\mathrm{H} & \mathrm{V} & \mathrm{E} & \mathrm{Q} & \mathrm{T} & \mathrm{T} & \mathrm{L} & \mathrm{K} & \mathrm{S} & \mathrm{S} & \mathrm{V} & \mathrm{Y} & \mathrm{A} & \mathrm{S} & \mathrm{W} & \mathrm{C} & \mathrm{I} & \mathrm{S} & \mathrm{S} & \mathrm{C}\end{array}$

2761 CAT GTG GAA CAG ACA ACA CTG AAG TCA TCT GTT TAT GCT TCA TGG TGT ATA AGC TCC TGC $\begin{array}{lllllllllllllllllllll}\mathrm{N} & \mathrm{P} & \mathrm{N} & \mathrm{P} & \mathrm{T} & \mathrm{G} & \mathrm{L} & \mathrm{N} & \mathrm{T} & \mathrm{K} & \mathrm{T} & \mathrm{S} & \mathrm{L} & \mathrm{A} & \mathrm{L} & \mathrm{L} & \mathrm{R} & \mathrm{S} & \mathrm{K} & \mathrm{Q} & 960\end{array}$

2821 AAT CCC AAC CCT ACA GGA CTT AAT ACC AAG ACT TCT TTA GCT CTT CTT CGA TCC AAG CAG $\begin{array}{lllllllllllllllllllll}\mathrm{R} & \mathrm{N} & \mathrm{A} & \mathrm{V} & \mathrm{E} & \mathrm{V} & \mathrm{Y} & \mathrm{T} & \mathrm{I} & \mathrm{A} & \mathrm{A} & \mathrm{M} & \mathrm{N} & \mathrm{R} & \mathrm{F} & \mathrm{G} & \mathrm{A} & \mathrm{G} & \mathrm{K} & \mathrm{L} & 980\end{array}$ 2881 AGG AAT GCA GTA GAA GTA TAT ACC ATT GCT GCT ATG AAT AGA TTT GGA GCT GGC AAA TTA $\begin{array}{lllllllllllllllllllll}T & S & S & N & V & W & K & Q & Q & F & A & Q & M & K & P & E & P & S & L & L & 1000\end{array}$

2941 ACA TCA TCA AAT GTT TGG AAG CAA CAA TTT GCA CAG ATG AAA CCT GAA CCA TCC TTA CTT

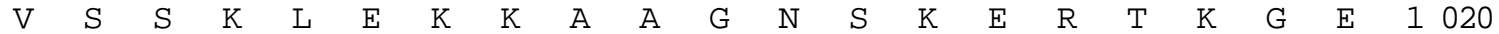
3001 GTT AGC AGC AAA TTG GAA AAG AAG GCT GCT GGA AAC AGC AAA GAA AGG ACA AAA GGA GAG $\begin{array}{lllllllllllllllllllll}\mathrm{S} & \mathrm{H} & \mathrm{G} & \mathrm{E} & \mathrm{K} & \mathrm{D} & \mathrm{I} & \mathrm{S} & \mathrm{A} & \mathrm{K} & \mathrm{Q} & \mathrm{T} & \mathrm{E} & \mathrm{P} & \mathrm{M} & \mathrm{R} & \mathrm{I} & \mathrm{K} & \mathrm{I} & \mathrm{F} & 1040\end{array}$

3061 TCC CAT GGA GAG AAA GAC ATT TCT GCT AAA CAA ACA GAG CCA ATG CGG ATT AAA ATC TTT $\begin{array}{lllllllllllllllllllllll}E & G & G & F & K & S & N & E & D & Y & V & Y & V & R & G & R & G & R & G & K & 1060\end{array}$

3121 GAA GGA GGT TTC AAA TCA AAT GAA GAC TAT GTA TAT GTA AGA GGA AGA GGC CGG GGG AAG $\begin{array}{lllllllllllllllllllll}Y & I & C & E & E & C & G & I & R & C & K & K & P & S & M & L & K & K & \text { H } & \text { I } & 1080\end{array}$

3181 TAC ATT TGT GAA GAA TGT GGC ATT CGC TGC AAA AAG CCA AGC ATG CTG AAG AAA CAC ATC

\begin{tabular}{lllllllllllllllllllll}
3241 & $\mathrm{R}$ & $\mathrm{T}$ & $\mathbf{H}$ & $\mathrm{T}$ & $\mathrm{D}$ & $\mathrm{V}$ & $\mathrm{R}$ & $\mathrm{P}$ & $\mathrm{Y}$ & $\mathrm{V}$ & $\mathbf{C}$ & $\mathrm{K}$ & $\mathrm{L}$ & $\mathbf{C}$ & $\mathrm{N}$ & $\mathrm{F}$ & $\mathrm{A}$ & $\mathrm{F}$ & $\mathrm{K}$ & $\mathrm{T}$ \\
$\mathrm{CGC}$ & ACC & CAC & ACA & GAT & GTG & AGA & CCT & TAT & GTG & TGC & AAG & CTC & TGC & AAC & TTT & GCC & TTC & AAA & ACA \\
\hline \hline
\end{tabular} 1100 $\begin{array}{llllllllllllllllllllll}K & G & N & \text { L } & \text { T } & \text { K } & \text { H } & \text { M } & \text { K } & \text { S } & \text { K } & \text { A } & \text { H } & \text { M } & \text { K } & \text { K } & \text { C } & \text { L } & \text { E } & \text { L } & 1120\end{array}$ 3301 AAA GGA AAT CTA ACA AAA CAT ATG AAG TCG AAA GCA CAT ATG AAG AAA TGC CTG GAG CTA $\begin{array}{lllllllllllllllllllll}G & V & A & M & T & S & V & D & D & A & E & A & E & E & S & G & N & T & E & D & 1140\end{array}$ 3361 GGA GTA GCA ATG ACA TCT GTA GAT GAT GCT GAA GCA GAG GAA TCA GGA AAC ACT GAA GAT $\begin{array}{llllllllllllllllllllll}\mathrm{T} & \mathrm{Q} & \mathrm{K} & \mathrm{E} & \mathrm{S} & \mathrm{D} & \mathrm{K} & \mathrm{S} & \mathrm{S} & \mathrm{P} & \mathrm{A} & \mathrm{I} & \mathrm{D} & \mathrm{H} & \mathrm{Q} & \mathrm{F} & \mathrm{S} & \mathrm{D} & \mathrm{A} & \mathrm{E} & 1160\end{array}$

3421 ACA CAG AAA GAG TCT GAC AAG AGC AGC CCT GCT ATA GAT CAT CAG TTC TCA GAT GCA GAG $\begin{array}{lllllllllllllllllllll}E & \mathrm{~S} & \mathrm{D} & \mathrm{V} & \mathrm{D} & \mathrm{D} & \mathrm{G} & \mathrm{D} & \mathrm{D} & \mathrm{N} & \mathrm{D} & \mathrm{D} & \mathrm{E} & \mathrm{D} & \mathrm{D} & \mathrm{D} & \mathrm{D} & \mathrm{E} & \mathrm{D} & \mathrm{F} & 1180\end{array}$

3481 GAA TCA GAT GTG GAT GAT GGT GAT GAT AAT GAT GAT GAA GAT GAT GAT GAT GAA GAT TTT $\begin{array}{lllllllllllllllllllll}\mathrm{D} & \mathrm{D} & \mathrm{Q} & \mathrm{G} & \mathrm{D} & \mathrm{I} & \mathrm{T} & \mathrm{P} & \mathrm{K} & \mathrm{T} & \mathrm{R} & \mathrm{S} & \mathrm{R} & \mathrm{S} & \mathrm{T} & \mathrm{S} & \mathrm{P} & \mathrm{Q} & \mathrm{P} & \mathrm{P} & 1200\end{array}$

3541 GAT GAC CAG GGA GAT ATA ACA CCA AAG ACT AGG TCA AGA AGC ACC AGC CCA CAG CCA CCC $\begin{array}{lllllllllllllllllllll}R & F & S & T & L & P & V & T & A & T & S & A & S & Q & R & A & S & P & E & A & 1220\end{array}$

3601 AGA TTT TCC ACC TTG CCT GTA ACT GCA ACT TCA GCA TCC CAG AGG GCA TCA CCT GAA GCC $\begin{array}{lllllllllllllllllllll}3661 & \text { S } & \text { I } & \text { G } & \text { H } & \text { S } & \text { S } & \text { L } & \text { M } & \text { S } & \text { Y } & \text { L } & \text { S } & \text { T } & \text { M } & \text { P } & \text { S } & \text { I } & \text { Q } & \text { I } & \text { T } \\ 3 & \text { CAT } & \text { TCA } & \text { TCT } & \text { TTG } & \text { ATG } & \text { AGT } & \text { TAC } & \text { CTA } & \text { TCG } & \text { ACT } & \text { ATG } & \text { CCC } & \text { AGT } & \text { ATT } & \text { CAG } & \text { ATT } & \text { ACA }\end{array}$ 1240 $\begin{array}{lllllllllllllllllllll}\mathrm{H} & \mathrm{L} & \mathrm{M} & \mathrm{S} & \mathrm{K} & \mathrm{S} & \mathrm{A} & \mathrm{M} & \mathrm{C} & \mathrm{G} & \mathrm{D} & \mathrm{S} & \mathrm{Q} & \mathrm{M} & \mathrm{M} & \mathrm{E} & \mathrm{Y} & \mathrm{Q} & \mathrm{R} & \mathrm{L}\end{array}$

3721 CAT CTC ATG TCA AAA AGT GCT ATG TGT GGA GAT TCA CAA ATG ATG GAG TAT CAA AGG CTT $\begin{array}{lllllllllllllllllllll}\mathrm{F} & \mathrm{L} & \mathrm{Q} & \mathrm{D} & \mathrm{M} & \mathrm{E} & \mathrm{H} & \mathrm{E} & \mathrm{R} & \mathrm{G} & \mathrm{K} & \mathrm{M} & \mathrm{D} & \mathrm{V} & \mathrm{P} & \mathrm{V} & \mathrm{G} & \mathrm{M} & \mathrm{D} & \mathrm{E} & 1280\end{array}$ 3781 TTT CTT CAA GAT ATG GAG CAT GAA CGT GGT AAA ATG GAT GTA CCT GTT GGC ATG GAT GAG $\begin{array}{lllllllllllllllllllll}\mathrm{D} & \mathrm{F} & \mathrm{M} & \mathrm{L} & \mathrm{T} & \mathrm{S} & \mathrm{E} & \mathrm{P} & \mathrm{S} & \mathrm{S} & \mathrm{S} & \mathrm{P} & \mathrm{K} & \mathrm{D} & \mathrm{L} & \mathrm{S} & \mathrm{S} & \mathrm{Y} & \mathrm{S} & \mathrm{R} & 1300\end{array}$ 3841 GAC TTT ATG CTT ACT TCT GAA CCT AGC TCC TCT CCC AAA GAC TTA TCA TCT TAT AGC CGC $\begin{array}{lllllllllllllllllllll}\mathrm{H} & \mathrm{S} & \mathrm{S} & \mathrm{P} & \mathrm{G} & \mathrm{Y} & \mathrm{D} & \mathrm{S} & \mathrm{S} & \mathrm{P} & \mathrm{C} & \mathrm{R} & \mathrm{D} & \mathrm{N} & \mathrm{S} & \mathrm{P} & \mathrm{K} & \mathrm{R} & \mathrm{Y} & \mathrm{L} & 1320\end{array}$

3901 CAT TCC TCA CCA GGC TAT GAT TCT TCT CCT TGC CGA GAT AAT TCA CCT AAA AGA TAT TTA $\begin{array}{lllllllllllllllllllllll}S & L & R & G & D & M & S & P & R & R & H & L & S & P & R & R & D & A & S & P & 1340\end{array}$ 3961 TCG TTA AGA GGA GAT ATG TCT CCC AGA AGG CAC CTG TCA CCA AGG AGA GAT GCA TCT CCC 
$\begin{array}{lllllllllllllllllllllllllll}M & \mathrm{R} & \mathrm{H} & \mathrm{L} & \mathrm{S} & \mathrm{P} & \mathrm{R} & \mathrm{K} & \mathrm{E} & \mathrm{A} & \mathrm{A} & \mathrm{I} & \mathrm{R} & \mathrm{R} & \mathrm{E} & \mathrm{L} & \mathrm{S} & \mathrm{P} & \mathrm{R} & \mathrm{R} & 1360\end{array}$

4021 ATG AGG CAC CTG TCA CCT AGA AAA GAA GCT GCA ATA AGG AGA GAA TTA TCT CCA AGA AGG

$\begin{array}{lllllllllllllllllllll}\mathrm{D} & \mathrm{V} & \mathrm{S} & \mathrm{P} & \mathrm{R} & \mathrm{R} & \mathrm{H} & \mathrm{L} & \mathrm{S} & \mathrm{P} & \mathrm{L} & \mathrm{R} & \mathrm{P} & \mathrm{M} & \mathrm{S} & \mathrm{P} & \mathrm{G} & \mathrm{K} & \mathrm{D} & \mathrm{L} & 1380\end{array}$

4081 GAT GTA TCA CCA CGG AGA CAT CTC TCA CCA TTG AGG CCA ATG TCA CCA GGA AAA GAT CTG

$\begin{array}{lllllllllllllllllllllll}S & S & G & R & D & I & S & P & R & R & E & R & K & Y & M & A & T & F & R & A & 1400\end{array}$

4141 TCA TCT GGG CGG GAT ATT TCT CCA CGA CGA GAG AGA AAA TAT ATG GCC ACA TTT AGA GCA

$\begin{array}{lllllllllllllllllllll}\mathrm{L} & \mathrm{S} & \mathrm{P} & \mathrm{R} & \mathrm{R} & \mathrm{R} & \mathrm{L} & \mathrm{H} & \mathrm{N} & \mathrm{T} & \mathrm{Y} & \mathrm{I} & \mathrm{H} & \mathrm{N} & \mathrm{T} & \mathrm{S} & \mathrm{L} & \mathrm{P} & \mathrm{M} & \mathrm{S} & 1420\end{array}$

4201 CTT TCA CCA AGA CGA CGT TTA CAT AAT ACA TAC ATA CAT AAT ACA AGT TTG CCA ATG AGT

$\begin{array}{lllllllllllllllllllllll}\mathrm{H} & \mathrm{Y} & \mathrm{L} & \mathrm{H} & \mathrm{S} & \mathrm{D} & \mathrm{S} & \mathrm{G} & \mathrm{F} & \mathrm{L} & \mathrm{G} & \mathrm{H} & \mathrm{G} & \mathrm{R} & \mathrm{Q} & \mathrm{N} & \mathrm{W} & \mathrm{P} & \mathrm{P} & \mathrm{V} & 1440\end{array}$

4261 CAT TAT TTG CAC TCA GAT TCA GGA TTT CTG GGC CAT GGA AGA CAG AAC TGG CCA CCG GTA

$\begin{array}{lllllllllllllllllllllll}\mathrm{P} & \mathrm{Y} & \mathrm{T} & \mathrm{S} & \mathrm{H} & \mathrm{H} & \mathrm{P} & \mathrm{E} & \mathrm{T} & \mathrm{V} & \mathrm{P} & \mathrm{G} & \mathrm{Q} & \mathrm{Q} & \mathrm{S} & \mathrm{P} & \mathrm{G} & \mathrm{Q} & \mathrm{A} & \mathrm{L}\end{array}$

4321 CCT TAT ACA AGT CAT CAT CCA GAA ACT GTT CCT GGA CAG CAA AGC CCT GGC CAA GCC CTT

$\begin{array}{lllllllllllllllllllll}\mathrm{E} & \mathrm{T} & \mathrm{H} & \mathrm{R} & \mathrm{D} & \mathrm{Y} & \mathrm{I} & \mathrm{F} & \mathrm{S} & \mathrm{H} & \mathrm{L} & \mathrm{P} & \mathrm{L} & \mathrm{H} & \mathrm{S} & \mathrm{Q} & \mathrm{Q} & \mathrm{Q} & \mathrm{V} & \mathrm{R} & 1480\end{array}$

4381 GAG ACT CAC AGG GAT TAT ATA TTC AGC CAC CTC CCT TTA CAC TCA CAG CAA CAA GTA CGA

$\begin{array}{lllllllllllllllllllll}A & P & \text { L } & \text { P } & \text { M } & \text { I } & \text { P } & \text { I } & \text { G } & \text { G } & \text { I } & \text { Q } & \text { M } & \text { I } & \text { H } & \text { S } & \text { N } & \text { S } & \text { T } & \text { I } & 1500\end{array}$

4441 GCA CCT TTA CCA ATG ATC CCT ATA GGT GGT ATT CAA ATG ATC CAC TCA AAT TCT ACA ATC

$\begin{array}{lllllllllllllllllllll}Q & \mathrm{~S} & \mathrm{~S} & \mathrm{~S} & \mathrm{H} & \mathrm{S} & \mathrm{S} & \mathrm{T} & \mathrm{A} & \mathrm{T} & \mathrm{Q} & \mathrm{L} & \mathrm{H} & \mathrm{L} & \mathrm{K} & \mathrm{S} & \mathrm{S} & \mathrm{D} & \mathrm{E} & \mathrm{K} & 1520\end{array}$

4501 CAG TCC AGT TCT CAT TCT TCT ACC GCC ACA CAA TTG CAC CTA AAG AGC TCA GAT GAA AAG

$\begin{array}{lllllllllllllllllllll}R & S & M & S & S & E & S & C & P & S & I & P & \text { L } & \text { H } & \text { L } & \text { D } & \text { K } & \text { H } & \text { S } & \text { S } & 1540\end{array}$

4561 AGA AGT ATG TCT TCG GAG TCA TGT CCG AGT ATC CCA TTG CAC CTT GAT AAA CAT TCT TCT

$\begin{array}{lllllllllllllllllllll}\mathrm{N} & \mathrm{V} & \mathrm{S} & \mathrm{L} & \mathrm{K} & \mathrm{D} & \mathrm{S} & \mathrm{S} & \mathrm{S} & \mathrm{E} & \mathrm{S} & \mathrm{D} & \mathrm{S} & \mathrm{T} & \mathrm{L} & \mathrm{L} & \mathrm{P} & \mathrm{S} & \mathrm{L} & \mathrm{G} & 1560\end{array}$

4621 AAT GTC TCT CTG AAA GAT TCT TCA TCT GAG TCT GAC TCC ACT TTA TTA CCT TCT CTT GGA

$\begin{array}{lllllllllllllllllllll}Q & S & P & T & D & E & S & S & Q & H & N & E & R & E & Q & E & E & N & I & R & 1580\end{array}$

4681 CAA AGC CCT ACA GAT GAA AGC TCC CAA CAC AAT GAA AGG GAA CAG GAG GAA AAT ATA CGT

$\begin{array}{lllllllllllllllllllll}\mathrm{T} & \mathrm{C} & \mathrm{T} & \mathrm{K} & \mathrm{A} & \mathrm{I} & \mathrm{A} & \mathrm{C} & \mathrm{L} & \mathrm{R} & \mathrm{I} & \mathrm{A} & \mathrm{T} & \mathrm{E} & \mathrm{E} & \mathrm{G} & \mathrm{L} & \mathrm{P} & \mathrm{Q} & \mathrm{K} & 1600\end{array}$

4741 ACT TGC ACA AAA GCC ATT GCT TGC CTG AGG ATT GCC ACG GAG GAA GGT TTA CCG CAG AAG

$\begin{array}{lllllllllllllllllllll}R & \mathrm{E} & \mathrm{L} & \mathrm{L} & \mathrm{S} & \mathrm{C} & \mathrm{P} & \mathrm{E} & \mathrm{P} & \mathrm{N} & \mathrm{Q} & \mathrm{K} & \mathrm{T} & \mathrm{E} & \mathrm{C} & \mathrm{A} & \mathrm{Q} & \mathrm{L} & \mathrm{S} & \mathrm{I} & 1620\end{array}$

4801 CGG GAA CTA CTT TCT TGT CCT GAG CCG AAT CAA AAA ACA GAA TGT GCA CAG CTC AGC ATT

$\begin{array}{llllllllllllllllllllll}R & \mathrm{H} & \mathrm{F} & \mathrm{S} & \mathrm{G} & \mathrm{L} & \mathrm{E} & \mathrm{A} & \mathrm{G} & \mathrm{T} & \mathrm{A} & \mathrm{L} & \mathrm{S} & \mathrm{S} & \mathrm{V} & \mathrm{S} & \mathrm{T} & \mathrm{T} & \mathrm{Y} & \mathrm{V}\end{array}$

4861 CGG CAC TTT AGT GGA CTT GAG GCG GGC ACT GCA CTT TCA AGC GTC TCA ACC ACC TAT GTT

$\begin{array}{lllllllllllllllllllll}E & \mathrm{~L} & \mathrm{Y} & \mathrm{G} & \mathrm{D} & \mathrm{N} & \mathrm{D} & \mathrm{S} & \mathrm{L} & \mathrm{G} & \mathrm{T} & \mathrm{S} & \mathrm{Q} & \mathrm{S} & \mathrm{T} & \mathrm{T} & \mathrm{A} & \mathrm{H} & \mathrm{S} & \mathrm{K} & 1660\end{array}$

4921 GAA TTG TAT GGA GAT AAT GAC AGT TTA GGT ACA TCA CAA TCT ACA ACT GCC CAT TCC AAA

$\begin{array}{lllllllllllllllllllll}\mathrm{F} & \mathrm{Y} & \mathrm{S} & \mathrm{K} & \mathrm{T} & \mathrm{M} & \mathrm{D} & \mathrm{M} & \mathrm{K} & \mathrm{K} & \mathrm{L} & \mathrm{G} & \mathrm{Y} & \mathrm{H} & \mathrm{G} & \mathrm{R} & \mathrm{K} & \mathrm{D} & \mathrm{E} & \mathrm{P} & 1680\end{array}$

4981 TTC TAC AGT AAA ACT ATG GAC ATG AAA AAG TTA GGC TAT CAT GGT AGG AAA GAT GAG CCA

$\begin{array}{llllllllllllllllll}\mathrm{P} & \mathrm{S} & \mathrm{V} & \mathrm{Q} & \mathrm{E} & \mathrm{V} & \mathrm{K} & \mathrm{D} & \mathrm{T} & \mathrm{A} & \mathrm{E} & \mathrm{S} & \mathrm{S} & \mathrm{K} & \mathrm{P} & \mathrm{H} & \text { * }\end{array}$

5041 CCA AGC GTG CAA GAG GTA AAA GAC ACA GCA GAA TCA AGT AAA CCA CAT TGA TTT TGG ATG

5101 GGC ATG GAG ACT TCA TGA CCT GGC TCA CAT TAA AAG CAT GTC TGA TAC TAA AAG TTA ATT

5161 TGC CCT TGA AAT AAG TAC TTG GAT GCT GAA TAC ACA CAT ACC CAC TTG TGT GTG TAT GGA

5221 TAT ATA TAT GTG TGT GCA CAC ACT TGT AGT ATA TTA TTT TAA GCC TGA CCA AAA TGA AAA

5281 TTT AAA CTC TTG TAT TGG GTC TGG TAC TTT TAA ATG TAC AGA TGT TTG TGC TTT TTC TTT

5341 ACT TTG CTT ATA TTC TTA TAA GCA TTT TAG CAG TAC CCT GTA TAT ATT TTA GAA TTT GTG

5401 TAA CTG CTT TGT AAT AAT TGT AAT TTT CTT TCT TTT TTG GAC ACT TGG GTC TAA TTG TAA

5461 AGA AAA AAT AGC ATC AAT ATA TAT GTG AGG TTG CAC TAA AAG ATA TTT TTA TAT GAT TGA

5521 AAC TGA ACA GCT TTT ATG TAC AGC TCT GAT CCT GTA ATA CTA ATA TTT ATT TAC TTT GTT

5581 TCA TAA AAT GTA AAT TTT TTC TTA ATG TTG TGA ATT ACT TTT TCT ATG TGA AGC ATG TGG

5621 TTT ACT GTT GCG TAA TTA GAA CAA AAT ATG TAT AGT GTA ATC AAT GTA TTT AAA ATT AAA

5681 TAT CAT CTT ATT GTG CAC TTA TGC ATT GGT TAA ACA AAA ACG ATT AAG GAT GTA TCA GTT

5741 CTT ATC TCT TGT AAT TTC TTT GTC CCT TGT TTG CTG AAT TGA CAA TAA CTT AAG TGC TGG

5801 TTG TGA TTT GAA AAT AAT AGT AAT GTA AAG CAT TAA AAG TAC AAA TGT GCT ATT GTG AGG

5861 TTC TCT CCC AAG GCT GTA TAA AAC AAT TAT AAA TAT AAA AAA AAA AAA AAA AAA AA 


\subsection{Xshn3 cDNA Sequenz und abgeleitete Peptidsequenz}

1 TGT AAA GCA GGC ACA TTG GTG GGC TGT GCA CAT CAC ATG TGA TTC ATA AAA CCA TGA ATG 61 ATC CAG AGG CGA GCA GCC AGC GAG ATC TTC ATG TGC AGA ATG ATG CTG TTT TGT TTT GCA 121 ATG TCC TCC AGG AGA TGC TGG ATT AAC TGA TGC ACT TGG CGG GTA TAT GGA GGT TCC TCT 181 CCT CCA GCA CTG CTC TCC ATT TTT GAG AAG GAA AAG CCA GGC ACC AGC AGG AGG AGG ATC $\begin{array}{lllllllllllllllllllllll}M & \mathrm{P} & \mathrm{R} & \mathrm{T} & \mathrm{K} & \mathrm{Q} & \mathrm{I} & \mathrm{H} & \mathrm{P} & \mathrm{K} & \mathrm{N} & \mathrm{L} & \mathrm{R} & \mathrm{D} & \mathrm{K} & \mathrm{I} & \mathrm{E} & \mathrm{E} & \mathrm{A} & \mathrm{Q} & 20\end{array}$

241 ATG CCT CGG ACA AAA CAG ATC CAC CCC AAA AAC CTA AGA GAT AAA ATA GAA GAA GCA CAA $\begin{array}{lllllllllllllllllllll}K & K & L & K & S & P & E & E & P & Q & A & E & I & V & E & A & G & S & R & A & 40\end{array}$

301 AAA AAA CTG AAA TCT CCA GAA GAA CCC CAA GCA GAG ATT GTT GAA GCT GGT TCC AGA GCT $\begin{array}{llllllllllllllllllll}C & \mathrm{~L} & \mathrm{E} & \mathrm{V} & \mathrm{V} & \mathrm{K} & \mathrm{G} & \mathrm{V} & \mathrm{K} & \mathrm{R} & \mathrm{K} & \mathrm{K} & \mathrm{I} & \mathrm{V} & \mathrm{T} & \mathrm{E} & \mathrm{N} & \mathrm{H} & \mathrm{L} & \mathrm{K}\end{array}$

361 TGC TTG GAA GTG GTA AAA GGT GTC AAG AGA AAA AAA ATT GTG ACA GAA AAT CAT CTG AAG 60 $\begin{array}{llllllllllllllllllll}K & I & P & K & S & P & L & R & N & A & G & K & G & K & Q & K & P & E & I & E\end{array}$ 421 AAA ATA CCA AAG TCC CCA TTG AGG AAT GCT GGT AAA GGG AAG CAG AAA CCT GAA ATA GAG $\begin{array}{lllllllllllllllllllll}A & \mathrm{~F} & \mathrm{P} & \mathrm{S} & \mathrm{S} & \mathrm{S} & \mathrm{C} & \mathrm{D} & \mathrm{P} & \mathrm{L} & \mathrm{V} & \mathrm{F} & \mathrm{G} & \mathrm{G} & \mathrm{C} & \mathrm{K} & \mathrm{D} & \mathrm{K} & \mathrm{Q} & \mathrm{C} & 100\end{array}$

481 GCA TTT CCT TCT TCA AGT TGT GAT CCT TTA GTA TTT GGT GGC TGC AAA GAT AAG CAG TGT

$\begin{array}{lllllllllllllllllllll} & \mathrm{L} & \mathrm{L} & \mathrm{D} & \mathrm{Q} & \mathrm{L} & \mathrm{R} & \mathrm{K} & \mathrm{Q} & \mathrm{D} & \mathrm{I} & \mathrm{K} & \mathrm{E} & \mathrm{S} & \mathrm{K} & \mathrm{A} & \mathrm{G} & \mathrm{E} & \mathrm{L} & \mathrm{T} & \mathrm{V} \\ 541 & \text { TTA } & \text { CTT } & \text { GAC } & \text { CAA } & \text { CTC } & \text { CGT } & \text { AAG } & \text { CAA } & \text { GAT } & \text { ATC } & \text { AAA } & \text { GAA } & \text { AGC } & \text { AAA } & \text { GCT } & \text { GGG } & \text { GAG } & \text { TTG } & \text { ACT } & \text { GTC }\end{array}$ $\begin{array}{lllllllllllllllllllll}K & S & L & K & P & G & T & S & M & Q & A & K & K & L & S & V & P & P & D & L\end{array}$

601 AAG TCT TTG AAA CCA GGG ACA TCA ATG CAG GCT AAA AAG CTT TCT GTT CCA CCA GAC TTA $\begin{array}{lllllllllllllllllllll}C & N & G & R & R & E & D & K & D & M & D & I & K & Q & T & L & S & R & Q & N\end{array}$

661 TGC AAT GGG AGA AGA GAA GAT AAA GAT ATG GAT ATC AAA CAG ACC TTA TCA AGG CAA AAT

$\begin{array}{llllllllllllllllllll}I & \mathrm{~S} & \mathrm{~S} & \mathrm{~S} & \mathrm{~L} & \mathrm{~N} & \mathrm{~N} & \mathrm{~T} & \mathrm{~K} & \mathrm{~S} & \mathrm{~A} & \mathrm{~N} & \mathrm{I} & \mathrm{S} & \mathrm{L} & \mathrm{E} & \mathrm{N} & \mathrm{M} & \mathrm{N} & \mathrm{K}\end{array}$

721 ATT TCT TCC AGC TTG AAC AAC ACA AAA AGT GCA AAT ATA TCT TTA GAG AAT ATG AAT AAA $\begin{array}{llllllllllllllllllll}\mathrm{P} & \mathrm{C} & \mathrm{S} & \mathrm{T} & \mathrm{A} & \mathrm{N} & \mathrm{S} & \mathrm{A} & \mathrm{F} & \mathrm{D} & \mathrm{V} & \mathrm{L} & \mathrm{L} & \mathrm{R} & \mathrm{A} & \mathrm{M} & \mathrm{E} & \mathrm{P} & \mathrm{E} & \mathrm{L}\end{array}$

781 CCC TGT TCA ACT GCA AAT TCT GCT TTT GAT GTA TTA CTA AGA GCA ATG GAG CCA GAA CTT

$\begin{array}{llllllllllllllllllll}S & N & L & N & Q & S & W & P & P & C & G & T & Q & T & E & K & Q & G & H & K\end{array}$

841 AGC AAC TTA AAT CAG TCT TGG CCA CCT TGT GGT ACA CAA ACT GAA AAA CAA GGC CAT AAG $\begin{array}{llllllllllllllllllll}V & A & P & E & T & T & A & S & N & S & S & V & S & Q & S & E & F & S & S & R\end{array}$

901 GTG GCA CCT GAA ACT ACT GCT TCA AAT TCA TCT GTT TCT CAA AGT GAA TTT AGT TCA AGA $\begin{array}{llllllllllllllllllll}Y & V & Y & Y & H & Q & G & D & Q & S & S & Q & I & S & Q & S & I & K & G & S\end{array}$

961 TAT GTC TAT TAT CAT CAA GGT GAT CAG AGC AGC CAG ATA AGC CAA TCA ATT AAG GGT TCT $\begin{array}{llllllllllllllllllll}\mathrm{T} & \mathrm{N} & \mathrm{V} & \mathrm{Q} & \mathrm{D} & \mathrm{R} & \mathrm{L} & \mathrm{G} & \mathrm{I} & \mathrm{E} & \mathrm{H} & \mathrm{E} & \mathrm{K} & \mathrm{C} & \mathrm{N} & \mathrm{S} & \mathrm{D} & \mathrm{T} & \mathrm{G} & \mathrm{L}\end{array}$

1021 ACT AAT GTT CAA GAC CGG TTA GGA ATC GAA CAT GAA AAA TGC AAT TCT GAC ACA GGG CTA

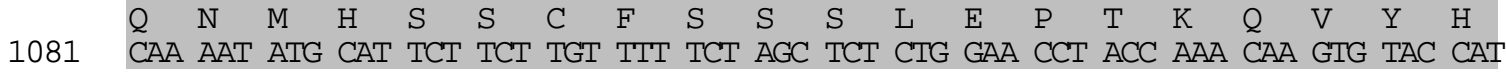

$\begin{array}{llllllllllllllllllll}\mathrm{V} & \mathrm{A} & \mathrm{L} & \mathrm{N} & \mathrm{P} & \mathrm{S} & \mathrm{I} & \mathrm{A} & \mathrm{D} & \mathrm{P} & \mathrm{S} & \mathrm{S} & \mathrm{S} & \mathrm{L} & \mathrm{T} & \mathrm{Q} & \mathrm{V} & \mathrm{L} & \mathrm{S} & \mathrm{L}\end{array}$

1141 GTA GCA TTA AAC CCT TCA ATA GCT GAC CCA TCA TCT TCT CTA ACT CAG GTC CTT TCT CTG

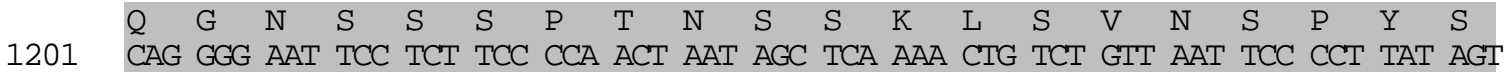

$\begin{array}{llllllllllllllllllll}\mathrm{L} & \mathrm{A} & \mathrm{Q} & \mathrm{V} & \mathrm{A} & \mathrm{S} & \mathrm{L} & \mathrm{I} & \mathrm{S} & \mathrm{G} & \mathrm{E} & \mathrm{Q} & \mathrm{M} & \mathrm{C} & \mathrm{N} & \mathrm{I} & \mathrm{V} & \mathrm{L} & \mathrm{K} & \mathrm{D}\end{array}$

1261 TTA GCT CAA GTA GCT TCA CTT ATA AGC GGA GAA CAG ATG TGC AAT ATT GTG TTA AAA GAT $\begin{array}{llllllllllllllllllll}Q & K & L & K & K & Q & G & K & Y & I & C & E & Y & \mathbf{C} & S & R & A & C & A & K \\ \end{array}$

1321 CAA AAA CTT AAA AAA CAA GGC AAG TAC ATA TGT GAA TAT TGT AGC AGG GCT TGT GCA AAA

1381 CCA AGT GTT CTC CTA AAA CAC ATT AGA TCT CAT ACT GGG GAA CGC CCC TAC CCT TGT GTG 
$\begin{array}{llllllllllllllllllll}H & A & I & K & \text { L } & G & \text { L } & G & \text { L } & \text { R } & \text { T } & \text { D } & \text { S } & \text { S } & \text { G } & \text { A } & \text { L } & \text { L } & \text { S } & \text { H }\end{array}$

1501 CAT GCA ATT AAA CTA GGA CTT GGC CTG CGG ACT GAT TCT AGT GGG GCG CTA CTT TCT CAT

$\begin{array}{llllllllllllllllllll}\mathrm{D} & \mathrm{S} & \mathrm{E} & \mathrm{K} & \mathrm{A} & \mathrm{L} & \mathrm{C} & \mathrm{I} & \mathrm{H} & \mathrm{S} & \mathrm{D} & \mathrm{V} & \mathrm{D} & \mathrm{E} & \mathrm{S} & \mathrm{G} & \mathrm{E} & \mathrm{S} & \mathrm{D} & \mathrm{D}\end{array}$

1561 GAT TCA GAA AAA GCA CTT TGT ATT CAT TCA GAT GTA GAT GAA AGT GGA GAA AGT GAT GAT $\begin{array}{llllllllllllllllllll}\mathrm{E} & \mathrm{Y} & \mathrm{I} & \mathrm{S} & \mathrm{E} & \mathrm{E} & \mathrm{R} & \mathrm{Q} & \mathrm{E} & \mathrm{D} & \mathrm{Q} & \mathrm{N} & \mathrm{V} & \mathrm{P} & \mathrm{E} & \mathrm{S} & \mathrm{Q} & \mathrm{C} & \mathrm{I} & \mathrm{K}\end{array}$

1621 GAG TAT ATC TCT GAA GAA AGG CAA GAG GAC CAA AAT GTT CCA GAA AGT CAA TGT ATT AAA

$\begin{array}{llllllllllllllllllll}R & P & D & D & S & E & M & V & P & Q & K & E & S & K & I & L & S & N & S & Q\end{array}$

1681 AGG CCA GAT GAT TCT GAA ATG GTA CCA CAA AAA GAA AGC AAA ATA CTT TCA AAT AGC CAA $\begin{array}{llllllllllllllllllll}V & \mathrm{~L} & \mathrm{~V} & \mathrm{~S} & \mathrm{~K} & \mathrm{~N} & \mathrm{~N} & \mathrm{~S} & \mathrm{~L} & \mathrm{Q} & \mathrm{G} & \mathrm{N} & \mathrm{G} & \mathrm{V} & \mathrm{E} & \mathrm{A} & \mathrm{R} & \mathrm{L} & \mathrm{T} & \mathrm{E}\end{array}$

1741 GTG CTA GTA TCA AAA AAT AAT TCT CTA CAA GGA AAC GGT GTA GAA GCA AGG CTG ACT GAA

$\begin{array}{llllllllllllllllllll}\mathrm{L} & \mathrm{P} & \mathrm{K} & \mathrm{V} & \mathrm{V} & \mathrm{V} & \mathrm{Y} & \mathrm{P} & \mathrm{V} & \mathrm{S} & \mathrm{T} & \mathrm{S} & \mathrm{P} & \mathrm{L} & \mathrm{R} & \mathrm{A} & \mathrm{D} & \mathrm{S} & \mathrm{P} & \mathrm{R}\end{array}$

1801 TTA CCC AAA GTT GTT GTT TAC CCA GTA AGT ACT TCT CCA CTA AGG GCT GAT AGC CCC AGA

$\begin{array}{llllllllllllllllllll}V & \mathrm{~L} & \mathrm{E} & \mathrm{S} & \mathrm{A} & \mathrm{S} & \mathrm{E} & \mathrm{H} & \mathrm{F} & \mathrm{V} & \mathrm{A} & \mathrm{Q} & \mathrm{I} & \mathrm{P} & \mathrm{E} & \mathrm{L} & \mathrm{H} & \mathrm{T} & \mathrm{Q} & \mathrm{K}\end{array}$

1861 GTT TTA GAG TCT GCC AGT GAA CAT TTT GTA GCA CAA ATT CCA GAA CTG CAT ACA CAA AAG

$\begin{array}{llllllllllllllllllll}K & \mathrm{~N} & \mathrm{P} & \mathrm{H} & \mathrm{V} & \mathrm{L} & \mathrm{S} & \mathrm{V} & \mathrm{C} & \mathrm{S} & \mathrm{L} & \mathrm{S} & \mathrm{E} & \mathrm{M} & \mathrm{E} & \mathrm{Q} & \mathrm{S} & \mathrm{C} & \mathrm{D} & \mathrm{K}\end{array}$

1921 AAG AAT CCG CAT GTG TTG TCA GTT TGT TCT TTA AGC GAA ATG GAA CAG TCA TGC GAT AAG

$\begin{array}{llllllllllllllllllll}\mathrm{N} & \mathrm{C} & \mathrm{E} & \mathrm{L} & \mathrm{A} & \mathrm{E} & \mathrm{I} & \mathrm{D} & \mathrm{D} & \mathrm{K} & \mathrm{Q} & \mathrm{Q} & \mathrm{I} & \mathrm{N} & \mathrm{N} & \mathrm{A} & \mathrm{T} & \mathrm{S} & \mathrm{H} & \mathrm{A}\end{array}$

1981 AAT TGT GAA CTT GCT GAG ATT GAT GAC AAA CAA CAA ATA AAT AAT GCA ACT TCT CAT GCA

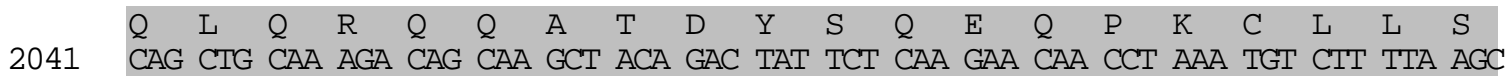

$\begin{array}{llllllllllllllllllll}P & R & S & L & G & S & T & D & S & G & Y & F & S & R & S & E & S & V & D & Q\end{array}$

2101 CCT AGA AGC TTA GGA AGT ACA GAC TCT GGT TAT TTT TCA CGT TCA GAG AGT GTA GAT CAA

$\begin{array}{llllllllllllllllllll}A & \mathrm{M} & \mathrm{S} & \mathrm{P} & \mathrm{P} & \mathrm{T} & \mathrm{P} & \mathrm{F} & \mathrm{L} & \mathrm{K} & \mathrm{L} & \mathrm{Q} & \mathrm{P} & \mathrm{S} & \mathrm{S} & \mathrm{E} & \mathrm{K} & \mathrm{D} & \mathrm{F} & \mathrm{S}\end{array}$

2161 GCA ATG AGT CCG CCA ACT CCT TTC CTA AAA CTT CAA CCC TCA TCT GAA AAA GAC TTT TCT

$\begin{array}{lllllllllllllllllllll}K & \mathrm{~N} & \mathrm{~L} & \mathrm{~S} & \mathrm{~S} & \mathrm{~V} & \mathrm{~T} & \mathrm{Q} & \mathrm{I} & \mathrm{N} & \mathrm{A} & \mathrm{T} & \mathrm{V} & \mathrm{T} & \mathrm{P} & \mathrm{L} & \mathrm{V} & \mathrm{Q} & \mathrm{Q} & \mathrm{I}\end{array}$

2221 AAG AAT CTG AGC TCA GTT ACA CAG ATT AAT GCC ACA GTA ACA CCT TTG GTA CAA CAA ATA $\begin{array}{llllllllllllllllllll}Y & V & E & K & P & T & I & I & T & G & A & M & R & P & P & L & V & T & K & T\end{array}$

2281 TAT GTT GAA AAA CCA ACA ATT ATT ACA GGT GCA ATG AGA CCT CCC TTG GTA ACC AAA ACC

$\begin{array}{llllllllllllllllllll}\mathrm{L} & \mathrm{E} & \mathrm{E} & \mathrm{R} & \mathrm{I} & \mathrm{S} & \mathrm{K} & \mathrm{L} & \mathrm{I} & \mathrm{S} & \mathrm{D} & \mathrm{N} & \mathrm{E} & \mathrm{A} & \mathrm{V} & \mathrm{V} & \mathrm{D} & \mathrm{D} & \mathrm{K} & \mathrm{Q}\end{array}$

2341 TTA GAG GAA CGC ATT TCC AAA TTA ATA TCA GAC AAT GAA GCT GTA GTG GAT GAC AAA CAA

$\begin{array}{llllllllllllllllllll}\mathrm{L} & \mathrm{D} & \mathrm{S} & \mathrm{V} & \mathrm{K} & \mathrm{P} & \mathrm{R} & \mathrm{R} & \mathrm{T} & \mathrm{S} & \mathrm{L} & \mathrm{S} & \mathrm{R} & \mathrm{R} & \mathrm{G} & \mathrm{S} & \mathrm{I} & \mathrm{D} & \mathrm{S} & \mathrm{P}\end{array}$

2401 CTA GAT AGT GTC AAA CCA AGA CGA ACC TCT CTT TCC AGA AGA GGC AGT ATA GAC TCA CCA

$\begin{array}{lllllllllllllllllllll}K & S & Y & I & F & K & D & S & F & Q & F & D & L & K & P & V & G & R & R & T\end{array}$

2461 AAG TCC TAC ATA TTT AAA GAT TCC TTT CAG TTT GAT TTA AAA CCT GTT GGT AGG CGC ACT

$\begin{array}{llllllllllllllllllll}S & S & S & S & D & I & P & K & S & P & F & T & P & T & D & K & S & K & Q & V\end{array}$

2521 AGC TCA AGT TCA GAC ATA CCA AAG TCC CCA TTC ACC CCA ACT GAT AAG TCA AAG CAA GTT

$\begin{array}{lllllllllllllllllllll} & \text { F } & \text { F } & \text { L } & \text { S } & \text { V } & \text { P } & \text { S } & \text { Q } & \text { F } & \text { T } & \text { S } & \text { M } & \text { D } & \text { C } & \text { L } & \text { P } & \text { I } & \text { T } & \text { R } & \text { S } \\ 2581 & \text { TTT } & \text { TTT } & \text { CTT } & \text { TCT } & \text { GTT } & \text { CCC } & \text { TCT } & \text { CAG } & \text { TTT } & \text { ACT } & \text { TCC } & \text { ATG } & \text { GAT } & \text { TGT } & \text { TTA } & \text { CCA } & \text { ATA } & \text { ACC } & \text { AGG } & \text { AGT }\end{array}$

$\begin{array}{llllllllllllllllllll}\mathrm{N} & \mathrm{S} & \mathrm{M} & \mathrm{P} & \mathrm{T} & \mathrm{T} & \mathrm{G} & \mathrm{Y} & \mathrm{S} & \mathrm{E} & \mathrm{V} & \mathrm{P} & \mathrm{P} & \mathrm{V} & \mathrm{M} & \mathrm{P} & \mathrm{A} & \mathrm{S} & \mathrm{H} & \mathrm{P}\end{array}$

2641 AAT TCA ATG CCC ACA ACA GGT TAT TCA GAA GTT CCM CCA GTT ATG CCA GCT TCA CAT CCT

$\begin{array}{lllllllllllllllllllll}L & R & G & S & H & S & F & D & E & K & I & G & S & L & C & D & D & V & F & V\end{array}$

2701 CTT CGA GGA AGT CAC TCA TTT GAT GAA AAA ATA GGA TCC CTT TGT GAT GAT GTA TTT GTA

2761 TCA GGA CCT TCA ACT CCT CAG CAA GTT GCT CAT CCT CGC ACT TTG GTA AGA CAG GCT GCT

2821 GTT GAA GAC TCC TCT GCT ACA GAA CAT TTT GGT CTC GGA CCA GCA AGA TCA ATG GAT GAA 
$\begin{array}{llllllllllllllllllll}Q & G & S & S & V & D & R & I & K & K & A & H & S & R & G & T & M & F & E & C\end{array}$

2941 CAG GGG TCC AGT GTG GAT AGA ATT AAA AAA GCA CAT AGC AGG GGA ACA ATG TTT GAA TGT

$\begin{array}{llllllllllllllllllll}\mathrm{E} & \mathrm{T} & \mathrm{C} & \mathrm{R} & \mathrm{N} & \mathrm{R} & \mathrm{Y} & \mathrm{R} & \mathrm{K} & \mathrm{L} & \mathrm{E} & \mathrm{N} & \mathrm{F} & \mathrm{E} & \mathrm{N} & \mathrm{H} & \mathrm{K} & \mathrm{K} & \mathrm{F} & \mathrm{Y}\end{array}$

940

3001 GAA ACT TGT AGA AAC AGA TAC AGA AAA TTA GAA AAT TTT GAA AAT CAC AAA AAA TTC TAC

$\begin{array}{lllllllllllllllllllllll}\text { C } & \mathrm{S} & \mathrm{E} & \mathrm{L} & \mathrm{H} & \mathrm{G} & \mathrm{P} & \mathrm{K} & \mathrm{S} & \mathrm{K} & \mathrm{T} & \mathrm{V} & \mathrm{C} & \mathrm{R} & \mathrm{E} & \mathrm{P} & \mathrm{E} & \mathrm{Q} & \mathrm{R} & \mathrm{T}\end{array}$

3061 TGT TCG GAA TTA CAC GGA CCA AAG AGT AAG ACA GTG TGT CGG GAA CCA GAG CAA AGA ACT

$\begin{array}{llllllllllllllllllll}\mathrm{T} & \mathrm{M} & \mathrm{N} & \mathrm{I} & \mathrm{S} & \mathrm{Q} & \mathrm{P} & \mathrm{Q} & \mathrm{I} & \mathrm{F} & \mathrm{H} & \mathrm{Y} & \mathrm{R} & \mathrm{V} & \mathrm{A} & \mathrm{A} & \mathrm{S} & \mathrm{T} & \mathrm{G} & \mathrm{A}\end{array}$

3121 ACC ATG AAC ATT TCT CAG CCT CAA ATA TTT CAC TAT AGA GTT GCT GCT TCT ACT GGG GCA

$\begin{array}{llllllllllllllllllll}\mathrm{L} & \mathrm{E} & \mathrm{Q} & \mathrm{P} & \mathrm{L} & \mathrm{Q} & \mathrm{I} & \mathrm{R} & \mathrm{K} & \mathrm{R} & \mathrm{R} & \mathrm{K} & \mathrm{M} & \mathrm{K} & \mathrm{S} & \mathrm{V} & \mathrm{G} & \mathrm{D} & \mathrm{D} & \mathrm{D}\end{array}$

3181 TTA GAA CAA CCT TTG CAG ATA AGA AAA AGG AGA AAG ATG AAA AGT GTA GGC GAT GAT GAC

$\begin{array}{lllllllllllllllllllll}\mathrm{E} & \mathrm{P} & \mathrm{Q} & \mathrm{Q} & \mathrm{S} & \mathrm{D} & \mathrm{S} & \mathrm{N} & \mathrm{T} & \mathrm{A} & \mathrm{P} & \mathrm{E} & \mathrm{N} & \mathrm{M} & \mathrm{E} & \mathrm{V} & \mathrm{L} & \mathrm{K} & \mathrm{N} & \mathrm{L}\end{array}$

3241 GAA CCT CAA CAA AGT GAT TCT AAC ACT GCT CCA GAA AAT ATG GAA GTT CTA AAG AAT TTA

$\begin{array}{llllllllllllllllllll}K & S & T & K & N & S & S & T & I & T & I & L & G & S & Q & S & C & S & V & S\end{array}$

3301 AAA AGT ACA AAG AAT TCA TCC ACT ATT ACT ATT TTG GGA TCA CAG TCA TGC TCT GTT TCA

1000

$\begin{array}{llllllllllllllllllll}\mathrm{T} & \mathrm{V} & \mathrm{S} & \mathrm{P} & \mathrm{Q} & \mathrm{I} & \mathrm{H} & \mathrm{F} & \mathrm{V} & \mathrm{S} & \mathrm{R} & \mathrm{N} & \mathrm{T} & \mathrm{D} & \mathrm{A} & \mathrm{S} & \mathrm{S} & \mathrm{E} & \mathrm{I} & \mathrm{K}\end{array}$

3361 ACT GTA AGT CCT CAA ATA CAT TTT GTG TCA AGA AAT ACA GAT GCT AGC AGT GAA ATC AAA

$\begin{array}{llllllllllllllllllll}\mathrm{L} & \mathrm{S} & \mathrm{T} & \mathrm{L} & \mathrm{E} & \mathrm{K} & \mathrm{N} & \mathrm{K} & \mathrm{N} & \mathrm{I} & \mathrm{V} & \mathrm{S} & \mathrm{Q} & \mathrm{E} & \mathrm{R} & \mathrm{V} & \mathrm{E} & \mathrm{V} & \mathrm{K} & \mathrm{C}\end{array}$

1080

3421 CTT TCT ACA TTG GAG AAA AAT AAA AAT ATT GTT TCC CAA GAA AGA GTG GAA GTG AAA TGT $\begin{array}{llllllllllllllllllll}Q & G & T & G & I & S & V & I & Q & H & T & N & S & L & S & K & P & N & S & F \\ \end{array}$

3481 CAA GGA ACA GGA ATA TCT GTT ATT CAG CAC ACT AAC TCA TTG AGT AAG CCT AAT TCT TTT

$\begin{array}{llllllllllllllllllll}\mathrm{E} & \mathrm{K} & \mathrm{I} & \mathrm{D} & \mathrm{S} & \mathrm{V} & \mathrm{E} & \mathrm{R} & \mathrm{N} & \mathrm{S} & \mathrm{P} & \mathrm{V} & \mathrm{P} & \mathrm{L} & \mathrm{Q} & \mathrm{E} & \mathrm{P} & \mathrm{Q} & \mathrm{K} & \mathrm{S}\end{array}$

3541 GAA AAA ATA GAC TCT GTT GAA AGA AAT TCA CCT GTT CCA TTA CAG GAA CCA CAG AAA AGT $\begin{array}{llllllllllllllllllll}\mathrm{L} & \mathrm{P} & \mathrm{L} & \mathrm{S} & \mathrm{I} & \mathrm{N} & \mathrm{A} & \mathrm{A} & \mathrm{V} & \mathrm{G} & \mathrm{S} & \mathrm{H} & \mathrm{E} & \mathrm{D} & \mathrm{K} & \mathrm{I} & \mathrm{A} & \mathrm{C} & \mathrm{T} & \mathrm{P}\end{array}$

3601 TTA CCT CTT TCC ATT AAT GCA GCT GTT GGC AGT CAT GAA GAC AAA ATT GCT TGC ACT CCT

$\begin{array}{lllllllllllllllllllll}Q & \mathrm{~N} & \mathrm{~S} & \mathrm{P} & \mathrm{T} & \mathrm{R} & \mathrm{S} & \mathrm{I} & \mathrm{D} & \mathrm{I} & \mathrm{P} & \mathrm{R} & \mathrm{S} & \mathrm{E} & \mathrm{V} & \mathrm{H} & \mathrm{D} & \mathrm{S} & \mathrm{N} & \mathrm{R}\end{array}$

3661 CAA AAT TCT CCT ACT AGG TCC ATT GAT ATT CCC CGG TCT GAG GTT CAT GAT AGT AAT CGA

$\begin{array}{llllllllllllllllllllllll}G & V & S & T & E & K & T & V & L & V & T & Q & S & R & L & V & R & Q & Y & N\end{array}$

3721 GGT GTT TCT ACT GAA AAA ACA GTA TTA GTT ACA CAA TCC CGT CTA GTA CGT CAA TAT AAT

$\begin{array}{lllllllllllllllllllll}I & Q & V & P & E & I & L & V & T & E & E & P & D & K & D & P & E & I & Q & A\end{array}$

3781 ATT CAG GTT CCA GAA ATT TTG GTT ACT GAA GAA CCA GAT AAA GAT CCA GAA ATC CAA GCA

$\begin{array}{llllllllllllllllllll}N & \mathrm{D} & \mathrm{Q} & \mathrm{E} & \mathrm{T} & \mathrm{H} & \mathrm{E} & \mathrm{K} & \mathrm{F} & \mathrm{S} & \mathrm{W} & \mathrm{P} & \mathrm{Q} & \mathrm{R} & \mathrm{S} & \mathrm{G} & \mathrm{S} & \mathrm{L} & \mathrm{S} & \mathrm{N}\end{array}$

3841 AAT GAC CAG GAA ACA CAT GAA AAA TTT AGT TGG CCT CAG CGC AGT GGC AGT CTT TCT AAT

1180

1200

$\begin{array}{llllllllllllllllllll}\mathrm{L} & \mathrm{P} & \mathrm{T} & \mathrm{E} & \mathrm{K} & \mathrm{L} & \mathrm{P} & \mathrm{P} & \mathrm{K} & \mathrm{K} & \mathrm{K} & \mathrm{R} & \mathrm{I} & \mathrm{R} & \mathrm{L} & \mathrm{A} & \mathrm{D} & \mathrm{L} & \mathrm{E} & \mathrm{H}\end{array}$

3901 TTG CCA ACA GAA AAA CTT CCT CCA AAA AAG AAA AGA ATT CGG TTA GCT GAC CTA GAA CAC

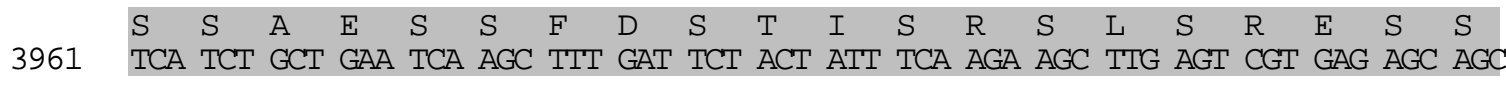
$\begin{array}{llllllllllllllllllll}\mathrm{L} & \mathrm{S} & \mathrm{R} & \mathrm{A} & \mathrm{S} & \mathrm{S} & \mathrm{F} & \mathrm{S} & \mathrm{A} & \mathrm{S} & \mathrm{F} & \mathrm{D} & \mathrm{K} & \mathrm{E} & \mathrm{E} & \mathrm{P} & \mathrm{F} & \mathrm{K} & \mathrm{S} & \mathrm{D}\end{array}$

4021 TTA TCT CGT GCA TCA AGT TTT TCA GCT TCT TTT GAC AAG GAG GAA CCT TTT AAA TCA GAT

$\begin{array}{llllllllllllllllllll}S & V & T & K & T & D & G & M & T & K & S & S & E & F & L & T & I & P & T & S\end{array}$

4081 AGT GTC ACA AAA ACT GAC GGG ATG ACC AAA TCA TCT GAA TTC CTT ACA ATA CCA ACC AGC

$\begin{array}{llllllllllllllllllll}\mathrm{L} & \mathrm{N} & \mathrm{T} & \mathrm{F} & \mathrm{G} & \mathrm{V} & \mathrm{S} & \mathrm{R} & \mathrm{E} & \mathrm{M} & \mathrm{R} & \mathrm{R} & \mathrm{S} & \mathrm{A} & \mathrm{S} & \mathrm{E} & \mathrm{Q} & \mathrm{I} & \mathrm{N} & \mathrm{C}\end{array}$

4141 CTA AAC ACT TTT GGT GTG TCA AGA GAA ATG AGA CGT TCT GCA TCA GAG CAG ATA AAC TGC

$\begin{array}{llllllllllllllllllll}\mathrm{T} & \mathrm{Q} & \mathrm{P} & \mathrm{S} & \mathrm{M} & \mathrm{E} & \mathrm{V} & \mathrm{I} & \mathrm{E} & \mathrm{Y} & \mathrm{R} & \mathrm{S} & \mathrm{K} & \mathrm{S} & \mathrm{F} & \mathrm{D} & \mathrm{C} & \mathrm{G} & \mathrm{S} & \mathrm{M}\end{array}$

4201 ACA CAA CCA TCC ATG GAA GTT ATT GAG TAT AGA AGT AAG TCT TTT GAT TGT GGA AGT ATG

$\begin{array}{llllllllllllllllllll}S & \mathrm{R} & \mathrm{S} & \mathrm{R} & \mathrm{S} & \mathrm{M} & \mathrm{S} & \mathrm{P} & \mathrm{T} & \mathrm{N} & \mathrm{S} & \mathrm{V} & \mathrm{T} & \mathrm{S} & \mathrm{K} & \mathrm{F} & \mathrm{Q} & \mathrm{S} & \mathrm{S} & \mathrm{M}\end{array}$

4261 TCT CGG TCA AGA TCT ATG TCA CCA ACT AAT TCA GTA ACC TCT AAA TTT CAG TCA AGT ATG

$\begin{array}{llllllllllllllllllll}\text { L } & \text { S } & \text { S } & \text { A } & \text { N } & \text { V } & \text { P } & \text { L } & \text { L } & \text { E } & \text { R } & \text { R } & \text { R } & \text { G } & \text { P } & \text { L } & \text { V } & \text { K } & \text { Q } & \text { I } \\ \text { TTA } & \text { AGT } & \text { AGT } & \text { GCC } & \text { AAT } & \text { GTG } & \text { CCT } & \text { CTG } & \text { TTA } & \text { GAA } & \text { AGG } & \text { AGG } & \text { AGA } & \text { GGT } & \text { CCT } & \text { TTA } & \text { GTA } & \text { AAA } & \text { CAA } & \text { ATA }\end{array}$ 
$\begin{array}{llllllllllllllllllll}\mathrm{S} & \mathrm{L} & \mathrm{N} & \mathrm{I} & \mathrm{G} & \mathrm{Q} & \mathrm{E} & \mathrm{S} & \mathrm{P} & \mathrm{V} & \mathrm{S} & \mathrm{T} & \mathrm{V} & \mathrm{K} & \mathrm{P} & \mathrm{K} & \mathrm{N} & \mathrm{L} & \mathrm{Q} & \mathrm{T}\end{array}$

4381 TCT TTA AAT ATT GGT CAA GAG AGC CCA GTT TCT ACA GTT AAA CCA AAA AAT CTC CAA ACG

$\begin{array}{lllllllllllllllllllll} & \text { E } & \text { K } & \text { G } & \text { I } & \text { L } & \text { S } & \text { Q } & \text { M } & \text { H } & \text { A } & \text { T } & \text { E } & \text { P } & \text { S } & \text { L } & \text { N } & \text { A } & \text { E } & \text { L } & \text { L } \\ 4441 & \text { GAA } & \text { AAA } & \text { GGC } & \text { ATT } & \text { CTA } & \text { TCT } & \text { CAA } & \text { ATG } & \text { CAT } & \text { GCA } & \text { ACT } & \text { GAG } & \text { CCA } & \text { AGC } & \text { CTG } & \text { AAT } & \text { GCA } & \text { GAG } & \text { CTT } & \text { TTG }\end{array}$ $\begin{array}{llllllllllllllllllll}\text { C } & \text { A } & \text { P } & \text { L } & \text { T } & \text { Q } & \text { H } & \text { S } & \text { L } & \text { C } & \text { S } & \text { S } & \text { S } & \text { L } & \text { N } & \text { S } & \text { S } & \text { H } & \text { K } & F \\ \end{array}$

4501 TGT GCT CCA CTT ACT CAG CAT TCA CTG TGC TCT AGC TCA CTT AAT AGC TCT CAC AAA TTC

$\begin{array}{llllllllllllllllllll}L & \mathrm{~L} & \mathrm{~N} & \mathrm{Q} & \mathrm{D} & \mathrm{F} & \mathrm{I} & \mathrm{S} & \mathrm{C} & \mathrm{V} & \mathrm{Q} & \mathrm{S} & \mathrm{S} & \mathrm{T} & \mathrm{E} & \mathrm{G} & \mathrm{E} & \mathrm{E} & \mathrm{K} & \mathrm{E}\end{array}$

4561 TTA CTA AAT CAG GAT TTC ATT TCT TGT GTA CAA AGT AGT ACA GAA GGA GAA GAA AAA GAA

$\begin{array}{llllllllllllllllllll}K & N & V & L & S & K & E & K & A & P & F & Y & A & P & K & Y & Q & L & K & F\end{array}$

4621 AAA AAT GTG CTT TCA AAG GAG AAA GCA CCT TTC TAT GCT CCA AAA TAT CAA CTA AAG TTC

1480

$\begin{array}{lllllllllllllllllllll}Q & K & T & R & E & S & K & L & S & A & S & K & H & S & I & R & T & T & A & D\end{array}$

4681 CAA AAA ACA CGA GAA AGC AAA CTT TCT GCA TCC AAA CAT AGC ATT AGA ACT ACG GCT GAC

$\begin{array}{llllllllllllllllllll}N & I & Y & E & V & H & S & S & V & S & T & I & S & D & I & K & G & A & V & S\end{array}$

4741 AAT ATC TAT GAA GTC CAT AGT AGT GTA TCT ACA ATA TCT GAT ATT AAA GGT GCT GTA TCT

1520

$\begin{array}{llllllllllllllllllll}\mathrm{N} & \mathrm{I} & \mathrm{C} & \mathrm{T} & \mathrm{L} & \mathrm{Q} & \mathrm{Q} & \mathrm{T} & \mathrm{E} & \mathrm{S} & \mathrm{S} & \mathrm{S} & \mathrm{G} & \mathrm{K} & \mathrm{S} & \mathrm{F} & \mathrm{G} & \mathrm{K} & \mathrm{I} & \mathrm{L}\end{array}$

4801 AAT ATT TGC ACA CTT CAA CAA ACT GAA AGC TCT TCT GGT AAA AGT TTT GGT AAA ATT CTA

$\begin{array}{llllllllllllllllllll}\mathrm{N} & \mathrm{T} & \mathrm{K} & \mathrm{T} & \mathrm{V} & \mathrm{V} & \mathrm{V} & \mathrm{P} & \mathrm{V} & \mathrm{H} & \mathrm{N} & \mathrm{Y} & \mathrm{S} & \mathrm{N} & \mathrm{S} & \mathrm{S} & \mathrm{Y} & \mathrm{C} & \mathrm{G} & \mathrm{Y}\end{array}$

1560

4861 AAC ACA AAG ACT GTG GTT GTG CCA GTT CAT AAC TAT TCT AAT TCT TCA TAT TGT GGA TAT

$\begin{array}{lllllllllllllllllllll} & \text { F } & \text { E } & \text { L } & \text { L } & \text { P } & \text { E } & \text { I } & \text { L } & \text { V } & \text { T } & Q & \text { D } & Q & \text { G } & \text { H } & \text { K } & \text { I } & \text { T } & \text { S } & \text { E } \\ 4921 & \text { TTT } & \text { GAA } & \text { TTG } & \text { CTC } & \text { CCA } & \text { GAG } & \text { ATT } & \text { TTA } & \text { GTG } & \text { ACC } & \text { CAG } & \text { GAT } & \text { CAG } & \text { GGA } & \text { CAC } & \text { AAA } & \text { ATT } & \text { ACT } & \text { TCT } & \text { GAA }\end{array}$

$\begin{array}{llllllllllllllllllll}\mathrm{A} & \mathrm{N} & \mathrm{S} & \mathrm{V} & \mathrm{S} & \mathrm{V} & \mathrm{P} & \mathrm{N} & \mathrm{P} & \mathrm{K} & \mathrm{D} & \mathrm{C} & \mathrm{I} & \mathrm{I} & \mathrm{M} & \mathrm{A} & \mathrm{K} & \mathrm{C} & \mathrm{P} & \mathrm{D}\end{array}$

4981 GCA AAT TCA GTG TCC GTG CCA AAT CCT AAA GAC TGC ATC ATA ATG GCA AAA TGT CCT GAT $\begin{array}{llllllllllllllllllll}\mathrm{E} & \mathrm{P} & \mathrm{S} & \mathrm{G} & \mathrm{P} & \mathrm{L} & \mathrm{T} & \mathrm{V} & \mathrm{A} & \mathrm{R} & \mathrm{K} & \mathrm{I} & \mathrm{C} & \mathrm{T} & \mathrm{Y} & \mathrm{K} & \mathrm{S} & \mathrm{S} & \mathrm{V} & \mathrm{Q}\end{array}$

5041 GAA CCC AGT GGA CCT CTT ACA GTT GCA CGC AAA ATT TGC ACT TAT AAA AGC AGT GTT CAG

$\begin{array}{llllllllllllllllllll}\mathrm{E} & \mathrm{S} & \mathrm{T} & \mathrm{R} & \mathrm{S} & \mathrm{I} & \mathrm{V} & \mathrm{P} & \mathrm{V} & \mathrm{S} & \mathrm{G} & \mathrm{L} & \mathrm{L} & \mathrm{T} & \mathrm{Q} & \mathrm{Q} & \mathrm{E} & \mathrm{T} & \mathrm{S} & \mathrm{A}\end{array}$

5101 GAA TCC ACT CGA TCA ATA GTG CCA GTT TCT GGT CTT CTT ACT CAA CAA GAG ACC TCT GCC

$\begin{array}{lllllllllllllllllllll}\mathrm{S} & \mathrm{S} & \mathrm{K} & \mathrm{R} & \mathrm{M} & \mathrm{L} & \mathrm{S} & \mathrm{P} & \mathrm{A} & \mathrm{N} & \mathrm{S} & \mathrm{L} & \mathrm{D} & \mathrm{I} & \mathrm{A} & \mathrm{M} & \mathrm{E} & \mathrm{K} & \mathrm{H} & \mathrm{Q}\end{array}$

1660

5161 TCT AGC AAG AGA ATG CTC TCG CCA GCA AAT AGT TTA GAT ATT GCC ATG GAA AAG CAC CAA

$\begin{array}{llllllllllllllllllll}K & \mathrm{R} & \mathrm{V} & \mathrm{K} & \mathrm{D} & \mathrm{E} & \mathrm{S} & \mathrm{G} & \mathrm{A} & \mathrm{A} & \mathrm{F} & \mathrm{N} & \mathrm{S} & \mathrm{N} & \mathrm{I} & \mathrm{Q} & \mathrm{I} & \mathrm{N} & \mathrm{L} & \mathrm{N}\end{array}$

5221 AAA CGT GTT AAA GAT GAA AGT GGG GCA GCG TTT AAT TCT AAC ATT CAA ATT AAT TTA AAT

$\begin{array}{llllllllllllllllllll}I & K & I & G & E & S & V & K & Q & R & K & P & M & L & V & R & Q & L & C & T\end{array}$

5281 ATT AAA ATT GGT GAG TCA GTT AAG CAA AGA AAA CCA ATG CTT GTG AGA CAG CTT TGC ACA

$\begin{array}{lllllllllllllllllllll}5341 & \text { T } & \text { D } & \text { P } & \text { G } & \text { E } & \text { S } & \text { L } & \text { D } & \text { Q } & \text { E } & \text { P } & \text { S } & \text { P } & \text { V } & \text { P } & \text { D } & \text { N } & \text { N } & \text { R } & \text { K } \\ & \text { GAA } & \text { AGT } & \text { TTA } & \text { GAT } & \text { CAG } & \text { GAA } & \text { CCT } & \text { TCT } & \text { CCT } & \text { GTG } & \text { CCT } & \text { GAT } & \text { AAT } & \text { AAC } & \text { AGG } & \text { AAG }\end{array}$

1700

1720

$\begin{array}{lllllllllllllllllllll} & \text { L } & \text { N } & \text { S } & \text { C } & \text { L } & \text { D } & \text { I } & \text { Q } & \text { L } & \text { S } & \text { G } & \text { L } & \text { N } & \text { C } & \text { A } & \text { G } & \text { K } & \text { S } & \text { H } & \text { N } \\ 5401 & \text { TTA } & \text { AAC } & \text { AGC } & \text { TGC } & \text { TTG } & \text { GAT } & \text { ATA } & \text { CAG } & \text { TTA } & \text { AGT } & \text { GGC } & \text { TTG } & \text { AAT } & \text { TGT } & \text { GCT } & \text { GGA } & \text { AAA } & \text { TCT } & \text { CAT } & \text { AAC }\end{array}$

$\begin{array}{lllllllllllllllllllll} & \text { I } & \text { F } & \text { D } & \text { K } & \text { S } & \text { E } & \text { E } & V & V & \text { E } & \text { A } & \text { E } & \text { K } & \text { N } & \text { K } & \text { L } & \text { L } & \text { E } & \text { S } & \text { S } \\ \text { ATA } & \text { TTT } & \text { GAT } & \text { AAA } & \text { TCA } & \text { GAA } & \text { GAG } & \text { GTT } & \text { GTA } & \text { GAA } & \text { GCT } & \text { GAA } & \text { AAA } & \text { AAT } & \text { AAA } & \text { TTG } & \text { TTA } & \text { GAG } & \text { TCA } & \text { TCA }\end{array}$

$\begin{array}{llllllllllllllllllll}C & S & A & V & S & \text { L } & P & E & N & S & T & V & N & T & Q & T & G & A & L & N\end{array}$

5521 TGC TCT GCA GTT AGT TTG CCA GAA AAT TCT ACA GTA AAT ACT CAG ACT GGT GCA TTG AAC

5581 TTT CTA TAT ACT AGT CAA GAG AGG AAA TCA CCT CTT GCT ACA AAG ACA GTT CAC ATT CAA

$\begin{array}{llllllllllllllllllll}G & Q & V & K & L & G & A & A & I & S & V & V & N & A & G & D & M & H & R & L\end{array}$

5621 GGC CAA GTA AAA CTA GGT GCT GCA ATA TCA GTA GTT AAT GCA GGG GAC ATG CAC AGA CTT

$\begin{array}{llllllllllllllllllll}S & F & P & S & L & K & T & S & T & S & F & T & W & C & Y & L & L & K & R & K\end{array}$

5681 TCA TTT CCA AGC CTC AAG ACC TCA ACA AGT TTT ACC TGG TGT TAT CTT TTA AAA CGG AAG $\begin{array}{llllllllllllllllllll}\text { P } & \text { M } & \text { H } & \text { L } & \text { P } & \text { Q } & \text { N } & \text { D } & \text { Q } & \text { K } & \text { I } & \text { S } & \text { A } & \text { Y } & \text { A } & \text { S } & \text { W } & \text { S } & \text { I } & \text { S } \\ \text { CCA } & \text { ATG } & \text { CAC } & \text { CTT } & \text { CCT } & \text { CAG } & \text { AAT } & \text { GAC } & \text { CAA } & \text { AAG } & \text { ATT } & \text { TCT } & \text { GCC } & \text { TAT } & \text { GCT } & \text { TCT } & \text { TGG } & \text { AGC } & \text { ATC } & \text { AGT }\end{array}$ 
$\begin{array}{lllllllllllllllllllll}5801 & \text { Y } & \text { N } & \text { N } & \text { P } & \text { N } & \text { P } & \text { M } & \text { R } & \text { L } & \text { P } & \text { T } & \text { K } & \text { V } & \text { A } & \text { L } & \text { S } & \text { L } & \text { L } & \text { N } & \text { S } \\ \text { AAT } & \text { CCC } & \text { AAT } & \text { CCC } & \text { ATG } & \text { CGT } & \text { TTA } & \text { CCT } & \text { ACC } & \text { AAA } & \text { GTG } & \text { GCA } & \text { CTT } & \text { TCA } & \text { CTT } & \text { CTG } & \text { AAT } & \text { TCT }\end{array}$

1880

$\begin{array}{lllllllllllllllllllll}K & Q & K & S & E & K & F & T & F & T & L & V & Q & T & S & H & P & K & H & D & 1900\end{array}$

5861 AAA CAG AAG TCT GAG AAA TTC ACC TTT ACT TTA GTA CAA ACC TCT CAT CCA AAG CAC GAT $\begin{array}{lllllllllllllllllllll}I & L & V & Y & S & S & K & \text { W } & \text { K } & \text { Y } & \text { S } & \text { T } & \text { K } & \text { K } & \text { S } & \text { P } & \text { E } & \text { S } & \text { Q } & \text { S } & 1920\end{array}$

5921 ATT CTC GTG TAT TCA AGC AAA TGG AAA TAT AGT ACA AAA AAG TCA CCT GAA AGT CAA TCA

$\begin{array}{lllllllllllllllllllllllll}\mathrm{N} & \mathrm{H} & \mathrm{L} & \mathrm{Q} & \mathrm{S} & \mathrm{L} & \mathrm{D} & \mathrm{P} & \mathrm{S} & \mathrm{T} & \mathrm{E} & \mathrm{Q} & \mathrm{D} & \mathrm{L} & \mathrm{E} & \mathrm{S} & \mathrm{F} & \mathrm{P} & \mathrm{N} & \mathrm{K} & & 1940\end{array}$

5981 AAT CAC CTT CAA AGT TTA GAC CCA AGT ACC GAA CAA GAT CTA GAA TCC TTT CCA AAT AAA

$\begin{array}{llllllllllllllllllll}N & E & P & R & R & V & K & I & F & D & G & G & Y & K & S & N & E & E & Y & V\end{array}$

1960

6041 AAT GAG CCA AGG AGA GTA AAG ATA TTT GAT GGC GGA TAC AAA TCA AAT GAA GAG TAT GTG

$\begin{array}{lllllllllllllllllllll}Y & I & R & G & R & G & R & G & K & Y & I & C & E & E & C & G & I & R & C & K & 1980\end{array}$

6061 TAC ATC CGT GGA CGG GGA AGA GGG AAG TAT ATT TGT GAA GAA TGT GGA ATA AGA TGT AAG

$\begin{array}{llllllllllllllllllllll}K & \mathrm{P} & \mathrm{S} & \mathrm{M} & \mathrm{L} & \mathrm{K} & \mathrm{K} & \mathbf{H} & \mathrm{I} & \mathrm{R} & \mathrm{T} & \mathbf{H} & \mathrm{T} & \mathrm{D} & \mathrm{V} & \mathrm{R} & \mathrm{P} & \mathrm{Y} & \mathrm{H} & \mathbf{C}\end{array}$

2000

6121 AAG CCT AGC ATG CTG AAA AAA CAT ATT CGC ACA CAC ACT GAT GTA CGA CCC TAT CAC TGC

$\begin{array}{llllllllllllllllllll}\mathrm{T} & \mathrm{Y} & \mathrm{C} & \mathrm{N} & \mathrm{F} & \mathrm{S} & \mathrm{F} & \mathrm{K} & \mathrm{T} & \mathrm{K} & \mathrm{G} & \mathrm{N} & \mathrm{L} & \mathrm{T} & \mathrm{K} & \mathbf{H} & \mathrm{M} & \mathrm{K} & \mathrm{S} & \mathrm{K}\end{array}$

6181 ACC TAC TGT AAT TTC TCT TTT AAG ACA AAA GGC AAT CTT ACA AAG CAT ATG AAG TCT AAG

2020

$\begin{array}{llllllllllllllllllll}\mathrm{A} & \mathrm{H} & \mathrm{S} & \mathrm{K} & \mathrm{K} & \mathrm{C} & \mathrm{L} & \mathrm{D} & \mathrm{M} & \mathrm{G} & \mathrm{G} & \mathrm{P} & \mathrm{V} & \mathrm{D} & \mathrm{D} & \mathrm{Q} & \mathrm{D} & \mathrm{T} & \mathrm{D} & \mathrm{D}\end{array}$

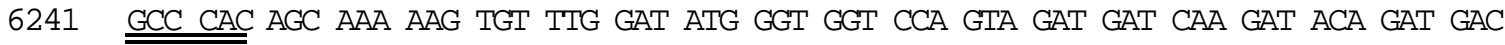
$\begin{array}{llllllllllllllllllll}S & G & E & R & Q & R & Y & T & G & E & R & T & G & F & D & A & D & D & S & D\end{array}$

6301 TCA GGT GAA AGG CAA CGA TAT ACT GGC GAG AGA ACA GGA TTT GAT GCA GAT GAT TCA GAT

$\begin{array}{lllllllllllllllllllll}G & G & D & D & D & D & N & E & D & E & D & E & D & S & Q & A & E & S & G & L & 2080\end{array}$

6361 GGA GGA GAC GAT GAT GAT AAT GAG GAT GAA GAT GAA GAC AGT CAA GCA GAG TCT GGT CTT $\begin{array}{llllllllllllllllllllllllll}S & A & T & P & S & V & T & A & S & P & Q & H & Y & P & F & R & N & S & Q & Q & 2100\end{array}$

6421 TCA GCT ACT CCG TCT GTC ACT GCT AGC CCA CAA CAT TAT CCC TTT CGG AAC AGC CAG CAA

$\begin{array}{llllllllllllllllllllllllllllll}A & A & S & N & T & D & E & D & P & Q & L & Q & H & C & F & S & Q & S & N & S\end{array}$

6481 GCG GCT TCT AAT ACT GAT GAG GAT CCA CAA TTG CAA CAT TGT TTT TCC CAG TCC AAT TCT

$\begin{array}{llllllllllllllllllllll}M & \mathrm{D} & \mathrm{S} & \mathrm{L} & \mathrm{P} & \mathrm{K} & \mathrm{A} & \mathrm{L} & \mathrm{I} & \mathrm{T} & \mathrm{R} & \mathrm{M} & \mathrm{T} & \mathrm{A} & \mathrm{M} & \mathrm{T} & \mathrm{T} & \mathrm{S} & \mathrm{T} & \mathrm{I} & 2140\end{array}$

6541 ATG GAC AGT CTT CCC AAA GCT TTA ATA ACC AGA ATG ACC GCA ATG ACA ACT TCC ACT ATC

$\begin{array}{llllllllllllllllllllllll}C & R & P & E & S & H & E & E & R & S & K & V & N & L & P & R & E & T & T & S & 2160\end{array}$

6601 TGC AGG CCA GAG AGC CAC GAG GAG AGG AGC AAA GTG AAT TTG CCA CGA GAA ACT ACA AGT

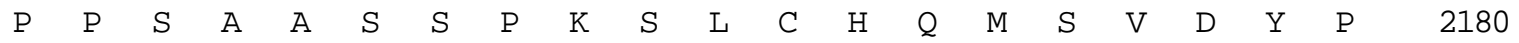

6661 CCA CCC AGT GCG GCA TCC TCT CCA AAG TCT TTA TGT CAT CAA ATG TCT GTG GAT TAT CCA

$\begin{array}{lllllllllllllllllllllllllllll}E & A & E & A & E & S & L & G & A & T & K & S & V & H & V & P & S & V & I & N\end{array}$

6721 GAG GCA GAA GCA GAG AGC CTG GGT GCC ACA AAA TCT GTG CAT GTA CCC AGT GTA ATT AAT

2200

$\begin{array}{lllllllllllllllllllll}\mathrm{L} & \mathrm{I} & \mathrm{P} & \mathrm{K} & \mathrm{E} & \mathrm{K} & \mathrm{L} & \mathrm{S} & \mathrm{M} & \mathrm{N} & \mathrm{M} & \mathrm{P} & \mathrm{S} & \mathrm{S} & \mathrm{P} & \mathrm{V} & \mathrm{D} & \mathrm{R} & \mathrm{S} & \mathrm{T}\end{array}$

2220

6781 TTA ATA CCA AAA GAA AAA TTG TCT ATG AAT ATG CCT TCT TCG CCA GTC GAC CGA AGT ACG $\begin{array}{llllllllllllllllllll}Q & \mathrm{~T} & \mathrm{M} & \mathrm{D} & \mathrm{S} & \mathrm{Y} & \mathrm{T} & \mathrm{D} & \mathrm{A} & \mathrm{T} & \mathrm{D} & \mathrm{S} & \mathrm{Y} & \mathrm{V} & \mathrm{H} & \mathrm{Q} & \mathrm{H} & \mathrm{K} & \mathrm{S} & \mathrm{T}\end{array}$

6841 CAG ACC ATG GAT TCC TAT ACA GAC GCC ACA GAT AGT TAT GTT CAC CAG CAT AAA TCA ACG

$\begin{array}{lllllllllllllllllllllll}K & S & T & Q & Q & P & S & S & T & E & P & P & H & T & H & L & F & S & H & L & 2260\end{array}$

6901 AAG TCC ACT CAG CAG CCT TCC TCA ACG GAA CCT CCT CAT ACA CAT CTT TTC AGC CAT TTA $\begin{array}{llllllllllllllllllllll}\mathrm{P} & \mathrm{L} & \mathrm{H} & \mathrm{S} & \mathrm{Q} & \mathrm{Q} & \mathrm{P} & \mathrm{A} & \mathrm{R} & \mathrm{S} & \mathrm{P} & \mathrm{Y} & \mathrm{S} & \mathrm{M} & \mathrm{I} & \mathrm{P} & \mathrm{V} & \mathrm{G} & \mathrm{G} & \mathrm{I} & 2280\end{array}$

6961 CCT TTG CAT TCA CAA CAG CCA GCA AGA TCA CCC TAC AGC ATG ATT CCA GTA GGG GGA ATT $\begin{array}{llllllllllllllllllllllllll}Q & \mathrm{~L} & \mathrm{~V} & \mathrm{P} & \mathrm{A} & \mathrm{G} & \mathrm{L} & \mathrm{A} & \mathrm{A} & \mathrm{Y} & \mathrm{S} & \mathrm{T} & \mathrm{F} & \mathrm{M} & \mathrm{P} & \mathrm{F} & \mathrm{Q} & \mathrm{A} & \mathrm{A} & \mathrm{P} & 2300\end{array}$

7021 CAG CTT GTT CCT GCT GGT TTA GCA GCG TAC TCC ACA TTT ATG CCA TTT CAG GCT GCT CCA $\begin{array}{llllllllllllllllllll}V & Q & \mathrm{~L} & \mathrm{~T} & \mathrm{I} & \mathrm{P} & \mathrm{A} & \mathrm{M} & \mathrm{G} & \mathrm{V} & \mathrm{I} & \mathrm{H} & \mathrm{R} & \mathrm{T} & \mathrm{S} & \mathrm{S} & \mathrm{A} & \mathrm{V} & \mathrm{G} & \mathrm{D}\end{array}$

7081 GTG CAG CTT ACC ATA CCT GCA ATG GGA GTT ATA CAT AGA ACT TCA TCT GCT GTC GGA GAT $\begin{array}{llllllllllllllllllll}K & \mathrm{~T} & \mathrm{~A} & \mathrm{E} & \mathrm{V} & \mathrm{P} & \mathrm{N} & \mathrm{T} & \mathrm{P} & \mathrm{N} & \mathrm{P} & \mathrm{I} & \mathrm{G} & \mathrm{V} & \mathrm{A} & \mathrm{E} & \mathrm{V} & \mathrm{N} & \mathrm{G} & \mathrm{V}\end{array}$

7141 AAG ACT GCA GAG GTA CCC AAC ACC CCA AAT CCT ATA GGA GTG GCT GAA GTA AAT GGT GTT 
$\begin{array}{llllllllllllllllllll}V & P & C & I & P & I & G & Q & I & N & M & A & G & L & S & A & P & S & L & Q\end{array}$

2360

7201 GTA CCA TGT ATT CCA ATA GGT CAG ATT AAC ATG GCT GGC TTA AGT GCA CCC AGT TTA CAG $\begin{array}{llllllllllllllllllll}\mathrm{P} & \mathrm{L} & \mathrm{N} & \mathrm{V} & \mathrm{E} & \mathrm{T} & \mathrm{L} & \mathrm{S} & \mathrm{I} & \mathrm{L} & \mathrm{G} & \mathrm{L} & \mathrm{S} & \mathrm{N} & \mathrm{T} & \mathrm{N} & \mathrm{V} & \mathrm{A} & \mathrm{P} & \mathrm{Q}\end{array}$

7261 CCA TTA AAT GTG GAA ACA CTG AGC ATA TTA GGT CTT TCT AAT ACA AAT GTA GCT CCA CAG

$\begin{array}{lllllllllllllllllllll} & \text { I } & \text { H } & \text { P } & \text { S } & \text { G } & \text { L } & \text { T } & \text { L } & \text { N } & \text { A } & \text { V } & \text { G } & \text { L } & \text { Q } & \text { Y } & \text { L } & \text { T } & \text { T } & \text { S } & \text { P } \\ 7321 & \text { ATT } & \text { CAC } & \text { CCT } & \text { TCT } & \text { GGG } & \text { CTT } & \text { ACT } & \text { CTG } & \text { AAT } & \text { GCA } & \text { GTT } & \text { GGC } & \text { TTG } & \text { CAG } & \text { TAT } & \text { TTA } & \text { ACT } & \text { ACA } & \text { AGT } & \text { CCC }\end{array}$ $\begin{array}{lllllllllllllllllllllllllllll}Q & S & N & P & S & P & Q & T & H & I & P & G & L & Q & I & L & N & I & A & L\end{array}$

7381 CAA AGC AAC CCA AGC CCA CAG ACT CAC ATT CCT GGC CTC CAA ATA TTG AAC ATA GCT CTG

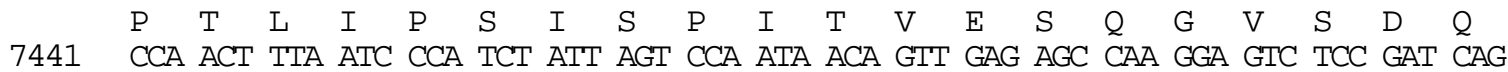
$\begin{array}{lllllllllllllllllllll}S & S & S & C & S & P & A & A & G & K & G & S & A & A & F & T & V & A & D & T\end{array}$

7501 TCA TCT TCA TGT AGT CCA GCA GCT GGG AAG GGT TCT GCC GCA TTT ACT GTG GCA GAC ACA $\begin{array}{lllllllllllllllllllllll}K & N & M & K & Q & T & E & S & L & Q & G & S & S & G & V & Q & D & C & H & K & 2480\end{array}$

7561 AAA AAT ATG AAA CAG ACT GAA TCC CTA CAA GGA TCT TCA GGG GTG CAG GAT TGC CAT AAG $\begin{array}{llllllllllllllllllll}I & \mathrm{~L} & \mathrm{R} & \mathrm{D} & \mathrm{L} & \mathrm{S} & \mathrm{V} & \mathrm{T} & \mathrm{E} & \mathrm{E} & \mathrm{K} & \mathrm{P} & \mathrm{L} & \mathrm{G} & \mathrm{G} & \mathrm{C} & \mathrm{L} & \mathrm{T} & \mathrm{A} & \mathrm{D}\end{array}$

7621 ATA TTA CGT GAT TTG TCA GTC ACA GAA GAA AAG CCT CTA GGT GGT TGT TTG ACT GCT GAC $\begin{array}{llllllllllllllllllll}K & G & P & Q & S & K & Q & C & S & N & I & S & S & S & K & V & K & I & S & S\end{array}$

7681 AAA GGA CCT CAA TCT AAG CAA TGT TCT AAC ATC AGC TCC AGT AAA GTA AAA ATC TCT TCA $\begin{array}{llllllllllllllllllllllll}\mathrm{S} & \mathrm{A} & \mathrm{D} & \mathrm{L} & \mathrm{Y} & \mathrm{V} & \mathrm{K} & \mathrm{A} & \mathrm{N} & \mathrm{S} & \mathrm{D} & \mathrm{S} & \mathrm{A} & \mathrm{N} & \mathrm{K} & \mathrm{P} & \mathrm{P} & \mathrm{V} & \mathrm{S} & \mathrm{H}\end{array}$

7741 TCA GCA GAT CTG TAT GTA AAG GCT AAT TCT GAC AGT GCC AAC AAG CCT CCT GTT AGT CAC $\begin{array}{llllllllllllllllllllllll}\mathrm{T} & \mathrm{F} & \mathrm{S} & \mathrm{L} & \mathrm{L} & \mathrm{R} & \mathrm{H} & \mathrm{Q} & \mathrm{R} & \mathrm{R} & \mathrm{T} & \mathrm{E} & \mathrm{M} & \mathrm{I} & \mathrm{S} & \mathrm{R} & \mathrm{Q} & \mathrm{S} & \mathrm{T} & \mathrm{V}\end{array}$

7801 ACT TTT TCT CTT TTA AGg CAT CAG AGA AGA ACA GAA ATG ATC TCT AGG CAG AGC ACT GTG

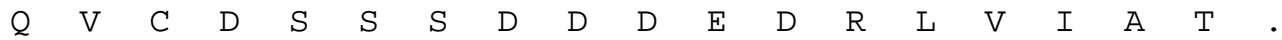

7861 CAG GTT TGT GAT TCC AGC AGT GAT GAT GAT GAA GAC AGG CTG GTT ATA GCA ACC TAA ATA 8041 ATT ACT TGT GCA ATC ATG AAC TCT AGA CCA ACA ATT ATT ATT TTT TTT TTT TAT ATT TTA 8101 TTG TTG TCT TCT ATT GCC ATT TTT TGT AAA TGT TGT ATA GAC AAT TGT GCC TTC AGA GTT 8161 TTA TGT GTA GAA ATC TGT ACA TAT TAG TGA ATA AAG AAA TAT ATA TAT ATA TAT ATA TAT 8221 ATA AAT ATG TAC ATA ACC AAG GTA GTT GCT TGT GTT TAG TAC AGA AAT ATC TCA TGT TGC 8281 GTT AAA AGA TTA AAT TAT ACT TCA CTT ATG TAT ATG TTG CAC TGT TAA ATG TCA TTT TTT 8341 TTA TGG ATG TGG GGC AAG TTA CTG TGT ACA GGT CTT GTA TGT AAA ACT CCA TAT TTA TTG 8401 TGT CCA TAT TAG TCT TGG AAA TGG TCC TGT CCA ACT TTG TGT ACA AGA AGG TAG CTT TAC 8461 ACT TAC AGA ATT TCT GTG TTA ACA AAT GTT CCA GTA AAT TTT TTA TTA CTG ACT TTA AAA

8521 AAA AAA AAA AAA AAA AAA AAA AAA AAA AAA AAA 


\section{Danksagung}

Mein herzlicher Dank gilt Prof. Dr. Tomas Pieler für die Überlassung des Themas und für die Betreuung der Arbeit.

Prof. Dr. M. Schäfer möchte ich für die Bereitschaft danken, meine Arbeit an der biologischen Fakultät der Universität Göttingen zu vertreten.

Herrn Prof. Dr. W. Engel danke ich für die Übernahme des Korreferats.

Meinen Kollegen aus der Arbeitsgruppe Prof. Dr. T. Pieler, der Arbeitsgruppe Dr. M. Kühl und der Arbeitsgruppe Dr. V. Haucke möchte ich für stete Hilfsbereitschaft und wertvolle Tips und Diskussionen danken.

Mein besonderer Dank gilt Thomas Hollemann, Frank Panitz, Katja Koebernick, Kirstie Murdoch, Suanne Loop, Marion Soelter, Petra Pandur und Wendy Gerber.

Und nicht zu vergessen sei die „Gang“, die mir besonders zum Ende der Promotionsarbeit Kraft und Motivation gegeben hat.

Ganz besonders danke ich meinen Eltern für ihre Unterstützung während der gesamten Ausbildungszeit! 


\section{Lebenslauf}

Name: $\quad$ Ulrike Dürr

Geburtsdaturm: $\quad$ 04.08.1969 in Hamburg

Nationalität: deutsch

Familienstand: ledig

Adresse:

Gartenstraße 25

37073 Göttingen

\section{Ausbildung:}

1975-1979

Besuch der örtlichen Grundschule in Hamburg-Duvenstedt

1979-1989

Besuch des Gymnasiums Ohlstedt in Hamburg

$1985-1986$

Aufenthalt in Normal, Illinois, USA, Besuch der Normal Community High School

1989

Abitur am 23.05.1989

Beginn des Studiums der Biologie (Diplom) an der Universität Göttingen

1991

Vordiplom am 18.09.1991

1992

1995-1997

sechsmonatiges Praktikum im Nationalpark Jasmund, Mecklenburg-

Vorpommern

Diplomarbeit: "Identifizierung und Charakterisierung von zum Drosophila melanogaster Zinkfinger Transkriptionsfaktor Schnurri homologen cDNAs im Krallenfrosch Xenopus laevis"

1997

Diplom am 07.03.1997

Seit April 1997

Promotionsarbeit am Institut für Biochemie der Universität Göttingen, Abteilung Entwicklungsbiochemie, Arbeitsgruppe Prof. Dr. T. Pieler

$1997-2001$

Stipendiatin der Deutschen Forschungsgemeinschaft, SFB 27, „Molekulare Genetik morphoregulatorischer Prozesse“

Göttingen, den 17.9.2001 